Religiöses Wissen in der Lyrik der Frühen Neuzeit 


\section{Episteme in Bewegung}

Beiträge zu einer transdisziplinären Wissensgeschichte

Herausgegeben von Gyburg Uhlmann im Auftrag des Sonderforschungsbereichs 980

„Episteme in Bewegung.

Wissenstransfer von der Alten Welt

bis in die Frühe Neuzeit"

\section{Band 3}

2015

Harrassowitz Verlag · Wiesbaden 


\title{
Religiöses Wissen in der Lyrik der Frühen Neuzeit
}

\author{
Herausgegeben von \\ Peter-André Alt und Volkhard Wels
}

2015

Harrassowitz Verlag · Wiesbaden 
Die Reihe „Episteme in Bewegung“ umfasst wissensgeschichtliche Forschungen mit einem systematischen oder historischen Schwerpunkt in der europäischen und nicht-europäischen Vormoderne. Sie fördert transdisziplinäre Beiträge, die sich mit Fragen der Genese und Dynamik von Wissensbeständen befassen, und trägt dadurch zur Etablierung vormoderner Wissensforschung als einer eigenständigen Forschungsperspektive bei.

Publiziert werden Beiträge, die im Umkreis des an der Freien Universität Berlin angesiedelten Sonderforschungsbereichs 980 „Episteme in Bewegung. Wissenstransfer von der Alten Welt bis in die Frühe Neuzeit" entstanden sind.

Herausgeberbeirat:

Eva Cancik-Kirschbaum (Freie Universität Berlin)

Anne Eusterschulte (Freie Universität Berlin)

Kristiane Hasselmann (Freie Universität Berlin)

Andrew James Johnston (Freie Universität Berlin)

Jochem Kahl (Freie Universität Berlin)

Klaus Krüger (Freie Universität Berlin)

Tilo Renz (Freie Universität Berlin)

Wilhelm Schmidt-Biggemann (Freie Universität Berlin)

Gedruckt mit freundlicher Unterstützung der Deutschen Forschungsgemeinschaft (DFG).

Abbildung auf dem Umschlag:

Georg Philipp Harsdörffer: Hertzbewegliche Sonntagsandachten

Nürnberg 1649, S. 53.

Bibliografische Information der Deutschen Nationalbibliothek

Die Deutsche Nationalbibliothek verzeichnet diese Publikation in der Deutschen

Nationalbibliografie; detaillierte bibliografische Daten sind im Internet

über http://dnb.dnb.de abrufbar.

Bibliographic information published by the Deutsche Nationalbibliothek

The Deutsche Nationalbibliothek lists this publication in the Deutsche

Nationalbibliografie; detailed bibliographic data are available on the internet

at http://dnb.dnb.de.

Informationen zum Verlagsprogramm finden Sie unter

http://www.harrassowitz-verlag.de

(c) Otto Harrassowitz GmbH \& Co. KG, Wiesbaden 2015

Das Werk einschließlich aller seiner Teile ist urheberrechtlich geschützt.

Jede Verwertung außerhalb der engen Grenzen des Urheberrechtsgesetzes ist ohne

Zustimmung des Verlages unzulässig und strafbar. Das gilt insbesondere

für Vervielfältigungen jeder Art, Übersetzungen, Mikroverfilmungen und

für die Einspeicherung in elektronische Systeme.

Gedruckt auf alterungsbeständigem Papier.

Druck und Verarbeitung: Hubert \& Co., Göttingen

Printed in Germany

ISSN 2365-5666

ISBN 978-3-447-10497-5

e-ISBN PDF 978-3-447-19413-6 


\title{
Zum Geleit
}

\author{
Andrew James Johnston und Gyburg Uhlmann
}

Der an der Freien Universität Berlin angesiedelte Sonderforschungsbereich 980 „Episteme in Bewegung. Wissenstransfer von der Alten Welt bis in die Frühe Neuzeit", der im Juli 2012 seine Arbeit aufgenommen hat, untersucht anhand exemplarischer Problemkomplexe aus europäischen und nicht-europäischen Kulturen Prozesse des Wissenswandels vor der Moderne. Dieses Programm zielt auf eine grundsätzliche Neuorientierung wissensgeschichtlicher Forschung im Bereich der Vormoderne ab. Sowohl in der modernen Forschung als auch in den historischen Selbstbeschreibungen der jeweiligen Kulturen wurde das Wissen der Vormoderne häufig als statisch und stabil, traditionsgebunden und autoritätsabhängig beschrieben. Dabei waren die Stabilitätspostulate moderner Forscherinnen und Forscher nicht selten von der Dominanz wissensgeschichtlicher Szenarien wie dem Bruch oder der Revolution geprägt sowie von Periodisierungskonzepten, die explizit oder implizit einem Narrativ des Fortschritts verpflichtet waren. Vormodernen Kulturen wurde daher oft nur eine eingeschränkte Fähigkeit zum Wissenswandel und vor allem zur - nicht zuletzt historischen - Reflexion dieses Wandels zugeschrieben. Demgegenüber will dieser SFB zeigen, dass vormoderne Prozesse der Wissensbildung und -entwicklung von ständiger Bewegung und auch ständiger Reflexion geprägt sind, dass diese Bewegungen und Reflexionen aber eigenen Dynamiken unterworfen sind und in komplexeren Mustern verlaufen, als es eine traditionelle Wissensgeschichtsschreibung wahrhaben will.

Um diese Prozesse des Wissenswandels fassen zu können, entwickelte der SFB 980 einen Begriff von ,Episteme', der sich sowohl auf ,Wissen' als auch ,Wissenschaft' bezieht und das Wissen als ,Wissen von etwas' bestimmt, $d$. $h$. als mit einem Geltungsanspruch versehenes Wissen. Diese Geltungsansprüche werden allerdings nicht notwendigerweise auf dem Wege einer expliziten Reflexion erhoben, sondern sie konstituieren sich und werden auch reflektiert in Formen der Darstellung, durch bestimmte Institutionen, in besonderen Praktiken oder durch spezifische ästhetische oder performative Strategien.

Zudem bedient sich der SFB 980 eines speziell konturierten Transfer-Begriffs, der im Kern eine Neukontextualisierung von Wissen meint. Transfer wird hier nicht als Transport-Kategorie verstanden, sondern vielmehr im Sinne komplex verflochtener Austauschprozesse, die selbst bei scheinbarem Stillstand iterativ in Bewegung bleiben. Gerade Handlungen, die darauf abzielen, einen erreichten 
Wissensstand zu tradieren, zu kanonisieren, zu kodifizieren oder zu fixieren, tragen zum ständigen Wissenswandel bei.

Gemeinsam mit dem Harrassowitz Verlag hat der SFB die Reihe „Episteme in Bewegung. Beiträge zu einer transdisziplinären Wissensgeschichte“ ins Leben gerufen, um die Ergebnisse der Zusammenarbeit zu präsentieren und zugänglich zu machen. Die Bände, die hier erscheinen, werden das breite Spektrum der Disziplinen repräsentieren, die im SFB vertreten sind, von der Altorientalistik bis zur Mediävistik, von der Koreanistik bis zur Arabistik. Publiziert werden sowohl aus der interdisziplinären Zusammenarbeit hervorgegangene Bände als auch Monographien und fachspezifische Sammelbände, die die Ergebnisse einzelner Teilprojekte dokumentieren.

Allen ist gemeinsam, dass sie die Wissensgeschichte der Vormoderne als ein Forschungsgebiet betrachten, dessen Erkenntnisgewinne von grundsätzlichem systematischen Interesse auch für die wissensgeschichtliche Erforschung der Moderne sind. 


\section{Inhalt}

Peter-André Alt und Volkhard Wels

Einleitung

Irmgard Scheitler

Konfessionelle Differenzen in Verbreitung und Gebrauch

religiöser Gesangslyrik

Andreas Lindner

„In Arbeit und Beruf“. Zur lyrischen Verinnerlichung lutherischer

Standes- und Berufsethik

Günter Butzer

Übung und Wissen in der religiösen Lyrik der frühen Neuzeit

61

Franz M. Eybl

Lyrische Inszenierung optischer Evidenz bei Spee, Greiffenberg, Brockes ..

79

Peter-André Alt

Allegorie und Paradoxie. Zur Organisation religiöser Denkmuster

in englischer und deutscher Lyrik des 17. Jahrhunderts

95

Gesa Dane

Christlicher Epikurismus? Lohensteins Preisgedicht Venus

Stefan Elit

Heiliger Ernst, das Ich und säkulares Spiel? Galante Lyrik, Religiosität und Individuierung um 1700

Ralph Häfner

Das burleske Martyrium der Polymathie.

Johann Christian Günther (1695-1723) und der prekäre Status der Muße im Zeitalter der Frühaufklärung

Andreas Beck

Episteme in Beharrung. Konventionelle Artistik und orthodoxes religiöses Wissen in der ,Lyrik' des Parnassus Boicus 
Simone De Angelis

Newton in der Dichtung

Mark-Georg Dehrmann

Deistische Gotteserkenntnis, Poetik und Enthusiasmus.

Der Hymnus an die Natur in Shaftesburys Moralists (1711)

203

Volkhard Wels

Zur religionshistorischen Verortung der ,Naturlyrik'

bei Barthold Heinrich Brockes

223

Hans-Georg Kemper

Un-/Biblischer Schöpfungsgesang. Psalm 8 und die Anfänge

der deutschen Naturlyrik

259

Jörg Robert

„Des Abgrunds Raum“. Lyrische Ekstase(n)

bei Barthold Heinrich Brockes

287

Kevin F. Hilliard

„Wo bin ich?“ Zur Orientierung der religiösen Lyrik im 18. Jahrhundert am Beispiel von Barthold Heinrich Brockes und Friedrich Hölderlin 309 


\title{
Einleitung
}

\author{
Peter-André Alt und Volkhard Wels
}

Die beiden zentralen Begriffe, die im Titel dieses Bandes firmieren - ,Lyrik’ und ,Religion' - sind als historische Größen für die Frühe Neuzeit problematisch. Der Begriff der Religion durchläuft in dieser Zeit einen fundamentalen Wandel, indem sich mit der Reformation selbst und dann wiederum mit den innerkonfessionellen Reformbewegungen vor allem des 17. Jahrhunderts eine zunehmende ,Verinnerlichung' des Glaubens vollzieht. Grob vereinfacht könnte man formulieren: Die akademische Theologie als logisch und systematisch strukturierte ,Theorie' des Glaubens wird gegenüber der ,Frömmigkeit' als dem ,gelebten Glauben', der ,praxis pietatis', zunehmend abgewertet. Diese ,Frömmigkeit' entzieht sich mehr und mehr der dogmatischen, logisch-argumentativen Verfügungsgewalt und wird privates und, paradoxes' Wissen.

Damit reagiert das religiöse Wissen in einer negativen Absetzungsbewegung auf einen Prozess der allgemeinen Wissensgeschichte, in dem genau gegenteilig nur noch das Wissen Gültigkeit beanspruchen kann, das sich als fortschrittsfähig und dynamisch behauptet. Dabei ist insbesondere an das (experimentelle) Wissen der sich konstituierenden, neuen ,Naturwissenschaften' zu denken, in denen sich das Paradigma der Fortschrittsfähigkeit exemplarisch herausbildet. Während dieses Wissen der ,Naturwissenschaften' einem permanenten Prozess der rationalen Kontrolle unterliegt, in dem jeder Widerspruch ein Argument gegen das ganze System darstellt, bilden Dichtung und Religion eine Wissensform heraus, die grundsätzlich als der Geschichtlichkeit überhoben gilt. Die ,ewigen', gleichermaßen aber subjektiven Wahrheiten der Dichtung und Religion werden zum Negativ eines ,wissenschaftlichen', niemals abgeschlossenen Wissens mit objektivem Anspruch.

Eine wichtige Konsequenz dieser ,Verinnerlichung' und ,Subjektivierung' des religiösen Wissens ist die Bildung zahlreicher Heterodoxien, ,Häresien' und individuellen Glaubensformen, die sich als solche nicht mehr einer kirchlich-konfessionellen und akademischen Kontrolle unterstellen. Einen signifikanten Punkt in dieser Entwicklung bilden die 1534 erscheinenden Paradoxa Sebastian Francks, die schon mit ihrem Untertitel zeigen, worauf Franck abzielt: „Wunderreden [...] auß der H. Schrifft/ so vor allem fleysch vngelaublich/ vnd vnwar/ aber doch wider der gantzen welt wahn vnnd achtung/ gewiß vnnd warhafftig seynd“. Das Verfahren der Paradoxa ist damit präzise bestimmt: die Lehren der Bibel sind

1 Sebastian Franck: Paradoxa. Hg. und eingel. von Siegfried Wollgast. Berlin 1995, S. 1. 
unglaublich, widervernünftig, bizarr, aber doch wahr und gewiss. Wenn das so ist, dann hat es keinen Sinn, diese Lehren der Bibel in ein dogmatisches, logisch strukturiertes Korsett zu zwingen, wie es die akademische Theologie tut. Man muss dann vielmehr auf das Wort Gottes selbst hören, wie es in der Bibel steht und wie Franck es in einer Art Sentenzensammlung zusammenstellt, ohne einen logischen Ausgleich oder eine Vermittlung der einzelnen Sentenzen zu versuchen. Man darf die Bibel nicht vor den „Richterstuhl der Vernunft “ zerren, wie es die akademische Theologie tut, sondern man muss das Wort Gottes im eigenen Inneren hören. Dieses Lauschen auf das „innere Wort“ Gottes wird damit zum eigentlichen Gegensatz einer immer bloß äußerlichen, begrifflich verfahrenden Vernunft.

Die Ablehnung der rational verfahrenden, dogmatischen Theologie steht damit von Anfang an in einem zumindest komplementären Verhältnis zur persönlichen, unmittelbaren, göttlichen Inspiration. Das ist es nämlich, was Franck meint, wenn er vom ,,inneren Wort" Gottes spricht, das über aller weltlichen Logik und Rationalität steht. Wer sich aber solcherart auf göttliche Inspiration beruft, der macht jede dogmatische Theologie überflüssig. Während Sebastian Franck seine paradoxen Geheimnisse des Glaubens noch in Prosa formuliert, sind hundert Jahre später (1656) die "geistreichen Sinn- und Schlußreime“ Johann Schefflers genau aus diesem Grund in poetischer Form verfasst. Bekannt geworden sind die Verse Schefflers als Cherubinischer Wandersmann unter dem Namen des Angelus Silesius, den Scheffler nach seiner Konversion zum Katholizismus angenommen hat. Der Cherubinische Wandersmann hat, wie die Paradoxa Francks, die paradoxen Überzeugungen des christlichen Glaubens zum Gegenstand, die doch, obwohl sie jeder Vernunft widersprechen, die höchste Wahrheit für sich beanspruchen können.

Wie Franck beansprucht auch Scheffler eine unmittelbare göttliche Inspiration, und wie Franck fordert auch Scheffler mit seinem Widerspruch gegen die Herrschaft der Vernunft und mit seiner Berufung auf unmittelbare göttliche Inspiration die protestantische Schultheologie heraus. Dieser Konflikt führt bei Scheffler unmittelbar zur Konversion zur katholischen Kirche, denn Scheffler glaubt die lange Tradition der Mystik und Spiritualität, in der er sich selbst stehen sieht, dort besser aufgehoben als bei den ,geistfeindlichen' Protestanten. Diese ,Geistfeindlichkeit' benennt Scheffler ausdrücklich, wenn er den Protestanten die „freventliche Verwerfung“ der Mystik und die "Abgötterei der Vernunft“ zum Vorwurf macht. ${ }^{2}$ Im Gegensatz zu Franck bedient sich Scheffler jetzt auch der poetischen Form, um seiner Opposition zur „Abgötterei der Vernunft“ in der akademischen Theologie sinnfälligen Ausdruck zu verleihen. Die Epigramme Schefflers sind nicht geschrieben, um argumentativ zu überzeugen, sondern sollen den Leser

2 Johannes Scheffler [Angelus Silesius]: Gründtliche Vrsachen vnd Motiven, warumb er von dem Lutherthumb abgetretten vnd sich zu der Catholischen Kyrchen bekennet hat. In ders.: Sämtliche poetische Werke. Hg. und eingel. von Hans Ludwig Held. München 1953, Bd. 1, S. 233-254, hier S. 240, Punkt XI. 
gerade an die Grenzen der Vernunft führen. Die poetische Form wird zur Herausforderung der akademischen Theologie.

Der Gegensatz von logischer verfahrender Vernunft und poetischer Form kommt in den paradoxen Konstruktionen Schefflers in besonders deutlicher Form zum Ausdruck, ist in weniger offensiver Form aber geradezu konstitutiv für die gesamte Andachts- und Erbauungsliteratur, der Schefflers Cherubinischer Wandersmann angehört. Schon von ihrem Umfang her handelt es sich bei dieser Andachts- oder Erbauungsliteratur um eine der bedeutendsten poetischen Erscheinungen des 17. Jahrhunderts. Was die Andachtsliteratur als poetische Form der Frömmigkeitsbewegung charakterisiert, ist ihre Ausrichtung auf die individuelle Frömmigkeit des Lesers, das heißt auf seine ,Bekehrung' zu einem tatsächlich frommen, christlichen Leben. ,Andacht' und ,Erbauung' bezeichnet insofern nichts anderes als eben eine alltäglich praktizierte Frömmigkeit. Zu diesem Zweck bedient sich die Andachtsliteratur überhaupt poetischer Formen. Die durch rhetorische Stilmittel erzeugte Anschaulichkeit und sinnliche Präsenz, die Musikalität der metrisch geordneten Sprache, die mnemotechnische Funktionalität des Verses dienen der Vergegenwärtigung und Verinnerlichung eines religiösen Wissens. Weil die Frömmigkeit eben nicht auf rationale Begründung und argumentative Überzeugung zielt, sondern auf eine dauernde Präsenz der Glaubensinhalte im „Herzen“ des Lesers, sind poetische Formen dieser Frömmigkeit wesentlich angemessener als abstrakte Argumente. Hier findet eine Annäherung von poetischer Form und religiösem Wissen statt, die mit der späteren ,Lyrik bereits ihre ,Subjektivität', ihre ,Innerlichkeit' und Bekenntnishaftigkeit gemeinsam hat.

In ihren radikalen Formen ist dieses genauso paradoxe wie subjektive religiöse Wissen in lyrischen Formen deshalb auch gar nicht mehr verständlich, das heißt der Vernunft überhaupt noch zugänglich. In Quirinus Kuhlmanns Kühlpsalter (1684) heißt es einleitend, dessen Gesänge könnten ,alleine in dem stande völlig verstanden werden, darinnen si geschriben. Denn si sind aus lebendiger Erfahrung hervorgeflossen, und wirstdu erst wissen, was hir geschriben, wann du es erst wirst wissen ". ${ }^{3}$ Hier bildet sich, so könnte es scheinen, der "Hermetismus der modernen ,Lyrik' mit seiner spezifisch religiös wie ,subjektiv' begründeten Unverständlichkeit.

Ihren historisch prominentesten Ausdruck hätte die Entwicklung dieser ,Lyrik' dann allerdings erst ein Jahrhundert später etwa bei Goethe erreicht, wenn dieser sein pantheistisches Bekenntnisgedicht „Eins und Alles“ mit den Worten begleitet: „Ich werde selbst fast des Glaubens, daß es der Dichtkunst vielleicht allein gelingen könne, solche Geheimnisse gewissermaßen auszudrücken, die in Prosa gewöhnlich absurd erscheinen, weil sie sich nur in Widersprüchen ausdrü-

3 Quirinus Kuhlmann: Der Kühlpsalter. Hg. v. Robert L. Beare. Tübingen 1971, Bd. 1, S. 3. 
cken lassen, welche dem Menschenverstand nicht einwollen. ${ }^{4}$ Hegel bringt dieses Wesen der neuen Gattung in die Formel, in der Lyrik spreche sich das Subjekt in seiner höchsten Subjektivität aus. ${ }^{5}$

$\mathrm{Zu}$ den Qualitäten dieser ,Lyrik' gehört damit per definitionem der Gegensatz zur rational-logischen Konstruktion. Als authentischer Ausdruck einer Empfindung gilt sie stattdessen, und je mehr sie sich von dieser ursprünglichen Empfindung entfernt, je artifizieller sie wird, als desto poetisch wertloser gilt sie jetzt. „Frey aus der schaffenden Sel enttaumeln“, solle das Gedicht, heißt es bei Klopstock, ${ }^{6}$ und damit ist der Gegensatz zur rational bewussten Konstruktion gemeint. Als „unstudierten Ausdruck der Empfindung“ bezeichnet Johann Elias Schlegel das Gedicht, und auch das bezeichnet den Gegensatz zur Logik. ${ }^{7}$

Weil die Vernunft die Konstruktion eines solchen ,Gedichts' per se nicht leisten kann, ist es eine vor- und überrationale Inspiration, die an ihre Stelle tritt. Dass es sich dabei um eine göttliche Inspiration handelt, behauptet nun allerdings kaum jemand mehr. Alexander Gottlieb Baumgarten etwa, der Begründer der Ästhetik, spricht von einer „Hebung des dunklen Grundes der Seele“, der vom Dichter bloß als Inspiration erlebt werde. ${ }^{8}$ Goethe spricht von einer „enthusiastischen Aufgeregtheit" als Wesen der "Lyrik", ${ }^{\prime \prime}$ und auch hier ist im Begriff des Enthusiasmus die ehemals göttliche Inspiration noch gegenwärtig. Die Versform, die bisher vor allem Ausdruck mnemotechnischer, musikalischer, metrischer und im weitesten Sinne ,artistischer', nämlich technischer Anforderungen einer ,Kunstfertigkeit‘ (ars) war, wird jetzt zum Ergebnis einer besonderen ,Inspiration', die sich der Kontrolle des Verstands entzieht oder zumindest entziehen kann.

Die vielleicht prominentesten Formen, die diese ,Lyrik' annehmen kann, treten in ,Naturlyrik' und ,Liebeslyrik' zutage. Im Unterschied zu einer älteren Dichtung, in der Natur nur als mehr oder weniger topischer Gegenstand der Beschreibung firmiert, konstituiert sich im frühen 18. Jahrhundert eine spezifische Ausdrucksform, in der die Natur als göttlich beseeltes Wesen erscheint, das dem ,lyrischen Ich' affektiv antwortet. Der Naturbegriff, der dieser ,Lyrik' zugrun-

4 Johann Wolfgang Goethe: Sämtliche Werke. Briefe, Tagebücher und Gespräche. Bd. II.9: Zwischen Weimar und Jena. Hg. von Dorothea Schäfer-Weiss. Frankfurt/M. 1999, S. 215 (Goethe an Riemer, 28. 10. 1821).

5 Georg Wilhelm Friedrich Hegel: Werke Bd. 15: Vorlesungen über die Ästhetik III. Hg. von Eva Moldenhauer und Karl Markus Michel. Frankfurt/M. 1986, S. 415-473.

6 Friedrich Gottlieb Klopstock: Alcäische Ode. 1747 - Auf meine Freunde, v. 6. In ders.: Werke und Briefe. Bd. 1.1: Oden. Hg. von Horst Gronemeyer und Klaus Hurlebusch. Berlin, New York 2010, S. 6.

7 Johann Adolf Schlegel: Vorrede zur Übersetzung von Charles Batteux: Einschränkung der schönen Künste auf einen einzigen Grundsatz. Aus dem Französischen übersetzt und mit Abhandlungen begleitet von Johann Adolf Schlegel. Leipzig 1770. Ndr. Hildesheim, New York 1976, S. XVII.

8 Alexander Gottlieb Baumgarten: Ästhetik. Übers., mit einer Einf., Anm. und Reg. hg. von Dagmar Mirbach. Hamburg 2007, § 80.

9 Johann Wolfgang Goethe: West-östlicher Divan. Hg. von Karl Richter. In ders.: Sämtliche Werke Bd. 11.1.2. München 1998, S. 194. 
deliegt, ist damit von vornherein religiös geprägt, ohne dass allerdings bisher in der Forschung eindeutig hätte geklärt werden können, welche Religion oder Frömmigkeit in diesem Naturbegriff zum Ausdruck kommt. Ähnliches gilt für die ,Liebeslyrik'. Viele Argumente sprechen dafür, dass der moderne Begriff einer "Liebe als Passion“ seine Wurzeln in der geistlichen Dichtung der Frühen Neuzeit hat, in der Hingabe etwa, mit der sich eine Greiffenberg Christus als dem "Seelenbräutigam" widmet, ${ }^{10}$ oder mit der sich ein Zinzendorf in die Wunden Christi vertieft. Auch für die ,Liebeslyrik', in der die Konstruktion der Innerlichkeit, Gefühlsintensität und ,Subjektivität’ des 18. Jahrhunderts ihren Höhepunkt findet, wäre damit zu fragen, inwiefern hier ein spezifisch religiöses Wissen transferiert und transformiert wird.

Daraus sollte auch deutlich geworden sein, dass uns bewusst ist, dass der Begriff der ,Lyrik' in Bezug auf die Frühe Neuzeit ein anachronistisches Konstrukt darstellt. Wer diesen Begriff unreflektiert auf die Frühe Neuzeit als analytische Kategorie anwendete, würde sich schwerster Verzerrungen schuldig machen, wie sie noch überall zu besichtigen sind, wo am Diltheyschen Begriff einer „Erlebnislyrik", abgeleitet aus der Dichtung der Goethezeit, die Geschichte einer ,Lyrik' als Gattung gemessen wird. Im strengen historischen Sinne gibt es keine ,Lyrik' des 17. Jahrhunderts. Der Begriff der ,Lyrik', dessen Genese uns interessiert, betrifft aber gerade nicht eine Gattungsgeschichte, verstanden im Hegelschen Sinne als quasi ontologische, substanzielle Kategorie, die sich ankündigt, entwickelt und dann zu einem bestimmten historischen Zeitpunkt ihre höchste Entfaltung gefunden hätte. Genau im Gegenteil geht es uns darum, Bausteine für eine Geschichte der Genese dieser ,Lyrik' als Gattung zu liefern. Im Sinne des wissensgeschichtlichen Programms des Sonderforschungsbereichs „Episteme in Bewegung" möchten wir gerade die Verschiebungen und Transfers rekonstruieren, die sich im religiösen und poetischen Wissen ereignen mussten, um eine Erscheinung wie die ,Lyrik' als Ausdruck eines paradoxen, ,subjektiven' Wissens herauszubilden.

Selbstverständlich möchten wir uns deshalb auch klar von jeder teleologischen Interpretation dieses Prozesses abgrenzen. Die Entstehung der ,Lyrik' als Gattung im engeren Sinne des 18. Jahrhunderts ist kein teleologischer, also zielgerichteter und zweckmäßig ablaufender Prozess, der dann womöglich noch in Goethe sein Ziel und seine höchste Entfaltung gefunden hätte. Auf der anderen Seite darf Teleologie jedoch nicht mit Kausalität verwechselt werden, und wer teleologische Prozesshaftigkeit bestreitet, muss deshalb nicht auch Kausalität bestreiten. Gegen die Rekonstruktion von Finalursachen im Sinne einer Teleologie kann und muss man im historischen Kontext polemisieren (wie es seit Kant ja auch immer wieder geschehen ist), gegen die Rekonstruktion von Wirkursachen

10 Der Aspekt der ,Liebeslyrik' ist leider in diesem Band nicht vertreten. Vgl. aber zuletzt HansGeorg Kemper: Hermetisch-poetischer Liebes-Zauber. Von der mystischen „Jeßus-wollust" zur ,Passion' der Liebesehe. In: Konzepte des Hermetismus in der Literatur der Frühen Neuzeit. Hg. von Peter-André Alt und Volkhard Wels. Göttingen 2010, S. 393-432. 
kann man dagegen nur polemisieren, wenn man dazu bereit ist - im Sinne etwa von radikal dekonstruktivistischen Ansätzen - den Begriff einer Geschichte als Abfolge von Ursache und Wirkung ganz aufzugeben. In diesem Sinne arbeiten wir tatsächlich an einer Geschichte der ,Lyrik' als einer spezifischen Wissensund Ausdrucksform, die sich im 18. Jahrhundert aus und in den Transferbewegungen des religiösen Wissens bildet.

Damit ist auch gesagt, dass wir nicht der Meinung sind, dass die Ausprägung einer solcherart ,subjektiven' und ,paradoxen' ,Lyrik' das Ergebnis einer irgendwie notwendigen Entwicklung war und keine anderen Formen metrisch und rhythmisch strukturierter Rede möglich gewesen wären und auch tatsächlich realisiert worden sind. Ganz im Gegenteil sind gerade diese Formen und Prozesse - wie sie etwa Irmgard Scheitler, Andreas Lindner und Andreas Beck in ihren Beiträgen untersuchen - von besonderem Interesse, denn vor ihrem Hintergrund werden die Ursachen, die den goethezeitlichen Begriff einer ,Lyrik' hervorgebracht haben, nur umso deutlicher.

Dass es im Übrigen Widersprüche und Gegensätze innerhalb der Beiträge dieses Bandes gibt, ist den Herausgebern bewusst und angesichts der Forschungslage auch nicht erstaunlich. Differenzen waren deshalb nicht einzuebnen, sondern sollten als Forschungsperspektiven produktiv gemacht werden.

\section{Die Beiträge des Bandes}

Eröffnet wird der Band mit einem Beitrag von Irmgard Scheitler, die die konfessionellen Differenzen in Verbreitung und Gebrauch religiöser Gesangslyrik untersucht und dabei einen Befund bestätigt, den man in dieser Form bereits erwartet hat: das katholische Liedschaffen ist erheblich geringer als das protestantischlutherische. Scheitler verleiht diesem Befund allerdings eine neue Plastizität, indem sie nicht nur nach der Anzahl der gedruckten religiösen Lieder oder der Gesangbücher fragt, sondern allgemein nach den Möglichkeiten, im Gottesdienst zu singen, nach den Zeugnissen für geistlichen Liedgesang im Alltag, nach der Kontrafakturpraxis bei Neudichtungen und nach der Verwendung von geistlichen Melodien in der Vokal- und Instrumentalmusik.

Andreas Lindner widmet sich mit seinem Beitrag zur lyrischen Verinnerlichung der lutherischen Standes- und Berufsethik einem besonderen Aspekt des lutherischen Liedschaffens, nämlich der Rubrik "In Arbeit und Beruf“, die sich seit dem 17. Jahrhundert in lutherischen Gesangbüchern findet. Lindner zeichnet an den Beständen der Gesangbücher nach, wie die Ethik einer bewussten Erfüllung der aus dem eigenen Stand resultierenden beruflichen Pflichten als Ausdruck lutherischer Frömmigkeit durch ein entsprechendes Liedgut tradiert wurde und das Gesangbuch dabei, mehr noch als die Bibel, zum eigentlichen Medium dieser Frömmigkeit wurde.

Daran schließt sich der Beitrag von Günter Butzer an, der Gedichte von John Donne, Catharina Regina von Greiffenberg, Thomas Traherne und Andreas Gryphius hinsichtlich des religiösen Wissens untersucht, das in diesen Gedichten als 
Formen der Übung oder Meditation eingeübt wird. Das religiöse Wissen dieser Gedichte erscheint dabei nicht als bloßer Import eines deklarativen, begrifflichen Wissens aus der Theologie in die Dichtung, sondern vielmehr als ein prozedurales, praktisches, episodisch-emotives und stimmungshaftes Wissen, das von der Dichtung selbst generiert wird.

Franz Eybl wendet sich der lyrischen Inszenierung optischer Evidenz bei Spee, Greiffenberg und Brockes zu. Eybl zeigt an deren Gedichten, dass zwischen dem Akt des Sehens als physiologischer Tätigkeit, der ,Betrachtung' als meditativerbaulicher Tätigkeit im Sinne der exercitia spiritualia und der poetischen Gestaltung des damit bezeichneten Meditationsprozesses im Sinne der rhetorischen evidentia unterschieden werden muss. Während bei Spee und Greiffenberg diese Techniken im Dienst einer Disziplinierung des Blicks stehen, zeichnet sich bei Brockes bereits die frühaufklärerische Transformation dieses Modells im Sinne eines neuen Paradigmas der geselligen Aufmerksamkeit ab.

Peter-André Alt widmet sich dem Verhältnis von Allegorie und Paradoxie in Gedichten von John Donne, George Herbert, Daniel von Czepko und Angelus Silesius. Alt zeigt, wie in diesen Gedichten ein paradoxes, religiöses Wissen durch die Mittel der Allegorie sprachlich dargestellt wird. Dabei dient die Allegorie allerdings nicht nur der sprachlichen Darstellung, sondern wird auch zum Medium für die reflexive Verarbeitung dieser Widersprüche und modelliert damit ein eigenständiges poetisches Wissen als ein über die Form konstituiertes Darstellungswissen.

Gesa Dane fragt in ihrem Beitrag nach dem Stellenwert religiösen Wissens in Daniel Casper von Lohensteins Preisgedicht "Venus“, einem Gedicht, das sich dadurch auszeichnet, dass es auf textinterne Hinweise zum richtigen Verständnis dieses Lobpreises des Eros gänzlich verzichtet. Dane zeigt jedoch, dass das Gedicht deshalb nicht unbedingt als Ausdruck eines christlichen Epikurismus gelten muss, indem also der antike Venus-Kult gegen die christliche Moderne ausgespielt würde, sondern auch als gelehrtes Spiel mit dem religiösen Wissen der Antike und der Gegenwart verstanden werden kann. Aufgrund seiner naturrechtlichen Prämissen kann Lohenstein das anthropologisch Gleichrangige menschlichen Verhaltens auch unter den Bedingungen unterschiedlicher Religionen herausarbeiten.

In eine ähnliche Richtung zielt Stefan Elit, der sich dem Stellenwert religiösen Wissens in der galanten Dichtung widmet. Auch wenn diese auf den ersten Blick eine rein säkulare Dichtung scheint, gibt es doch eine begrenzte Zahl von Spielarten, wie sich die galanten Dichter zu religiösen Fragen äußern. Innerhalb dieser Äußerungen lässt sich sogar eine Entwicklung beobachten, die eine zunehmende Ernsthaftigkeit in religiösen Fragen bezeugt. Diese Tendenzen bestätigen sich hinsichtlich der an die galante Dichtung anschließenden Anakreontik, die nachhaltiger als diese eine christlich-ethische Ästhetik mit individualisierenden Tendenzen verknüpft. 
Ralph Häfner untersucht in seinem Beitrag den prekären Status der Muße im Zeitalter der Frühaufklärung an Hand von Johann Christian Günthers Verssatire „Der entlarvte Crispinus“(1718). Günther pathologisiert in dieser Satire auf den Polyhistor Theodor Krause das oberflächliche, gesellschaftlich irrelevante Vielwissen und bedient sich dabei der geistlichen Odenform in burlesker Umkehrung. Die Satire wird zur Kontrafaktur einer Märtyrerlegende.

Andreas Beck widmet sich in seinem Beitrag dem Münchner Augustinereremiten Gelasius Hieber und seinen 1725 im Parnassus Boicus provokant unter dem opitzianischen Titel „Von der teutschen Poeterey“ veröffentlichten Poetik und deren Beispielgedichten. Noch zu Beginn des 18. Jahrhunderts sind deren Verse geprägt von einem orthodox katholischen, religiösen Wissen und in einer konventionell artistisch gestalteten, verständlichen Verssprache formuliert, fernab von subjektiv-paradoxen Entwicklungen.

Simone De Angelis zeigt in seinem Beitrag, wie sich der neue, empiristische Naturbegriff von Alexander Pope und Albrecht von Haller nicht nur im NewtonBild widerspiegelt, das deren Dichtungen propagieren, sondern auch im Nachdruck auf einem natürlichen, das heißt nicht von ,phantastischer', ,unnatürlicher Bildlichkeit geprägten Stil beider Autoren. Dieser ,natürliche Stil` korreliert mit dem neuen Empirismus der ,Wissenschaften vom Leben', wie sie Haller als Experimentalphysiologie paradigmatisch repräsentiert, im Gegensatz zu der mit Newton assoziierten, geometrisch-mathematischen Methode. Genauso hängt auch der moralische Anspruch von Hallers Dichtung mit der naturrechtlichen Prägung seines Naturbegriffs zusammen.

Mark-Georg Dehrmann widmet sich der spezifischen Rolle, die die Dichtung um 1700 im Prozess der Gotteserkenntnis übernehmen kann und wie sie Shaftesbury Moralists (1709/1711) vorführen. Die Moralists inszenieren eine enthusiastische Gotteserkenntnis ohne Rekurs auf genuin christliche Dogmen und sind damit dem Vorwurf des Deismus ausgesetzt. Indem sich diese enthusiastische Gotteserkenntnis in einer poetischen Hymne vollzieht, reflektieren die Moralists nicht nur über den Enthusiasmus als solchen, sondern auch über den besonderen Status der Dichtung in dieser Erkenntnisbewegung, die eine Teilhabe am göttlichen Geist ermöglichen soll.

Volkhard Wels erörtert in seinem Beitrag den Naturbegriff von Barthold Heinrich Brockes' Irdischem Vergnügen in Gott, indem er diesen von einem lutherischen Begriff der Natur als Ausdruck der biblischen Offenbarung abgrenzt, andererseits aber dennoch in einer auf Melanchthon zurückgehenden, protestantischen Tradition verortet, in der die Natur als Schöpfung Gottes erscheint. Dieser Melanchthonische Begriff der Natur ist wiederum anschlussfähig an den mechanistischen Naturbegriff der ,new sciences', so dass protestantische Schultheologie und neue ,Naturwissenschaft' nicht mehr als Oppositionen erscheinen.

Im Gegensatz dazu führt Hans-Georg Kemper in seinem anschließenden Beitrag den Naturbegriff der entstehenden ,Naturlyrik' auf eine hermetisch-pantheistische Religiosität zurück. Der religionsgeschichtliche Kontext hat dabei zwar 
eine gattungsbildende ,Vorgeschichte' im engeren Sinne verhindert, durch seine pantheisierende kosmotheologische Religiosität aber die Aneignung der hermetischen Tradition gefördert. Kemper zeichnet diesen Prozess an der Rezeption des Psalms 8 von Luther über Gerhardt, Gellert, Greiffenberg und Brockes nach, bis hin zu den Lyrikern des Sturm und Drang und ihrer ,Naturlyrik'.

Auch im Mittelpunkt von Jörg Roberts Beitrag steht Brockes. Robert ordnet Brockes' „Firmament" in eine Tradition mystischer Ekstase-Erfahrungen ein. Einerseits sind in diesem Gedicht zwar noch die semantischen Ressourcen mystischen Erlebens und Sprechens präsent, andererseits findet aber bereits ein Transfer auf Felder statt, in denen der Transzendenzbezug bereits zurücktritt gegenüber innerweltlichen Erschließungs- und Erfahrungsweisen. Lyrische Ekstasen erscheinen so als Gedichte, die bereits den Versuch unternehmen, das Erlebnis der Ekstase narrativ und performativ nachzuvollziehen und damit präadaptive Formen von Erlebnis- und Erlebenslyrik ausbilden. Als ein solcher narrativer Nachvollzug stehen sie in einer erstaunlichen Parallele zu Berichten über Nahtoderlebnisse.

Im letzten Beitrag des Bandes schließlich skizziert Kevin Hilliard anhand der Sinnfrage menschlicher Existenz die Kontroversen zwischen Philosophie, Theologie und Dichtung um das Recht, diese Frage zu beantworten. Lyrische ,Subjektivität' konstituiert sich dabei geradezu in einer Allianz von Theologie und Dichtung gegen die Rationalitätsansprüche der Philosophie seit Descartes. Erst in der lyrisch-affektiven Steigerung des Staunens über die eigene Existenz (paradigmatisch in der Erfahrung des Sonnenaufgangs) kann die Antwort auf die Grundfragen menschlicher Existenz gelingen. Wiederum insbesondere an Brockes zeigt Hilliard, wie dieses gattungskonstituierende Staunen der Lyrik im Sinne einer prisca theologia fruchtbar gemacht wird. Bei Hölderlin ist es dann umgekehrt, erzwungen durch den Verlust der theologischen Rückendeckung, die profanierende Ernüchterung des Sonnenuntergangs, in dem sich das Verstummen poetischer Inspiration ausdrückt.

Die Beiträge dieses Bandes sind aus den Vorträgen hervorgegangen, die auf der gleichnamigen, von der Deutschen Forschungsgemeinschaft finanzierten Tagung an der Freien Universität Berlin vom 26. bis 28. September 2014 gehalten wurden. Veranstaltet wurde die Tagung vom Sonderforschungsbereich 980 „Episteme in Bewegung", innerhalb dessen die beiden Herausgeber ein Teilprojekt zu Paradoxien als Indikatoren epistemischer Umbrüche im 16. und 17. Jahrhundert bearbeiten. Die Herausgeber danken dem Sonderforschungsbereich für die finanzielle Unterstützung und die Aufnahme des Bandes in seine Schriftenreihe. Den Autorinnen und Autoren der Beiträge sei insbesondere für ihre konstruktive Mitarbeit gedankt, die eine zügige Fertigstellung des Bandes ermöglicht hat. 
(C) 2015, Otto Harrassowitz GmbH \& Co. KG, Wiesbaden ISBN Print: 9783447104975 — ISBN E-Book: 9783447194136 


\title{
Konfessionelle Differenzen in Verbreitung und Gebrauch religiöser Gesangslyrik
}

\author{
Irmgard Scheitler
}

Die folgenden Ausführungen konzentrieren sich unter Berücksichtigung des 16. Jahrhunderts auf das 17. Jahrhundert. Sie wollen weniger in bekannter Weise nach der Anzahl der gedruckten religiösen Lieder, der Distribution der Gesangbücher oder dem Proporz geistlicher Lyrik in Personaldrucken fragen; vielmehr sollen andere, praxisnahe Kriterien für den Nachweis von Verbreitung angelegt werden. Gefragt werden soll nach den Möglichkeiten, im Gottesdienst zu singen, und nach den Zeugnissen für geistlichen Liedgesang im Alltag. Beleuchtet wird die Kontrafakturpraxis bei Neudichtungen als Beweis für die Kenntnis einer Melodie und mithin des mit ihr verbundenen Liedes und zwar am Korpus des populärsten Mediums, des Liedflugblatts. Aber auch die Verwendung von geistlichen Melodien in der Vokal- und Instrumentalmusik soll als ein aufschlussreiches Beweismittel für die Vertrautheit von Komponist und Publikum mit geistlichen Melodien genützt werden. Schließlich wird die innerliterarische Verwendung von Kirchenliedern, vornehmlich in Schauspielen, in den Blick kommen.

Gemäß der Forschungslage muss den drei großen Konfessionen sehr verschiedenes Gewicht eingeräumt werden. Dass die reformierte Konfession unbeachtet bleibt, erklärt sich durch die nahezu monopolistische Stellung, die in der fraglichen Zeit der Lobwasser-Psalter in ihr innehat. ${ }^{1}$ Doch auch im Vergleich zum Luthertum werden die nachfolgenden Betrachtungen der wesentlich schlechter erforschten katholischen Seite viel mehr Aufmerksamkeit schenken müssen. Von Anfang an sei darauf hingewiesen, dass dem Wissenschaftler, was die katholische Hymnologie anbetrifft, ein vermessenes Fundament fehlt, auf dem er aufbauen könnte.

\section{Verbreitung und Gebrauch religiöser Gesangslyrik in der evangelischen Konfession}

In der Formula Missae (1523) und der Deutschen Messe (1526) hatte Luther den Wunsch nach Einbeziehung des Volksgesangs in den Gottesdienst geäußert. Das letzte zu Lebzeiten des Reformators erschienene ,Babstsche Gesangbuch' (Leipzig 1545) enthält in zwei Teilen ca. 100 deutsche Strophenlieder, die mit ihren

1 Vgl. auch Der Genfer Psalter und seine Rezeption in Deutschland, der Schweiz und den Niederlanden. 16.-18. Jahrhundert. Hrsg. von Eckhard Grunewald, Henning P. Jürgens und Jan R. Luth. Tübingen 2004. 
Melodien fortan den Kern der lutherischen Gemeindegesangbücher bildeten. Die Liedproduktion ging aber weiter. Der Protestantismus legte im 16. Jahrhundert ca. 500 Gesangbücher mit nahezu 4000 Liedern vor. Das alte Kirchenlied errang schnell den Status eines Glaubenssymbolon. Die Agenden schrieben gewisse Gesänge für die Sonn- und Feiertage fest, der deutsche Liedgesang war damit etabliert. Dass weiterhin lateinisch musiziert wurde, tut dem keinen Abbruch, ebenso wenig wie die Tatsache, dass weniger das Volk Gottes, als vielmehr die Schüler und die Chöre sangen. Im Gegenteil: Nachdem das Deutsche im Gottesdienst voll legitimiert war, öffneten sich Tür und Tor für kunstvolle deutsche Vokalmusik.

Das Sonntag für Sonntag im Gottesdienst gehörte, in der Kinderlehre erlernte, in der Liedpredigt und der Postille wieder aufgegriffene und erläuterte Lied wurde zu einem festen Bestandteil des kollektiven Bewusstseins. Es war im Alltag gegenwärtig, der gläubige Christ sang die Lieder zur Arbeit, zur Hausandacht und zur Entspannung im Freundeskreis, er wählte sie zur Taufe und Hochzeit seiner Kinder aus und widmete sie ihnen, er ließ sich von einem Gesang beim Sterben begleiten und bestellte das selbst ausgewählte Grablied vorweg. ${ }^{2}$

Das Lied war in der Kirche und im Alltag präsent. Was Wunder, dass es dem Dichter in den Sinn kam, wenn er sich zum Verfassen eines lyrischen Gebildes anschickte? Will man die selbstverständliche Präsenz eines Liedes und seiner Melodie im kulturellen Leben einer Gesellschaft nachweisen, so ist die Kontrafaktur ein hervorragendes Beweismittel. Eine schier unermessliche Zahl erbaulicher Lieder auch bedeutender Barockautoren wurde auf geläufige geistliche Melodien geschrieben, mögen sie auch noch eine moderne Generalbasskomposition bekommen haben. Dies lässt sich von Birken bis Paul Gerhardt, von Gryphius bis Rist beobachten.

$\mathrm{Ob}$ in Choralfantasie oder Kantate, im schlichten Kantionalsatz für den Schülerchor, in Motette, Passion oder Oratorium: Choräle sind in der evangelische Kirchenmusik präsent und garantieren die konfessionelle Identität. Das Lied erklingt mit vollem Text als eigener Satz, liegt als Cantus firmus über einer konzertanten eigenständigen Komposition, wird variiert, modifiziert, harmonisch und polyphon durchgearbeitet. Der Christ erkennt es sogar im bloßen Melodiezitat. Die Tonfolge allein genügt, um den Sinn zu transportieren: Musik wird seman-

2 Vgl. die zahlreichen Beispiele für die Verwendung bei Irmgard Scheitler: Das Geistliche Lied im deutschen Barock. Berlin 1982. Vgl. Christian Weise: Curieuser Körbelmacher/ Wie solcher auff dem Zittauischen Theatro den 26. Octobr. 1702 von Etlichen Studirenden praesentiret worden/ Anietzo aus gewissen Ursachen herausgegeben. Görlitz: Rohrlach 1705, Akt I, Szene 1: Korbmacher singen während der Arbeit die Schlussstrophe von „Aus meines Herzens Grunde“: „So streck ich aus meine Hand/ I Greiff an das Werck mit Freuden/ I Wozu mich Gott hat bescheiden I In meinem Beruf und Stand“. Philipp Wackernagel: Das deutsche Kirchenlied von der ältesten Zeit bis zu Anfang des XVII. Jahrhunderts. 5 Bde. Leipzig 1864-1877, Reprint Hildesheim 1964, Bd. V Nr. 248; Das deutsche Kirchenlied. Kritische Gesamtausgabe der Melodien. Vorgelegt von Joachim Stalmann, bearbeitet von Karl-Günther Hartmann, Hans-Otto Korth u. a. (= Das deutsche Kirchenlied III/1-4) Kassel 1993 ff. (im Folgenden zitiert EdK mit Sigle), EdK A247B;D;E;G;H. 
tisch besetzt. Beispiele finden sich in großer Zahl. So erinnert in Johann Sebastian Bachs Kantate „Wachet, betet" (BWV 70) das Rezitativ des Basses in Satz 9 an das drohende Ende des Lebens und das kommende Gericht. Die Trompete intoniert den Choral „Es ist gewisslich an der Zeit“ und interpretiert die Dichtung. ${ }^{3}$

Knapp 100 verschiedene Kirchenlieder kommen in den Schauspielen des 16. und 17. Jahrhunderts vor. Sie erklingen zur Eröffnung und zum Ausklang, zur Begleitung der Tableaux, als Repliken, als Zwischenaktchöre, als Bühnenlieder, ja sogar als zitiertes geflügeltes Wort. Die Häufigkeitsliste wird angeführt von „Vom Himmel hoch da komm ich her" und „Ein feste Burg ist unser Gott" ${ }^{4}$ Kirchenlieder werden von den ersten Dramen eines Burkart Waldis oder Sixt Birck bis zu Rollenhagen, Rinckart und Stieler eingesetzt. Im 17. Jahrhundert treten dann die neuen Lieder Rists an die Stelle der altehrwürdigen, die aber gleichwohl nicht völlig verschwinden. ${ }^{5}$ Angelus Silesius ist, obgleich während der Entstehungszeit seiner Geistlichen Hirtenlieder konvertiert, mit mehreren Liedern in evangelischen Schauspielen vertreten, der heute so hochgeschätzte Paul Gerhardt fehlt hingegen ganz. Friedrich von Spees „O Traurigkeit, o Herzeleid“ kam in Adaptation durch Rist zu ungeahnter Verbreitung in Passion und Schauspiel. ${ }^{6}$

\section{Verbreitung und Gebrauch religiöser Gesangslyrik in der katholischen Konfession}

\section{Im Gottesdienst}

Welche Bedeutung das Lied für die Verbreitung der neuen Lehre hatte, erkannten die Katholiken sehr bald. Der propagandistische Erfolg des Liedgesangs war so offensichtlich, dass man ihn auf altkirchlicher Seite nicht übersehen und übergehen konnte. ${ }^{7}$ Bald schon begannen auch altkirchliche Theologen, Georg

3 Weitere Beispiele aus dem Kantatenwerk bieten z. B. BWV 9; 19; 70; 106, 163; 77; 106; 172.

4 Vgl. Irmgard Scheitler: Schauspielmusik. Funktion und Ästhetik im deutschsprachigen Drama der Frühen Neuzeit. Bd. I: Materialteil. Tutzing 2013. Das Weihnachtslied kommt siebzehnmal, das Kampflied fünfzehnmal vor.

5 Vgl. Irmgard Scheitler: Die Rezeption der Lieder Rists im Schauspiel der Frühen Neuzeit. In: Johann Rist (1607-1667). Profil und Netzwerke eines Pastors, Dichters und Gelehrten. Hrsg. von Johann Anselm Steiger, Bernhard Jahn, Axel E. Walter. Berlin u. a. 2015, S. 240-257.

6 Vgl. Irmgard Scheitler: Deutschsprachige Oratorienlibretti. Von den Anfängen bis 1730. Paderborn 2005, Liedregister S. 428. Scheitler: Schauspielmusik (Anm. 4), S. 217; 305; 366; 920.

7 Zum Folgenden vgl. auch: Michael Härting: Das deutsche Kirchenlied der Barockzeit. In: Geschichte der katholischen Kirchenmusik. Hrsg. von Karl Gustav Fellerer. Bd. 2: Vom Tridentinum bis zur Gegenwart. Kassel u. a. 1976, S. 108-118. Hans Schmidt: Kirchenlied, katholisch. In: MGG, 2. Aufl. Sachteil, Bd. 5. Kassel u. a. 1996, Sp. 110-115. Philipp Harnoncourt: Deutscher Gemeindegesang im katholischen Gottesdienst seit Beginn der Reformation. In: Gesamtkirchliche und teilkirchliche Liturgie. Studien zum liturgischen Heiligenkalender und zum Gesang im Gottesdienst unter besonderer Berücksichtigung des deutschen Sprachgebiets. Freiburg i. Br. 1974, S. 317-354. Irmgard Scheitler: Geistliche Lyrik. In: Hansers Sozialgeschichte der deutschen Literatur vom 16. Jahrhundert bis zur Gegenwart. Bd. II: Das 17. Jahrhundert. Hrsg. von Albert Meier. München 1999, S. 347-377. Irmgard Scheitler: Geistliches Lied. In: Literaturlexikon. Hrsg. von Walther Killy. Bd.13: Begriffe, Realien, Methoden. Hrsg. von Volker Meid. Gütersloh, München 1992, S. 348-351 und Kirchenlied, Gesang- 
Witzel, ${ }^{8}$ Michael Vehe, ${ }^{9}$ und v. a. Johann Leisentrit, ${ }^{10}$ Lieder für den gemeinschaftlichen Gebrauch zusammenzustellen. Stets berief man sich dabei auf die bis in die früheste Zeit zurückgehende Tradition gottesdienstlichen Singens. Deutsche Lieder sollten nach den Vorstellungen der katholischen Reformer, die eine Abwanderung ihrer Gläubigen befürchteten, aber nicht nur wie im Mittelalter vor und nach der Predigt oder zur Elevation, sondern auch zum Credo, Offertorium, Vaterunser und zur Kommunion erklingen. ${ }^{11}$ Die kirchlichen Behörden setzten diesen Bemühungen immer wieder ihr Veto entgegen. Die Frage, wie viele Lieder in einem katholischen Gottesdienst im 17. Jahrhundert tatsächlich gesungen werden durften, lässt sich wegen der enormen regionalen Unterschiede nicht beantworten. In manchen Gegenden wurde der Liedgebrauch relativ großzügig gehandhabt; dabei handelte es sich, wie sich denken lässt, vornehmlich um Diasporagebiete.

Nachdem bereits 1602 Nicolaus Beuttner eine Rubrik „bey dem Ambt der H. Meß" vorgesehen hatte, ${ }^{12}$ unternahm das Mainzer Cantual 1605 den offensichtlich erfolgreichen Versuch, das Kirchenlied an mehreren Stellen zur Messe singen zu lassen. Dieser Vorschlag, der irgendwie halboffiziell gewesen zu sein scheint, setzte sich in der Folgezeit als Faustregel durch: Im gesungenen Amt, der Missa cantata, ist lateinischer Chorgesang die Norm. Sollte aber kein Chor vorhanden sein, so soll das Volk lateinisch oder deutsch singen, und zwar deutsch an folgenden Stellen: vor dem Graduale, zur Sequenz, vor der Predigt, zum Offertorium, nach der Elevation, zum Agnus Dei (außer an Festtagen), sub communione, am Schluss. In der Stillmesse, der Missa lecta, ist deutscher Gesang generell erlaubt. ${ }^{13}$ Wesentlich zurückhaltender ist das Paderborner Gesangbuch, das mit kirchlicher Druckerlaubnis 1609 herauskam: Indem es deutschen Liedgesang nur sub elevatione und sub communione gestatten will, kehrt es zur ältesten Praxis

buch. In: Ebd. S. 477-483. Irmgard Scheitler: Geistliches Lied. In: Reallexikon der deutschen Literaturwissenschaft. Hrsg. von Klaus Weimar. Berlin, New York 1997, Bd. I, Sp. 680-683.

8 Georg Witzel: Psaltes Ecclesiasticus. Chorbuch der Heiligen Catholischen Kirchen/ Deutsch/ itzundt new ausgegangen. Köln: Quentel/ S. Victor b. Mainz: Behem 1550. Odae Christianae: Etliche Christliche Gesenge/ Gebete und Reymen/ für die Gotsförchtigen Läyen. S. Victor bei Mainz: Behem 1541.

9 Michael Vehe: New Gesangbüchlin. Leipzig: Wolrab 1537. Reprint, hrsg. von Walther Lipphardt. Mainz 1970.

10 Johann Leisentrit: Geistliche Lieder und Psalmen. Bauzen 1567. 2. Aufl. 1573, 3. verm. Aufl. 1584. Reprint hrsg. von Walther Lipphardt. Kassel 1966.

11 Der Bistumsadministrator Leisentrit warb für die Lieder, damit durch „zulassung/ der gemeine einfeltige ungelerte Man/ in gehorsam Heiliger Christlicher Kirch möcht erhalten werden“. Leisentrit (Anm. 10), Bl. 301v.

12 Nicolaus Beuttner: Catholisch Gesang=Buch. Graz: Widmanstetter 1602. Reprint hrsg. von Walther Lipphardt. Graz 1968.

13 Bd. I: Catholisch Manual. Bd. II: Catholisch Cantual. Mainz: Lipp 1605 (Hildesheim 1619), Vorrede. Zit. Joseph Kehrein: Katholische Kirchenlieder, Hymnen, Psalmen, aus den ältesten deutschen gedruckten Gesang- und Gebetbüchern zusammengestellt. 3 Bde. Würzburg 1859-1863. Reprint Hildesheim 1965, Bd. I, S. 80-85, hier S. 82 f. 
zurück. ${ }^{14}$ Es ist ungewiss, wieweit die kirchlichen Bestimmungen den liturgischen Alltag regeln konnten.

Das Vorhandensein zahlreicher katholischer Lieder in einer stets wachsenden Zahl von Gesangbüchern sollte nicht vorschnell mit einer Verwurzelung dieser Gesänge im Volk gleichgesetzt werden. ${ }^{15}$ Das Tridentinum hatte nicht nur den gregorianischen Gesang uniformiert und reglementiert, sondern förderte ihn in der kirchlichen Praxis. Die Tatsache, dass das Volk im 18. Jahrhundert zäh an der lateinischen Gregorianik festhielt, beweist deren weite Verbreitung. ${ }^{16}$

Letztendlich bleibt das deutsche katholische Lied - insbesondere im Vergleich zu der lutherischen Praxis - in einer Randstellung. Es wird weniger in der Messfeier als in Katechismusunterricht, Bruderschaftsandacht, Rosenkranzgebet, Wallfahrt und Prozession gepflegt. Besonders interessiert an der Gesangbuchproduktion ist die Societas Jesu. Sehr schnell entwickelten sich im deutschsprachigen Gebiet Jesuitengesangbücher, die ihren Bestand weitergaben.

\section{Neudichtung zur persönlichen Erbauung}

Die Herausgeber katholischer Gesangbücher zeigen sich ebenso wie ihre evangelischen Kollegen von dem Ehrgeiz beseelt, weltliches Liedgut zu verdrängen. Sie wünschen sich den Gesang ihrer Lieder bei der Arbeit und am Feierabend. Aber wie weit mag dieses Ziel erreicht worden sein? Zu dem Stellenwert frommer Lieder im Alltag katholischer Christen liegen keine soziologischen Forschungen vor.

Nun war unter Katholiken weder die Bibellektüre noch das Lesen von Postillen und das Abhalten von Hausandachten auch nur annähernd so verbreitet wie bei den Protestanten. Die Privatandacht, die im Protestantismus eine echte Alternative zum Kirchgang darstellte, ${ }^{17}$ konnte für den Katholiken keinen Gottesdienstbesuch ersetzen. Die erste wirklich von katholischen Laien rezipierte Postille, die Hauspostill oder Christ-Catholische Unterrichtungen von allen Sonn- und Feyr-Tagen des gantzen Jahrs (1690) von dem Prämonstratenser Leonhard Goffiné, entfaltete ihre Wirkung erst im 18. Jahrhundert. Sie enthält aber keine Lieder. Hingegen kamen nach dem Vorbild der Pia Desideria von Hermann Hugo (1624) im 17. Jahrhundert Erbauungsbücher multimedialer Art, bestehend aus Prosa,

14 Alte Catholische Geistliche Kirchengesäng [...] durch gnedigen Consens deß Hochwürdigen Fürsten und Herrn, Herrn Dietherichen Bischoffen deß Stiffts Paderborn etc. außgangen. Paderborn: Pontanus 1609. Neuauflagen Paderborn 1616; 1617; 1628; Erfurt 1622.

15 Das Münsterisch Gesangbuch [...] Jetzo auffs new übersehen. Münster: Raeßfeldt 1677 sieht eine relativ liberale Praxis vor. Die extrem "fortschrittliche“ Diasporagemeinde in Friedrichstadt im heutigen Schleswig-Holstein sang bereits 1687 das ganze Ordinarium deutsch mit Orgelbegleitung. Vgl. Andreas Heinz: Die Jesuiten als Förderer deutscher Meßlieder. Ein frühes Zeugnis für die Praxis des „Deutschen Hochamts“. In: Liturgisches Jahrbuch 35 (1985), S. 158-167.

16 Vgl. die eindrucksvollen Beispiele bei Wilhelm Bäumker: Das katholische deutsche Kirchenlied in seinen Singweisen. 4 Bde. Freiburg i. Br. 1883-1911, Bd. III, S. 15.

17 Vgl. die Zeugnisse aus Sigmund von Birkens Tagebüchern und von anderen Autoren bei Scheitler: Das Geistliche Lied im deutschen Barock. Berlin 1982, S. 403 f. 
Lied mit Komposition und Bild von Friedrich von Spee, Prokop von Templin oder Laurentius von Schnüffis auf den Markt. Ihre Widmungen zeigen, dass sie sich häufig an Klosterfrauen und erst in der 2. Jahrhunderthälfte auch an Kleriker und gebildete Laien wandten. ${ }^{18}$

Die im Katholizismus bedeutend schwächere Stellung der Laien scheint ein wesentlicher Hinderungspunkt für die Verbreitung deutscher geistlicher Lyrik gewesen zu sein. Während die Nicht-Theologen Paul Fleming, Simon Dach, Andreas Gryphius, Sigmund von Birken, Georg Philipp Harsdörffer oder Christian Knorr von Rosenroth Lieder zur persönlichen Erbauung dichteten, die nach einer gewissen Bewährungszeit sogar in den gottesdienstlichen Gebrauch übergehen konnten, war im Katholizismus die Produktion von Erbauungsliteratur nahezu ausschließlich Sache des Klerus, weitgehend der Ordensleute. Von dieser Regel gibt es nur wenige Ausnahmen, und diese auch erst in der zweiten Hälfte des 17. Jahrhunderts. ${ }^{19}$

Eine weitere Konfessionsdifferenz von großer Tragweite ist die unterschiedliche Wertschätzung geistlicher Lieder. Sie drückt sich auch in der Verbindung von Dichtung und Dichternamen aus. Im katholischen Bericht blieben Lieder noch bis in die zweiten Hälfte des 17. Jahrhunderts anonym, während die hohe Würde, die dem Lied im Luthertum zukam, früh auf den Autor überging. So ist aus dem 16. Jahrhundert eine große Zahl hochberühmter Autoren auf evangelischer Seite namentlich bekannt. Sie wurden von ihren Glaubensgenossen verehrt, man widmete ihnen biographische Abhandlungen und Predigten und verzeichnete ihre Namen unter ihren Liedern. Die Geschichte des katholischen Kirchenliedes kann auf Gesangbuchherausgeber verweisen. Namentlich bekannte Liederdichter dürfte es aus dem 16. Jahrhundert kaum mehr als ein halbes Dutzend geben.

\section{Popularisierung und Popularität}

Das wichtigste Medium zur Verbreitung von Liedern war nicht das Gesangbuch oder die Lyriksammlung, sondern das Fliegende Blatt oder die Liedflugschrift. Diese Kleindrucke, die in großer Zahl verlegt und relativ preiswert abgegeben werden konnten, erreichten ein breites Publikum. Die Reformation erkannte sehr schnell den unschätzbaren Wert dieses Propagandamittels und nützte es. Der erhaltene Bestand an Flugschriften entspricht zwar wegen der hohen Verlustrate bei diesen Kleindrucken nicht annähernd dem ursprünglich Vorhandenen, doch werden beide Konfessionen etwa gleiche Einbußen erlitten haben.

18 Spees Güldenes Tugendbuch ist für Klosterfrauen gedacht. Prokop von Templin widmete Hertzen=Frewd und Seelen=Trost, Judicale und Tugend=Spiegel Klostervorsteherinnen. Die Widmungen an Bischöfe etc. unterzeichnete hingegen der Salzburger Verleger Mayr.

19 Vgl. die Aufstellung bei Scheitler: Das katholische Kirchenlied zur Zeit Paul Gerhardts. In: Paul Gerhardt - Dichtung, Theologie, Musik. Wissenschaftliche Beiträge zum 400. Geburtstag. Hrsg. von Dorothea Wendebourg. Tübingen 2008, S. 117-140, hier S. 127-135. 
Das Korpus der Berliner Liedflugschriften erfasst den Bestand bis $1650 .{ }^{20}$ Weil das Bild, das dieses Korpus ergibt, möglicherweise durch den protestantischen Sammelort Berlin verzerrt sein könnte, wurde die Bibliographie Wilhelm Bäumkers ergänzend herangezogen, und zwar wiederum bis $1650 .{ }^{21}$

Die Durchsicht ergibt das übereinstimmende Bild: Katholiken sind bei der Flugblattproduktion weit unterrepräsentiert. Die großen evangelischen Liederbuchdruckorte Nürnberg, Augsburg, Basel, Straßburg waren zugleich die Stätten, die besonders viele Liedflugblätter hervorbrachten. ${ }^{22}$ Katholische Druckorte, Dillingen, Ingolstadt, München, Luzern spielen eine untergeordnete Rolle. Während die großen lutherischen Dichter wie etwa Nikolaus Herman, Erasmus Alber, Michael Weisse in Flugschriften mit ihren Liedern breit vertreten sind, von Luther und Hans Sachs ganz zu schweigen, und auch fromme Lieder von den Autoren des 17. Jahrhunderts in Kleindrucken verbreitet wurden, findet man unter den Katholiken aus dem 16. Jahrhundert nur Johann Haym von Themar und aus der ersten Hälfte des 17. Jahrhunderts einzig Johann Khuen.

Blicken wir auf die Lieder selbst. Deutlichster Hinweis für die Bekanntheit eines Liedes ist ein Verweis auf dessen Melodie. Evangelische Autoren hielten sich beim Dichten sehr häufig an die Melodien bekannter Kirchenlieder. So ist die Zahl der verschiedenen evangelischen Lieder, deren Melodien wiederverwendet wurden, im Berliner Korpus nahezu unübersehbar. Einige Lieder wurden darüber hinaus sehr oft kontrafaziert, z. B. „Erhalt uns Herr bei deinem Wort“ 24mal, „Kommt her zu mir spricht Gottes Sohn“ ca. 60mal. Das katholische Kontingent sieht hingegen schmal aus. Auf katholischer Seite war das Bedürfnis nach Liedflugblättern im 16. Jahrhundert offensichtlich wesentlich geringer als in der lutherischen Konfession; es lief erst zögerlich im 17. Jahrhundert an. Andererseits gab es auch fast keine zündenden Lieder und Liederdichter, die sich Berühmtheit verschafft hätten.

Auffallend viele katholische Flugschriften drucken eine Melodie mit ab, setzen also die Notenkenntnis, immerhin ein Zeichen deutlich gehobener Bildung, bei ihrem Publikum voraus. Offensichtlich wenden sie sich damit eher an Geistliche oder Kantoren als an das einfache Volk. Die meisten Lieder verweisen auf einen weltlichen Thon; bei Schweizer Drucken ist das Tellenlied besonders beliebt. ${ }^{23}$ Nicht wenige beziehen sich auf die Melodie protestantischer Lieder ${ }^{24}$ oder dru-

20 Berliner Liedflugschriften. Katalog der bis 1650 erschienenen Drucke der Staatsbibliothek Berlin Preußischer Kulturbesitz. Bearb. von Eberhard Nehlsen. Hrsg. von Gerd-Josef Bötte u. a. 3 Bde. Baden-Baden $2008 \mathrm{f}$.

21 Bäumker: Kirchenlied (Anm. 16), Bd.I, S.51-107; Bd. II, S. 26-26. Ergänzt durch: Eberhard Nehlson: Der Sammelband Luzern-Crecelius. Rekonstruktion einer verschollenen Quelle von Liedflugschriften. In: Jahrbuch für Liturgik und Hymnologie 53 (2014), S. 208-251.

22 Siehe die Aufstellung Berliner Liedflugschriften (Anm. 20), Bd. I, S. XVII.

23 Bäumker: Kirchenlied (Anm. 16), Bd. I, Bibliographie Nr. 226; 242; 306; 369.

24 Bäumker: Kirchenlied (Anm. 16), Bd. I, Bibliographie Nr. 364: „Im Thon: Kommt her zu mir“. Der öfters erwähnte „Geistliche Buchsbaum" (Bäumker: Kirchenlied Bd.I, Bibliographie Nr. 171; 338) hat ein weltliches Ursprungslied; die geistliche Fassung, auf die die Flugblätter 
cken evangelische Gesänge als gut katholische Lieder. ${ }^{25}$ Einige Flugschriften verweisen auf vorreformatorische Lieder, vornehmlich auf „Da Jesus an dem Kreuze stund“. Caspar Ulenbergs Psalter (Köln 1582), der heute als herausragend betrachtet wird, liefert, soweit ich sehe, nur einmal eine Melodie. Es wird aber nicht auf sie verwiesen, sondern sie wird abgedruckt. ${ }^{26}$

Am häufigsten (aber unter zehnmal) erscheint als Melodieverweis „Der grimmig Tod mit seinem Pfeil“, ein Lied, über dessen konfessionelle Zuordnung Unklarheit besteht. ${ }^{27}$ Als Melodieangaben mit genuin katholischer Provenienz findet man in dieser Reihenfolge der Häufigkeit „Maria zart“ (viermal), „In schwarz will ich mich kleiden“, „Freu dich, du Himmelskönigin", „Solls sein so seis, wie mein Gott will“, "Ist das der Leib Herr Jesu Christ", „O Wunder groß“. Die meisten der genannten Melodieverweise lassen sich nur ein- bis zweimal zählen. „Freu dich, du Himmelskönigin“ wird ausschließlich von Drucken jesuitischer Provenienz und Verwendung zitiert. Sie beziehen sich damit auf eine Liedtradition aus Gesangbüchern ihres Ordens, die sie in ihren Kreisen als bekannt voraussetzen. ${ }^{28}$ Damit ist ein sehr kleiner Kreis von Liedern abgeschritten. Die Autoren von Flugschriften hatten offenbar in die Kirchenliedkenntnis ihres Publikums wenig Vertrauen.

\section{Liedverweise im CEuvre bekannter katholischer Autoren des 17. Jahrhunderts}

Evangelische Dichter des 17. Jahrhunderts haben ihre Texte, wie oben festgestellt, weitgehend so abgefasst, dass sie auf bekannte Kirchenliedmelodien gesungen werden konnten. Dies gilt aber nicht für katholische Autoren. Melodieverweise sucht man vergebens bei Friedrich von Spee, Albert Curtz, Angelus Silesius, Johann Khuen und Laurentius von Schnüffis. Sie geben stattdessen schöne Generalbasskompositionen bei. Dass weltliche Lieder und Tanzweisen hin und wieder für die Melodien Pate standen, ist bei Laurentius wie auch bei Scheff-

verweisen („Nun höret zu ihr Christenleut“), entstammt aber dem Babstschen Gesangbuch, Leipzig 1545. Der Luzerner Drucker Hautt bringt 1637 „Wie schön leucht uns der Morgenstern“ (Bäumker: Kirchenlied Bd. I, Bibliographie Nr. 326) und verweist im gleichen Jahr auf den „Morgenstern" als Thon (Bäumker: Kirchenlied Bd. I, Bibliographie Nr. 327).

25 Bäumker: Kirchenlied (Anm. 16), Bd. I Bibliographie Nr. 162: „Sechs schöne catholische Lieder", 1586. Alle Lieder sind lutherisch.

26 Bäumker: Kirchenlied (Anm. 16), Bd. I Bibliographie Nr. 222: Zwey schöne newe Geistliche Lieder. Graz: Widmanstetter 1613. Für „All Tugend schon, viel Ehr' und Lohn“ wird die Melodie zu Ulenbergs Psalm 60 „O Herr mein Gott in dieser Not“ verwendet. EdK (Anm. 2), Gc45, a [AK].

27 Es ist nicht zu entscheiden ist, ob das Lied von dem Jesuiten Peter Franck oder von dem Stuttgarter Stiftsprediger Balthasar Bidembach stammt. EdK (Anm. 2), B103. Auf katholischer Seite zuerst München 1604, Bäumker: Kirchenlied (Anm. 16), Bd. I Bibliographie Nr. 198.

28 Bäumker: Kirchenlied (Anm. 16), Bd. I Bibliographie Nr. 252; 254; 319. Das Lied ist im verlorenen Brachelschen Gesangbuch Köln 1623 erstbelegt. Vgl. Friedrich von Spee: Auserlesene, Catholische, Geistliche Kirchengesäng. Hrsg. von Theo G. M. van Oorschot. (= Sämtliche Werke. Bd.IV). Tübingen, Basel 2005, S. 281. Zur weiteren Verbreitung vgl. Bäumker: Kirchenlied (Anm. 16), Bd. II, Lied Nr. 10. 
lers Tonsetzer Georg Joseph offensichtlich. ${ }^{29}$ Albert Curtz' Harpffen Davids ${ }^{30}$ kennt ebenfalls keine Thonangaben, stellt es aber jedem frei, auch andere als die beigegebenen neu komponierten Generalbass-Melodien zu benützen. Mithin hätten auch weltliche Melodien verwendet werden können. ${ }^{31}$ Der Münchner Geistliche und Dichterkomponist Johann Khuen, der zwischen 1635-1674 ein umfängliches und originelles Euvre von ca. 30 Bänden vorlegte, gibt an, Melodien aus weltlichen Liedern entlehnt zu haben. ${ }^{32}$ Nicht einbekannt hat er, dass er für das 1637 in einer Flugschrift veröffentlichte "Solls sein so seis" de facto auf eine protestantische Vorlage zurückgriff, nämlich auf das sehr verbreitete Kirchenlied von Albrecht Herzog von Preußen „Was mein Gott will, das gscheh allzeit“. ${ }^{33}$ Khuens Lied hätte auf die im Protestantismus geläufige Melodie aus dem 16. Jahrhundert gesungen werden können, doch diese ist gar nicht erwähnt. Vielmehr gehört zu dem Lied bei der Erstveröffentlichung eine Generalbasskomposition des Dichters. Dieser verwendet selbst zwar keine Thonangaben, seine eigenen Lieder aber stellen ihre Bekanntheit dadurch unter Beweis, dass sie ihrerseits für solche herangezogen wurden. Khuen, der jesuitisch erzogen worden war und der Gesellschaft Jesu nahestand, war wohl der populärste katholische Dichter. Dies zeigt nicht nur die Verbreitung in Liedflugblättern, sondern auch die Rezeption bei Dichterkollegen. ${ }^{34}$

Conrad Vetters Paradeißvogel ${ }^{35}$ bringt zu drei Liedern Noten, darüber hinaus aber keine Melodiehinweise. Gleichwohl handelt es sich überwiegend nicht um

29 Angelus Silesius (d.i. Johann Scheffler): Heilige Seelen-Lust. Reprint der fünfteiligen Ausg. Breslau 1668. Hrsg. von Michael Fischer. Kassel 2004, Nr. 2: „Ach, wann kommt die Zeit heran“. Melodie aus: Musikalisch Neu erbaute Schäfferey. Königsberg 1641 bzw. VenusGärtlein (1656), vgl. Bäumker: Kirchenlied (Anm. 16), Bd. III, Lied Nr. 165. Scheffler Nr. 38: „Liebster Jesu, was vor Müh“. Melodie aus: Enoch Gläser: Schäffer=Belustigung Anderes Buch. Altdorf 1653, vgl. Bäumker: Kirchenlied Bd. IV, Lied Nr. 295.

30 Albert Curtz: Harpffen Davids. Augsburg: Aperger 1659; Augsburg: Utzschneider 1669.

31 Curtz: Harpffen Davids (Anm. 30), §.IX „Man hat sich bemühet die allergemainiste weiß der Teutschen Reinem maistentheils zugebrauchen / damit nach eines jeden belieben/ umb so vil desto mehr/ und unterschidliche Melodieyen/ welche etwas da/ oder dorten gebräuchig/ und annemblich/möchten underlegt werden. Zumalen wir die andächtige Harpffenschlägerin/gar nit wollen verbunden haben/ eben disen ton/ welcher vor einem jeden PsalmLied verzaichnet ist/ zugebrauchen/ ob schon selbige von underschidlichen/ in der Singkunst maisterhafften Künstlern zusammen getragen: unnd in die Musicnoten verstellt seynd."

32 Johann Khuen: Tabernacula Pastorum. München: Wagner, Straub 1650, Ende des Inhaltsregisters zum ersten Teil: „NB. Die Melodeyen seyn maistenthails von Weltlichen Gesängern genommen: Weil sie vorhin bekandt/ auch eben darumben der Geistliche Text desto leichter eingelegt/ unnd ergriffen wird."

33 Khuens Lied in: Drey schöne newe Geistliche Lieder. München: Leysser 1637 [12: Res/ P.o.germ. 314]. Melodie von „Was mein Gott will“ EdK (Anm. 2), A514.

34 Zur Aufnahme in Gesangbücher vgl. Bernd Genz: Johann Kuen. Eine Untersuchung zur süddeutschen geistlichen Lieddichtung in 17. Jahrhundert. Diss. masch. Köln 1957, S. 18 f. Corner nahm in sein Gesangbuch Geistliche Nachtigall 1676 zwölf Lieder von Khuen auf, und zwar unter Angabe des Verfassers. Aussagekräftiger ist die häufige Kontrafaktur von Khuens Farbenlied „In schwarz will ich mich kleiden“.

35 Conrad Vetter: Paradeißvogel. Ingolstadt: Angermayer 1613 u.ö. 
Leselyrik. Der Autor betont im Vorwort, die Lieder seien „nicht allein zulesen/ und zubetrachten/ sonder [sic] auch andächtig zusingen bequem/ unnd schon ohne daß vorhin jedes in seiner Melodey und Thon/ mit beygesetzten Noten/ getruckt außgangen“. ${ }^{36}$ Diese Aussage kann sich nicht nur auf einige Texte beziehen. Der Autor macht drei Lieder namhaft, die bereits mit Noten gedruckt seien. Eines davon, „Maria rein, dein Klag allein“, hat auch im Paradeißvogel einen vierstimmigen Satz bei sich. ${ }^{37}$ Ein weiteres konnte mit seinen 90 Strophen im verdoppelten Vagantenmuster auf die Melodie seiner lateinischen Vorlage gesungen werden: „Nachtigall Daß H. Bonaventure Facht an im Latein Philomela praevia, etc. Nachtigall dein edler Schall“ ${ }^{38}$ Dass eine Singweise vorlag, zeigt eine Parodiemesse von Claudin de Sermisy (Paris 1558).

Aufschlussreich ist auch das dritte von Vetter erwähnte Lied: „Jesu dulcis memoria“. Hier greift Vetter nicht auf die dem lateinischen Gesang zugehörige Melodie zurück, sondern gibt "Gelobet seist du, Jesu Christ" als Thon an. ${ }^{39}$ Da nicht die im Luthertum geläufige, sondern nur die in katholischen Büchern seit 1599 notierte Variante in Frage kommt, ${ }^{40}$ bezieht sich Vetter auf die Gesangbuchtradition seines Ordens. Damit zeigt sich, wie schon bei den Flugblättern, die Sonderstellung der Gesellschaft Jesu.

"Nachtigall dein edler Schall“, dem wir bei Vetters Paradeißvogel zum ersten Mal begegnen, wurde tatsächlich ein beliebtes Lied. Vetters Ordensbruder Jacob Bidermann hat es in sein Himmelglöcklein, ein Liederbuch ohne Noten, aufgenommen und es sogar auch noch kontrafaziert. ${ }^{41} \mathrm{Ob}$ es freilich zu einer volksliedartigen Verbreitung kam, wie Vetter sie wünschte, muss man dahingestellt lassen.

36 Vetter: Paradeißvogel (Anm. 35), Bl. )(6r.

37 Vetter: Paradeißvogel (Anm.35), S. 87: „Planctus Mariae Virginis [...] in Thon Maria zart.” „Maria rein dein Klag allein ist über alles Klagen“, 52 Strophen. Entgegen der Angabe des Autors lässt sich der Text wegen seines abweichenden Strophenmusters nicht auf eine der Melodien von „Maria zart” adaptieren. Vielmehr verzeichnet Bäumker: Kirchenlied (Anm. 16), Bd. II, Lied Nr. 27 die von Vetter beigegebene Melodie bei dem Text „Himmel und Erd".

38 Vetter: Paradeißvogel (Anm. 35), S. 50. Der Text nimmt eine Sonderstellung ein, weil er einer von zwei trochäischen Texten im Paradeißvogel ist. Seit 1625 ist mit Vetters Text in Gesangbüchern eine anspruchslose, aber schöne Melodie im F-Modus verbunden, die schon 1605 bei einem anderen lateinischen Text im Mainzer Cantual stand, vgl. Bäumker: Kirchenlied (Anm. 16), Bd. I, Lied Nr. 310.

39 Vetter: Paradeißvogel (Anm. 35), S. 9.

40 Die 2. Zeile ist bei Bäumker: Kirchenlied Bd. I, Lied Nr. 30/ II. um eine Silbe länger als in Lied Nr. 30/ I. Nur die Fassung II kann gemeint sein.

41 Jacob Bidermann: Himmelglöcklein/ Das ist: Catholische/ Außerlesene/Geistliche Gesäng/ auff alle zeit deß Jahrs. An Jetzo zum Drittenmal gedruckt/ und nach Notturfft verbessert. Dillingen: Sermodi 1627. Hrsg. von Wolfgang Schürle. Eingeführt und erläutert von Otto Holzapfel und Hans Pörnbacher. Weißenhorn 2000, S. 137. Bidermann vermerkt bei seinem noch heute bekannten Sakramentslied "Sei gegrüßt du edle Speis": „Im Thon: der Geistlichen Nachtigall“. S. 320. "Geistlich" heißt diese „Nachtigall“, weil das Incipit so klingt wie das weltliche Lied „O Nachtigall dein edler Schall“. Vgl. Gotteslob. Gebet- und Gesangbuch für das Bistum Eichstätt. Eichstätt 1970, S. 797 mit der Melodie von „Philomela praevia“. 
Er schreibt: „Unnd warumben solte es den jungen Knaben und Jungfrawen nicht tausentmal lustiger und lieblicher seyn/ S. Bonaventure holdselige Nachtigall/ in den Sommerrayen auff der Gassen nachzusingen/ als andere leichtfertige Bulenlieder?" 42

Dichtungen im trochäischen Versmaß waren in den ersten beiden Jahrzehnten des 17. Jahrhunderts selten und modern. So verwundert es nicht, dass Bidermann auch das zweite trochäische Lied seines Vetters, den Marienpreis „Alle Tage sing und sage“ ins Himmelglöcklein übernahm. ${ }^{43}$ Insgesamt enthält das Himmelglöcklein 128 Lieder. Davon tragen zwanzig Texte Thonangaben - was außergewöhnlich für ein katholisches Buch ist. Die Verweise zielen auf zwölf verschiedene Melodien. Sechsmal handelt es sich um Melodien aus vorreformatorischer Zeit. Zwei Lieder sind eindeutig katholischer (und eigentlich jesuitischer) Provenienz: neben der erwähnten „geistlichen Nachtigall“ noch „Wohlauf zu Gott mit Lobesschall“ aus dem jesuitisch beeinflussten Münchener Gesangbuch von 1586. ${ }^{44}$ Bei einem Lied ist die evangelische Provenienz eindeutig: „Wann mein stündlein vorhanden ist", zu singen „In der alten bekanten Melodey“; diese stammt aber wie der Text von dem Joachimsthaler Kantor Nikolaus Herman. Drei Gesänge wurden von beiden Konfessionen benützt. - Man stellt mit Erstaunen fest, welch verschwindend kleine Rolle bei den Melodieangaben die inzwischen seit ca. 100 Jahren in der katholischen Kirche gedichteten und gedruckten Kirchenlieder spielen.

Reicher werden unsere Funde erst im großen Euvre von Prokop von Templin. Der aus Brandenburg stammende Kapuziner war ursprünglich Protestant. Lange Zeit wirkte er als Seelsorger in der Passauer Maria Hilf-Wallfahrt. Neben reinen Liederbüchern veröffentlichte er vor allem postillenartige Predigtsammlungen mit Liedern. Seine über 570 Texte wurden von verschiedenen Komponisten in die Musik gesetzt. Prokop äußerte den Wunsch, diese Lieder möchten „zu Hauß/ zu Feld/ in Kirchen/ bey Prozessionen/ Andachten und dergleichen vielfältigen Begebenheiten" gesungen werden. ${ }^{45}$ Vermutlich aber konzentrierte sich die Rezeption auf Klöster. Prokop ist der Einzige, bei dem man Melodieangaben oder - mit diesen fast gleichwertig - Initialkontrafakturen in größerem Ausmaß findet. Thonangaben stehen, wie man es von den Liederbüchern der protestantischen Dichter des 17. Jahrhundert kennt, als Alternativen zu den neuen Melodien über den Versen. In neun Fällen macht Prokop Anleihen bei Khuen, mit dem er

42 Vetter: Paradeißvogel (Anm. 35), Bl. )(7r.

43 Bidermann: Himmelglöcklein (Anm. 41), S. 335 (verkürzt). Bei Vetter S. 28 ein vierstimmiger Satz.

44 Bäumker: Kirchenlied (Anm. 16), Bd. I, Lied Nr. 370. Das „mit Geistlicher und Weltlicher Obrigkeit bewilligung" gedruckte Gesangbuch ist Ergebnis der Kulturpolitik Kurfürst Maximilians I.

45 Prokop von Templin: Hertzen=Frewd und Seelen=Trost. Das ist: Himmelische Betrachtungen und [...] Lobgesänger [...] Auff jeden Tag des gantzen Jahrs eine oder zwey frische Betrachtung und Gesang sampt eigner Melodey und Orgel-Baß gerichtet. I. Tl. Passau: Höller 1660, Vorrede Bl. A7r. 
befreundet war. Darunter ist dreimal „Solls seyn so seys“. ${ }^{46}$ Er benützt „Nachtigall dein edler Schall“ von Vetter, ${ }^{47}$ "Der grimmig Tod mit seinem Pfeil“ ${ }^{48}$ und Grimmelshausens „Komm Trost der Nacht“ aus dem Simplicissimus. ${ }^{49}$ Erstmals treffen wir nun auch auf ein Lied aus Leisentrit: „Wir wollen heute loben“. ${ }^{50}$ Mehrere andere Thonangaben beziehen sich auf ursprünglich evangelische Lieder. Da ist zunächst „Wie schön leuchtet der Morgenstern," ${ }^{11}$ das aber schon in den katholischen Gesang übergegangen war. Deutlicher evangelisch ist „Nun frewt euch liebe Christen gmein ${ }^{\prime \prime}{ }^{52}$ das zweimal im Liederbuch Hertzen=Frewd als Thonangabe auftaucht. Es gehört immerhin zu den lutherischen Kern- und Kampfliedern. Wolfgang Dachsteins „An Wasserflüssen Babylon“ verwendet Prokop am Sonntag Quinquagesimae, als er in dem Lied „Ein Gottvergeßnes Babylon“ über ein "Jetziges Babylon/ Sodoma und Gomorra" handelt. ${ }^{53}$ Und sehr oft schließlich trifft man auf die Thonangabe: „Wie nach einer [sic] Wasserquelle“, ${ }^{, 54}$ einem Psalmlied aus dem Lobwasser, jenem Liederbuch, das Prokop nach eigenen Angabe so faszinierte, dass er glaubte, die Konfession Calvins müsse die richtige sein. Bei keinem dieser Lieder gibt es Belege für eine anderweitige katholische Verwendung. ${ }^{55}$

Das Gros der katholischen Autoren sah mithin keinen Anlass, Melodien katholischer Lieder als Singweisen anzugeben. Entweder bestand die Attraktion der Veröffentlichungen in der Beigabe neuer Melodien, was bedeutet, dass nur

46 Genz: Khuen (Anm. 34), S. 20 und S. 217. Khuen bedachte zwei Werke Prokops mit Ehrengedichten. Ebd. S. 20. „Solls sein“ in Funerale. Salzburg: Mayr 1670, S. 67a; Adventuale. München: Jäcklin 1666, S. 653, Hertzen=Frewd II, S. 78.

47 Prokop von Templin: Dominicale Aestivale. Salzburg: Mayr 1667, S. 41: Auf die Speisung der 4000 „im Thon: Nachtigall dein edler Schall. Wieder: Prokop: Hertzen=Frewd (Anm. 45) I, S. 563. Aus Vetter: Paradeißvogel (Anm. 35), S. 50.

48 Prokop von Templin: Hertzen=Frewd I (Anm. 45), S. 252, beim ersten der „12 Trostreiche =Gesänge" zur Fastenzeit. Wieder in Hertzen=Frewd I, S. 608.

49 Prokop von Templin: Patrociniale, Das ist: Hundert sonderbahre Predigen [sic]/ In welchen Mit einer gantz neuen biß dato noch nie gesehenen Manier [...] gelehrt [...] wird/ wie der Allmächtige gütige Gott durch seine Heiligen [...] viel Gnaden erzeiget. Salzburg: Mayr 1674, S. 646: Wenn einer des Gotteslobs überdrüssig wird, so rät Prokop: „Ich wünschete/ daß der Simplicius Simplicissimus hier vorhanden wäre/ der würde uns erzehlen/ wie er und sein Vatter lange Zeit im Wald solche Freud am Gesang der Nachtigalln gehabt/ also daß sie/ wie auch Sanct Franciscus gethan/ manchesmal mit ihnen in der Wett gesungen/ wie sie denn auch das schöne Lied darvon componirt: Komb Trost der Nacht/ O Nachtigall“.

50 Prokop von Templin: Hertzen=Frewd (Anm. 45) II, S. 237. Bäumker: Kirchenlied (Anm. 16), Bd. I, Lied Nr. 389. Aufgenommen in mehrere Gesangbücher.

51 Prokop von Templin: Hertzen=Frewd I, S. 49.

52 Prokop von Templin: Hertzen=Frewd (Anm. 45) I, S. 8; II, S. 70.

53 Prokop von Templin: Hertzen=Frewd (Anm. 45) II, S. 216, alternative Melodieangabe S. 219.

54 Prokop von Templin: Hertzen=Frewd (Anm. 45) II, S. 455.

55 D.h. sie stehen nicht bei Bäumker: Kirchenlied, ja nicht einmal bei Werlin. Der Benediktiner Johannes Werlin (1588-1666) legte nach 1646 einen siebenbändigen Katalog von 1365 strophischen Texten und Melodien an: Rhitmorum varietas [12: cgm 3636-342]. Dorothea Hofmann: Die „Rhitmorum varietas" von Johannes Werlin aus Kloster Seeon. Augsburg: Wissner 1994. 
Benützer mit der Fähigkeit, Noten zu lesen als intendierte Leser in Frage kommen. Oder man rechnete gar nicht mit der Kenntnis katholischer geistlicher Lieder, einige ganz wenige Perlen ausgenommen. So müssen wir die merkwürdige Tatsache feststellen, dass der katholische Autor, der die meisten geistlichen Lieder kontrafazierte, sie also parat hatte, ein Konvertit war und bei seinen Lesern auch die Bekanntheit evangelischer Lieder voraussetzte. Allerdings ist hier eine Einschränkung zu machen: Von Prokops Büchern gab es zwar Zweitauflagen, was für ihre Beliebtheit spricht, seine Lieder daraus wurden aber nur sehr spärlich in Gesangbücher aufgenommen. ${ }^{56}$ Prokop stellte sich zwar im Ehrenkränzel vor, sie könnten ",sowol anheimbs als auch zu Feld und auff den Kirchfaehrten" und „bey Processionen und dergleichen viefältigen Begebenheiten“ gesungen werden, ${ }^{57}$ es hat jedoch nicht den Anschein, dass dies der Fall war. Eher passen die Generalbasslieder in die Hausmusik gebildeter Stände, wie denn auch Hertzen=Frewd und Mariale Dominicale davon schreiben, sie seien "mit allerhand Musicalischen Instrumenten auffzumachen“. Bischof Max Gandolf von Salzburg ordnete mit Erlass vom 31. Juli 1676 an, das das von „P. Prokopio verfaßte und neugedruckte Catechismale von allen Pfarren, Vikaren des Landes soll angekauft werden [...] damit sich desselben die Kuraten bedienen mögen" ${ }^{58}$

Der Befund, Lieder seien hauptsächlich durch Klosterleute verbreitet worden, wird durch einen Blick in die Predigtliteratur bekräftigt. Gleichzeitig kann Predigtliteratur als gutes Indiz für Liedkenntnis gelten, denn der Sprecher setzt doch wohl voraus, dass wenigstens einige seiner Zuhörer (oder Leser) den zitierten Liedtext wiedererkennen. Wieder zeigt sich die Bedeutung von „Der grimmige Tod mit seinem Pfeil“. Der Augustiner Abraham a Sancta Clara führt die erste Strophe in seiner Schrift: Judas der Ertz=Schelm an. ${ }^{59}$ Noch andere süddeutsche Predigter zitieren das Lied: der Augustiner-Eremit Ignatz Ertl bringt es ebenso wie der Laufener Kollegiatsstiftherr Andreas Strobl. ${ }^{60}$ Der Barnabit (Paulaner) Florentius Schilling, einer der bedeutendsten Prediger Wiens, gibt in einer

56 Ins Gesangbuch ging ein „O edle Mutter, höre an“, vgl. Bäumker: Kirchenlied (Anm. 16), Bd. III, Lied Nr. 80 - zuerst in einer Vertonung des Passauer Domorganisten Georg Kopp in Maria Hülff Ehren Kräntzel (1642), später in Lob=Gesang (1659) und Mariale (1667); „Ave, o Fürstin mein", vgl. Bäumker Bd. I, Lied Nr. 419, aus Lob=Gesang.

57 Veit Gadient: Prokop von Templin. Sein Leben und seine Werke. Regensburg 1912, S. 218.

58 Gadient: Prokop (Anm. 57), S. 40 f.

59 Abraham a Sancta Clara: Judas der Ertz=Schelm/ für ehrliche Leuth oder: eigentlicher Entworff/ und Lebens=Beschreibung deß iscariotischen Bößwichts. Salzburg: Haan 1686, S. 511. Die Fassung „Der grimmige Tod“ statt „Der grimmig Tod“ war sehr verbreitet. Khuens aus einem Flugblatt von 1639 (Bäumker: Kirchenlied [Anm. 16] Bd. I Bibliographie Nr. 353) stammendes Lied vom Schnitter Tod bringt P. Abraham im Gedenkbuch der Armenseelenbruderschaft: Große Todten=Bruderschafft/ Das ist: Ein kurtzer Entwurff deß Sterblichen Lebens. Salzburg: Haan 1684, S. 24 mit seiner gesamten 1. Strophe: „Es ist ein Schnitter haist der Todt".

60 Ignatz Ertl: Sonn= und Feyertägliches Tolle Lege. 2. Aufl. Nürnberg 1708, S. 319. Andreas Strobl: Ovum Paschale Novum. 2. Aufl. Salzburg 1700, Tl. 1, S. 410. Vgl. Elfriede Moser-Rath: 
Grabrede an: „In vorstehender dreytägiger Besingnuß ${ }^{61} /$ wird zweifels ohn/ daß anmüthige teutsche Gesang/ der Grimmige Tod gehöret und gesungen werden“ und zitiert die erste Strophe, um an sie seine Gedanken anzuknüpfen. ${ }^{62}$

\section{Kirchenlied und Geistliches Lied in mehrstimmiger Vokalmusik}

Die Tatsache, dass im Amt deutscher Chorgesang nicht vorgesehen war, hatte eine weitreichende Konsequenz: Es fehlt deutschsprachige geistliche mehrstimmige Musik, also jene, die in der evangelischen Kirche in verschiedenen vokalen Gattungen und musikalischen Stilen eine überragende Rolle spielt. Zwar gibt es hin und wieder einfache mehrstimmige Kantionalsätze, elaborierte Sätze deutscher Lieder für religiösen Gebrauch sind aber im Vergleich zur reichen protestantischen Produktion verschwindend selten. Die wenigen herausragenden Beispiele sind leicht genannt:

Andreas Giglers zweiteilige Gesang Postill von 1569 und 1574 ist eine dezidiert zum gottesdienstlichen Gebrauch gedachte Sammlung von Evangelienliedern für das ganze Jahr. ${ }^{63}$ Die Gesänge folgen formal alle der Lutherstrophe, lassen sich also auf zahlreiche Melodien singen. Im Anhang beigegeben sind zwanzig schlichte vierstimmige Tonsätze von Johannes de Cleve mit dem Cantus firmus im Tenor. Unter den Liedern befinden sich zehn protestantische Choräle, darunter acht Lutherlieder. Das für den katholischen Bereich absonderliche Werk erklärt sich aus der Situation Giglers. Der Grazer Stadtpfarrer von St. Egyd gehört - verkürzt gesprochen - noch der konfessionell unentschlossenen Zwischengeneration an. Er war ein irenischer, verheirateter Pfarrer, der von seinen Kollegen als katholisch angesehen wurde, sich selbst aber als evangelisch betrachtete. ${ }^{64}$

Für den Gebrauch an Schulen sind die vierstimmigen Tonsätze zu Kaspar Ulenbergs katholischem Psalter durch Conrad Hagius aus dem Jahr 1589 gedacht. ${ }^{65}$ Der Komponist ist persönlich keiner Konfession so recht zuzuordnen. Der weitreichende Einfluss des Ulenbergschen Psalters zeigt sich an den fünfstimmigen Liedmotetten des Protestanten Abraham Praetorius. ${ }^{66}$

Als Musica riservata, rein für die Rezeption in der obersten Gesellschaftsschicht, sind die von Orlando di Lasso und seinem Sohn Rudolph dreistimmig

Volkstümliches Liedgut in barocken Predigtwerken. In: Jahrbuch des Österreichischen Volksliedwerkes 8 (1959), S. 52-73, hier S. 55.

61 Gemeint sind die dreitägigen Exequien.

62 Florentius Schilling: Mirandula Austriacus, Grabrede für Johann Wilhelm Mannagetta, gehalten in Wien, St. Stefan 1666. In: Catholisch Todten-Gerist: Daß ist, Wolgegründte EhrnGedächtnuß [...] Bd. 2, Wien: Rickesin 1676, S. 406 f.

63 Andreas Gigler: Gesang Postill. Vollständige Faksimile-Ausgabe der Steiermärkischen Landesbibliothek. Graz: Akademische Druck- und Verlagsanstalt 1950.

64 Karl Amon: Der Grazer Stadtpfarrer Andre Gigler und seine Gesangpostille. In: Jahrbuch für Liturgik und Hymnologie 15 (1970), S. 1-31.

65 Konrad Hagius: Die Psalmen Davids. Düsseldorf: Buyß 1589. 2., verm. Aufl. Oberursel: Sutor 1606.

66 Abraham Praetorius: Newe Geistliche Teutsche des Königlichen Propheten Davidis Psalmen ganz lieblich zu singen und auff allerley Instrumenten zu gebrauchen. Greifswald 1592. 
komponierten fünfzig Teutschen Psalmen nach Texten von Ulenberg gedacht. ${ }^{67}$ Ebenso wenig ließen sich Lassos wenige geistliche deutsche Lieder, darunter einige Lutherlieder, für den allgemeinen Gottesdienst benützen.

In die gleiche Kategorie fürstlicher Privatmusik gehört Gregor Aichingers dreistimmige deutsche Liedsammlung. ${ }^{68}$ Das Werk ist der Gattin Johann Fuggers von Bebenhausen zugedacht und umfasst 21 Liedsätze, darunter sechs Ulenbergpsalmen sowie die sieben deutschen Lieder des Münchner Kleindrucks von $1604 .{ }^{69}$ Auch Aichingers zweites Werk mit deutschen, nun vierstimmigen Liedern dürfte zu fürstlichem Gebrauch gedacht sein. ${ }^{70}$ Der Druck umfasst achtzehn Nummern und enthält Vertonungen ausgewählter Strophen von „Der grimmig Tod mit seinem Pfeil“, ausgewählter Strophen von Sigismund Bachamers SJ „Komm her, wer Kron und Infel trägt ${ }^{\prime \prime}{ }^{71}$ ferner den 129. Psalm und das Canticum Simeonis von Ulenberg.

Einzig in seiner Art ist das 1604 unter dem Titel Rosetum Marianum. Unser lieben Frawen Rosengertlein erschienene Sammelwerk des Augsburger Priesters und Domkapellmeisters Bernhard Klingenstein. Es handelt sich um eine Folge von 33 Motetten von eben so vielen Komponisten über die 33 Strophen des Liedes „Maria zart". ${ }^{72}$ Die Tonsätze stammen z.T. von bedeutenden Meistern aus dem süddeutsch-österreichischen Raum. Interessant ist dabei, dass die Konfession der Komponisten offenbar nicht den Ausschlag gab. Die Gebrüder Jakob und Hans Leo Haßler waren z. B. keine Katholiken. Ein anderer Beiträger, der Böhme

67 Orlando und Rudolph di Lasso: Teutsche Psalmen: Geistliche Psalmen/ mit dreyen stimmen/ welche nit allain lieblich zu singen/ sondern auch auff aller hand art Instrumenten zugebrauchen. München: Berg 1588 .

68 Gregor Aichinger: Teutsche Gesenglein Auß dem Psalter des H. Propheten Davids. Dillingen: Meltzer 1609.

69 Bäumker: Kirchenlied (Anm. 16), Bd. I Bibliographie Nr. 198. Enthält „Der grimmig Tod“.

70 Gregor Aichinger: Zwey Klaglieder vom Tod und Letzten Gericht. Dillingen: Hänlin 1613. Das übrige umfangreiche geistliche Chorwerk Aichingers ist lateinisch. Ein Großteil ist liturgisch verwendbar; es finden sich aber auch Werke, die wohl eher zum privaten Gebrauch geeignet sein dürften, z. B. die Odaria lectissima auf mystische Texte des PseudoBernhard oder die Divinae laudes und das Encomium auf Dichtungen des Jesuiten Jacobus Pontanus.

71 Dieses Lied ging in etliche Gesangbücher ein, vgl. Paderborner Gesangbuch 1617 (Bäumker: Kirchenlied [Anm. 16] Bd. II, Lied Nr. 371) und Drucke der Kölner Jesuiten von 1636 (Bäumker: Kirchenlied Bd. I Bibliographie Nr. 316 f.) 1615 wurde es ins Lateinische übersetzt, weshalb Corner wohl annahm, es sei aus dem Lateinischen ins Deutsche gekommen. Vgl. Bäumker: Kirchenlied Bd. I Bibliographie, 234. Wackernagel (Anm. 2), Bd. V, Nr. 1487.

72 Bernhard Klingenstein: Rosetum Marianum. Unser lieben Frawen Rosengertlein, Von drey und dreyßsig lieblichen schönen Rosen oder Lobgesangen Gott dem Almechtigen, und dessen würdigsten Muotter und Junckfrawen Marie, durch drey und dreyßsig beriembte Musicos und Componisten, mit sondern fleiß auff ein Subiectum, mit fünff Stimmen Componirt, und letztlich zusamen getragen. Durch Bernhardum Klingenstein, hoher Stifft Augspurg, Chori Musici praefectum. Dillingen: Adam Meltzer 1604. Neuausgabe in 2 Bdn. von William E. Hettrick. Madison 1977. 
Christoph Harant, wurde sogar in den gegenreformatorischen Wirren 1621 als Utraquist enthauptet. ${ }^{73}$

Johann Degens Catholisches Gesangbuch von 1628 ist ein nach evangelischen Mustern geschaffenes Kantionale und darf für seine Zeit als Unikum gelten. ${ }^{74}$ Die vierstimmigen schlichten Tonsätze mit dem Cantus firmus im Diskant dienen zur Begleitung des Gesangs der Gemeinde durch einen Schülerchor. Damit ist gleichsam das in die Praxis umgesetzt, was das Mainzer Cantual 1605 angeregt hatte.

Was sonst an mehrstimmigen geistlichen Liedern von den Meistern des 16. und frühen 17. Jahrhunderts veröffentlicht wurde, gehört in den Kreis bürgerlicher Musikübung. Es versteht sich, dass im Collegium musicum neben weltlichen hin und wieder auch geistliche Lieder gesungen wurden. Genuin katholische Gesangbuchlieder spielen dabei aber keine Rolle. ${ }^{75}$

\section{Liedzitate in Kompositionen}

Im evangelischen Bereich bestimmt der Choral, das Kirchenlied, nicht nur die Vokalmusik, sondern auch die Instrumentalmusik. Von Jan Pieterszoon Sweelinck bis Johannes Brahms schrieben die Komponisten Choralvorspiele, von Michael Praetorius bis Hugo Distler sind uns Orgelchoräle und Choralfantasien überliefert. Dieses gesamte Euvre beruht auf der mühelosen Wiedererkennbarkeit einer Liedmelodie. Die katholische Kirchenmusik des 16. und 17. Jahrhunderts hat keine vergleichbaren Werke aufzuweisen und integriert in ihre Passionsmusiken auch keine geistlichen Lieder. Auch die trotz des tridentinischen Verbots weiterhin geschriebenen Parodiemessen verwenden so gut wie keine deutschen Lieder als Cantus firmus, während aus der evangelischen Kirchenmusik viele solcher Parodiemessen, insbesondere aus dem 17., ja noch bis ins 18. Jahrhundert hinein bekannt sind ${ }^{76}$ Einziges Gegenbeispiel für die Verwendung eines typisch katho-

73 The New Grove, Bd. 8, S. 156.

74 Johann Degen: Catholisches Gesangbuch Auß unterschiedlichen/von der Römischen Catholischen Kirchen approbierten Gesangbüchern [...] colligirt. Bamberg: Crinesius 1628. Faksimile hrsg. von Wolfgang Spindler. Bamberg 1992.

75 Als Beispiel sei eine kleine Sammlung des Oberpfälzers Johann Pühler genannt: Schoener außerleßner Geistlicher und Weltlicher Teutscher Lieder XX. von beruembten diser Kunst mit Vier Stimmen gesetzt und Componiert gantz lieblich zu singen und auff allerley Instrumenten artlich und lustig zugebrauchen. Durch Ioannem Pühlerum Schwandorffensem, weylandt Kaisers Ferdinandi (hochloeblicher gedechtnuß) Capelnsingers jetzund Fuerst: Bayrischem Provisioner zu Regenspurg zusam Colligirt und in Truck verfertigt. München: Adam Berg 1585.

76 Die Ostermesse des frühprotestantischen Komponisten Johannes Galliculus verwendet "Christ ist erstanden"; Messen von Christoph Bernhard beruhen auf "Christ, unser Herr, zum Jordan kam“ und „Durch Adams Fall“, Messen von Sebastian Knüpfer auf „Freu dich sehr, o meine Seele“ und „Herr Jesu Christ, wahr Mensch und Gott“. Für freundliche Auskunft danke ich Herrn Maik Richter, M.A., Halle. Eine Übersicht über die Vorlagekompositionen im 16. und frühen 17. Jahrhundert (ohne die evangelischen sog. Liedmessen seit der 2. Hälfte des 17. Jahrhunderts) bietet Andreas Waczkat: Parodietechniken in deutschen Messenkompositionen des 17. Jahrhunderts. Untersuchungen zu Theorie und kompositorischer 
lischen Cantus firmus ist vielleicht die Missa "Maria zart“ des in Brabant und Italien lebenden Komponisten Jacob Obrecht. Erst recht tut man sich schwer, ein Liedzitat zu finden, das dem oben angeführten textlosen Einsatz eines Chorals aus einer Bachschen Kantate gleichkommt. Offenbar waren zu wenige katholische Kirchenlieder wirklich geläufig und im Volk verankert.

Die einzigen Ausnahmen finden sich im Werk von Heinrich Ignaz Franz Biber. Man könnte verführt sein, Bibers Kirchenliedaffinität aus seiner böhmischen Herkunft abzuleiten, war doch Böhmen von jeher die liederfreudigste Region. Der Geigenvirtuose und Salzburger Kapellmeister verwendet in der XI. Rosenkranzsonate die Cantio „Surrexit Christus hodie“ und verzeichnet das lateinische Incipit sogar in den Noten. Die Melodie stimmt mit der Singweise von „Erstanden ist der heilig Christ“ überein, die in kleinen Varianten in verschiedenen katholischen Gesangbüchern seit alters vorliegt. ${ }^{77}$ Dass Biber in der Auferstehungssonate dieses Osterlied zitiert und als Thema in einer Serie von acht Variationen kontrapunktisch verarbeitet, scheint zunächst wenig überraschend. In Wahrheit ist es höchst ungewöhnlich und ohne Parallele. Auch sind die Rosenkranzsonaten - entgegen ihrem Namen - weder programmatisch, noch liturgisch funktional, vielmehr sogar bewusst unveröffentlicht und in einer schön gestalteten Handschrift privat dem Fürsterzbischof zugedacht: Musica riservata ohne praktischkirchliche Bestimmung. Bei der Ostersonate drängte sich dem Komponisten aber doch die Melodie auf, die er sicher von Kindesbeinen an kannte.

Ein weiteres, höchst bemerkenswertes Kirchenliedzitat versteckte Biber in seine Sonata a 6 in B „die Pauernkirchfahrt genandt" für Streicher und Basso continuo. Hier verwendet er das Wallfahrtslied „O Mutter Gottes außerkorn“ aus David Gregor Corners Groß Catholisch Gesangbuch (Nürnberg ${ }^{3} 1631$ ) bzw. dessen Catholischer Nachtigal (Wien 1676). ${ }^{78}$ Beide Sammlungen waren weit verbreitet, gerade in Österreich. Auch wenn man die Sonate nicht zur Programmmusik herabwürdigen will, so kann man sie doch teilweise als die Nachzeichnung einer Wallfahrt ansehen. Zu Anfang eilen die Menschen herbei, ab Takt 30 erklingt das Lied, dessen Einsatz sozusagen mimetisch gemeint ist: Es stellt den Gesang der Pilger dar.

Einen anderen Charakter hat das Zitat von „Der grimmige Tod mit seinem Pfeil“ in Bibers Oper "Chi la dura la vince.${ }^{79}$ Hier versteckte der Komponist anspielungsreich die Melodie, die ihm bei dieser Textstelle in den Sinn kam. Am

Praxis. Diss. Rostock 1996, S. 225-242. Für die katholische Seite sind nur die Parodiemessen „Ein Kind geborn in meiner Seel“ des Tirolers Christoph Sätzl sowie „Missa super Christ ist erstanden“ (1646) und „Missa super Joseph, lieber Joseph mein“ von Augustin Plattner (1624) einschlägig. Plattner war Organist in der Deutschordensresidenz Bad Mergentheim. Die verwendeten Lieder sind allerdings vorreformatorisch.

77 Vgl. Bäumker: Kirchenlied (Anm. 16), Bd. I, Lied Nr. 244.

78 Bäumker: Kirchenlied (Anm. 16), Bd. II, Lied Nr. 57.

79 Heinrich Ignaz Franz Biber: Chi la dura la vince. Dramma musicale in drei Akten. Faksimile der Partitur Hs 560 aus dem Besitz des Salzburger Museums Carolino Augusteum. Hrsg. von Sibylle Dahms. Salzburg 2004, Bl. 51r. 
Ende von Akt I spielt der Basso continuo zum fingierten Tod von Herchino eine zwölftaktige Melodie. Unter die ersten Noten der Melodie schrieb Biber: „Der grimmige [sic] Todt: [sic] ${ }^{\prime \prime}{ }^{80}$ Der Kontext ist ironisch, denn just als das Lied mit seiner Todeswarnung erklingt, erholt sich Herchino: „Gli risornan le forze" lautet der Vermerk in der Partitur. Die Anspielung auf das Lied muss begreiflich gewesen sein und legt ein weiteres Mal von dessen enormer Verbreitung Zeugnis ab. Der Liedeinsatz entspricht ziemlich genau der Semantisierung von Choralmelodien bei J.S. Bach und stellt meines Wissens einen einzigartigen Fall in der katholischen Musikliteratur der Zeit dar.

\section{Katholische Kirchenlieder in Schauspielen}

Den ca. 100 oben erwähnten evangelischen Kirchenliedern im Schauspiel des 16. und 17. Jahrhunderts, von denen etliche sehr häufig verwendet wurden, stehen auf katholischer Seite wenig mehr als das vorreformatorische "Christ ist erstanden“ sowie „Maria zart" gegenüber. Beide wurden im Luzerner Osterspiel eingesetzt. Die Bedeutung beider Lieder ist über jeden Zweifel erhaben. „Christ ist erstanden“ sang man schon in den Osterspielen des Mittelalters. „Maria zart" konnte sehr schnell eine außerordentliche Stellung erringen; sein Gesang wurde sogar mit einem Ablass versehen. ${ }^{81}$ In die Luzerner Aufführungen brachte es der damalige Spielleiter, der Luzerner Stadtverordnete Rewart Cysat, eine führende Figur der Gegenreformation. Cysat hatte das Lied bereits redigiert und erweitert herausgegeben. ${ }^{82}$ In den mehrtägigen Luzerner Aufführungen erscheint es in herausgehobener Position am Spielanfang und -ende. ${ }^{83}$ Die einem Meistergesang ähnliche Strophenform ist so charakteristisch, dass die Melodieangabe unnötig wird. Wenn der Schweizer Hermann Haberer den Prolog von Ein gar schön Spyl

80 Eine genaue Vorlage für die Melodie suchen zu wollen, ist hier ebenso wenig sinnvoll wie bei „Erstanden ist der heilig Christ“. Werlin (Anm. 55), X/8 Bl. 3118. verzeichnet ca. 1650 bereits 32 verschiedene Singweisen für "Der grimmig Tod“. Biber folgt im Wesentlichen der Melodie, die im Rheinfelsischen Gesangbuch (1666) belegt ist. Bäumker: Kirchenlied (Anm. 16), Bd. II, Lied Nr. 329.

81 Wackernagel (Anm. 2), Bd. II Nr. 1035 ff. Geistliche Gesänge des deutschen Mittelalters. Melodien und Texte handschriftlicher Überlieferung bis um 1530. Hrsg. von Max Lütolf. (= Das deutsche Kirchenlied II) 6 Bde. Kassel 2003-2009, Bd. III Nr. 500-501. Bäumker: Kirchenlied (Anm. 16), Bd. I, Bibliographie Nr. 2: Der Rosenkranz von U. L. Frawen und Ußlegung des Psalters etc. Straßburg 1470. Enthält „Maria zart" mit 21 Strophen. Birgit Lodes: „Maria zart" und die Angst vor Fegefeuer und Malafrantzos. Die Karriere eines Liedes zu Beginn des 16. Jahrhunderts. In: Musikalischer Alltag im 15. und 16. Jahrhundert. Hrsg. von Nicole Schwindt. Kassel u. a. 2001, S. 99-131.

82 Hie folget der Schoene andächtige Text Lied und Gedicht [...] Maria zart/von Edler art/ Ein Ros ohn allen doren. O.O. 1580 [12: Res/4 P.o.germ. 231,24]; Ein schön andächtigs Liedt und gedicht, von unser lieben Frawen, jetzt von newen ubersehen, gebessert, und inn ein kömblichere Ordnung gestellt etc. Dillingen: Johan Maier 1593. 33 Strophen. Bäumker: Kirchenlied (Anm. 16), Bd. I Bibliographie Nr. 176; vgl. zusätzlich ebd. Nr. 203.

83 Vgl. Scheitler: Schauspielmusik (Anm.4), Nr.1318: Zum Beschluss der Aufführung am 1. Spieltag 1583 und 1597 und zum Beginn und Ende des 2. Spieltages 1583 ist der Gesang von „Maria zart" zur Orgel verzeichnet. Es ist von Chorgesang auszugehen. 
von dem glöubigen vatter Abraham (zuerst 1554) in das bezeichnende Muster setzt, so versteht sich geradezu von selbst, dass er auf die bekannte Melodie gesungen wurde. ${ }^{84}$

Gegenüber „Maria zart“ ist die Verwendung anderer Kirchenlieder nur mehr von peripherer Bedeutung: Der Benediktiner Simon Rettenpacher schrieb 1682 in seinem Drama Frauen=Treu einen Zwischenaktchorus auf das Strophenmuster von „Wie schön leuchtet der Morgenstern“, ohne den Thon zu erwähnen. ${ }^{85}$ Das Lied Philipp Nicolais war, wie schon erwähnt, auch bei den Katholiken verbreitet. Der Kremsmünsterer Konventuale Rettenpacher ist eine Ausnahmefigur unter den katholischen Dramatikern, denn er zeigt eine ungewöhnliche Belesenheit in hochdeutscher barocker Lyrik. Hingegen bestätigt sich am Beispiel des Kölners Paul Aler SJ die mehrfach gemachte Beobachtung, dass sich Jesuiten auf die Lieder ihrer Ordensbrüder beziehen. Aler, Lehrer am Gymnasium Trium Coronatum, macht 1710 für den Text einer vierzeiligen Aria Anleihen bei der 14. Strophe von Spees „Bei stiller Nacht“. Die Melodie hätte sich verwenden lassen. ${ }^{86}$

Wenn damit das von mir einsehbare Kontingent erschöpft ist, so mag das auch an dem enormen Forschungsrückstand liegen, unter dem die Kenntnis über Verbreitung und Gebrauch katholischer religiöser Gesangslyrik leidet. Trotzdem bleibt festzuhalten: Die konfessionellen Differenzen sind erheblich. Die geringe gottesdienstliche Verwendung mag der Ausgangspunkt des Unterschiedes sein. Insbesondere die Gesellschaft Jesu förderte den Liedgesang in der Kinderlehre, gebräuchlich war er in den Versammlungen der Bruderschaften und Kongregationen ebenso wie bei Wallfahrten und Andachten. Mit der fehlenden liturgischen Würde mag die mangelnde Wertschätzung zusammenhängen, mit der schlechteren Stellung des Laien die geringere Verbreitung und Verwendung zur persönlichen Erbauung. Für deutsche Vokalmusik war in der katholischen Kirche kaum Platz, sodass Kirchenlieder, anders als im Protestantismus, auch nicht im Zentrum gottesdienstlicher Kunstmusik standen. Nimmt man die Kontrafaktur als Beleg für vorausgesetzte Kenntnis einer Melodie und eines Liedes, so ergibt sich ein ernüchterndes Bild: Das katholische Volk war mit einigen vorreformatorischen Gesängen sowie mit ausgewählten Melodien von Liedern der Reformation vertraut. Die vielen im Zuge der katholischen Reform verfassten und publizierten Lieder schlugen aber offenbar wenig Wurzeln. Als tatsächlich weit verbreitet dürfen das im Grunde noch vorreformatorische "Maria zart" und das in seiner konfessionellen Provenienz unsichere „Der grimmig Tod mit seinem Pfeil“ gelten.

84 Scheitler: Schauspielmusik (Anm. 4), Nr. 397 ff.

85 Scheitler: Schauspielmusik (Anm. 4), Nr. 814, III,5, zugleich Chor nach Akt III.

86 Scheitler: Schauspielmusik (Anm. 4), Nr. 30, II,4. 
(C) 2015, Otto Harrassowitz GmbH \& Co. KG, Wiesbaden ISBN Print: 9783447104975 — ISBN E-Book: 9783447194136 


\section{„In Arbeit und Beruf" \\ Zur lyrischen Verinnerlichung lutherischer Standes- und Berufsethik}

Andreas Lindner

\section{Die Genese der lutherischen Standes- und Berufsethik}

Schlägt man die aktuelle Ausgabe des Evangelischen Gesangbuchs sowohl in seiner Version für die lutherischen als auch für die unierten Landeskirchen der „Evangelischen Kirche in Deutschland" auf, so findet sich in Ihnen jeweils die Rubrik „Arbeit" als ein kleiner Abschnitt mit jeweils vier Liedern. Auch in der Vorgängerausgabe des Evangelischen Gesangbuchs, dem Evangelischen Kirchengesangbuch gibt es diese Rubrik in beiden konfessionellen Versionen, hier noch unter dem Titel „In Arbeit und Beruf“ mit jeweils fünf identischen Titeln. Das Wort ,Beruf lässt noch eher die Wurzel der ja nicht unbedingt zwingenden Tatsache erkennen, dass geistliche Liedersammlungen die menschliche Arbeit thematisieren. So kennt das katholische Gesangbuch Gotteslob eine solche Rubrik nicht.

Gleichwohl findet sich die Wurzel des lutherischen Arbeitsethos im Kloster und in der monastischen Lebensweise. Dorothea Wendebourg hat das Erbe des Mönchs Martin Luther für die evangelische Kirche eindrücklich beschrieben. In einem Bild zusammengefasst habe Luther die Mauern des Klosters nach außen in die Welt gekehrt. Er habe die auf dem Psalmengebet basierte monastische Spiritualität in die neue reformatorisch-häusliche Spiritualität transponiert. Das klösterliche Leben war durch den Rhythmus der Tagzeitengebete und die dazwischen gelagerten Arbeitszeiten streng strukturiert. Für Müßiggang gab es keinen Platz und als der schlimmste Feind des Mönchs war schon seit der Spätantike der Dämon der mittäglichen Trägheit identifiziert,; ${ }^{1}$ unter dem Namen der Acedia ${ }^{2}$ die

1 Evagrius Ponticus (ca. 345-399), aus der Provinz Pontus stammend, theologisch geprägt von dem Kreis der Nicäner um Basilius den Großen, hatte sich 383 den Eremiten in der ägyptischen Wüste angeschlossen. Er zählt zu den Leitfiguren der sogenannten Wüstenväter, gehört zum Verfasserkreis der Apophthegmata patrum und ist Autor einer Reihe weiterer geistlicher Schriften zum Mönchsleben. In letzteren formuliert er eine Acht-Laster-Lehre, aus der sich die Anschauung von den Sieben Todsünden entwickelte. Vgl. Evagrius Ponticus: Ad Monachos. Ad Virginem Institutio ad Monachos. Der Mönchsspiegel. Der Nonnenspiegel. Ermahnung an Mönche. In: Fontes Christiani. Zweisprachige Ausgabe christlicher Quellentexte aus Altertum und Mittelalter. Im Auftrag der Görres-Gesellschaft hrsg. von MarcAeilko Aris u. a., Bd. 51, eingeleitet und übersetzt von Christoph Joest. Freiburg/ Br. 2012.

2 Acedia ist lateinisches Lehnwort vom griechischen $\dot{\alpha} \kappa \eta ́ \delta \varepsilon เ \alpha$, wörtlich: Sorglosigkeit, Nachlässigkeit. 
letzte in der Reihe der Sieben Todsünden: Schlimmer als alle anderen, indem sie diese quasi erst ermöglicht. Auf Gedanken des Hochmuts (superbia), des Geizes (avaritia), der Wollust (luxuria), des Zorns (ira), der Selbstsucht (gula), des Neids (invidia) kommt erst, wer sich weder dem Gebet noch der Arbeit widmet. Die Acedia sollte im Hause lutherischer Eltern ebenfalls keine Chance haben. Auch hier sollte der Alltag im Normalfall durch Gebet und Arbeit strukturiert werden. ${ }^{3}$

Diese so aus dem Kloster als das Tagwerk übernommene Struktur hatte Luther geheiligt, denn wie ursprünglich die Mönche und Nonnen den ,Beruf' dazu hatten, sich durch ihre Lebensweise ganz Gott zu weihen, so hatte dies nun jeder Mensch. Luther heiligt den bürgerlichen Alltag. In einer Predigt von 1534 äußert er:

Sihe vor, ut credas in Christum et baptisantus, Post vide vocationem: Ego vocatua ad praedicandum, quando praedico, facio opus sanctum, quod deo placet, [dass du an Christus glaubst und getauft bist. Danach sieh auf deinen Beruf: Ich bin berufen zum Predigen, wenn ich predige, tue ich ein heiliges Werk, das Gott gefällt]. Si es pater, mater, Crede in Iesum Christum [Bist du Vater, Mutter: glaube an Jesus Christus], so bistu ein heiliger vater, muter, Hore zu morgen deine kinder, lasse sie betten, straffe, steuppe sie, Sihe, wie es im hause zugehe, wie man kocht, sind eitel heilige werck, Quia [denn] du bist dazu geruffen. Das heisst ein heilig leben, quod in verbo dei et vocatione [das in Gottes Wort und in der Berufung] hergeht." ${ }^{4}$

Und zwei Jahre zuvor 1532 in den Wochenpredigten über Matthäus 5-7:

Bist du ein Handwerksmann, so findest du die Bibel gelegt in deine Werkstatt, in deine Hand, in dein Herz, die dich lehrt und dir vorpredigt, wie du dem Nächsten tun sollst. Sieh nur an, dein Werkzeug, deine Nadel, dein Bierfaß, deinen Kram, deine Waage, Elle und Maß, so liest du diesen Spruch darauf geschrieben, daß du nirgendhin sehen kannst, das dir's

3 „Im Anhang zum Kleinen Katechismus, dem wichtigsten religiösen Lehrbuch der lutherischen Tradition und einer der dogmatischen Grundlagen der lutherischen Kirche, finden sich ein Morgen- und ein Abendgebet, [...] der „Morgen-,, und der „Abendsegen“. Diese Gebete sind gedacht als geistlicher Beginn und Ausklang des Tages, wie ihn die ganze Familie täglich halten soll. Mit ihnen verbunden sind andere liturgische Stücke, wie das Vater unser, das Glaubensbekenntnis, ein Choral - ein kleines Stundengebet für das christliche Haus. Hat schon diese ganze Einrichtung einen unverkennbar monastischen Anklang, so gilt das erst recht für jene Gebete, die in ihrer Mitte stehen: Der Morgensegen, nach dem Luther auch den Abendsegen gebildet hat, ist seinem Ursprung nach ein Morgengebet für Glieder monastischer Gemeinschaften, das nun hier, leicht abgewandelt, in die „Welt" übernommen wird. D. h. lutherische Familien haben jahrhundertelang, und tun es z.T. noch heute, jeden Tag mit einem Gebet begonnen und beschlossen, das ursprünglich in den monastischen Rahmen gehört, das aber nun, in die Weite der Kirche übernommen, Allgemeingut aller Christenmenschen geworden ist." Dorothea Wendebourg: Der gewesene Mönch Martin Luther. Sein Erbe für die evangelische Kirche heute. Erfurt 2006, S. 19.

4 Martin Luther: Werke. Kritische Gesamtausgabe (Weimarer Ausgabe). Weimar 1910. Ndr. Weimar, Graz 1964. Bd. 37, S. 480, Z. 2-8, (Predigt am 5. Sonntag nach Trinitatis, 5. Juli 1534). 
nicht unter die Augen stoße, und kein Ding, mit dem du täglich umgehst, so gering ist, daß es dir solches nicht ohne Unterlaß sage, wenn du es hören willst. ${ }^{5}$

Solche Äußerungen ziehen sich durch das gesamte Wirken Luthers. Für die frühe Phase seien hier genannt die Programmschrift Von der Freiheit eines Christenmenschen (1520) mit dem zweiten Teil ihres bekannten Leitmotivs „Ein Christenmensch ist ein dienstbarer Knecht aller Dinge und jedermann untertan" sowie die Schrift Von weltlicher Oberkeit, wie weit man ihr gehorsam sey von 1523, in der er 200 Jahre vor dem aufgeklärten Absolutismus den Fürsten zum ersten Diener seines Staats erklärt, der vor Gott alle Verantwortung dafür trägt, wie er dieser Aufgabe gerecht wird. Für die späte Phase steht seine Predigt zur Einweihung der Torgauer Schlosskirche am 5. Oktober 1544, in der er vor dem kurfürstlichen Hofstaat vom Kanzler bis zur Küchenmagd allen Ständen ins Stammbuch schreibt, dass sie vor Gottes Angesicht alle gleich viel wert seien, sofern sie den Pflichten des Standes, in den sie hineingeboren sind, nachkommen. In diesem Sinne hat nicht einmal eine Kaiserin einen Vorrang vor der Küchenmagd, während diese es nicht nötig hat, neidisch auf die Kaiserin zu sein. Dieses Konzept ist dabei kein erzkonservativer Versuch, die vorgegebene Ständegesellschaft gleichsam erstarren zu lassen, ${ }^{6}$ denn Luther selbst war als gesellschaftlicher Aufsteiger, wie viele andere, ein Beispiel dafür, dass Standesschranken z. B. durch Bildung durchlässig waren. ${ }^{7}$

\section{Das Gesangbuch als Hauptmedium lutherischer Standes- und Berufsethik}

Verinnerlicht wurde diese Ethik einer bewussten Erfüllung der aus dem eigenen Stand resultierenden beruflichen Pflichten als Ausdruck bewussten Christ-Seins und zugleich Ausdruck lutherischer Frömmigkeit von Generation zu Generation durch ein entsprechendes Liedgut. Mehr noch als die Bibel wurde das Gesangbuch zum eigentlichen Medium. Der Psalter als Gebetbuch des Mönchtums, von Luther im Kloster lieb gewonnen wie keine andere biblische Schrift, mutierte über das Gesangbuch zur ,Laienbibel' des Luthertums.

Dabei lassen sich hinsichtlich der Standes- und Berufsethik drei Entwicklungsphasen der Gattung ,Gesangbuch' feststellen. In der ersten Phase sind lutherische Gesangbücher nach rein systematisch theologisch-heilsgeschichtlichen

5 Luther: Werke (Anm. 4), Bd. 32, S. 495, Z. 29-33 (Das fünffte, Sechste und Siebend Capitel S. Matthei gepredigt und ausgelegt. 1532).

6 Formulierungen, die das nahe legen könnten, wie: „Allein bleib inn deinem Stande und sey zufriden, du sitzest oben oder unten an," (WA 49, 609, 23-24) richten sich primär zugleich gegen den Hochmut der oberen Stände über die unteren wie in umgekehrter Richtung gegen den möglichen Neid der unteren.

7 Luther propagierte das auch. Seine „Predigt, das man die Kinder zur Schule halten solle“ von 1530 ist eine einzige Werbeschrift für gesellschaftlichen Aufstieg durch Bildung. 
bzw. nach katechetischen Gesichtspunkten geordnet. Das gilt für alle Gesangbücher des 16. Jahrhunderts bis hinein ins 17. Jahrhundert und zum Ende des Dreißigjährigen Kriegs. Exemplarisch sei hier genannt Johann Georg Schott: Psalmen und Gesang=Buch/Darinnen die Geistlichen Lieder D. Mart. Lutheri/ ond anderer Christen begrieffen, Frankfurt/M. 1603. Dieses Gesangbuch gliedert sich wie folgt: kompletter Psalter, Katechismusgesänge, Festgesänge, Lehrgesänge mit Lehr-, Trost-, Bet-, Klag-, Lob- und Dank-Liedern. Weitere Beispiele mit prinzipiell gleichem Aufbau lassen sich in großer Zahl und geographisch weit verteilt beibringen. ${ }^{8}$ Eine stärkere Ausdifferenzierung zeichnet sich seit den 1620er Jahren ab. So bei Johann Hermann Schein: Cantional Oder Gesangbuch Augspurgischer Confession [...] So in Chur= vnd Fürstenthümern Sachsen [...] gebräuchlich, Leipzig 1627: 1. Abschnitt: Jesus Christus: Von der Menschwerdung bis zur Aussendung des Heiligen Geistes; 2. Abschnitt: Die heilige Dreifaltigkeit, besondere Fest- und Aposteltage, die 10 Gebote, der christliche Glaube, Gebet, Taufe, Buße, Abendmahl, Morgenlieder, Abendlieder, Vor dem Essen, Nach dem Essen, Von der Rechtfertigung, Vom christlichen Leben und Wandel, Psalmenlieder, Von Kreuz, Verfolgung und Anfechtung, Vom Wort Gottes und der christlichen Kirche, Vom Tod und Sterben, Vom jüngsten Tage und der Toten Auferstehung, Ordnung der deutschen Messe und deutsche Litanei. ${ }^{9}$

Die Ordnung all dieser Gesangbücher spiegelt die lutherische Heiligung des Lebens. Die Botschaft kommt über die Lieder - ohne ,Lyrik' keine reformatorische volkskirchliche Spiritualität. Noch aber kennen diese Gesangbücher keine Standes-, Amts- oder Berufsrubriken. Eine weitere Ausdifferenzierung in diese Richtung und damit die zweite Phase, deutet sich das erste Mal greifbar in einem Nürnberger Gesangbuch von 1657 an: Bey 1000 Alte und Neue Geistliche Psalmen/ Lieder und Gebete. Es enthält eine Rubrik „Lieder zur Hauß=Taffel gehörig“ mit fünfzehn Liedern, unter denen als Autor der in Nürnberg aufgewachsene Nikolaus Selnecker (1530-1592) besonders stark vertreten ist. Bedacht werden ,Stände wie Obrigkeit, Eltern, Kinder, Witwen sowie als Berufe Pfarrer und Kaufmann. ${ }^{10}$ Der Begriff ,Hauß=Tafel' ist dabei durch seine Zuordnung zu den Verhaltensanweisungspassagen in Kol 3,18-4,1 und Eph 5,21-6,9 eindeutig ethisch konnotiert. Luther hatte diese Verse neben weiteren aus dem 1. Timotheus-, Titus-, Römer- und

8 Matthäus Pfeilschmidt: Geistliche Lieder vnd Kirchengesänge/ so in der Christlichen Gemein zu Hof [...] gebreuchlich, o.O. 1608. 754 Außerlesene/ Reine Geistliche Lieder vnd Psalmen [...] Für die Kirchen vnd Schulen im [...] Hertzogthumb Württemberg, Tübingen 1608. Geistliche Psalmen Hymnen Lieder vnd Gebet, Jena und Nürnberg 1614.

9 Ein weiteres Beispiel wäre Johannes Stumpf: Margräffisch Brandenburgisch Gesangbuch. Coburg 1630.

10 Paul Sturm: Das evangelische Gesangbuch der Aufklärung. Barmen 1923, S. 35, behauptet diese Entwicklung habe bereits Mitte des 16. Jahrhunderts eingesetzt, kann das aber nicht belegen. Sein einziger Quellennachweis betrifft den Entwurf zu einem nicht ausgeführten Gesangbuch für die calvinistische Grafschaft Nassau-Dillenburg von 1601 mit „[...] 70 Liedergruppen für die verschiedenen Stände und Berufe, darunter Lieder eines Kuh=, Schaf= und Sauhirten." (ebd.). 

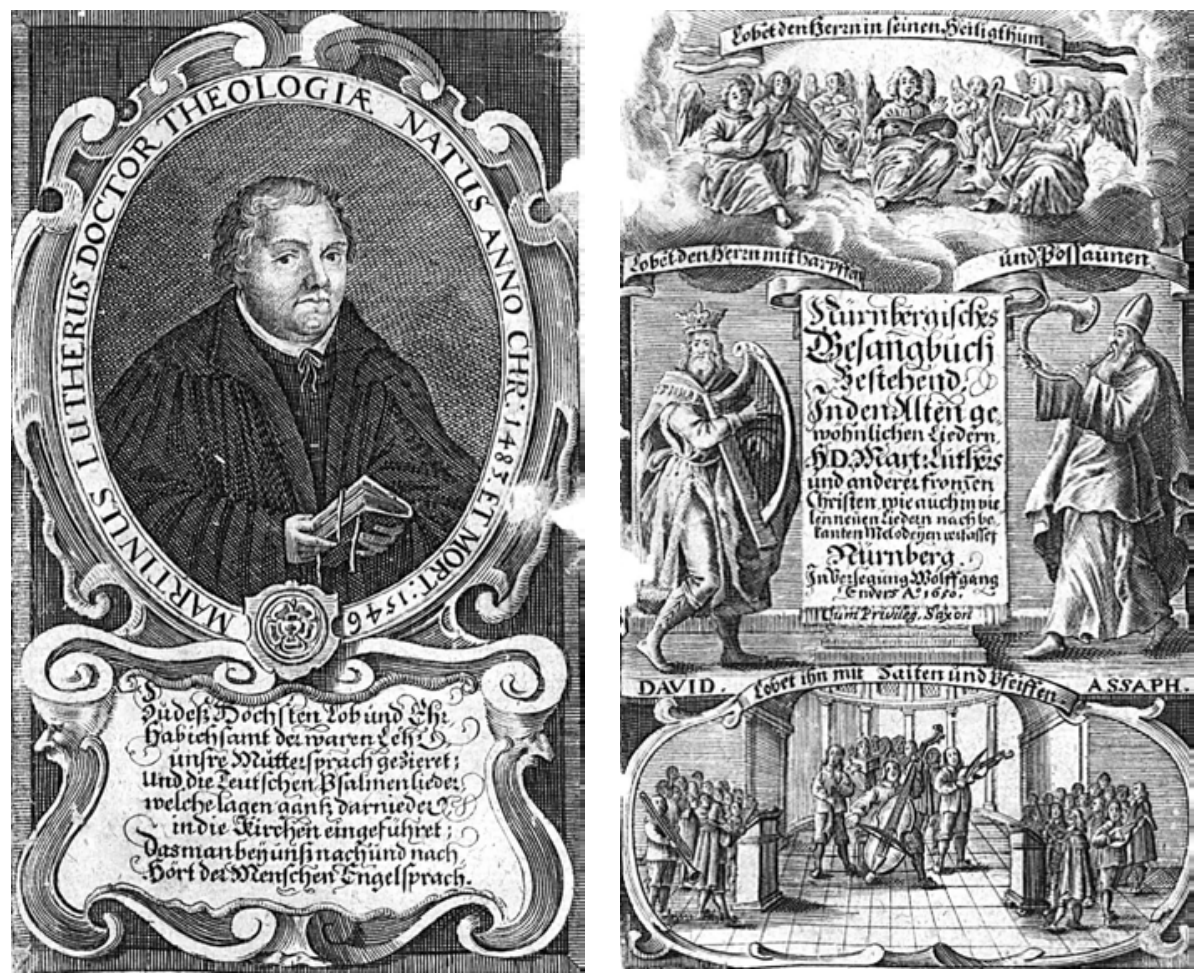

Abb. 1

Frontispiz und Kupfertitel Nürnbergisches Gesangbuch von 1550 als Vorsatz zu: Bey 1000 Alte und Neue Geistliche Psalmen/ Lieder und Gebete., Nürnberg 1657. Das Frontispiz illustriert die Luther-Basierung der Gesangbücher bis zu deren Neukonzeption durch Pietismus und Aufklärung. Luthers Lieder und sein Kleiner Katechismus bildeten die ideelle Klammer; FB Gotha Cant. Spir $8^{\circ} 00291$.

1. Petrusbrief unter der Überschrift „Die Haustafel/ Das ist/ etliche Sprüche für allerlei heilige Orden und Stände/ dadurch dieselbigen/ als durch eigen Lektion ihres Ampts und Diensts zu ermahnen" 1529 an den Kleinen Katechismus angehängt. ${ }^{11}$

Schnell entwickelt sich dann daraus die Rubrik "Von den drei Hauptständen“ bzw. "Standes-Lieder“. So in: Neu=vermehrtes vollständiges Gesangbuch (Braunschweig 1661) mit der Rubrik „Von den dreyen Hauptständen und umb Göttliche Regierung“ mit insgesamt 25 Liedern. Die klassische Drei-Stände-Lehre des Mittelalters und der Frühen Neuzeit von Wehrstand, Lehrstand und Nährstand

11 Das Phänomen der „Haustafel“ am Kleinen Katechismus ist komplett analysiert und beschrieben bei: Albrecht Peters: Kommentar zu Luthers Katechismen, Bd. 5: Die Beichte. Die Haustafel. Das Traubüchlein. Das Taufbüchlein. Göttingen 1994, S. 95-118. 
spiegelt sich hier wider. In den nächsten 60 Jahren hält diese Rubrik Einzug in eine Vielzahl von Gesangbüchern, wobei allenfalls die Reihenfolge der Stände schwankt. Der Umfang kann von außerordentlicher Differenzierung bis hin zu nur wenigen Liedern reichen. Ein Beispiel für eine starke Differenzierung bietet der sächsische Oberhofprediger Johannes Olearius mit Geistliche Singe=Kunst Und ordentlich verfassetes vollständiges Gesang=Buch, Leipzig 1671:

Das V. Buch Standes=Lieder. I. Allgemeine Andacht vor alle Standes=Personen [2 Lieder] II. Sonderbare Andacht. [sechs Lieder] Die I. Claß Vom Lehrstande I. Der Prediger [... $]^{12}$ III. Der Lehrmeister in Schulen IV. Die Lehrschüler und Studenten. Die II. Claß Vom Wehrstande [23 Lieder] I. Regenten Andacht [darin 19 Lieder: „Symbola und Wahlsprüche hoher Personen/ und darauf gerichtete Lieder": unter anderem auf Gustav II. Adolph von Schweden, Kurfürst Johann Friedrich der Großmütige, Albrecht Alkibiades von Brandenburg-Ansbach, Kurfürst August von Sachsen] II. Eines Gottseligen Kriegsmanns III. Gottseliger Unterthanen Ermunterung Die III. Claß Vom Nehr=Stande [17 Lieder] I. Insgemein (Ps 127 u. 128) II. Insonderheit.

In diesem letzten Teil sind zusammengefasst: Ehegatten, Eltern, Kinder, Hausväter, Witwer/ Witwen, Waisen, Alte, junge Leute, Jungfrau, Diener, Handelsleute, Handwerksleute, Ackersleute, Fischer, Reisende und Fremdlinge. Das wurde unter Umständen noch weiter getrieben bis ins Situative, wie etwa bei Johannes Guenther: Andächtiger Seelen geistliches Brand=und Gantz=Opfer/ Das ist: vollständiges Gesangbuch/ In acht unterschiedlichen Theilen Leipzig 1697. Der siebente Teil enthält: Stand=Lieder/ Nach den drey Haupt=Ständen eingerichtet/ Reise=Lieder Zu Land und Wasser/Item Krieg= Hunger= und Pest=Lieder. Hier finden sich dann auch Lieder für folgende Fälle, bei denen man von einer Ereigniskette mit allen möglichen Alternativen sprechen kann: Ehe, Unfruchtbarkeit/ Schwangerschaft, Kreisende, die (bei der Geburt) Umstehenden, die in Kindesnöten sterben, wenn das Kind tot zur Welt kommt, Danklied, wenn Gott aus Kindesnöten geholfen, Wiegenlieder, Bei unglücklicher Ehe, Eltern und Kinder, Witwen und Waisen, Jünglinge und Jungfrauen.

Eher nebenbei, nämlich ohne ausdrücklich benannt $\mathrm{zu}$ werden, erscheinen Standeslieder zur Ehe, zum Predigtamt und zur Obrigkeit in Gesangbüchern wie dem von Zerbst $1707^{13}$ oder Gotha 1719, in dem die Rubrik: „Von den drey Hauptständen" aus nur drei Liedern besteht. ${ }^{14}$ Dazwischen gibt es ein breites Mittelfeld von Christian von Stökkens Holsteinischem Gesang=Buch, Rendsburg $1681^{15}$ (25 Lie-

12 Ein Abschnitt II. existiert nicht; auf I. folgt III.

13 Zerbstisches Gesang Buch. Zerbst 1707.

14 Johann Andreas Reyher: Geistliches neu=vermehrtes Gothaisches Gesang=Buch. Gotha 1719: Nr. 471. Johann Lindemann: Ein Lied über alle drei Stände zuzüglich der beiden Standard-Psalmenlieder des Luthertums für den Hausstand zu Ps 127 und 128.

15 Christian von Stökken: Holsteinisches Gesang=Buch. Rendsburg 1681. FB Gotha, Cant. Spir $8^{\circ} 00633$. 

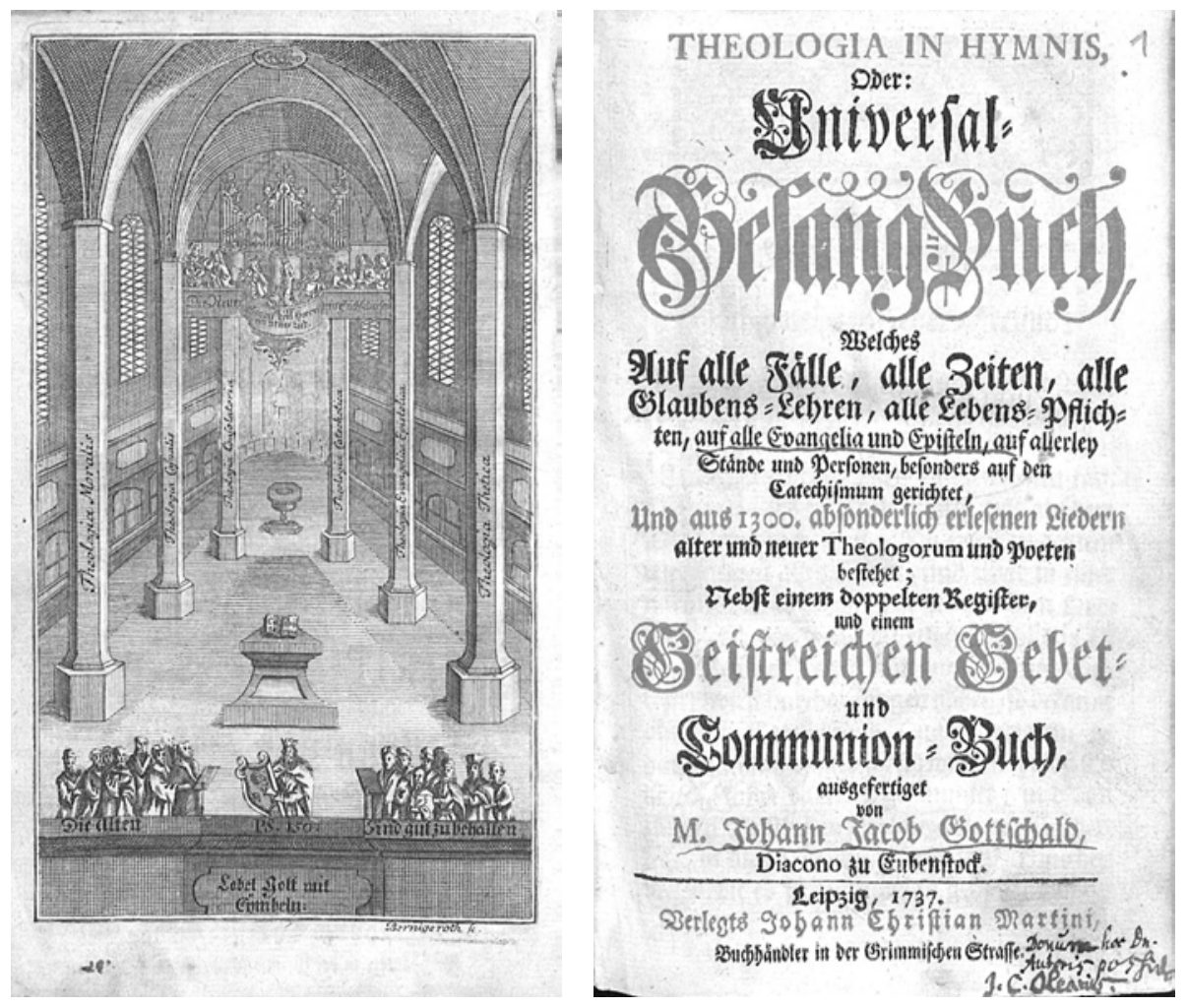

Abb 2:

Gesangbücher wie Johann Jacob Gottschalds Universal=Gesang=Buch von 1737 verdeutlichen schon über ihr Titelblatt das Streben nach allumfassender Durchdringung - Heiligung - des Lebens mit geistlichen Liedern und Gebeten; FB Gotha Cant. Spir $8^{\circ}$ 00022a.

der) über Johann Christoph Olearius' Neu=Verbessertes Arnstädtisches Gesangbuch von 1700 (fünfzehn Lieder), Carl Andreas Redels Gesangbuch für Altenburg 1721 (24 Lieder), das Fürstliche Gesangbuch für Eisenberg 1734 (37 Lieder), Johann Georg Webers Der Singende Glaube des Weimarischen Zions Oder Neu=eingerichtetes Weimarisches Gesang=Buch 1739 (57 Lieder).

Zeitlich parallel taucht ab 1720 in der Rubrik der Standes-Lieder die Erweiterung durch den Begriff ,Beruf ${ }^{\prime}$ auf. So enthält Johann Martin Schamelius: Naumburgisches glossiretes Gesang=Buch (Naumburg 1720), die Rubrik „Standes= und Beruffs=Lieder" mit neun Liedern, die sich aber nur noch mit dem Wehrund dem Lehrstand befassen, während der Hausstand ausgegliedert ist in die nächstfolgende Rubrik „Hauß= und Ehe=Lieder". Weitere Gesangbücher, die auf diese Begriffsausweitung einschwenken sind Johann Philipp Treuner: Schuldiges Lob Gottes Oder: Geistreiches Gesang=Buch, Weimar 1725 (vierzehn Lieder) 
und die Evangelische Lieder=Theologie Oder vollkommenes Lehr=und Geistreiches Gesang=Buch, Hannover und Göttingen 1737 mit einer großen Rubrik: „Berufs= und Standes=Lieder für besondere Personen in ihrem Beruf und Stande" (39 Lieder). Christian Siegmund Greens Neu=vermehrtes Rochlitzer Gesang=Buch In 1500 Auserlesenen Liedern, Rochlitz $1746^{16}$ enthält eine Rubrik: ,XXVII. Stand= Amts= und Beruffs=Lieder" mit insgesamt 63 Liedern für alle drei Hauptstände. Das Neue Gesang=Buch [...] der Stadt Straßburg, Straßburg 1743, schiebt die "Berufs=Lieder" (insgesamt vier) als eigene Rubrik zwischen die Lieder „Vom Predigt=Amt" und „Vom Ehstand“, also zwischen Lehr- und Hausstand.

Zieht man bis hierher Bilanz, so fällt auf, dass die lutherische Standes- und Berufsethik erst nach dem Dreißigjährigen Krieg mit einem eigenen spezifischen Liedgut in die entsprechend gekennzeichneten Rubriken der Gesangbücher einzog. Das geschieht gleichzeitig mit der verstärkten Hinwendung der späten lutherischen Orthodoxie zu einer Verbindung von Frömmigkeit und Alltagsleben. Namen, die hier zu nennen wären, sind Joachim Lütkemann (1608-1655), Theophil Großgebauer (1627-1661), Heinrich Müller (1631-1675), und Christian Scriver (1629-1693). Diese Entwicklung wurde durch den Pietismus unter dem Schlagwort der ,praxis pietatis` bis zur Dominanz gesteigert. Eines der erfolgreichsten Gesangbücher des 17. und 18. Jahrhunderts, das des Berliner Lehrers und Kantors Johann Crüger führte schon seit der zweiten Auflage 1647 - also noch vor dem Einsetzen der pietistischen Bewegungen im Luthertum - im Titel das Motto "Praxis pietatis melica". ${ }^{17}$ Das Thema an sich hatte weder allgemein theologisches noch spezifisch moraltheologisches Streitpotential, so dass die Frage des rechten christlichen Verhaltens in Beruf und Alltag unberührt von theologischen Streitigkeiten blieb. Es hätte allenfalls in den Dissens über die Adiaphora zwischen Orthodoxie und Pietismus hineingezogen werden können, was aber hinsichtlich des hier behandelten Liedguts nicht geschah.

Wenn man sich wirklich profilieren wollte, war die Standes- und Berufsethik nicht das geeignete Thema. Das wird daran deutlich, dass gerade in Gesangbuchausgaben, die sich dezidiert pietistischer oder orthodoxer Theologie zuordnen, Standes- und Berufslieder kaum präsent sind. Zu nennen sind hier der Prototyp pietistischer Gesangbücher, Johann Anastasius Freylinghausens Neues Geist=reiches Gesang=Buch ${ }^{18}$ von 1703 oder auch Georg Friedrich Rogalls strukturell an diesem orientierter Kern alter und neuer Lieder, Königsberg 1744. Beide sind nach dem Muster der pietistischen Soteriologie, im damaligen Sprachgebrauch

16 1. Auflage 1720, 2. Auflage 1730.

17 Vgl. Christian Bunners: Johann Crüger (1598-1662) - Berliner Musiker und Kantor, lutherischer Lied- und Gesangbuchschöpfer. Aufsätze, Bildnisse, Textdokumente. Berlin 2012.

18 Mir vorliegend in der 3. Auflage, Halle 1726, in deren Vorrede Freylinghausen ausdrücklich anmerkt: „Es kommt demnach dieses andere und neue Gesang=Buch mit dem ersten fast in allen Stücken überein. [...] So ist in beyden Büchern einerley Ordnung sowol der rubricirten Materien der Lieder, als der unter iegliche Rubric gehöriger Lieder selbst" (Vorrede, Bl. 5v). 
der "Oeconomie und Ordnung des Heils" ${ }^{19}$ aufgebaut. Freylinghausen berücksichtigt diese Lieder gar nicht, Rogall nimmt drei Berufslieder auf. Ihre Entsprechung stellen zum Beispiel von der orthodoxen Stadtgeistlichkeit in Halle herausgegebene Gesangbücher dar, wie das Hällische Neu=eingerichtete Gesang=Buch von 1711 und Johann George Kirchners Eines sämtlichen Stadt=Ministerii zu Halle Gesang=Buch von $1744^{\prime \prime}{ }^{20}$ beide ohne Standes- und Berufslieder.

Eine erneute Verschiebung im Sprachgebrauch und damit die dritte Phase tritt mit der Aufklärung ein, jetzt wieder im Sinne einer Verallgemeinerung. Zum neuen zentralen Terminus entwickelt sich die ,Pflicht', wobei die alten Begrifflichkeiten noch immer mitgenommen werden, zumal das Standes-Schema bis in die Industrialisierung hinein aktuell blieb. ${ }^{21}$ Den theologische Horizont, in dem sich dieser Wandel vollzog, bietet Johann Lorenz von Mosheims Sitten-Lehre der Heiligen Schrift, die ab 1735 in neun Teilen erschien und schon 1753 eine „Vierte, vermehrte und verbesserte Auflage“ erlebte. In den Teilen fünf bis neun wird der Kanon der [...] allgemeinen Pflichten, die allen Christen obliegen" vorgestellt, beginnend mit den „Pflichten gegen Gott“ (T. 5 und 6) über die „Pflichten der Christen gegen sich selber" (T. 6), "Aeusserliche Pflichten der Christen gegen andere überhaupt oder gegen einzelne Personen“ (T. 7) bis zu den „,...] besondern Pflichten, welche die Christen in gewissen Gesellschaften und Ständen“ zu beobachten haben (T. 8 und 9). Letztere unterteilen sich dabei in ,[...] Pflichten, welche die Christen als Glieder der natürlichen Gesellschaft zu erfüllen schuldig sind“ (T. 8) und „Pflichten der Christen in der bürgerlichen Gesellschaft" (T. 9). Gleich zu Beginn der Gesamtthematik diskutiert Mosheim den Begriff der ,Pflicht'. In Abgrenzung von einem traditionellen weiten Verständnis, das Glaube, Buße, Wiedergeburt und Heiligung sowie die Bewegungen der Seele und des Herzens - modern gesprochen: die Spiritualität - als Pflichten eines Christenlebens betrachtet, plädiert er für ein engeres Verständnis. Da alles Genannte, im systematischen Sinne also das Heilswerk, letztendlich Gott zum Urheber habe, könne es nicht als menschliche Pflicht betrachtet werden:

Ich meyne, daß nichts im eigentlichen Verstande den Namen einer Pflicht tragen könne, als was ich selber durch den rechten Gebrauch der Gnadenkraft, die mir in der Bekehrung ist verliehen worden, verrichten kann. [...] Ich trete also zu denen, die dem Worte Pflicht eine enge Bedeutung beylegen, und dadurch nichts, als Handlungen meynen, die mit der Vorschrift des Gesetzes übereinstimmen. [...] Das Gesetz verbindet die Christen nicht nur zur äusserlichen Verrichtung, sondern auch zu einem solchen

19 Freylinghausen: Neues Gesang=Buch (Anm. 18), Vorrede, Bl. 5v.

20 Systematisch gegliedert in Theologia thetica, Theologia morali und Thelogia paracletici.

21 Es gibt auch Beispiele, die diese Entwicklung nicht mitmachen und im klassischen frühneuzeitlichen Schema verharren. So das Vermehrte Kirchen= und Haus=Gesangbuch für das Königlich Schwedische Herzogthum Pommern und Fürstenthum Rügen, Stralsund 1804, das unter "Von denen Ständen in der christlichen Kirche“ drei eigene Rubriken „Vom Lehrstande“ "Vom Wehrstande" und „Vom Nährstande“ zusammenfasst. 
Gebrauch der Kräfte ihrer Seelen, der den Absichten des Höchsten gemäß ist. Viele Werke werden entweder verdrossen und unwillig, oder nachläßig und unvollkommen geschehen, oder gar versäumet werden, wo der Verstand und der Wille nicht vorher in eine gewisse Ordnung, die sich zu den Wercken schickt, sind gebracht worden. ${ }^{22}$

Die praktische Anwendung erfolgt im $\S$ XV. des "Sechsten Theils“ unter dem Begriff der "Arbeitsamkeit“. Hier heißt es einleitend:

Lasset uns nunmehr wiederum zu den wesentlichen Pflichten der Christen kommen, und unter denselben der Arbeitsamkeit die erste Stelle einräumen. Es ist kaum nöthig, zu beweisen, daß die Christen zur Arbeit, oder zur nützlichen Anwendung aller ihrer verschiedenen Kräfte, und zur tugendhaften Überwindung aller damit verknüpften Beschwerlichkeiten verbunden sind: sie, dieses auserwählte Volk, welches Jesus Christus mit seinem Blute sich dazu erkaufet, und durch seinen Geist geheiliget hat, daß sie eifrig, fleißig und fruchtbar in guten Werken seyn sollen: Tit. 2,14. Aber man kann sie auch zugleich nicht oft und nachdrücklich genug daran erinnern, daß sie vorzüglich nur die nöthigsten und nützlichsten Geschäfte und zwar unter diesen diejenigen, wozu sie theils einen besondern Beruf, und theils die beste Gelegenheit haben, mit der größten Willigkeit und Emsigkeit, oder möglichsten Zurathehaltung der kostbaren und unaufhaltbaren Augenblicke, und einer redlichen Anwendung aller ihrer Kräfte verrichten, und dabey zugleich die rechte Ordnung und bequemste Zeit beobachten, Sprüchw. 12, 9, 11. 13, 4. 20, 12. Dadurch werden sie nicht nur den eben so schädlichen als schändlichen Müßiggang, und die, den Weichlingen selber so beschwerliche Langeweile und Faullenzerey vermeiden; als welche letztere nicht nur selber ein Laster, sondern auch die Mutter unzähliger Sünden ist 1 Thessal. 4, 11. Sir. 33, 29. Sondern sich auch vor der unnützen und wollüstigen Geschäftigkeit verwahren, 2 Thess 3, 10. Nur muß die Arbeitsamkeit nie so übertrieben werden, daß man nicht sich auch wiederum durch eine mäßige und anständige Musse erholete. ${ }^{23}$

22 Johann Lorenz von Mosheim: Sitten=Lehre der Heiligen Schrift. Fünfter Theil. Helmstädt 1761, S. $26 \mathrm{f}$

23 Johann Lorenz von Mosheim: Sitten=Lehre der Heiligen Schrift. Sechster Theil. Helmstädt 1762, S. 294 f. In der Durchführung (S. 295-309) stellt Mosheim sechs Regeln eines christlichen Arbeitsverständnisses auf: 1: allgemeine Beförderung des Nutzens der Menschen und der Ehre Gottes; 2: Nachahmung des unausgesetzt wirkenden Gottes; 3: Dankbarkeit für die von Gott geschenkten Seelen- und Körperkräfte; 4: Erfüllung der Bestimmung des Menschen im Gesamtkontext der Schöpfung; 5: Nächstenliebe; 6: fortwährende Stärkung und Ausbildung der eigenen Seelen- und Körperkräfte, der Gesundheit und schließlich eines ruhigen Gewissens im Angesicht des Rechenschaft fordernden Gottes im Sinne des Gleichnisses von den anvertrauten Talenten (Lk 19,12-27, Mt 25,14-30). In einem Zwischenschritt werden die „Reichen und Grossen“ (S. 298) kritisiert, die es sich leisten können, sich dem Müßiggang zu ergeben. Die ganze Schöpfung zeugt in ihrem tätigen Charakter gegen sie. 
Bei dem aufgeklärten Theologen bleibt der Dämon der Acedia in zentraler Weise präsent, wenn er den Müßiggang auch nicht als Dämon begreifen würde und bereits auf das Wechselspiel von Arbeit und Erholung verweist.

Der Müßiggang bleibt ebenso im Liedgut der wesentliche Gegenpol zur lutherischen Pflichtethik. ${ }^{24}$ In Lieder für den öffentlichen Gottesdienst des Berliner Verlegers David Gottlieb Schatz 1768 (erste Ausgabe 1765) thematisieren zwei der insgesamt drei Lieder der Rubrik „Von der Arbeitsamkeit und Treue im zeitlichen Beruf" diesen Gegensatz gleich in der ersten Strophe, wie etwa in Nr. 206:

Du hast uns, HErr, die Pflicht zur Arbeit auferleget. und Fleiß in dem Beruf uns ernstlich eingepräget.

Der Müßiggang ist dir, o GOtt, verhaßt, für uns der Laster Netz, und unserm Nächsten Last.

Ihr Geist fällt zurück auf den Status eines Embryos. Mosheim argumentiert hier, wie schon bei der vierten der sechs Regeln, physikotheologisch. Sind diese Regeln eher theoretisch ausgerichtet, so folgen nunmehr noch sieben Regeln für die Arbeitspraxis der "durch den Geist Gottes mit einem neuen Leben, mit einer neuen Wirksamkeit begabte[n] Christen" (S. 298): 1: Jeder sollte sich eine gesellschaftlich nützliche Tätigkeit wählen. Dabei sind alle Arten von Arbeit im Horizont der Vorsehung Gottes gleich viel wert. Mosheim verweist auf das Bild vom Leib mit den vielen Gliedern, Röm 12,4 f. 2: Die gesamte Lebenszeit ist Tag für Tag intensiv zu nutzen. Dies ist das Kennzeichen der Menschen, deren Leben man nicht mit den Worten: „,sie haben gegessen, getrunken, geschlafen, geheyrathet, und sind gestorben." (S. 303) beschreiben kann. Mosheim nennt Paulus, Luther, Melanchthon, Gerhard, Grotius und Spener. 3: Soll Arbeitsamkeit eine Tugend sein, so bedarf sie der Motivation, Ausdauer und Effizienz. 4: Thematisiert noch einmal Effizienz im Sinne des Achtens auf Synergieeffekte und die Wahl des richtigen Zeitpunktes für eine Tätigkeit. 5: Man gönne sich Muse zur Regeneration. Dies darf vergnüglich sollte aber nicht lasterhaft sein. Statthaft sind $\mathrm{Mu}-$ sik, Malerei; Drechseln, Gartenarbeit („Lustgärtnerey“), Spaziergänge, Besuche, das Spielen mit seinen Kindern; verwerflich sind Müßiggehen auf der Straße, Trinken, Spielen, Schlafen und das Lesen von Romanen. 6: Man mische sich nicht in anderer Leute Tätigkeiten, die einen nichts angehen. 7: Faulheit jeglichen Grades ist zu meiden. Mosheim kennt drei: diejenigen, welche überhaupt nichts tun; die Bequemen, die nichts in geringster Weise Anstrengendes tun und die Saumseligen, die ihre Aufgaben nicht zur rechten Zeit erledigen. Ihnen allen schreibt er zwei Seiten lang ins Gewissen, bevor er sich am Ende des Paragrafen kurz den übertrieben Arbeitsamen widmet. Deren Habitus ist akzeptabel, wenn sie aus gemeinnützigen Gründen handeln wie der Erhaltung einer großen Familie oder besonderen Berufspflichten, nicht aber wenn sie aus Habsucht und Ruhmbegierde handeln.

24 Die entspricht auch im 18. Jahrhundert völlig ungebrochen dem Ansatz Luthers: „Das schöne Leben der Heiligen [...] erfordert vor allen Dingen eine grosse Mannigfaltigkeit von lauter guten Handlungen, die alle darin miteinander übereinstimmen, daß der Christ durch das Leben des Glaubens und der Liebe getrieben, Gott und Jesum Christum verherrliche und zu dem Ende unaufhörlich mit allen seinen, sowohl durch seinen eigenen Fleis erworbenen, als auch durch die Gnade erhöheten und geschenkten Kräften wirke. In so fern er sich dazu durch die Vollkommenheit Gottes, durch die Wohlthaten und das Exempel seines Heilandes, und durch die heiligen Wahrheiten des Evangelii, antreiben läst: so wird dadurch sein ganzes Leben und Wirken ein beständiger Gottesdienst, und er lebet göttlich.“ (Mosheim: Sitten=Lehre, Anm 22, S. 296). 
Das Gesangbuch war weiterhin das populäre Medium der Tradierung. Ein frühes, prägnantes Beispiel für das Mosheimsche Schema ist das Neu eingerichtete Sachsen=Weimar=Eisenach= und Jenaische Gesang=Buch bestehend aus 1140 Alten und neuen Liedern, Weimar $1763 .^{25}$ Dessen fünfter Teil ist überschrieben: „Von den Evangelischen Heils=Pflichten.“ Diese gliedern sich „1. Von den allgemeinen Christen=Pflichten" (christliches Leben und Wandel im Alltag und zu Festzeiten) und „2. Von besonderen Christen=Pflichten Ueberhaupt: bey dem äusserlichen Beruff" und hier eingebunden dann wieder "Von den drey Haupt=Ständen“. Vom Schema her ganz ähnlich gegliedert ist das Neu=Vermehrte Frankfurter Gesang=Buch, Frankfurt/O. 1766 in seiner Rubrik „VIII. Von den christlichen Pflichten und Tugenden".

Schließlich bürgert sich ein klares Pflichtenschema ein in der Reihenfolge: Pflichten gegen Gott, Pflichten gegen uns selbst, Pflichten gegen den Nächsten, Pflichten in allen Gesellschaften, besonderen Zeiten, Lebensarten, und Umständen. In diesem Schema werden die Pflichten innerhalb der Stände regelmäßig in dieser letzten Abteilung untergebracht, während Lieder zum Thema "Arbeit und Beruf" sich innerhalb der „Pflichten gegen uns selbst" finden. Beispiele hierfür sind das Allgemeine Gesangbuch [...] der Deutschen in Kopenhagen von 1784; Gottfried Christian Cannabich: Sammlung neuer und verbesserter geistlicher Lieder, Sondershausen 1794; Johann Gottfried Herder: Sachsen $=$ Weimar $=$ Eisenach $=$ und Jenaisches Gesang=Buch, Weimar $1789^{26}$ und das Neue Anhalt=Dessauische Gesangbuch von 1794. Das Dresdnische Gesangbuch von 1798 ersetzt bei gleichem Schema den Begriff der ,Pflicht' durch ,Verhalten'. Möglicherweise ist das dem soziokulturellen Unterschied des sächsisch-preußischen Antagonismus geschuldet, der sich im Verlaufe des 18. Jahrhunderts entwickelt hatte. ${ }^{27}$ Das Neue Thüringische Gesangbuch, oder Sammlung neuer auserlesener Religionsgesänge, Kölleda, Erfurt 1798, bringt die Begriffe in der Formulierung „Vom pflichtmäßigen Verhalten“ zusammen. Das Stift Naumburg=Zeitzische Gesangbuch, Zeitz 1799, kombiniert dann „Von den Gesinnungen und Pflichten."

25 Mosheim plädiert in seiner Sitten=Lehre der Heiligen Schrift Neunter und letzter Theil. Verfasset von D. Johann Peter Miller [Mosheims Nachfolger als Theologieprofessor in Göttingen]. Göttingen, Leipzig 1770 in „§. LXXXXII. [...] über das Verhalten der Lehrer in Ansehung des öffentlichen Betens und Singens" für eine grundlegende Gesangbuchreform, da die alten Lieder merkliche Schwächen in Inhalt, Ausdruck und Reim hätten. „Man hat in den meisten Provinzen sehr starcke Gesangbücher, die größtentheils aus 600 bis 1000 Gesängen bestehen. Wäre es nicht besser, man läse aus dieser grossen Menge ungefehr 150 bis 200 der besten Gesänge aus, die zum allgemeinen Gebrauche beym öffentlichen Gottesdienste geschickt wären“ (S. 456 f). Daran hielt man sich allerdings nur bedingt und zunehmend erst gegen Ende des Jahrhunderts wie dieses Sachsen=Weimarische Gesangbuch ausweist. Selbst das Stift Naumburg=Zeitzische Gesangbuch von 1799 beinhaltet 805 Lieder.

26 Herder handelt das recht kurz ab: „Fünfter Theil Von den Evangelischen Heils=Pflichten. 1. Von den allgemeinen Christen=Pflichten [...] 2. Von besonderen Christen=Pflichten. Ueberhaupt: bey dem äusserlichen Beruf."

27 Vgl.: Preussen und Sachsen. Szenen einer Nachbarschaft. Erste Brandenburgische Landesausstellung Schloss Doberlug 2014. Hg. v. Frank Göse u. a. [Dresden 2014]. 
Auf dem Höhepunkt der Aufklärung kommt es zur Auswanderung der lutherischen Pflichtethik aus den Kirchengesangbüchern in säkulare Kontexte. In Christian Gotthilf Salzmanns Gesangbuch für seine philanthropische Erziehungsanstalt Schnepfenthal von $1792^{28}$ wird sie unter dem Stichwort „Fleiß“ in völlig eigener, schon säkularer Weise stilisiert:

1. Weil ich jung bin, soll mein Fleiss

Eifrig sich bestreben,

Dass ich einst mög als ein Greis,

Recht zufrieden leben.

2. Zwar will ich mich jugendlich

Meiner Tage freuen,

Doch nicht also, dass es mich

Darf im Alter reuen. ${ }^{29}$

Ein zweites Beispiel:

Süsser angenehmer Fleiss!

$\mathrm{O}$, wie herrlich ist der Preis,

Den er jedem Menschen beut,

Der ihm seine Kräfte weiht!

2. Wann die Langeweile jähnt,

Und sich krank nach Possen sehnt:

Hüpft, in froher Tätigkeit,

Die ihm nicht zu lange Zeit.

3. Ja auf seidnen Schwingen fliehn

Seine Stunden vor ihm hin;

Den verlohrnen Augenblick

Nichts sonst, wünscht er sich zurück. ${ }^{30}$

Das aus dem Alten Testament geläufige theologische Konstrukt des Tat-ErgehensZusammenhangs wird hier aufgegriffen. Die Lieder verheißen diesen Zusammenhang erneut, allerdings jetzt statt des Gerechten dem Fleißigen. In Potsdam ertönte seit 1797 jeweils zur halben Stunde vom Turm der Garnisonkirche die aus

28 Gesangbuch für die Erziehungsanstalt zu Schnepfenthal; Salzmann (1744-1811) war durch sein Elternhaus und sein Theologiestudium in Jena noch völlig orthodox sozialisiert, ließ dieses Milieu aber im Zuge der Entwicklung seiner pädagogischen Interessen hinter sich. Vgl. zuletzt: Christian Gotthilf Salzmann interdisziplinär: seine Werke und Wirkungen in Theologie, Pädagogik, Religionspädagogik und Kulturgeschichte. Hrsg. von Rainer Lachmann, Andreas Lindner und Andrea Schulte. Jena 2013.

29 Gesangbuch für die Erziehungsanstalt zu Schnepfenthal. Schnepfenthal 1792. Tischlieder Nr. 38.

30 Gesangbuch für die Erziehungsanstalt zu Schnepfenthal (Anm. 29), Tischlieder Nr. 39. 
Mozarts Zauberflöte entliehene Melodie ${ }^{31} \mathrm{zu}$ Ludwig Christoph Heinrich Höltys „Üb immer Treu und Redlichkeit":

Üb' immer Treu und Redlichkeit

Bis an dein kühles Grab,

Und weiche keinen Finger breit

Von Gottes Wegen ab

Dann wirst du wie auf grünen Au'n

Durch's Pilgerleben geh'n

Dann kannst du sonder Furcht und Grau'n

dem Tod ins Auge seh'n.

Dann wird die Sichel und der Pflug

In deiner Hand so leicht,

Dann singest du beim Wasserkrug,

Als wär dir Wein gereicht.

Dem Bösewicht wird alles schwer,

Er tue was er tu,

Ihm gönnt der Tag nicht Freude mehr,

Die Nacht ihm keine Ruh.

Der schöne Frühling lacht ihm nicht,

Ihm lacht kein Ährenfeld,

Er ist auf Lug und Trug erpicht,

Und wünscht sich nichts als Geld.

Der Wind im Hain, das Laub im Baum

Saust ihm Entsetzen zu,

Er findet, nach des Lebens Raum

Im Grabe keine Ruh.

Drum übe Treu und Redlichkeit

Bis an dein kühles Grab,

Und weiche keinen Finger breit

Von Gottes Wegen ab!

Dann suchen Enkel deine Gruft

Und weinen Tränen drauf,

Und Sonnenblumen, voll von Duft,

Blüh'n aus den Tränen auf. ${ }^{32}$

31 Es handelt sich um die Arie des Papageno „Der Vogelfänger bin ich ja“ aus dem ersten Aufzug. 32 Neues Saalfeldisches Gesangbuch. Saalfeld 1819, Nr. 231, S. 205 f. 
Der Text weist es als Gewissens-Lied aus, ohne den Begriff zu benutzen. Über seine erste und siebente Strophe ist es fromm, aber nicht kirchlich fromm, sondern in einer sehr privaten, individuellen Art und Weise. Der Text muss nicht einmal im Sinne des christlichen Glaubens verstanden werden. Das Lied hat es deshalb auch nur selten zur Ehre der Gesangbücher gebracht, so im Neuen Saalfeldischen Gesangbuch von 1819 zutreffenderweise in der Rubrik „Von der Glückseligkeit des Frommen und dem guten Gewissen“. In seiner populären kurzen, achtstrophigen Version ${ }^{33}$ vereint es aber Pietismus und Aufklärung in einer kongenialen Art und kennzeichnet das Preußen des 18. Jahrhunderts in einer Weise, dass man von einer inoffiziellen Staatshymne ${ }^{34}$ sprechen kann. Der säkulare Aspekt dieses Liedes und seiner besonderen Kommunikation über das Potsdamer Glockenspiel bestand darin, dass es alle Einwohner der Haupt- und Residenzstadt ohne Ansehen ihrer religiösen Überzeugungen oder Zugehörigkeit hören mussten. Seine Tradierung fand dann auch in säkularen Gesangbüchern statt, vor allem in den preußischen Schulgesangbüchern, ${ }^{35}$ aber ebenso im Liederbuch des Königin-Luise-Bundes seit 1923.

Für die weitere Entwicklung der Gesangbücher gilt, dass im 19. Jahrhundert das Erscheinungsbild vielfältig wird und die territorial differenzierten Entwicklungen hinsichtlich der landeskirchlichen Ausrichtungen in Theologie und Frömmigkeit abbildet. So erscheinen weiter Ausgaben, in denen bis in die zweite Hälfte des Jahrhunderts das aufgeklärte Schema mit der Dreiteilung von „Glaubenslehre", "Sittenlehre“, „Besondere Zeiten, Umstände und Personen" dominiert. Unter der Überschrift „Arbeitsamkeit und Berufstreue“ sind der Sittenlehre sowohl Berufslieder als auch Standeslieder zugeordnet, ohne dass die letzteren in allen Fällen noch so bezeichnet werden. Beispiele für diesen langen Atem des theologischen Rationalismus sind das Lobenstein=Ebersdorfische Gesangbuch von 1843, die Sammlung geistlicher Lieder zur öffentlichen und häuslichen Gottesverehrung, in achter Auflage, Lübben 1859, das Dresdner Gesangbuch von 1861, das Altenburgische Gesangbuch von 1871, das Neue Gesangbuch für die protestantischen Gemeinden des Herzogthums S. [achsen] Coburg von 1889 und noch das Gesangbuch für die Fürstlich Reuß=Plauischen Lande Älterer Linie in 21. Auflage, Greiz 1903.

Daneben erfolgt die Rückwendung auf eine stärker genuin reformatorische Ausrichtung, die dazu führt, dass der Kleine Katechismus und die Confessio Au-

33 In der längeren Version sind zwischen der 6. und der 7. Strophe weitere 8 Strophen eingeschoben, die weder pietistisch noch aufgeklärt sind und eher dem Charakter eines Bänkelgesangs entsprechen.

34 Da Preußen Zeit seiner Existenz ein Staat ohne Staatsnation war, wird der Begriff "Staatshymne" hier bewusst und in terminologischer Absetzung von "Nationalhymne" benutzt. Eine solche hatte Preußen nie.

35 Im Zentralblatt für die gesamte Unterrichtsverwaltung in Preußen, Jahrgang 1912, S. 624, vorgeschrieben als Pflichtlied für die fünfte Klasse; Josef Bohn: Schulgesangbuch für höhere Lehranstalten, Trier 1912; F. W. Sering: Lieder für die Unter- und Mittelklassen höherer Mädchenschulen. Neu bearbeitet von Georg Rolle, 17. und 18. Auflage, Lahr 1919; auch hier jeweils in der kurzen Version. 
gustana als Anhänge aufgenommen werden. Die Gliederung des Liedteils greift ebenfalls vor die Aufklärung zurück, ${ }^{36}$ benennt den zweiten Teil des aufgeklärten Schemas, die Sittenlehre um in „Das christliche Leben“ und ordnet Berufs- und Standeslieder einer eigenen Rubrik zu, deren Bezeichnung vielfältige Formen annehmen kann, etwa „Für besondere Stände und Zeiten“ in Evangelisches Gesangbuch, Greifswald 1866, oder nur „Hausstandslieder“ im Gesangbuch für die Evangelischen Gemeinden der Provinz Posen von 1875.

Nach der Reichseinigung und in den gegen Ende des Jahrhunderts zunehmenden Vereinheitlichungstendenzen der einzelnen Landeskirchen verfestigte sich dieses Schema in der Begrifflichkeit von Heiligung, Gottvertrauen, Kreuz und Trost mit der Rubrik „Beruf und Haus“ bzw. „Haus und Beruf“ und wanderte in dieser Form ins 20. Jahrhundert. So in den Ausgaben des Evangelischen Gesangbuchs [...] in der Provinz Brandenburg seit 1886, im Schlesischen Provinzial=Gesangbuch, Breslau 1918; im Thüringer evangelischen Gesangbuch, Erfurt 1928; im Einheitsgesangbuch der Evangelisch=lutherischen Landeskirchen in Schleswig=Holstein=Lauenburg, Hamburg, Mecklenburg=Schwerin, Lübeck, Mecklenburg=Strelitz, Eutin, erschienen Schwerin 1930 und im Gesangbuch für die Provinz Sachsen und Anhalt, Halle 1931. Dabei gab es natürlich zu keiner Zeit eine sprachlich völlig gleichförmige Entwicklung. Umso dezidiert lutherischer man sich verstehen wollte, umso altertümlicher blieb der Sprachgebrauch. So kennt das Mecklenburgische KirchenGesangbuch in Neu verbesserter Ausgabe 1905 "Standeslieder", das Gesangbuch für die Grafschaft Stolberg=Roßla, Halle 1922 "Standes= und Berufslieder" und das altlutherische Gesangbuch für die Evangelisch Lutherische Kirche, Breslau 1937 eine Rubrik „In allerlei Ständen und Anliegen“.

Die Bezeichnung in "Arbeit und Beruf" taucht 1901 zum ersten Mal im Gesangbuch für die evangelisch-lutherische Kirche im Fürstentum Schwarzburg=Rudolstadt (Rudolstadt 1901) auf. Danach folgt die Rubrik „Haus= und Ehestand“. Nach dem Zweiten Weltkrieg setzt sich die Bezeichnung "In Arbeit und Beruf“ in den Gesangbüchern der einzelnen Landeskirchen durch. ${ }^{37}$

Eine Sonderrolle spielen Gesangbücher, die dem Thema der Lebens- bzw. Berufspflichten in Gänze gewidmet sind. Solche Themengesangbücher sind selten.

36 Mancherorts legte man auch Gesangbücher lutherisch-orthodoxer Prägung wieder auf. Das gilt für Zittau mit einer erweiterten Neuausgabe des ersten Zittauer Gesangbuchs von 1712 im Jahr 1829: M.G. andächtiger Seelen vollständiges Gesangbuch und für Königsberg, wo man Johann Jacob Quandts Gesangbuch von 1735 als Neue Sammlung alter und neuer Lieder, die in den Preußischen Kirchen gesungen werden ebenfalls in erweiterter Form 1845 und noch 1883 neu auflegte. Ebenso erschien auch das Rogall'sche Gesangbuch von 1744 als Neues Rogall'sches Gesangbuch, Königsberg 1859. Des Weiteren für Magdeburg, wo man 1846 aus Anlass von Luthers 300. Todestag das Vollständige Gesang=Buch, in sich haltend 1000 geistreiche und auserlesene Lieder, sowohl [...] D. Martin Luthers [...] als auch anderer gottseligen Männer, Magdeburg 1596 mit Vorrede von 1738 wieder herausgab; in zweiter Auflage 1851; und für Halberstadt, wo man das Halberstädtische Kirchen= und Haus=Gesang=Buch in seiner letzten Ausgabe von 1740 in unveränderter Fassung 1832 und in revidierter Fassung 1855 neu herausgab.

37 Evangelisches Kirchen=Gesangbuch der Kirchenprovinz Sachsen. Leipzig 1953. 
Der Pfarrer von Crizkov und Weitendorf bei Güstrow, Laurents Hartmann gab 1716 Des Geistlichen und Evangelischen Zions Neue StandesLieder/ Darin ein Christ zu GOttes Ehre/ und zu seinem Trost ersiehet/ und lernet/ Wie er seinen Stand mit guten Gewissen GOtt gefällig führen/ auch dabey sich Gnade/ Segens/ Beystandes und Schutzes des Allerhöchsten/ bey allen Beschwerden/ und mannigfaltigen Hindernissen getrösten könne heraus. ${ }^{38}$ Die Lieder sind in alphabetischer Reihenfolge nach Berufen geordnet, von „Ackersmann" bis „Zuhörer, wann ein neuer Prediger ihm angewiesen“. Insgesamt listet Hartmann 148 Berufe auf: ${ }^{39}$

Ackersmann oder Bauer/ Advocat/ Alte/ Ammen/ Amtmann/ Amtsschreiber eines Statthalters, adeliger Güter oder einer Ausgeberin/ Apotheker/ Arzt oder Medicus/ Assessor oder Beisitzer im Gericht eines Rats oder Ratsherren/ Bader/ Ballmeister/ Barbier oder Feldscherer/ Baumeister/ Bäcker/ Beutler/ Bildhauer oder Bildschnitzer/ Bötticher oder Fassbinder/ Brauer/ Buchbinder/ Buchdrucker/ Buchhändler oder Buchverleger/ Büchsenmacher/ Bürger/ Bürgermeister/ Closter Jungfer oder Closter=Fräulein/ Dienstmädchens oder Dirnen/ Drescher/ Drechsler oder Dreher/ Drommeter/ Ehefrau oder Hausmutter/ Eisenkrämer/ Ernd=Meher oder Schnitter/ Färber/ Fechtmeister/ Fischer/ Forstmeister, Wald=Förster, Holzvogt/ Gärber/ Gärtner, Baum=Gärtner, Liebhaber der Gärten/ Geselle oder Jungfrau der oder die heiraten will/ Getreidehändler oder Kornkäufer und -verkäufer/ Gewandhändler oder Gewandschneider/ Glasmacher oder Glashändler/ Glaser/ Glockengießer/ Goldschmied/ Handlungsbedienter/ Handwerkslehrjunge/ Handwerksgeselle/ Handwerksmeister/ Hebergirer, Gastgeber, Wirt oder Krüger/ Hofbedienter/ Hofmeister junger Herren/ Hüter, Hutmacher oder Hutstafierer/ Jägermeister oder Jagt=Bedienter/ Jungfer oder Fräulein/ Jungfrau, die heiraten will/ Jungfrau, die nicht heiraten will/ Kannengießer/ Kaufmann/ Kind/ Kirchenvorsteher/ Kleiber/ [= Lehmverarbeiter] Kliplerin, Spitzen- oder Bortenmacher/ Knecht oder Diener/ Koch oder Köchin/ Köhler oder Kohlenbrenner/ Kramer insgemein/ Kriegs=Offizier insgemein/ Kupferschmied/ Kürßner oder Bundmacher/ Küster/ Laternen= oder Leuchtenmacher/ Leinenweber/ Lichtzieher/ Maler oder Conterfeyer/ Marschall des hohen Ministers am Hofe/ Maurer/ Messerschmied/ Müller insgemein/ Münzmeister/ Nachtwächter oder Wächter in der Stadt/ Nadler/ Oberschenk/ Organist oder Orgelbauer/ Page oder junger adliger Bediensteter am Hofe/ Papiermüller oder Papiermacher/ Paruqvenmacher [= Perückenmacher]/ Pauker oder Paukenschläger/ Kunstoder RegimentPfeiffer/ Pflüger oder Häker/ Praeceptor oder Schulmeister/

38 Das Buch hatte eine Vorstufe in Des geistlichen und Evangelischen Zions Neue Fest=und Freuden= Lieder: Sammt einem Anhang etlicher Sorgen- und Standes-Lieder, Güstrow 1713. Standes- und berufsbezogene Lieder bilden hier allerdings noch eine kleine Gruppe von 28 Liedern bei einem Gesamtbestand von 187.

39 Davon 123 Berufe im modernen Verständnis des Begriffs. Die anderen Lieder beziehen sich zumeist auf Lebensphasen bzw. persönliche Umstände. 
Präsident oder Direktor im Gericht/ Prediger/ Radmacher oder Wagner/ Reicher/ Reisender/ Rentmeister oder Rentschreiber/ Riemer/ Säemann/ Sattler/ Schiffsmann/ Schlachter, Metscher oder Fleischhauer/ Schlösser/ Schmied insgemein/ Schneider oder Kleidermacher/ Schüler, der noch klein ist/ Großer Schüler/ Schülerin/ Schulregierer oder Rector/ Schuster oder Schuhmacher/ Schuhflicker/Schwerdtfeger/ [= Schwertschleifer]/ Seiler oder Reifschläger/ Soldaten insgemein/ Studiosi, wann er des Morgens anfängt zu studieren/ Studiosi insgemein/ Studiosi, der ein geringes vor anderen von GOtt empfangen/ dürfftiger Studiosi/ Studiosi Philosophiae/ Studiosi Thelogiae/ Studiosi Juris/ Studiosi Medicinae/ Studiosi, wann er disputieren will/ Studiosi, wann er aufhört zu studieren/ Syndicus/ Tagelöhner/ Tanzmeister/ Teichgräber oder Teichmeister/ Torhüter, Torwächter, Pförtner/ Tischer/ Töpfer/ Tuchmacher/ Viehhirte/ Uhrmacher, Uhrensteller/ Vogelfänger/ Wäscherin/ Wehe-Mutter, Bade-Mutter Heb-Amme/ Windmüller/ Witwe insgemein/ Wundarzt/ Ziegler oder Ziegelmeister/ Zimmermann/ Zöllner, Zoll=Accise, Licent= oder Kopfsteuer Einnehmer/ Zuhörer, wann ein neuer Prediger ihm angewiesen.

Es folgen noch Lieder für bestimmte Handlungen des Alltags:

Wann mans Morgens erwacht/ Wann der Tag anbricht/ Wann man vom Bett auffstehet/ Wann man die Kleider anzeucht/ Wann man die Haare kämmet/ Wann man sich gewaschen hat/ Wann man sich zum Gebet vorbereitet/ Wann man in der Bibel lesen will/ Lutheri Andacht, wann man in der Bibel lesen wil/ Wann man in der Bibel gelesen hat/ Um den Segen zu den Wercken des Gottesdienstes/ Um gesegneter Verrichtung der Wercke unseres Berufs/ Ein ander um gesegneter Verrichtung der Wercke unseres Berufs/ Um Gnade und Kraft Gottes zu dencken und zu thun/ Wann man speisen will/ Wann man die Allmosen gibet/Wan mans Abends ein Licht anzündet/ Nach verrichter Berufs=Arbeit/ Wenn man sich entkleidet/ Wann man sich will zur Ruhe legen/ Wann man das Licht ausleschet. ${ }^{40}$

Dieses Programm entspricht Luthers Frömmigkeitstransformation vom klösterlichen zum gewerblichen und häuslichen Bereich. Das verdeutlicht auch das ebenfalls gereimte Eingangsvotum des Güstrower Superintendenten Johann Christian Schaper:

Nach deiner Kunst und werck/ nach deinem Ampt und Ehre/

Ist dieses Lieder=Buch/ mein Leser eingericht.

Die Blätter sind gefüllt mit Gottes Weisheits=Lehre/

Du feh[l]st nicht seinen Preiß/ hier deine Christen=pflicht.

Vor Heermanns/ Franckens Thon/ und Gerhards schöne Lieder

40 Laurents Hartmann: Des geistlichen und Evangelischen Zions Neue Standes=Lieder. Rostock 1716. 
Sieht dieses Psalm=Gedicht Herr Hartmann gar nicht aus/

Doch Was für deinen Stand du suchest hin und wieder/

Das findst du hier allein für dich/ und deinen Hauß.

Des Dichters Absehn ist/ dich einig zu erbauen

In deinen Welt Beruf/ in Seel und Leibes Noth/

Er sucht nicht eitlen Ruhm/ dem kanst du sicher trauen/

Wirst du bekehrt dadurch/ so danckt er seinen GOtt. ${ }^{41}$

Im selben Jahr 1716 erschien bereits in dritter Auflage in Schneeberg der Seelen=Schatz Oder: Christlicher Bergkleut/ Gotteseliger Gewercken und aller frommer Christen Gebet= und Gesang=Buch des "Gewesenen Bergk=Steigers und Eltisten" der Berg- und Schmelzer-Knappschaft zu Graßlitz, Matthäus Wieser, der 1672 als Exilant ins sächsische Freiberg gekommen war. Das Gesangbuch hat ein eigenes Titelblatt: Geistreiches und Vollständiges Bergk=Gesang=Buch/Darinnen viel schöne Bergk=Reyen/Wie auch Des seligen D. Martini Lutheri und anderer hocherleuchteten GOttes=Männer alte und neue in unserer Evangelischen Lutherischen Kirchen gebräuchliche Lieder zu finden. Wieser tritt als Gesangbuchherausgeber das erste Mal mit 230 Christliche Gebet/ Geistliche Lieder/ und andächtige Wünsche, Hof 1657/58 in Erscheinung. Daraus ist offensichtlich das Gesangbuch für die Bergleute erwachsen, denn noch 1716 führt es eine Vorrede von Johannes Küfner, Superintendent in Hof von 1654 bis $1659 .{ }^{42}$ Es hat dabei noch nicht einen so ausschließlich auf den Bergbau bzw. die Gewerke fokussierten Liedbestand wie der Geistliche Bergbau, oder Sammlung von Berg=Gebeten und geistreichen Berg=Gesängen für christliche Berg-

41 Im Anschluss an die zitierten Verse heißt es: „So urtheilet von Herrn Hartmanns Standes Liedern Johann Christian Schaper/ Der Heil Schrift Doctor, Hoch=Fürstl. Mecklenburgischer Consistorial=Rath/ und des Güstrowischen Districts Superintendens." Hartmann: Neue Standes=Lieder (Anm. 40), unpag.

42 Die Vorrede ist auf den 9. April 1658 datiert, so dass das Buch wohl auch erst in diesem Jahr erschienen ist. Wiesers Lebensdaten sind in einer kleinen Schrift des Klingentaler Pfarrers Nicolaus Spranger überliefert, der sich im Rahmen der frühen hymnologischen Forschungen mit der Liedgattung der „Berg=Reyhen“ beschäftigt: Send=Schreiben von Bergmännischen Geistlichen Liedern oder Berg=Reyhen/ an [...] Hrn. Jo. Christoph. Olearium, Fürstl. Schwartzburg=Arnstädtischen Consist. o.O. 1723. Spranger wiederum beruft sich als Quelle auf die ungedruckte Leichenpredigt Wiesers von 1678 durch den Frühprediger an der Freiberger St. Petri-Kirche Immanuel Gerber. Demnach wurde Wieser am 26. April 1617 in Graßlitz als Sohn des Bergknappschaftsältesten und Kirchenvorstehers Ambrosius Wieser und einer aus Sehbotten (Seeboden) in Kärnten stammenden Exilantin geboren. Durch den Krieg bedingt sei er nicht zur Schule gegangen, sondern habe Bergarbeit verrichtet und „in dem 18ten Jahre seines Alters noch keinen Buchstaben lesen können“ (S. 20). In diesem Zusammenhang wird der Eindruck vermittelt, er habe sich weitgehend als Autodidakt mit Gottes Hilfe gebildet. Inwieweit das der Wahrheit entspricht oder bereits Propaganda war, muss unbeantwortet bleiben. Fakt ist, dass Spranger ihn als einen „ungelehrten" anspricht (S. 20), der gleichwohl, beginnend mit dem Seelen=Schatz zwischen 1658 und 1678 vier Bücher herausgegeben hat. Zugleich sieht Spranger in ihm einen der Hauptautoren von Bergmannsliedern und weist ihm insgesamt 19 Titel zu (S. 25 f). Das wiederum passt zu den von ihm überlieferten intensiven Arbeitserfahrungen seiner Kindheit. 


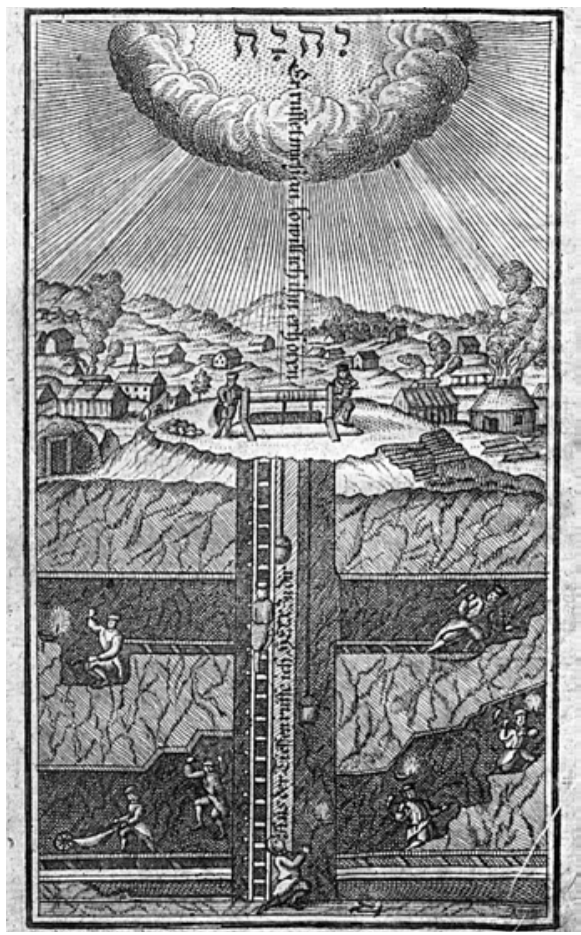

Weil. Set't'

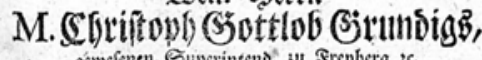 gecwefenten Supcrinteno? ju Srenberg :t.}

(B) eifftid)er

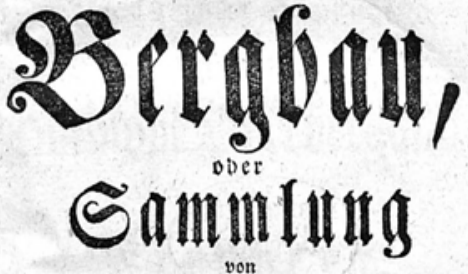

รetg= Sંebeten,

unis

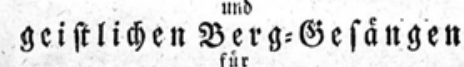

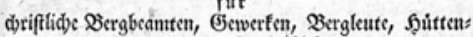
f̧amuner $=$ und Farb $=2$ frbeiter

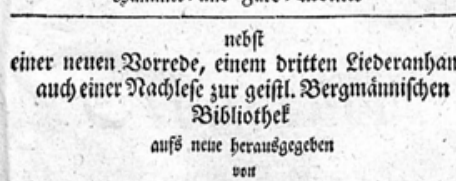

M. (Sarl Sheintid Tromler;

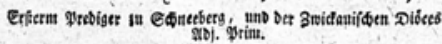

Edbnecberg, gebruift unb verlegt bey Dan. Seinr. Fulbe.

Abb. 3:

Christoph Gottlob Grundig: Geistlicher Bergbau, Schneeberg (1716); FB Gotha

Cant. spir $8^{\circ} 00310$.

beamten, Gewerken, Bergleute, Hütten= Hammer= und Farb=Arbeiter des Freiberger Superintendenten Christoph Gottlob Grundig, Schneeberg 1750, das es $1781 \mathrm{zu}$ einer zweiten erweiterten Auflage durch den Schneeberger Pfarrer Carl Heinrich Tromler brachte. ${ }^{43}$

43 Spranger: Send=Schreiben (Anm. 42) sieht 1723 in den Bergmannsliedern ein unbearbeitetes Feld: „solte man sich nicht unbillig verwundern/ warum die Geistlichen Berg=Lieder und deren Autores, fata und andere Umstände/ biß auf diese Zeit gäntzlich praeteriret/ und von allen berühmten/ gelehrten Männern [...] nicht das geringste gedacht/ noch erwehnet worden“ (S 3 f). Dass „die Berg=Gesangbücher sehr sparsam anzutreffen/ auch einige Berg=Reien selbst gar rar und seltsam sind" (S. 4), führt er auf deren lebensweltliche Begrenzung auf die Bergbaureviere zurück. Als Väter der Bergmannslieder benennt er den unter anderem durch seine Predigtsammlung Sarepta oder Berg=Postille für das Thema prädestinierten Joachimstaler Pfarrer Johann Mathesius (1504-1565) und dessen Kantor Nikolaus Hermann (1500-1561). Mathesius habe seine „Berg-Predigten“ in Bergmannshabit aus Schachtmütze und Grubenkleid gehalten, das ihm von den Gewerken verehrt worden sei (S.12). Hier war ein Pfarrer eng verbunden mit der spezifischen Lebens- und Arbeitswelt 
Diese Art von Spezialgesangbüchern ist eine umfangreiche Fundgrube an sozial- und kulturgeschichtlichen Gegebenheiten. Als Beispiele sollen zwei Lieder aus Laurents Hartmanns Stände-Gesangbuch dienen, die gerade in ihrer ,Exotik' belegen, dass die Pflichtethik das Leben lutherischer Christen in jedweder Profession und Situation durchdringen konnte. Das Lied Eines Ballmeisters weist diesen in der sechsten und siebten Strophe als einen Vorläufer heutiger Fitnesstrainer aus:

Meister in dem ballspiehl waren

Cheraphan/ Demoteles/

Und besonders drinn erfahren

Der berühmte Socrates.

Ja der arzt Galenus hat

Von den ballen den tractat/

Wie man soll denselben treiben/

Eigenhändig wollen schreiben

Will man von gesundheit sagen/

Fängt man es [also das Ballspiel] vor essen an/

Dann erwärmet es den magen/

Der darauf gut däuen kann.

Wahr ists/ daß er aus dem leib

Arge feuchtigkeiten treib/

Aus der blas und aus den lenden

Sol die stein=pein er weg wenden.

Das Ballhaus als Sportstätte der Frühen Neuzeit existierte in fürstlichen Residenzstädten und in Universitätsstädten wie Tübingen oder Jena. Ballmeister repräsentierten einen für damalige Verhältnisse außergewöhnlichen Beruf. Das hinderte nicht daran, ihre Tätigkeit als Metapher christlicher Glaubenswahrheiten zu deuten, wie das Lied in der zehnten Strophe zeigt:

Wie man auch den ball herschläget/

Und man schlägt ihn wieder hin/

Wird vom satan oft erreget

Böses wider seel und sinn:

seiner Gemeinde. Spranger kann (S. 28 f) insgesamt drei weitere Titel nennen, unter denen ein Berg-Gebetbuch und ein Gesangbuch in Kombination erschienen: 1. Christian Zeidler: Gottgelassener Berg=Mann, Saalfeld 1679; dieses erlebte eine vermehrte Neuauflage durch den Sulzaer Schulrektor Johann Georg Zimmermann, Jena 1693, wobei der Kern der Erweiterungen aus Liedern Wiesers besteht; 2. Ohne Angabe des Herausgebers: Geistlicher Berg=Schatz, Saalfeld 1692 bzw. Neuer Geistlicher Berg=Schatz, Saalfeld 1702; 3. Johann Adam Laértis: Andächtiger Gott=ergebener Berg=Mann, Hof 1704, das wiederum wesentlich auf Liedern Wiesers basiert. 
GOTT hilff mir nach deiner huld/

Daß ich es nicht lange duld/

Und es schnell zurücke schlage/

Ja von mir den teufel jage. ${ }^{44}$

Das Lied „Eines Gesellen oder Jungfrauen, die nicht heyrathen wollen“ widerspricht in seinem Ansatz der lutherischen Anthropologie. Freiwillig unverheiratet blieben allenfalls Gelehrte, die sich Personal leisten konnten. Und doch begründet das Lied diese Möglichkeit für jedermann schriftgemäß und bezeugt zugleich die besonderen Pflichten, die aus dieser Situation erwachsen:

Der ehestand gefält Gott wohl/

Darin der mensch sich mehren soll/

Daß erd und himmel wird erfüllt/

Und hurerey todt eingehüllt/

Auch daß man zum gehülffen hab/

An dem man sich in liebe lab.

2. Doch GOttes Geist durch Paulus spricht:

Gut ist dem menschen/ wann er nicht

Ein eheweib nimmt und berührt/

Wann die verfolgung wird geführt/

Zwar/ wer da freyt/ macht es gut/

Doch wer nicht freyet/ besser thut.

3. Weil du denn GOtt berufst auch mich/

Daß ausserm ehestande ich/

So wohl am geist als auch am leib

In heilger zucht hie bin und bleib

Ach so gib fort die gnaden=gab/

Und daß ich nicht verreitzung hab.

4. Auch gib mir, weil ich ledig bin/

Daß meine wercke/ wort und sinn/

Ohn hinderniß ich überall

$\mathrm{Zu}$ dir richt/ und nur dir gefall/

Mein hertz auch von der welt gekehrt/

Nur sorge/ was man von dir lehrt. ${ }^{45}$

Inwiefern solche Texte als gesungene Lieder tatsächlich einen Sitz im Leben hatten, ist eine interessante Frage. Da der Ballmeister sich kaum über Genese und

44 Hartmann: Neue StandesLieder (Anm. 40), Nr. 10 Eines Ballmeisters.

45 Hartmann: Neue Standes=Lieder (Anm. 40), Nr. 39 Eines Gesellen/ oder Jungfrauen die nicht heyrathen wollen. 
Charakter seines eigenen Berufes belehren musste, bleibt als gesicherte Erkenntnis nur, dass solche Texte die Gelehrsamkeit ihrer Verfasser bis hin zur kreativen Kompetenz in theologischer Allegorese spiegeln. Allerdings gibt Hartmann durchgehend keine Verfasser an. Dem heutigen Leser zumindest drängt sich bei der Lektüre von Texten wie dem „Lied des Ballmeisters“ der Eindruck auf, hier würde eine polyhistorische, zugleich säkulare wie auch fromme Selbstbespiegelung des Protagonisten stattfinden. Das völlig andere Verständnis der Zeitgenossen erhellt aus der Vorrede zu Hartmanns Stände-Gesangbuch durch den Rostocker Konsistorialrat und Superintendenten Johann Fecht, ${ }^{46}$ der behauptet, er habe, inspiriert vom Erfolg des Gesangbuchs von 1713, Hartmann gedrängt, ein reines Stände-Gesangbuch herauszugeben, denn:

Ich bin völlig versichert/ das keine Lieder mit grösserm Ernst und Eyfer/ auch mit mehrerm effect und Würckung/ als dies gesungen werden könnten/ dergleichen doch meines wissens biß dahero nicht in Druck gekommen. Mit was vor Freude/ und ungezweiffelter Hoffnung der Erhörung muß/ unter andern/ auch ein frommer einfältiger Handwercks=Mann/ Tag=Löhner/ Schaffner/ und Arbeiter seine Geschäfte vornehmen und ausrichten/ wann er seinem GOtt vorstellet/ daß seine vorhabende Arbeit/ und Nahrung/ nicht nur in GOttes Wort gegründet/ sondern auch mit Göttlichen reichen Segen/ so offt und vielmahl begabet worden. Er hält GOTT dem HErrn seine selbst eigene Worte mit getrostem Muthe vor/ und zwinget ihn gleichsam sein Wort zu halten/ und seinen Segen zu ertheilen. Heisset das nicht so viel/ als mit David GOTT gleichsam obligiren/ daß er uns erhören müsse/ wo anders sein Wort wahr seye? Mein Hertz/ saget er: hält dir für dein Wort/ ihr solt mein Antlitz suchen/ darum suche ich auch/ HERR/ Dein Antlitz/ verbirge dein Antlitz nicht für mir/ und verstoß nicht im Zorn deinen Knecht/ denn du bist meine Hülffe. Laß mich nicht und thue nicht von mir die Hand ab Ps. 27 8.9. Das machet ein Himmel=vestes Vertrauen gegen GOTT/ wann er ihm so oft/ und so nachdrücklich seine Worte von seinem Beruf und Handwerck vorwirft/ und damit das Göttliche Vater=Hertz nöthiget/ und zwinget/ ihn zu erhören. Es kan in Warheit kein nachdrücklicher/ und kräftiger Gebet erdacht werden. ${ }^{47}$

Gleichzeitig geht er auf den Umstand ein, dass jeder Stand nur mit einem Lied vertreten sei. Er meint, so könne man sich mit den anderen Berufen vor Gottes Angesicht solidarisieren, indem man auch deren Lieder singe.

46 Johann Fecht (1636-1716) war seit 1690 Theologieprofessor in Rostock und kümmerte sich im Rahmen seiner Möglichkeiten um die Reform des Kirchen- und Schulwesens in Mecklenburg im Sinne der lutherischen Spätorthodoxie. Hartmann gehörte in dieser Hinsicht zu seinem Netzwerk.

47 Hartmann: Neue Standes=Lieder (Anm. 40), Vorrede unpag. 


\section{Johann Heermanns Choral "O Gott, du frommer Gott" als Ausdruck bis in die Gegenwart präsenter lutherischer Berufsethik}

Eingangs wurde bereits erwähnt, dass der Liedbestand der Rubrik „In Arbeit und Beruf" bzw. „Arbeit" in den evangelischen Gesangbüchern der Gegenwart jeweils nur vier bis fünf Lieder umfasst. An diesen Liedern fällt auf, dass sie mit einer Ausnahme aus dem 17. Jahrhundert stammen. Im Evangelischen Kirchengesangbuch - und zwar völlig parallel in der unierten wie in der lutherischen Ausgabe - sind das: Johann Heermann: „O Gott, du frommer Gott”, 1630; Paul Gerhardt: „Ich weiß mein Gott, daß all mein Tun“", 1653; Salomo Liskow: „In Gottes Namen fang ich an“, 1672; Johann Betichius: „Das walte Gott der helfen kann“, 1697. Dazu kommt Johann Friedrich Möller: "Geh hin nach Gottes Willen" von 1822. Im Evangelischen Gesangbuch, wiederum in beiden Ausgaben parallel, sind Betichius, „Das walte Gott" und Möller, „Geh hin nach Gottes Willen“, weggefallen und stattdessen ein weiterer, allerdings nur einstrophiger Text von Johann Heermann, „Laß dich, Herr Jesu Christ“, aufgenommen. Es erfolgte also eine Reduktion ausschließlich auf einen Bestand aus dem 17. Jahrhundert.

Die beiden ,Klassiker' in diesem Minimalbestand sind, erstens, Johann Heermanns „O Gott, du frommer ${ }^{49}$ Gott":

O Gott, du frommer Gott,

Du Brunnquell guter Gaben,

Ohn' den nichts ist, was ist,

Von dem wir alles haben:

Gesunden Leib gib mir,

Und daß in solchem Leib

Ein' unverletzte Seel'

Und rein Gewißen bleib'.

2. Gib, daß ich tu' mit Fleiß,

Was mir zu tun gebühret,

Wozu mich dein Befehl

In meinem Stande führet!

Gib, daß ich's tue bald,

Zu der Zeit, da ich soll,

Und wenn ich's tu', so gib,

Daß es gerate wohl!

48 Es existiert auch eine plattdeutsche Fassung: Ick weit, min Gott, dat all min Daun. In Walter Schröder: Plattdütsch Kirchenleeder. Stettin o.J.

49 Die heute seltsam klingende Titelzeile mit dem Prädikat „fromm“ für Gott erklärt sich aus der Bedeutung des Wortes "fromm" als "gut, gerecht". Vgl. Jacob und Wilhelm Grimm: Deutsches Wörterbuch, Nachdr. der Erstausgabe Leipzig 1878, München 1991, Bd. 4, Sp. 242. 
3. Hilf, daß ich rede stets,

Womit ich kann bestehen,

Laß kein unnützes Wort

Aus meinem Munde gehen;

Und wenn in meinem Amt

Ich reden soll und muß,

So gib den Worten Kraft

Und Nachdruck ohn' Verdruß!

4. Find't sich Gefährlichkeit,

So laß mich nicht verzagen;

Gib einen Heldenmut,

Das Kreuz hilf selber tragen!

Gib, daß ich meinen Feind

Mit Sanftmut überwind'

Und, wenn ich Rats bedarf,

Auch guten Rat erfind'!

5. Laß mich mit jedermann

In Fried' und Freundschaft leben,

Soweit es christlich ist.

Willst du mir etwas geben

An Reichtum, Gut und Geld,

So gib auch dies dabei,

Daß von unrechtem Gut

Nichts untermenget sei!

6. Soll ich auf dieser Welt

Mein Leben höher bringen,

Durch manchen sauern Tritt

Hindurch ins Alter dringen,

So gib Geduld. Vor Sünd'

Und Schanden mich bewahr',

Auf daß ich tragen mag

Mit Ehren graues Haar!

7. Laß mich an meinem End'

Auf Christi Tod abscheiden,

Die Seele nimm zu dir

Hinauf zu deinen Freuden,

Dem Leib ein Räumlein gönn

Bei frommer Christen Grab,

Auf daß er seine Ruh'

An ihrer Seite hab'. 
8. Wenn du an jenem Tag

Die Toten wirst aufwecken,

So tu auch deine Hand

$\mathrm{Zu}$ meinem Grab ausstrecken;

Laß hören deine Stimm'

Und meinen Leib weck auf

Und führ ihn schön verklärt

Zum auserwählten Hauf'! ${ }^{50}$

Das Lied besteht aus drei Themenkreisen. Strophe eins bis vier zeigen das angestrebte Verhalten bzw. die richtige Haltung; Strophe fünf und sechs die immerhin mögliche Hoffnung auf irdischen Lohn. Das ist insofern interessant, als das Neue Testament hier selbst härter ist, indem das Gleichnis vom Knechtslohn Lk 17,7-10 keinen Lohn kennt, da alles, was getan wird, Pflicht ist. Strophe sieben und acht bringen dann die eschatologische Hoffnung.

Der zweite ,Klassiker' ist Paul Gerhardts „Ich weiß mein Gott, daß all mein Tun", von dem hier nur die ersten drei Strophen zitiert seien:

1. Ich weiß, mein Gott, dass all mein Tun und Werk in deinem Willen ruh'n, von dir kommt Glück und Segen; was du regierst, das geht und steht auf rechten, guten Wegen.

2. Es steht in keines Menschen Macht, dass sein Rat werd ins Werk gebracht und seines Gangs sich freue;

des Höchsten Rat, der macht's allein, dass Menschenrat gedeihe.

3. Es fängt so mancher weise Mann ein gutes Werk zwar fröhlich an und bringt's doch nicht zum Stande; er baut ein Schloss und festes Haus, doch nur auf lauter'm Sande. ${ }^{51}$

Sowohl das Leben des Schlesischen Pfarrers Heermann, geboren 1585 in Raudten im Herzogtum Glogau, als auch das des Brandenburgischen Pfarrers Gerhardt, Jahrgang 1607, war geprägt vom Dreißigjährigen Krieg und der Notwendigkeit, Gewalt, Tod, Familienleid und Angriffe auf ihre innersten Glaubensüberzeugungen zu verarbeiten. Heermann wurde ein Opfer der habsburgischen Intoleranz

50 Johann Heermann: O Gott, du frommer Gott (1630), zit. nach Evangelisches Gesangbuch Nr. 495.

51 Paul Gerhardt: Ich weiß mein Gott, daß all mein Tun (1653), zit. nach Evangelisches Gesangbuch Nr. 497. 
und musste 1638 sein Pfarramt in Köben bei Glogau aufgeben. Gerhardt wurde ein Opfer der brandenburgischen Toleranz des Großen Kurfürsten und zum Exilanten im eigenen Land. Das hat sie beide nicht aus der Bahn geworfen. Sie gehören mit ihrem lyrischen Werk zu den herausragenden Vertretern einer Dichtergeneration, die wie keine zweite in der deutschen Literaturgeschichte Texte des Gottvertrauens, Lebensmutes und Lebenswillens hervorgebracht hat. ${ }^{52}$

Die beiden Lieder verbindet, dass sie im Vergleich zu den anderen, die sich heute in der Gesangbuch-Rubrik "Arbeit" befinden, eine durchgehende starke Präsenz in der Gesangbuchtradition aufweisen. Allein eine Stichprobe im Gesangbuchbestand der Forschungsbibliothek Gotha ergibt für den Zeitraum von 1650 bis 180064 Gesangbücher lutherischer, teilweise auch reformierter Städte und Territorien zwischen Riga und Straßburg sowie zwischen Kopenhagen und Reutlingen, in denen „O Gott, du frommer Gott" enthalten ist; in 45 davon zugleich „Ich weiß mein Gott, dass all mein Tun“. Beide Lieder kommen dabei häufig in der Rubrik „Vom christlichen Leben und Wandel“ vor, aber eher selten bei den Standes- bzw. Berufsliedern, nämlich nur fünfmal. Erst in den Ausgaben des Evangelischen Gesangbuchs [...] in der Provinz Brandenburg seit 1886 werden sie in der Rubrik „Beruf und Haus“ zusammengefasst, wo sie sich dann in den Gesangbuchausgaben des 20. Jahrhunderts bis heute regelmäßig finden. Das hat damit zu tun, dass sie für die Popularisierung genuin lutherischer Pflichtethik in einem allgemeinen und nicht auf einen bestimmten Stand oder Beruf spezialisiertem Sinne dienen und deshalb bis heute jeden politischen, soziokulturellen und mentalen Wandel überstanden haben, denen Lieder wie das des Ballmeisters oder derjenigen lutherischen Christenmenschen, die nicht heiraten wollen, wie generell Standes- und Berufslieder notwendigerweise zum Opfer fallen mussten.

Für Heermanns Lied „O Gott, du frommer Gott" liegt eine greifbare und ins Leben übergreifende literarische Rezeption vor. Es erschien 1630 in Heermanns Liedersammlung Devotio Musica Cordis. Das ist Allerley geistliche Lieder/ aus den H. Kirchenlehrern und selbst eigener Andacht/ Auff bekandtel und in unsern Kirchen ubliche Weisen verfasst über einen Breslauer Verleger in Leipzig gedruckt. 1644 folgte eine zweite Auflage. Das „in unsern Kirchen ublichen Weisen“ war nicht so einfach, denn mit seiner Versform in Alexandrinern hatte es eine gewisse Sprödigkeit gegenüber gängigen Melodien. Die beiden heute im Gesangbuch ausgewiesenen Melodien stammen dann auch erst von 1648 und 1675. In seinen acht Strophen fasst es nichts weniger als ein ganzes Christenleben von der Geburt, in der wir von Gott Gaben, Leib, Seele und Gewissen erhalten, bis zur Auferstehung. Das lyrische Ich nimmt eine Grundhaltung der Bescheidenheit - geistlich ausgedrückt:

$52 \mathrm{Zu}$ Heermann vgl. Bernhard Liess: Johann Heermann (1585-1647). Prediger in Schlesien zur Zeit des Dreißigjährigen Krieges. Diss. Theol. Neuendettelsau 1999. Münster 2003. Zu Gerhardt vgl. Christian Bunners: Paul Gerhardt: Weg, Werk, Wirkung. 3. aktualisierte Aufl., Göttingen 2007. 
der Demut - und des Gottvertrauens ein. Diese Grundhaltung ist nicht mit Stoizismus oder Quietismus zu verwechseln. Sie wirkte im Gegenteil aktivierend. ${ }^{53}$

In diesem Sinne hat Heermanns Lied ein Eigenleben in Form einer pietistisch praktisch-frommen, literarischen Rezeption entwickelt. So verfasste Christian Friedrich Hilscher (1679-1756), Pfarrer in Auerswalde bei Chemnitz 1710 einen eigenen Kommentar: Hymnus Heermanianus: O Gott, du frommer Gott, rhythmis latinis expressus, brevi commentariolo illustratus. ${ }^{54}$ Das Korrespondenzverzeichnis August Hermann Franckes weist Hilscher als einen der wenigen Pietisten aus, der in der ersten Hälfte des 18. Jahrhunderts in einem sächsischen Pfarramt überdauern konnte. Das ist insofern bezeichnend, als der Liedtext in der weiteren Literatur zur Quelle pietistisch eingefärbter Anekdoten wird, die mit Vorliebe im Württemberg spielen. So im vierten Band von Eduard Emil Kochs Geschichte des Kirchenlieds, ${ }^{55}$ einer erbaulich geschriebenen Hymnologie, und darauf fußend in Paul Dorsch: Das deutsche evangelische Kirchenlied und sein Segensgang durch die Gemeinde. ${ }^{56}$

Das einzige preußische Exempel in dieser Reihe sind die Grenadiere Friedrichs des Großen, die am Morgen der Schlacht von Leuthen unter Gesang der zweiten Strophe „Gib, daß ich tu mit Fleiß, was mir zu tun gebühret, wozu mich dein Befehl in meinem Stande führet. Gib, daß ich's tue bald, zu der Zeit da ich soll, und wenn ich's tu so gib, daß es gerate wohl“ ins Feld gezogen seien. Der König, von einem Offizier befragt, ob die Soldaten schweigen sollten, habe geantwortet: „Nein! Lasse Er das, mit solchen Leuten wird Gott mir heute gewiß den Sieg verleihen." ${ }^{57}$ Koch gibt als Quelle der Anekdote den Schriftsteller und Aufklärungsphilosophen Thomas Abbt (1738-1766) an, der die Episode darin habe ausklingen lassen, Friedrich habe sich hier die Kraft der Religion eingestanden. ${ }^{58}$

53 So blieb Heermann trotz schwerer Krankheit in den letzten neun Jahren seines Lebens intensiv schriftstellerisch tätig; vgl. Liess: Johann Heermann (Anm. 52), S. 49-58.

54 Der Titel ist nicht mehr ermittelbar.

55 Emil Koch: Geschichte des Kirchenlieds und Kirchengesangs der christlichen, insbesondere der deutschen evangelischen Kirche. Stuttgart 1853, S.31-35.

56 Paul Dorsch: Das deutsche evangelische Kirchenlied und sein Segensgang durch die Gemeinde. Stuttgart 1890, S. 115-119.

57 Koch: Geschichte des Kirchenlieds (Anm. 55), S. 33.

58 Die Angaben sowohl Kochs als auch Dorschs halten einer Überprüfung der Quelle aber nicht stand. Diese wird von Koch: Geschichte des Kirchenlieds (Anm. 55), hier S. 34 angegeben mit: Das verdienstreiche Berlin, 1768, S. 257. Dabei handelt es sich um die „Abhandlung vom Verdienste", die als erster von sechs Teilen 1768 in Thomas Abbts Vermischten Werken von Friedrich Nicolai herausgegeben wurde. Hier heißt es S. 257 lediglich: „Das erbauliche Lied, welches das preußische Heer auf dem Wege, zum Angriff bey Lissa, sang, war zehen Heldengedichte und auch eben so viele Bataillons werth." Das Zitat gehört in den Abschnitt „Vom Verdienste des Schriftstellers, des Künstlers und des Predigers" und hier wiederum in die Würdigung der Wirkung lutherischer Erbauungsliteratur auf das einfache Volk. Die einzigen beiden Namen, die genannt werden, sind Arndt und Scriver. Zu Abbt vgl. zuletzt Wilhelm-Ludwig Federlin: Art. Abbt, Thomas. In: Killy Literaturlexikon. 2., vollständig überarbeitete Auflage. Hg. v. Wilhelm Kühlmann. Berlin, New York 2008, Bd.1, S. 2-5. Außerdem Friedrich Nicolai: Ehrengedächtniß Herrn Thomas Abbt. Berlin, Stettin 1767. In Friedrich 
Dorsch macht daraus nicht weniger als die Behauptung, Friedrich habe sich im Alter quasi bekehrt. ${ }^{59}$

Immerhin wird Heermanns Lied so zur kleinen Schwester des Chorals von Leuthen - und mehr Pflichterfüllung ist nicht denkbar. Der Text aller acht Strophen blieb in den Gesangbüchern der Aufklärungszeit unverändert. Das ist angesichts der Intensität, mit der das alte lutherische Liedgut, sofern man es nicht aussortierte, aufklärungstheologisch angepasst wurde, bemerkenswert. ${ }^{60}$ Auf jeden Fall nicht legendarisch ist hingegen die Verbindung des Liedtextes mit der Parabelerzählung „Von den Arbeitern im Weinberg“, Mt 19,27-20,16 durch den Arnstädter Superintendenten und Hymnologen Johann Christoph Olearius in seinem Evangelischen Lieder=Schatz, Jena 1705, T. 1, S. 123. Wilhelm Nelle füllt das 1918 in seinem Schlüssel zum Evangelischen Gesangbuch im Rheinland und Westfalen mit folgender Charakteristik:

Als Ganzes ist es ein Berufslied. Insbesondere eignet es sich bei Einführung eines Pfarrers oder Beamten. Strophe 1-3 als Frühgesang am Synodaltage. Seine 3. Strophe sollte das ständige Gebet eines Synodalen und Parlamentariers sein. Beherzigenswert ist es beim Antritt eines jeden Amtes; wider alle Kriecherei nach oben und nach unten, vor den Hohen und vor dem Volke vermag es das Rückgrat zu stärken, ein Lied der Gewissenhaftigkeit und Wahrhaftigkeit. ${ }^{61}$

Martin Rößler übersetzt das im ersten Band seiner Reihe Liedermacher im Gesangbuch, Stuttgart 1990 für die Gegenwart der Bundesrepublik:

In der Tat ein Lied der gewissenhaften Tugend; Zivilcourage gegen alle Kriecherei nach oben und unten ist herauszuhören, und es hat manchem

Nicolai: Gesammelte Werke. Hg. v. Bernhard Fabian und Marie-Luise Spieckermann. Bd. 12: Opera Minora I. Hildesheim, Zürich, New York 1995. Zur Herausbildung und den Problemen eines preußischen Patriotismus, allerdings ohne auf hymnologische Aspekte einzugehen, vgl. zuletzt: Angelika Dörfler-Dierken: „Friderikus ruft, unser König: Allons, frisch ins Gewehr". Oder: Die Formierung einer opferbereiten Erregungsgemeinschaft. In: Glaube und Vernunft. Studien zur Kirchen- und Theologiegeschichte des späten 18. Jahrhunderts. Hrsg. von Albrecht Beutel, Thomas K. Kuhn und Markus Wriedt. Leipzig 2014, S. 302-322.

59 Tatsächlich lässt sich für das Lied eine frühe biographische Verinnerlichung in einem Brief Friedrichs an seinen Vater aus der Küstriner Haftzeit vom 28. November 1730 nachweisen. Hier zitiert er die Zeile „durch manchen sauern Tritt“ aus Strophe 6, um seine Situation zu beschreiben. Vgl. Euvres de Frédéric le Grand. Bd. 27,3: Correspondance de Frédéric II roi de Prusse. Hg. v. J. D. E. Preuß. Berlin 1856, S. 13.

60 Als prominentes Beispiel kann hier Luthers Kampf- und Bekenntnislied „Erhalt uns Herr bei deinem Wort" von 1543 (EG 193) gelten, das in Aufklärungsgesangbüchern, abgesehen von der Titelzeile, vollständig zu einer Ode an Gewissensfreiheit und Toleranz umgedichtet wurde. Vgl. Andreas Lindner: Leben im Spannungsfeld von Orthodoxie, Pietismus und Frühaufklärung. Johann Martin Schamelius, Oberpfarrer in Naumburg. Gießen 1998, S. $314 \mathrm{ff}$.

61 Wilhelm Nelle: Schlüssel zum Evangelischen Gesangbuch im Rheinland und Westfalen. Gütersloh 1918, S. 176. 
Hofprediger und einfachen Untertanen in den Fängen des absolutistischen Staates den Rücken gestärkt und sie zum aufrechten Gang ermutigt. ${ }^{62}$

Hier wird eine Tradition greifbar, die das Lied zu dem Ordinationslied für lutherische Pfarrer bis heute werden ließ. So drückt es in seiner altertümlichen Sprache die immer noch gültige Berufsethik zumindest - um nicht von geistlichem Stand zu reden - für die Berufsgruppe der Pfarrer im lutherischen Sinne aus. Wie viele dem gerecht werden, war und ist eine andere Frage.

62 Martin Rößler: Liedermacher im Gesangbuch. Zit. nach der 2., durchgesehenen Auflage. Stuttgart 1992, S. 167. 


\title{
Übung und Wissen in der religiösen Lyrik der frühen Neuzeit
}

\author{
Günter Butzer
}

\section{Vorbemerkungen}

Die Ausführungen beruhen auf den folgenden Verwendungen der titelgebenden Begriffe: (1.) ,Übung' wird in einem weiten Sinn verstanden als Inbegriff mental-physischen Trainings, wie es durch die antiken Konzepte der askēsis und des exercitium bzw. der meditatio bezeichnet und von der christlichen Kultur übernommen wurde. ${ }^{1}$ Im Unterschied zur frühneuzeitlichen Disziplin ist die Übung nicht auf die Ausbildung , gelehriger Körper ${ }^{\prime 2}$ gerichtet, sondern basiert auf einer holistischen - in moderner Terminologie: psychosomatischen - Anthropologie, was für die spezifischen Wissensformen der Übung eine wichtige Rolle spielen wird. (2.) ,Religiöse Lyrik' verstehe ich im Folgenden als ,meditative Lyrik', ${ }^{3}$ wobei offen bleiben soll, ob beide Begriffe tatsächlich deckungsgleich sind oder die meditative nur als Teilbereich der religiösen Lyrik fungiert (da der Begriff der Lyrik für die frühe Neuzeit zumeist anachronistisch verwendet wird, bewegen wir uns ohnehin in einem recht diffusen Feld). Ausschlaggebend für die Zuordnung eines Texts zur meditativen Lyrik ist dessen intertextuelle Einzel- bzw. Systemreferenz auf Meditationsanleitungen, -techniken und Prosameditationen und damit seine Situierung im Kontext religiöser Übung und Textverarbeitung, die in der christlichen Tradition unlösbar zusammenhängen. ${ }^{4}$ (3.) Geht man davon aus, dass religiöses Wissen nicht oder zumindest nicht nur ein Wissen über Religion meint, wie es die Religionswissenschaft oder die Theologie hervorbringt, öffnet sich der Terminus für unterschiedliche Wissensformen, ${ }^{5}$ die der Religion eigen

1 Vgl. Paul Rabbow: Seelenführung. Methodik der Exerzitien in der Antike. München 1954; Pierre Hadot: Exercices spirituels et philosophie antique. Paris 1981; Michel Foucault: Der Gebrauch der Lüste. Sexualität und Wahrheit 2. Übers. von Ulrich Raulff und Walter Seitter. 5. Aufl. Frankfurt/Main 1997.

2 Vgl. Michel Foucault: Überwachen und Strafen. Die Geburt des Gefängnisses. Übers. von Walter Seitter. Frankfurt/Main 1994, S. $173 \mathrm{ff}$.

3 Der Begriff wurde etabliert von Louis L. Martz: The Poetry of Meditation: A Study in English Religious Literature of the Seventeenth Century. 2. Aufl. New Haven 1962 (1. Aufl. 1954).

4 Vgl. Günter Butzer: Soliloquium. Theorie und Geschichte des Selbstgesprächs in der europäischen Literatur. München 2008, S. 34 f.

5 Der Begriff wurde in jüngster Zeit geprägt von Karen Gloy in Auseinandersetzung mit dem verengten Wissensbegriff der Wissenschaftsgeschichte und dem Begriff der Wissenskulturen, wie er v. a. vom Frankfurter Sonderforschungsbereich/Forschungskolleg 435 „Wis- 
oder die zumindest von ihr in spezifischer Weise adaptiert worden sind und die sich vom theoretischen Wissen der Theologie deutlich unterscheiden. Religiöses Wissen in der Lyrik der frühen Neuzeit, so meine im Folgenden auszuführende These, ist nicht bzw. nicht zuvorderst als Wissensimport aus der Theologie in die Literatur zu beschreiben, sondern vielmehr als ein Wissen, das von der Lyrik selbst generiert wird. Vier Formen dieses von der Lyrik produzierten religiösen Wissens sollen im Folgenden - ohne Anspruch auf Vollständigkeit - anhand einschlägiger Textbeispiele aus der englischen und deutschen Lyrik vorgestellt werden.

\section{Frömmigkeit als prozedurales Wissen (John Donne)}

Anders als noch im früheren und hohen Mittelalter, in dem die Meditation eng an die lectio divina gekoppelt war, mit der sie lange Zeit weitgehend identifiziert wurde, ${ }^{6}$ versteht die frühe Neuzeit die Meditation weithin als Kunstlehre $(\text { ars })^{7}$ - allerdings mit signifikanten Modifikationen. Sind die artes seit der Antike am Modell der poiēsis orientiert und geben die Anleitung zur kunstfertigen Hervorbringung von Objekten (ob nun Dichtwerke, Reden oder Bauten), so stellt sich die Frage, was denn die Kunst der Meditation eigentlich produziere? Eine geläufige Antwort lautet: sie produziert fromme Menschen, und damit wird die Besonderheit der meditativen Kunst bereits deutlich: es handelt sich nämlich um eine ethopoietische Selbsttechnik im Sinne Foucaults, in der Subjekt und Objekt zusammenfallen. Anders gesagt: der Meditierende bringt durch technē einen religiösen Habitus bei sich hervor, der eine Ausbildung bzw. Veränderung des èthos impliziert. ${ }^{8}$ Dass sich dieses neue èthos dann auch in einer veränderten Handlungsweise - als Orthopraxie - artikuliert, ist eine auch für die frühe Neuzeit zentrale Konsequenz meditativer technē. Dadurch, dass diese unmittelbar charakterbildend wirkt, erzeugt sie indirekt auch eine ,ethische Praxis', an der man wiederum den Erfolg der Ethopoiesis erkennen kann. ${ }^{9}$ Insofern bildet der für die frühe Neuzeit über die Konfessionsgrenzen hinweg abundierende Begriff der praxis pietatis den Kernbegriff meditativer Selbsttechnik, weil er den Habitus der

senskultur und gesellschaftlicher Wandel“ eingeführt wurde. Näheres dazu im Schluss-Abschnitt dieses Beitrags.

6 Vgl. Heinrich Bacht: „Meditatio“ in den ältesten Mönchsquellen. In: Geist und Leben 28 (1955), S. 360-373.

7 Vgl. R.J. Corthell: Joseph Hall and Protestant Meditation. In: Texas Studies in Literature and Language 20 (1978), S. 367-385. - Zum Zusammenhang von Meditation und Rhetorik vgl. Günter Butzer: Art. ,Meditation'. In: Historisches Wörterbuch der Rhetorik. Hrsg. von Gert Ueding. Bd. 5. Tübingen 2001, Sp. 1016-1023.

8 Vgl. Michel Foucault: Technologien des Selbst. In: Technologien des Selbst. Übers. von Michael Bischoff. Hrsg. von Luther H. Martin, Huck Gutman und Patrick H. Hutton. Frankfurt/ Main 1993, S. 24-62.

9 Vgl. Ilsetraut Hadot: Seneca und die griechisch-römische Tradition der Seelenleitung. Berlin 1969. 
Frömmigkeit an die richtige Handlung knüpft und damit die Eigenart meditativer technē als Produktion eines praxisrelevanten èthos auf den Punkt bringt.

Doch welche Rolle spielt nun das Wissen in dieser Kunstlehre? Wie in jeder ars wird es als doctrina als bereits gegeben vorausgesetzt. Wie man gute Dichtung oder gute Reden schafft, ist ebenso wenig eine offene Frage für die entsprechenden Kunstlehren wie diejenige, wie man ein frommer Mensch wird. Das Entscheidende ist vielmehr, wie man sich das vorhandene Wissen darüber aneignet und dadurch gelungene Ergebnisse erzielt. Die beiden Verfahren hierfür sind bekanntlich Nachahmung und Übung, die man im Konzept einer exercitatio per imitationem zusammenfassen kann. Damit ist zugleich der Kern der meditativen Technik als übende Aneignung doktrinären Wissens benannt. Als exercitium ist die Übung integraler Bestandteil jeder Kunstlehre; für die ars meditativa stellt sie gewissermaßen eine mise en abyme dar, sofern hier die Übung im Sinne des exercitiums das Zentrum der Übung im Sinne der meditatio bildet. Als Beispiel für diesen Aneignungsprozess kann das siebte Sonett aus John Donnes Holy Sonnets fungieren:

Spitt in my face yee Iewes, and peirce my side,

Buffett, and scoff, scourge, and crucifie mee,

For I haue sinn'd, and sinn'd, and only hee

Who could doe none iniquitie hath dyed.

But by my Death cannot bee satisfied

My sinnes which pass the Iewes impietie;

They kill'd once an inglorious man, but I

Crucifie him daily, being nowe glorified.

Oh lett mee then his strange loue still admire,

Kings pardon, but hee bore our punnishment; 10

And Iacob came cloathed in vile harsh attire,

But to supplant, and with gainfull intent;

God cloath'd himself in vile mans fleash that soe

Hee might bee weake enough to suffer woe. ${ }^{10}$

Donne bearbeitet in diesem Sonett die christliche Kardinaldoktrin der Menschwerdung Gottes zur Erlösung der Menschheit von ihren Sünden. Er tut dies, indem der Sprecher sich zunächst selbst an die Stelle Jesu im Passionsgeschehen versetzt und die „Iewes“ (v. 1) dazu aufruft, ihn zu kreuzigen, um damit auf die dogmatische Paradoxie aufmerksam zu machen, dass mit Jesus ein Unschuldiger für die Sünden anderer gestorben ist. Die Verse 3 und 4 formulieren die theologische Doktrin, die der Sprecher sich nicht nur in der ersten Person zueigen macht („I haue sinn'd, and sinn'd“), sondern in Vers 1 bis 2 als ,inneres Schauspiel“ in-

10 John Donne: The Holy Sonnets 7 [in der Zählung der Revised Sequence]. In: The Variorum Edition of the Poetry of John Donne. Hrsg. von Gary A. Stringer. Bd. 7/1. Bloomington, Indianapolis 2005, S. 24. 
szeniert. ${ }^{11}$ Gemäß den Vorgaben der frühneuzeitlichen Meditationsanleitungen ${ }^{12}$ begibt sich der Sprecher imaginativ an den historischen Schauplatz der Kreuzigung und interagiert mit den beteiligten Personen, die er direkt anspricht (,Spitt in my face yee lewes, and peirce my side"). Auf diese Weise wird dem intratextuellen Sprecher - aber durch die meditative Kommunikationsstruktur auch dem Autor und dem Leser - nicht nur eine theologische Wahrheit in den Mund gelegt, sondern er agiert diese Wahrheit aus. Genauso verhält es sich mit dem zweiten Theologoumenon, das zu Beginn der zweiten Strophe vorgetragen wird: „But by my Death cannot bee satisfied / My sinnes which pass the Iewes impietie" (v. 5 f.). Damit vollzieht der Text zugleich den Übergang vom historischen Geschehen zur Gegenwart des Sprechers: „They kill'd once an inglorious man, but I / Crucifie him daily, being nowe glorified“" (v. 7 f.). ${ }^{13}$ Der Sprecher, der anfangs noch von den „Iewes" gekreuzigt werden wollte, rückt nun selbst auf deren Position, ja er übertrifft ihre „impietie“ (v. 6) durch die beständige Wiederholung der Kreuzigung

11 Zur Meditation als innerem Schauspiel vgl. Jörg Jochen Berns: Nachwort. In: Gedächtnislehren und Gedächtniskünste in Antike und Frühmittelalter. Dokumentsammlung mit Übersetzung, Kommentar und Nachwort. Hrsg. von Jörg Jochen Berns. Tübingen 2003, S. 523-597, hier S. 548-560; Ders.: Inneres Theater und Mnemonik in Antike und Früher Neuzeit. In: Kunst der Bewegung. Kinästhetische Wahrnehmung und Probehandeln in virtuellen Welten. Hrsg. von Christina Lechtermann und Carsten Morsch. Bern [u. a.] 2004, S. 23-44.

$12 \mathrm{Zu}$ denken ist hier zunächst an die Exercitia spiritualia des Ignatius von Loyola, der den vehementen Einsatz der imaginatio beim Meditieren empfiehlt und den Martz zum zentralen Gewährsmann für die englische religiöse Lyrik um 1600 gekürt hat (vgl. Martz: The Poetry of Meditation [Anm. 3], S. 25 ff.). Zur Bedeutung der Exercitia spiritualia für die frühneuzeitliche Lyrik vgl. auch Christian Wehr: Geistliche Meditation und poetische Imagination. Studien zu Ignacio de Loyola und Francisco de Quevedo. München 2009. - Helen Gardner hat wenige Jahre vor Martz' Studie im Vorwort zu ihrer einflussreichen Ausgabe von Donnes Divine Poems den engen Anschluss der Struktur und der Abfolge der Holy Sonnets an die ignatianischen Exerzitien postuliert (vgl. John Donne: The Divine Poems. Hrsg. von Helen Gardner. Oxford 1952, S. 1-lv). Zur Problematik dieser Position vgl. die folgende Fußnote.

13 Wie Barbara Lewalski überzeugend gezeigt hat, folgt diese Wendung weg vom historischen Geschehen hin zur eigenen Schuld des Sprechers der protestantischen Meditationsauffassung, die auf der Auslegung des Passionsgeschehens nach den beiden Aspekten des propter me (Jesus ist wegen meiner Sünden gestorben) und des pro me (Jesus ist stellvertretend für mich gestorben) basiert (vgl. Barbara Kiefer Lewalski: Protestant Poetics and the Seventeenth-Century Religious Lyric. Princeton, NJ 1979, S. 270 f.). Damit steht die von Gardner, Martz und zahlreichen anderen Forschern postulierte enge Anbindung der Holy Sonnets an die ignatianischen Exerzitien generell in Frage (vgl. John Stachniewski: The Persecutory Imagination. English Puritanism and the Literature of Religious Despair. Oxford 1991, S. 254 ff.). Berücksichtigt werden sollten bei dieser Diskussion allerdings zwei Punkte: zum einen sind die ignatianischen Meditationstechniken in den Exercitia spiritualia bei weitem nicht so systematisiert, wie dies die spätere jesuitische Tradition behauptet (vgl. Butzer: Soliloquium [Anm. 4], S. 226 ff.); zum andern wurden die ignatianischen Exerzitien interkonfessionell über ganz Europa verbreitet und fanden, etwa in Gestalt des Booke of the Christian Exercise des Jesuiten Robert Parson, eine intensive Rezeption bei den Autoren protestantischer Meditationsliteratur, so dass von einer exklusiven Zuschreibung der ignatianischen Meditationstechniken zum Katholizismus keine Rede sein kann (vgl. Udo Sträter: Sonthom, Bayly, Dyke und Hall. Studien zur Rezeption der englischen Erbauungsliteratur in Deutschland im 17. Jahrhundert. Tübingen 1987). 
immer dann, wenn er sündigt. Umso bewundernswerter ist die selbstlose Erlösungstat Jesu, deren Bedeutung in der comparatio der dritten Strophe - durch den Vergleich mit weltlichen Herrschern und mit dem Patriarchen Jakob - verstärkt wird. Das Couplet formuliert schließlich noch einmal komprimiert die Kardinaldoktrin von der erlösenden Menschwerdung Gottes: „God cloath'd himself in vile mans fleash that soe / Hee might bee weake enough to suffer woe" (v. 13 f.).

Wollte man das von Donne angewandte textuelle Verfahren genauer beschreiben, so könnte man von einer personalen Aneignung doktrinärer Gemeinplätze durch deren imaginative Inszenierung sprechen. Dabei werden die loci communes in imagines agentes verwandelt, die im doppelten Sinn bewegend wirken: rhetorisch als Aktivierung der Affekte, theatral als mentales Ausagieren weniger der historischen als der geistigen Bedeutung der doctrina. Dabei schafft bzw. verstärkt die mentale Simulation weitgehend dieselben neuronalen Bahnungen, die auch in der realen szenischen Aktion (die ja weit mehr ist als eine bloße motorische Handlung) aktiviert werden. ${ }^{14}$ Unterstützt wird diese Innervation doktrinalen Wissens durch die sinnlich stimulierende Wirkung von Rhythmus und Reim, die, wie schon Seneca im psychagogischen Zusammenhang der Epistulae morales ausführt, auf die unbewussten Regionen der menschlichen Psyche wirken und dadurch quasi natürliche Effekte erzielen. ${ }^{15}$ Auf diese Weise wird ein implizites, im Kern als prozedural anzusprechendes religiöses Wissen erzeugt, das man zeitgenössisch als pietas benannt hat. ${ }^{16}$ Es entsteht aus der mit Hilfe mentaler szenischer Simulation vollzogenen Verarbeitung eines expliziten deklarativen Wissens in Form theologischer Gemeinplätze, die von der Strukturierung des zeitgenössischen Wissens nach der ramistischen loci-Methode unterstützt wird.

14 Zum Zusammenhang von Meditation und Neurobiologie vgl. Wolf Singer und Matthieu Ricard: Hirnforschung und Meditation. Frankfurt/Main 2008.

15 Vgl. Seneca: Ep. 94, 27 f.: „Praeterea ipsa quae praecipiuntur, per se multum habent ponderis, utique si aut carmini intexta sunt aut prosa oratione in sententiam coartata [...]. Aduocatum ista non quaerunt: affectus ipsos tangunt et natura uim suam exercente proficiunt."

16 Der Begriff, prozedurales Wissen' ist in Analogie zum kognitionswissenschaftlichen Begriff des ,prozeduralen Gedächtnisses' gebildet, das alles das beinhaltet, „was man ,ohne nachzudenken' weiß oder kann" (Gerhard Roth: Das Gehirn und seine Wirklichkeit. Kognitive Neurobiologie und ihre philosophischen Konsequenzen. 6. Aufl. Frankfurt/Main 2001, S. 191), und betont die habituelle Komponente dieses Wissens im Sinne eines gewohnheitsmäßigen, auf Übung beruhenden Verhaltens. Doch wie auch das prozedurale Gedächtnis nicht nur auf kognitive Prozesse zurückgeht, sondern auch mit diesen interagiert, beinhaltet ein , prozedurales Wissen' durchaus kognitive Aspekte - wie die Bedeutung der Imagination für die Meditation deutlich macht. 


\section{Weisheit als praktisches Wissen (Catharina von Greiffenberg)}

Weisheit hat Walter Benjamin einmal als die „epische Seite der Wahrheit" bezeichnet. ${ }^{17}$ Sie liefere ein praxisbezogenes Wissen, das sich in einer Moral, in praktischen Anweisungen, Sprichwörtern oder Lebensregeln äußert. Die sprachliche Form der Weisheit wäre demnach die Sentenz, ihre literarische Form das encheiridion, die Spruchsammlung, die in der frühen Neuzeit u. a. in den Florilegien, Adagia, Apophthegmata und Aphorismen prosperiert. Karen Gloy bestimmt entsprechend Weisheit als "praktisch-moralisches [und] pragmatisches Wissen"; es habe eine "gesellschaftskonstituierende und identitätsstiftende Funktion" und reiche vom „reine[n] Sachwissen" bis zum „Wissen um die Seele und die gute Lebensführung". ${ }^{18}$ Im Verlauf der frühen Neuzeit ist nun zu beobachten, dass sich Weisheit im Sinne von sophia bzw. sapientia immer mehr vom wissenschaftlich definierten Wissen im Sinne der episteme bzw. scientia absondert und esoterisch wird, weil sie auf einem analogischen Denken beruht, das als veraltet disqualifiziert wird. ${ }^{19}$ Das theologische Wissen passt sich dem neuen epistemischen Paradigma an, das religiöse Wissen hingegen verharrt im Modus der Weisheit und wird auf Grund seines lebenspraktischen Bezugs (zumindest teilweise) hermetisch. Das gilt insbesondere für eine auf psychagogische Effekte wie die Reinigung der Seele und die Vereinigung mit dem Göttlichen ausgerichtete Weisheit, die zum Gegenspieler eines zunehmend vom èthos des Wissenschaftlers losgelösten Wissens gerät. (Aber vielleicht sollte man besser von einem èthosWandel der Wissenschaft sprechen. ${ }^{20}$ Das verdeutlicht das Eingangsgedicht zu den Passionsbetrachtungen Catharina Regina von Greiffenbergs:

LEsch aus / die ganze Welt. Die Tafel der Gedanken rein werd gewischet ab. Nichts bleib / als JEsus Christ.

Nichts will ich dulten sonst. Es soll nichts in den schranken der Angedächtnis seyn / als der / der Alles ist.

Es mag die wiß=begier vil schönes wesen reitzen:

mich labt mein JESUS nur / vor tausend=wissenschaft.

Die Welt mag / wie nach Geld / nach Kunst und Weißheit geitzen: ich will und weiß sonst nichts / als seine Creuzes=kraft.

Der Gall= und Essig=Schwamm lesch' aus all' Eitelkeiten: nur der Gekreutzigte bleib stehn in meinem Sinn.

Wie weit / wann sie allein / die Allheit sich ausbreiten und alles wenden kan / das siht man klar hierinn.

17 Walter Benjamin: Der Erzähler. Betrachtungen zum Werk Nikolai Lesskows. In ders.: Gesammelte Schriften. Hrsg. von Rolf Tiedemann und Hermann Schweppenhäuser. Bd. II/2. Frankfurt/Main 1980, S. 438-465, hier S. 442.

18 Karen Gloy: Einführung: Die verschiedenen Wissenstypen. In: Weisheit - Wissen - Information. Hrsg. von Karen Gloy und Rudolf zur Lippe. Göttingen 2005, S. 7-19, hier S. 10.

19 Gloy: Einführung: Die verschiedenen Wissenstypen (Anm. 18), S. 13.

20 Wie Hans Blumenberg in Der Prozeß der theoretischen Neugierde (Frankfurt/Main 1973) gezeigt hat, beruht auch das Wissensideal der Neuzeit auf einem èthos: dem der curiositas. 
Die Allheit ich allein will im Gedächtnis haben:

so hab ich alls / und sie gekreutzigt noch darzu.

Nur unerreichlicher sind ihre Gnaden=Gaben /

je mehr sie angehäfft. Jn ihm / ist meine Ruh. ${ }^{21}$

Wenn Greiffenberg in diesem Gedicht die „wiß=begier“ (v. 5) der Jesus-Liebe gegenüberstellt, aktualisiert sie den erwähnten Gegensatz von Wissen - dem die Sünde der curiositas zugewiesen wird - und Weisheit. Die Autorin vollzieht einen auf der platonischen Tafelmetapher des Gedächtnisses basierenden Auslöschungsprozess (s. v. 1: „LEsch aus / die ganze Welt"), der jegliches Weltwissen betrifft und, wie das lemma der zugehörigen pictura angibt, "Nichts als Jesus" übrig behält: „Der Gall= und Essig=Schwamm“ der Passion soll, wie es in Vers $9 \mathrm{f}$. heißt, ,all' Eitelkeiten“ vernichten - „nur der Gekreutzigte bleib stehn in meinem Sinn. “ ${ }^{22}$ Dieser bildet indessen kein partikulares Element der episteme, sondern er ist, ganz im Sinne der christlich adaptierten sophia-Auffassung, schlechthin "Alles" (v. 4): Jesus ist für Greiffenberg "die Allheit" (vv. 11, 13), das hen kai pan hermetischer Weisheit. Dieses wird in strikte Opposition zum epistemischen Wissen gesetzt: „Es mag die wiß=begier viel schönes wesen reitzen: / mich labt mein JESUS nur / vor tausend=wissenschaft" (v. 5 f.). ${ }^{23}$

Mit den letzten Worten des vorliegenden Gedichts „In ihm / ist meine Ruh“ (v. 16) macht Greiffenberg den praktischen Charakter dieses Wissens von Jesus nachdrücklich deutlich, und tatsächlich sind ja ihre Meditationen als schrittweises Reinigungsritual und Einübung in die ekstatische Christus-Erfahrung $\mathrm{zu}$ verstehen, die den Graden der mittelalterlichen scalae meditatoriae folgen: ausgehend von der lectio eines Bibelwortes vollführt sie zunächst eine in Prosa gefasste Betrachtung mit Hilfe der Einbildungskraft, der Vernunft und des Gedächtnisses, ${ }^{24} \mathrm{zu}$ der auch die Identifikation der Sprecherin mit dem Text der biblischen Rede gehört; diese mündet in eine Gebetsanrufung Jesu im Sinne eines meditativen colloquiums, das vor allem der affektiven Vertiefung des durch Fantasie und Vernunft nachvollzogenen Geschehens dient und schließlich mit einem Gedicht endet. Dieses nimmt mithin den strukturellen Ort ein, den in der

21 Catharina Regina von Greiffenberg: Erklärung des Tittel=Kupfers. In dies.: Sämtliche Werke. Hrsg. von Martin Bircher und Friedhelm Kemp. Bd. 9. Millwood, N.Y. 1983, o. P.

22 Vgl. Barbara Thums: Zur Topographie der memoria in frühneuzeitlicher Mystik: Catharina Regina von Greiffenbergs „Geistliche Gedächtnisorte“. In: Meditation und Erinnerung in der Frühen Neuzeit. Hrsg. von Gerhard Kurz. Göttingen 2000, S. 251-272.

23 Dass in Vers 7 des untersuchten Gedichts von der Wissenschaft als "Weißheit" die Rede ist, spricht m.E. nicht gegen diese Opposition; das Wort „Weißheit“ wird hier der Wissenschaft zugeschlagen und vom Greiffenberg durchaus geläufigen Begriff der Weisheit unterschieden, wie er etwa im vierten und fünften Gedicht der Geistlichen Sonnette / Lieder und Gedichte verwendet wird. Vgl. Catharina Regina von Greiffenberg: Sämtliche Werke (Anm. 21), Bd.1, S. $4 \mathrm{f}$.

24 Vgl. Catharina Regina von Greiffenberg: Des Allerheiligst- und Allerheilsamsten Leidens und Sterbens Jesu Christi Zwölf andächtige Betrachtungen. In dies.: Sämtliche Werke (Anm. 21), Bd. 9, S. 15. 
scala meditatoria die contemplatio innehat, und tatsächlich gestaltet Greiffenberg in diesen lyrischen Texten ihre aus dem meditativen Gang entsprungene Erfahrung von Inspiration und mystischer Ekstase. ${ }^{25}$ Im Gedicht artikuliert sie ihre Inspirationstopik vom „Flammen=Brunn der Seelen“, dem "Geist=Geschmak in meiner Seele kehlen", dem göttlichen „Lieb=Nectar=Thau“ als Erfahrung von Begierde, Wollust und Verzückung. ${ }^{26}$ Es ist diese mystische Gotteserfahrung, die Greiffenberg als Weisheit dem weltlichen Wissen entgegenhält und für die sie die lyrische Form wählt, weil diese nicht nur eine psychagogische Wirkung aufs Unbewusste im oben erläuterten Sinne Senecas erzeugt, sondern die gebundene Rede zugleich im hermetischen Zusammenhang eine magische Wirkung (im Sinne des alchimistischen solve et coagula) entfaltet, die Jesus im Gedicht an die Sprecherin binden soll. ${ }^{27}$ Dem gemäß heißt es in einer Apostrophe Jesu der Andächtigen Betrachtungen: „Ich kan mich nicht ersättigen / mit dir Verbindlichsten in gebundner Sprache zu reden / dich damit mir zu verbinden und anzubinden “ ${ }^{28}$ Das Gedicht hat damit für Greiffenberg eine ähnliche Funktion wie das Abendmahl, das sie als mystische unio erlebt, in der Gott für sie spürbar und in gewisser Weise auch verfügbar wird. ${ }^{29}$ So gerät Weisheit bei Greiffenberg zu einem aus der meditativen Übung hervorgehenden, zugleich hermetischen und an den Ritus des Abendmahls geknüpften religiösen Wissen von der göttlichen Allheit, das in der lyrischen „Binde=Kunst“ textuell gebannt wird. ${ }^{30}$

\section{Kindheit als episodisches Wissen (Thomas Traherne)}

Wie Louis Martz in seinem Buch The Paradise Within ausgeführt hat, spielt neben der ignatianischen Methodik der Exerzitien ab der Mitte des 17. Jahrhunderts zunehmend die weniger methodisch verfahrende, die Spuren des Göttlichen im eigenen Inneren suchende augustinische Meditation eine wichtige Rolle für die

25 Vgl. Butzer: Soliloquium (Anm. 4), S. $282 \mathrm{f}$.

26 Die Zitate entstammen dem Sonett "O JEsu meine Lieb / du Flammen=Brunn der Seelen“ aus der ersten Passionsbetrachtung (In: Greiffenberg: Sämtliche Werke [Anm. 21], Bd.9, S. 20). Vgl. dazu Conrad Wiedemann: Engel, Geist und Feuer. Zum Dichterselbstverständnis bei Johann Klaj, Catharina von Greiffenberg und Quirinus Kuhlmann. In: Literatur und Geistesgeschichte. Festgabe für Heinz Otto Burger. Hrsg. von Reinhold Grimm und Conrad Wiedemann. Berlin 1968, S. 85-109.

27 Vgl. Burkhard Dohm: Poetische Alchimie. Öffnung zur Sinnlichkeit in der Hohelied- und Bibeldichtung von der protestantischen Barockmystik bis zum Pietismus. Tübingen 2000, S. 50. - Zum hermetischen und poetikgeschichtlichen Kontext vgl. Peter Cersowsky: Magie und Dichtung. Zur deutschen und englischen Literatur des 17. Jahrhunderts. München 1990, S. 26 ff., sowie Hans-Georg Kemper: Religion und Poetik. In: Religion und Religiosität im Zeitalter des Barock. Hrsg. von Dieter Breuer. Bd. 1. Wiesbaden 1995, S. 63-92, hier S. 83 ff.

28 Catharina Regina von Greiffenberg: Der Allerheiligsten Menschwerdung, Geburt und Jugend JEsu Christi Zwölf Andächtige Betrachtungen. In dies.: Sämtliche Werke (Anm. 21), Bd.3, S. 473.

29 Vgl. Dohm: Poetische Alchimie (Anm. 27), S. 86 ff.

30 Der Titel der Poetik Sigmund von Birkens, des Mentors Greiffenbergs, der deren Dichtungsauffassung zweifellos nahe steht, lautet bezeichnenderweise Teutsche Rede-bind und DichtKunst (1679). 
religiöse Lyrik. ${ }^{31}$ Mit Hilfe dieser Übungstechnik wird eine neue Form des religiösen Wissens erzeugt, die mit den Kategorien der simplicitas und der docta ignorantia (beides Konzepte der sapientia, nicht der scientia) ${ }^{32}$ operiert. Gemäß der Meditationsauffassung Augustins ist es möglich, durch die introspektive Erforschung des eigenen Selbst und mit Unterstützung des göttlichen Lichts zu den Spuren eines vom Sündenfall noch nicht korrumpierten Menschen vorzudringen (jedenfalls wurde er im 17. Jahrhundert so verstanden). ${ }^{33}$ Ein solcher Prozess scheint sich auch in Thomas Trahernes Gedicht „Eden“ abzuspielen. Man vergleiche dazu die erste Strophe:

A learned and happy Ignorance

Divided me

From all the Vanity,

From all the Sloth, Care, Sorrow, that advance

The Madness and the Misery

Of Men. No Error, no Distraction, I

Saw cloud the Earth, or over-cast the Sky. ${ }^{34}$

Traherne spricht hier von einer "learned and [...] happy Ignorance“ (v. 1), die ihn von der "Vanity“, "Madness" und "Misery" (vv. 3/5) des postlapsalen Menschen getrennt habe, welche unter dem Zeichen von „Error“ und „Distraction“ (v. 6) stehen. Im weiteren Verlauf des Gedichts wird eine für die christliche Ideologie zentrale Korrelation zwischen Wissen und Sünde auf der einen Seite und zwischen Unwissenheit und Glück auf der anderen Seite aufgebaut; ja, das Wissen wird in einer auf den bliblischen Sündenfall rekurrierenden, zugleich aber kulturtheoretischen Argumentation an die Sterblichkeit des Menschen geknüpft, während der Sprecher die Unwissenheit der „Immortality“ (v. 14) des Paradieses zuschreibt. Die dritte Strophe listet die Eigenschaften dieses paradiesischen Zustands im Detail auf:

31 Vgl. Louis Martz: The Paradise Within. Studies in Vaughan, Traherne, and Milton. New Haven, London 1964. Daran anschließend Günter Butzer: Injizierte Himmel: die künstlichen Paradiese der Meditation (Dante, Baudelaire, Milton). In: Projizierte Himmel in der Frühen Neuzeit. Hrsg. von Jörg Jochen Berns und Thomas Rahn. Wiesbaden 2015 [i.E.].

32 Vgl. A. Speer: Art. ,Weisheit'. In: Historisches Wörterbuch der Philosophie. Hrsg. von Joachim Ritter, Karlfried Gründer und Gottfried Gabriel. Bd.12. Darmstadt 2004, Sp.371-397, hier Sp. 384.

33 Vgl. Martz: The Paradise Within (Anm. 31), S. 17-31.

34 Thomas Traherne: Eden [Text nach der Ausg. der Poems of Felicity]. In ders.: Centuries, Poems, and Thanksgivings. Hrsg. von H.M. Margoliouth. Bd. 2. Oxford 1958, S. 13/15. Trahernes Gedicht wird wegen seines Umfangs nur mit den für meine Argumentation relevanten Strophen zitiert. 
Joy, Pleasure, Beauty, Kindness, charming Lov, Sleep, Life, and Light,

Peace, Melody, my Sight

Mine Ears and Heart did fill and freely mov;

All that I saw did me delight:

The Universe was then a World of Treasure

20

To me an Universal World of Pleasure.

Die Lust, die hier insistent beschworen wird (und die übrigens auch das zentrale Charakteristikum des Paradieses bei Milton bildet), entspringt einer unkorrumpierten Sinnlichkeit, ${ }^{35}$ die eine gegenüber dem postlapsalen Wissen völlig andere Beziehung zur Welt ermöglicht, zu der man über die Meditation (wieder) Zugang erlangt. ${ }^{36}$ Die Pointe des Gedichts besteht aber darin, dass dieser Zustand der „Original Simplicity“ (v. 35) nicht oder nicht nur ein phylogenetischer, sondern zugleich ein ontogenetischer ist. Dem gemäß heißt es zu Beginn der 6. Strophe (vv. 36-39):

Those things which first his [sc. Adam's] Eden did adorn,

My Infancy

Did crown: Simplicity

Was my Protection when I first was born.

35 Entsprechend heißt es in dem Gedicht „The Præparative“ (In: Traherne: Centuries, Poems, and Thanksgivings [Anm. 34], S. 21-25): "'Tis not the Object, but the Light, / That maketh Hev'n: 'Tis a clearer Sight" (v. 57 f.). Zu dieser Wendung vom Objekt zum Modus der Wahrnehmung und zur daraus resultierenden Betonung der "experience“ vgl. James J. Balakier: Felicitous Perception as the "Organizing Form" in Thomas Traherne's Dobell Poems and Centuries. In: XVII-XVIII. Bulletin de la société d'études anglo-américaines des XVIIe et XVIIIe siècles 26 (1988), S. 53-68, hier S. 57 ff. - Dass es sich bei diesem unkorrumpierten Wahrnehmungsmodus tatsächlich um das Resultat einer "serious Meditation“ handelt, macht Trahernes Gedicht Innocence, das in unmittelbarem Zusammenhang mit Eden steht, unmissverständlich deutlich. Vgl. die zweite Strophe: „A serious Meditation did employ / My Soul within, which, taken up with Joy, / Did seem no outward thing to note, but fly / All Objects that do feed the Ey: // Which it those very Objects did / Admire, and prize, and prais, and lov, / Which in their Glory most are hid; / Which Presence only doth remov; // Their constant daily Presence I / Rejoicing at did see; / And that which takes them from the Ey / Of others, offer'd them to me“ (In: Traherne: Centuries, Poems, and Thanksgivings [Anm. 34], S. 17).

36 Im Hintergrund steht natürlich die neuplatonisch-christliche Unterscheidung zwischen den äußeren, weltlichen und den inneren, geistlichen Sinnen (vgl. Karl Rahner: Die geistlichen Sinne nach Origenes. In ders.: Schriften zur Theologie. Bd. 12: Theologie aus Erfahrung des Geistes. Bearb. von Karl-Heinz Neufeld SJ. Zürich, Einsiedeln, Köln 1975, S. 111-136) - welch letztere ganz im Sinne Augustins dem ,inneren Paradies' zugeordnet werden. Auf diese Auffassung greift auch Ignatius mit seiner Technik der applicatio sensuum zurück (vgl. Hugo Rahner: Die „Anwendung der Sinne“ in der Betrachtungsmethode des hl. Ignatius v. Loyola. In: Zeitschrift für katholische Theologie 79 [1957], S. 434-456, und Fridolin Marxer: Die inneren geistlichen Sinne. Ein Beitrag zur Deutung ignatianischer Mystik. Freiburg, Basel, Wien 1963). 
Diese Verknüpfung von Paradies und Kindheit und deren Semantisierung als einfältig und unschuldig im Sinne des zeitgenössischen Neuplatonismus ${ }^{37}$ stellt zugleich eine frühe Formulierung der modernen Kindheitsauffassung dar, wie sie dann im 18. Jahrhundert Rousseau paradigmatisch vertreten hat. ${ }^{38}$ Sie impliziert, dass der Meditant über die Erinnerung der eigenen Kindheit einen Weg zurück ins Paradies findet und derart durch eine unkorrumpierte Sinnlichkeit - Traherne spricht vom „Infant-Ey“39 - ein verschüttetes Wissen aktualisiert, das dem profanen Wissen der Erwachsenen nicht mehr zugänglich ist. ${ }^{40}$ Das so erzeugte Wissen wird in der siebten und letzten Strophe als "Great", "Divine", "Pure“, „fair and sweet" und „tru“ (vv. 43-45) bezeichnet und ermöglicht den Zugang zu den "glorious Wonders of the DEITY" (v. 49), die durch weltliches Wissen nicht erfasst werden können.

Der Soziologe Alois Hahn hat in Bezug auf die religiösen Übungen von „Biographiegeneratoren" gesprochen. ${ }^{41}$ Obwohl er vornehmlich die katholische Tradition der Generalbeichte und der direction spirituelle im Sinne François de Sales' im Blick hat, können die protestantischen Techniken der Selbsterforschung und der Autobiografik einem ähnlichen Effekt zugeordnet werden, der zwar zunächst noch anderen Zielen wie der Suche nach den signa electionis dient, aber dennoch ein biografisches Wissen produziert, das man im Anschluss an die Gedächtnis-

37 Alison J. Sherrington spricht von „the Neo-Platonic theory of the soul's original purity and the consequent innocence of childhood" (Mystical Symbolism in the poetry of Thomas Traherne. St. Lucia, Queensland 1970, S. 70). Tahernes Ziel ist dementsprechend die meditative Rückgewinnung dieses Zustands ursprünglicher Unschuld.

38 "His theological disposition is to return to the paradise of prelapsarian Eden. In terms of a Christian Platonism, he yearns, Wordsworth-like, for a recovery of childhood innocence with its proximity to preexistent purity" (Barry Spurr: Felicity Incarnate: Rediscovering Thomas Traherne. In: Discovering and (Re)Covering the Seventeenth Century Religious Lyric. Hrsg. von Eugene R. Cunnar und Jeffrey Johnson. Pittsburgh 2001, S. 273-289, hier S. 285). Wie später Rousseau, führt auch Traherne in seinem Gedicht The Apostacy die Korruption des ursprünglich unschuldigen und reinen Kindes auf den Einfluss der (erwachsenen) Zivilisation zurück und resümiert: „All Bliss / Consists in this, / To do as Adam did; / And not to know those superficial Joys / Which were from him in Eden hid" (vv. 37-41; in: Traherne: Centuries, Poems, and Thanksgivings [Anm. 34], S. 95-97, hier S. 96).

39 Vgl. das Gedicht "An Infant-Ey“, das den Verlust des unschuldigen Wahrnehmungsmodus der Kindheit beklagt (in: Traherne: Centuries, Poems, and Thanksgivings [Anm. 34], S. 86 f.). Die Poems of Felicity sollten laut Sherrington (Mystical Symbolism [Anm. 37], S. 79) ursprünglich den Untertitel „,Divine Reflections' On The Native Objects of ,An Infant-Ey“" tragen.

40 Vgl. das Eingangsgedicht der Sammlung, „The Salutation“ (In: Traherne: Centuries, Poems, and Thanksgivings [Anm. 34], S. 4/6), das - allerdings nur in der Manuskript-Fassung, die Strophe wurde in den Poems of Felicity gestrichen! - deutlich macht, dass für das Kind die Welt selbst zum Paradies wird: „Long time before / I in my Mothers Womb was born, / A GOD preparing did this Glorious Store, / The World for me adorne. / Into this Eden so Divine and fair, / So Wide and Bright, I com his Son and Heir" (vv. 31-36) - als ob der Sündenfall nie stattgefunden hätte.

41 Vgl. Alois Hahn: Zur Soziologie der Beichte und anderer Formen institutionalisierter Bekenntnisse: Selbstthematisierung und Zivilisationsprozeß. In: Kölner Zeitschrift für Soziologie und Sozialpsychologie 34 (1982), S. 407-434. 
forschung episodisch nennen könnte, weil es dem autobiografischen Gedächtnis angehört, dessen Besonderheit darin besteht, deklaratives Wissen über das eigene Leben mit einer besonderen Intensität emotionaler Bewertung zu verknüpfen. ${ }^{42}$ Dieses episodische Wissen hat, wie allgemein anerkannt wird, seinen Ursprung in religiösen Übungstechniken und kann daher vor allem für das späte 17. und frühe 18. Jahrhundert als religiöses Wissen angesprochen werden, auch wenn es in seiner Bedeutung weit darüber hinaus reicht. ${ }^{43}$ Sein Kennzeichen ist - noch vor jeder biografischen Narration - eine dem Episodischen eigene Situativität, wie sie etwa bei Brockes zu finden ist. Dem gemäß wäre die Struktur der später (von Hegel und Dilthey) so genannten Gelegenheits- und Erlebnislyrik derselben episodischen Wissensform zuzuordnen, die in der augustinischen Selbsterforschung ihren Ursprung hat. ${ }^{44}$ Darüber hinaus wird der von Traherne exponierte und mit dem episodischen Wissen unlösbar verknüpfte unkorrumpierte Wahrnehmungsmodus - im Sinne einer tiefergehenden, ganzheitlichen, unschuldigen Auffassung der Welt - zu einem Spezifikum der Lyrik seit dem 18. Jahrhundert werden.

\section{Selbstthematisierung als Gestimmtheit (Andreas Gryphius)}

Neben der Erzeugung von emotional gefärbtem episodischen Wissen ermöglicht die religiöse Lyrik eine gleichfalls in meditativer Übung verankerte Selbstbetrachtung und Selbstbeobachtung, die in der frühen Neuzeit zwar nicht erfunden wurde, aber über die Frömmigkeitsbewegungen größere Teile der Bevölkerung erfasst hat. ${ }^{45}$ Die Verpflichtung zur Selbstbetrachtung und Selbstanalyse äußert sich - um nur zwei prominente Beispiele zu nennen - in der zunehmenden Differenziertheit der Beichtmanuale ebenso wie in den um die Wende vom 17. zum 18. Jahrhundert auch auf den bürgerlichen Verkehr übergreifenden, zunächst aber religiös fundierten und einer ausgefeilten Topik folgenden Anleitungen zur Selbst- und Fremderkenntnis. ${ }^{46}$ Der Vollzug dieser neuen Form der Selbstbetrachtung wird aber insbesondere in der religiösen Lyrik darstellbar. Hier finden jene Prozesse der Spaltung, Objektivierung und Reflexion des Selbst statt, die ein ganz neues, nicht-episodisches Wissen vom Ich generieren, dass man Ende

42 Vgl. Hans-Joachim Markowitsch: Dem Gedächtnis auf der Spur. Vom Erinnern und Vergessen. Darmstadt 2002, S. 131. Ausführlich zum emotionalen Gedächtnis vgl. Harald Welzer: Das kommunikative Gedächtnis. Eine Theorie der Erinnerung. München 2002, S. 111-137.

43 Traherne vermengt offensichtlich einen religiös-philosophischen Begriff der Gotteskindschaft mit einem autobiografischen Kindheitsbegriff und legitimiert dadurch ein episodisches Wissen, das ansonsten in der frühen Neuzeit kein Interesse beanspruchen dürfte.

44 Vgl. Günter Butzer: Schicksale des lyrischen Ich. In: Sprache und Literatur 30/2 (1999), S. 3-15.

45 Vgl. Stephanie Wodianka: Mitleid, innwendige Höllenpein, Selbstentfremdung und Anspruch an sich selbst. Das meditative Gewissen in der Lyrik des 17. Jahrhunderts. In: Sprache und Literatur 30/2 (1999), S. 16-27.

46 Vgl. Günter Butzer: Psychagogik in der Frühen Neuzeit. In: Diskurse der Gelehrtenkultur in der Frühen Neuzeit. Ein Handbuch. Hrsg. von Herbert Jaumann. Berlin, New York 2011, S. 715-746. 
des 18. Jahrhunderts als Selbstbewusstsein bezeichnen wird. Zu ihren philosophischen Programmschriften im 17. Jahrhundert gehören Descartes' Meditationes de prima philosophia, welche, wie Manfred Riedel gezeigt hat, eng mit der mittelalterlichen Meditationspraxis verflochten, aber nunmehr auf die Ausbildung eines transzendentalen Subjekts ausgerichtet sind. ${ }^{47}$ Den vornehmlichen Ort der Selbstbetrachtung bildet im 17. Jahrhundert aber nicht die philosophische Meditation im Sinne Descartes', sondern die lyrische meditatio mortis, die die „vanitasund memento mori-Topik als Selbstthematisierung " ${ }^{48}$ inszeniert. Als Beispiel kann Andreas Gryphius' bekanntes Sonett „An sich selbst“ dienen:

Mir grauet vor mir selbst ; mir zittern alle glieder,

Wenn ich die lipp' und nas' und beider augen klufft,

Die blind vom wachen sind, des athems schwere lufft

Betracht' und die nun schon erstorbnen augen-lieder.

Die zunge, schwartz vom brand, fällt mit den worten nieder 5

Und lallt, ich weiß nicht was; die müde seele rufft

Dem großen tröster zu, das fleisch reucht nach der grufft,

Die ärtzte lassen mich, die schmertzen kommen wieder.

Mein cörper ist nicht mehr als adern, fell, und bein.

Das sitzen ist mein tod, das liegen meine pein.

Die schenckel haben selbst nun träger wol vonnöthen.

Was ist der hohe ruhm und jugend, ehr und kunst?

Wenn diese stunde kommt, wird alles rauch und dunst,

Und eine noth muss uns mit allem vorsatz tödten. ${ }^{49}$

In diesem Text wird die religiöse Erinnerung an die Vergänglichkeit und Sterblichkeit des Menschen in Richtung auf eine anatomische Selbstzergliederung überschritten. Im Modus der objektivierenden Selbstbeobachtung vollzieht der Sprecher en detail den eigenen körperlichen Verfall nach. Der sezierende Blick diagnostiziert einen pathologischen Zustand, der als Selbstentfremdung erfahren wird. Die körperlichen Kennzeichen der Identität, Gesicht und Stimme, sind der Kontrolle des Ich entzogen; das Gesicht geht in die facies hippocratica, der Leib ins corpus mortuum über. Erst in der Schlusswendung des zweiten Terzetts wird die vanitas-Topik explizit realisiert, zuvor ergeht sich der Sprecher in einer Beschreibung, die durch den Titel als Selbstreflexion im Wortsinn ausgewiesen ist. ${ }^{50}$ Denn Selbstanrede, wie sie etwa Fleming in seinem Gedicht „An sich“ prak-

47 Manfred Riedel: Grund und Abgrund der Subjektivität. Nachcartesianische Meditationen. In: Deutsche Vierteljahrsschrift für Literaturwissenschaft und Geistesgeschichte 61 (1987), S. 377-398.

48 Stephanie Wodianka: Betrachtungen des Todes. Formen und Funktionen der ,meditatio mortis' in der europäischen Literatur des 17. Jahrhunderts. Tübingen 2004, S. 210.

49 Andreas Gryphius: An sich selbst. In ders.: Werke in drei Bänden mit Ergänzungsband. Hrsg. von Hermann Palm. Bd. 3. Hildesheim 1961, S. 125.

50 Wolfram Mauser greift demnach zu kurz, wenn er "das Phänomen Krankheit zum Grundbestand der Argumentation gegen die Sündhaftigkeit des Menschen“ rechnet und damit 
tiziert, findet sich bei Gryphius allenfalls in der letzten Strophe, die allerdings bereits, wie erwähnt, wieder nach topischer Verallgemeinerung strebt (markiert durch den Plural der ersten Person im letzten Vers). Das übrige Gedicht stellt eine distanzierte Betrachtung dar, welche sogar die "müde Seele“, die „[d]em grossen Tröster zue[ruft]“ (v. 6 f.), noch in der dritten Person erfasst. Die christliche, auf den Bußpsalmen beruhende Korrelation von Krankheit und Sünde ist hier nur noch indirekt zu erkennen, an ihre Stelle tritt eine vergegenständlichte, über weite Strecken deskriptive Selbstwahrnehmung, die die Distanz des Ich gegenüber sich selbst in den Vordergrund rückt. ${ }^{51}$ Wo sich Fleming im stoischen Paradigma auf die Stabilität der res cogitans zurückzieht,, 52 setzt sich Gryphius der Selbstentfremdung in der res extensa aus. Und aus diesem Zustand der Nicht-Identität entsteht eine Gestimmtheit, die hier als Grauen erfahren wird.

Diese Gestimmtheit des Ich scheint mir, als genuines Produkt meditativer Selbstbetrachtung, eine eigenständige Wissensform $\mathrm{zu}$ bilden. ${ }^{53}$ Sie ist nicht durch die dihairetische Topik der Manuale zur Selbstzergliederung vorgeprägt, sondern geht bei Gryphius aus einer Störung des Selbstbewusstseins hervor, die sich als Verwirrung des Ich äußert. „MJr ist ich weis nicht wie“, heißt es im Eingang des Gryphschen Sonetts "Threnen in Schwerer Kranckheit" , ${ }^{44}$ und gerade diese Divergenz zwischen der Wahrnehmung eines subjektiven Zustands einerseits (,MJr ist") und der Unmöglichkeit des kognitiven Wissens darüber andererseits (,ich weis nicht wie $\left.{ }^{\prime \prime}\right)$ erweist sich als produktiv für ein Wissen um die Befindlichkeit des Ich. ${ }^{55}$ Die Bestürmung der Seele, von der in Vers 7 des Gedichts die Rede ist („Die seele wird bestürmt, gleich wie die see im Mertzen“), meint daher mehr als nur die perturbatio animi der affektiven Überwältigung; sie bezeichnet eine Gestimmtheit, die trotz bzw. in ihrer Negativität ein Wissen über sich selbst vermittelt. „[...] vnd was sind vnser thaten?", fragt der Sprecher am Ende und gibt zur Antwort: „Ein mitt viel herber angst durchaus vermischter

den topischen Charakter dieses und ähnlicher Gedichte betont (vgl. Wolfram Mauser: Dichtung, Religion und Gesellschaft im 17. Jahrhundert. Die ,Sonette' des Andreas Gryphius. München 1976, S. 143).

51 Vgl. Wodianka: Betrachtungen des Todes (Anm. 48), S. $220 \mathrm{ff}$.

52 Vgl. Wilhelm Kühlmann: Selbstbehauptung und Selbstdisziplin. Zu Paul Flemings An Sich. In: Gedichte und Interpretationen. Bd.1: Renaissance und Barock. Hrsg. von Volker Meid. Stuttgart 1982, S. 160-166.

$53 \mathrm{Zu}$,Stimmung' und ,Gestimmtheit' als Wissenformen vgl. Karen Gloy: Von der Weisheit zur Wissenschaft. Eine Genealogie und Typologie der Wissensformen. Freiburg, München 2007, S. $139 \mathrm{ff}$.

54 Vgl. Andreas Gryphius: Threnen in Schwerer Kranckheit. In ders.: Werke in drei Bänden mit Ergänzungsband (Anm. 49), S. $123 \mathrm{f}$.

55 Zum Begriff der Befindlichkeit, der in enger Beziehung zu dem der Gestimmtheit steht, vgl. Martin Heidegger: Sein und Zeit. 16. Aufl. Tübingen 1986, S. 134 ff. Dazu Rosmarie ParadiseDahinden: Da-sein als Befindlichkeit. In: Weisheit - Wissen - Information (Anm. 18), S. 141150 . 
traum" (v. 13 f.). ${ }^{56}$ Auch wenn es so klingen mag: Ich will diese Befunde nicht modernistisch uminterpretieren, sondern lediglich darauf aufmerksam machen, dass in der meditativen Selbstthematisierung neben der topischen Erfassung von Sünde und Vergänglichkeit ein Wissen um die existenzielle Gestimmtheit des Ich erzeugt wird, das sich nicht nur als wegweisend für das lyrische Genre ab der Mitte des 18. Jahrhunderts erweisen wird, sondern zudem ein Selbstverhältnis konstituiert, das um 1800 unter dem Begriff des Selbstgefühls eine Antwort auf die Aporien des Selbstbewusstseins zu geben sucht. ${ }^{57}$

\section{Schluss}

Religiöses Wissen, wie es sich aus der Sicht der meditativen Lyrik darstellt, ist stets gebunden an ein theologisches Wissen, an das die Texte durch die Verwendung von loci communes anknüpfen. Insofern spielt deklaratives Wissen eine wichtige Rolle in den Gedichten, was angesichts der topischen Verfasstheit frühneuzeitlicher Dichtung niemand verwundern wird. ${ }^{58}$ Bei diesem Befund und der daraus resultierenden Identifikation theologischer Wissenselemente in poetischen Texten sollte man jedoch nicht stehen bleiben. Zieht man neben der kognitiv-deklarativen auch anderen Wissensformen in Betracht, erweist sich die meditative Lyrik als äußerst produktiv im Hinblick auf die Generierung von Wissen, das insbesondere im prozeduralen, praktischen, episodisch-emotiven und stimmungshaften Bereich zu lokalisieren ist. ${ }^{59}$ Dabei wirken die hier unterschie-

56 Insofern erscheint es problematisch, das Gedicht vom Ende her zu lesen, wie dies Wolfram Mauser paradigmatisch und wirkungsvoll getan hat. Vgl. Wolfram Mauser: Was ist dies Leben doch? Zum Sonett Thränen in schwerer Kranckheit von Andreas Gryphius. In: Meid: Gedichte und Interpretationen (Anm. 52), S. 223-230.

57 Vgl. Manfred Frank: Selbstgefühl. Eine historisch-systematische Erkundung. Frankfurt/ Main 2002.

58 Der Begriff ,deklaratives Wissen' ist wiederum gebildet in Analogie zum Begriff des ,deklarativen Gedächtnisses' und umfasst „,all das Wissen [...], das wir bewußt reproduzieren können" (Roth: Das Gehirn und seine Wirklichkeit [Anm. 16], S. 209). Markowitsch bezeichnet das deklarative Gedächtnis auch als „Wissenssystem“ (Markowitsch: Dem Gedächtnis auf der Spur [Anm. 42], S. 88 f.).

59 Der Beitrag versteht sich demnach als ein Plädoyer, der in den Kognitions- wie in den Kulturwissenschaften in den vergangenen Jahrzehnten vollzogenen Ausdifferenzierung des Gedächtnisses eine entsprechende Ausdifferenzierung des Wissens an die Seite zu stellen. Derzeit kurrente Auffassungen wie Michael Titzmanns Konzeption des ,kulturellen Wissens' (vgl. Michael Titzmann: Kulturelles Wissen - Diskurs - Denksystem. Zu einigen Grundbegriffen der Literaturgeschichtsschreibung. In: Zeitschrift für französische Sprache und Literatur 99 [1989], S. 47-61), Joseph Vogls Entwurf einer ,Poetologie des Wissens' (vgl. Joseph Vogl: Poetologie des Wissens. In: Einführung in die Kulturwissenschaft. Hrsg. von Harun Maye und Leander Scholz. München 2011, S. 49-71) oder das Konzept der ,Wissenskulturen' (vgl. Wolfgang Detel: Wissenskulturen und universelle Rationalität. In: Wissenskulturen. Über die Erzeugung und Weitergabe von Wissen. Hrsg. von Johannes Fried und Michael Stolleis. Frankfurt/Main, New York 2009, S. 181-214) weisen zwar in ihrer Überwindung des rein szientifischen Wissensbegriffs in die richtige Richtung, bedürfen aber einer zugleich phänomenologischen und kognitionswissenschaftlichen Fundierung und Ausarbeitung, wie sie Karen Gloy erstmals unternommen hat (vgl. Gloy: Von der Weisheit 
denen Wissensformen im konkreten Text häufig zusammen, was keinen Zufall darstellt, handelt es sich doch um eine Kohärenz übender Techniken, die nur auf der Ebene der Typologie strikt auseinanderzuhalten sind.

Karen Gloy hat ein Drei-Schichten-Modell historischer Wissensformen vorgeschlagen, das im Übrigen von der kognitionswissenschaftlichen Forschung weitgehend bestätigt wird. Dieses unterscheidet eine mental-begriffliche Ebene des expliziten, deklarativen Wissens von einer handlungsbezogenen Ebene, die ein prozedurales, implizites Erfahrungswissen beinhaltet, und schließlich einer emotional-vitalen Ebene der Gestimmtheit und Befindlichkeit, die ein Wissen hervorbringt, das womöglich bis zu den Instinkten reicht. Dabei wird die letztere Schicht als präreflexiv und präkognitiv gekennzeichnet; bei ihr geht es „weder um ein explizites begriffliches Verstehen [wie in der deklarativen Schicht, G.B.] noch um ein praktisch-pragmatisches Wissen [wie in der prozeduralen Schicht, G.B.], sondern um ein affektives, emotionales Betroffensein, das den ganzen physisch-psychisch-geistigen Menschen einschließlich seiner Leiblichkeit und Befindlichkeit betrifft" ${ }^{\prime 60} \mathrm{Zu}$ berücksichtigen ist freilich, dass diese drei Ebenen sich in stetiger Interaktion befinden. So betont beispielsweise der Neurobiologe Gerhard Roth, dass in unbeschädigten Gehirnen „Kognition [...] nicht ohne Emotion möglich “61 sei und dass prozedurale Prozesse weder ohne emotive Bewertung noch ohne kognitive Anteile auskommen, von denen sie im Lern- und Erfahrungs- (in unserem Kontext: im religiösen Übungs-)prozess in der Regel ihren Ausgang genommen haben (sofern sie nicht rein instinktiv sind).

Zwar liegt Gloys Schichten-Modell des Wissens weder eine wertende noch eine entwicklungsgeschichtliche Priorisierung zu Grunde, gleichwohl können interne Relationen von Dominanz und Subordination zur Beschreibung historischer Wissensformationen genutzt werden. In diesem Sinn würde die Betonung des prozeduralen, emotionalen und praktischen sowie des von Gloy nicht eigens erwähnten episodisch-autobiografischen Wissens in der religiösen Lyrik ein Ge-

zur Wissenschaft [Anm.53]). Sie kann dabei an die phänomenologische Erweiterung des Wissensbegriffs in der Wissenssoziologie anknüpfen, die Berger und Luckmann bereits in den 1960er Jahren vollzogen haben (vgl. Peter L. Berger und Thomas Luckmann: Die gesellschaftliche Konstruktion der Wirklichkeit. Eine Theorie der Wissenssoziologie. Übers. von Monika Plessner. Frankfurt/Main 1980 [engl. Erstausg. 1966]). Vgl. die ähnliche Intention einer Öffnung des Wissensbegriffs hin auf „ein spezifisches Wissen der Literatur “ und eine „literarische Epistemologie“ bei Bernadette Malinowski und Michael Ostheimer: Ödipus zum Beispiel: Zur Komparatistik als Wissenspoetik. In: Theorien der Literatur. Grundlagen und Perspektiven. Hrsg. von Günter Butzer und Hubert Zapf. Bd. 6. Tübingen, Basel 2013, S. 9-30, hier S. 26. In eine vergleichbare Richtung zielen die Arbeiten von Ottmar Ette (z. B. Ottmar Ette: ÜberLebenswissen. Die Aufgabe der Philologie. Berlin 2004; Ders.: ZusammenLebensWissen. List, Last und Lust literarischer Konvivenz im globalen Maßstab. Berlin 2010). Weitgehend unberührt von solchen Überlegungen präsentiert sich der Band: Literatur und Wissen. Theoretisch-methodische Zugänge. Hg. von Tilmann Köppe. Berlin, New York 2010.

60 Gloy: Einführung: Die verschiedenen Wissenstypen (Anm. 18), S. 15.

61 Roth: Das Gehirn und seine Wirklichkeit (Anm. 16), S. 211. 
gengewicht schaffen zur verstärkten Favorisierung des deklarativen Wissens in der Kultur der frühen Neuzeit. Dass diese Favorisierung, die mit der Ausbildung des modernen Wissenschaftsbegriffs korreliert, an die Erfindung und Verbreitung der Drucktechnik gebunden ist, steht außer Frage, obschon sie sich, wie etwa Ivan Illich gezeigt hat, bereits seit dem hohen Mittelalter abgezeichnet hat. ${ }^{62}$ Mit ihr verknüpft ist eine weitgehende Autonomisierung und Objektivation des Wissens, die mit der "Trennung der theoretischen Sphäre von der ethischen "63 einhergeht und gegen die das religiöse Wissen der frühneuzeitlichen Lyrik opponiert. Durch die Fundierung des Wissens in der Übung gewährleistet die religiöse Lyrik eine Einheit von Kognition, Emotion und Handlung, die der von Ulrike Bollmann eingeforderten Bedeutung der Leiblichkeit für das Problem des Wissens gerecht wird. ${ }^{64}$ Rudolf zur Lippe hat mit ähnlicher Intention von einem "leibhaftige[n] Wissen“ gesprochen und ihm einen mimetischen Charakter zugeschrieben; es ist nicht bzw. nicht vollständig explizierbar, sondern kann „,nur im handelnden Vollzug geäußert werden ${ }^{\prime 6}{ }^{65}$ Ein solches mimetisches Wissen scheint mir die religiöse Lyrik der frühen Neuzeit hervorzubringen und gegen die Verwissenschaftlichung nicht nur des Glaubens ins Feld zu führen. Für dieses Wissen gilt der (womöglich im schlechten Sinn rhetorische) Satz Augustins: „,si nemo ex me quaerat, scio; si quaerenti explicare velim, nescio". 66

62 Vgl. Ivan Illich: Im Weinberg des Textes. Als das Schriftbild der Moderne entstand. Ein Kommentar zu Hugos „Didascalicon“. Übers. von Y. Eriksson-Kuchenbuch. Frankfurt/Main 1991.

63 Gloy: Von der Weisheit zur Wissenschaft (Anm. 53), S. 38.

$64 \mathrm{Vgl}$. Ulrike Bollmann: Wandlungen neuzeitlichen Wissens. Historisch-systematische Analysen aus pädagogischer Sicht. Würzburg 2001, S. $248 \mathrm{ff}$.

65 Vgl. Rudolf zur Lippe: Epistemische und andere Formen des Wissens. In: Weisheit - Wissen - Information (Anm. 18), S. 23-38, hier S. 27.

66 Augustinus: Conf. 11, 14, 17. 
(C) 2015, Otto Harrassowitz GmbH \& Co. KG, Wiesbaden ISBN Print: 9783447104975 — ISBN E-Book: 9783447194136 


\title{
Lyrische Inszenierung optischer Evidenz bei Spee, Greiffenberg, Brockes
}

\author{
Franz M. Eybl
}

"Ich sahe mit betrachtendem Gemüthe“: Im Eingangsvers von Brockes' berühmter „Kirschblüte“ verweisen "Sehen“ und „Betrachten“ auf zwei im Zuge der Aufklärung immer stärker als Antagonismen geschärfte Wissensbestände, einerseits ein anthropologisches bzw. medizinisches Wissen um die Physik des Sehens und seine Physiologie, andererseits ein theologischer bzw. philosophischer Wissensbestand, der die Gotthaltigkeit der Welt ebenso umfasst wie die Frage nach deren Erkennbarkeit. „Ich sahe mit betrachtendem Gemüthe“ überspielt einen epistemologischen Widerspruch. Mit diesen Eingangsworten Brockes' sind Sachverhalte angesprochen, deren Divergenz im Wahrnehmungsmodell der Frühen Neuzeit eine viel problematischere Geschichte aufweist als es die harmlos beiordnende Formulierung des Hamburger Senators ausstellt. Insofern ist bereits der erste Vers mehr als der "pleonastisch-rationalistische Eingang“ ${ }^{1}$ zum Kirschblütengedicht, er rückt vielmehr die programmatische und problematische Koppelung der Wissensbereiche um Sinnesleistung und Betrachtung ins Bewusstsein.

Der physiologische Wissensbestand betrifft die naturwissenschaftliche Konzeption der Sinne und insbesondere des Gesichtssinns. Im optischen Modell der Humoralpathologie war das Auge als Relais winziger Korpuskeln gedacht, die ausgesendet bzw. aufgefangen und mittels der den Körper steuernden Säfte dessen kognitiver Verarbeitung zugeführt werden. Dieses auf Galen und Hippokrates beruhende Modell spendete der Literatur den ganzen weiten Bereich jener in der Liebeslyrik massiv zur Wirkung gelangenden Blicke, etwa der tödlich durchbohrenden Blitze bei Hofmannswaldau: „Ein blick/ der blitze führt und männer niederleget“ („Beschreibung vollkommener Schönheit“), aber auch in Brand setzen kann: „Mein Liecht entzünde mich mit deiner Augen Brunst“, schreibt Opitz nach Ronsard, ${ }^{2}$ oder, in einem geistlichen Gedicht über die Teile des Körpers, in

1 Hans-Georg Kemper: Gottebenbildlichkeit und Naturnachahmung im Säkularisationsprozeß. Problemgeschichtliche Studien zur deutschen Lyrik in Barock und Aufklärung. Bd.1. Tübingen 1981, S.345; vgl. insgesamt die einlässliche, vor allem an der hermetischen Tradition der Naturauslegung interessierte Interpretation des Gedichts S.343-354. - Zu Brockes' Hermetismus vgl. auch ders.: Deutsche Lyrik der frühen Neuzeit. Tübingen 1991, Bd. 5/I: Aufklärung und Pietismus, S. 114 f.; Bd. 5/II: Frühaufklärung, S. 60 f., 74 u.ö.

2 Martin Opitz: Ich wil diß halbe mich/ was wir den Cörper nennen. In ders.: Weltliche Poemata, 1644, Faks. Neudr. Hrsg. von Erich Trunz. Tübingen 1975, Sonnet Nr. XXXV, S. 378; das Gedicht übersetzt Ronsards Sonett ",Je veus brusler pour m'en voler aux cieux“. 
dem Opitz auch an Galen erinnert: „Sie sind der Sinnen Bild/ der Spiegel vnd das Liecht/ Darbey die Liebe pflegt jhr Fewer anzuzünden/ Der Weg/ durch den sie sich kan in das Hertze finden ${ }^{\prime 3}$ Der Blick der Augen ist ein Beschuss:

Wenn nun zwei Paar Augen sich gegenseitig fixieren, so beschießen sie sich gegenseitig mit Lichtpfeilen und setzen auf diese Weise mehrere physiologische Transformationen in Gang [...] Bei ihrem Eintritt in den Körper verwandeln sich die visualisierten Lebensgeister in das Blut zurück, aus dem sie geschaffen sind. Sie ,verdicken' sich, heißt es, und prägen ihre Qualität in das fremde Herz ein. ${ }^{4}$

Die Intro- bzw. Extramissionstheorien des Auges spielen sowohl für die Barocklyrik wie noch für Brockes eine nicht unbeträchtliche Rolle ${ }^{5}$ und bleiben neben neueren physiologischen Modellen des Sehens bis ins 18. Jahrhundert hinein in Geltung. Hervorzuheben bleibt die gegenüber den Vorgängerepochen überragende frühneuzeitliche Rolle des Sehsinns insgesamt, der seine Vorrangstellung mit den Instrumentarien des Mikroskops wie auch des Fernrohrs in beide Dimensionen des mit freiem Auge nicht mehr Sichtbaren ausgedehnt hat. Diese Dominanz kann als zeittypischer optischer Quantensprung ${ }^{6}$ mit dem Begriff des „skopischen Regimes ${ }^{\prime 7}$ bezeichnet werden, ein kulturelles Dispositiv, das Raumwahrnehmung, Zentralperspektive, Selbstinszenierung und Beobachtungstechniken neu justierte und damit bestimmte neue Formen von Evidenz ermöglichte.

3 Martin Opitz: Auff den Anfang deß 1621. Jahrs. In ders.: Geistliche Poemata, 1638, Faks. Neudr. Hrsg. von Erich Trunz. Tübingen 1966, S. 272-278, hier S. 274. Das Neujahrsgedicht gibt eine Beschreibung des menschlichen Körpers und nennt S. 276 Galen.

4 Albrecht Koschorke: Körperströme und Schriftverkehr. Mediologie des 18. Jahrhunderts. München 1999, S. 118. - Vgl. auch Franz M. Eybl: Vom Blick zur Brunst, vom Schimpf zum Schlag. Körpersteuerung bei Grimmelshausen und Beer. In: Simpliciana 31 (2009), S. $273-$ 287.

5 Vgl. Wilhelm Kühlmann und Robert Seidel: Askese oder Augenlust? Sinnesvermögen und Sinnlichkeit bei Jakob Balde SJ und Barthold Heinrich Brockes. In: Iliaster. Literatur und Naturkunde in der Frühen Neuzeit. Festgabe für Joachim Telle zum 60. Geburtstag. Hrsg. von Wilhelm Kühlmann und Wolf-Dieter Müller-Jahncke. Heidelberg 1999, S. 131-166, hier S. 139 f. für Balde und S. 154 über die noch im 18. Jh. beobachtbare „Vielzahl kursierender Theorien" des Sehens. Zu diesem Kontext auch Karl Richter: Teleskop und Mikroskop in Brockes' Irdischem Vergnügen in Gott. In: Prägnanter Moment. Studien zur deutschen Literatur der Aufklärung und Klassik. Festschrift für Hans-Jürgen Schings. Hrsg. von PeterAndré Alt u. a., Würzburg 2002, S.3-17, hier S. 8 f.

6 Robert Jütte: Augenlob - oder die (Neu-)Bewertung des Sehsinns in der Frühen Neuzeit. In: Evidentia. Reichweiten visueller Wahrnehmung in der Frühen Neuzeit. Hrsg. von Gabriele Wimböck, Karin Leonhard und Markus Friedrich. Berlin u. a. 2007, S. 39-56, hier S. 42.

7 Der Begriff stammt von Christian Metz und wanderte über die Fassung von Martin Jay in die deutschsprachige Forschungsdiskussion ein. Christian Metz: The Imaginary Signifyer: Psychoanalysis and the Cinema [zuerst frz. 1977]. In: Der imaginäre Signifikant. Psychoanalyse und Kino. Münster 2000, dort als „Das skopische Kino-Regime“ im Abschnitt „Der imaginäre Signifikant", S. 56 ff. - Martin Jay: Scopic Regimes of Modernity. In: Vision and Visuality. Hrsg. von Hal Foster. Seattle 1988, S.3-23; online: http://beauty.gmu.edu/AVT307/ AVT307-001/martin\%20jay\%20vision\%20and\%20visuality\%20copy.pdf (4.1.2015). 
Daneben bleibt der theologische Wissensbestand die Bezugsgröße des Denkens und Forschens, wobei in diesem Bereich eine zwischen Theorie und Praxis angesiedelte religiöse Technik der Weltannäherung belangreich wurde, die wir als Meditation und Betrachtung kennen, mit Akzenten auf den Körperleistungen von phantasia bzw. visus. Sie ist Theorie, insofern sie auf Wahrnehmungs- und Imaginationskonzepten beruht, die eine Abfolge von Sinneseindruck, verstandesgemäßer Beurteilung und verhaltensorientierter Willensleistung ansetzen, in einem input-output-Modell, das auf Augustinus zurückgeht und für die Frühe Neuzeit weitgehend verbindlich blieb - Philipp Melanchthon etwa verwendet in De anima ein Seelenmodell, „das die Bewegungsimpulse der Affekte durch den urteilenden Verstand und den auswählenden Willen zu lenken versteht. ${ }^{8}$ Die ignatianischen Exercitia spiritualia von 1548 (Ejercicios espirituales, 1541) beginnen mit der Konzentration auf einen Gegenstand oder ein Thema (argumentum), sie entwerfen dann eine Raumvorstellung (compositio loci), konzentrieren sich auf die angemessene Empfindung und verarbeiten dann die einzelnen Gesichts-Punkte, um zuletzt in ein Gebet einzutreten, als colloquium mit Gott. Auf dieser Grundlage entwickeln sich Theorie und Praxis der in der frühneuzeitlichen Literatur so mächtigen Funktion der Meditation und Erbauung. ${ }^{9}$

Die epochenspezifische Spannung zwischen diesen frühneuzeitlichen Wissensfeldern, die einander auch wechselseitig bedingen, lässt sich mit dem Konzept der Evidenz gut beschreiben. Denn als drittes steht die zwischen den Wissensbereichen und dem lesenden Publikum vermittelnde sprachlich-diskursive Inszenierung in Frage, die poetische Gestaltung durch die Dichter unter jeweils differenzierten ästhetischen Rahmenbedingungen. Die Rhetorik vermittelt das Einleuchtende, denn es „kommt der Suggestion von Augenschein die zentrale Bedeutung zu, so sehr, daß evidentia weithin nichts anderes als ,rhetorisch hergestellter Augenschein' heißt." ${ }^{10}$ Damit reicht das Evidenzkonzept in die medialen Formationen von Bild, Text und Theater hinein, die insgesamt von der Diskursfigur der Barockrhetorik beherrscht werden.

Der Akt des Sehens - so die kurze propositio dieser Skizze - gehört zur Physiologie und Anthropologie, der Akt der Bildverarbeitung bedarf der Abbildungsund Erkenntnistheorie, der Akt des Sprechens ist in der Rhetorizität und Medialität der frühneuzeitlichen Poetik verankert. Dieser Kombination aus optischer

8 Vgl. dazu die Einleitung in Irmgard M. Wirtz: Affekt und Erzählung. Zur ethischen Fundierung des Barockromans nach 1650. Habil. Bern 2007, hier S. 16.

9 Günter Butzer: Meditation. In: Historisches Wörterbuch der Rhetorik. Bd. 5. Tübingen 2001, Sp.1016-1023. Zur interkonfessionellen Tradition der Meditationstechnik immer noch grundlegend Udo Sträter: Meditation und Kirchenreform in der lutherischen Kirche des 17. Jahrhunderts. Tübingen 1995. - Vgl. zur Erbauungsfunktion der religiösen Barocklyrik den Abschnitt „Erbauung als Meditationspraxis“ bei Volkhard Wels: Manifestationen des Geistes. Frömmigkeit, Spiritualismus und Dichtung in der Frühen Neuzeit. Göttingen 2014, S. 336-341.

10 Jan-Dirk Müller: Evidentia und Medialität. Zur Ausdifferenzierung von Evidenz in der Frühen Neuzeit. In: Wimböck / Leonhard / Friedrich: Evidentia (wie Anm. 6), S. 59-81, hier S. 61. 
Technik, Reflexion der erbaulichen Verarbeitung und literarischer Gestaltung wird nun an einigen Gedichten nachgegangen, die dem Anschauungs- und Darstellungstypus der „zufälligen Andacht“ angehören, ein mit Luther und Ignatius von Loyola bereits im 16. Jahrhundert entwickeltes und bis ins 18. Jahrhundert reich differenziertes Gattungs- und Handlungsmuster. ${ }^{11}$ Es geht darum, die Tauglichkeit der Fragestellung zu unterstreichen und ihre Geltung historisch ein Stück weit zu verfolgen.

\section{Theologische Bildtheorie: Friedrich von Spee}

Friedrich von Spee bevorzugt in der Trutz-Nachtigall (1649) generell, wie im Titel programmatisch genannt, das Gehör vor dem Gesichtssinn und bleibt nicht selten auch dort unanschaulich, wo Naturbetrachtungen gestaltet werden. Das hängt einerseits mit der spezifischen Gestaltung visueller Eindrücke zusammen, denn bekannt ist die durch und durch „literarische Natur der Speeschen Bäche, Blumen und Wälder", die zum großen Teil Zitate und Paraphrasen lateinischer Klassiker sind. ${ }^{12}$ Andererseits beruht dies auf der Imaginations- und Gedächtnistheorie des Dichters, die eine geistliche Gewichtung des Blicks zur Folge hat. Im „Liebgesang" der Seele „Zum Anfang der Sommerzeit“ wird der Lieblichkeit des anbrechenden Sommers das innere Leid des Christussuchers entgegengesetzt, das jeden optischen Eindruck entwertet:

$$
9 .
$$

Was nützet mir dan schöne zeit?

Was glantz, vnd schein der Sonnen?

Was bäum gar lieblich außgebreit?

Was klang der klaren Brunnen?

Was athem lind

Der kühlen wind?

Was Bächlein krum geleitet?

Was edler Mey?

Was vogelschrey?

Was Felder grün gespreitet? ${ }^{13}$

11 Im Überblick Karl Baier: Meditation und Moderne. Zur Genese eines Kernbereichs moderner Spiritualität in der Wechselwirkung zwischen Westeuropa, Nordamerika und Asien. 2 Bde. Würzburg 2009; Markus Friedrich: Das Hör-Reich und das Sehe-Reich. Zur Bewertung des Sehens bei Luther und im frühneuzeitlichen Protestantismus. In: Wimböck / Leonhard / Friedrich: Evidentia (wie Anm. 6), S. 451-475; dort zur Entwicklung der „okkasionellen Meditation“ als religiöser Aufladung visueller Praktiken Abschnitt 3: „Kontrolliertes Sehen als frommer Akt".

12 Stefan Busch: Die Lieblichkeit der Schöpfung und der Dichtung. Zur Poetik der Naturschilderungen bei Friedrich Spee. In: Spee-Jahrbuch 2 (1995), S. 67-88, hier S. 73.

13 Friedrich Spee: Anders Liebgesang der gespons JESV. Zum Anfang der Sommerzeit. In ders.: Trutz-Nachtigall. Hg. v. Theo G. M. van Oorschot. Bern 1985 (Sämtliche Schriften, Bd. 1), Nr. 8, S. 42-45, hier S. 44. 
Wo zugleich mit dem poetischen Sprechen ein Blick inszeniert wird, finden sich freilich Elemente einer spezifischen theologischen Bildtheorie, die auf Heilsgeschichte und Schöpfungstheologie beruht. Sie unterstellt das skopische Regime den Momenten der Zeitlichkeit und einer spezifischen Bildtheorie von Abbild und Urbild.

Unter dieser religiösen Blickregie untergräbt die Macht der Zeitlichkeit die Evidenz des Augenblicks. Im "Conterfey des Menschlichen Lebens" heißt es beim frühmorgendlichen Anblick eines Sommerblümleins: „Da wolt ich je noch warten, Biß es vollkommen ward. “ ${ }^{14}$ Nicht die momentane Erscheinung, sondern deren Veränderlichkeit steht im Zentrum des betrachtenden Interesses. Auch die Beschreibung der Blütenschönheit versetzt das Sichtbare sogleich unter den Aspekt der Temporalität, die den Augenblick zunichte macht, wenn er in die Dauerhaftigkeit des Wandels eingeschrieben wird: „Noch heut wirst müssen sterben, Nur zeitlich denck zum Grab. ${ }^{15}$ Der augenblickliche Augen-Blick erfasst nichts Festes, und das Dargestellte verweist auf die heilsgeschichtliche Vergänglichkeit alles Sichtbaren. Der Dichter stellt malend dem Leser statt dem Gesehenen dessen transzendenten Status vor Augen und schließt mit dem pastoralen Appell der Besinnung und Einkehr:

12.

O Mensch hab Dir gemahlet

So gar ob augen dein,

Recht wie der Tod vns holet,

Wan wir in wolstand sein.

O nie nitt traw der Schöne,

Dem Blut, noch Farben traw,

Dich nur mitt Gott versöhne,

Nur auff zum Himmel schaw.

Diese Besinnung ist als Blickregie gestaltet, wenn der Blick sich in der Hoffnung auf Versöhnung von der Erde zum Himmel heben soll.

Eine spezifische Relation von Abbild und Urbild entfaltet Spee in der Allegorie des Malens, in Andeutung in der Betrachtung „Anleitung zur erkandtnuß vnd Liebe des Schöpffers auß den Geschöpffen“ mit dem Refrain „O Mensch ermeß im Herzen dein, Wie wunder muß der Schöpffer sein!" ${ }^{\prime 16}$ deutlicher im darauf folgenden „Lob Gottes auß einer weitleuffigen Poetischen beschreibung der frölichen SommerZeit“. In dieser malenden Poesie erscheint dem Blick die Welt als Abbild eines göttlichen Bildentwurfs.

14 Spee: Conterfey des Menschlichen Lebens. In ders.: Trutz-Nachtigall (Anm. 13), Nr. 13, S. 71 75 , hier S. 72.

15 Spee: Conterfey des Menschlichen Lebens. In ders.: Trutz-Nachtigall (Anm.13), Vers $57 \mathrm{f}$., S.73. Vgl. Vers 29 f., S. 72: „So säfftig, vnd so blütig, Als wär der tod noch fehr."

16 Spee: Anleitung zur erkandtnuß vnd Liebe des Schöpffers auß den Geschöpffen. In ders.: Trutz-Nachtigall (Anm. 13), Nr. 21, 98-103, 18 Strophen. 
10.

Mein saget an, ihr Blümlein zart, Vnd last michs ie doch wissen

Weil ihr an euch kein farb gespart, Wer hats euch vorgerissen?

Wo nahmet ihr das Muster her,

Davon ihr euch copeyet?

Das Vorbild wolt ich schawen ger,

Welchs ihr habt conterfeyet.

O Gott ich sing von hertzen mein

Gelobet muß der Schöpffer sein. ${ }^{17}$

Die rhetorischen Fragen der zehnten Strophe, die das sprechende Ich im Dialog mit der Welt zeigen, aber noch keine Antwort eintragen, werden zuletzt durch den Leserappell ersetzt und überboten, alles „recht“ zu bedenken, was zur Verzückung führt:

20.

Wo nur das aug man wendet hinn

Mitt lusten wirds ergetzet;

Ergetzet wird fast ieder Sinn,

Vnd alles wunder schetzet;

Ohn maß ist alle Welt geschmuckt /

Wer künstler mögts erdencken?

Wers recht bedenckt, wird gar verzuckt

Das haupt thut nidersencken.

O Gott, ich sing von herzten [sic] mein,

Gelobet muß der Schöpffer sein. ${ }^{18}$

Markiert ist damit der Übergang vom Erfassen zum Bedenken, jenen vorbereitenden Schritten, die François de Sales 1608 in seiner Meditationslehre der vom Adepten intendierten Vergegenwärtigung Christi voranstellt. ${ }^{19}$ Mit dieser tritt die Verzückung ein, und wenn das Haupt sinkt, so ist der Vorgang des Sehens abgebrochen. Zugleich referiert der Vers auf den bescheidenen Zöllner Lk 18,13, der im Bewusstsein seiner Sündhaftigkeit die Augen niederschlägt: „Der Zöllner aber blieb ganz hinten stehen und wagte nicht einmal, seine Augen zum Himmel zu erheben [...]" (Einheitsübersetzung).

17 Spee: Lob Gottes auß einer weitleuffigen Poetischen beschreibung der frölichen SommerZeit. In ders.: Trutz-Nachtigall (Anm. 13), Nr. 22, 104-110, 21 Strophen, hier S. 106.

18 Spee: Lob Gottes auß einer weitleuffigen Poetischen beschreibung der frölichen SommerZeit. In ders.: Trutz-Nachtigall (Anm. 13), S. 109.

19 Abschnitt „Meditation und Kontemplation bei François de Sales“, Baier: Meditation und Moderne (Anm. 11), S. $131 \mathrm{ff}$. 
Nach einer Formulierung der Vorrede ist Spees Trutz-Nachtigall „zum Brauchen, vnd nicht nur zum Lesen gemacht" und damit in einen performativen Zusammenhang der Meditation und Erbauung hineingestellt. ${ }^{20}$ In einem Kapitel seines Guldenen Tugend-Buchs reflektiert Spee ausführlich die mit kundiger Phantasieleistung erzeugbare Gedächtniseinprägung visueller Eindrücke. Nicht die optische, sondern die imaginative und meditative Verarbeitung der sinnlichen Signale ist sein Zugang, wobei es ihm auf die doppelte Speicherung des Bildeindrucks ankommt, denn dem lebenslang haltbaren, aber dennoch vergänglichen der Phantasie steht ein anderer Bildeindruck gegenüber, der ewig in die Seele eingesenkt bleibt. ${ }^{21}$

Die hinter Spees Naturdarstellung wirksame Bildtheorie steht im Hinblick auf die Zeitlichkeit sub specie aeternitatis und ist in den heilsgeschichtlichen Horizont eingeschrieben. Stets ist der sensus historicus im Sinne literarischer ekphrasis mit dem sensus allegoricus so verkoppelt, dass die Entfaltung optischer Evidenz entbehrlich bleibt. ${ }^{22}$ Im Hinblick auf den ontologischen Status des Sichtbaren argumentiert Spee zugleich schöpfungstheologisch, denn das Gesehene ist neuplatonisch gedachtes Abbild eines unerreichbaren Bildes. Doch entspricht die Doppelung von Malvorlage und Bild einer naturwissenschaftlichen Differenzierung, die mit Johannes Kepler verbunden ist: „Kepler verlegt [...] das Wahrnehmungsorgan in den Augengrund, den wir heute Netzhaut nennen. " ${ }^{23}$ Erst die poetisch erzeugte Evidenz vermittelt ein korrektes Bild, und zwar nicht des Augenscheins, um mit Kepler zu differenzieren: nicht der pictura auf der Netzhaut, sondern der Evidenz der Sache selbst, der imago rei. Auf diese Weise kommt die alte Lehre vom vierfachen Schriftsinn ganz unverhofft mit der frühneuzeitlichen Differenzierung des naturwissenschaftlichen Sehmodells in Einklang.

\section{Greiffenbergs Lesen und Beschreiben: Von der Meditation zur Poesie}

Der Themenbereich des Sehens und Blickens ist bei Catharina Regina von Greiffenberg von ihrem deutlichen Rückgriff auf die meditativen Vorlagen der Zeit moderiert. Manche Erwähnungen des Blickens bleiben als visueller Akt unausge-

20 Friedmann Harzer: „Bilde dir für ...“[.] Meditation und Imagination in Friedrich Spees „Güldenem Tugend-Buch“. In: Meditation und Erinnerung in der Frühen Neuzeit. Hrsg. von Gerhard Kurz. Göttingen 2000, S. 291-305.

21 Friedrich Spee: Güldenes Tugend-Buch. Hg. v. Theo G. M. van Oorschot. München 1968 (Sämtliche Schriften, hg. v. Emmy Rosenfeld, Bd. 2), Kap. 25, S. 449-464. Vgl. dazu auch Harzer, ebd., Abschnitt II, S. 204-301.

22 Busch: Die Lieblichkeit der Schöpfung und der Dichtung (Anm. 12), S. 75. Dies unterstreicht Busch sodann mit der Poetik des Pontanus und belegt es mit der Trutz-Nachtigall; vgl. den Abschnitt „Erbauliche Dichtung, poetische Erbauung“, S. 83-88.

23 Barbara Duden: ,De oculo morali': Ivan Illich zur Blickgeschichte und zum bedrohten Blicken heute. In: Wimböck / Leonhard / Friedrich: Evidentia (wie Anm.6), S. 481-503, hier S. 499. Zu Keplers Theorie des Sehens in Illichs Darstellung S. 498-501. 
führt, etwa im Sonett "Glaubens-Blick und Bericht von GOttes Gnaden-Herze“: ${ }^{24}$ Hier thematisiert allein der Titel den optischen Sinnbereich, wobei das Kompositum das Visuelle ins Geistliche hinüberspielt und das Gedicht in den Rang einer Vision erhebt. Erkennbar stellt sich die Dichterin in die Tradition des Buchs der Natur, denn „Das Sichtbare/ weiset unsichtbare Ding“, ${ }^{25}$ eine im Sinne des allegorischen Sinns auch bei Spee grundlegende Erkenntnisfigur, die für sie indessen auch eine poetologische Figur wird. Die Dualität von Lesen und Stoff der Lektüre gestaltet sie durch die thematische Beistellung der dichterischen Ausdrucksform zu einer dynamischen Triade, dem Rezipieren von Bild und Schrift steht die sprachliche Äußerung gleich zur Seite. Das „wolbekandte Blümlein: Vergiß mein nicht "26 gibt nicht nur als „Sitten-Lehrer“ in der Betrachtung Auskunft über den Schöpfer („Von dir kleinem Sitten-Lehrer lern' Geheimnus jederman“), sondern legt der Dichterin im letzten Terzett durch seinen Namen Poetisches in den Mund: „Ach vergiß mein nicht / O Schöpffer!“ Die beiden Erklärungsrichtungen poetischer Naturbetrachtungen, die Evidenz des Sichtbaren und des dahinterstehenden geistlich Unsichtbaren, sind um die Dimension des Poetischen erweitert, Lesen und Schreiben aufs Engste verklammert, wie im „Lust Liedlein bey dem Ypserfluß ${ }^{\prime 27}$ angesprochen:

9.

Jn dem weissen Blüte-Buch/

ich aufsuch

die Erschaffungs-Wunder:

setze dann an jedes Blat/

an die statt/

Lob und Preiß darunter.

Die Strophe verbindet poetisch die doppelte Funktion von Schrift als Aufzeichnungs- wie als Kommunikationsmedium. Greiffenbergs Allegorisierung der Natur als Buch mit dem blanken Weiß des Papiers basiert auf der doppelten Funktionalisierbarkeit von Schrift, deren medialer Träger, das Blatt, einerseits gelesen und sein Text als „Erschaffungs-Wunder“ entziffert, sodann aber mit „Lob und Preiß" weiter beschriftet werden kann. Die Dichterin überschreibt die Wunder des Buchs der Natur mit ihrem eigenen Lobpreis, der „an die statt“ der Schöpfungsoffenbarung die Poesie setzt.

24 Catharina Regina von Greiffenberg: Glaubens-Blick und Bericht von GOttes Gnaden-Herze. In dies.: Geistliche Sonnette/ Lieder und Gedichte/ zu Gottseligem Zeitvertreib/ erfunden und gesetzet. Nürnberg 1662. Faks. Neudr. Darmstadt 1967, S. 100.

25 Greiffenberg: Auf eben dieselbe [liebliche Sommer- und Ernde-Zeit]. In dies.: Geistliche Sonnette (Anm. 24), S. 241.

26 Greiffenberg: Uber das kleine wolbekandte Blümlein: Vergiß mein nicht. In dies.: Geistliche Sonnette (Anm. 24), S. 238.

27 Greiffenberg: Geistliche Sonnette (Anm. 24), S. 349-351. 
Das einzigartige Verfahren der Dichterin wird in ihrer Betrachtung der Blütenpracht im Kirschgarten deutlich.

Göttlicher Gnade Betrachtung/ in der Blühe. ${ }^{28}$

1.

MJtten in der schönen Blüh/

sitz' ich voller Freuden hie/

voller Freud' ob GOttes Güte/

die den Sinnen und Gemüte

ihre Wunderwerk vorstellt.

Weiß nicht/ wo ich mich hinwende/

wo Anfange oder Ende:

alles mir so wol gefällt/

daß/ aus Uberfluß des Willen/

sich die Wörterqvellen stillen.

Nicht unter Markierung einer Perspektive, sondern umringt von visuellen Eindrücken sitzt das sprechende Ich, dessen Verdoppelung der Freudenbeteuerung gleich eingangs jenen Sprung vom Naturerlebnis zur geistlichen Betrachtung vollendet, den der Gedichttypus der „zufälligen Andacht“ erst als Ergebnis kennt. Die örtliche Bestimmung als Umrundung spielt sogleich ins Zeitliche („wo Anfange oder Ende“, meisterlich geben sich die Verben des Anfangens und Endens als Nomina und umgekehrt) und ins Poetische, denn copia fecit me inops, die Fülle machte mich stumm, der Ausdruckswille verstopft die Quellen (beides stimmig im hydrostatischen Bild).

Darüber hinaus bietet die Eingangsstrophe eine Kürzestfassung der Meditationstheorie, deren Schritte von der Wahrnehmung und Überlegung über die Ergriffenheit zum Willen laufen und auch in die Sprache münden, ins Gebet. Das Gedicht schiebt, gerade indem sie markiert werden, die Gattungskonventionen der Erbaulichkeit und der Erbaulichkeit erzeugenden Dichtung kurzerhand zur Seite.

2.

Zwar ist dessen Ursach leicht/

weil der Geist im Himmel streicht

ganz verzuckt ins Engel-Wesen/

daß ihm traumend macht genesen/

zieht nach sich der Sinnen Krafft.

Also kan er nichts vorbringen/

weil er mit viel höhern Dingen/

als die Zeitlichkeit/ behafft:

wie der Reiger in dem fliegen/

läst er alles Nidre ligen.

28 Greiffenberg: Geistliche Sonnette (Anm. 24), S. 357-358. 
Denn der Zustand des sprechenden - schreibenden - Ich ähnelt dem Flug des Reihers (der emblematische Reiher wird sich dann nicht ganz überzeugend in einen Storch verwandeln). In der Emblematik verabscheut der Reiher den Regen, er will zur Sonne und liefert damit ein Bild der Seele in ihren irdischen Anstrengungen - „serenâ caeli quiete gaudens, supra nubes efferi solet" setzt Picinellis Beschreibung ein, und Greiffenberg greift diese verbreitete Auslegung auf. ${ }^{29}$ Der Geist „zieht" die Sinne „nach sich“, weil er sich mit Ewigem befasst. Doch nicht die Beeinträchtigung des Wahrnehmungsapparats ist damit gemeint, sondern des kommunikativen Apparats: Die Strophe spricht vom Verstummen, denn das Ich kann „nichts vorbringen“.

3.

Wie der treue Storch die Speiß/

die er kriegt auf seiner Reiß/

durch den langen Kragen windet/

daß in dieser Speiß-Arch findet

ihre Nahrung sein Geschlecht:

also pflegt mein Geist in gleichen

seine Beut zu überreichen

meinen Reimen/ die mit Recht

seine Kinder und Nachkommen/

wann er dieser Welt entnommen.

Für sein Verwahrung von Nahrung in einer markanten „Speiß-Arch“ bekannt jedenfalls in Wolf Helmhard von Hohbergs Georgica Curiosa, jenem umfassenden Hausbuch adeligen Landlebens, das in Greiffenbergs unmittelbarer niederösterreichischer Nachbarschaft entstand - ist nicht der Storch, sondern ebenfalls der in Strophe zwei erwähnte Reiher: Die "Fisch-Raiger" haben „einen ungemeinen weiten Kropff, in welchem man eine gute Maas füllen kan." ${ }^{30}$ Dem entspricht auch die Atzung ihrer Brut durch das Hervorwürgen der gekröpften Nahrung: „wenn die reiher ihren jungen keine nahrung verschaffen können, speien sie die genossene speise wieder von sich und geben sie den jungen zu fressen. ${ }^{31}$ Doch ist das Bild der Nahrung, die "mein Geist" auf seiner Reise durch die Welt betrachtend aufliest, mittels Personalpronomen in "meinen Reimen" auf das geistliche Wort der Dichtung bezogen, worin die alte Predigtforderung anklingt, „den

29 Filippo Picinelli: Mundus Symbolicus, in emblematum universitate formatus, explicatus et [...] illustratus [...] traductus à [...] Augustino Erath. Köln 1687. Neudr. Hrsg. von Dietrich Donat. Hildesheim 1979, Tl I, Buch IV: Aves, cap. IX: Ardea, S. 277. Das erste Motto ist „SUBLIMITATE SECURITAS“, das Auslegungsstichwort der Marginalie „Spes in Deo“.

30 Wolf Helmhard von Hohberg: Georgica Curiosa Aucta. Oder Adelichen Land- und FeldLebens [...] Dritter Theil. Nürnberg 1749, Buch 11: „Nützliches Supplementum, oder curieuser Zusatz Von der Fischerey“, Kap. 17 „Von denen zahmen und wilden Schwanen, Storch, Fisch-Rayger, Rohrdommel und Trappen", hier S. 319.

31 „Reiher“, Deutsches Wörterbuch. Bd. 14, Sp.656-660, hier Sp. 659: „beobachtetes, volksglauben, aberglauben". 
Kleinen das Brot zu brechen". Greiffenberg kombiniert auch hier die geistliche mit der klassischen Poesiedefinition, denn neben ihre Nahrhaftigkeit tritt die ihr beigelegte Funktion der Zeitüberwindung: die Reime erscheinen „mit Recht" als „Nachkommen“ des Dichters, der Dichterin, die ihren Tod überdauern und, aere perennius (Horaz), deren Ruhm der Ewigkeit einschreiben.

\section{4.}

GOttes ausgefallne Güt/

tausend mahl viel schöner blüht/

als der weisse Weichsel-Garten.

Ach ich will auch noch erwarten/

mit der GOtt-beliebten Zeit/

Herzergetzungs-frische Früchte/

gebend Himmlisch Lobgerüchte

GOtt in Zeit und Ewigkeit.

Daß in GOtt versenkt Verlangen/

ist bereit in Würckung gangen.

Die Schlussstrophe greift wiederum auf eine geläufige meditative Amplifikationstechnik der comparatio a minore ad maiorem zurück, ${ }^{32}$ wenn Gottes Güte die Pracht der Sauerkirschenblüte weit übertrifft. Die exclamatio entspricht dem Gebet des Meditierenden, adressiert aber Gott gerade nicht, sondern verharrt im Modus einer poetischen Selbstaussage. Birgt jede Strophe insbesondere in den neologistischen Komposita eine kleine Überschreitung des sonst durchgängigen sermo humilis, von den „Wörterqvellen“ über das „Engel-Wesen“ und die „SpeißArch" bis zur "GOtt-beliebten Zeit", so markiert das kühne Kompositum der „Herzergetzungs-frische[n] Früchte“ hier die Klimax dieser Reihe. Die Schlusssentenz bekräftigt die Teilhabe des Ich an einem guten, gottgerichteten Leben im Bild von Samen und Reife, mit dem Wortspiel des „Versenkens" als allegorischer Klammer.

Die Heilsgeschichte ist bei Greiffenberg als persönliche Hoffnung individualisiert, und ebenso ist es das Schreiben. Greiffenbergs skopisches Regime verortet das Ich nicht, und keine Perspektive markiert die Erkenntnisrichtung zwischen Subjekt und angeschautem Objekt. Hier geht es um eine implizite Poetik, die die barocken Formen des Dichtens und des Betrachtens nicht erfüllt, sondern voraussetzt und überschreitet. Fest steht aber auch, dass in den Naturgedichten Greiffenbergs die allegorische Tauglichkeit der Welt schwerer wiegt als ihre empirische Gestalt und deren optische Untersuchung, dass, könnte man zuspitzen, die Präsenz des Glaubenserlebnisses mehr gilt als die Hermeneutik seines Zustandekommens. Bei Montaigne ist der Formenreichtum der Natur nicht mehr „zu überschauen, das heißt in eine umfassende Ordnung zu bringen", und die „Selbstkontextualisierung“ des Erkennenden „ist insofern nicht eine Selbstplat-

32 Vgl. Baier: Meditation und Moderne (Anm. 11), S. 92. 
zierung in einem [...] erfassten Ganzen, sondern vielmehr eine Art vertrauensvolle Selbstabgabe an das nicht mehr gekannte aber doch immerhin als gegeben gewusste Ganze der Natur. " 33 Man wird kaum danebengreifen, wenn man diesen auch auf Greiffenbergs Gedicht passgenauen Befund als bereits hier realisierte Konstruktion von Innerlichkeit versteht.

\section{Brockes geschilderte Blicke - und ihre Erzeugung}

Wenn literarische Anschaulichkeit als die ästhetische Qualität des 18. Jahrhunderts in Geltung tritt, dann ist Barthold Heinrich Brockes ihr definitiver Propagator, indem er sprachmalend seine visuellen Eindrücke „in imagines des Rezipienten“ umzusetzen bestrebt ist. ${ }^{34}$ Dabei verbindet er Elemente der naturwissenschaftlichen Episteme sowie das traditionelle religiöse Meditationswissen mit einer spezifischen poetisch-didaktischen Durchdringung und Darstellung der Natur.

Bekannt und gerühmt ist sein Bezug auf den aktuellen Kenntnisstand der vielen von ihm durchmessenen Wissensbereiche, er ist in vieler Hinsicht Eklektiker. ${ }^{35}$ Breit erforscht ist insbesondere Brockes' mehrfach thematisiertes Interesse für die optischen Instrumente (Perspektiv, Mikroskop) ${ }^{36}$ auch seine Beschreibung des Auges („Das Gesicht“) ${ }^{37}$ innerhalb des Lehrgedichts „Die fünf Sinne“, dessen Verbindungen mit der Antike, Herleitung aus Scheuchzers Physica und theoretische Bezugspositionen ebenso aufgearbeitet sind ${ }^{38}$ wie die Heterogenität mehrerer nebeneinander referierter physiologischer Theorien zur optischen Mechanik des Auges. Die alte Humoralpathologie ist darin jedenfalls überwunden, Keplers Differenzierung eingearbeitet, Brockes befindet sich auf der Höhe der physiologischen Debatte und besitzt den Kenntnisstand der Frühaufklärung. ${ }^{39}$ Statt der

33 Moritz Reiffers: Das Ganze im Blick. Eine Kulturgeschichte des Überblicks vom Mittelalter bis zur Moderne. Bielefeld 2013, S. 157-158.

34 „Die visiones des Dichters müssen sich in imagines des Rezipienten umsetzen, die ihn illusionieren [...].“ Müller: Evidentia (Anm. 10), S. 64. Müller fährt fort: „Im Gefolge dieser Auffassung wird im 18. Jahrhundert Anschaulichkeit zu einer ästhetischen Kategorie“.

35 Kemper: Deutsche Lyrik der frühen Neuzeit (Anm. 1), Bd.5/I, S. 115 u.ö.; vgl. Kühlmann / Seidel: Askese oder Augenlust (Anm. 5), S. 145.

36 Vgl. neben Richter: Teleskop und Mikroskop (Anm.5) Florian Welle: Der irdische Blick durch das Fernrohr. Literarische Wahrnehmungsexperimente vom 17. bis zum 20. Jahrhundert oder Das Subjekt zwischen Selbstermächtigung und Selbstverlust. Würzburg 2009, zu Brockes' "Gedancken über ein Perspectiv“ S. 60-82.

37 Barthold Heinrich Brockes: Auszug der vornehmsten Gedichte aus dem Irdischen Vergnügen in Gott, 1738, Faks. Neudr. Hrsg. von Dietrich Bode. Stuttgart 1965, S. 606-622; zuerst T1 II (1727): Irdisches Vergnügen in Gott. Erster und Zweiter Teil. Hrsg. von Jürgen Rathje. 2 Bde. Göttingen 2013 (Werke 2.1-2). Bd. 2, S. 684-696.

38 Kühlmann / Seidel: Askese oder Augenlust (Anm. 5), S. 142-158.

39 Jörn Steigerwald: Das göttliche Vergnügen des Sehens. Barthold Hinrich Brockes' Techniken des Betrachters. In: Convivium. Germanistisches Jahrbuch Polen 2000, S. 9-41, hier S. 16-23 mit Erarbeitung des zeitgenössischen Diskussionsstandes, insbesondere der Übereinstimmung Brockes' mit Zedler, darüber hinaus mit medienhistorischem Ziel. 
Bezeichnung „Lehrgedicht“ wurde jüngst der Begriff „Wissensgedicht" ${ }^{40}$ vorgeschlagen, was den Blick von der Didaxe auf die mimetische Leistung der Wissensdarstellung umlenkt.

Die Wissensformation der religiösen Betrachtung speist Brockes' bevorzugten Gedichttypus der „deskribierenden Nachahmung“ zwecks „Herstellung der ,imago Dei ${ }^{\prime \prime}{ }^{41}$ Er nennt auch die bekannten Elemente der religiösen Meditation, im Gedicht „Der Kürbis“ heißt es etwa „Auf denn, mein Geist, betrachte mit Vergnügen Das fruchtbare Gewächs ${ }{ }^{42}$ Das steht ganz in der Tradition von Sinneseindruck, Verstandestätigkeit und Gedächtnisspeicherung. Allerdings ist die tradierte Abfolge der betrachtenden Begleitung des Sehsinns bereits poetisches Spielmaterial geworden, wenn Brockes die dreigliedrige Abfolge von Beobachtung, Reflexion und zuletzt immer Lobpreis Gottes ${ }^{43}$ verkehrt, was auf die Aufklärung deutet: die Verstandestätigkeit geht der gelenkten Sinneswahrnehmung voraus und führt zu dauerhafter Einprägung. In seiner „,unsere Seele, durchs Gesicht, zur Ehre GOttes aufmunternde Schönheit der Felder, im Frühlinge“ schreitet die Anrede auf diese Weise von der kognitiven Erwägung über die Betrachtung zur Befestigung im Gedächtnis voran:

Erwege doch ohn Unterlaß,

Daß, wenns der Schöpfer nicht vergönnte,

Kein Blat, kein Strauch, kein Spierchen Gras,

Kein einzigs Blühmchen, wachsen könnte. [...]

Betrachte, wie sein grosses Wort

Allein die Quelle dieser Welt [...]

Bemercke,

Daß GOtt [...]

Dich, durch die Spiegel deiner Augen,

Vor solcher Anmuht, sinnlich macht; ${ }^{44}$

40 Roland Borgards: „Das Thierreich“. Anthropologie und Zoologie bei Barthold Heinrich Brockes. In: Zeitschrift für Germanistik 23 (2013), 1, S. 47-62, hier S. 58.

41 Kemper: Gottebenbildlichkeit und Naturnachahmung (Anm. 1), S. 12. - Im Gegensatz zu Kemper beziehen meine Ausführungen das „,betrachtende Gemüth“ (ebd., S. 349) nicht auf die verborgenere hermetische Tradition, sondern auf die religionsgeschichtlich offen zutage liegende der Betrachtungs- und Erbauungspoesie.

42 Brockes: Der Kürbis. In ders.: Irdisches Vergnügen II (Anm. 37), S. 669-674, hier S. 670, V. 13 f.; Auszug (Anm.37), S. 329-330, hier S.330. Zum semantischen Feld der Meditation gehört auch, wenn in „Die uns zur Andacht reitzende Vergnügung des Gehörs im Frühlinge, in einem Sing-Gedichte“ (Irdisches Vergnügen I, 1721 (Anm.37), S. 24-28; Auszug S.4-9) als "Recitierende“ abwechselnd die "Aufmunterung" und die „Betrachtung" auftreten.

43 Welle: Der irdische Blick durch das Fernrohr (Anm. 36), S. 80; Richter: Teleskop und Mikroskop (Anm. 5), S. 11 mit der Akzentuierung: „Die Phase der ,Betrachtung' ist der zentrale Bereich der physikotheologischen Argumentation."

44 Brockes: Die unsere Seele, durchs Gesicht, zur Ehre GOttes aufmunternde Schönheit der Felder, im Frühlinge. In ders.: Irdisches Vergnügen I, 1721 (Anm. 37), S. 37-40, hier S. 39 f.; Auszug S. 12-16, hier S. 15 f. 
Zuerst kommt die wägende voluntas (immer noch im Rahmen einer Theodizee), zuletzt der auf Dauer zielende Lerneffekt, womit das Denken den Vorrang erhält. Es ist gewiss kein Zufall, wenn eine lakonische Formel im Gedicht „Das Menschliche Wissen“ (zuerst) mit einem mehrfach wiederholten Refrain „Das weiß ich nicht“ zuletzt zur Basisdefinition des cartesianischen Subjekts gelangt: „Ich weis: Ich bin. Warum? ich denke“ - so paraphrasiert Brockes Descartes. ${ }^{45}$

Die epistemologischen Problemfelder überlagern sich ${ }^{46}$ und werden mit Anstrengung auf poetischem Wege auszugleichen versucht. Johann Jakob Breitinger liest das Irdische Vergnügen 1740 ganz und gar nicht als religiöse Poesie, er nimmt vielmehr den Überhang einer auf Vollzähligkeit setzenden akribischen Aufzählungskunst wahr, die er einer wissenschaftlichen Formation zuschlägt, indem er sie "historisch" nennt (was die Wahrheitsgeltung bezeichnet) und als Tugend „,eines Naturforschers“ versteht. Er führt aus, „daß Hr. Brockes in seinen Beschreibungen mehr ein Historicus als ein Poet ist; Er stellet uns die Sachen, die er beschreiben will, nicht nur etwan von derjeniger Seiten vor, die vor andern einen starcken Eindruck auf das Gemüthe des Lesers machet, sondern er giebt uns dieselben in allen möglichen Gesichts-Puncten zu besehen," wobei er nicht um poetische Wirkung, sondern „mit der grösten Sorgfalt eines Naturforschers bemühet ist, auch die kleinsten Umstände einer Sache aufzusuchen, und keinen einzigen dahinten zu lassen." ${ }^{47}$

Das greift deshalb ein wenig zu kurz, weil es die Intention Brockes übersieht, sein Tun demonstrativ im kulturellen Feld der Literatur zu inszenieren. So individuell sich Brockes Gedichte geben, so stark verankert sind sie im Publikationsbetrieb. Denn manchmal tritt zum Vorschein, wie konsequent seine Poeterei der Verwertungskette sowohl der literarischen Warenwelt wie auch der Patronage eingegliedert ist.

Im „Hirten-Gedicht. Als der grosse und gelehrte Fürst, Günther, zu Schwartzburg, Die Göttlichen Wunder, in Vermehrung des Getraides, von mir betrachtet, verlangte", ein wunderbar christlich-erbauliches laus ruris in Horazischer Tradition, wird das Verlangen des Gönners als Erfüllung des eigenen poetischen Wunsches in Szene gesetzt. Dem gerade den Sommer besingenden Dichter (,,So sang ich dazumahl“) „lief“ „unverhofft ein Brief, Von meinem werthen Freund,

45 Brockes: Das Menschliche Wissen. In ders.: Irdisches Vergnügen II (Anm. 37), S. 853-855, hier S. 854 V. 25; Auszug S. 695-697, hier S. 697. - Als Ausdruck von Brockes' „Verbindung von ,Vergnügen' und Bewunderung Gottes" liest das Gedicht Steigerwald: Das göttliche Vergnügen des Sehens (Anm. 39), S. 13 f. - Die Spannungen zu Brockes Anticartesianismus (Kemper: Deutsche Lyrik der frühen Neuzeit (Anm. 1), Bd. 5/I, S. 92-107) u. a. in Bezug auf die Belebtheit der Materie kann ich hier nicht ausführen.

46 Zur Auseinandersetzung Brockes' mit der theologischen Tradition Kemper: Deutsche Lyrik der frühen Neuzeit (Anm. 1), Bd. 5/II, S. 57-75.

47 Johann Jacob Breitinger: Der vierzehnte Abschnitt. Von den Gleichnissen in Brockes irdischem Vergnügen in GOtt. In ders.: Critische Abhandlung Von der Natur den Absichten und dem Gebrauche der Gleichnisse. Zürich 1740. Faks. Neudr. Hrsg. von Manfred Windfuhr. Stuttgart 1967, S. 427-458, hier S. 432. 
Durander, Mir ungefehr zu Händen“, der den Auftrag des Patrons enthält, den Sommer zu besingen. „Wie ward mein Geist gerührt und meine Seele froh! Wie inniglich ward ich ergetzet, Als eben das, was ich mir vorgesetzet, Von mir verlanget ward“. Gerne wird die Auftragsarbeit übernommen, und das Zitat setzt fort: ,ja nicht allein verlangt; Es war ein weiser Plan dem Schreiben angebogen, Ein Abriß, den der Geist des Fürsten selbst gezogen“. Das dichtende Ich liefert bereitwillig die Ausführung des vorgegebenen Programms: „Ich fieng hierauf mein Singen, Nach seiner Vorschrift, an“. Doch auch einer der Gesprächspartner hat in fürstlichem Auftrag gedichtet:

Darauf nahm Segenfeld ein Blatt Papier,

Aus seinem Taschen-Buch', und reicht' es Hirtenau,

Mit diesen Worten, ein: Dieß war des Fürsten Wille,

Was ich beschreiben sollt'. Ließ, ob ich nicht genau

Geschrieben, was er schrieb. Ich les' indessen dir,

In dieser Einsamkeit, in dieser süssen Stille,

Was ich davon gereimet, für.

Nach Verlesung ist Hirtenau gerührt und zu einem Danklied angeregt, das den Schluss des „Hirten-Gedichts“ bildet: „Und fielen ihm dazu die Worte wieder ein, Die einmahl, zu dem Zweck, von ihm gesungen seyn: I Du ewiger Gnaden allmächtiger Wille! Unendlicher Ueberfluß ewiger Fülle!“48 Die mit dieser Apostrophe Gottes einsetzenden gebetsartigen Verse des Dankliedes sind ein Selbstzitat, denn Brockes hatte sein ausladendes Gedicht „Der Sommer" aus dem ersten Band des Irdischen Vergnügens (1721) mit ihnen unter der Vortragsbezeichnung „Affetuoso“ beschlossen. Brockes versteckt diesen Bezug nicht, sondern stellt sein intertextuelles Spiel aus, denn im Auszug von 1738 steht es nur 32 Seiten entfernt, die man gerade gelesen hatte oder zurückblättern konnte. ${ }^{49}$

Ein lyrisches Schreiben, das bei Brockes die Inszenierung einer subjektiven Begegnung mit der gottdurchwalteten Natur beständig wiederholt, ist hier in einen Brief- und Schreibverkehr eingegliedert und medial kontextualisiert, womit Brockes die diskursive Komplexität religiösen Dichtens im frühen 18. Jahrhundert entfaltet. Parameter seines Dichtens ist die im System der Patronage selbstverständliche „Vor-Schrift" als Thematisierung des poetischen Schreibvorgangs und der Inspiration, ist der Verweis auf die Schreib- und Lesestoffe, die das Personal des „Hirten-Gedichts" in die zu betrachtende Natur mitnimmt, sind die Briefe, die dorthin expediert werden und die bukolischen Rollenträger an ihre realen Pflichtenhefte erinnern. Brockes thematisiert das Feld der literarischen Zirkulation, denn wo in der barocken Inszenierung der Kombination von Sehen

48 Brockes: Hirten-Gedicht. Als der grosse und gelehrte Fürst, Günther, zu Schwartzburg, Die Göttlichen Wunder, in Vermehrung des Getraides, von mir betrachtet, verlangte. In ders.: Irdisches Vergnügen (zuerst V/1736), Auszug (Anm. 37), S. 158-173, hier S. 165-167 und $172 \mathrm{f}$.

49 Brockes: Der Sommer. In ders.: Irdisches Vergnügen I, 1721 (Anm. 37), S. 92-98, hier S. 98; Auszug S. 140. 
und Erbaulichkeit - obzwar eben im Rahmen rhetorischer Ich-Aussage - ein Individuum anzutreffen war, zeigen sich bei Brockes Figuren der Textwelt. Wie bei Greiffenberg ist die Blickrichtung als organisierende Denkrichtung und skopisches Regime aufgegeben, der Raum aber aufgeladen mit intertextuellen Verbindungen.

Daran zeigt sich, dass die Welt der literarischen Texte die Geltung des frühneuzeitlichen skopischen Regimes wie auch der religiösen Wissenshorizonte bereits überflügelt hat. Mit seinem Kürbis verzichtet Brockes programmatisch auf die traditionelle emblematische Ausdeutung als so schnell wachsendes wie welkendes Gewächs, was unter Rekurs auf Jona 4,5-11 breite Auslegungstradition war (wo die Einheitsübersetzung heute vom „Rizinusstrauch“ redet, übersetzten Luther und Dietenberger noch „Kürbis“) und die Vergänglichkeit der Welt vorzüglich illustrierte. ${ }^{50}$ Brockes demonstriert seine profunde Kenntnis von Bibel und Exegese, wenn er wünscht, dass die große Feldfrucht „zwar für mich, doch nicht für mich allein, Wie Jonas Kürbs, von mir möcht angesehen seyn!“ Er schöpft aber diesen meditativen Mehrwert poetisch nicht mehr aus, sondern schließt vielmehr mit einer erzählten Illustration, die gegenüber der meditativen Affekterregung die Textualität und Medialität seiner Dichtung in den Vordergrund schiebt: „Eh wir nun dieß Gedicht beschließen, Werd' ich, mein Leser, dir noch was, So ich einmal vom Kürbs erbaulichs las, Vorher erzählen müssen ". ${ }^{51}$ Es folgt erzählte Lektüre, geschrieben für Leser, die Fabel vom Bauern, der die Kleinheit der Eichel gegenüber der Mächtigkeit des Kürbis tadelt, dann aber mit Gott einverstanden und ganz froh ist, als ihm auf den Hut statt der schweren Feldfrucht nur - eine Eichel fällt. Die sehr beliebte, später in zahlreichen Gedichtund Prosaversionen kursierende Fabel stammt von Lafontaine („Die Eichel und der Kürbis“, Les Fables, livre IX, fable 4), und Brockes wechselt damit auch poetisch von der Dichtung des besinnlichen Augenblicks ins Feld der aufgeräumt konversierenden Aufklärung. Nicht mehr Meditation und Disziplinierung des Blicks ist deren Ziel, sondern, als neues Paradigma, gesellige Aufmerksamkeit. ${ }^{52}$ Erbaulichkeit wird nun in der Gattung der Fabel von der Literatur bereitgestellt.

50 Immer noch erhellend die Studie Albrecht Schönes zur Kürbishütte Simon Dachs und Heinrich Alberthins: Albrecht Schöne: Kürbishütte und Königsberg. Modellversuch einer sozialgeschichtlichen Entzifferung poetischer Texte. Am Beispiel Simon Dach. München 1975.

51 Brockes: Der Kürbis (Anm. 42), S. 672 V. 26 f. und S. 674 V. 8-11; Auszug S. 333 und S. 335. Zum Übertritt des Erbaulichen in die Literatur vgl. Franz M. Eybl: Vom Verzehr des Textes. Thesen zur Performanz des Erbaulichen. In: Aedificatio. Erbauung im interkulturellen Kontext in der Frühen Neuzeit. Hrsg. von Andreas Solbach. Tübingen 2005, S. 95-112, hier S. 104-110.

52 Ohne Bezug auf Brockes, aber den Diskurszusammenhang zwischen Moral und der neuen Disziplin der Ästhetik überzeugend skizziert Barbara Thums: Aufmerksamkeit: Zur Ästhetisierung eines anthropologischen Paradigmas im 18. Jahrhundert. In: Reiz, Imagination, Aufmerksamkeit. Erregung und Steuerung von Einbildungskraft im klassischen Zeitalter (1680-1830). Hrsg. von Jörn Steigerwald und Daniela Watzke. Würzburg 2003, S. 55-74. 


\section{Allegorie und Paradoxie \\ Zur Organisation religiöser Denkmuster in englischer und deutscher Lyrik des 17. Jahrhunderts}

Peter-André Alt

\section{1}

Religiöses Wissen wird in poetischen Texten des 17. Jahrhunderts nicht selten durch Verfahren der Allegorie transportiert, die - von der Forschung unzureichend erschlossen - paradoxe Elemente einbeziehen können. Die spirituelle Dimension des allegorisch-paradoxen Schreibens entsteht durch die Kombination von Bildlichkeit und Scharfsinnigkeit, die hier als Formprinzip wirkt. Exemplarisch wird sie in englischen und deutschen Lyriksammlungen der Zeit, so in John Donnes Holy Sonnets (1633), George Herberts The Temple (1633), in Daniel von Czepkos Mono-Disticha (1640-47) und Angelus Silesius' Cherubinischem Wandersmann (1675). Die Gemeinsamkeit dieser Zyklen besteht darin, dass sie paradoxe Denkformen als Merkmal eines in poetischer Form entfalteten Glaubensdiskurses mit den Mitteln der Allegorie organisieren. Dabei machen sie religiöses Wissen in Grenzbereichen der Logik operabel, indem sie es durch die Sprache der lyrischen Poesie reflektieren und mit Hilfe rhetorischer Pointierung ausstellen. ${ }^{1}$ Während die Paradoxie den religiösen Diskurs dezidiert zuschärft, elaboriert die Allegorie den spirituellen Sinn, der in der von Gott erschaffenen Natur zutagetritt. Beide Konzepte ergänzen sich in lyrischen Texten des 17. Jahrhunderts auf produktive Weise, insofern sie den Widerspruch und das Nicht-Sichtbare durch Zeichen darstellen und damit eine, logisch betrachtet, unwahrscheinliche Kommunikationsleistung erbringen.

Das allegorische Verfahren bedeutet im 17. Jahrhundert keine Erzeugung des zweiten Sinns im Bild, sondern eine imitatio, die Annäherung an eine Realität, in deren Zeichen der spirituelle sensus immer schon vorgegeben ist. Das gilt vor allem für die metaphora continua, die durch mehrere Bildglieder konsequent fortgesetzte Metapher, wie sie schon die Cicero zugeschriebene Herennius-Rhetorik als

1 Zur Allegorieforschung vgl. den von Anselm Haverkamp und Bettine Menke verfassten Artikel in: Historisches Wörterbuch ästhetischer Grundbegriffe. Hrsg. v. Karlheinz Barck, Martin Fontius, Dieter Schlenstedt, Burkhart Steinwachs u. Friedrich Wolfzettel. Bd. I. Stuttgart 2000, S. 49-104. Zur Allianz von Allegorie und Hermetik im 16. und 17. Jahrhundert vgl. Peter-André Alt: Imaginäres Geheimwissen. Untersuchungen zum Hermetismus in literarischen Texten der Frühen Neuzeit. Göttingen 2012, S. 105 ff. 
typische Allegorieform bestimmt. ${ }^{2}$ Und es gilt für die allegoria tota, die Allegorie ohne explizite Bilderläuterung, die Quintilians Institutio oratoria von der allegoria permixta abgrenzt (sie entspricht dem, was wir heute als Gleichnis bezeichnen). ${ }^{3}$ Im spezifischen Kontext des 17. Jahrhunderts prägt die Allegorie eine besondere Form der imitatio aus, insofern sie die in die Welt hineingeschaffene spirituelle Bedeutung aller Erscheinungen hervortreibt. Die Allegorie aktiviert die semantische Entelechie der Welt, indem sie zeigt, was hinter den Dingen steckt. Die Ähnlichkeit von Bild und Begriff, wie sie bereits die Herennius-Rhetorik als Merkmal der metaphora continua definiert, ist kein Resultat einer artifiziellen Operation, die den Zusammenhang zwischen den Erscheinungen über eine letzthin abstrakte Analogie stiftet. Vielmehr repräsentiert alles, was die Allegorie zeigt, einen Teil der Natur, die sie reflektiert. Ihr epistemischer Charakter liegt darin begründet, dass sie die enge Beziehung zwischen res und signa als Merkmal eines Denkens verdeutlicht, das Sprache und Ding nicht trennt. Angesichts dessen gehört sie einer übergreifenden Naturordnung an, in der keine Differenz zwischen Tropus und eigentlicher Rede existiert. Die Allegorie ist die sinnbildliche Sprache eines ontologischen Systems, das die Einheit von Modalität und Gegenstand vorgibt, indem es deren innere Verwandtschaft fundiert.

In religiöser Dichtung des 17. Jahrhunderts kann sich dieses Konzept der Allegorie mit einer paradoxen Form verbinden. Nach Niklas Luhmann ist das System der Religion generell durch immanente Paradoxien bestimmt, die aus der Spannung zwischen Glauben und Vernunft resultieren. Religiöse Diskurse gelten ihm als Formen der "Paradoxieentfaltung", in denen die konstitutiven Widersprüche von Glaubenssätzen kurrent werden. ${ }^{4}$ Folgt man Luhmanns Exordialdefinition, so lassen sich für die christliche Religion, zunächst außerhalb dogmen-, konfessions- und frömmigkeitsgeschichtlichtlicher Differenzierungen, eine Reihe von leitenden Prämissen ausmachen, die im Zeichen paradoxer Logik stehen. Zu ihnen gehören die Vorstellung eines unbedingten, von einem unspezifizierten Chaos ausgehenden Schöpfungswerks, die Annahme eines unsichtbaren Schöpfers, der Gedanke der Einheit in der Vielheit der Natur, die Trennung zwischen causa (Gott) und effectus (Naturprozess), das Zugleich von Sterblichkeit und Unsterblichkeit in der Gestalt des Gottessohns und die Setzung einer Kategorie der Ewigkeit als Gegenpol irdischer Zeiterfahrung. Sämtliche dieser Modelle müssen als die Grenzen der Logik sprengende Deutungsmuster betrachtet werden, deren

2 Auctor ad Herennium: De ratione dicendi, editit Fridericus Marx. Hildesheim 1966 (Nachdruck der Ausgabe Leipzig 1894), IV, 34, 46 f.

3 Marcus Fabius Quintilianus: Institutionis oratoriae libri XII / Ausbildung des Redners 12 Bücher. Hrsg. u. übers. v. Helmut Rahn. Lateinisch/Deutsch. Darmstadt 1972, VIII, 6,44 ff. Vgl. Anselm Haverkamp: Metaphora dis/continua: Figure in de/construction. Mit einem Kommentar zur Begriffsgeschichte von Quintilian bis Baumgarten. In: Allegorie. Konfigurationen von Text, Bild und Lektüre. Hrsg. v. Eva Horn u. Manfred Weinberg. Opladen 1998, S. 29-45.

4 Niklas Luhmann: Die Religion der Gesellschaft. Hrsg. v. André Kieserling. Frankfurt/M. 2000, S. 64 . 
zuverlässige, also vom Nachdenken über Widersprüche befreite Funktionsweise die christliche Tradition durch sehr unterschiedliche Hilfsmittel sicherstellt: durch den Rekurs auf feste Lehrsätze (Dogmatik), durch rituelle Organisation im Vollzug von Andacht und Gottesdienst, durch ein Arsenal symbolischer Figuren und Objekte, durch Spielräume für Aber- und Wunderglauben im Zeichen einer seit dem Mittelalter verstärkt sich entwickelnden Volksfrömmigkeit. Seit Beginn der christlichen Überlieferung tritt neben diese Techniken die lyrisch-bibelpoetische Darstellung als Medium der ,Paradoxieentfaltung', mithin ein genuin literarisches Verfahren. Die Paradoxie wird zur Form, in der die Widersprüche des Glaubens Ausdruck finden. Luhmanns grundlegende Definition erfährt in seinen gemeinsam mit Peter Fuchs veröffentlichten Studien über Reden und Schweigen (1989) eine historische Spezifizierung im Hinblick auf das 16. und 17. Jahrhundert; hier zeigt sich, dass die mystisch-hermetische Religiosität, wie sie sich im Ausgang des Spätmittelalters ausprägt, eine besonders radikale Spielart der für religiöse Denkformen generell typischen Paradoxie bildet. ${ }^{5}$ Die Tendenz zum paradoxen Stil repräsentiert mit Luhmann/Fuchs eine für den Glaubensdiskurs der Frühen Neuzeit prinzipiell virulente Affinität zum Denken im Widerspruch, die im mystischen Kontext nochmals gesteigert wird. Die Sprache der Mystik, so heißt es, habe „immanent mit Transzendenz, transzendent mit Immanenz" zu tun. ${ }^{6}$ Sie gewinnt ihre Eigentümlichkeit aus der grenzüberschreitenden Bewegung, in der sie Welt und Spiritualität, Außen und Innen ständig neu verbindet.

Die Paradoxie lässt das Phänomen der Grenzüberschreitung gleichsam als internes Projekt religiösen Denkens sichtbar werden. Für die sprachliche Umsetzung dieses Vorhabens ist im 17. Jahrhundert vielfach die allegorische Form zuständig. Sie zielt auf die Kommunikation der Aporien, die religiöse Diskurse konstituieren: auf eine Funktion, die den Widerspruch mit Hilfe der Paradoxie in den Dienst der Darstellbarkeit nimmt und rhetorisch fruchtbar macht. Durch die Allegorie wird die Paradoxie zu einem Medium der Transformation religiöser Grundsätze, deren dogmatische Aussage sie zuspitzt und damit ins Heterodoxe verlagert. Der vorliegende Beitrag soll erkunden, auf welche Weise literarische Stilmittel wie emblematische Zitate, sinnbildliche Topoi, Personifikationen und bibelpoetische Motive die Organisation widersprüchlichen Wissens befördern und ermöglichen. Ins Zentrum rückt dabei die Frage, inwiefern der religiöse Diskurs in seiner allegorisch-poetischen Ausgestaltung spezifische Formen eines eigenen Wissens ausbildet und wo diese Formen die Spuren von Umbruchprozessen im religiösen System selbst anzeigen. Von besonderer Bedeutung ist hier, dass die allegorischen Muster der Paradoxie nicht nur als ,Auskleidung' von Widersprüchen, sondern jeweils als Medium für deren reflexive Verarbeitung und Organisation mit dem Effekt eines dynamischen Wissenstransfers auf epistemischer Ebene genutzt werden. Das Zusammenwirken von Allegorie und

5 Niklas Luhmann, Peter Fuchs: Reden und Schweigen. Frankfurt/M. 1999, S. 70 ff.

6 Luhmann, Fuchs: Reden und Schweigen (Anm. 5), S. 73. 
Paradoxie lässt sich daher am Beispiel der oben genannten lyrischen Texte aus der englischen und deutschen Literatur als Musterfall für die Modellierung eines eigenständigen poetischen Wissens - eines über die Form konstituierten Darstellungswissens - untersuchen.

\section{2}

Das Zusammenwirken von Allegorie und Paradoxie ist nun an den genannten Beispielen von John Donne, George Herbert, Daniel von Czepko und Angelus Silesius zu überprüfen. Die 1633 publizierten Sammlungen Herberts (The Temple) und Donnes (Holy Sonnets) werden zumeist unter dem Rubrum „Metaphysical Poetry" geführt. Sie sind ausgezeichnet durch scharfsinnige Argumentation, chiastischen Aufbau, Pointenstil, mystische Topoi, allegorische Bildsprache und paradoxe Übertreibung - Grundmuster, die prägend für das Genre wurden. Ihre stilistischen Innovationen haben Richard Crashaw, Abraham Cowley (in seinem Frühwerk), Andrew Marvell, Thomas Traherne und Henry Vaughan wenige Jahre später, noch während der Regierungszeit Charles I., zu wichtigen Nachahmungen und Weiterführungen veranlasst. Herbert gliedert die "sacred Poems" des Temple in drei Teile. Am Anfang steht "The Church-porch" (Vorhalle), den Hauptteil bildet die "Church", den Schluß die „Church militant". Während die Vorrede sich auf lebenspraktische Ratschläge für das angemessene Verhalten des Gläubigen beschränkt (bescheidene Kleidung, wenig Muße, fleißiges Arbeiten, nicht mehr als zwei Gläser Wein am Tag), bietet das Ende einen Abriss der Kirchengeschichte von Rom bis zur Christianisierung Amerikas. ${ }^{7}$ Kunstvoller ist das Mittelstück, das den Blick auf ein prunkvoll ausgestaltetes Stück allegorischer Poesie eröffnet. Am Beginn bietet Herbert eine Darstellung der Leidensgeschichte Christi, die in den Paradies-Eintritt mündet. Topisch für die Sammlung ist die ökonomische Metaphorik, die sich zu einer Allegorie mit paradoxem Grundtenor verdichtet: „In heaven at his manour I him fought: I They told me there, that he was lately gone I About some land, which he had dearly bought I Long since on earth, to take possession. ${ }^{8}$ Das Land, das Gott erwarb, ist das Paradies, das Christus nun erreicht. Wenn Gott das Paradies ,gekauft' hat („,bought“), dann steht das in merkwürdigem Widerspruch zu der reinen Spiritualität der christlichen Erlösungsidee. Der Mechanismus, nach dem Gott Geld gegen ewiges Leben tauscht, ist insofern paradox, als er eine Verwandlung von Materiellem in Geistiges betrifft. Herberts Bildlichkeit beleuchtet die Inkommensurabilität der christlichen Idee des ewigen Lebens, die sich jeglicher rationalen Logik entzieht;

7 George Herbert: The Temple. Sacred Poems and Private Ejaculations (1633). Mit einer deutschen Versübersetzung v. Inge Leimberg. Münster, New York, München, Berlin 2002, S. 12 42; S. 378-392.

8 Herbert: The Temple (Anm. 7), S. 72. „An seinem Himmels-Sitz ich ihn nicht fand; I Man sagte mir, er sei auf einer Reise, I Um in Besitz zu nehmen jenes Land, I Das er erworben einst zu teurem Preise." (S.73). 
sie schließt die logisch unwahrscheinliche Verwandlung von Materialität in Spiritualität als Teil ihres Heilsversprechens ein.

Der Tauschmechanismus, der Geld in Geist, Materie in Spiritualität und begrenztes in dauerhaftes Leben überführt, taucht mehrfach bei Herbert auf. So an jener Stelle, da der Gläubige sich Gottes im Abendmahl vergewissert: „Not in rich furniture, or in fine aray, I Nor in a wedge of gold, I Thou, who from me wast sold, I To me dost now thy self convey; I For so thou should'st without me still have been; I Leaving within mesinne." ${ }^{\prime 9}$ Mit Gold hat Gott dem Menschen einst sein Leben erkauft, nun aber den schnöden Besitz beiseitegeworfen, wenn er sich dem Gläubigen anbietet. Im Gebet kommuniziert dieser allein mit einem geistigen Schöpfer, der ohne die Insignien seines Reichtums erscheint. Der Wandel, den der Mensch auf dem Weg von seiner irdischen Existenz zum ewigen Leben vollzieht, wird in Herberts für die Ohren zeitgenössischer deutscher Leser blasphemisch klingenden Versen auf Gott projiziert. Der Schöpfer muss als ewiges Prinzip erkannt und seines rein äußerlichen Glanzes entkleidet werden. Die Perspektive des Gläubigen, der das richtige Gottesbild entfalten soll, gerät zur alleinigen Grundlage für die Beschreibung des himmlischen Herrschers.

Ähnlich heißt es hier: „Scatter, or binde them all to bend to thee: I Though elements change, and heaven move, I Let not thy higher Court remove, I But keep a standing Majestic in me. " ${ }^{10}$ Damit Gott seine spirituelle Majestät in der Seele des Gläubigen entfalten kann, muss er auf das Prinzip der Dauer konzentriert werden. Auch Gott, so ließe sich formulieren, ist der Vergänglichkeit zu entreißen, die der äußere Glanz seiner Herrlichkeit in falschen Bildern missverstandener Andacht vermitteln könnte. Die Vanitas-Diagnose, die hier auf ungewöhnliche Weise anklingt, kleidet eines der schönsten Gedichte der Sammlung in die Aussage, dass das Fleisch das Glas sei, welches den Staub der vergehenden Zeit anzeige: "And wanton in thy cravings, thou mayst know, I That flesh is but the glasse, which holds the dust I That measures all our time; which also shall I Be crumbled into dust.." ${ }^{11}$ Seine wahre Würde und Herrlichkeit erlangt Gott, wo er im Herzen des Gläubigen wohnt, weder Furcht noch Schrecken sät, erfahrbar wird in der unmittelbaren Begegnung durch das Gebet. Hier taucht, verkoppelt mit mystischen Denkmustern, das Motiv der natürlichen Religion auf, wie es Edward Herbert, der Bruder des Verfassers und erste Lord Cherbury, mit seiner Schrift De veritate (1626) begründete. Gott ist, anders als in der theistischen Lehre der lutherischen Orthodoxie, kein der Schöpfung äußerliches Prinzip, sondern

9 Herbert: The Temple (Anm. 7), S. 96. „Nicht in Gerätschaft reich und Pracht-Talar I Noch in 'nem Barren Gold, I Bringst du, der einst den Sold I Für mich gezahlt, dich selbst mir dar; I Sonst würd'st du außer mir geblieben sein; I Und in mir Sündenpein." (S. 97).

10 Herbert: The Temple (Anm. 7), S. 106. „Zerstreue, oder bind' und beug' sie dir. I Ob Stoff sich wandelt, Sphären kreisen, I Laß deinen Hof nicht weiterreisen; I Halt' fest an deiner Majestät in mir." (S.107).

11 Herbert: The Temple (Anm. 7), S. 124. „Du einst wirst fett und geil, dir ward die Kunde I Daß Fleisch nichts als das Glas, das hält den Staub I Der uns're Zeit mißt, und das gleichfalls all' | Zerkrümelt wird zu Staub." (S. 125). 
vermittelt sich in den Naturprozessen direkt über die Wahrnehmung des Menschen - eine Position, die man in Deutschland als ketzerisch brandmarkt.

Wenn Gott im Plädoyer des Gedichts auf die Rolle des Menschen zurückgeführt wird, entspricht das der Logik des Tauschs. Herbert spielt mit der Stilfigur der Inversion, die das formale Äquivalent des ökonomischen Waren- und Geldverkehrs ist. So wie Materie gegen Geist eingetauscht wird, verwandelt sich Gott in den Menschen, der seine Fixierung auf die körperliche Welt hinter sich lassen muss, um für das ewige Leben bereit zu sein. Die Allegorie des Warenverkehrs wird durch die paradoxe Verschiebung der Rollen ergänzt. Die Struktur, die sich hier offenbart, ist chiastisch: der Tausch - als Sinnbild der Verwandlung - vollzieht eine Transformation, die logisch undenkbar bleibt (aus Materie entsteht Spiritualität); die einfache Tauschallegorie wird komplex durch die Paradoxie, die nicht den Menschen, sondern Gott zum Subjekt des Wandlungsprozesses macht. Damit erfüllt sich wiederum der tiefere allegorische Sinn dieser Verse in der Inkommensurabilität der Verheißung, die das ewige Leben bedeutet. Das Geschenk, das Gott dem Menschen durch die Opferung des eigenen Sohns zuteil werden lässt, bleibt letzthin unerschöpflich. Die diskursive Sprache kann es nicht einholen, denn nur im widersprüchlichen Sinnbild erschließt es seine arkane Botschaft. ${ }^{12}$

Das Gebet bietet das Medium, das die Annäherung an den ambivalenten Charakter des ewigen Lebens möglicht macht. Es fungiert als Paradiesvogel Phönix („,bird of Paradise“), als Milchstraße zur wahren Erkenntnis, als Blut der Seele. ${ }^{13}$ Nicht zuletzt gelingt im Gebet jene Vermenschlichung Gottes, die der Temple durchweg reflektiert. Dieser Topos wiederum steigert Gedankenmotive der natürlichen Religion zu einer mystischen Annäherung, indem er einen signifikanten Rollenwechsel offenbart. Gott, wie er sich dem Gläubigen im Gebet präsentiert, ist körperlich, er besitzt Gold, hat physische Macht und muss selbst abwerfen, was physisch bleibt. "Affictions“ - Anfechtungen - ereilen auch ihn; ${ }^{14}$ er liebt und leidet wie sein Sohn, und seine menschlichen Züge sind unübersehbar. Dass Christus bei Herbert mit seinem Vater mehrfach zu einer Einheit verschmilzt, wird auch an anderen Stellen sichtbar. Wenn das Blut als Heilmittel für den Menschen aus dem Himmel tropft (,There is a balsome, or indeed a bloud, I Dropping from heav' $\left.n^{\prime \prime}\right),{ }_{1}^{15}$ dann zeigt das an, wie eng göttliche Gnade und Opferung des Sohnes zusammenhängen.

Vermenschlichung des Schöpfers, Identifizierung von Vater und Sohn sowie Transformation der Materialität in Spiritualität finden sich als Topoi auch in „The

12 Vgl. zu den imaginativen Aspekten dieses Allegoriekonzepts Verena Olejniczak Lobsien, Eckhard Lobsien: Die unsichtbare Imagination. Literarisches Denken im 16. Jahrhundert. München 2003, S. 62 ff.; Verena Lobsien: Jenseitsästhetik. Literarische Räume letzter Dinge. Berlin 2012, S. $87 \mathrm{ff}$.

13 Herbert: The Temple (Anm. 7), S. 96.

14 Herbert: The Temple (Anm. 7), S. $117 \mathrm{f}$.

15 Herbert: The Temple (Anm. 7), S. 292. 
Bag“. Hier erscheint Gott im Staatsornat zu Pferde („,The God of power, as he did ride I In his majestick robes of glorie" $){ }_{1}^{16}$ ehe er sich unter die Menschen mischt und seine prunkvolle Kleidung ablegt. Die Wolken erhalten seinen Bogen, der Blitz gewinnt den Speer, das Blau des Mantels fällt an den Himmel, sodass Gott sich mit seinen Attributen gleichsam in der Natur manifestiert. An die Stelle des alten Ornats tritt ein einfacher Habit, in dem er auf Erden wandelt und nach einer Herberge sucht. Er ist jetzt in die Gestalt seines Sohnes gefahren, opfert sich den Menschen und sichert ihnen damit ewiges Leben („That I shall minde, what you impart I Look, you may put it very neare my heart. $\left.{ }^{\prime \prime}\right) .{ }^{17}$ Das Gedicht ist unter zwei Aspekten bemerkenswert: Es beschwört ein pantheistisches Gottesbild, indem es den Schöpfer mit den Attributen seiner Schöpfung gleichsetzt, die er an die Welt weitergibt, wenn er die Insignien seiner Macht veräußert. Die erneut auftretende Allegorie des himmlischen Regenten, die Gottes Majestät sehr realistisch als politisch-mundane Rolle zeichnet, wäre ebenso wie die heterodoxe Gleichsetzung seiner Eigenschaften mit denen der natura naturata für deutsche Leser beider Konfessionen inakzeptabel gewesen. Hinzu tritt die ungewöhnliche Identifizierung Gottes mit seinem Sohn, die dazu führt, dass sich Christi Opfer als direkte Selbstpreisgabe des Schöpfers deuten lässt. Der Widerspruch, der zwischen der neutestamentlichen Idee der Stellvertretung und dieser direkten Schilderung des Opfertodes besteht, wird im Text nicht aufgelöst. Die Allegorie zeitigt den eigentümlichen Effekt, dass die sinnbildliche Imagination des himmlischen Herrschers wörtlich erscheint: Der sensus allegoricus ist hier eigentlich ein sensus literalis, die buchstäbliche Annahme einer göttlichen Majestät mit sämtlichen Attributen der Macht. Paradoxe Züge trägt die Konstruktion, weil sie die Inkommensurabilität Gottes durch das Bild des einfachen Menschen ersetzt, ohne diese Substitution näher zu begründen. An die Stelle von Transzendenz tritt Immanenz, wie es für mystische Texte seit dem Mittelalter typisch ist. Deren Widersprüchlichkeit besteht darin, dass sie eine höhere, sich den Einsichten der Vernunft entziehende Instanz mit sprachlichen Mitteln zu beschreiben suchen. ${ }^{18}$ Sie bedienen sich also des Logos, um das Prinzip Gottes als das NichtErkennbare, Unsagbare und Inkommensurable aufzuweisen. ${ }^{19}$ Herbert greift an solchen Punkten auf die Tradition einer mystischen Ambivalenz zurück, die sich im Logos gerade als Widerspruch reflektiert. ${ }^{20}$ Erst am Ende des Gedichts tritt diese paradoxe Perspektive in den Dienst eines Lobes des Glaubens und des Paradieses. Der heilsgeschichtliche Sinn und die Preisung ewigen Lebens, welche

16 Herbert: The Temple (Anm. 7), S. 300.

17 Herbert: The Temple (Anm. 7), S. 302.

$18 \mathrm{Zu}$ den literarischen Implikationen des Konzepts vgl. Hans-Georg Kemper: Deutsche Lyrik der frühen Neuzeit. Bd. 3 (Barock-Mystik). Tübingen 1988, S. Xf.

19 Kurt Ruh: Geschichte der abendländischen Mystik. Erster Bd. 2. Aufl. (zuerst 1990). München 2001, S. 15.

20 Hierzu Alois M. Haas: Das mystische Paradox. In: Das Paradox. Eine Herausforderung des abendländischen Denkens. Hrsg. v. Paul Geyer u. Roland Hagenbüchle. Tübingen 1992, S. 273-294, hier S. $288 \mathrm{f}$. 
die Allegorese-Tradition im sensus allegoricus und im sensus anagogicus verankert, rücken hier zusammen. Damit verliert die Paradoxie ihre Zumutung für den orthodoxen Leser, sie wird selbst zum argumentum spirituale. ${ }^{21}$

Dazu passt konsequent, dass der Zyklus zunehmend, je weiter er fortschreitet, ein spirituelles Gottesbild vorführt, das die Tendenz zur mystischen Vermenschlichung des Schöpfers überlagert. Zunächst lässt sich das als Hervortreten der eschatologischen Perspektive deuten, die für klare Gewichtungen sorgt. Die Welt, so heißt es in einem allegorisch sehr einheitlich gestalteten Gedicht („,The World“), ist durch menschliche Weisheit, Vergnügen, Sünde und Tod stetig bearbeitet worden. Aber die Verschönerungen, die das bewirkte, bleiben relativ, weil die wahren Werte im Jenseits liegen. Liebe, Gnade und Glorie bauen daher die Welt nach ihren eigenen Vorstellungen neu im Paradies wieder auf: „But Love and Grace took Glorie by the hand, I And built a braver Palace then before." ${ }^{22}$ Solche am Prediger Salomo geschulte Klage über den Verfall der Welt und die Vergänglichkeit aller Dinge bildet einen gesamteuropäischen Topos, der in der spanischen, englischen und deutschen Allegorik des Barockzeitalters große Bedeutung hat. ${ }^{23}$ Gespiegelt wird dieses Muster bei Herbert in The Quip („Die Stichelei“), wo Schönheit, Ruhm und Witz um die Gunst des Menschen buhlen, am Ende aber die jeweilige Antwort auf ihre Avancen durch Gott gegeben wird. ${ }^{24}$ Ähnliche Eindrücke vermittelt das Gedicht Time, das die theologisch einschlägige Stufenhierarchie von Lebenszeit und Paradieseszeit als systematisches Modell einer hierarchischen Ordnungsstruktur sichtbar macht. ${ }^{25}$ Hier ist nicht mehr die Rede von einer körperlichen Seite des Schöpfers, von dessen Verwickeltsein in die physische Welt. Mystische Annäherung im Gebet und natürliche Begründung der Religion treten hinter orthodoxen Positionen zurück, die das antithetische Spiel von Vanitas-Diagnostik und Eschatologie freisetzen. Es dominieren klare Abgrenzungen im Sinne einer Antithetik, die zwar auf ein ganzheitliches Weltbild abstellt, aber dieses wesentlich über orthodoxe Gegensätze definiert.

Die Argumentationslogik, die jetzt bei Herbert regiert, unterscheidet sich stark von den paradoxen Konstruktionen am Anfang des Zyklus. Die Antithetik der eschatologisch geprägten Textpassagen entfaltet binäre Muster, die nirgends verwischt werden. Die traditionell-christliche Zeitreflexion verzichtet auf die Darstellung widersprüchlicher Glaubenserfahrungen, wie sie zur Körper- und Tauschmetaphorik der Mystik gehören. Es ist bezeichnend, dass die Paradoxie

21 Über die Verbindung von darstellerischer und hermeneutischer Potenz vgl. Hans-Georg Kemper: Allegorische Allegorese. Zur Bildlichkeit und Struktur mystischer Literatur (Mechthild von Magdeburg, Angelus Silesius). In: Formen und Funktionen der Allegorie. Symposion Wolfenbüttel 1978. Hrsg. v. Walter Haug. Tübingen 1979, S. 90-125, hier S. 108 f.

22 Herbert: The Temple (Anm. 7), S. 162.

23 Immer noch mustergültig zu solchen Formen der Topik ist die Darstellung bei Wilfried Barner: Barockrhetorik. Untersuchungen zu ihren geschichtlichen Grundlagen. Tübingen 1970, S. $86 \mathrm{ff}$.

24 Herbert: The Temple (Anm. 7), S. 216.

25 Herbert: The Temple (Anm. 7), S. 240. 
in diesen fast lutherisch argumentierenden Passagen des Zyklus, die vielfach an Martin Opitz und Paul Gerhardt erinnern, nahezu verschwindet. An ihre Stelle tritt eine Verklärung des Todes als Heilsbringer, der seine abschreckende Wirkung verliert und anziehende Züge gewinnt. Die Personifikation des Knochenmanns („Nothing but bones“) wird ersetzt durch die Allegorie des ewigen Lebens, eine verjüngte Gestalt, die der Seele ein neues Kleid anträgt („When souls wear their new aray“). ${ }^{26}$ Das Paradies färbt den Tod in Tönen der Verklärung, nicht als hippokratisches Gesicht. Und am Ende wandelt sich bei Herbert die Vision des Todes in eine Allegorie des Paradieses, deren letzte Paradoxie darin besteht, dass das Ende des Lebens ein Akt der Wiedergeburt ist.

John Donnes Holy Sonnets erschienen 1633; es folgten zwei Jahre später in der Neuausgabe vier weitere Sonette, und postum veröffentlichte Edmond Gosse nochmals drei, die aus dem sogenannten Westmoreland-Manuskript stammten. Der Zyklus - mit dem Untertitel Divine Meditations - umfasst zwölf Sonette in klarer Anordnung, gestützt auf eine prägnante Argumentation, die ihre jeweilige Quintessenz nach bildhaftem Exordium und Exempla im Oktett gnomischsententiös formuliert. Das erste Sonett formuliert ein Gebet, das mit der Sorge schließt, Gott werde das gläubige Ich nicht aufnehmen, sodass es dem Teufel anheimfalle: „That thou lov'st mankind well, yet wilt' not chuse me, I And Satan hates mee, is loth to lose me." ${ }^{27}$ Das zweite, dritte und vierte Sonett beschwören Elemente der Eschatologie, Visonen von höllischer Bestrafung, Himmelspilgerschaft und Jüngstem Gericht. Gott wird angefleht, das Ich in Gnade zu erlösen und für seine Sünden nicht zu verdammen: „Teach mee how to repent; for that's a good I As if thou' hadst seal'd my pardon, with thy blood.“ ${ }^{28}$ Das fünfte und sechste Sonett markieren eine Zäsur, denn jetzt zeigt sich das Ich als Sieger über Tod und Verdammnis. Selbstbewusst geworden durch Zuversicht und Gottvertrauen, artikuliert es neuen Mut, weil der Tod nunmehr bezwungen ist. Nach einem zeittypischen, auch in der Malerei verbreiteten Motiv, das später Jacob Balde und Andreas Gryphius aufgreifen, figuriert er nicht mehr als mors triumphans, sondern als mors devincta: ${ }^{29}$ "One short sleepe past, wee wake eternally, I And death shall be no more, Death shalt die. ${ }^{\prime 30}$ Die eigentlichen Höhepunkte des Zy-

26 Herbert: The Temple (Anm. 7), S. 370.

27 John Donne: The Divine Poems. Ed. with Introductions and Commentary by Helen Gardner. Oxford 1952, S. 6.

28 Donne: The Divine Poems (Anm. 27), S. 8.

29 Das dialektische Wechselspiel von siegreichem und besiegtem Tod ist Gegenstand zahlreicher Deckenfresken und Grabbilder der Epoche. Literarisch einschlägig hier Jacob Balde: Enthusiasmen. In: Opera Poetica Omnia. Bd. VIII. München 1729 (zuerst 1660), Sylvarum liber VII, VIIII, liber II, XXXIX; Andreas Gryphius: Kirchhoffs=Gedancken (1657). Gesamtausgabe der deutschsprachigen Werke. Hrsg. v. Marian Szyrocki u. Hugh Powell. Bd. III. Tübingen $1963 \mathrm{ff}$., S. $19 \mathrm{ff}$. Als Materialsammlung diesbezüglich immer noch instruktiv: Friedrich-Wilhelm Wentzlaff-Eggebert: Der triumphierende und der besiegte Tod in der Wort- und Bildkunst des Barock. Berlin, New York 1975, S. $74 \mathrm{ff}$.

30 Donne: The Divine Poems (Anm. 27), S. 9. 
klus finden sich in der zweiten Hälfte, ab dem siebenten Sonett. Thema der Texte ist der Dialog des Gläubigen mit Gott, seine Partizipation an der divinatorischen Gnade, seine eigene Passio als Mitleiden an den Schmerzen der Menschheit, seine mystische Nähe zum Schöpfer. Hier tauchen auch jene paradox gesteigerten Wendungen auf, für die Donnes Sonette berühmt geworden sind.

Die abschließenden fünf Sonette zeigen ein gestärktes Ich, das im Gespräch mit Gott die tiefsitzende Angst vor dem Ende seines irdischen Daseins ablegt. Das siebte Sonett rückt dem Schöpfer näher, indem es ihn in menschlicher Gestalt zeigt. Gott habe sich ein fleischliches Kleid übergestreift und auf diese Weise jene Schwäche erlangt, die es erlaube, Schmerz zu fühlen: „God cloth'd himselfe in vile mans flesch, that so I He might be weake enough to suffer woe." ${ }^{31}$ Die allegorische Konstruktion weist den Körper als Kleid von Fleisch aus, das man an- und ablegen kann; die Paradoxie zielt auf die für die Mystik gängige Verschränkung von menschlichem Gott und göttlichem Menschen. ${ }^{32}$ Denn wenn der Schöpfer sich dazu herablässt, den Körper seines Geschöpfs anzunehmen, ermöglicht das auch den Umkehrschluss, dass das Geschöpf seinem Schöpfer gleiche. Die Paradoxie besagt, dass der Mensch so göttlich sei wie Gott menschlich. Das eben ist der Kern einer mystischen Annäherung, die im Gewand der Allegorie durch den bewussten Widerspruch die Grenze zwischen Diesseits und Jenseits in Frage stellt. Nach dem Muster des Chiasmus kreuzt der Text Attribut und Nomen, indem er das Sterbliche ewig und das Ewige sterblich macht: eine rhetorische Figur, die zugleich als Denkprinzip fungiert. ${ }^{33}$

Das zehnte Sonett beschwört die Befreiung vom Teufel und bittet Gott um Besserung seiner Seele. Das Ich vergleicht sich mit einer besetzten Stadt (, an usurpt town“ ${ }^{\prime 34}$ ), die gefangen ist von den Mächten der Finsternis. Der Teufel okkupiert die Psyche, hält von der endgültigen Erlösung ab und erweist sich als düsterer Herrscher, der große Beharrungskraft besitzt. Nicht Demut jedoch, sondern Selbstbewusstsein bildet die Haltung, in der das Ich sich in dieser Situation Gott nähert. In Übereinstimmung mit den Rollenmustern barocker Liebeslyrik inszeniert es sich als überlegene Schönheit, die ihren Bewunderer auffordert, er solle sie gut unterhalten, damit ihr Herz entflammt werde. Nur wenn Gott die Seele begeistern und entzücken kann, gewinnt das Ich Freiheit vom Bösen und Mäßigung im Trieb. Das Couplet charakterisiert dieses ungewöhnliche Konzept wiederum in vertrauter chiastischer Konstruktion: „Except you' enthrall mee, never shall be free, I Nor ever chast, except you ravish mee." ${ }^{35}$ Die besetzte Stadt steht

31 Donne: The Divine Poems (Anm. 27), S. 9.

32 Das ist eine Konstruktion, die sich rhetorisch wiederum in der Form des Chiasmus manifestieren kann; kaum zufällig begegnet man ihr in zahlreichen Texten des Zyklus wieder.

$33 \mathrm{Zu}$ Recht spricht Heinrich F. Plett daher im Blick auf die Paradoxie auch von, Scheinwidersprüchen' (Das Paradoxon als rhetorische Kategorie. In: Das Paradox. Hrsg. v. Paul Geyer u. Roland Hagenbüchle. S. 89-104, hier S. 90).

34 Donne: The Divine Poems (Anm. 27), S. 11.

35 Donne: The Divine Poems (Anm. 27), S. 11. 
allegorisch für die vom Teufel okkupierte Seele, deren Heilung durch göttliche Begeisterung ermöglicht wird. Die Paradoxie der Argumentation resultiert daraus, dass nicht Buße und Mühsal, Entsagung und Pflicht, sondern Enthusiasmus und Liebe das Antidot für Satans Verlockungen darstellen.

Die Summe des Zyklus wird bereits im vorletzten, dem elften Sonett gezogen. Indem es die Leistungen der heilenden Meditation beschreibt, die den Menschen Gott näher bringt, beleuchtet es zugleich die spirituelle Reflexionsleistung der Gedichte als deren metapoetische Dimension. Gottes Gnade besteht darin, dass er den Menschen in seiner Brust wie in einem Tempel wohnen lässt. Die metaphorisch-allegorisch im Topos der Wohnung beschworene Nähe zwischen Schöpfer und Gläubigem findet erneut in der paradoxen Hyperbolisierung des Couplets ihre Quintessenz. Das Wunder der creatio Dei beruhte, so heißt es, nicht nur darauf, dass der Mensch Gott gleich geschaffen wurde; vielmehr offenbarte es sich auch in der verblüffenden Menschenähnlichkeit Gottes: „'Twas much, that man was made like God before, I But, that God should be made like man, much more." ${ }^{36}$ Wenn der Gläubige in Gottes Brust wie in einem Tempel wohnt, bedeutet das gemäß dieser Logik, dass er in sich selbst enthalten ist. Denn Gott gleicht dem Menschen, womit jede einfache Differenz aufgehoben wird. In der paradoxen Darstellung erscheint wieder das Prinzip der Ordnungsstörung, das die Allegorie der Wohnung mystisch-heterodox pointiert: Der Mensch ist Teil jenes Gottes, der ihm selbst ähnlich bleibt. ${ }^{37}$ In der zirkulären Struktur vergeht die Unterscheidung von irdischem und ewigem Leben - ihre paradoxe Form reflektiert die Idee der Erlösung, die alle profanen Gegensätze auflöst.

Die Paradoxie bedeutet vor solchem Hintergrund keinen Widerspruch zur binären Logik, sondern deren formale Aufhebung. Die Bedeutsamkeit dieses Prinzips unterstreicht ein Beispiel aus dem ganz anderen Genre des höfischen Theaters. In einem 1594 vor Elisabeth I. aufgeführten Maskenspiel tritt die Figur des Paradoxes auf, die drei Köpfe trägt und damit „Masculine, Femine, and Neuter" verkörpert. ${ }^{38}$ Das Prinzip der Mitte reflektiert einen Topos aus dem platonischen Symposion - das Ideal aller Liebenden, die eine Einheit beider Geschlechter anstreben, um in deren Verbindung Eros erleben zu können. Im Maskenspiel heißt es dazu: „Every lover's ayme is vertous; for virtus est in medio." ${ }^{39}$ An die Stelle einer klaren Opposition tritt das ,in medio' als Quintessenz der Paradoxie. Genau diese Praxis der Verschmelzung, die auf zwei Polen beruhende Unterscheidun-

36 Donne: The Divine Poems (Anm. 27), S. 11.

37 Dass nicht jeder Text des Zyklus Allegorie und Paradoxie verbindet, erweist das postum veröffentlichte achtzehnte Sonett, das aus den nachgelassenen Westmoreland-Manuskripten stammt. Es thematisiert im Sinnbild der Braut Gottes das Schisma der Kirchen, die Trennung zwischen römischer und lutherischer ecclesia, ohne dass es aber zu einer paradoxen Schlussfügung kommt. Donne: The Divine Poems (Anm. 27), S. 15; vgl. den Kommentar S. $127 \mathrm{ff}$.

38 The Progresses and Public Processions of Queen Elizabeth. 3 Volumes. Hg. v. John Nichols. Vol. III. London 1823. Reprint New York 1965, S. 337.

39 The Progresses and Public Processions of Queen Elizabeth (Anm. 38), Vol. III, S. 340. 
gen aufhebt, ist auch im mystischen Prozess der Vermählung zwischen Gläubigem und Gott bezeichnet. Und es dürfte kein Zufall sein, dass er bei Donne und Herbert durch genau jene Figur der Paradoxie dargestellt wird, die formal wie inhaltlich die Tilgung der binären Differenz reflektiert.

\section{3}

Daniel von Czepkos Sammlung von sechshundert „Schluß-Reimen“, die Monodisticha, entstand zwischen 1640 und 1647. Zu Lebzeiten des Autors zirkulierten Abschriften nur im engeren Freundeskreis, weil die Zensur in Schlesien den Druck des tendenziell häretischen Zyklus verhindert hätte. Die Publikation erfolgte erst 1882 auf der Grundlage einer Handschrift aus dem Jahr 1723. ${ }^{40}$ Sein knappes spirituelles Programm formuliert Czepko in seiner Vorrede „Aufwecker an die Reime", in der es heißt: "Wer inner sich das ScheideWasser hat, I Dadurch die Seel auflöst die Ding im Wesen, I Wird euern Kern stracks brechen in der That, I Und Gott in Ihm, Natur in ihn sich lesen." ${ }^{41}$ Die Poesie ist die Hebamme für diese innere Weisheit, die es dem Gläubigen erlaubt, auf den Kern der Dinge, die Natur Gottes zu schauen. ${ }^{42} \mathrm{Im} 1653$ verfassten Widmungsgedicht an Wilhelm IV. von Sachsen-Weimar, das Oberhaupt der „Fruchtbringenden Gesellschaft" (genannt „der Schmackhafte“), beschwört Czepko Hermes Trismegistos als Präzeptor, der dem Menschen des Altertums das „Buch in der Natur ${ }^{443}$ nahegebracht habe. Hermes lehre im Pimander von "Gottes Güte", ${ }^{44}$ so heißt es - eine Anspielung auf die Übersetzung von 14 Traktaten des spätantiken Corpus Hermeticum, die Marsilio Ficino 1471 im Auftrag Cosimos di Medici unter dem ursprünglich für den ersten Traktat resevierten Titel Pimander veröffentlichte. ${ }^{45}$ Mit seiner Reminiszenz stellt Czepko sofort eine Verbindung zum als ketzerisch geltenden Gedankengut der Hermetik her. Natur erscheint unter der hier bemühten Perspektive als „Schrifft", die der göttlichen Wahrheit feste Zeichen zuordnet. ${ }^{46}$ Dieses ist die Grundlage für die mystischen Paradoxien, mit denen der Text arbeitet. Zu ihnen gehört der

40 Vgl. Volker Meid: Die deutsche Literatur im Zeitalter des Barock. Vom Späthumanismus zur Frühaufklärung. München 2009, S. 279.

41 Daniel von Czepko: Sexcenta Monodisticha Sapientum. In: Sämtliche Werke. Hrsg. v. HansGert Roloff und Marian Szyrocki. Bd. I,2. Berlin, New York 1980 ff., S. 519-672, hier S. 523.

42 Vgl. dazu grundlegend Hans-Georg Kemper: Religion und Poetik. In: Religion und Religiosität im Zeitalter des Barock. Hrsg. v. Dieter Breuer. Bd. I. Wiesbaden 1995, S. 63-92; vgl. Peter Cersowsky: Magie und Dichtung. Zur deutschen und englischen Literatur des 17. Jahrhunderts. München 1990, S. $154 \mathrm{ff}$.

43 Czepko: Sexcenta Monodisticha Sapientum (Anm. 41), Bd. I,2, S. 535.

44 Czepko: Sexcenta Monodisticha Sapientum (Anm. 41), Bd. I,2, S. 535.

45 Marsilio Ficino: Mercurii Trismegisti Liber de potestate et sapientia Dei cui titulus Pimander. In: Marsilii Ficini Opera Omnia. 2 Vol. Basel 1576; Nachdruck: Con una lettera introduttiva di Paul Oskar Kristeller e una premessa di Mario Sancipriano. Vol. II. Torino 1962, S. 1836-1873. Vgl. Paul Oskar Kristeller: Marsilio Ficino e Lodovico Lazzarelli. Contributo alla diffusione delle idee ermetice nel rinascimento (1938). In ders.: Studies in Renaissance Thought and Letters. Bd. I. Rom 1956, S. 221-247.

46 Czepko: Sexcenta Monodisticha Sapientum (Anm. 41), Bd. I,2, S. 542. 
Topos von Gott als Mensch, der sich in Fleisch und Blut verwandelt; die Vorstellung, der Schöpfer sei ein „Nicht“, das der Gläubige ansieht und dadurch erst zu seinem existierenden Gegenüber macht; der auf den Hermetismus zurückgehende Gedanke, dass Schweigen das göttliche Reden sei; ${ }^{47}$ die Behauptung, der Mensch schreite in seinem Leben nicht zum Alter, sondern zur Verjüngung fort, sofern er den wahren Glaube pflege; die Phantasie vom Himmel, in dem allein der Gläubige wie Gott selbst lebt; die Annahme, dass einzig das Eindringen in Gottes Wesen die Möglichkeit bietet, ihn auch wahrzunehmen. ${ }^{48}$ Zahlreiche Leitmotive des Konvoluts umspielen heterodoxes Gedankengut, denn sie stellen die Grenze in Frage, die zwischen Gott und Mensch besteht. Im Akt der mystischen Verschmelzung, den der wahre Glaube begründet, existiert sie nicht mehr; das ist der wesentliche Sinn, den Czepkos Paradoxien in epigrammtischer Form vermitteln.

Sukkurs erhalten sie durch die Allegorie: Das Kreuz als Zeichen der passio Christi ist zugleich Bahn des Lebens; Gott und Mensch sind füreinander die Kleidung, in die sie sich hüllen; die Schrift im Herzen spiegelt durch die Vergeistigung des Buchstabens den rechten Glauben; der innere Mensch erscheint als fester, stehender Stab, der äußere als von externen Einflüssen bewegter Zirkel. ${ }^{49}$ Der Regelfall ist das isolierte Vorkommen von Allegorie oder Paradoxie, jedoch wirken beide an prägnanten Punkten des Zyklus auch zusammen. In Überbietung des Enthusiasmuskonzepts aus Platons Phaidros, das Ciceros De oratore unter Rekurs auf Demokrit (Fragment 18 B) adaptiert, ${ }^{50}$ heißt es über die Sprache der Poesie als himmlische Rede: „Was ist die Schöpffung? Nichts als ein geschloßner Reim, als Reim I Der klingt, der Gott sein Wort schallt GLEICHLAUTS wieder herein. ${ }^{41}$ Die allegorische Konstruktion bezeichnet die Schöpfung als Reim, im Sinne eines musikalisch organisierten Textes, der durch lautlich-klangliche Ähnlichkeiten bestimmt wird. Gott hat als selbst Begeisterter die Natur wie ein Gedicht geschaffen, dessen Schönheit durch den Wohlklang seines Reimprinzips entsteht. Nicht nur der Dichter, sondern auch der Schöpfer stehen im Bann des

47 Im ersten Traktat heißt: „Denn der Schlaf des Körpers war zur Nüchternheit der Seele geworden und das Schließen der Augen zum wahren Sehen, und mein Schweigen trug das Gute in sich und das Zu-Grabe-Tragen des Redens wurde zum Ans-Licht-Bringen des Guten." (Das Corpus Hermeticum Deutsch. Im Auftrag der Heidelberger Akademie der Wissenschaften bearbeitet u. hrsg. v. Carsten Colpe u. Jens Holzhausen. Die griechischen Traktate und der lateinische ,Asclepius', übers. u. eingeleitet v. Jens Holzhausen. Stuttgart-Bad Cannstatt 1997, S. 21.) Der 16. Traktat, der einen fiktiven Brief des Asklepios an den ägyptischen Pharao Ammon wiedergibt, tadelt das „Wort-Getöse" der griechischen Philosophie (Das Corpus Hermeticum Deutsch, S. 207); nur durch den Geist wird der Mensch „ein sterblicher Gott”, und nur im Logos, der Spiritus und Fleisch verbindet, nähert er sich dem Schöpfer an. Die hermetische Lehre liefert ganz offenkundig das Grundmuster, dem Czepko hier folgt.

48 Czepko: Sexcenta Monodisticha Sapientum (Anm. 41), Bd. I,2, S. 551, 555, 553, 637, 653.

49 Czepko: Sexcenta Monodisticha Sapientum (Anm. 41), Bd. I,2, S. 580, 581, 651, 598.

50 Cicero: De oratore/Über den Redner. Lat./Dt., übers. u. hrsg. v. Harald Merklin. Stuttgart 2006, S. 328 (II, 194).

51 Czepko: Sexcenta Monodisticha Sapientum (Anm. 41), Bd. I,2, S. 654. 
Enthusiasmus, und die Perfektion ihrer Werke verdankt sich dieser Prägung. So wie die Reime durch Korrespondenzen verbunden sind, arbeiten die Elemente der Natur in einem großen Analogiesystem zusammen und offenbaren darin ihre geistige Verwandtschaft. Der allegorische sensus gewinnt Kontur gemäß der augustinischen Formel ,a visibilibus ad invisibilia', welche die höhere Logik der Schöpfung aufzeigt. Hinter der sensuellen Dimension des divinatorisch produzierten Reims erscheint ein spiritueller Sinn: die Macht der Analogie, in deren Prinzip sich Gottes Schöpferwille abzeichnet. Dadurch, dass die Zeichen der Natur durch Ähnlichkeiten verbunden sind, zeigt sich ihr geistiges Organisationsgesetz. Der Reim ist nicht nur Klang, sondern auch Offenbarung göttlicher Potenz und Hinweis auf die Schönheit der Analogien, die die Natur durchziehen. Am Ende des vierten Zyklus heißt es daher auch: „Sind in Gott alle Ding, ist Gott in allen Dingen: । Helf alle Welt: MEIN GOTT UND ALLE DINGE, singen.“ 52

Ein anderes Beispiel zeigt die wechselseitige Ergänzung von Allegorie und Paradoxie im Kontext einer fast blasphemischen Deutung der Passionsgeschichte: „Das von dem Creutz ins Hertz uns fält, ist Gottes Blut: Gottes Blut: I Das tilgt die Sünd: umbsonst wirckt fremde Buß und Glut. ${ }^{\text {53 }}$ Der paradoxale Charakter der Verse entsteht durch die Vorstellung, dass Gott einen fleischlich-vergänglichen Leib besitze. ${ }^{54}$ Nicht sein Sohn, sondern er selbst blutet am Kreuz, aber sein Tod ist nur der Ursprung des wahren Glaubens und damit die Bedingung ewigen Lebens - ein Motiv, das schon in Herberts Temple auftauchte. ${ }^{55}$ Die metaphora continua des Kreuzes als Sinnbild der Passionsgeschichte und der Paradiesverheißung reflektiert das widersprüchliche Modell der aus dem Sterben geborenen vita aeterna, die das ewige Leben durch das Kreuzesopfer begründet findet. Als Teil der christlichen Dogmatik ist dieses Modell gut vertraut, jedoch pointiert Czepko seine Botschaft auf besondere Weise, indem er Gott selbst durch seine eigenwillige Allegorie als Gekreuzigten darstellt. Damit gewinnt auch die Aussage über den heilsgeschichtlichen Kern der Passio Christi eine neue Dimension, denn das ewige Leben geht hier aus dem Tod des Schöpfers selbst hervor. Diese Logik des Kreislaufs ist typisch für den mystischen Tenor der Monodistichen; formal wird sie durch die paradoxe Zuspitzung der an sich traditionellen Kreuzesallegorie zum Ausdruck gebracht.

Das Moment des Zyklischen taucht am Ende der Sammlung wiederholt auf. Unter der Überschrift „Letztes Gerichte“ heißt es: „Seht wie die gantzer Welt im Feuer Urtheil steht. I Zur Rechten heist es: Kommt: Zur Lincken heist es: Geht." ${ }^{56}$ Das Jüngste Gericht setzt die Seele dem Feuer aus, mit dem Resultat, dass die Sünder von den Frommen geschieden werden. So strikt diese Opposition hier anmu-

52 Czepko: Sexcenta Monodisticha Sapientum (Anm. 41), Bd. I,2, S. 630.

53 Czepko: Sexcenta Monodisticha Sapientum (Anm. 41), Bd. I,2, S. 667.

$54 \mathrm{Zu}$ Vorläufern vgl. Kurt Ruh: Geschichte der abendländischen Mystik. Vierter Band. Die niederländische Mystik des 14.-16. Jahrhunderts. München 1999, S. 231 ff.

55 Herbert: The Temple (Anm. 7), S. 292.

56 Czepko: Sexcenta Monodisticha Sapientum (Anm. 41), Bd. I,2, S. 672. 
tet, so relativ ist doch ihre Distinktionsleistung; denn das Gesetz des Kreislaufs als Prinzip der Schöpfung stellt die Differenz zwischen ,Gehen' und ,Kommen' fundamental in Frage. Im letzten Monodistichon wirken Paradoxie und Allegorie erneut zusammen, wenn es heißt: „Das End ist hier: doch wer zurücke kehren kan I Der trifft den Anbeginn im Ende wieder an. ${ }^{57}$ Ende und Anfang sind eins, wie auch der Blick auf das erste Monodistichon der Sammlung lehrt: „Das Ende, das du suchst, das schleuß in Anfang ein, I Wilt du auf Erden weis', im Himmel seelig seyn. ${ }^{58}$ Die Paradoxie der Einheit von Anfang und Ende folgt der uns bekannten Logik, der Aufhebung des binären Unterschieds zugunsten einer Verschränkung, die sich im kompositorischen Chiasmus von erstem und letztem Monodistichon spiegelt. Sie entspricht im übrigen Platons Timaios, der die Idee der ursprünglichen Eingeschlechtlichkeit des Menschen mit dem Bild der Kreisförmigkeit verbindet. ${ }^{59}$ Im ersten Traktat des Corpus Hermeticum, auf den Czepkos einführendes Lehrgedicht mit Anspielung auf dessen mythischen Verfasser, den Hirtengott Poimander, verwiesen hatte, wird eine vergleichbare Idee des Kreises beleuchtet..$^{60}$ Im vierten Traktat heißt es: „Das, was schwindet, wird mit Notwendigkeit wieder erneuert sowohl durch die Erneuerung der Götter als auch durch den sich nach Zahlgesetzen vollziehenden Naturkreislauf." ${ }^{61}$ Für Czepko kann es in Übereinstimmung mit dem Hermetismus keine Differenzierung zwischen Beginn und Schluss geben, weil die Schöpfung selbst dem Prinzip des Zyklischen gehorcht. Vor diesem Hintergrund ist auch die Frage nach der klaren Trennung zwischen den Sündern, die in die Hölle fahren, und den Frommen, die im Himmel aufgenommen werden, durchaus hinfällig. Weil die Natur einem zyklischen Grundzug gehorcht, kann jede Wirkung auch wieder eingeschränkt, jedes Absolutum relativiert und jedes Resultat wieder aufgehoben werden. Es gehört zu Czepkos heterodoxer Kunst, dass solche Botschaften durch die paradoxe Zuschärfung der Allegorie vermittelt werden.

Das allegorische Sinnbild des Kreislaufs reflektiert aber mehr als nur den Gedanken der in sich geschlossenen Natur, wo Ursprung und Ende eine Einheit bilden. Gleichzeitig beleuchtet es die Poetik Czepkos, das mystische Programm der Annäherung an die Welt des Schöpfers. Die literarische Selbstreflexion geschieht in der paradoxen Allegorie des Kreislaufs, in der sich der poetische Text als mimetische Wiederholung des Naturzyklus zeigt. So wie Anfang und Ende unterschiedslos sind, so verschmelzen auch Kunst und Natur. Die Poesie ist eine Allegorie der Natur, die sie darstellt, und in dieser Konfiguration zugleich

57 Czepko: Sexcenta Monodisticha Sapientum (Anm. 41), Bd. I,2, S. 672

58 Czepko: Sexcenta Monodisticha Sapientum (Anm. 41), Bd. I,2, S. 546.

59 Timaios 31c-34c. Platon: Sämtliche Werke. Nach der Übers. v. Friedrich Schleiermacher mit der Stephanus-Numerierung hrsg. v. Walter F. Otto, Ernesto Grassi, Gert Plamböck. Bd. V. Reinbek b. Hamburg 1958, S. 15 f. Vgl. Wilhelm Schmidt-Biggemann: Philosophia perennis. Historische Umrisse abendländischer Spiritualität in Antike, Mittelalter und Früher Neuzeit. Frankfurt/M. 1998, S. 211 f.

60 Das Corpus Hermeticum Deutsch (Anm. 47), S. 16 (Traktat I).

61 Das Corpus Hermeticum Deutsch (Anm. 47), S. 41 (Traktat III). 
ein Mittel der Teilhabe an deren göttlicher Architektur. Die literarische Selbstreflexion, die der Zyklus hier ermöglicht, beleuchtet auch die Tatsache, dass das poetische Verfahren ebenso wie die Paradoxie, auf die es sich stützt, nicht mehr in den Verankerungen einer binären Ordnung ruht, sondern über diese hinauszielt. Der Autor, der in der Sprache von Allegorie und Paradoxie redet, entäußert sich seines klaren logischen Standpunkts. Er geht ein in die Rhetorik einer mystischen Verschmelzung, die dafür sorgt, dass die rationalen Unterschiede gelöscht, Kausalitäten durch Korrelationen ersetzt und bipolare Oppositionen aufgehoben werden. Die nach Luhmann für den religiösen Diskurs typische Form der ,Paradoxieentfaltung' gewinnt damit den Charakter einer Gegenrede, in der Poesie und Glauben eine neue Welt der Spiritualität jenseits von Ratio, Finalität und Kausalität entwickeln.

Auch in Angelus Silesius' Cherubinischem Wandersmann (1675), der ohne Czepkos Monodistichen nicht entstanden wäre, spielen Allegorie und Paradoxie auf der Basis einer sehr präzisen Arbeitsteilung zusammen. Die allegorische Konstruktion schafft die bildhafte Grundlage für die widersprüchliche Zuspitzung der Paradoxie. So heißt es im zweiten Buch: „Mein Leib ist eine Schal' in dem ein Kuechelein | Vom Geist der Ewigkeit will außgebruettet seyn.“ " ${ }^{62}$ Der Körper als Schale, gedacht im Modus der Allegorie, nimmt den ewigen Geist, zugespitzt im Modus der Paradoxie, als gleichsam physische Komponente in sich auf. Die paradoxe Struktur bedeutet eine Balance der Gegensätze, die häufig durch formale Strukturen wie Chiasmen oder die Mittelzäsur im Sonett getragen wird. Indem Silesius das geistige Prinzip im Körper zu vergegenwärtigen sucht, löst er sich von den gängigen Antithesen der barocken Liebeslyrik. Es bildet einen Effekt der paradoxen Sprache, die hier angestimmt wird, dass die traditionelle allegorische Topik nicht bei der Darstellung von Dualismen stehenbleibt, sondern in den Dienst der mystischen Reflexion tritt, die der Verschmelzung von Gegensätzen gilt. Ähnliche Befunde wie beim zitierten Beispiel vermittelt Silesius im Brauttopos als Chiffre für die seelische Vereinigung mit Gott oder in der Liebesmetaphorik zahlreicher Epigramme. Auch hier offenbart die allegorische Antithetik im Moment des paradoxen Ausdrucks eine einheitsstiftende Tendenz zur coincidentia oppositorum: "Jch bin die Turteldaub/ die Welt ist meine Wüste/ Gott mein Gemahl ist weg: drumb sitz ich ohn geniste.“63

Wesentliche Themenfelder für allegorische Modelle sind die Zeit und der Körper. Beide werden bei Silesius in eine spirituelle Perspektive integriert, die wiederum mit paradoxen Stilelementen verbunden ist. Gemäß der patristischen Allegorese-Tradition erscheint die Ewigkeit als stillgestellte Zeit, wie in Gryphius' Trauerspiel Catharina von Georgien (1657), wo sie als Personifizierung des dauerhaften Strafgerichts am Ende den Schuldigen verdammt, indem sie ihn mit den

62 Angelus Silesius (d.i. Johann Scheffler): Cherubinischer Wandersmann (1675). Kritische Ausgabe. Hrsg. v. Louise Gnädinger. Stuttgart 1985, S. 84 (II, 87). Vgl. Hans-Georg Kemper: Deutsche Lyrik der frühen Neuzeit (Anm. 18). Bd. 3 (Barock-Mystik), bes. S. 208 ff.

63 Silesius: Cherubinischer Wandersmann (Anm. 62), S. 229 (V, 285). 
Maßstäben einer nicht mehr zeitlich-irdischen Urteilsinstanz konfrontiert. ${ }^{64}$ Bei Silesius liest man: „Die Gottheit ist mein Safft: was auß mir gruent und blueht/ I Das ist sein Heilger Geist/ durch den der trib geschiht." 65 Allegorisch betrachtet, ist Gott der lebensspendende Saft, der den Körper durchpulst und einen eigenen ,Trieb' begründet. Die paradoxe Seite dieser Aussage besteht darin, dass das höchste geistige Prinzip des Schöpfers im Sinne der mystischen Versenkung zu einem leiblichen Grundsatz wird. Dieser spiegelt die Intensitität der Annäherung des Gläubigen an ihn, die dahinterstehende erotische Kraft und Sinnlichkeit des gesamten Prozesses. Zu bedenken bleibt, dass die allegorische Darstellung noch im 17. Jahrhundert den Gesetzen der Allegorese folgt („Schreiben, wie die Bibel gedeutet wird“, so lautete die einschlägige Formel). Jenseits der reinen Literalität erschließen sich bekanntlich drei Ebenen des allegorischen Zweitseins: der sensus tropologicus (seu moralis) verdeutlicht die moralische Dimension des Dargestellten, der sensus allegoricus die ekkelsiologisch-heilsgeschichtliche Qualität, der sensus anagogicus den Gedanken der Ewigkeit und des dauernden Lebens im Reich Gottes. Unter dem Diktat der Paradoxie verändert sich bei Silesius die seit den Kirchenvätern klar geregelte Zuordnung der drei Stufen des Zweitsinns: Der sensus tropologicus, der gemeinhin mit dem Leben im Zeichen der Andacht in Verbindung steht, wandelt sich zum sensus allegoricus, in dem die heilsgeschichtliche Dimension aller Ereignisse aufscheint - eine Tendenz, die auch schon bei Herbert zutage trat. Letzthin gewinnt die moralische Ebene sogar implizit die Züge des sensus anagogicus, indem sie die eschatologische Pointe aller Dinge und Taten anzeigt. Die dreifache Schichtung des allegorischen Sinns verdichtet sich in einer einzigen Konfiguration, die das Epigramm durch seine paradoxe Pointierung hervortreibt. An die Stelle der scholastischen Architektur der Allegorese-Hierarchie rückt, passend zur Einheitsbotschaft der von Silesius praktizierten Mystik, das geschlossene Prinzip eines ens universale.

Die topische Logik, die hinter diesem Konzentrationsgeschehen steht, wird durch den Begriff des Ortes umrissen, in Übereinstimmung mit der spätantiken, seit Cicero vertrauten Loci-Tradition: ${ }^{66}$ „Nicht du bist in dem Orth/ der Orth der ist in dir! I Wirfstu jhn auß/ so steht die Ewigkeit schon hier.“ ${ }^{67}$ Ein solches Ineinanderenthaltensein begründet die paradoxe Struktur des gesamten Zyklus. Das

64 Andreas Gryphius: Catharina von Georgien. Oder Bewehrete Bestaendikeit. In: Dramen. Hrsg. v. Eberhard Mannack. Frankfurt/M. 1991, S. 221 (V, v. 408 f.).

65 Silesius: Cherubinischer Wandersmann (Anm. 62), S. 40 (I, 89).

66 Marcus Tullius Cicero: Topik. Lateinisch-Deutsch, übers. u. hrsg. v. Hans Günter Zekl. Hamburg 1983, 2,7 ff.; Marcus Tullius Cicero: De oratore/Über den Redner (Anm. 50), II, 36-38 (zur Differenzierung zwischen loci= ethischen Wahrheiten und loci communes = Ordnungssystemen). Vgl. als immer noch leitendes Standardwerk zu den Folgewirkungen der ciceronischen Lehre in der Frühen Neuzeit: Wilhelm Schmidt-Biggemann: Topica universalis. Eine Modellgeschichte humanistischer und barocker Wissenschaft. Hamburg 1983, S. 7 ff.; ders.: Apokalypse und Philologie. Wissensgeschichten und Weltentwürfe der Frühen Neuzeit. Hrsg. v. Anja Hallacker u. Boris Bayer. Göttingen 2007, S. 229 ff.

67 Silesius: Cherubinischer Wandersmann (Anm. 62), S. 54 (I, 185). 
Äußere gehört zum Inneren, das Innere zum Äußeren: Die Allegorie bezeichnet, im Kontext mystischer Rede, eine Offenbarung der verborgenen Bedeutung. Die Differenz zwischen Zeit und Ewigkeit wird ebenso wie jene zwischen Körper und Geist, Wort und Schöpfung systematisch kassiert. ${ }^{68}$ Ähnlich heißt es im fünften Buch: „Mensch allererst bistu fuer Gott geschikt und recht: I Wenn du zugleiche bist ein Koenig und ein Knecht. ${ }^{\prime 69}$ Erneut erscheint hier die Einheit von Hohem und Niedrigem, die ein Merkmal der mystischen Spiritualität ist. Auf formaler Ebene betont auch Silesius diese Einheit durch die nach Luhmann und Fuchs für den mystischen Diskurs typische Verknüpfung von Transzendenz und Immanenz, indem er das Allegorische ins Literale zurückführt. ${ }^{70}$ Dabei lässt sich erkennen, dass die Paradoxie mit der Allegorie gemeinsam an einer Aufklärung der spirituellen Dunkelheit arbeitet. Der geheime Sinn offenbart sich im paradoxen Diskurs, er erhellt sich durch die Paradoxie und hilft, den von ihr formulierten Widerspruch spirituell produktiv zu machen.

Nicht selten kommt es zur Verwendung topischer Allegorien, die durch den Einsatz paradoxer Hyperbolisierungen semantisch umgedreht und in ihrer Aussage komplett verwandelt werden. So hier: „Die Lieb ist ein Magnet/ sie ziehet mich in Gott: I Unnd was noch groesser ist/ sie reisset Gott inn Tod. ${ }^{471}$ Die Konsequenz der Magnetismus-Allegorie besteht üblicherweise darin, dass der Sterbliche durch seine starke Liebe zu Gott die Garantie seiner Unsterblichkeit empfängt. In einer anderen Variante hat er teil an Christus, mit dem er sich erotisch vereinigt, wie es Silesius' Heilige Seelenlust Oder Geistliche Hirtenlieder der in Ihren Jesum Verliebten Psyche (1657) und Gryphius' Leichabdankung Magnetische Verbindung des HErrn JESVI und der in Jhn verliebten Seelen (1660) reflektiert. ${ }^{72}$ Bei Silesius geht es um einen chiastisch anmutenden Effekt, insofern der Mensch göttlich, Gott aber menschlich wird. Wenn der Schöpfer in den ,Tod' eintritt, bekundet das genau diese paradoxe Wirkung der Liebe, die der Gläubige ihm entgegenbringt. Die Magnetismus-Allegorie macht deutlich, dass die Verbindung, die Leben und Ewigkeit, Geist und Fleisch zusammenführt, natürlich und kraftvoll zugleich ist. Damit gewinnt die allegorische Konstruktion wieder den Charakter einer Grundlage für die paradoxe Zuspitzung, und umgekehrt unterwirft die Paradoxie das allegorische Verweisungsprinzip einer eigenen Dynamik, die ihre traditionelle Zuordnungsstruktur unterminiert: Immanenz und Transzendenz verschmelzen. Die mystische Dimension der Gottesliebe wird durch diese formale Allianz zum

68 Vgl. Hans-Georg Kemper: Allegorische Allegorese (Anm. 21), S. 105.

69 Silesius: Cherubinischer Wandersmann (Anm. 62), S. 207 (V, 134).

70 Luhmann, Fuchs: Reden und Schweigen (Anm. 5), S. 73 f.

71 Silesius: Cherubinischer Wandersmann (Anm. 62), S. 72 (II, 1).

72 Angelus Silesius: Heilige Seelenlust Oder Geistliche Hirtenlieder der in Ihren Jesum Verliebten Psyche (1657). Hrsg. v. Georg Ellinger. Halle a.S. 1901; Andreas Gryphius: Dissertationes funebres, Oder Leich=Abdanckungen. Leipzig 1667 (zuerst 1666), bes. S. 119 f.: Vgl. auch das in denselben Kontext gehörende Epicedium auf Mariane von Popschitz: Andreas Gryphius: Gesamtausgabe der deutschsprachigen Werke. Hrsg. v. Marian Szyrocki u. Hugh Powell. Bd. III. Tübingen 1963 ff., S. 136. 
Ausdruck gebracht, wie es das folgende Epigramm sehr treffend belegt: "Gott küst sich in sich selbst/ sein Kuß der ist sein Geist/ I Sein Sohn ist den er küst/ der Vater ders geleist." ${ }^{73}$ Die allegorische Konstruktion illustriert die Liebe Gottes zu seinem Geschöpf, die Paradoxie verdeutlicht den Kreislauf, der in dieser Liebe in Gang kommt; der Schöpfer küsst sich selbst, wenn er seinen Sohn küsst. Während die Allegorie die mystisch-erotische Dimension jeglicher Annäherung an Gott beschwört, fällt es der Paradoxie zu, die jenseits der irdischen Logik liegenden Kontradiktionen des spirituellen Wissens zu reflektieren.

Benjamin hat am Allegorischen des Barock bekanntlich eine besondere Dialektik aus Profanisierung und Heiligkeit wahrgenommen, dabei allerdings die Stufenlogik der hier nachwirkenden mittelalterlichen Allegorese vernachlässigt, die für solche Kombinationen charakteristisch ist. ${ }^{74}$ Zwar erkennt er die Bedeutung der Konvention allegorischer Schriftexegese für die Barockallegorie an, jedoch nur im Sinne einer formalen Triebkraft, die den dialektischen Eigenimpuls des allegorischen Verfahrens steuert. ${ }^{75}$ Der Weg von der literalen zur spirituellen Welt ist für die Allegorie des 17. Jahrhunderts in der Tat durch das hermeneutische Prinzip der Allegorese vorgezeichnet. ${ }^{76}$ Zur dialektischen Struktur aber findet die Allegorie im 17. Jahrhundert zuallererst durch die Kombination mit der Paradoxie, weil nur hier die Verschränkung von profanem und heiligem Sinn, von geistlichem und irdischem Bezug greift, die Benjamin an der Spannung zwischen Märtyrer und Tyrann in Gryphius' Trauerspielen wahrnahm. Silesius' Epigramme, die durch Czepkos Monodistichen geschult sind, zeigen die innere Einheit der dialektischen Gegensätze, wie sie Benjamins bekannte Antinomien dokumentieren, durch eine Arbeitsteilung auf komplementärer Grundlage. In-

73 Silesius: Cherubinischer Wandersmann (Anm. 62), S. 282 (VI, 238).

74 Walter Benjamin: Ursprung des deutschen Trauerspiels. In: Gesammelte Schriften. Hrsg. v. Rolf Tiedemann u. Hermann Schweppenhäuser. Bd.I. Frankfurt/M. 1972-1987, S. 351 f. Zur Kritik auch Hans-Jürgen Schings: Walter Benjamin, das barocke Trauerspiel und die Barockforschung. In: ,Dass eine Nation die ander verstehen möge'. Festschrift f. Marian Szyrocki. Hrsg. v. Norbert Honza u. Hans-Gert Roloff. Amsterdam 1988, S. 663-676, Peter-André Alt: Begriffsbilder. Studien zur literarischen Allegorie zwischen Opitz und Schiller. Tübingen 1995, S. $141 \mathrm{ff}$.

75 Benjamin: Ursprung des deutschen Trauerspiels (Anm. 74), Bd.I, S. 351: „Die Allegorie des XVII. Jahrhunderts ist nicht Konvention des Ausdrucks, sondern Ausdruck der Konvention. Ausdruck der Autorität mithin, geheim der Würde ihres Ursprungs nach und öffentlich nach dem Bereiche ihrer Geltung. Und wiederum die gleiche Antinomik ists, die bildnerisch begegnet im Konflikt der kalten schnellfertigen Technik mit dem eruptiven Ausdruck der Allegorese." Ob Benjamins Theorie der Allegorie tatsächlich ein Versuch war, das allmächtige Dogma einer konfessionalistischen Prägung barocker Texte außer Kraft zu setzen, darf man bezweifeln (so die These bei Jane Newman: Benjamin's Library. Modernity, Nation, and the Baroque. Ithaca, New York 2011, S. 144 f.. Vgl. zu Benjamins Allegoriekonzept auch Heinz J. Drügh: Anders-Rede. Zur Struktur und historischen Systematik des Allegorischen. Freiburg i. Br. 2000, Achim Geisenhanslüke: Der Buchstabe des Geistes. Postfigurationen der Allegorie von Bunyan zu Nietzsche. München 2003.

76 Das ignoriert auch Paul de Man in der Nachfolge Benjamins (Blindness and Insight. Essays in the Rhetoric of Contemporary Criticism. Minneapolis 1983, S. 187-228, hier S. 188). 
dem sie das Allegorische zum Modell der Topik, die Paradoxie aber zum dynamischen Movens des Widerspruchs machen, erzeugen sie die Balance zwischen religiösem Wissen und überraschender Reflexion des logischen Ausnahmezustands.

$\mathrm{Zu}$ den Metaphern des Fleisches, der geistlichen Wollust und Vereinigung gesellt sich bei Silesius jene des Essens. Sie ist im klassischen Sinn metaphora continua und damit, wie schon die antike Rhetorik definiert, Allegorie. Hier ein typisches Beispiel: „Gott jsst die Hertzen gern: Wiltu jhn stattlich speisen/ I So richt jhm deines zu: Er wird es ewig preisen. " 77 Gott verleibt sich essend die Gläubigen ein, indessen diese sich ihm als Mahlzeit darbieten, um von ihm aufgenommen zu werden. Der geistige Akt ist zugleich ein körperlicher, durch den der Mensch an der göttlichen Ordnung teilhat. Erotisch direkt heißt es unter den geistlichen Schlußreimen des sechsten Buchs über das Reich der Seligkeit: „Hier schaut man Gottes glantz und suesses Angesicht/ I Hier wird man ueberformt von seiner Gottheit Licht. I Hier senkt man sich in Jhn/ und giebt jhm tausend kuesse. ${ }^{\prime 78}$ Der allegorische Sinn besteht darin, den spirituellen Vorgang der Versenkung physisch zu fassen; die Paradoxie beruht darauf, dass nicht nur der Mensch, sondern Gott der leibgebundene Esser und sinnlich Liebende sein kann.

Wie eng die körperliche Dimension unter dem Regiment der Allegorie mit der geistigen verbunden ist, verrät ein Diktum Sigmund von Birkens, das aus der Teutschen Rede-bind- und Dicht-Kunst (1679) stammt. Dort heißt es im Blick auf das ,Ausschreiben' poetischer Vorlagen und die Aneignung fremder Quellen als Basis der Inventio: „Man muß entnehmen/ wie die Bienen ihr Honig aus den Blumen. Man muß das Gehirne zum guten Magen machen/ der die Speise/ nicht wie er sie empfangen wieder herauskotze/ sondern verdaue und in eignen NahrungSaft verwandele. “79 Das Gehirn ist diätetisch, das heißt: im Sinne eines physiologischen Systems zu behandeln. Seine Peristaltik soll durch angemessene Nahrungszufuhr so eingestellt werden, dass es die aufgenommene Speise verwerten kann. Das Gehirn bildet den Magen des Dichters, der sich an fremden Texten stärkt. Dem Rezeptionsvorgang entspricht ein körperinterner Verarbeitungsprozess, der die aufgenommenen Materialien durch Hinzusetzung von Fermenten in ein eigenes, dem Leib zuträgliches Gemisch verwandelt. Silesius' Vergleich zwischen Essen und Andacht, Verdauung und Versenkung folgt derselben Logik wie Birkens Bild. Die Allegorie macht mithilfe der Paradoxie sichtbar, dass Geist und Materie eine geheime Einheit darstellen. Im Essvorgang, der im Geist statthat, bekundet sie sich ebenso wie in der Verdauung durch Gott.

77 Silesius: Cherubinischer Wandersmann (Anm. 62), S. 202 (V, 99). Vgl. auch S. 269 ((VI, 148) mit Blick auf die Anagoge: „Wie dass der Fraß nicht kommt zum ewgen Abendessen/ I Er mag nicht weil er hier sich hat zu satt gefressen."

78 Silesius: Cherubinischer Wandersmann (Anm. 62), S. 247 (VI, 9).

79 Sigmund von Birken: Teutsche Rede-bind- und Dicht-Kunst [...] (1679). Faksimile-Neudruck. Hildesheim, New York 1973, S. 178. 
Bei manchen Unterschieden im Detail, die durch religiöse Traditionen und Prägungen zustandekommen, offenbart das hier herangezogene Textmaterial doch klare Gemeinsamkeiten. Die allegorische Form erzeugt in den angeführten Beispielen zumeist einen Konnex von Bild und episteme, während die Paradoxie Logos und episteme trennt. Wo die Erkenntnis im Fall der Allegorie durch das Bild lanciert wird, tritt sie im Fall der Paradoxie gerade jenseits der argumentativen Ebene auf: Was sie vermittelt, kann nicht durch die logische Darstellung, sondern allein im Widerspruch zu ihr erschlossen werden. Die teils unterschwellige, teils offenkundige Heterodoxie der mystischen Rede über Gott, die Idee des ewigen Lebens und des absoluten Glaubens brechen sich so in der spirituellen Funktion, die sie erfüllen. Denn hinter den Zurüstungen der paradoxen Rede erklingt das Preislied auf die Verheißung des Paradieses.

Martin Mulsow hat das Prekariat des Wissens als besonderes Merkmal für bestimmte epistemische Ordnungen der Frühen Neuzeit herausgestellt. Prekär ist Wissen dann, wenn seine Quellen materiell oder unter Kanonaspekten ungesichert bleiben, wenn es in methodischen Nischen entsteht, auf riskoreichen Transferleistungen beruht oder durch die Überschreitung herkömmlicher Erkenntnisformen zustandekommt. ${ }^{80}$ Sämtliche dieser Merkmale sorgen dafür, dass diejenigen, die prekäres Wissen akkumulieren, persönliche Gefährdungen auf sich nehmen - vom akademischen Statusverlust bis zur Bedrohung des eigenen Lebens. Legt man Mulsows Definition zugrunde, so muss man festhalten, dass das religiöse Wissen, wie es bei Herbert, Donne und Scheffler aufscheint, keinen prekären Charakter trägt, auch wenn es nicht rational fundiert ist. Unter den vier berücksichtigten Autoren hat einzig Czepko darauf verzichtet, seinen Text zu Lebzeiten zu veröffentlichen, weil er scharfe Zensurmaßnahmen fürchtete. Tatsächlich ist der Grad der Ablösung von orthodoxen Mustern bei Czepko ausgeprägter als bei den drei anderen Verfassern - das gilt vor allem für den Gedanken der Materialität Gottes, die Idee seiner Leiblichkeit und die daraus resultierenden Vereinigungstopoi. Auch bei Czepko ist die allegorisch-paradoxe Konstruktion jedoch eingebunden in ein Kontinuum topischer Traditionen, die auf Mystik und Hermetismus zurückgehen. ${ }^{81}$

Das hier kommunizierte religiöse Wissen repräsentiert eine Ordnung jenseits des begrifflichen Diskurses, die aufgehoben ist in den Sinnbildern der Allego-

80 Martin Mulsow: Prekäres Wissen. Eine andere Ideengeschichte der Frühen Neuzeit. Frankfurt/M. 2012, S. $14 \mathrm{ff}$.

81 Diese Traditionen wiederum stützen sich auf poetische Repertoires, die ihrerseits Teil einer technischen Grundausrichtung auch der ,inspirierten' Literatur sind. Vgl. dazu die Arbeiten von Volkhard Wels: Imaginatio oder Inventio. Das dichterische Schaffen und sein Gegenstand bei Puttenham, Sidney und Temple. In: Poetica 37 (2005), S. 65-91; ders.: Zur Vorgeschichte des Begriffs der kreativen Phantasie. In: Zeitschrift für Ästhetik und Allgemeine Kunstwissenschaft 50 (2005), S. 199-226; ders.: Rationalistische Begründung der Dichtung und Kritik des Enthusiasmus. Die Poetik Campanellas. In: Scientia Poetica 9 (2005), S. 14-38; ders.: ,Verborgene Theologie'. Enthusiasmus und Andacht bei Martin Opitz. In: Daphnis 36 (2007), S. 223-294. 
rie und der formalen Gegenrede des paradoxen Sprechens. Es entzieht sich der einfachen Ökonomie buchstäblicher Darstellung durch die Chiffrierungstechnik des allegorischen Verfahrens; und es entwindet sich der binären Logik durch deren Aufhebung in einer neuen Dimension des Sowohl-als-Auch, die keine Unterscheidungen, sondern nur die Kohärenz des ursprünglich Getrennten kennt. Fleisch und Geist, Eros und Askese, Gott und Mensch werden so zu einer Einheit geführt, wie sie dem Prinzip des spirituellen Realismus entspricht. In den paradoxen Zurüstungen der mystischen Rede findet so auch die Allegorie zur Erfüllung ihres Prinzips, das Buchstabe und Geist, Körper und Sinn verbindet. Die paradoxe Logik verwirklicht das Gesetz der Allegorie, das in der bildhaften Darstellung Gottes Präsenz zur Sprache bringt.

Neben dieser strikt religiösen Bindung beleuchtet das Textmaterial aber auch eine Metaebene. Sie offenbart den Autor als enthusiastisch Sprechenden, der in den Zeichen seiner Rede Buchstabe und Geist verknüpft. Seine Kreuzzüge gegen die rationale Logik etablieren eine neue Form der Poesie, die Mimesis als Versenkung und Argumentation als Beschwörung fasst. Allegorie und Paradoxie verbünden sich zur Konstitution einer poetischen Ordnung, die permanent Entgrenzungen organisiert. Für das dichtungstheoretische Selbstverständnis der Zeit bezeichnete die sinnbildliche Rede jedoch keinen Gegensatz zur Vernunft, sondern deren Stimulation. Im dritten Teil seines Poetischen Trichters (1648-1653) beschreibt Georg Philipp Harsdörffer den intellektuellen Mechanismus, den die scharfsinnig-allegorische Sprache freisetzt:

Der Lehrbegierige Verstand hat zwey Mittel sich zuvergnuegen: 1. in Erkantniß der Sachen selbsten/ ohne Betrachtung/ was derselben Eigenschaft/ und Beschafenheit seye/ wann sie mit andern vereinbaret wird. 2. Durch die Gegenhaltung gleichstaendiger Sachen/ wann man vil auf einmahl anschauet/ und solche gegeneinander hält/ ihre Gleichheit und Ungleichheit betrachtet/ und diese Erkaentniß vergnüget den Verstand so vielmehr/ so viel weiter sie sich erstrecket/ eine Sache vollstaendiger an das Liecht setzet/ und gleichsam von einer Warheit in die andere leitet. ${ }^{82}$

Die Allegorie bedeutet, gerade in ihrer scharfsinnigen Ausprägung, kein Mittel der bloßen Verkleidung oder Übersetzung, sondern eine epistemische Operation, die der Annäherung an begrifflich inkommensurable Bezirke dient. Die religiöse Poesie des 17. Jahrhunderts zeigt durch ihre mystisch-allegorische Rede, was 150 Jahre später bei Novalis, Schlegel, Byron, Shelley und Keats nochmals zu Gesicht kommt: die Einheit von Buchstabe und Geist in einer literarischen Form, die Inspiration rhetorisch inszeniert.

82 Georg Philipp Harsdörffer: Poetischer Trichter. Die Teutsche Dicht= und Reimkunst/ ohne Behuf der lateinischen Sprache/ in VI. Stunden einzugiessen. Drei Theile. Nürnberg 1648 1653. Dritter Theil, Faksimileneudruck. Darmstadt 1969, S. 57. 


\title{
Christlicher Epikurismus? \\ Lohensteins Preisgedicht Venus
}

\author{
Gesa Dane
}

Daniel Casper von Lohensteins Preisgedicht Venus auf die Dimension des religiösen Wissens hin zu befragen, setzt einen Religionsbegriff voraus, wie er erst seit der europäischen Aufklärung möglich geworden ist, seitdem nämlich wird er nicht mehr ausschließlich auf die christliche Religion bezogen. Die vielleicht bekannteste Definition stammt von Friedrich Schleiermacher, der Religion als „Sinn und Geschmack für das Unendliche ${ }^{\prime 1}$ bestimmt. Diese Erklärung hat ihre theologiegeschichtlichen und religionsphilosophischen Voraussetzungen im 17. Jahrhundert. In Lohensteins Lebenszeit fallen die großen westeuropäischen innerprotestantischen theologischen Umformungsprozesse und damit, als eine Reaktion auf die konfessionellen Streitigkeiten, ${ }^{2}$ die Herausbildung der Vorstellung von der natürlichen Religion. Eine bedeutende Rolle kommt hier Edward Herbert von Cherbury zu, in De religione gentilium (1645; veröffentlicht 1663) wird der Begriff Religion auch auf die antiken Götter bezogen. Freilich deutet er diese symbolisch, in ihnen werde letztlich doch ein höchster Gott verehrt. ${ }^{3}$ Dies hat Folgen auch für seine Interpretation der Göttin Venus, die im Sinne christlicher Vorstellungen eine Aufwertung erfährt: weniger eine Dirne als eine schamhafte junge Frau sei in dieser verehrt worden. ${ }^{4}$

Über die christliche Religion erfährt man in Lohensteins Venus nichts, ebenso wenig über christliche Frömmigkeit oder Erbauung. Dieses fast 2.000 Alexandrinerverse umfassende Preisgedicht exponiert vielmehr Wissen über die antiken

1 Friedrich Schleiermacher: Über die Religion. Reden an die Gebildeten unter ihren Verächtern. Mit einer Einleitung und Anmerkungen. Hrsg. von Andreas Arndt. Hamburg 2004, S. 30 .

2 Vgl. Emanuel Hirsch: Geschichte der neuern evangelischen Theologie im Zusammenhang mit den allgemeinen Bewegungen des europäischen Denkens. Neu hrsg. und eingeleitet von Albrecht Beutel. Bd. 1, Waltrop 2000, S. 244 ff.

3 Sie erfüllen die Grundbedingungen für natürliche Religionen, weil sie Frömmigkeit, Sünde, Reue und Umkehr wie auch Vorstellungen von einer göttlichen Gerechtigkeit kennen. Vgl. Hirsch: Geschichte der neuern evangelischen Theologie (Anm. 2), S. 248 f. und S. 250 f. Herbert von Cherbury hat gleichwohl die antiken Religionen ,in ihrer empirischen Gestalt zu billigen oder gar für besser als die christliche zu halten" gewagt. Günter Gawlick: Einleitung. In: Edward Lord Herbert of Cherbury: De religione gentilium errorumque apud eos causis. Faksimile der Ausgabe Amsterdam 1663. Hrsg. und eingeleitet von Günter Gawlick. Stuttgart-Bad Cannstatt 1967, S. V-XIX, hier S. X.

4 Siehe hierzu Cherbury: De religione gentilium (Anm. 3), S. 134: „Venerem in Deos relatam, non meretrices tantum, sed pudice etiam puella colebant." 
Vorstellungen von der Liebesgöttin Venus. Die Weise, in der dies instrumentiert wird, sowie die intertextuellen Bezüge und Traditionen, in denen Lohensteins Preisgedicht steht, lassen eine eigentümliche Verschränkung von christlichen mit epikureischen Positionen erkennen. Dass hier durchaus Provozierendes vorgetragen wird, mag die Wendung von der ,ungewaschnen Lippe ${ }^{5}$ anzeigen, die sich in der captatio benevolentiae findet, mit der der Preisende, das Lyrische Ich, sich an Venus wendet. Denn ,ungewaschne Lippe' konnte auch „freche, schmutzige reden führen" ${ }^{\prime 6}$ bedeuten.

Lohensteins Venus-Gedicht stellt die in seiner Entstehungszeit wohl ungewöhnliche Konstellation von weltlicher Liebesthematik und verborgenem geistlichen Sinn dar. Lohenstein hat es bezeichnenderweise nicht in seine Gedichtsammlung Blumen (1680) aufgenommen, und man darf sich fragen, ob dies allein dem Umfang von fast 2.000 Alexandrinerversen geschuldet ist, wie dies Charlotte Brancaforte vermutet hat. ${ }^{7}$ Nicht völlig von der Hand zu weisen ist die Annahme, dass Lohenstein in der nur von literarisch gebildeten Lesern zu entziffernden Verschränkung von Religion und Eros einen Hinderungsgrund für eine Publikation sah. Das Gedicht erschien erst zwölf Jahre nach Lohensteins Tod in Benjamin Neukirchs Anthologie Herrn von Hoffmannswaldau und andrer Deutschen auserlesener und bißher ungedruckter Gedichte erster Theil erstmals 1695, dann wiederaufgelegt 1697. In vieler Hinsicht ist dieses Venus-Gedicht einer der gewagtesten Texte, die Lohenstein geschrieben hat, weil es auf textinterne Hinweise zum rechten Verständnis des Gegensinns dieses Lobpreises der Göttin gänzlich verzichtet. Wie hat ein Lutheraner, der Lohenstein doch ohne Zweifel war, dieses Lob der römischen Göttin Venus verstanden wissen wollen? Was bezweckte er damit? Eines ist unzweifelhaft: Von den drei Dimensionen des abendländischen Liebesbegriffs, Eros, Agape und Philia, findet sich hier ausschließlich Eros.

Albrecht Schöne hat darauf hingewiesen, dass „ein Originalitätsdenken, welches die Unterscheidung von der poetischen Konvention zum Wertmaßstab der Poesie erhebt, und ein Wahrheitsbegriff, der die Überzeugungskraft der Dichtung von ihrem Beichtcharakter abhängig sieht [...], dem Autor des 17. Jahrhunderts im Tiefsten fremd ${ }^{\prime 8}$ gewesen sei. Privates Erlebnis und individuelles Ausdrucksverlangen mussten vielmehr allgemeinen symbolischen Ordnungen und überindi-

5 Vgl. Daniel Casper von Lohenstein: Venus. In: Charlotte Brancaforte: Lohensteins Preisgedicht ,Venus'. Kritischer Text und Untersuchung. München 1974, S. 16, Vers 33; nach dieser Ausgabe wird Lohensteins Venus-Gedicht unter Angabe der Verszahl im Fließtext zitiert.

6 Deutsches Wörterbuch von Jacob und Wilhelm Grimm. Nachdruck der Erstausgabe. Bd. 24. München 1984, S. 910; diesen Hinweis verdanke ich Dr. Christiane Caemmerer (Berlin); , "ungewaschene Gusche“ im Sinne von ,frechem Mundwerk' verwendet auch Gryphius. Vgl. Andreas Gryphius: Absurda Comica Oder Herr Peter Squentz. Schimpfspiel. In ders.: Dramen Bd. 3. Hrsg. von Eberhard Mannack. Frankfurt a.M. 1991, S. 577-619, hier S. 602.

7 Charlotte Brancaforte: Druckgeschichte und Kritik. In dies.: Lohensteins Preisgedicht,Venus' (Anm. 5), S. 9.

8 Albrecht Schöne: Vorbemerkung des Herausgebers. In: Das Zeitalter des Barock. Texte und Zeugnisse. Studienausgabe. München 1988, S. V-XX, hier S.VII. 
viduellen Ausdrucksformen unterworfen werden, losgelöst von der Zufälligkeit individuellen Erlebens. Dichtung im 17. Jahrhundert sei eine „kunstverständige, regeltreue, gattungsgerechte Handhabung des dem Menschen verfügbaren Wortund Bilder- und Formenschatzes, ein Ausweis und Muster rechten menschlichen Verhaltens überhaupt ${ }^{\prime \prime}$ gewesen. Damals wurde als „komplementär begriffen und verklammert", ${ }^{10}$ was inzwischen als unvereinbar erscheint: nämlich Jenseits und Diesseits, Frömmigkeitshaltung und Galanterie, Devotion und Obszönität Maria und Venus. Weite Teile der Lyrik des 17. Jahrhunderts seien von diesem „spannungsreichen Miteinander des Gegensätzlichen“,11 etwa von geistlichem und weltlichem, religiösem und erotischem Sinn, geprägt.

Exemplarisch finden sich diese Komplementarität und Verschränkung des Gegensätzlichen in der von Lohenstein 1680 in Breslau zum Druck gebrachten Lyrik-Sammlung Blumen wieder. Die Abschnitte Himmels-Schlüssel, also geistliche Gedichte und Begräbnis- bzw. Gedächtnis-Gedichte, sowie Hyazinthen und Rosen, also Hochzeits- und Liebesgedichte, stehen schroff nebeneinander. Lohenstein setzt einen mit lyrischen Traditionen, Gattungen und Motiven vertrauten Leser, einen Literatus und Politicus voraus, der die Zusammengehörigkeit von Verschiedenem begreift. So schreibt er in der Vorrede zu seiner Sammlung, es richte diese sich an einen Freundeskreis von wenigen Gleichgesinnten: „das meiste/ was aus meiner Feder geflossen/ hat die Begierde vornehmen und vertrauten Freinden damit zu dienen/ so wol anfangs gebohren/ als itzt selbten zuzueignen veranlasset ". ${ }^{2}$

In seiner geistlichen Lyrik zeigt Lohenstein sich als ein in der lutheranischen Tradition verankerter Autor. Sie kreist, wie Gerhard Spellerberg ausgeführt hat, „um die beiden zentralen, mit dem Glaubensgeheimnis der Dreieinigkeit verbundenen christlichen Heilstatsachen, die Menschwerdung Gottes zum einen, Leiden und Sterben des menschgewordenen Gottes zum anderen", und zwar in einer „weniger vom inbrünstigen Sich-Versenken“ als vielmehr „,vom gedanklichen Sich-Verbohren bestimmte[n] Glaubenshaltung “. ${ }^{13}$ Das Gedicht Die Thränen der Maria Magdalena zu den Füssen Unsers Erlösers, das die Gottesebenbildlichkeit des Menschen und die Buße thematisiert, ist dafür nur ein Beispiel. ${ }^{14}$ Lohen-

9 Schöne: Vorbemerkung (Anm. 8), S. VIII.

10 Schöne: Vorbemerkung (Anm. 8), S. IX.

11 Schöne: Vorbemerkung (Anm. 8), S. IX.

12 Daniel Casper von Lohenstein: Vorrede zu ,Blumen'. In ders.: Lyrica. Die Sammlung ,Blumen' (1680) und ,Erleuchteter Hoffmann' (1685) nebst einem Anhang. Gelegenheitsgedichte in separater Überlieferung. Hrsg. und mit einem Nachwort versehen von Gerhard Spellerberg. Tübingen 1992, S. [7]-[16], hier S. [16].

13 Gerhard Spellerberg: Nachwort. Zur Lyrik Daniel Caspers von Lohenstein. In: Lohenstein: Lyrica (Anm. 12), S. $23^{*}-54^{*}$, hier S. 37*. „Es ist die im Ausloten der paradoxalen Glaubenswahrheiten gemachte Erfahrung des Scheiterns der Vernunft, die den Menschen sich vom Glauben ergreifen und dann unirritierbar leiten läßt, die den Menschen begründeterweise zur Andacht als Grundhaltung führt." (Ebd.).

14 Dazu: Franz M. Eybl: Problematische Harmonie. Lohensteins ,Thränen der Maria Magdalena zu den Füßen Unsers Erlösers'. In: Studien zum Werk Daniel Caspers von Lohenstein. 
steins geistliche Lyrik vermittelt eine "hochreflektierte Pathetik "15 die keinen Unterschied zwischen Theologie und individueller Frömmigkeit, theologischem Dogma und persönlicher Glaubenshaltung kennt. Die Bezüge zu Bibeltexten, die argumentativen und scheinargumentativen Schlussverfahren und der reiche sprachliche Ornatus appellieren an Verstand und Reflexion des Lesers, ohne doch auf die Affekterregung zu verzichten. Bei Lohenstein stellen lyrisch-appellative und logisch-argumentative Ausdrucksformen keineswegs Gegensätze dar, und die Theologie als ,Lehre von Gott - oder den Göttern' findet sich gegenüber dem gelebten Glauben keineswegs abgewertet.

Auch die weltlichen Gedichte der Rosen, zumeist Casualgedichte oder Preisreden anlässlich von Hochzeiten von Verwandten oder adligen Widmungsträgern, sind von der Komplementarität des Gegensätzlichen geprägt: einerseits eine in vielem mit Christian Hoffmann von Hoffmannswaldaus Liebeslyrik konkurrierende, ja sie überbietende erotisch-galante Direktheit der Aussage, andererseits die Exposition von theologisch-metaphysischen Prämissen, welche dem Wissenden $\mathrm{zu}$ verstehen geben, dass auch die Beschreibung des scheinbar weltlichsten Liebesgeschehens, ja selbst noch dessen physiologische Vorgänge auf einen verborgenen geistlichen Sinn verweisen. Dies ist ein explizites Thema etwa in Lohensteins Preisrede Vereinbarung der Sterne und Gemüther anlässlich der Heirat seines Bruders. Die spekulativen Voraussetzungen eines Makro- und Mikrokosmos umspannenden Denkens werden hier auf einen Nenner gebracht:

Der weise Baumeister dieses Allen hat theils eine ergätzende Wiederwärtigkeit gewissen Sachen eingepflantzet/ meist aber die grossen Geschöpffe der Welt mit einer wunderbaren Kette der Eintracht vereinigt/ und ihre an sich selbst wiederwärtige Eigenschafften durch eine annehmliche Zusammenstimmung mit einander vermählet. ${ }^{16}$

„Izt liebt die gantze welt!“ (V. 1), so hebt das Venus-Gedicht an, ein paganer Lobgesang, ohne den geringsten Hinweis auf christliche Vorstellungen, im Übrigen von einer spielerischen Heiterkeit, wie sie in Lohensteins Werk selten ist - als wolle er selber das Urteil über die eigene Poesie, diese habe aufgrund der Ernsthaftigkeit seiner Rechtgeschäfte als Syndicus „eine gewisse Säure an sich", ${ }^{17}$ Lügen strafen. Schwerer wiegt noch, dass jede Referenz auf Vorgänge, die über der antiken Welt hinaus liegen, vermieden wird, und die Moderne mit ihrem christlichen Monotheismus keineswegs als die überlegene Kultur ins Spiel gebracht wird, wie dies zeitgleich die sogenannten ,Modernes' in Frankreich in ihrer ,Querelle' mit den ,Anciens' tun.

Anlässlich der 300. Wiederkehr des Todesjahres. Hrsg. von Gerald Gillespie und Gerhard Spellerberg. Amsterdam 1983, S. 23-46, bes. S. 44 ff.

15 Gerhard Spellerberg: Nachwort. In: Lohenstein: Lyrica (Anm. 12), S. 23*-54*, hier S. $38^{*}$.

16 Lohenstein: Vereinbarung der Sterne und Gemüther. In ders.: Lyrica (Anm.12), S. 116 [350], vgl. auch: S. 126 [360].

17 Lohenstein: Vorrede. In ders.: Lyrica (Anm. 12), [S. 15]. 
Das Lobgedicht ist ein gelehrtes Spiel mit dem Wissen von der antiken Götterwelt und mit philosophischen Gedanken, die auf Lukrez' großes Gedicht De rerum natura zurückgehen, freilich mit den Mitteln barockmanieristischer Stilkünste. Dass Lohenstein mit den römischen Dichtern in Wettstreit eintreten wollte, macht seine captatio benevolentiae deutlich, in der er sein Gedicht als ein Dankopfer für Venus in den den Musen geweihten Quellen am Fuße des Helikon in Aganippe bzw. Enippe ausgibt:

[...] Verzeihe mir nur hier

Du Gnidus=königin/ daß ich diß schlechte dir

Auff dein bekräntzt altar mit ungewaschner lippe

Im gläser=hellen qvell des pferde=brunns Enippe

$\mathrm{Zu}$ opffern mich erkühn. O milde geberin

Der viel beredsamkeit/ nimm diß mein deutschen hin.

$\mathrm{Gib} / \mathrm{da}$ ein lauter schwan von deinen mir es zeige/

Wie ich dich singen soll. Laß meine lorbeer=zweige

Bey deinen myrthen blühn. [...]

(V. 31-40)

Lohenstein hat zeitgenössische literarische Vorbilder benutzt, vor allem das Adonis-Gedicht des Italieners Giambattista Marino L'Adone, das im Jahre 1612 erstmals publiziert worden war. Dieses Langgedicht mit seinen rund 40.000 Versen hatte hinter der Figur der Venus, der Tochter Jupiters, die "santa madre d'Amor" ${ }^{18}$ also Maria, durchscheinen lassen. Damit konnte dies Gedicht als „Kontrafaktur des in den Marienhymnen üblichen Anrufs “ ${ }^{19}$ dechiffriert werden, wie Hugo Friedrich aufgezeigt hat. Dergleichen wird man bei Lohenstein vergeblich suchen, so nahe er der italienischen Lyrik mit dem Prunk seiner gelehrt-arguten Vergleiche, den Ausgriffen in antike Mythologie und Geographie sowie der Verfänglichkeit seiner Darstellung des erotischen Begehrens steht. Maria als Gottesmutter konnte bei einem Lutheraner wie Lohenstein nicht denselben Stellenwert einnehmen wie bei Marino.

Marino legte, wie zuvor schon William Shakespeare in seinem Langgedicht Venus and Adonis (1593) und später Jean de La Fontaine in seinem Adonis-Gedicht (1658), den Schwerpunkt auf die von Ovid skizzierte Venus-Adonis-Handlung. Lohenstein dagegen reduziert diese narratio auf eine vergleichsweise kurze Episode seines Langgedichts (Vers 1600 bis 1702) und entwickelt für die Großstruktur eine dispositio, welche die Topoi der Abstammung, der Herkunft und Geburt der Venus, des Empfangs im Himmel durch Jupiter und der Wirkung der Liebe ex actis ausführen, verbunden mit zahlreichen eingestreuten Exkursen und Kurzer-

18 Giambattista Marino: L'Adone. Hrsg. von Giuseppe Guido Ferrero. Neapel 1954, S. 4.

19 Hugo Friedrich: Epochen der italienischen Lyrik. Frankfurt a. M. 1964, S. 691. „Marino lässt Venus fromm vom christlichen Kreuz sprechen; ihr Tempel heißt ,Kirche'; als sie sich dem Adonis zu erkennen gibt, wird sie mit der ,reinen Jungfrau' verglichen: es gibt Venusprozessionen, Venusgelübde, Venusheilige." (Ebd.). 
zählungen. In Lohensteins Venus gibt es keine fortlaufende Handlungslinie, die erzählt würde, sondern einen entsprechend der antiken epideiktischen Literatur geformten, wohldurchdachten, wenn auch nicht leicht zu durchschauenden rhetorisch-topischen Aufbau. ${ }^{20}$ Wie auch Herbert von Cherbury in De religione gentilium stellt Lohenstein die unterschiedlichen Überlieferungen des Venus-Mythos dar. ${ }^{21}$

„Izt liebt die gantze welt!“. Lohenstein macht mit den dann folgenden Versen klar, dass die „gantze Welt" hier nicht ausschließlich die höfische Welt oder, noch weiter gefasst, die Menschenwelt meint. Vielmehr sind die antike Götterwelt und die Natur, also Mythologie und Naturphilosophie, mit eingeschlossen:

Izt liebt die gantze welt! des Titans glut wird mächtig

Die erde zu vermähln/ der himmel machet trächtig

Mit regen ihren schooß/ das blumen-gelbe jahr

Beschwängert ihren bauch/ der blumen sommer=haar

Bekleidet allbereits die unbelaubten wipffel:

Des Demus kahlen kopff/ und die unwirthbarn gipffel/

Die hier der süd versengt/ und dort der schnee ableckt/

Hat schon der bunte lentz mit kräutern überdeckt.

(V. 1-9)

Feuer und Wasser, Erde und Himmel - die vier Elemente der antiken ElementenLehre erweisen sich als von Liebe durchdrungen, zumal in Frühling und Sommer. Wie es später im Gedicht heißt: „Lufft/ erde/ see und feur/ ja diese gantze welt/ Wird durch der liebe geist begeistert und erhellt“ (V. 1412 f.). Lohenstein nimmt das Bild von der Umarmung von Himmel und Erde von Hesiod auf, doch verweist die allegorisch ausgesponnene Metapher von Vermählung, Schwängerung und Schwangerschaft über Hesiod hinaus auf sein anderes großes literarisches Vorbild: auf Lukrez' De rerum natura. Dieses philosophische Lehrgedicht beginnt ja mit einer Anrufung der Venus als „Mutter der Aeneaden, der Menschen und der Götter Wonne, Venus, Spenderin des Lebens [...]. Dir verdankt alles Belebte Empfängnis, den ersten Blick auf der Sonne Licht.“22 Für Lukrez ist die Venus-Liebe das schlechthin lebenserhaltende Prinzip, ohne „den leidenschaftlichen Trieb, [...] sich zu mehren ", ${ }^{23}$ würde keine Tier- und Pflanzengattung und auch der Mensch nicht überleben. Diesen Gedanken variiert Lohenstein:

Wo würde frucht und brut/ und alles marck der erden

In der versiegnen art gezeuget können werden/

Bey mangel deiner glut? [...]

(V. 77-79)

20 Vgl. dazu: Charlotte Brancaforte: Struktur des Gedichts ,Venus'. In dies.: Lohensteins Preisgedicht, Venus' (Anm. 5), S. 78-100.

21 Vgl. Cherbury: De religione gentilium (Anm. 3) S. $133 \mathrm{ff}$.

22 Lukrez: Über die Natur der Dinge. In deutsche Prosa übertragen und kommentiert von Klaus Binder. Mit einer Einführung von Stephen Greenblatt. Berlin 2014, S. 39.

23 Lukrez: Über die Natur der Dinge (Anm. 22), S. 39. 
[...] Daß dieses alles alle

Nicht stracks in einem nu in einen klumpen falle/

Hält Deine gutthat auff. [...]

(V. 81-83)

Was bei Lukrez in die elegante und begrifflich konzise Versform eines philosophischen Lehrgedichts gegossen ist, erscheint bei Lohenstein als rhetorisch amplifizierter und reich geschmückter epideiktischer Diskurs, als Lobgesang. Für Lohenstein ist die Idee von der Liebe als schlechthin generativer Kraft in Natur- und Menschenwelt eine Vorstellung, auf die er in vielen Gedichten, in den Reyen zu seinen Trauerspielen und in seinem Arminius-Roman immer wieder zurückkommt. ${ }^{24}$ Schon Lukrez verstand die Venus-Figur rein allegorisch, da er, entsprechend der Religionskritik Epikurs, die traditionellen griechischen und römischen Göttervorstellungen ablehnte, ja bekämpfte. Auch Lohenstein lag es fern, diese Göttin anders denn als allegorisch zu verstehen. Allerdings hatte er andere Gründe dafür: Während für Lukrez, wie schon für Epikur, die Götter ohne Möglichkeit der Einflussnahme auf das irdische Geschehen in irgendeinem kosmischen Intermundium leben, unterstellt Lohenstein einen Schöpfergott, der die Welt wohl geordnet hat und der auch der Liebe bzw. der Wollust ihren festen Platz in seinem Schöpfungsplan zugewiesen hat. Eine Göttin Venus hat in seinem monotheistischen Glaubenssystem keinen Platz, auch wenn sie hier beinahe mit der Macht eines monotheistischen Gottes ausgestattet ist.

Diese gedankliche Verbindung des polytheismuskritischen antiken Epikureismus mit christlichen Gottesvorstellungen war durch den neuzeitlichen Rezeptionsprozess des 1417 wiederentdeckten Lehrgedichts Lukrez' möglich geworden. Von dem Florentiner Philosophen Marsilio Ficino über Niccolò Machiavelli und Giordano Bruno bis hin zu Michel de Montaigne fand es eine teils untergründige, teils provokativ öffentliche Rezeption, über die das religionskritische Denken Epikurs in die europäische Geistesgeschichte einging. ${ }^{25}$ Nachdem Lukrez' Gedicht einmal über die Druckerpresse verbreitet worden war, konnte es als wichtigster antiker Vermittler von Epikurs Denken nicht länger unterdrückt werden. Der katholische Priester und Mathematiker Pierre Gassendi unternahm dann in der ersten Hälfte des 17. Jahrhunderts den Versuch, Epikurs Lehre mit christlichen Glaubenspostulaten zu versöhnen: In seinem De vita et moribus Epicuri (1647) versuchte er, die seit der Antike übliche Diffamierung Epikurs zu

24 Dazu: Reinhart Meyer-Kalkus: Wollust und Grausamkeit. Affektenlehre und Affektdarstellung in Lohensteins Dramatik am Beispiel von Lohensteins ,Agrippina'. Göttingen 1986.

25 Eine kurze Rezeptionsgeschichte hierzu bietet Stephen Greenblatt: Einführung. In: Lukrez: Über die Natur der Dinge (Anm. 22), S.9-17. Vgl. umfassend: Die Rezeption der atomistischen Philosophie. In: Grundriss der Geschichte der Philosophie. Begründet von Friedrich Ueberweg. Die Philosophie des 17. Jahrhunderts. Bd. 2: Frankreich und Niederlande. Hrsg. von Jean-Pierre Schobinger. Basel 1993, S.199-230; zu seiner Wirkungsgeschichte ebd., S. 231-257. 
widerlegen. Später publizierte er eine systematische Darstellung von Epikurs Philosophie unter dem Titel Philosophiae Epicuri syntagma, die sich auf antike Autoritäten wie Lukrez, Diogenes Laertios, Cicero und Seneca stützt. Obgleich Gassendi eine mechanistische Deutung von Natur und menschlichen Empfindungen entwickelte, vertrat er in seiner Physik einen göttlichen Ursprung der Schöpfung. In seiner Ethik legte er dar, dass das Streben nach Lust, Seelenfrieden und Schmerzfreiheit die höchsten Ziele menschlichen Strebens sind.

Es sind keine Zeugnisse für eine direkte Rezeption Gassendis durch Lohenstein überliefert, dennoch lassen sich Elemente dieses christlichen Epikureismus in seinen Schriften nachweisen. In seinem Arminius-Roman heißt es über Epikur in einem der philosophischen Gespräche des ersten Bandes: „Er hat geirret/ wie alle Weltweisen in andern Stücken; wo es anderst wahr ist/ daß er unsere Seelen für sterblich gehalten/ und keine göttliche vorsehung geglaubt“ “. ${ }^{26}$ Epikur könne man aber zu Gute halten, er habe

die Eitelkeit der Griechischen Abgötter verworffen/ die Vielheit der Gottheiten als den Grund aller ihrer Tempel und Andacht über einen Hauffen zu werffen angezielet; der lasterhafften Seelen künfftige Angst aber durch ihre Sterbligkeit angedeutet [...]. Massen denn auch einige seiner Feinde gestehen/ daß er nicht so wohl die Versehung Gottes/ als daß das ewige/ unsterbliche und allergütigste Wesen einiger Schwachheit der Sorgfalt unterworffen sey/ geleugnet habe. [...] Denn Epicurus hat zwar die Wollust auf den Königs-Stul des höchsten Gutes erhoben/ nicht aber die üppige und schlammichte/ sondern die ruhige /welche aus dem Besitzthum der Tugend und insonderheit aus der süssen Erinnerung dessen/ was man voriger Zeit gutes gethan hat/ entspringet; also auch zwischen Fesseln und Folterbanck ihre unabtrennliche Gefährtin ist. Diese Wollust ist sicher nichts anders/ als die Beruhigung des Gemüthes/ und die Freude eines guten Gewissens. ${ }^{27}$

Epikur hat also geirrt im Hinblick auf die Unsterblichkeit der Seele und die Vorsehung in Natur und Geschichte. Im Hinblick auf ein vernünftiges und tugendhaftes Streben nach Lust kann man ihm aber durchaus folgen. Lohenstein war bekanntlich kein Anhänger des Stoizismus und dessen Verdammung der Affekte. Nach Thomas Borgstedt hat Lohenstein seine Ablehnung der stoischen Kritik noch epikureisch zugespitzt: „Die epikureische Idee der Ataraxie als einer milden und angenehmen Seelenbewegung ", ${ }^{28}$ die sich einer Lenkung des Strebens nach Lust durch Vernunft und Tugend verdanke, verweise schon auf die frühaufklärerischen Glückseligkeits-Lehren, etwa von Christian Thomasius.

26 Daniel Casper von Lohenstein: Großmüthiger Feldherr Arminius. 2 Bde. Leipzig 1689/90. Neudruck. Hrsg. von Elida Maria Szarota. Hildesheim, New York 1973. Bd. 1, S. 617b.

27 Lohenstein: Arminius (Anm. 26), S. 617b-618a.

28 Thomas Borgstedt: Reichsidee und Liebesethik. Eine Rekonstruktion des Lohensteinschen Arminiusromans. Tübingen 1992, S. 85. 
In seinem Venus-Gedicht stehen allerdings weniger Ataraxie und sanfte Affekte als vielmehr die extremen Affektstufen von Liebe und Wollust und deren Gefährdungen im Vordergrund. Lohenstein konnte auch hier an Lukrez anknüpfen, hatte dieser doch im vierten Gesang das Streben nach Lust als höchstes Ziel des Menschen und aller Lebewesen grundsätzlich gerechtfertigt, zugleich aber, an Epikur anschließend, die Verirrungen und pathologischen Abwege scharfsinnig analysiert. „Begehren und Wollust ist Venus für uns; von daher der Liebe Namen; von daher tropft uns Venus zuerst süßen Tau ins Herz, und darauf folgen abkühlend Kummer und Sorge. " 29

Das Motiv der Liebeskrankheit variiert Lohensteins Venus-Gedicht in vielen Episoden, teilweise durchaus auf heiter-scherzhafte Weise, wenn er etwa darstellt, wie der ganze Götterhimmel, und zumal der oberste Gott Jupiter, durch das Erscheinen der Venus in helle Aufregung versetzt werden, oder wenn Cupido seine Liebespfeile der Venus selber ins Herz versenkt, so dass sie in Liebe zu Adonis verfällt. Lohenstein findet eine an die petrarkistischen Liebesparadoxien anknüpfende Sprache, wenn er die Perspektive des vom Liebesgift Infizierten narratologisch gesprochen: in interner Fokussierung - vergegenwärtigt:

Ich weiß nicht/ was ich will/ ich will nicht/ was ich weiß!

Ich bin nach kranckheit kranck/ und will doch nicht erkrancken;

Was ists denn/ das mich kränckt? Sinds nichtige gedancken?

Ich denck ja allezeit nicht mehr zu dencken dran?

Ich fühl es warheit seyn/ und ist doch nur ein wahn.

Lieb' ich aus zwang? Wie kan ich mich denn selber zwingen?

Lieb ich freywilliglich/ was muß mich denn so dringen?

Die wunde fühl' ich zwar/ fühl aber keinen pfeil;

Ich bin begarnt/ bestrickt/ allein kein band/ kein seil/

Kein netze schau ich nicht. Entschlag dich dieser schmertzen/

Mein hertze! Thörichter! Ich rede zu dem hertzen/

Und hab es eingebüst. Ich leb' in lust und noth.

Leb ich? Ich sterbe ja. Ich sterb und bin nicht tod.

(V. 1269-1281) ${ }^{30}$

29 Lukrez: Über die Natur der Dinge (Anm.22), S. 163; Stephen Greenblatt fasst dies zusammen: „Die Unstillbarkeit des sexuellen Verlangens ist, nach Lukrez' Ansicht, eine der durchtriebenen Strategien der Liebesgöttin Venus. [...] Lukrez will nicht bestreiten, dass die wiederholten Umarmungen zutiefst befriedigend sind, ihn beunruhigt diese List jedoch, das Aufpeitschen aggressiver Impulse, das ungute Gefühl, das auf den Akt folgt, und vor allem das Gefühl, dass noch der Augenblick der Ekstase etwas zu begehren übrig lässt.“ Stephen Greenblatt: Die Wende. Wie die Renaissance begann. Übersetzt von Klaus Binder. München 2013, S. 206.

30 Mit Vers 1269 zitiert Lohenstein wörtlich die Zeile „Ich weiß nicht was ich will/ ich will nicht/ was ich weiß" aus Martin Opitz' Gedicht Auß dem Italienischen Petrarchae. In: Schöne: Das Zeitalter des Barock (Anm. 8), S. 716. 
Nur schwer wird sich ein anderes Beispiel für eine solche fluide und zugleich argumentativ durchreflektierte Sprache für den Gemütswirrwarr der Liebe im 17. Jahrhundert finden, und zwar ohne dass man deshalb gleich von einer Verinnerlichung im Sinne der Literatur der Empfindsamkeit sprechen könnte. Denn Affekte sind hier, bei Lohenstein, gleichsam gegenständliche Mächte, welche die Menschen von außen und innen anfallen.

Gegenüber Lukrez räumt Lohenstein allerdings der "sonne der vernunft“ (V. 108) neben der Venussonne eine ebenbürtige, wenn nicht größere Macht ein. Der Mensch ist seiner Venusliebe nicht wehrlos ausgeliefert, sofern er nur seinen Verstand gebraucht und sich vor den Abwegen seiner Leidenschaften hütet. Für Lohenstein hat die Vernunft, bzw. die Prudentia, in letzter Instanz sogar die Oberhand. Auch deshalb ist es fraglich, ob man von Lohensteins Venus-Kult als „Sakrament einer säkulären Liebes-Religion“" 31 sprechen kann. Dem Kult der Venus-Liebe wird als Gegenmacht die Prudentia entgegengesetzt, und was als ,Liebes-Religion' erscheinen mag, ist ein gelehrtes Spiel, ein ,scherzo' im Sinne der italienischen Barocklyrik. Bei einem Autor wie dem Verfasser des ArminiusRomans hätte nichts näher gelegen, als dass er die Grenzen der römischen Welt schonungslos aufzeigt. Doch Lohenstein verschmäht eine moralisch und religiös aufgeladene Konfrontation von modern und antik, von christlich und heidnischvielgötterisch, von germanisch und römisch. Aufgrund seiner naturrechtlichen Prämissen kann er das anthropologisch Gleichrangige menschlichen Verhaltens auch unter den Bedingungen unterschiedlicher Religionen herausarbeiten, so wie er Keuschheit oder Ehre einer afrikanischen Fürstin, Sophonisbe, ebenso zugestehen kann wie den Heroinen in seinem Roman. „Ich liefer nur ein Spiel“ ${ }^{32}$ heißt es in der Widmungsvorrede zu Lohensteins Trauerspiel Sophonisbe, und dies hätte er auch hinsichtlich seines Venus-Gedichts sagen können. Doch dieses Spiel mit dem religiösen Wissen der Antike und Gegenwart wäre nicht möglich gewesen ohne die aufgrund von Reisen, Reiseberichten und dem Buchdruck bewirkte Erweiterung des Horizonts in räumlicher wie in zeitlicher Hinsicht, sowohl gegenüber außereuropäischen als auch gegenüber nicht-christlichen Religionen, die in bemerkenswerter Objektivität vergegenwärtigt werden.

31 So Hans-Georg Kemper: Geschichte der deutschen Lyrik. Bd.2: Von der Reformation bis zum Sturm und Drang. Stuttgart 2012, S. 113.

32 Daniel Casper von Lohenstein: Sophonisbe. In ders: Sämtliche Werke. Historisch-kritische Ausgabe. Abteilung II: Dramen: Ibrahim Sultan - Sophonisbe. Hrsg. von Lothar Mundt, Wolfgang Neuber, Thomas Rahn. Teilband 1: Text. Hrsg. von Lothar Mundt, Berlin 2013, S. 394, V. 19. 


\title{
Heiliger Ernst, das Ich und säkulares Spiel?
}

\section{Galante Lyrik, Religiosität und Individuierung um 1700}

\author{
Stefan Elit
}

Wie spiegelt sich christliches Wissen in galanter Lyrik? Raffiniert natürlich: So wendet sich Hoffmannswaldaus Liebesklage Ich singe tauben Ohren in der fünften und letzten Strophe in typischer Wendung an die angebetete Dame, eine hochfahrende „Melinde“, die das lyrische Ich nicht erhört:

Doch wilt du göttin heißen/

$\mathrm{Zu}$ der dich deine tugend macht?

So must du auch bey solcher pracht

Dich der erbarmung stets befleissen.

Reiß deinen kalten vorsatz ein/

Nicht mache meine noth zum schertze/

Die hölle lehret grausam seyn/

Der himmel/ dem du gleichst/ verträgt kein steinern hertze. ${ }^{1}$

Gespielt wird hier das übliche Spiel der doch nicht ganz so hohen Minne: Zwar wird die Frau auf den ersten Blick einer paganen Gottheit gleich verehrt, und der sich selbst erniedrigende Geliebte beklagt ihre abweisende hoheitliche Haltung; aber es gibt auch die letztliche Erwartung beziehungsweise den subkutanen Anspruch, dass sich eine Vereinigung der Liebenden schon noch wieder herstellen sollte, weil sich die Angebetete den barock-rationalen Argumenten des Verehrers wohl wird beugen müssen. Besonders interessant ist jedoch an diesem Gedicht, dass das in Anschlag gebrachte, altbekannte liebesreligiöse Bildfeld gegen Ende dezidiert christlich eingefärbt erscheint, indem ",tugend“, "erbarmung“, "hölle“ und "himmel" argumentativ eingebracht werden. - Aber ist es das in der Galanterie nicht auch schon gewesen, was die Frage der Verschaltung von an sich grundsäkularem erotischem Spiel und Religiosa betrifft? Haben Hoffmannswaldau und andere nicht bestenfalls einen latent blasphemischen Zugriff, wenn sie christliche Themen und Motive ins Genre einblenden, statt in zeitüblicher Weise die Sphären literarisch strikt getrennt zu halten und im galanten Genre brav respektive in ausblendender Weise mythologisch antik-pagan zu bleiben?

1 Christian Hoffmann von Hoffmannswaldau: Ich singe tauben Ohren. In: Benjamin Neukirchs Anthologie. Herrn von Hoffmannswaldau und andrer Deutschen auserlesener und bißher ungedruckter Gedichte erster theil. Nach einem Druck von 1697 mit einer kritischen Einleitung und Lesarten. Hg. von Angelo George de Capua u. Ernst Alfred Philippson. Tübingen 1961, S. 379 . 
Was sodann die Frage von religiösem Wissen in der Kopplung mit modernen Individuierungstendenzen betrifft, ist die galante Lyrik in Deutschland wie auch sonst in Europa doch zudem über weite Strecken hoch formelhaft und von daher sozusagen die falsche Adresse: Zum einen entstammt das bukolische Setting der hellenistischen Antike und wurde bereits seit der Renaissance wie viele andere Stoffe und Motive nach dem Prinzip von Imitatio und Aemulatio neulateinischen und volkssprachlichen Werken zugrunde gelegt, nicht zuletzt in Kopplung mit dem europäischen Petrarkismus. Zum anderen erweiterten lasziv-erotische Elemente in der Façon Giambattista Marinos die ansonsten vor allem amplifizierte Motivik, und schon die barocke deutschsprachige Schäferdichtung erschien nur mehr als eine von vielen rhetorischen Variationsübungen, die die Bildung und das Leistungsvermögen der Autoren, oder in galanter Perspektive: deren Bon Gout nachweisen sollten. Entsprechende Anerkennung zollte ein adliges und stadtbürgerliches Publikum, das auf angemessene Weise zu unterhalten war, und diese Delectatio verhalf den Dichtern vielleicht zu einer gefestigten Position in Hof- und weiteren Berufskreisen.

Darüber hinaus war das Verfertigen galanter und wie es zeitgenössisch hieß: ,verliebter' oder scherzhaft-satirischer Gedichte nur eines von vielen literarischen Mitteln zum anerkennungsmäßigen Zweck, wenn man die Oeuvres von Hoffmannswaldau über Hunold bis Günther betrachtet. Denn deren Werkausgaben sind in aller Regel, und in typischer Weise abteilungsmäßig rubriziert, zugleich Sammlungen diverser, ernsthafter' säkularer und religiöser Gelegenheitsdichtungen sowie von Epigrammen und anderen Kleinformen oder späterhin bisweilen sogar von Kirchenliedern. Von der ethisch-ästhetischen Vereinbarkeit des Schreibens in allen diesen Formen wird dabei in barocküblicher Weise anscheinend ausgegangen, auch wenn durchaus ein gewisser Legitimationsdruck vorgelegen haben mag, wie sich an einzelnen Vorreden zu Ausgaben erkennen lässt. Aber nicht zuletzt erwies eben das Produzieren in diesem ganzen Formenspektrum die Verfasser als gute Traditionsvertreter, deren ,Individualität' sich - wenn man diese Kategorie denn verwenden will - im Bespielen und Variieren der Gattungskanones herstellte.

Auf den ersten Blick hat literarische Galanterie also kaum etwas mit individualistischen Entwicklungen des religiösen Wissens oder auch mit modernen Lyriktendenzen um 1700 gemein. Rhetorisch gesehen ist bei der galanten Strömung mit der Zeit lediglich eine Verschiebung auf der Ebene der Elocutio bzw. des Stils von einem spätbarocken Pleonasmus hin zu einem (wieder) klassizistischen beziehungsweise frühaufklärerischen Claritas-Ideal festzustellen. Auf den Ebenen der Inventio, also des Motivbestands, und der Dispositio, der typischen Themenanordnung, sind hingegen bis zum Ende der Strömung gegen 1720 nur wenige signifikante Veränderungen mit Blick auf die in diesem Rahmen interessierenden Modernisierungsschübe zu erkennen.

Kurzum: Muss man die Galanten an dieser Stelle nicht schlicht ein weiteres Mal ,überspringen', so wie dies mit deren literarischen Erzeugnissen - scheinbar 
mangels Wert und Bedeutung - sowieso jahrzehntelang geschehen ist, wenn es um die Entwicklung der deutschsprachigen Lyrik vom Barock zur Aufklärung ging? Bis auf wenige Ausnahmen zumal gegen Ende der galanten Strömung könnte man dies durchaus konstatieren, denn eine deutliche und ,positive' Verbindung stellt sich wie gesagt weder hinsichtlich zeitgenössischer Individualisierungstendenzen noch hinsichtlich etwaiger Transformationsleistungen religiösen Wissens her. - Ergo: vielen Dank, der Nächste bitte?

So rasch sei die galante Lyrik nun doch nicht entlassen, denn bei genauerem Hinsehen gibt es immerhin interessante thematische Konvergenzen oder auch Beziehungen ex negativo, wie die eingangs zitierte kleine ,Blasphemie', und es lässt sich daher nicht zuletzt die Frage aufwerfen, wie sich sozusagen ein galanter Parallellauf neben der hier interessierenden doppelten Innovierung der zeitgenössischen Lyrik gehalten hat respektive wie die galante Strömung womöglich zumindest indirekt auf religiöse und individualistische Tendenzen reflektiert haben könnte.

Um diese etwas intrikate Korrelation zumindest in einigen Ansätzen zu verfolgen, seien folgende Sondagen unternommen: Erstens sind Selbstpositionierungen der Galanten gegenüber ethischen und oft zugleich religiösen Anforderungen im Kontext zeitgenössischer höfischer Theorie auszuloten. Zweitens werden Spielarten von galanten Stellungnahmen zu kirchlich-religiösen Fragen in den Blick genommen. Drittens lässt sich für ausgewählte Beispiele beobachten, wie die Topik der galanten Strömung bei einzelnen Autoren durch eine Art ,Ernsterwerden' mit religiösen und individualisierenden Tendenzen gekoppelt wird; und viertens, und damit ausblickartig abschließend, soll ein kleiner Vergleich zu einer Entwicklung in der epochal ja unmittelbar nachfolgenden Anakreontik gezogen werden.

\section{Galanterie und christliche Ethik in der höfischen Theorie}

Eine erste Ebene, auf der sich fragen lässt, wie sich die galante Lyrik in allgemeiner Form ethisch selbst positioniert und in welches Verhältnis zur zeitgenössischen Morallehre vor allem christlicher Provenienz sie sich setzt, ist die akademische Handlungslehre beziehungsweise dann die explizite Poetik zentraler Vertreter der Galanterie in Deutschland. Mit Blick auf die Handlungslehre können exemplarisch Setzungen von Christian Thomasius und August Bohse herangezogen werden. Bei Thomasius ist es eine 1689 publizierte Vorlesung zur allerdings dezidiert außerliterarischen Galanterie, die in ihrer veröffentlichten Form die zu lehrende oberste Verhaltensmaxime zugleich mit einer basalen Sensibilität für die Sphäre des Religiösen in ihrem Titel verkündigt:

Christian Thomasius eröffnet Der Studierenden Jugend Einen Vorschlag, Wie er einen Jungen Menschen, der sich ernstlich fürgesetzt, GOtt und der Welt dermahleins in vita civili rechtschaffen zu dienen, und als ein honnet 
und galant homme zu leben, binnen dreyen Jahre Frist in der Philosophie und singulis Jurisprudentiae partibus zu informiren gesonnen sey. ${ }^{2}$

Was genau einen "galant homme" ausmacht, führt Thomasius im 13. Abschnitt aus, in dem er den Begriff der Galanterie aufschlussreich an seine dreigeteilte praktische Philosophie, sprich: Ethik, Politik und Ökonomik, anschließt:

Über dieses ist in der Welt aber noch was besonders, das nebst dem honesto, utili und jocundo dem Thun und Lassen der Menschen eine gemeine Richtschnur ist, absonderlich aber Polite, Welt-kluge und höffliche Leute von plumpen, groben und ungeschickten Tölpeln absondert. Dieses wird von den Lateinern Decorum, von denen Frantzosen Galanterie genennet. ${ }^{3}$

Thomasius' Begriff des Decorum als eine Art in der höfischen Welt angemessenes Verhalten erscheint hier gleichsam als Kern weniger einer Ethik denn einer Ästhetik des Galant Homme - darauf wird auch noch zurückzukommen sein. Im weiteren Abschnitt legt Thomasius jedoch Wert darauf, dass das Decorum nicht mit dem anscheinend eng benachbarten Honestum, also der Zentralkategorie der Ethik, zu verwechseln sei. Er korreliert dann aber den Begriff des Decorum vor allem mit dem Pudor als seinerseits ja ethischem Kernbegriff der ehrfürchtigen Scheu und Scham, und spricht auch von "dem decoro, als andern bonis". ${ }^{4}$ Thomasius suggeriert so zumindest, dass Galanterie letztlich nur ein zutiefst sittsames, ja geradezu religiös schamhaftes Verhalten sein könne.

Wenig später postuliert dann der Rhetorikprofessor und Schriftsteller August Bohse Ähnliches, wobei Bohse für seinen Begriff von Galanterie respektive ebenfalls: des Decorum noch mehr als Thomasius Bezug nimmt auf den Rahmen christlich-religiöser Moral, den er für höfisches Verhalten gesetzt sieht; und zwar behauptet Bohse unter seinem Pseudonym Talander 1706 in der Lehrschrift Der getreue Hoffmeister adelicher und bürgerlicher Jugend gleich zu Anfang (§ 2): „Die erste Schuldigkeit nun, welche einer zu beobachten hat, damit er so wol seiner ewigen Wohlfarth rathe, als auch bey der honêtten Welt sich in guten Credit setze, ist diese, daß er eine rechte Ehrerbietung gegen GOTT und Liebe zu dessen Wort von sich leuchten lasse. ${ }^{5}$ Diese allgemeine Maxime für den galanten jungen Mann bedeutet für ihn allerdings recht pragmatisch, dass man sich etwa bei Kirchgängen gut zu betragen habe, also zum Beispiel beim Betreten einer Kirche immer schön den

2 Christian Thomasius: Der Studierenden Jugend [...]. Halle 1689.

3 Thomasius: Der Studierenden Jugend (Anm. 2), S. 33 (s. auch in: Der galante Stil. 16801730. Hg. von Conrad Wiedemann. Tübingen 1969, S. 4-6, hier: S. 4). Vgl. zur Erläuterung und Abgrenzung zur philosophischen Fundierung bei den voranstehenden Franzosen Jörn Steigerwald: Galanterie. Die Fabrikation einer natürlichen Ethik der höfischen Gesellschaft (1650-1710). Heidelberg 2011, S. 25-55, bes. S. 44 f.

4 Thomasius: Der Studierenden Jugend (Anm. 2), S. 36 (s. auch in: Der galante Stil [Anm. 3], S. 5).

5 Talander: Der getreue Hoffmeister adelicher und bürgerlicher Herkunft [...]. Leipzig 1706, S. 70 (s. auch in: Der galante Stil [Anm. 3], S. 16 f., hier: S. 16). 
Hut abnehmen und erkennbar mitbeten müsse; ${ }^{6}$ außerdem solle man sich etwa weder über geistliche Lieder noch Prediger lustig machen. ${ }^{7}$ Wie pragmatisch beziehungsweise wieder mehr ästhetisch denn wirklich ethisch Bohse fokussiert, zeigt sich schließlich in einer Nebenbemerkung: „Selbst diejenigen Staatisten [!] und Hof-Leute, welche lieber wolten, daß kein Gott wäre [...], werden sich doch beym Gottesdienst allezeit sittsam und bescheiden aufführen, damit sie theils von sich eine gute Opinion machen; theils andere nicht ärgern [...]." 8

Von galanter Literatur, oder aus der Perspektive von Thomasius und Bohse: von deren Verfertigung durch Galant Hommes, ist interessanterweise praktisch nicht die Rede, und Wiedemann hat daher für die beiden Autoren bereits konstatiert: „Im System der streng utilitaristisch orientierten galanten Lebenslehre hat [...] die Poesie in der Regel keinen Platz. ${ }^{\prime 9}$ Befragt man jedoch noch stärker pragmatisierte beziehungsweise konkreter auf Beschäftigungen bei Hofe bezogene Lehrschriften galanter Couleur, erscheint literarisches Schreiben, neben anderen Kunsttätigkeiten, durchaus sinnvoll. Etwa in einer Schrift des Nürnberger Naturwissenschaftlers und Schriftstellers Johann Leonhard Rost finden sich entsprechende Ausführungen, die Rost 1713 unter dem Pseudonym Meletaon und mit dem Titel Von der Nutzbarkeit des Tantzens veröffentlicht hat. Aufschlussreich sind diese Ausführungen nicht nur wegen ihrer besonders typischen Definitionselemente für Galanterie, sondern auch wegen einer kleinen ,Vorneverteidigung' gleich zu Beginn:

Die Galanterie ist nichts anders, als eine schertzhaffte und dabey kluge Artigkeit: und diese ist weder in der Biebel [!] noch sonsten verbotten. Sie ist das Mittel, grosse Gesellschafften zu unterhalten: Sie ist der Weeg, sich bey Hohen und Niedern beliebt zu machen. [...] Ein galanter Mensch muß in allem seynem Thun natürlich seyn, und gleichwol, so natürlich er ist, so muß er doch auch in allen Dingen etwas besonders haben. Tantzet er, so muß er es ohne Affectirung der Kunst, aber doch mit Verwunderung aller Zuschauer thun: Singet er, so muß er gefallen, redet er, so muß er ergötzen, machet er Verse, so müssen sie durchdringen [...]. ${ }^{10}$

Die konkreten Maximen verweisen vor allem offen auf den latent paradoxen Imperativ höfischen Verhaltens: ,Erscheine effektvoll natürlich', den Thomasius und Bohse noch umschifft hatten, indem sie eine notwendige ethische Korrektheit der Galanterie behaupteten. Je näher man an die galante Literatur kommt, so ließe sich sagen, desto ethisch verminter wird das Gelände jedoch sogleich. Bemerkenswerter erscheint aber wie gesagt zu Eingang des Zitats die defensive

6 Vgl. Talander: Der getreue Hoffmeister (Anm. 5), S. 71 (s. auch in: Der galante Stil [Anm. 3], S. 16).

7 Vgl. Talander: Der getreue Hoffmeister (Anm. 5), S. 76 f.

8 Talander: Der getreue Hoffmeister (Anm. 5), S. 72.

9 Nachwort, in: Der galante Stil (Anm. 3), S. 149-151, hier: S. 149.

10 Meletaon: Von der Nutzbarkeit des Tantzens [...]. Frankfurt/Main, Leipzig 1713, S. 7 f. 
Linie, die Rost in die wiederum recht ästhetisch galante Lehre mit Bezug auf die christliche Ethik einzieht und die davon zeugt, dass Galanterie und allgemeine ethische Maßstäbe der Zeit wohl doch nicht einfach konform erschienen, denn (siehe oben): „Die Galanterie ist nichts anders, als eine schertzhaffte und dabey kluge Artigkeit: und diese ist weder in der Biebel noch sonsten verbotten."

Darüber hinaus wird das Verfassen galanter Dichtung zeitgenössisch problematisiert, wenn es um Autoren geht, deren Hauptaugenmerk eigentlich der christlichen Lehre oder allenfalls ,ernsthafter' religiöser Dichtung zu gelten hatte - das barocke gleichzeitige Bespielen verschiedenster Gattungen wird anscheinend spätestens dann angreifbar, wenn ein Geistlicher sich auch in galanter Lyrik übt. Erkennbar wird diese Problemlage in Christian Friedrich Hunolds berühmter „Vorrede“, die dieser unter seinem Pseudonym Menantes zu der 1707 von ihm herausgegebenen Poetik Die Allerneueste Art, Zur Reinen und Galanten Poesie zu gelangen verfasst hat. Hunold nimmt dort Bezug auf die bereits von Johann Burckhard Mencke gestellte Frage, „Ob ein Poete wohl Superintendens seyn könne?", 11 und er referiert zustimmend dessen Argumentation, dass es gute historische Beispiele gebe, nach denen die eigene moralische Integrität, ja sogar eine besonders große Frömmigkeit durch das Abfassen selbst ",sehr verliebter Verse ${ }^{\text {"12 }}$ nicht zweifelhaft werde. Insbesondere das Thema Liebe dürfe allerdings in Dichtung nicht missbraucht im Sinne von entwürdigt werden. ${ }^{13}$ Hunold beschließt die Diskussion sodann mit einer Verallgemeinerung, die die galante Dichtung wohl mit einschließen soll und die einer beliebten Argumentation der liberalen Literaturvertreter um 1700 entspricht: „Daß keine vergnügtere und dabey edlere Beschäfftigung ist/ als seine Poesie dem Himmel/ sich selber/ oder seiner Gemüths=Zufriedenheit/ und hohen/ wie auch andern tugendhafften/ oder Tugend=bedürfftigen Personen zu Gefallen und Ruhm verfertigen. " ${ }^{14}$

Die Ausgangsfrage, „Ob ein Poete wohl Superintendens seyn könne?", hatte Menke in einem Gratulationsgedicht auf seinen Leipziger Studienfreund, den frisch in einem solchen Amt (in Sorau) bestallten Erdmann Neumeister gestellt; Hunold stellt dies zu Beginn seiner kleinen Erörterung auch durchaus klar, nicht explizit geklärt wird jedoch der springende Punkt, dass auch die ganze von Hunold herausgegebene galante Poetik von ebenjenem Neumeister stammt - ,Poet sein' durfte ein Superintendent also schon, offener poetologischer Verfechter einer wenn auch vergleichsweise zurückhaltenden respektive noch von älterem Gelehrtentum geprägten literarischen Galanterie aber wohl doch besser nicht. ${ }^{15}$

11 Menantes: Vorrede, in: [Erdmann Neumeister:] Die Allerneueste Art, Zur Reinen und Galanten Poesie zu gelangen [...]. Hg. von Menantes. Hamburg 1707 [unpag.].

12 Menantes: Vorrede (Anm. 11).

13 Vgl. Menantes: Vorrede (Anm. 11).

14 Menantes: Vorrede (Anm. 11).

15 Zur Verfasserfrage sowie zu Neumeisters Poetik vgl. Helmut K. Krausse: „Die unverbotne Lust". Erdmann Neumeister und die galante Poesie. In: Daphnis 9 (1980), S. 133-161, bes. S. 139, sowie Dieter Merzbacher: Ob ein Poete wohl Superintendens seyn könne? Erdmann Neumeisters Kantatendichtungen im Spiegel seiner Poetik. In: Erdmann Neumeister (1671- 
Was die bei Neumeister zu beobachtende Zurückhaltung in Eroticis betrifft: Die immer stärkere Selbstbeschränkung, zumal gemessen an den Ausgängen bei Hoffmannswaldau, wird auch an den Beispielen deutlich, die Neumeister entsprechenden Kapiteln seiner Poetik beifügt, und diese Tendenz verstärkt sich ja nach 1700 allenthalben. Erinnert sei exemplarisch an die entsprechende Entwicklung der berühmten ursprünglich von Benjamin Neukirch herausgegebenen Bände Herrn von Hoffmannswaldau und andrer Deutschen auserlesener und bißher ungedruckter Gedichte: Spätestens mit dem sechsten Band von 1709 kommt es zu einer starken Zurücknahme der marinistischen Erotik zugunsten dezenterer, gleichsam wieder petrarkistischer Formen. Die Metzgers, wissenschaftliche Editoren unter anderem dieses Bandes, konstatierten diese Tendenz konkret am Wechsel der Herausgeberschaft ab Band fünf, das heißt von Christian Hölmann zu Gottlieb Stolle, und sahen schon in Stolles Herausgeber-Pseudonym „Leander" ein Signal hin zu mehr ,ernsterer' Elegik beziehungsweise zu einem ,moralischeren' Zeitgeschmack, auf den die verlegerisch stark erfolgsorientierte Reihe ausgerichtet war. ${ }^{16}$

Und eine weitere zusammenfassende Beobachtung: Nachdem die ersten allgemeinen Theoretiker der Galanterie diese de facto beinahe modern vornehmlich ästhetisch ${ }^{17}$ bestimmt haben, sehen die Theoretiker der literarischen Galanterie doch wieder einen zunehmenden ethischen Selbstrechtfertigungsbedarf, und gegen Ende der Strömung scheinen die christlich begründeten moralischen Grenzen enger und enger zu werden. Die Geschichte der galanten Poetik ist insofern auch die einer Entwicklung von einer höfisch-liberalen ästhetischen Autonomisierung zu einer immer stärkeren moralisch begründeten Defensive und schließlich ,neuen Keuschheit‘. Die sich verstärkende Übernahme von christlichethischen Maßstäben lässt die Strömung so gewissermaßen in einer neuen Ethisierung enden, in die sich die Dichter womöglich in einer nun aufgeklärt-modern begründeten und gewissermaßen auch individualisierten Selbstbeschränkung ergeben. Vor der vollen individualistischen Autonomie der bürgerlichen modernen Lyrik des 18. Jahrhunderts steht aber erst einmal noch das Versiegen einer ästhetischen Freiheit der höfischen Galanterie.

Die Selbstpositionierung der Galanten in explizit poetologischen Schriften und auf der Ebene der allgemeinen ethischen Gattungstendenzen ist jedoch das

1756). Wegbereiter der evangelischen Kirchenkantate. Hg. von Henrike Rucker. Rudolstadt, Jena 2000, S. 75-95.

16 Erika A. Metzger, Michael M. Metzger: Einleitung. In: Benjamin Neukirchs Anthologie. Herrn von Hoffmannswaldau und andrer Deutschen auserlesener und bißher ungedruckter Gedichte Sechster Teil. Nach dem Druck vom Jahre 1709 mit einer kritischen Einleitung und Lesarten. Hg. von dens. Tübingen 1988, S. IX-XXXVIII, hier: S. XXI.

17 Besonders pur ästhetisch erscheint außerdem noch die Def. "galante Dichter" in der "Vorrede $^{\prime \prime}$ des Herausgebers Neukirch. In: Neukirchs Anthologie 1 (Anm. 1), S. 6-22, hier: S. 18/Z. 455-458: „feurige und aufgeweckte gemüther, welche in der galanterie sehr wohl erfahren, im erfinden kurz, in der ausarbeitung hurtig, und in allen ihren gedanken seltsam seyn." 
eine, ein anderes sind die mehr oder weniger impliziten galanten Positionsnahmen gegenüber Religiösem und Klerikalem, die sich auf mindestens drei Ebenen und vor allem in epigrammatischen Dichtungen zeigen und die nun gesichtet werden sollen, und zwar a) bibel- und klerikerbezogene erotische sowie andere Anzüglichkeiten, b) tendenziell ernstere Kirchen- und Religionskritik und c) scherzhaft-parodistische Gelegenheitsgedichte auf der Basis ernsthaft-religiöser literarischer Gattungen.

\section{Galante Positionsnahmen gegenüber Kirche, deren Vertretern und Religion}

Als Ausgangspunkt ist zum Vergleich freilich noch einmal auf explizite galante Theorie zurückzugreifen, und zwar interessiert hier namentlich der generelle Antiklerikalismus des Christian Thomasius, der ja ebenso bekannt ist wie dessen subkutane grundsätzliche Entfernung vom Christentum in Richtung auf einen verkappten Epikureismus mit typisch ,privatistischen' Tendenzen. An Thomasius' strukturelle Kritik machtpolitischer und moralisch bigotter Kirchenaktivitäten, sei es auf katholischer, sei es auf protestantischer Seite, sei ebenfalls erinnert. ${ }^{18}$

In den nachfolgend zu diskutierenden lyrischen Stücken, vornehmlich aus der Neukirch'schen Sammlung, ist zwar eine solche Grundsätzlichkeit eher selten zu finden, statt auf höchste Machtstrukturen richten sich die Gedichte eher auf kritikables Verhalten einfacher Kleriker, die generelle Stoßrichtung erscheint jedoch vergleichbar: Es geht gegen klerikale Autoritätsansprüche und Bigotterie und implizit damit um einen selbstbewussteren Umgang mit der Kirche sowie um einen individuelleren Zugang zu religiösem Wissen. Dass die meisten Positionsnahmen dieser Art anonym abgedruckt sind, verweist zudem auf die Gefahren, die diese für die Autoren als empirische Individuen mit sich bringen mochten. Als tendenziell ,privatistisch' bzw. ,individualisierend' könnte man Lyrik dieser Art im Übrigen insofern ansehen, als ihre spöttische Hinterfragung von Kirchenpersonal und -dogmen nicht nur ein genüssliches ,Vorführen' bedeutet, sondern indirekt gewissermaßen eine Lanze für mehr Toleranz gegenüber andersartigen Lebensweisen bricht - was dann zugleich eine moralische Kritik als Plädoyer für weniger Scheinmoral wäre oder womöglich sogar eine allgemeine Propagation galanter Lebensästhetik.

\section{a) Bibel-und klerikerkritische Erotica und andere Anzüglichkeiten}

Schon bei Figuren des Alten Testaments setzen galante Thematisierungen an. Dabei geht es um Personen, deren Lebensweise aus christlicher Sicht zwar bereits kritikabel erscheint, die nun aber auch als typisch menschlich und gewissermaBen galant gedeutet wird. Dies ist etwa der Fall in dem anonymen Epigramm Auf den Loth aus Band 6 der Neukirch'schen Sammlung:

18 Vgl. Frank Grunert: Antiklerikalismus und christlicher Anspruch im Werk von Christian Thomasius. In: Les Lumières et leur combat. La critique de la religion et des Églises à l'époques des Lumières / Der Kampf der Aufklärung. Kirchenkritik und Religionskritik zur Aufklärungszeit. Hg. von Jean Mondot. Berlin 2004, S. 39-56. 
ZWey engel haben dich aus einem brand' erlöst, Zwey weiber haben dir den andern eingeflöst.

Aus was die flucht dich bracht, drein stürtzt dich die begier;

Ein Sodom läst du dort, das andre findst du hier. ${ }^{19}$

Wenige Seiten später folgt im selben Band ein an die Damenwelt gerichtetes Pendant, und zwar in Form eines Benjamin Neukirch zuzuschreibenden Epigramms, das laut Titel aus dem Mund von Davids Frau Abigail kommt:

Ich habe Davids zorn mit freundlichkeit versöhnt,

Daß er mein wittwen=lied mit seiner liebe crönt.

Ihr weiber, dencket nach! War ich nicht klug und schlau?

Ich gab ihm einen korb, so ward ich seine frau. ${ }^{20}$

Die beliebteste Rubrik ist jedoch in zeitloser Perspektive das Leben von einfachen Klerikern, sprich: Priestern, Mönchen und Nonnen, und insbesondere deren starkes erotisches Begehren, aber auch dasjenige gegenüber ihnen, sowie weitere menschliche Schwächen. Ein besonders pikantes Beispiel ist das von Christoph G. Burghart in dem Einstropher An eine Nonne ausgemalte sexuelle Verlangen; in der Fiktion wird entweder tatsächlich eine Nonne adressiert oder im Bild des Nonnenlebens eine besondere Erotik gefunden und mit Galanterie-typischen Bilder ausgemalt; der Reiz könnte genau in der diesbezüglichen Unentscheidbarkeit liegen, die bis zum Schluss anhält:

Darff sich was weltliches in deine zelle wagen?

Darff wohl, o heilige, bey dir ein sünder stehn?

Du pflegest sonsten zwar mit engeln umzugehn;

Jedoch Gott selber will sein hauß uns nicht versagen,

Wann wir nur an die brust mit leyd und reue schlagen;

Mich drückt der sünden last; du wirst dein lob erhöhn,

Woferne du mich läst bey dir zur beichte gehen;

So laß mich doch um rath vor mein gewissen fragen,

Du bist die priesterin; dein leib ist mein altar,

Die beyden lichter drauff sind deiner augen paar;

Der tempel aber selbst ist deine dunckle zelle,

Ach sprich mich, heilige, von meinen sünden loß,

Die straffe leg' ich dir gantz willig in die schooß,

Wo nicht, so bringet mich die schuld noch in die hölle. ${ }^{21}$

19 Neukirchs Anthologie 6 (Anm. 16), S. 104.

20 Neukirchs Anthologie 6 (Anm. 16), S. 106.

21 Christoph G. Burghart: An eine Nonne. Zit. nach: Der galante Stil (Anm. 3), S. 114. 
Eine größere Tradition hat freilich die Kritik des Nonnenlebens in Form der Unterstellung, dass es mit deren Keuschheit realiter nicht ganz soweit her sei, sondern vielmehr allenthalben galant-erotisches Verhalten zu finden wäre. Ein frühes Beispiel für Lyrik dieser Art hat Hoffmannswaldau geliefert, wobei sich die Kritik interessanterweise nicht nur auf die Frau, sondern auch auf ein anthropologisches Problem des Nonnentums richtet:

Auf eine Nonne.

MAn nahm mir meinen schmuck/ und ließ nur fleisch und blut/

Man schnitt die haare weg/ und ließ mir meine glut.

Im beten hat mir stets der glaube sehr behaget/

Weil er von aufferstehn des fleisches etwas saget. ${ }^{22}$

Andere Gedichte suchen gewissermaßen nach einer Ursache für die Lasterhaftigkeit von Nonnen und finden sie nicht zuletzt in deren vorangehender Lebensweise, die wohl als typischer Vorlauf unterstellt wird; man vergleiche etwa ein anonymes Epigramm aus dem Band 6 der Sammlung Neukirch mit dem für sich sprechenden Titel Auf eine ins Kloster gehende courtisanin ${ }^{23}$ oder die vermutliche Anklage einer unkeuschen Klosterfrau unter dem Titel Als sie sich als eine Nonne verkleidete, verfasst von einem bisher nicht ermittelten Celander von $1716 .^{24}$

Gegen Mönche und einfache Priester geht es ebenso; bei diesen stellt das Liebesleben allerdings nur einen der aufs Korn genommenen Bereiche dar, weil sich genderspezifisch ein breiteres Betätigungsfeld kritisieren lässt. Den Anfang macht hier Hoffmannswaldaus fiktionales Grabepigramm Eines tadelhafftigen Mönchs, der ex post seine Verzweiflung ob der Heillosigkeit seines Lebenswandels ausdrückt. ${ }^{25}$ Exemplarisch noch grundsätzlicher wird eine von Hoffmannswaldau inszenierte fiktionale Selbstanklage in der Grabschrifft eines lasterhafften geistlichen, weil dieser ein breiteres amoralisches Wirkspektrum entfaltet konnte, das als standestypisch suggeriert wird: Es geht um Kupplerdienste für Mächtige, Kriegstreiberei, Hochmut und nur scheinbare Gottgläubigkeit. ${ }^{26}$

Noch einmal deutlicher hinsichtlich der Usualität sexueller Verfehlungen wird dann in Band 5 der Sammlung Neukirch der nicht identifizierte Verfasser „L.R.B." unter dem Titel Als ihm der Closterstand I. D. S. P. vorgeworffen wurde:

DU narr du tadelst zwar den heilgen closter=stand/

Es müst ein armer Münch so fromm und einsam leben/

Allein/ laß dir so viel zu deiner nachricht geben:

22 Neukirchs Anthologie 1 (Anm. 1), S. 127.

23 Vgl. Neukirchs Anthologie 1 (Anm. 1), S. 107.

24 Vgl. Der galante Stil (Anm. 3), S. 123.

25 Vgl. Neukirchs Anthologie 1 (Anm. 1), S. 127.

26 Vgl. Benjamin Neukirchs Anthologie. Herrn von Hoffmannswaldau und andrer Deutschen auserlesener und bißher ungedruckter Gedichte dritter theil. Nach dem Erstdruck von 1703 mit einer kritischen Einleitung und Lesarten. Hg. von Angelo George de Capua u. Ernst Alfred Philippson. Tübingen 1970, S. 121. 
Ich habe manche nacht auffs Nonnen=fleisch gewand/

Denn was der Pater thut/ kann auch der Münch versuchen/

Wer will ein junges bluth zur einsamkeit verfluchen. ${ }^{27}$

Weitere Gedichte insbesondere in Band 6 der Sammlung Neukirch fokussieren auf den ersten Blick galante junge Damen und deren Liebesbegehren, die epigrammatischen Pointen stellen jedoch letztlich klar, dass die eigentlich galanterotisch Umtriebigen die ihnen begegnenden Kleriker sind; dies ist der Fall etwa in dem anonymen Gedicht Auf Dorindes unnützes kirchen-gehen, in dem es darum geht, dass man auch in Kirchen flugs schwanger werden kann, ${ }^{28}$ oder in dem Gedicht des Bandherausgebers Stolle Von der geistlichen liebe der Cloris, das mit kleruskritischer Spitze berichtet, die Cloris schlafe nur mehr mit Priestern, um ,geistlicher' zu leben. ${ }^{29}$

\section{b) Tendenziell ernstere Kirchen- und Religionskritik}

Ist auch das Gros galanter Epigrammatik heiter bis bissig-spöttisch, erscheint zumindest eine kleine Zahl etwas ernster in der Auseinandersetzung mit dem Kirchenleben oder bisweilen auch dem Glauben an sich. Noch ganz in der Thematik des Nonnentums steht dabei ein längeres Gedicht Hoffmannswaldaus mit dem Titel Seine geliebte wolte ins kloster gehen, das in typischer Perspektive an eine junge Frau appelliert, nicht Nonne zu werden und so die galanten Freuden des Daseins aufzugeben - die anderswo unterstellte Möglichkeit eines erotischen Klosterdaseins wird hier gerade nicht erwogen. ${ }^{30}$ Eine spätgalante Variation des nämlichen Themas findet sich in der Aria (= Titel der ersten Fassung) Als sie ins Kloster ziehen wollte (= Titel der zweiten Fassung) von Johann Christian Günther. ${ }^{31}$

Jenseits der Liebesthematik, damit aber lediglich am Rande von im engeren Sinne galanter Dichtung, finden sich kirchenkritische Töne wiederum vornehmlich in Band 6 der Sammlung Neukirch, etwa bezogen auf allgemeine Verletzungen des klerikalen Armutsgebots in Christian Hölmanns Epigramm Die faulen prediger $^{32}$ oder sogar ganz vorsichtig bezogen auf höchste Instanzen beispielsweise in dem sicherlich nicht zufällig anonymen Epigramm Auf den ertz-bischoff von Cammerich, in dem der zeitgenössische Papst für ein Buchverbot kritisiert wird. ${ }^{33}$

27 Benjamin Neukirchs Anthologie. Herrn von Hoffmannswaldau und andrer Deutschen auserlesener und bißher noch nie zusammen-gedruckter Gedichte Fünffter Teil. Nach dem Druck vom Jahre 1705 mit einer kritischen Einleitung und Lesarten. Hg. von Erika A. Metzger u. Michael M. Metzger. Tübingen 1981, S. 364.

28 Vgl. Neukirchs Anthologie 6 (Anm. 16), S. 120.

29 Neukirchs Anthologie 6 (Anm. 16), S. 140.

30 Neukirchs Anthologie 1 (Anm. 1), S. 72 f.

31 Vgl. Johann Christian Günther: Werke. Hg. von Reiner Bölhoff. Frankfurt/Main 1998, S. 776778 (in zwei Fassungen).

32 Vgl. Neukirchs Anthologie 6 (Anm. 16), S. 121.

33 Vgl. Neukirchs Anthologie 6 (Anm. 16), S. 109. 
Die Frage, was für einen Glauben man überhaupt haben könne, wird ebenso in Band 6 der Sammlung Neukirch ventiliert, etwa in den provokativ flapsigen anonymen Epigrammen Auf eine schrift von mehr als einer welt ${ }^{34}$ und Die schönen glaubens-brüder; letzteres Stück erinnert im Egalismus an antikrömische Haltungen à la Martial:

Was glaubst du? ward gefragt. Die antwort kam geflogen:

Ich glaube nichts. Warum? so werd ich nicht betrogen.

So glaub ich alles denn, warff ihm ein andrer ein,

Es muß ja etwas wahr von dem geglaubten seyn. ${ }^{35}$

Noch pointierter kritisch gegenüber dem institutionalisierten Christentum äußert sich wenig später Johann Christian Günther etwa in folgendem Zweizeiler: „Warum man mich in keiner Kirche sieht?/ Du weist ja, daß mein Herz der Heuchler Umgang flieht.“ ${ }^{36}$ Auf eine Erörterung dieser für den Dichter ungewöhnlich deutlichen Spitze sei jedoch an dieser Stelle verzichtet, da Hans-Georg Kemper dieses und andere Epigramme im Kontext von Günthers persönlich motivierter Orthodoxiekritik bereits ausgeleuchtet hat. ${ }^{37}$

\section{c) Parodistische Gelegenheitsgedichte}

Vielmehr soll es nun noch um eine andere Ebene galanter Perspektivierungen religiöser Themen gehen, und zwar um das Phänomen der satirischen oder auch heiter scherzhaften Parodien beziehungsweise Kontrafakturen von ernsthaften kasuallyrischen Gattungen. Gemeint sind damit zunächst die bereits aus inhaltlichen Gründen angesprochenen fiktionalen epigrammatischen "Grabschrifften“ à la Martial wie Hoffmannswaldaus Eines tadelhafftigen Mönchs und Grabschrifft eines lasterhafften geistlichen ${ }^{38}$ oder auch spätere Texte wie Ephraim Gerhards Grabschrifft eines ketzer-machers ${ }^{39}$ und Christian Friedrich Weichmanns Das wol-aufgenommene Leichen-Gedicht. Eine besondere Rubrik stellen hierbei "Grabschrifften" auf wohl bei Hofe gelebt habende Tiere dar, wie sie Hans Assmann von Abschatz in einer eigenen Werkausgaben-Abteilung heiter-leichter "Schertz-Grabschrifften "40 ver-

34 Vgl. Neukirchs Anthologie 6 (Anm. 16).

35 Neukirchs Anthologie 6 (Anm. 16), S. 100.

36 Günther: Werke (Anm. 31), S. 530 (=<Auf den vorhergehenden [Bavius].>).

37 Vgl. Hans-Georg Kemper: Deutsche Lyrik der frühen Neuzeit. Band 4/II. Barock-Humanismus: Liebeslyrik. Tübingen 2006, S. 300-335, bes. S. 305 f. u. 325 f.

38 Vgl. erneut Neukirchs Anthologie 1 (Anm. 1), S. 127 bzw. Neukirchs Anthologie 3 (Anm. 26), S. 121.

39 Vgl. Neukirchs Anthologie 5 (Anm. 27), S. 138.

40 Vgl. Hans Assmann von Abschatz: Schertz-Grabschrifften. In ders.: Poetische Übersetzungen und Gedichte. Faksimile-Druck nach der Gesamtausgabe von 1704 mit der Vorrede von Christian Gryphius. Hg. von Erika Alma Metzger. Bern 1970, S. 61-68 (= separate Paginierung im Sammelband). 
sammelt hat oder wie sie sich in moralisch-satirischer Tonart wieder besonders in Band sechs der Sammlung Neukirch finden. ${ }^{41}$

Neben der Gattung des Grabgedichts findet sich der Typus des Hochzeitsgedichts mindestens bei einem späten Autor auf galante Weise variiert und mit leichten religionskritischen Spitzen versehen, und zwar bei einem ,Großproduzenten' scherzhaft-heiterer, bisweilen auch recht kalauernder Gelegenheitsgedichte, und zwar bei dem Bach-(Kantaten-)Librettisten Christian Friedrich Henrici, der unter dem Pseudonym Picander in vier Werkbänden (in Erstauflagen von 1727-1737) nicht zuletzt zahlreiche Hochzeitscarmina publiziert hat. So präsentiert er unter dem Titel Auf die F. und H. Hochzeit, 1728. Des Frauenzimmers Tugend=Spiegel eine augenzwinkernde quasi-galante Verhaltenslehre, deren Strophen immer beginnen mit „Ein Mägdgen soll“; die sechste beginnt „Ein Mägdgen soll auch christlich seyn" und dann heißt es:

Sie muß oft in die Kirche gehen,

Und sey der Tugend zugethan.

Hingegen soll sie nicht verstehen,

Was Lomber=Spiele und Roman.

Der Mode nach galant zu leben,

Kann freylich grosses Ansehn geben,

Viel Seegen bringt es nur nicht ein,

Drum soll ein Mägdgen Christlich seyn. ${ }^{42}$

Ein wenig ernster wird Henrici allerdings, wenn er die Frage der Priesterehe aufgreift, so in dem antizölibatären Bey der G. und W. Hochzeit, in Gröst, den 16. Jul. 1726, das mit den Zeilen beginnt: „EIn Priester soll sich nicht beweiben,/ So lehret Rom, die grosse Stadt", ${ }^{43}$ oder in dem recht extensiven, teils scherzhaften, teils ernsten Gedicht Auf die B. und F. Hochzeit./ Oppurg, den 1. Mart. 1729./ Der Vortheil,/ Einen Priester zu heyrathen. ${ }^{44}$

\section{Galanter Ernst auf dem Weg zu einer neuen (christlichen) Individualität?}

Was sich soeben auch schon zeigen sollte: Gewisse ,ernsthaftere` Tendenzen in Kreisen galanter Autoren lassen sich in kirchen- und religionsbezogener Epigrammatik und Gelegenheitsdichtung durchaus konstatieren, und dabei zeichnen sich ganz indirekt sogar individualistische Tendenzen ab, etwa in Form von dialektisch sich ergebenden Toleranzpostulaten. Aber enthält im engeren Sinne galante Lyrik ebenfalls religiöses Wissen beziehungsweise zumindest christliche Motivik einerseits sowie Individuierungstendenzen respektive moderne Ich-Positionen andererseits?

41 Vgl. Neukirchs Anthologie 6 (Anm. 16), z. B. S. 107.

42 Picander: Ernst=Scherzhafte und Satyrische Gedichte Anderer Theil. Leipzig 1729, S. 448451, hier: S. 450; vgl. unter den „Vermischten Gedichten“ ähnlich scherzhaft an junge Frauen: In ein Gebeth-Buch, ebd., S. 551-553.

43 Picander: Ernst=Scherzhafte und Satyrische Gedichte. Leipzig 1727, S. 470-473.

44 Picander: Gedichte Anderer Theil (Anm. 42), S. 486-490. 
Auf eine Grundtendenz wurde im Abschnitt zu den höfischen Theorien bereits hingewiesen: Nach 1700 wird die marinistische Erotik immer stärker zugunsten wieder dezenterer, gleichsam erneut petrarkistischer Formen zurückgenommen, und dies kann als Ausdruck eines allgemein ,moralischeren' Zeitgeschmacks verstanden werden - eine Moralisierung, die sowohl mit der ethischen wie stilprägenden Entwicklung der Aufklärung in dieser Zeit zu erklären ist als auch mit neueren religiösen Anforderungen, die von den nun vermehrt schreibenden bürgerlichen Autoren mehr Moralität verlangen. Diese doppelte Tendenz wirkt sich nun in der Tat in galanter Lyrik aus, und zwar zum einen im Sinne eines ,Ernsterwerdens' und einer größeren ,Tugendhaftigkeit' und zum anderen ansatzweise im Sinne von Individualisierung und stärker empirischen Ich-Positionen.

Als erster Beispielautor sei der "Poet' und 'Superintendens' Erdmann Neumeister angeführt, dessen ethische Verteidigung wie erwähnt bereits Hunold und andere unternommen haben. Entsprechende Gedichte sind in Neumeisters Poetik Die Allerneueste Art, Zur Reinen und Galanten Poesie zu gelangen zu finden; unter diesen sticht eines mit dem Titel Im Nahmen einer gewissen hohen Persohn, an eine noch höhere ${ }^{45}$ hervor, bei dem es sich um eine galante Liebeserklärung handelt. Schon die pauschale Benennung von Sender und Adressat steht für eine bezeichnende Festlegung: Man soll sozusagen dem Hochadel Angemessenes erwarten, sprich: gewisse Schicklichkeitsgrenzen. Gleich die allerersten Zeilen setzen einen entsprechenden Ton, der auch eine Verbindung von Christlichkeit und persönlicher Aufrichtigkeit stiftet, wie man sie ansonsten eher ein halbes Jahrhundert später erwartet; Vers 1-4 lauten:

ERöffne dieses Blat, das dir ein offnes Hertze,

Und dann den Schlüssel auch zu meiner Seele bringt.

Hier ist die Feder frey von allem freyen Schertze,

Weil Seel und Hertz zugleich auf Ernst und Wahrheit dringt. ${ }^{46}$

Aufschlussreich ist ferner, mit welchem Argument die Aufrichtigkeit dieser Liebeserklärung im weiteren Eingangsabschnitt beteuert wird, bevor eine Kette von eher säkularen Bildern in Hoffmannswaldau'scher Manier folgt: „Wer sich von aussen nur denckt Engeln gleich zu schmincken,/ Wird von dem Himmel selbst den Teufeln gleich geschätzt.. ${ }^{47}$ Das Stichwort der „Engel“ greift der lyrische Sprecher im zentralen, der Adressatin huldigenden Teil dann wiederholt auf und lädt so das übliche galante Lobspektrum christlich auf:

Mein Hertze liebet dich, weil du ein Engel bist.

Dein Bildnis muss mir nur in den Gedancken schweben,

Als wie ein Heiligthum, das man im Glas küsst:48

45 [Neumeister:] Die Allerneueste Art (Anm. 11), S. 92-95.

46 [Neumeister:] Die Allerneueste Art (Anm. 11), S. 92-95, hier S. 92.

47 [Neumeister:] Die Allerneueste Art (Anm. 11), Z. $11 \mathrm{f}$.

48 [Neumeister:] Die Allerneueste Art (Anm. 11), S. 92-95, hier S. 94. 
Benachbarte Gedichtbeispiele weisen ähnliche Züge auf, wenn auch oft in schwächerer Form; noch , authentischer' und christlicher wird es freilich, wenn Neumeister eine neuere Gedichtform zwischen galanter und ernsterer kasuallyrischer Form bewusst innovativ nutzt: Etwas später in der Beispielreihe steht ein Dialoggedicht mit der Vorbemerkung: „Weil es auch grande Mode worden, Hochzeit=Gratulationes in Form der Briefe, als ob Bräutigam und Braut einander schreiben, abzufassen, wollen wir ebenfalls einen Versuch in folgenden thun ". ${ }^{49}$ Hunold als Herausgeber der Poetik dachte vermutlich auch an solche Gedichte, als er in seiner "Vorrede“ zu Neumeisters Poetik betonte, dass die Verbindung von „Schönheit“ und „Tugend“ das zentrale Ziel sei. ${ }^{50}$ Ein weiteres Beispiel für eine Verbindung von grundständig galantem Duktus, dabei aber ernsterem Thema und ,individuellerem' Zuschnitt gibt im Übrigen Hunold selbst in einer seiner Lyriksammlungen, und zwar in Form eines pauschalisierten Gelegenheitsgedichts mit dem Titel Als eine kluge Dame Aebtissen wurdel Im Nahmen eines andern. ${ }^{51}$ Ganz im Gegensatz zu den oberhalb thematisierten anzüglichen Imaginationen von Klosternovizinnen wird galante Liebes- und Naturtopik hier eingesetzt, um eine komplett ernste und ,keusche', aber dennoch ,verliebte' Lobadresse abzusetzen.

Als letzter Beispielautor kann an dieser Stelle Johann Christian Günther natürlich nicht unerwähnt bleiben, zu dessen hier interessierenden Tendenzen allerdings bereits verschiedene Untersuchungen vorliegen, ich nenne nur Ursula Regeners Günther-Dissertation, ${ }^{52}$ die bereits auf die signifikant höhere Dezenz im Vergleich zu anderen Galanten hingewiesen hat, oder Hans-Georg Kempers einschlägiges Kapitel in seiner Untersuchungsreihe Deutsche Lyrik der frühen Neuzeit, Band 4/II: Barock-Humanismus: Liebeslyrik. ${ }^{53}$ Als auf ihre Weise innovativ galant und religiös und persönlich seien aus Günthers Werk daher in aller Kürze nur zwei Gedichte herausgestellt, und zwar aus den „Verliebten Gedichten“ dasjenige mit dem Titel Als er ungefehr auf dem Kirchhofe mit seiner Leonore zusammen kam, ${ }^{54}$ gefolgt von einem Liebesdialog auf ebenjenem Friedhof (Titel: Als Leonore sich endlich zum Lieben bewegen ließ. Leipzig, A<nno> 1719. den 26. Jun<ii>. Aria), ${ }^{55}$ und ferner das Gedicht An seine Braut, ${ }^{56}$ ebenfalls auf "Leonore“, sprich: Johanna Barbara Littmann, aus dem Frühjahr 1721.

49 [Neumeister:] Die Allerneueste Art (Anm. 11), S. 103.

50 Menantes: Vorrede, in: Die Allerneueste Art (Anm. 11), [unpag.]. Zu weiteren individualistischen Tendenzen Neumeisters vgl. Ann Le Bar: Die subjektive Dichtkunst des jungen Erdmann Neumeister. In: Neumeister. Wegbereiter (Anm. 15), S. 97-107, bes. S. 103 f.

51 Vgl. Menantes: Galante, Verliebte und Satyrische Gedichte. Erster und Anderer Theil. Hamburg 1704, S. 125-127.

52 Ursula Regener: Stumme Lieder? Zur motiv- und gattungsgeschichtlichen Situierung von Johann Christian Günthers Verliebten Gedichten. Berlin, New York 1989.

53 Kemper: Deutsche Lyrik der frühen Neuzeit 4/II (Anm. 37), S. 300-334 (= „Distanz und Nähe / Günther").

54 Vgl. Günther: Werke (Anm. 31), S. 795-801.

55 Vgl. Günther: Werke (Anm. 31), S. 801-803.

56 Vgl. Günther: Werke (Anm. 31), S. 826 f. 
Letzteres Gedicht liefert eine christlich-galante und individuelle Liebesdichtung und Brautbeschreibung, die laut dem Günther-Herausgeber Bölhoff, „[d] urch die programmatische Abkehr von früherem Liebesleichtsinn und die Berufung auf [eine] tugendhafte Gönnerin“" vor allem den Brautvater beeindrucken sollte. ${ }^{57}$ Die beiden ersteren Gedichte verbinden hingegen auf geradezu aparte Weise das Sujet des galanten Rendezvous respektive des bukolischen Dialoggedichts mit Verweisen auf die biographische Authentizität und mit einem dezidiert christlichen Setting, das eine neue Ernsthaftigkeit ,im Angesicht des Todes' produziert, da eben ein Friedhof als locus amoenus fungiert - freilich nur, so die letzten zwei Verse des ersten der beiden Stücke, „[b]is daß die Dämmerung mit Macht darzwischen kam,/ Und dieß verliebte Paar den Weg nach Hause nahm. “58

\section{Ein Da-capo? ,Ernste' und individualisierte Anakreontik der Empfindsamen}

Dass bukolische Lyrik aus konservativer christlich-moralischer Sicht rasch kritikabel war, wurde in den 1740er Jahren nicht weniger gesehen als zuvor; Friedrich Hagedorn verlangte daher von seinen jüngeren Mitstreitern in seinem Gedicht Anacreon, Strophe 2:

Ihr Dichter voller Jugend,

Wollt ihr bei froher Muße

Anacreontisch singen:

So singt von milden Reben,

Von rosenreichen Hecken,

Vom Frühling und von Tänzen,

Von Freundschaft und von Liebe;

Doch höhnet nicht die Gottheit,

Auch nicht der Gottheit Diener,

Auch nicht der Gottheit Tempel.

Verdienet, selbst im Scherzen,

Den Namen ächter Weisen. ${ }^{59}$

Zumindest implizit war damit eine zeitgenössisch wie bei den späten Galanten notwendig erscheinende Dezenz poetologisch schon einmal gefordert, und man kann wohl sagen, dass etwa der Leipziger Kreis der späten 1740er Jahre, Johann Arnold Ebert, Johann Andreas Cramer, Karl Christian Gärtner und andere, ihrem Vorbild Hagedorn in dieser Hinsicht auch folgten.

Implizit nahmen die Anakreontiker zudem wie die Galanten kirchen- und religionskritische Positionen ein, die zuletzt Ernst Fischer luzide kulturhistorisch analysiert hat, namentlich anhand von Hagedorns Anacreon-Gedicht und in Ab-

57 Informationen und Zitat: Günther: Werke (Anm. 31), S. 1470.

58 Günther: Werke (Anm. 31), S. 801, V. 199 f.

59 Friedrich v. Hagedorn: Oden und Lieder in fünf Büchern. Hamburg 1747, S. 82. 
grenzung von Gleims kritischerer Haltung..$^{60}$ Eine unmittelbare Verbindung von anakreontischen Topoi und Christlichkeit sowie auch von moderner Individualität ergibt sich aber erst, als deutlicher religiös orientierte Autoren sich der Sujets für ihre zärtlich-empfindsamen beziehungsweise empfindsam-erhabenen Zwecke bedienen; insonderheit zu nennen sind hier Ewald von Kleist oder Friedrich Gottlieb Klopstock, man denke bei Letzterem nur an die empfindsam-erhabene Ode Der Zürchersee oder das kleine, zärtlich-empfindsame Gedicht Das Rosenband. Deren Transformation des ,heiteren Spiels' in ,ernstere' Formen erscheint angesichts der bei den späten Galanten beobachteten Tendenz als frappante Wiederholung, allerdings mit einer wesentlichen Variation: Religiosität und IchPositionen erfahren im bukolischen Rahmen eine deutliche programmatische Aufwertung und finden zeitgenössisch auch mehr Widerhall. Die empfindsame Anakreontik erscheint so gewissermaßen erfolgreicher beziehungsweise ,nachhaltiger' darin, eine neue christlich-ethische Ästhetik mit individualisierenden Tendenzen zu erreichen.

60 Ernst Fischer: „Er spielt mit seinen Göttern“. Kirchen- und religionskritische Aspekte der anakreontische Dichtung in Deutschland im 18. Jahrhundert. In: Les Lumières et leur combat (Anm. 18), S. 71-85. 
(C) 2015, Otto Harrassowitz GmbH \& Co. KG, Wiesbaden ISBN Print: 9783447104975 — ISBN E-Book: 9783447194136 


\title{
Das burleske Martyrium der Polymathie
}

\author{
Johann Christian Günther (1695-1723) \\ und der prekäre Status der Muße im Zeitalter der Frühaufklärung
}

\author{
Ralph Häfner
}

\section{Einleitung}

Als Scapin Mitte des 19. Jahrhunderts die Bühne von Honoré Daumiers imaginärem Theater betritt, wird der verschlagene Held von seinem Kumpanen Crispin begleitet. Das Duo berät offenbar Streiche der hinterlistigsten Art. Wer genau ist Crispin? Versuchen wir, eine Antwort zu geben, indem wir zunächst fragen: Wer ist Scapin? In Molières Komödie Les fourberies de Scapin, erstmals 1671 im Theater des Palais royal ${ }^{1}$ in Paris aufgeführt, ist Scapin der Typus des skrupellosen Betrügers (,fourbe“), der über Leichen geht, um seine perfiden Ziele zu erreichen. Das Spektakel ist auf der untersten Theaterhierarchie angesiedelt; auf dem Brettergerüst der Jahrmarktsbühne (,théâtre de la foire') zieht das Stück, in dem es um Liebe auf Leben und Tod geht, ein schaulustiges gemischtes Publikum an. Ein berühmter Zeitgenosse Molières, Paul Scarron, hat in dem Gedicht La Foire S. Germain Einblicke in die auch im Bild oft dargestellte Halbwelt der Jongleure und Trickkünstler, der Masken und Marionettenspieler, gegeben. ${ }^{2}$ In Daumiers Bilderfindung handelt Scapin nicht allein; gleich einem Doppelgänger, dessen schwarzer Umhang das weiße Gewand Scapins - die sprichwörtliche ,weiße Westé (,être blanc comme neige') - interpretiert, erscheint Crispin im verlorenen Profil; es lässt die schlimmen Schurkereien, die die Physiognomie Scapins zum Ausdruck bringt, nur erst erahnen. Erich Klossowski hat in seiner Daumier gewidmeten Monographie von 1923 - unübertroffen in der Schärfe der Analysen - Scapin als den ins Derbe verwandelten Watteau'schen Pierrot aufgefasst: „Eine derbe proletarische Kraft hat sich in den geheiligten Schnee des Gewandes gekleidet. Und was ist dieses Geheimnis, das ihm der schwarze Gefährte ins Ohr flüstert. Es muss, man spürt es an dem Reflex der Miene, eine fürchterliche Intrige sein. Es ist ein infernalisches Lächeln, das die fahle Miene zu einem grauenerregenden Behagen verzerrt. In dem Auge schwimmt ein satanischer Triumph, der sich am Brande Roms zu weiden scheint. ${ }^{\prime 3}$ Daumier hat die Figuren der Commedia dell'Arte sehr genau gekannt und studiert. Etwa zur selben Zeit arbeitete Maurice

1 Vgl. Daniel Snowman: The Guilded Stage. A Social History of Opera. London 2009, S. 52-56.

2 Vgl. Paul Scarron: La Foire S. Germain. In ders.: Recueil des œuvres diverses et choisies en vers burlesques. Lyon 1695, S. 33-44.

3 Vgl. Erich Klossowski: Honoré Daumier. München 1923, S. 51. 
Sand, der künstlerisch hoch begabte Sohn der Schriftstellerin George Sand, an den Illustrationen des 1860 erschienenen Werks Masques et bouffons. Comédie italienne. Maurice Sand hatte die Geschichte der Stegreifbühne bis auf die Urbilder der Typenkomödie in der Antike (im Theater der sogenannten ,Atellanen') zurückverfolgt. ${ }^{4}$ Die gesellschaftlich subversive Kraft der Stegreifbühne bewährte sich immer dann, wenn sich das Spiel als eine Handlung herausstellte, die die Distanz zwischen dem imaginären Raum der Bühne und dem ,wirklichen' Leben, dem die Zuschauer auf einige Stunden entkommen zu sein schienen, aufhob. Der gespielte Totschlag wird zum ,wirklichen' Totschlag, wie Ruggero Leoncavallo in seiner veristischen Oper I Pagliacci (1892) vor Augen führt. Jacques Callot (ca. 1592-1635) interpretiert in den „Balli di Sfessania“ (1621/1622) das Leben in der Kunstform des Tanzes. Der zur Arabeske ausblühende Tanz schafft Möglichkeiten eines vielfach facettierten Bewusstseins, das E.T.A. Hoffmann 1820 in Prinzessin Brambilla, jenem „Capriccio nach Jacob Callot", ins Werk setzen wird.

Antoine Watteau hat im frühen 18. Jahrhundert diese Distanz, die die ,Wirklichkeit' von der Bühne üblicherweise trennt, als eine solche aufgefasst, die von den Typen der Commedia dell'Arte bewusst überschritten wird. Indem die Theatertruppe vor den die Trennung anzeigenden Vorhang tritt, durchbricht sie die Distanz, die das raumzeitliche Kontinuum zwischen Zuschauern und Schaustellern üblicherweise impliziert; das Leben selbst wird zur - mitunter grausamen - Improvisation. Anders als in Daumiers Erfindung gut einhundert Jahre später ist Crispin allein der Betrüger, der vor Schändung und Ehebruch nicht zurückschreckt. Durch die Bildunterschrift des oft wieder aufgelegten Kupferstichs (Abb. 1) nach Watteaus Gemälde aus dem Umkreis der "fêtes galantes ${ }^{\prime 5}$ wird der Tanz auf dem Proszenium unvermittelt zum Tanz des Lebens. Die beiden französisch und deutsch beigestochenen Vierzeiler lauten:

Arlequin, Pierrot et Scapin

En dancant ont l'Ame rauie,

Pendant que le fourbe Crispin

En conte à la jeune sylvie.

Ce que t'offre ici le pinceau,

Quoique prit de la Comédie,

N'est que trop souvent le tableau

De ce qui se passe en la vie.

4 Vgl. Maurice Sand: Avant-propos. In ders.: Masques et Bouffons. Comédie italienne. Texte et dessins par Maurice Sand. Gravures par A. Manceau. Preface par Georges Sand. Tome premier. Paris 1862 [zuerst 1860], S. 1-15.

5 Vgl. Robert Tomlinson: La Fête galante. Watteau et Marivaux. Genf, Paris 1981; Mary Vidal: Watteau's Painted Conversations. Art, Literature, and Talk in Seventeenth- and EighteenthCentury France. New Haven, London 1992; [Kat.] Watteau et la fête galante. Musée des Beaux-Arts de Valenciennes. 5 mars - 14 juin 2004. Paris 2004; Antoine Watteau. Perspectives on the Artist and the Culture of his Time. Hrsg. von Mary D. Sheriff. Newark, N.J. 2006. 


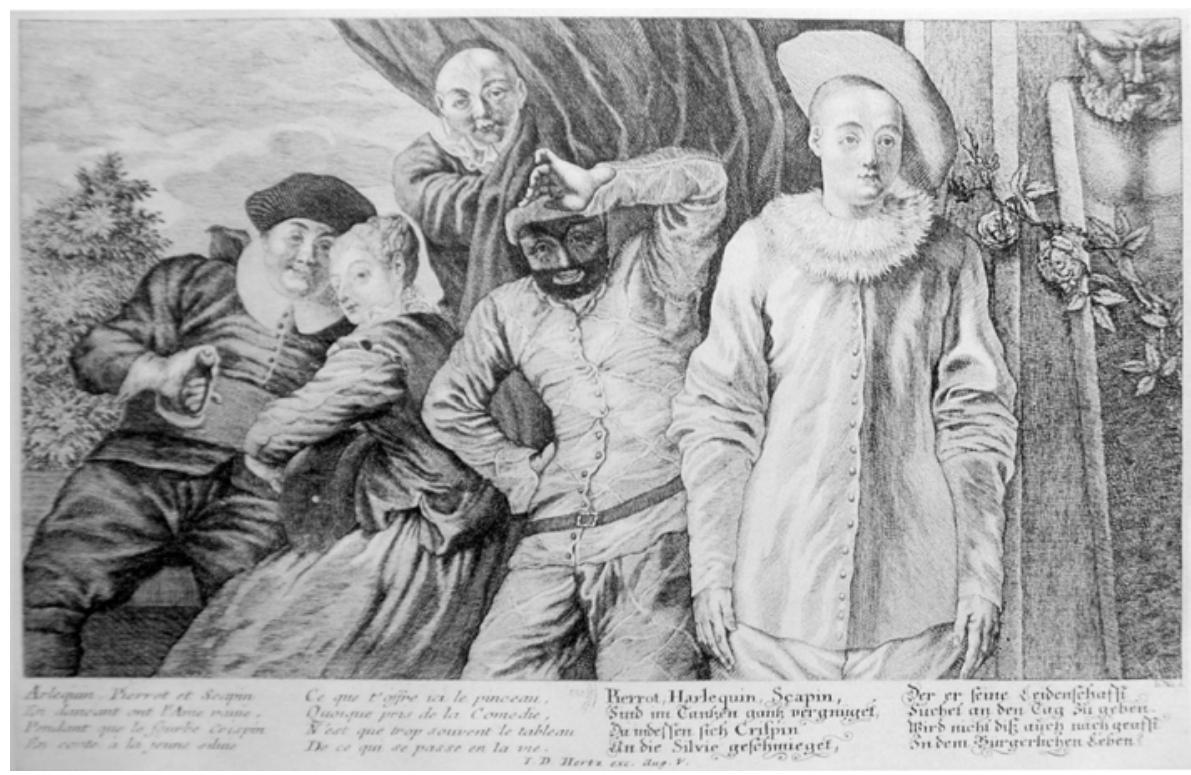

Abb. 1

Pierrot, Harlequin, Scapin

Sind im Tantzen gantz vergnüget,

Da indessen sich Crispin

An die Silvie geschmieget,

Der er seine Leidenschafft

Suchet an den Tag zu geben.

Wird auch diß nicht nachgeafft

In dem Bürgerlichen Leben?

Enden die Verse im Deutschen geschickt mit einer rhetorischen Frage, so ist die französische Version noch pointierter. Das Geschehen auf der Bühne gleicht dem Sujet eines Gemäldes, dessen Illusionismus performativ aufgehoben wird. Die Handlung ist gar nicht illusionär, sie ist das Leben selbst, oder umgekehrt: Das Leben aktualisiert Verlaufsformen des ,Wirklichen', die im imaginären Raum der Typenkomödie vorgezeichnet sind; mit dem Bild des deutschen Verses könnte man auch sagen: das alltägliche („,bürgerliche“) Leben äfft die typischerweise längst bekannten Handlungsverläufe, in denen sich das Leben realisiert, mehr oder weniger bewusst nach. 


\section{Johann Christian Günthers Verssatire Der entlarvte Crispinus (1718)}

Es ist diese „,bürgerliche“, definitionsgemäß in der Komödie verortete Welt, die Johann Christian Günther (1695-1723) im Juli 1718 in seinem Gedicht Der entlarvte Crispinus zur Darstellung gebracht hat. ${ }^{6}$ Der vollständige Titel des Werks lautet: „Der entlarvte Crispinus, von Schweidnitz aus Schlesien, oder die von denen $\mathrm{Mu}$ sen gestriegelte Tadel-Sucht." Dass das Gedicht in postumen Gesamtausgaben der Werke Günthers mitunter in der Sammlung der "Stanzen “ erscheint, ${ }^{7}$ ist weniger durch seinen gedankenlyrischen als vielmehr performativen Charakter gerechtfertigt, der es in eine Beziehung zum komisch-heroischen Epos der Boiardo, Berni, Ariosto und Scarron (Le Virgile travesti, 1648-1653) setzt. Stanzen wie Scarrons Versburleske La Foire S. Germain erwecken durch rhetorische Stilmittel der Enargeia das ausgelassene, oft gegen soziale Konventionen verstoßende Treiben auf dem Jahrmarkt zu sinnlicher Präsenz. Üblicherweise findet man Günthers Gedicht indes in der Gruppe seiner Verssatiren („Satyren oder Straff-Gedichte “ ${ }^{8}$ ) im Stil der lateinischen Satiren der Horaz, Iuvenal und Persius. Formal handelt es sich bei Günthers Strophe um die Kombination eines kreuzgereimten Quartetts $(\mathrm{abab})$ und zweier Terzette mit Schweifreim (cddcee). Zurecht hat man anlässlich dieses Typs auf François Malherbe verwiesen, dessen Oden in der geistlichen Lyrik des 17. Jahrhunderts vielfach variiert worden sind. ${ }^{9}$

Der Hinweis auf die geistliche Odenform ist dabei keineswegs abwegig. Dem Gehalt nach eignet dem Werk Günthers etwas von einer Kontrafaktur der Märtyrerlegenden im Gewand der lateinischen Personalsatire. Günther bringt die burleske Umkehrung eines geistlichen Genres bereits in der verspielten Leservorrede zum Ausdruck, die er dem Erstdruck vorangestellt hat; der Autor versetzte sich darin versuchsweise in die Rolle eines "von seinem Bekehrungs-Amte“ überzeugten Märtyrers, der „fürwahr keinen Satyr zum Apostel machen“ dürfe, wenn er sein Ziel, die „Besserung der Gemüther", zu erreichen beabsichtigte. Die „boßhafftige Grobheit" seines Gegners - gemeint ist der Polyhistor Theodor Krause - lasse indes gar nicht mehr an Besserung denken, so dass es gerechtfer-

6 Nachweis des Erstdrucks: Johann Christian Günther: Textkritische Werkausgabe in vier Bänden und einer Quellendokumentation Bd. I.2. Hrsg. von Reiner Bölhoff. Berlin, Boston 2013, S. 99, Einzeldruck 18 (Juli 1718). - Zu dem Gedicht vgl. Harald Flentge: Zur frühaufklärerischen Satire Johann Christian Günthers. Davis 1987, 1990; Reiner Bölhoff: Probleme der Günther-Edition. In: Johann Christian Günther (1695-1723). Oldenburger Symposium zum 300. Geburtstag des Dichters. Hrsg. von Jens Stüben. München 1997, S. 289-323, hier S. 295 f.

7 So in der Ausgabe: Gedichte. Sechste, verbesserte und geänderte Auflage. Breßlau, Leipzig 1764, S. 603-622.

8 So in der Ausgabe: Sammlung von Johann Christian Günthers, aus Schlesien, bis anhero edirten deutschen und lateinischen Gedichten, auf das neue übersehen. [2. Auflage]. Breßlau, Leipzig 1739, S. 491-507.

9 Vgl. Horst Joachim Frank: Handbuch der deutschen Strophenformen. München, Wien 1980, S. $713 \mathrm{f}$. 
tigt sei, „die Regeln und Schranken einer Christlichen Gelassenheit", wie sie ein geistliches Klagelied hätte befolgen müssen, beherzt zu überschreiten. ${ }^{10}$

Günther stellte seinem Werk zwei Motti aus Satiren des Horaz und des Juvenal voran. Der Autor erläutert anhand dieser Motti den Namen "Crispinus“, der damit zum Urtypus einer bis auf Krause hinab reichenden illustren Ahnenreihe wird: Der Betrüger, Hochstapler und Schmarotzer Crispinus ist ein uralter Typ, der sich in der Gesellschaft immer von neuem wieder verkörpert. Er stirbt nie, wenn er sich unter der Maske von Horazens Thrax, von Molières Tartuffe oder dem Gargil des französischen Philologen Gilles Ménage verbirgt. Gleich einem Marktschreier auf der Bretterbühne einer fahrenden Schauspieltruppe verkündet Günthers Sprecher-Ich, dass der Crispin, dessen Betrug er entlarven wolle, alle seine Vorgänger in den Schatten stellen werde:

Tartuffe, Thrax, Gargil und wer ihr alle seid!

Die ihr am Helicon als Thorheits-Märtrer leidet,

Die ihr biß diesen Tag zum Theil auf Hecheln schreyt,

Zum Theil wie Marsias das nackte Fleisch entkleidet;

Seyd froh, nunmehr erscheint das Ziel erlittner Schmach,

Die Blösse des Crispins bemäntelt eure Schande.

Macht Platz! er nimmt den Rang; der Schaum von eurer Bande

Geht ihm, so klein er ist, an grober Boßheit nach.

Jetzt habt ihr Fug und Recht, die Dichter zu verklagen,

Die euch der Ewigkeit so heßlich vorgetragen. ${ }^{11}$

Die Figur des Crispin ist in der französischen Komödie in den Jahrzehnten um 1700 allgegenwärtig. Ungezählt sind die Stücke, in denen er als zwergenhafter Diener (Günther: „so klein er ist“) seines Herrn - in der Regel ist es der junge Liebhaber einer ins Burleske spielenden Liebesintrige - die Rolle des verruchten, auf eigene Rechnung agierenden Intriganten spielt. $\mathrm{Zu}$ denken ist an eine Reihe von Werken von damals bekannten Komödiendichtern in der Nachfolge Molières, wie Florent Carton Dancourt (1661-1725), Raymond Poisson oder Jean François Regnard (1655-1709). Nicht selten gehört es zur Rolle Crispins, seinen Herrn betrügerisch zu hintergehen, wie in Alain-René Lesages einaktiger Komödie Crispin, rival de son mâtre (1707). Im Blick auf Günthers Satire steht Crispins anmaßender Anspruch auf Gelehrsamkeit im Mittelpunkt, die ihn zum halbgelehrten Charlatan macht. In dieser Rolle erscheint er wiederholt in Komödien von

10 Johann Christian Günther: „Bescheidener Leser“ (= Leservorrede zu: Der entlarvte Crispinus). In ders.: Textkritische Werkausgabe in vier Bänden und einer Quellendokumentation Bd. II.1. Hrsg. von Reiner Bölhoff. Berlin, Boston 2013, S. 281 f. - Vergleichend wurde herangezogen: Johann Christian Günther: Werke. Hrsg. von Reiner Bölhoff. Frankfurt/M. 1998, S. 498-525, 1242-1255 (Anmerkungen).

11 Johann Christian Günther: Der entlarvte Crispinus. In ders.: Textkritische Werkausgabe in vier Bänden und einer Quellendokumentation Bd. II.1. Hrsg. von Reiner Bölhoff. Berlin, Boston 2013, S. 280-302, hier S. 283 f. (Günther: Gedichte [1764] (Anm. 7), S. 603). 
Gaspard Abeille (1648-1718), der im Verein mit dem Schauspieler Jean François Juvenon de La Thuillerie (1653-1688) einschlägige Werke publiziert hat; der Autor von Crispin précepteur (1679) hat in der Komödie Crispin bel esprit (1681) auch den Zirkel von konversationellem, die Mußestunden füllendem Halbwissen und höfischer Galanterie ausgemessen. Mitunter schlüpft Crispin auch in die Rolle des Liebhabers von Stande, wie in Charles Chevillet de Champmeslés (1642-1701) Komödie Les Grisettes, ou Crispin chevalier (1683). Joseph de La Font (1686-1725) endlich hat ihm 1710 mit der Komödie Le Naufrage ou La Pompe funèbre de Crispin das Grab bereitet - ohne zu ahnen, dass sein Held von Marivaux bis Daumier noch oft auf der Bühne der menschlichen Tollheiten wieder auferstehen würde. Wenn Günther vom „entlarvten“ Crispin spricht, so stellt er explizit einen Bezug zur Stegreifkomödie her. Crispin soll durch die Satire dem Publikum ohne Larve - ohne Maske - in seiner wahren Gestalt gezeigt werden. Günther wendet Krauses Angriff auf ihn selbst zurück, der den ,poeta lauretaus' als , poeta larvatus' (,verhexter Dichter') verspottet hatte..$^{12}$ In seinem kurzen Nachwort, mit dem er das Gedicht beschließt, schrieb Günther, dass er "mich alsdenn mit besserm Rechte einen Poëtam larvatum nennen kann, weil ich einem so elenden Stümper die Larve einer eingebildeten Gelehrsamkeit von dem Gesichte gezogen“. ${ }^{\prime 3}$

Man muss bedenken, dass Günther die Satire Der entlarvte Crispinus in jenem Leipzig publizierte, das mit seinem Förderer Johann Burkard Mencke (1674-1732) ein Schmelztiegel der Gelehrtensatire war. Mencke hatte sich 1715 der Form der akademischen Rede bedient, als er die Gelehrtenparodie De charlataneria eruditorum ans Licht brachte. Das sehr bekannte Titelkupfer zeigt die von Pritschenträgern und Akrobaten umgebenen Halbgelehrten auf einer Bretterbühne, die ihre trickreichen rhetorischen Kunststückchen auf dem Jahrmarkt der intellektuellen Eitelkeiten ausstellen. Über dem Baldachin, der den Theaterhimmel abschließt, liest man in grotesk entstelltem Latein: „Muntus fuld tezibi“ - ,Die Welt will betrogen sein'. Es ist genau dieser Typus, den Günther in seiner Satire zeichnet. Günther überschreibt das aus Iuvenals vierter Satire genommene Motto entsprechend; hatte Juvenal Crispin als Lüstling und Ehebrecher vorgestellt (,sola libidine fortes' und ,adulter'), so lässt ihn Günther als krankhaften Schwätzer (,linguae libidine fortis') die Bühne der gelehrten Welt betreten: „Ja, schon wieder Crispinus, und wirklich muss ich ihn oft auf die Bühne (d. h. in seine Rolle, ,ad partes') rufen, ein Scheusal, dessen Laster durch keinerlei Tugend aufgewogen werden, zerrüttet und allein durch die Zügellosigkeit seiner Zunge stark. ${ }^{14}$

12 Vgl. hierzu den Kommentar von Reiner Bölhoff, in: Günther: Werke (Anm. 10), S. 1255.

13 Günther: Der entlarvte Crispinus (Anm. 11), S. 302.

14 Günther: Der entlarvte Crispinus (Anm. 11), Motto: „Ecce iterum Crispinus, et est mihi saepe vocandus / Ad partes monstrum nulla virtute redemptum / A vitiis, aeger Linguaeque libidine fortis." (Die deutsche Übersetzung folgt - bis auf das von Günther hinzugefügte „Linguaeque“ - der Tusculum-Ausgabe von Joachim Adamietz). - Günthers Parodie von Juvenals Satire ist in den Ausgaben von Reiner Bölhoff nicht nachgewiesen. 
Günthers Satire auf Crispin ist eine Kontrafaktur der Märtyrerlegenden. Der Helikon, Sitz der Musen und Quellgebirge der dichterischen Inspiration, wird zum Kalvarienberg, auf dem die „Thorheitsmärtrer“ aller Zeiten leiden. Tartuffe, Thrax und Gargil, so versichert das Sprecher-Ich, seien indes, "So dumm, so arg sie sind, noch klug und fromme Leute“, wenn man sie "dem Pfuscher" Crispin „an die Seite“ setze.

Der entlarvte Crispinus, von Schweidnitz aus Schlesien ist eine Personalsatire, die ihr Formrepertoire über die genannten Komödien hinaus aus dem Possenspiel und der derb-komischen Burleske bezieht. Die Persönlichkeit, die sich hinter der ,persona' Crispinus verbirgt, ist der Jurist und Gelehrte Theodor Krause (Crusius, 1688-1740). Krause hatte seit 1713 in Leipzig die Vergnügung müßiger Stunden oder allerhand nützliche zur heutigen galanten Gelehrsamkeit dienende Anmerkungen publiziert, deren Hefte im Umfang von etwa 70 bis 100 Seiten bis 1732 auf zwanzig Lieferungen anwuchsen. ${ }^{15}$ Die „galante Gelehrsamkeit“ ist das Produkt einer Muße, die Räume imaginärer Kommunikation stiftet. Das Merkmal „müßiger Stunden“ ist die Auslöschung des Bewusstseins von Zeit. Die Polemik, mit der Krause den Lebenswandel des frisch verlobten Günther anprangerte, ${ }^{16}$ war für den jungen, sozial noch völlig ungesicherten Dichter in höchstem Maße rufschädigend. Günthers Satire ist aber nicht nur die bittere Abrechnung eines desillusionierten dichtenden Studenten mit dem „prætendirenden Polyhistor in Schweidnitz, welcher in der gelehrten Welt gerne eine Figur machen wollte ". ${ }^{17}$ Sie ist zugleich eine Polemik gegen den Typus "galanter Gelehrsamkeit", die sich in der geschwätzigen Anhäufung disparatester Wissenspartikel gefällt. Die erläuternden Fußnoten, die Günther seinem Gedicht beigefügt hat, sind in diesem Sinne integraler Bestandteil des Werks; ja, man könnte geradezu von einer Interaktion zwischen der anspielungsreichen Dichtung und der die Anspielungen aufdeckenden Anmerkungsprosa sprechen. Dieses Verfahren, die eigene Dichtung zu kommentieren, war nach der neulateinischen Dichtung der Renaissance seit Daniel Heinsius und Martin Opitz auch in der Volkssprache übrigens gang und gäbe und diente der sachlich amplifizierenden Steigerung der im poetischen Text exponierten Stilfiguren. Günther spielt dabei mit dem Modell der durch den gelehrten Kommentar zu öffnenden poetischen Matrix. Die in den Fußnoten zur Schau gestellte Gelehrsamkeit wird selbst zur Farce. Die eigentlich so genannte ,Entlarvung' des im Gedicht der "Schmiererey“ bezichtigten "Stümpers" Crispin, der „an Eulenspiegeln denken“ lasse, findet in den Anmerkungen statt. ${ }^{18}$

15 Vgl. Theodor Krause: Vergnügungen müßiger Stunden. 20 Bde. Leipzig 1713-1732.

16 Vgl. Eike Fuhrmann: Günther, Johann Christian. In: Neue Deutsche Biographie 7 (1966), S. 269-271 (Onlinefassung).

17 Günther: Der entlarvte Crispinus (Anm.11), S.283, Anm.c) (Günther: Gedichte [1764] (Anm. 7), S. 603).

18 Vgl. Uwe-K. Ketelsen: Innovation und Transformation. Von der Entstehung aufklärerischer Lyrik im Verfall der barocken Poetik. In: The Enlightenment and Its Legacy. Studies in German Literature in Honor of Helga Slessarev. Hrsg. von Sara Friedrichsmeyer und Barbara Becker-Cantarino. Bonn 1991, S. 43-53. 
Dort entlarvt Günther Krauses „gelehrte Windmachereyen" ${ }^{19}$ als „thörichte Polyhistor-Streiche ${ }^{\prime 2}{ }^{20}$ In der derben Bildlichkeit der Dichtung wird der „Klügling“ Krause dann vollends zum „Schwein“, das die Gärten der Musen auf dem Helikon durchwühlt. In der bildhaften Brutalisierung ruft Günther theriomorphe Elemente des antiken Mythos auf:

Ihr Musen! ist es nicht ein unverdienter Lohn

Den eure Mildigkeit um Har und Scheitel windet,

So stäupt, so züchtigt mir den geilen Midas-Sohn,

Biß sein vertracktes Fell die späte Reu empfindet.

Ihr seht, er will mit Macht der Straffe würdig seyn,

Es klaubt sein Unverstand zur Nahrung neid'scher Flammen

Hier einen Weiber-Spruch, dort einen Reim zusammen,

Um den verwegnen Gifft mit Fudern auszuspeyn;

Gewährt, wornach er ringt! und laßt den Klügling fühlen,

Daß Schweine nicht umsonst in euren Gärten wühlen. ${ }^{21}$

Günther führt eine ganze Reihe von Stilelementen in seiner Satire zusammen, die dem derb-dramatischen Genre der frühneuzeitlichen Farce entspricht. (1) Da ist zunächst die Aktivierung der burlesken Mythologie, die sich um Midas und Marsyas rankt. Marsyas wird geschunden, weil er sich anmaßt, schöner als Apoll zu singen; dem König Midas wachsen Eselsohren, die er unter einer phrygischen Mütze zu verbergen sucht, weil er im Wettstreit zwischen Apoll und Pan dem letzteren den Vorzug gibt. Derart burleske Mythologien eröffneten ein formelles Zeichensystem, innerhalb dessen individuelle Ereignisse am Maßstab traditioneller Allegorese gemessen und pointiert bewertet werden konnten. Johann Sebastian Bach wird den Midas-Stoff 1729 in der burlesken Kantate „Geschwinde, ihr wirbelnden Winde" (BWV 201) aufgreifen. Auch im Genre übrigens entspricht die halbdramatische Form der Kantate dem performativen Charakter der Verssatire. Wie im Falle Günthers diente die mythologische Form auch bei dem berühmten Leipziger Komponisten der präzis zu benennenden Personalsatire. Wie das Beispiel zeigt, ist die Burleske gattungsunspezifisch. Sie bezeichnet viel-

19 Die Metapher geht unmittelbar auf Horaz, Sat. I,4,14-20, zurück. André Dacier kommentiert das Lemma „At tu conclusas hircinis follibus auras“ (v. 19) wie folgt: „Il [sc. Horace] s'adresse à Crispinus, qu'il compare aux soufflets d'une forge, \& ses Ouvrages au vent qui en sort: Comme ces soufflets soufflent tant qu'on veut, \& sont toûjours prests, sans avoir besoin d'aucune preparation, Crispinus \& tous ceux qui se piquent de cette facilité, travaillent de mesme. Ils n'ont besoin d'aucune meditation; mais aussi leur travail n'a rien de solide. C'est un vent qui passe, \& ne dure point. Cette comparaison est d'autant plus juste, qu'elle marque aussi l'orgueil ordinaire de ces sortes de gens, qui sont toûjours remplis de vent, comme les soufflets des forges." ([André Dacier:] Remarques critiques sur les œuvres d'Horace, avec une nouvelle traduction. Tome sixième. Paris 1687, S. 316 f.).

20 Günther: Der entlarvte Crispinus (Anm.11), S.294, Anm.i) (Günther: Gedichte [1764] (Anm. 7), S. 614).

21 Günther: Der entlarvte Crispinus (Anm. 11), S. 284 f. (Günther: Gedichte [1764] (Anm.7), S. 604). 
mehr einen Stil, der der Komödie ebenso angemessen sein kann wie performativen Formen der Lyrik, in unserem Beispiel der Satire und der weltlichen Kantate, und der Prosa. Man denke nur an die Abenteuer des Ragotin in Paul Scarrons Roman comique (1651/1657). Der Jesuit François Vavasseur (1605-1681) hatte 1658 in der wiederholt aufgelegten Abhandlung De ludicra dictione die Poetik des Burlesken - wenn auch in polemischer Absicht - grundgelegt. ${ }^{22}$ (2) Das Bild der von Schweinen durchwühlten Gärten ist leicht als die burleske Umkehrung des Bildes von den Bienen zu dechiffrieren, die den Honig aus den Blüten saugen. Es handelt sich also um eine äußerst derbe Parodie des im übrigen anmutigen Bildes der ,Blütenlese', mit der der Gelehrte einen Raum imaginärer Kommunikation etabliert. Krauses Gelehrsamkeit, so erläutert Günther in einer Fußnote, sei das Ergebnis einer oberflächlichen Lektüre bereits vorhandener Florilegien; was die Anthologie Vergnügung müßiger Stunden präsentierte, waren Auszüge aus Auszügen:

Wenn der Herr Polyhistor keine Polyantheen, Diversitées curieuses (die er sich vorher muß exponiren lassen), Herrn Reichels Hanß Wursten, das gelehrte Frauen-Zimmer-Cabinet, u.d.g. nicht zu reithen hätte, so würde es um seine Gelehrsamkeit sehr mißlich stehen, und in seinem Kopffe so aussehen, wie in dem ersten Capitel des ersten Buches Mosis auf der Erden. ${ }^{23}$

Die Häufung anspielungsreicher Aperçus, die zuletzt noch in das sprichwörtliche ,Tohuwabohu' am Anfang der biblischen Schöpfungsgeschichte mündet, erinnert nicht zufällig an den burlesken Stil François Rabelais', wie er von Paul Scarron, diesem Meister der Burleske, nachgeahmt worden ist. In der Tat steht Günthers Spottgedicht auch in der Tradition der Mazarinaden, ${ }^{24}$ der burlesken Verspottung Kardinal Mazarins, die ihren Höhepunkt in den 1640er Jahren erreichte; Scarron war nicht zuletzt durch sie bekannt geworden. (3) Zum burlesken Stil gehört auch die Verwendung eines derb-niederen, oft der Küchen- und auch der Fäkalsprache entlehnten Wortschatzes, so etwa, wenn Günther ein Kommentarwerk des Gelehrten Krause der Lächerlichkeit preisgibt: „Hier liegt Sarckmasius, man koste nur die Brüh, / Die unser Sudel-Koch darüber hergegossen; “ ${ }^{25}$ hierhin gehört auch die Rede von der „Eckel“ und Brechreiz erregenden „Brüh“ des Krause'schen Buchs im ganzen. ${ }^{26}$ Gewöhnlich beziehen frühneuzeitliche Dichter eine so spezialisierte Lexik aus dem Satyricon des spätantiken Romanciers Petro-

22 Vgl. François Vavasseur: De ludicra dictione liber in quo tota iocandi ratio ex veterum scriptis aestimatur. Paris 1658.

23 Günther: Der entlarvte Crispinus (Anm.11), S.296, Anm.n) (Günther: Gedichte [1764] (Anm. 7), S. 617, Anm. n). - Anspielung auf ,Tohuwabohu' bei Bölhoff nicht nachgewiesen.

24 Vgl. Hubert Carrier: Les Muses guerrières. Les Mazarinades et la vie littéraire au milieu du XVII ${ }^{e}$ siècle. Paris 1996.

25 Günther: Der entlarvte Crispinus (Anm. 11), S. 293 (Günther: Gedichte [1764] (Anm. 7), S. 614). - Gemeint sind die Acta Sarcmasiana ad usum reipublicae literariae in unum corpus collecta à Theodoro Crusio. [Leipzig?] 1711 (Sarcmasius ist die gräzisierte Form des Namens des Universalgelehrten Conrad Samuel Schurtzfleisch, 1641-1708).

26 Günther: Der entlarvte Crispinus (Anm. 11), S. 294. 
nius Arbiter (ca. 14-66 n. Chr.). Günther hatte ihn übrigens in seiner Leservorrede an die Seite des Aristophanes gestellt. ${ }^{27}$ Diese Lexik ruft vor allem aber auch die älteste lateinische Satire des Lucilius auf. Das fragmentarisch überlieferte Werk des Satirikers Lucilius (180-102 v. Chr.), noch für Horaz eine Referenz ersten Grades und von Günther ausdrücklich genannt, ${ }^{28}$ war seit dem späten 16. Jahrhundert in guten Editionen greifbar. ${ }^{29}$ Das Frontispiz (Abb. 2) zur zweiten - postumen - Ausgabe von Günthers Gedichten setzt trefflich die sprichwörtliche ,lanx satura' ins Bild; die bocksgestaltigen Satyrn tragen das in der Satire zusammengebrachte ,Allerlei' von Früchten auf einer üppig dekorierten Schüssel (lanx) herbei: „Zwey Satyrn bringen hier auf einer Schaale Früchte: / Von gleicher Gattung sind auch folgende Gedichte. “30

Günthers Gedicht ist eine derartige ,lanx satura', wenn sie die Personalsatire mit der facettenreichen, die kontrafaktische Struktur der Martyriologie aufnehmenden Gelehrtenkritik zusammenmischt. Krauses schmales Werk zur Prosopographie der evangelischen Theologen, Die berühmte Schlesische Priester-Quelle (ca. 1714), ist für das Sprecher-Ich des die Dialogizität einer Farce evozierenden Gedichts Der entlarvte Crispinus nur ein weiteres Zeugnis der eitlen Selbstbespiegelung eines Repräsentanten der gelehrten Halbwelt. Nach dem Sudelkoch also abermals der Schmierer:

Wer sich dabey erbricht und auff den Eckel flucht,

Der spühle nur den Mund aus seiner Priester-Quelle.

Diß Werckgen, sehts doch an, vertritt des Glases Stelle,

Wenn sich die Einfalt putzt und zu bespiegeln sucht;

Nur schade, daß dadurch viel theure Männer [Variante: Märtrer] leiden,

Da wir vor ihr Verdienst so grobe Federn schneiden. ${ }^{31}$

Wiederum ist das kontrafaktisch verkehrte Spiegelbild der Märtyrerlegende sichtbar. Günthers punktuelle Polemik ist seine Antwort auf eine Diskussionslage, die die Gelehrtenrepublik seit 1692 beschäftigt hatte. Damals veröffentlichte der Mystiker Pierre Poiret eine Abhandlung mit dem Titel De eruditione solida, superficiaria et falsa. Das Werk, das unter dem Stichwort ,oberflächliche und falsche Gelehrsamkeit' mit einer grundsätzlichen Kritik schulgelehrten Wissens aufwartete, wurde von dem damals dem Pietismus zugeneigten Christian Thomasius (1655-1728) mit Begeisterung aufgenommen; zwei Jahre später, 1694, hat

27 Vgl. Günther: „Bescheidener Leser“ (= Leservorrede zu: Der entlarvte Crispinus) (Anm. 10), S. 282.

28 Günther: Der entlarvte Crispinus (Anm. 11), S. 298 (Günther: Gedichte [1764] (Anm. 7), S. 618). - In der Ausgabe von Bölhoff nicht nachgewiesen.

29 Wichtig wurde vor allem die von dem niederländischen Philologen Franciscus Dousa hergestellte Ausgabe der Satyrarum quae supersunt reliquiae. Hrsg. von Franciscus Dousa. Leiden 1597.

30 Vgl. die Ausgabe von 1739 (Anm. 8), Frontispiz.

31 Günther: Der entlarvte Crispinus (Anm. 11), S. 294 (Günther: Gedichte [1764] (Anm. 7), S. 614, hier: „Märtrer" anstelle von „Männer“). 


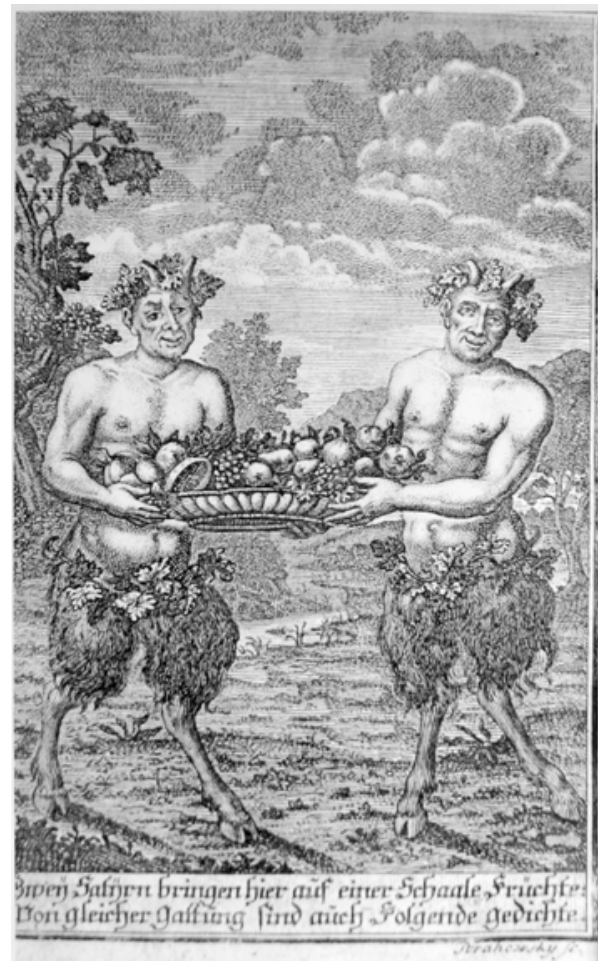

Abb. 2

er es von neuem zum Druck gebracht. ${ }^{32}$ Für Thomasius war das Werk insofern auch später noch von Wert, insofern als es ihm Aspekte der rationalen Vorurteilskritik vorformulierte. Genau in dieser Perspektive integrierte Günther im Juli 1718 die Polemik gegen das oberflächliche Wissen der Polyhistoren, das er als Scheinwissen entlarvte. In der Abfolge von Personifikationen, die Günther der Reihe nach auftreten lässt, nimmt seine Satire vollends die quasidramatische Form der Farce oder, wenn man die allgegenwärtige französische Tradition einbezieht, der sotie an..$^{33}$ Der „Narr" wird von Günther selbst im Kontext der alten Komödie des Plautus aufgerufen. Krause ist der Vertreter einer traditionsreichen Narrenzunft, an deren Physiognomie Erasmus von Rotterdam mit seinem Lob der Torheit (1511) ebenso gearbeitet hat wie Sebastian Brant mit dem Narrenschiff (1494). In den pointierenden Schlussversen ihrer Rede spottet Günthers Personifikation der "Thorheit" wie ein an Erasmus" Schrift geschulter Thomasianer:

Versäume die Vernunfft mit niederträcht'gem Wißen,

Und sey biß in das Grab auff keinen Zweck beflissen. ${ }^{34}$

Ganz im Sinne von Christian Thomasius verknüpft Günther die derart aufgewiesene Vernunftwidrigkeit polyhistorischen Wissens mit dessen sozialer Irrelevanz. Der Müßiggang ist aus dieser Perspektive grundsätzlich eine moralisch zutiefst verwerfliche weil a-soziale Haltung. Mit Sarkasmus zitiert Günthers Sprecher-Ich den „Stümper“ Krause mit den Worten: „Ich und mein Müßiggang;

32 Vgl. Ralph Häfner: Das Erkenntnisproblem in der Philologie um 1700. Zum Verhältnis von Polymathie und Aporetik bei Jacob Friedrich Reimmann, Christian Thomasius und Johann Albert Fabricius. In: Philologie und Erkenntnis. Hrsg. von Ralph Häfner. Tübingen 2001, S. 95-128, hier S. 104-110.

33 Vgl. Heather Arden: Fool's Plays. A study of satire in the sottie. Cambridge u. a. 1980; vgl. auch Barbara Swain: Fools and Folly During the Middle Ages and the Renaissance. New York 1932.

34 Günther: Der entlarvte Crispinus (Anm. 11), S. 290 (Günther: Gedichte [1764] (Anm. 7), S. 611). 
ihr seyd ein braves Paar!“" ${ }^{35}$ Die in der Vergnügung müßiger Stunden aufgehäuften Kenntnisse stellten indessen nur Scheinwissen vor, „Blendwerk und Betrug“, wie der personifizierte „Schein“ in einer an derben Grobianismen reichen „Predigt" auch hier also die Kontrafaktur geistlicher Beredsamkeit - diagnostiziert:

Lern' alles oben hin, und laß von Jung und Alten

Den Fürniß deines Koths vor reines Gold-Ertz halten. ${ }^{36}$

Merkmal des oberflächlichen Wissens ist sein bloß memorativer Charakter, mit Günther: es ist bloßes „Gedächtniß-Werck“, das der Prüfung der Vernunft nicht weiter mehr unterliegt. ${ }^{37}$ Crispin wird zum gelehrten Charlatan, dessen krankhafte Gelehrteneitelkeit seinem Müßiggang entspringt. Die Freude am gelehrten Müßiggang wächst sich im Falle des Halbgelehrten zu einer Art von Manie aus; Krause, der sich „prächtig“ ausspricht, ist der Krankheit der Logomachie, der blindwütigen Wortfechtereien, verfallen. ${ }^{38}$ Günther pathologisiert das oberflächliche, gesellschaftlich irrelevante Vielwissen im Sinne von Christian Thomasius, wenn er sein Sprecher-Ich konstatieren lässt:

Crispin ergab sich ietzt der Polyhistorie,

Zog Schwänck' und Mährchen ein, die Jung' und Mägde brachten,

Und ward vor Freuden kranck, wenn etwan der und die

Vom Pöbel über ihn und sein Gemächte lachten.

Er las' und überlas', was er mit Angst geschmiert,

Er sprach sich prächtig aus, wenn Preß' und Druck vergonnte,

Daß er sein Anfangs C im Nahmen lesen konnte,

Den er beym Schlaffen-gehn aus Liebe buchstabiert;

Nun wird man, dacht' er offt, in allen Bücher-Sälen

Auch deinen Müßiggang zur klügsten Arbeit zehlen. ${ }^{39}$

Die Bibliothek - der dem Vergängnis enthobene Raum der Muße - wird zum bloßen „Gedächtniß-Werck“, von dessen nutzlosem Ballast die praktische Vernunft erdrückt wird.

\section{Gilles Ménage und die Funktion der Intertexte}

Günthers Satire entstand in einem intellektuellen Umfeld, in dem es nicht zuletzt auch um den sozialen Status des Gelehrten ging. In Hamburg beispielsweise, im Umkreis von Johann Albert Fabricius und Barthold Heinrich Brockes, hatte man grundsätzlich Vorbehalte gegenüber dem von Thomasius absolut gesetzten Kriterium der Nützlichkeit gelehrten Wissens, seiner gesellschaftlichen Relevanz,

35 Günther: Der entlarvte Crispinus (Anm. 11), S. 294 (Günther: Gedichte [1764] (Anm. 7), S. 614).

36 Günther: Der entlarvte Crispinus (Anm. 11), S. 291 (Günther: Gedichte [1764] (Anm. 7), S. 611).

37 Günther: Der entlarvte Crispinus (Anm. 11), S. 292 (Günther: Gedichte [1764] (Anm. 7), S. 612).

38 Vgl. Samuel Werenfels: Dissertationes de logomachiis eruditorum, et de meteoris orationis. Frankfurt/M. 1724. - Die beiden Abhandlungen erschienen zuerst einzeln 1688 und 1692.

39 Günther: Der entlarvte Crispinus (Anm. 11), S. 293 (Günther: Gedichte [1764] (Anm. 7), S. 613). 
ohne dass man sich auf die polemischen Diskussionen innerhalb der Öffentlichkeit der Gelehrtenrepublik hätte einlassen wollen. Dafür waren die gesellschaftlichen Verhältnisse, die sich nach dem erbitterten Kampf zwischen radikalem Pietismus und lutherischer Orthodoxie erst wieder geordnet hatten, in der Freien Reichsstadt noch zu labil. In der Bücherstadt Leipzig, neben Halle die Hochburg der Thomasianer, vermochte Johann Burkard Mencke mit den von seinem Vater übernommenen Acta eruditorum zu zeigen, dass die Wissensvermittlung in einer raschen Umbrüchen unterliegenden Gesellschaft anderen Kriterien als dem gelehrten Müßiggang zu gehorchen hatte. Günthers Satire ist in diesem Umfeld kein Einzelfall, auch wenn seine Polemik der gattungsgemäßen Logik des Derben und Burlesken, der Farce und der sotie, folgt. Dass es sich dabei um eine höchst elaborierte Form der Satire handelt, macht der Autor selbst nicht zuletzt durch die Vielzahl intertextueller Verweise deutlich. Werfen wir daher einen vergleichenden Blick auf Gilles Ménage und seine Satire In Gargilium indignatio (,Gedicht der Entrüstung gegen Gargilius', 1643).

Neben Tartuffe und Thrax gehört Gargilius zu den drei der von Günther genannten „Thorheitsmärtrer[n]“, deren soziales Parasitentum sich in Crispin von neuem darstellt. Sie alle sind Exempla einer burlesken Märtyrerlegende. Ménage (1613-1692), einer der großen Philologen des 17. Jahrhunderts, war vor allem durch sprachgeschichtliche Forschungen hervorgetreten, die der im Umkreis des Pariser ,Cabinet Dupuy ${ }^{40}$ betriebenen Spracharchäologie verpflichtet war. Sein Hauptwerk, Les origines de la langue françoise (1650), ein Werk sprachvergleichender Etymologie ${ }^{41}$ ist Pierre Dupuy in seiner Eigenschaft als Conseiller d'Etat gewidmet; zusammen mit seinem Bruder Jacques Dupuy unterhielt Pierre einen offenen Intellektuellenzirkel, das ,Cabinet des frères Dupuy', zu dem übrigens auch Martin Opitz während seines Aufenthalts in Paris Zugang hatte. Ménage war durch Forschungen dieser Art so sensibel wie kaum ein anderer im Blick auf den lexikalischen Reichtum der Sprachen. Veraltete Wortformen, die niedere und mitunter derbe Sprache des Volks, kunstvolle oder aus dem Alltag heraus ent-

40 Vgl. vor allem die Arbeiten von Jérôme Delatour, dessen maßgebliche Studie zu den Brüdern Dupuy (hervorgegangen aus einer thèse der Ecole des chartes) demnächst erscheinen soll, sowie die beiden Studien von Klaus Garber: A propos de la politisation de l'humanisme tardif européen. Jacques Auguste de Thou et le, Cabinet Dupuy à Paris. In: Le juste et l'injuste à la Renaissance et à l'âge classique. Actes du colloque international tenu à Saint-Etienne du 21 au 23 avril 1983. Hrsg. von Christiane Lauvergnat-Gagnière und Bernard Yon. Saint-Etienne 1986, S. 157-177, und: Paris, die Hauptstadt des europäischen Späthumanismus. Jacques Auguste de Thou und das Cabinet Dupuy. In: Res Publica Litteraria. Die Institutionen der Gelehrsamkeit in der frühen Neuzeit. 2 Teile. Hrsg. von Sebastian Neumeister und Conrad Wiedemann. Wiesbaden 1987, S. 71-92.

$41 \mathrm{Vgl}$. Isabelle Leroy-Turcan: Introduction à l'étude du „Dictionnaire étymologique ou origines de la langue françoise“ de Gilles Ménage (1694). Les étymologies de Ménage, science et fantaisie. Lyon 1991; Gilles Menage (1613-1692) - grammairien et lexicographe. Le rayonnement de son œuvre linguistique. Actes du colloque international tenu à l'occasion du tricentenaire du „Dictionnaire étymologique ou Origines de la langue françoise“ (1694). Hrsg. von Isabelle Leroy-Turcan. Lyon 1995. 
standene Neologismen formten einen intellektuellen Kosmos, der für den Autor von Gelegenheitssatiren zur unerschöpflichen Fundgrube wurde. Dabei stellte sich Ménage selbst in eine bis auf den derb-erotischen altgriechischen Satiriker Hipponax (6. Jh. v. Chr.) zurückreichende Tradition und nannte Daniel Heinsius und Giambattista Marino als Beispiele der Gelehrtensatire seiner Zeit. ${ }^{42}$

Das Gedicht In Gargilium indignatio ist nur ein Beispiel unter einer Vielzahl von Werkchen, mit denen Ménage den am Collège royal tätigen Gräzistik-Professor Pierre de Montmaur attackiert hat. $\mathrm{Zu}$ nennen ist wenigstens noch die dem Dichter und Freund Guez de Balzac gewidmete Satire Gargilii Macronis parasitosophistae metamorphosis, die die Verwandlung des ,schwatzhaften Schmarotzers' Gargilius in einen Papagei zum Inhalt hat. ${ }^{43}$ Stilistisch arbeitet Ménage mit einem reichen mythologischen Apparat, Makkaronismen und einer Fülle literarischer Anspielungen. Die Satire In Gargilium indignatio ist demgegenüber kürzer, entfaltet aber einen Reichtum derben, ja, fletrierenden Wortschatzes, der hinter der klassischen Form des Horaz die älteste Satire der Lucilius und Hipponax transparent werden lässt. Einige der Schimpfwörter, die Ménage zu Beginn in dichter Parataxe aneinanderreiht, mögen genügen, um einen Eindruck von dieser für Günther vorbildlichen Art der Personalsatire zu bekommen: ,Faex literarum' (,Abschaum der Gelehrsamkeit'), ,Literatorum probrum' (,Schmach der Gelehrten'), ,Pindi cloaca' (,Kloake des Pindus'), ,carcinoma saeculi' (,Krebsgeschwür des Zeitalters'), ,Apollinaris lixa' (,dem Apoll geweihter Marktschreier'), ,mundi cymbalum' (,Zimbel des Universums'), ,ineptus' (,Pedant'), ,vecors' (,Unsinniger'), ,Literator insolens' (,ahnungsloser Halbgebildeter'), ,Tu Paedagoge, tu Magister garrule (,geschwätziger Lehrer und Meister'), ,Fallax Sophista' (,betrügerischer Sophist'), ,Circulator impudens' (,unverschämter Trödler'), ,Propago terrae' (,Auswurf der Erde'), ,furcifer' (,Galgenstrick'), ,tenebrio' (,Schwindler'), ,esuritor' (,Hungerleider'), ,vorax' (,Vielfraß`), ,helluo' (,Prasser'), ,Nidoris auceps' (,stinkender Wortkrämer'), usw. Ménage entwirft das Bild eines Schmarotzers (,parasitus'), der innerhalb der Gelehrtenrepublik zum Typus des aus fremden Quellen borgenden - sich mit fremden Federn schmückenden - Gelehrten geworden ist. Der Ausdruck ,mundi cymbalum' mag als Anspielung auf Bonaventure des Périers' Götterburleske Cymbalum mundi (1538) gedeutet werden, die im Stil der Fazetien die gelehrten und konfessionellen Streitigkeiten der Zeit verspottete.

Neben Ménage beteiligten sich auch Jean François Sarrazin (1611-1654), Henri Valois (1603-1676) und der notorische Paul Scarron an der Rufmordkampagne gegen Montmaur - nicht zufällig standen alle drei in mehr oder weniger enger Verbindung zur Pariser ,Académie' der Brüder Jacques und Pierre Dupuy. Ménage zog einem damals angesehenen Gelehrten die burleske Maske des Gargil

42 Vgl. Gilles Ménage: Miscellanea. Paris 1652, S. 38. - Ménage bezieht sich auf Daniel Heinsius' menippeische Satire gegen Caspar Schoppe (Leiden 1608) und Giambattista Marinos Invektiven gegen den Dichter Gaspare Murtola (1570-1624).

43 Vgl. Gilles Ménage: Gargilii Macronis parasitosophistae metamorphosis ad Io. Lud. Balzacium. In ders.: Poemata, secunda editio auctior \& emendatior. Paris 1656, S.3-9. 
über. Der aus dem Bordelaiser Jesuitenmilieu stammende Pierre de Montmaur (1576-1650) hatte eine Zeitlang in Rom Grammatik gelehrt; in Avignon ließ er sich als Arzneimittelhändler nieder und gelangte zu ansehnlichem Reichtum. Später wurde er ans Pariser Collège royal berufen. Pierre Bayle, der ihm in seinem Dictionnaire historique et critique (zuerst 1697) einen Artikel gewidmet hat, berichtet, dass er als größter Schmarotzer seiner Zeit galt und sich bei den „Schöngeistern" („beaux Esprits“) verhasst gemacht habe. Der Konflikt bildet ziemlich genau den sozialen Antagonismus zwischen Hof und Respublica literaria ab. Bayle schränkte im Horizont einer radikalen Vorurteilskritik die Wahrheitsfähigkeit der Satire allerdings grundsätzlich ein und bekräftigte die eigentlich triviale Feststellung, dass die Satire ein Spiegel der Wirklichkeit, nicht aber die Wirklichkeit selbst sei. Mitunter handelt es sich eben um einen Zerrspiegel.

„Mir scheint,“ so führte er aus, „dass man, ohne einer Täuschung zu unterliegen, sagen kann, dass dieser Mensch nicht im entferntesten so verachtenswert war als wie man ihn vorstellt. Er liebte wohl allzu sehr eine reich gedeckte Tafel; er speiste öfter als nötig bei den Großen; er war dabei allzu geschwätzig, daran zweifle ich nicht. Wenn aber die Fruchtbarkeit seines Gedächtnisses, seine Belesenheit, seine Geistesgegenwart, ihn nicht empfohlen hätten, hätte er dann so sehr Zugang zum Chancelier, zu dem Président de Mesmes und zu einigen anderen Personen gehabt, die sich durch ihren Rang, ihren guten Geschmack und ihre Gelehrsamkeit ausgezeichneten?“ Bayle schloss: „Hüten wir uns davor, die satirischen Beschreibungen, die man von seiner Person und von seinen Handlungen gemacht hat, für ein treues Porträt zu halten." ${ }^{44}$

Die größten Geister der Zeit hätten sich zusammen getan, um Montmaur „in einer Art von Kreuzzug“ („,cette espece de croisade“ ${ }^{45}$ der Lächerlichkeit preiszugeben. Die satirische Fiktion sei ein Spiel des Witzes (,jeu d’Esprit“), die in der ,historischen Erzählung' („le Narré Historique“) nicht gegründet sei. Bayle, der für sich die historische, d. h. vorurteilsfreie und mutmaßlich verlässliche ,Erzählung' beansprucht, beendet den Artikel indes mit einem vielsagenden "On dit“: „Man sagt, dass er fünftausend Pfund Rente bezogen hat und dass er sehr geizig war." ${ }^{46}$ Bayles Artikel ist ein gutes Beispiel für die in der Ambiguität der

44 Pierre Bayle: Dictionnaire historique et critique. Tome troisième. Troisième édition. Rotterdam 1720, S. 2005: „Il me semble qu'on peut dire sans se tromper que cet homme-là n'étoit pas à beaucoup près aussi méprisable qu'on le représente. Il aimoit trop la bonne chere; il alloit manger chez les Grans plus souvent qu'il n'eût falu; il y parloit avec trop de faste, je n'en doute point; mais si la fécondité de sa mémoire, si sa lecture, si sa présence d'esprit, ne l'eussent rendu recommandable, auroit-il eu tant d'accès chez Monsr. le Chancelier, chez Mr. le Président de Mesme, \& auprès de quelques autres personnes éminentes, \& par leur rang, \& par leur bon goût, \& par leur érudition? Gardons nous bien de prendre pour un fidele portrait les descriptions satiriques que l'on fit \& de sa personne \& de ses actions."

45 Bayle: Dictionnaire historique (Anm. 44), S. 2006.

46 Bayle: Dictionnaire historique (Anm. 44), S. 2008. 
Argumente offen gehaltene Argumentationsform. Diese Form wiederholt sich, wie sich zeigen ließe, auch in dem bekanntermaßen ausufernden Anmerkungsapparat, von dem die Artikel des Dictionnaire begleitet werden.

\section{Der prekäre Status der Muße im Zeitalter der Frühaufklärung}

Dass Konflikte von der Art, wie sie sich um Montmaur entzündeten, nicht selten Konflikte der sozialen Hierarchie innerhalb der idealerweise sozial offenen Gelehrtenrepublik spiegelten, macht Günthers Satire auf den längst arrivierten Polyhistor Theodor Krause deutlich. Krause, der sich in Schweidnitz als Rechtsanwalt niedergelassen hatte, füllte seine Mußestunden mit der scherzhaft-anekdotischen Verdichtung gelehrten Wissens, wie sie die ana-Sammlungen seit dem 17. Jahrhundert bereitgestellt hatten. ${ }^{47}$ Die in unregelmäßigen Abständen erscheinende Vergnügung müßiger Stunden stellt sich bewusst in diese Tradition. Krause verweist neben den Chevreana, die er ausgiebig benutzt hat, auf Kompilationen vom Typus der Otia und Horae subcessivae. Dem Leser teilte er mit: „Die Uberschrifft stellt dir die Vergnügung müßiger Stunden dar: und hat mit denen Büchern, so unter dem Titul: Otia, Observationes, Anmerkungen, Feyerabend, Zeit-Vertreib, etc. etc. bekannt gemacht worden, fast einerley Absicht." ${ }^{48}$ Gleich Ciceros Maxime ,vivas in litteris' stilisiert sich Krause zu jenem Polyhistor, der nur in und mit seinen Büchern wahres Lebensglück findet. Die Beispiele, die er in der geistreichen Leservorrede zum ersten Heft der Vergnügung 1713 anführt, sind dabei selbst Zeugnisse der Lektüre eines Juristen, der über genügend Zeit und Geld verfügt, sich der gelehrten Muße hinzugeben:

Der vortreffliche Juriste Corrasius sagte einsmahls, so ihn jemand seiner Bücher beraubete, so benähme er ihm alle Lust, allen Trost, alle Begierde zu leben; Und der gelehrte König in Engelland Jacobus [gemeint ist Jacob I. (1566-1625); der Initiator der King-James-Bible war auch als Dichter hervorgetreten] wüntschte öffters, wenn er sollte gefänglich bewahret werden, daß ihm die Bodlejanische Bibliothec darzu möchte destiniret werden; Ja Caelius Calcagninus verordnete gar, daß sein Cörper in seiner Bibliothec der Erden sollte anvertraut werden. ${ }^{49}$

Krauses Beispiele sind signifikant. Mit dem französischen Juristen Jean de Coras (Corrasius, 1513-1572) benennt er einen Kollegen der eigenen Profession; das Diktum Jacobs I. verdeutlicht, dass das ,otium cum dignitate auch höchsten Standespersonen ansteht; Celio Calcagnini (1479-1541) endlich ist das Muster eines ,uomo universale'. Der Ferraresische Humanist und Platoniker bringt mit der Parodie der Auferstehung von den Toten pointiert die innigste Hoffnung des Po-

47 Vgl. Francine Wild: Naissance du genre des Ana 1574-1712. Paris 2001.

48 [Theodor Krause:] „Günstiger Leser“. In ders.: Vergnügung müßiger Stunden, oder allerhand nützliche, zur heutigen galanten Gelehrsamkeit dienende Anmerkungen. Der I. Theil. Leipzig 1713, S. 4-8, hier S. 4.

49 [Theodor Krause:] „Günstiger Leser“ (Anm. 48), S. 7. 
lyhistors zum Ausdruck. War die Seele einst im Kerker des Körpers begraben, so ersparte sich der Leib bei seiner Auferstehung den Umweg über das Tal Josephat; er würde vielmehr gleich wieder in seiner Bibliothek lebendig. Die Bibliothek ist der Raum imaginärer Kommunikation, der deshalb an das Paradies erinnert, weil die Präsenz des Wissens die historische Zeit gänzlich hinter sich lässt. Sie ist das genaue Widerspiel von Dantes Hölle; wer in die Bibliothek eintritt, ist alles irdischen Vergängnisses enthoben.

Krauses Beispiele sind geistreiche Variationen auf das ciceronianische Thema ,vivas in litteris'. Nur der Büchermensch - der, der es sich aufgrund seines sozialen Status leisten kann, in und mit einem reichen Bücherschatz zu leben - ist wahrhaft glücklich. Zumindest in Calcagninis Parodie öffnete diese Einschätzung auch eine eschatologische Perspektive.

Krause erhielt seine intellektuelle Sozialisation durch Christian Thomasius und Nicolaus Hieronymus Gundling. Die Vergnügung müßiger Stunden ist gewissermaßen die Miniaturausgabe der Gundlingiana (seit 1715). In vier bis sechs Aufsätzen pro Lieferung handelte Krause verschiedenste Gegenstände aus der ,Historia literaria' ab; die Darstellungen zeichnen sich durch witzig-pointierten Stil und durch fortgesetzte Referentialisierung aus, die den Text in eine intertextuelle Textur, mit einer alten Metapher könnte man auch sagen: in einen Teppich vielfältiges Wissens, verwandelt. Dieses - in der Frühen Neuzeit nicht ungewöhnliche - Verfahren lässt den Text zugunsten der Intertexte mitunter völlig zurücktreten. Günther sah in Krauses Schriften einen Missbrauch der Vernunft: Es ist der Eigensinn (der „eigne Dünckel“"), der die Vernunft vergewaltigt und die „Wissenschafft" zur „Grillenfängerey“ herabwürdigt. ${ }^{50}$ Das ,Werk' der Vernunft wird, so Günthers Sprecher-Ich, zum geistlosen Register, das die ,galanten` Topoi nach Belieben durchläuft:

Wer wacker schwatzen kan, Register-Schreiber braucht,

Mit Nahmen um sich wirfft, davon die Ohren gällen,

Den unverschämten Kiel in Gall und Lügen taucht,

Zehn alte Schincken liest, den eilfften darzustellen;

Wer, sag' ich, etwan kaum ein dutzend Drucker kennt,

Und her zu schnattern weiß, was Brown und Hobbes glaubte,

Wie viel Gelehrte seyn, die man Johannes nennt,

Der heist galant gelehrt; ich rede mit der Mode.

Crispin ist so ein Fisch, jedoch aus ärgrem Sode. ${ }^{51}$

„Galant“ - damit benutzte Günther ein Reizwort der Epoche, ${ }^{52}$ das unmittelbar gegen Krauses Anspruch auf „galante Gelehrsamkeit“ zielte. Im Nachwort versi-

50 Günther: Der entlarvte Crispinus (Anm. 11), S. 298 (Günther: Gedichte [1764] (Anm. 7), S. 618).

51 Günther: Der entlarvte Crispinus (Anm. 11), S. 298 (Günther: Gedichte [1764] (Anm. 7), S. 619).

- Gemeint sind Sir Thomas Browne und Thomas Hobbes.

52 Vgl. Noémi Hepp: La galanterie. In: Les lieux de mémoire. Bd.3. Hrsg. von Pierre Nora. Paris 1997, S.3677-3710; Christophe Losfeld: Galanterie in Frankreich. Genese und Nieder- 
cherte Günther, dass es ihm niemand verdenken könne, wenn er „die vom ernsthafftigen Studiren mir erlaubte Zeit mit einem gelehrten Affen verspiele. ${ }^{\prime 53}$ Die in Günthers polemischer Satire zum Ausdruck kommende Differenz ist sicherlich auch darin begründet, dass ihr Autor - trotz der gemeinsamen intellektuellen Herkunft aus dem Thomasius-Umfeld - eine andere Auffassung von der Gemeinnützigkeit des Wissens vertrat als Krause alias Crispin. Zugleich ist sie Folge des sozial völlig ungesicherten Status eines Dichters, der sich 1716 durch seine Dichterkrönung verschuldet hatte. Wenn das Gedicht Der entlarvte Crispin mit einer Huldigung an den seit 1711 regierenden Kaiser Karl VI. ausklingt („Dein CARL, dein Käyser lebt, dein Herr, dein irdscher Gott; / Sein Adler schencket dir die Fittich hoher Gnaden." ), ${ }^{54}$ so klingt darin auch der Wunsch an, der Kaiser möge den Verfechter wahrer "Wissenschafft" den eitlen „Thorheits-Kindern" vom Schlage des Crispin vorziehen. Dabei ist das Gedicht ohne das Leipziger Umfeld um Johann Burkhard Mencke kaum denkbar. Der performative Grundzug des Werks setzt das humanistische Bild eines absurden Welttheaters in der spezifischen Form in Szene, die Mencke mit seiner Schrift über die Charlatanerie der Gelehrten - auch er wählt bekanntlich die performative Form der öffentlichen Rede - aktiviert hatte. Trotz der Bemühungen Menckes blieb Günther eine Anstellung oder mäzenatische Versorgung in seinem kurzen Leben verwehrt; die ,Fittiche hoher Gnaden' hat der Dichter, der das Scheinwissen galanter Gelehrsamkeit als eine Marter empfand, nie erhalten. Stilistisch ist Günthers Satire aus burlesken Schreibverfahren hervorgegangen, wie sie im 17. Jahrhundert zumal in Frankreich, in der Tradition der Mazarinaden, durch Paul Scarron und in den neulateinischen Gedichten eines Gilles Ménage, ausgebildet worden waren. Die satirischen Autoren des 17. Jahrhunderts, an deren Stil Günther partizipiert, gingen bewusst hinter die von Horaz gesetzte Norm, auf Lucilius und die altgriechische Satire des Hipponax, auf die spätantiken Grobianismen des Petronius und die Komödie der Aristophanes und Plautus, zurück. In ihnen erblickten sie alternative Schreibverfahren, die die performativen Gattungen der sotie und der Farce zu integrieren vermochten.

gang eines Verhaltensideals. In: Galanterie und Frühaufklärung. Hrsg. von Daniel Fulda. Halle/S. 2009, S. 13-50; ders.: Politesse, morale et construction sociale. Pour une histoire des traités de comportements (1670-1788). Paris 2011; Jörn Steigerwald: Galanterie als Kristallisations- und Kreuzungspunkt um 1700: eine Problemskizze. In: Galanterie und Frühaufklärung. Hrsg. von Daniel Fulda. Halle/S. 2009, S. 51-79. Zum Verhältnis von Galanterie und Roman vgl. Florian Gelzer: Konversation, Galanterie und Abenteuer. Romaneskes Erzählen zwischen Thomasius und Wieland. Tübingen 2007. Für den gesamten Kontext weiterhin grundlegend: Emmanuel Bury: Littérature et politesse. L'invention de l'honnête homme (1580-1750). Paris 1996.

53 Günther: Der entlarvte Crispinus (Anm. 11), S. 302.

54 Günther: Der entlarvte Crispinus (Anm. 11), S. 301 (Günther: Gedichte [1764] (Anm. 7), S. 622). - Zu Günthers Verhältnis zum Kaiserhof vgl. Burkhard Bittrich: Johann Christian Günther und das Haus Habsburg. In: Johann Christian Günther (1695-1723). Oldenburger Symposium zum 300. Geburtstag des Dichters. Hrsg. von Jens Stüben. München 1997, S. 77-87. 


\title{
Episteme in Beharrung
}

\section{Konventionelle Artistik und orthodoxes religiöses Wissen in der ,Lyrik' des Parnassus Boicus}

\author{
Andreas Beck
}

Im „17. Jahrhundert[]“, so der call for papers zu unserer Tagung, ${ }^{1}$ vollziehe sich „eine zunehmende ,Verinnerlichung' des Religionsbegriffs “; ",religiöse[s] Wissen“ werde "zunehmend [...] privates und ,paradoxes" Wissen", und dem korrespondiere „[i]m selben historischen Zeitraum“ die Entstehung der „moderne[n] Gattung einer ,Lyrik' als Konstruktion eines ,privaten' Raums, eines ,inneren Ausdrucks' persönlicher Gefühle, Empfindungen und Überzeugungen." Damit werde der Vers, der „,bis zu diesem Zeitpunkt vor allem Ausdruck [...] im weitesten Sinne ,artistischer' (im Sinne von ,Kunstfertigkeit') Anforderungen war, [...] jetzt Ergebnis einer besonderen ,Inspiration', die sich der Kontrolle des Verstands entzieht oder zumindest entziehen kann“. "Religion und ,Lyrik'“, hieß es weiter, „geraten in ein enges Verhältnis, indem sich persönliche, ,subjektive' religiöse Überzeugungen [...] jetzt in lyrischer Form äußern können. Logische und lyrische Form werden zu Gegensätzen."

Hierzu möchte ich mit meinem Beitrag einen Kontrapunkt setzen und gerade nicht jene „Entwicklung" von „,Lyrik“" ausbuchstabieren, die sich, so eines der ersten Zentnerworte im call for papers, im Zeichen der "Reformation“ vollzieht. Wenigstens ansatzweise möchte ich den Rahmen jenes Narrativs zu verlassen suchen, mittels dessen die germanistische Literaturwissenschaft (zumeist unbewusst) die Geschichte ihres nationalliterarischen Gegenstands als eine protestantische Erfolgsgeschichte erzählt. ${ }^{2}$ Solche (krypto)teleologische Sicht nämlich impliziert problematische Wertmaßstäbe, die die Abwertung und Ausblendung andersartiger literarischer Phänomene begünstigen. Betroffen hiervon scheinen mir insbesondere katholisch-oberdeutsche poetische Produktionen; sie machen, meiner Leseerfahrung zufolge, jenen literarhistorischen ,Fortschritt' vielfach nicht mit; die Dichtung des katholischen deutschen Südens formuliert bzw. er-

1 Vgl. die mit ihm vielfach wörtlich übereinstimmende Tagungsankündigung im elektronischen Veranstaltungsarchiv der Freien Universität Berlin, URL: http://www.sfb-episteme. de/Listen_Read_Watch/Veranstaltungsarchiv/Tagung_A06_Religioeses_Wissen.html (31.12.2014) - Dort fehlt indes der im Folgenden angeführte Passus zur Versgeschichte, weswegen ich mir erlaube, aus jenem unpublizierten Text zu zitieren.

2 Hierauf hat Dieter Breuer vielfach konstruktiv-kritisch hingewiesen; vgl. exemplarisch Dieter Breuer: Deutsche Nationalliteratur und katholischer Kulturkreis. In: Nation und Literatur im Europa der Frühen Neuzeit [...]. Hrsg. von Klaus Garber. Tübingen 1989, S. 701-715, hier S. 701-703. 
zeugt noch bis weit ins 18. Jahrhundert hinein unter anderem orthodoxes religiöses Wissen durch konventionell artistisch gestaltete, verständig-verständliche Verssprache. Die Stimme dieser verdrängten Dichtung nun, die in beachtlicher Persistenz und, nicht nur vereinzelt, auf bemerkenswertem Niveau von einer ,Episteme in Beharrung' zeugt, sie gilt es zu hören, wenn die allmähliche Annahme einer literarischen Hauptgattung ,Lyrik' in der deutschen poetologischen Diskussion des 18. Jahrhunderts zur Debatte steht.

Denn nicht erst 1735 bei Alexander Gottlieb Baumgarten begegnet - en passant - „zum erstenmal in Deutschland die triadische Gattungseinteilung in Lyrik, Epik und Dramatik",3 ",[s]chon zehn Jahre vorher", darauf hat Otto Knörrich hingewiesen, „veröffentlichte Gelasius Hieber“, ein Münchner Augustinereremit, „i[n] [...] der bayerischen Gelehrtenzeitschrift ,Parnassus Boicus' [...] eine Gattungslehre, die [...] bereits deutlich eine selbständige lyrische Hauptgattung erkennen läßt. ${ }^{4}$ Im Parnassus Boicus stand 1725 zu lesen:

WIr haben [...] auß Aristotele vernommen / wie die Poeterey in vier HauptGattungen sich außtheile / Erstrich / in die Epopœiam, zu welcher alle vnd jede Helden-Lieder / vnd Helden-Verß sowohl die Männlich / als Weibliche gehören; Zweytens / in die Comødiam oder Lust-Spihl / DRITTENS / in die Tragcdiam oder Trauer-Spihl / [...] vnd dann vierdtens / in die Dithyrambica oder Lyrica, welche zu verschidenen sanfften Instrumenten, alters hin gesungen wurden. Wie nun zu diser vierdten Reyen alle vnd jede Verß vnd Lieder gehören / welche in der ersten oder heroischen Gattung nit eingeschlossen / also seynd deren eine vnzahlbare Anzahl. ${ }^{5}$

3 Otto Knörrich: Lexikon lyrischer Formen. Stuttgart 1992, S. XXII; vgl. Alexander Gottlieb Baumgarten: Meditationes Philosophicae de Nonnvllis ad Poema Pertinentibvs. Halle/Saale [1735], S. 36 (§ CVI): „lyricum, epicum, dramaticum cum subdiuisis generibus“ (,die lyrische, epische und dramatische [Gattung] mit ihren Untergattungen'); vgl. Dieter Burdorf: Lyriktheorie. In: Reallexikon der deutschen Literaturwissenschaft. Hrsg. von Harald Fricke u. a. Bd. 2. Berlin und New York 2000, S. 502-505, hier S. 503.

4 Knörrich: Lyrische Formen (Anm. 3), S. XXII; Knörrich knüpft an Guillaume van Gemert an, der bereits darauf hingewiesen hatte, dass bei Hieber ,[d]ie dithyrambische Gattung [...] schon explizit ,lyrische' genannt wird"; Guillaume van Gemert: Oberdeutsche Poetiken als Forschungsproblem. Zur Dichtungslehre des „Parnassus Boicus“ (1725/1726). In: Zeitschrift für bayerische Landesgeschichte 47 (1984), H. 1, S. 277-296, hier S. 292. - Zu Hiebers Dichtungen und poetologischen Aufsätzen im Parnassus Boicus vgl. Dieter Breuer: Oberdeutsche Literatur 1565-1650. Deutsche Literaturgeschichte und Territorialgeschichte in frühabsolutistischer Zeit. München 1979, S. 89; van Gemert: Oberdeutsche Poetiken; Andreas Beck: Die Straßburger Eide in der Frühen Neuzeit. Modellstudie zu vor- und frühgermanistischen Diskursstrategien. Wiesbaden 2014, S. 190-202 und S. 218-259 (dort ausführliche bibliographische Hinweise).

5 Parnassus Boicus, Oder: Neu-eröffneter Musen-Berg / [...] Sechzehende Unterredung. München 1725, Hundert vnd vierzehender Bericht, S. 253; Teilzitat bei Knörrich: Lyrische Formen (Anm. 4), S. XXIII, nach van Gemert: Oberdeutsche Poetiken (Anm. 4), S. 292. - Zitate aus dem Parnassus Boicus im Folgenden unter Angabe von Unterredungs-, Berichts- und Seitenzahl innerhalb des fortlaufenden Texts; Markierung (auch bei Zitaten aus anderen Tex- 
Knörrich sieht hier „[d]ie Herausbildung eines umfassenden Gattungsbegriffs ,Lyrik' [...] in greifbare Nähe gerückt", und zwar - was mir im Hinblick auf das Tagungsthema relevant erscheint - ohne dass eine „Einengung auf die Darstellung von Empfindungen oder Affekten" erfolgt. ${ }^{6}$ Stattdessen bestimmt Hieber die undramatische poetische „Haupt-Gattung[]“ ,Lyrik' rein technisch-formal von der Metrik her dahingehend, dass sie alles umfasse, was nicht im „HeldenVerß", das heißt: im Alexandriner gehalten sei.

Diese Definition verdankt sich eigenwilliger Lektüre des „Frantzösischen Ronsard“, in dessen Abbregé de l'Art Poetique, in dessen „Poeterey-Kunst" es „am 418. Blat" (XVI/114, 253 f.) heißt:

,Die alexandrinischen und die gemeinen Verse sind die einzigen, die (nach der sechsten beziehungsweise vierten Silbe) eine Zäsur aufweisen. Die übrigen gehen nämlich ungezwungen einher, ihnen genügt schon eine bestimmte Silbenzahl, die du nach Belieben einrichten kannst, wie du willst, bald sieben- bis acht-, bald sechs- bis sieben-, bald fünf- bis sechs-, bald vier- bis dreisilbig, [...] je nach der Laune, die dich ergreift. Diese Verse passen wunderbar zur Musik, zur Lyra und anderen Instrumenten, und wenn du sie ,lyrisch' nennst, wirst du ihnen nicht unrecht tun.' ${ }^{7}$

,Lyrisch' meint bei Ronsard kein übergeordnetes Dichtungsgenre, sondern eine Hauptgattung von Versen - ein kategorialer Unterschied, den Hieber nivelliert. Er amalgamiert beide Ebenen (unter Absehung vom vers commun, den er nirgends behandelt), und so wartet er vielleicht als erster deutscher Poetologe mit ,Lyrik als einer literarischen Hauptgattung neben Epik und Dramatik auf.

Aber wie belastbar ist dieses technische Gattungsverständnis, das den Verdacht bloßer terminologischer Sorglosigkeit erweckt? Schon „Anfangs deß 106. BERICHTS am 164. BLAT" (XVI/114, 253) hatte Hieber die poetischen Hauptgattungen nach Aristoteles aufgeführt - und die „vierdte“ Gattung dort schlicht „Dithyrambica" (XV/106, 164) genannt, ohne ,lyrischen' Zusatz. Auch in anderer Hinsicht nimmt sich Hiebers ,Lyrik’ fragwürdig aus: Die unsystematische Behandlung

ten) von Antiqua im Fraktursatz durch Kursive, von Hervorhebungen, z. B. durch größeren Schriftgrad oder Schwabacher, durch KapITäLcheN.

6 Knörrich: Lyrische Formen (Anm. 3), S. XXIII.

7 „LEs vers Alexandrins $\mathcal{E}$ les communs sont seuls entre tous qui reçoiuent cesure, sur la sixiesme $\mathcal{E}$ quatriesme syllabe. Car les autres marchent d'vn pas licencieux, et se contentẽt seulemẽt d'vn certain nõbre que tu pourras faire à plaisir, selon ta volonté, tantost de sept à huict syllabes, tantost de six à sept, tantost de cinq à six, tantost de quatre à trois, [...] selon que la caprice te prendra. Tels vers sont merueilleusemẽt propres a la Musique, la lyre, $\mathcal{E}$ autres instrumens, quand tu les appelleras lyriques, tu ne leur feras point de tort“; Pierre de Ronsard: Abbregé de l'Art Poetiqve Francois. In: Les Evvres de Pierre de Ronsard [...]. Augmentees de plusieurs Poësies de l'Auteur, qui n'estoyent en la precedente edition [...]. Bd. 3. Les Qvatre Premiers Livres de la Franciade [...]. Lyon 1592, S. 399-424, hier S. 418. - Diese Ausgabe des Abbregé verwendete auch Georg Philipp Harsdörffer, vgl. ders.: Specimen Philologiæ Germanicæ [...]. Nürnberg 1646, S. $36 \mathrm{f}$. 
der Versmaße weist Leerstellen auf, ${ }^{8}$ und Beispielverse werden vielfach falsch klassifiziert. ${ }^{9}$ Warum also sich mit dieser ,Lyrik' befassen, der systematisch-begriffliche Stimmigkeit abzugehen scheint? Weil Hiebers Darlegungen im Parnassus Boicus oft das Entscheidende nicht explizit, sondern implizit äußern, durch zitierend-adaptierenden kombinatorischen Umgang mit den Quellen. ${ }^{10}$ Und wer dieses Vorgehen unbekümmert um terminologisch-systematische Irritationen rekonstruiert, begegnet dem stringenten Entwurf einer literarischen Hauptgattung ,Lyrik', die sich der Vermittlung religiösen Wissens verschreibt und dieses religiöse Wissen entschieden durch technisch-artistische, rhetorische, kunsthandwerkliche Operationen entwickelt und vermittelt.

Jene Bestimmung der Gattung ,Lyrik' im Rückgriff auf Ronsard steht nicht isoliert, sondern ergänzt den ebenfalls metrisch-formal orientierten Rekurs auf eine andere Quelle. Wenn im Parnassus Boicus die ,lyrischen' Exempelgedichte zu den verschiedenen Metren aufsteigend nach Silbenzahl der Verse gereiht werden, dann übernimmt dies, unter Anpassung an den knappen „Raumb deß Papiers“ (XVI/114, 254) in der Zeitschrift, die Darbietungsform der "REIMARTEN", der "gener[a] Carminum" 11 aus Justus Georg Schottels Ausführlicher Arbeit von der Teutschen HaubtSprache - von wo Hieber nicht nur dieses Ordnungsraster, sondern auch Versmaterial bezieht. ${ }^{12}$

Schottels tabellarisch-formales Vorgehen übernimmt Hieber mit bezeichnenden Einschränkungen. Die Auflistung der Ausführlichen Arbeit kennt natürlich die "Zwölffsylbig-“ und „Dreyzehnsylbig-Kurtzlange[n]“ Verse, „welche man

8 Die Aufzählung der „Metra“ nennt „Trochaica [...] / [...] Jambica [...] / [...] Dactylica“, sie vergisst den Anapäst (XVI/114, 254) - während die nachfolgenden praktischen Beispiele „Trochaische [...] Dactylische [...] Anapæstische Verß" (XVI/114, S. 254-256) bieten, so dass jetzt der Jambus leer ausgeht.

9 Die meisten von Hiebers Daktylen sind zeitgenössisch als Anapäste zu klassifizieren, die Mehrzahl seiner Anapäste hingegen als Daktylen - die auch, soweit sie aus Schottels Ausführlicher Arbeit entlehnt sind, dort als solche rubriziert werden (wie etwa der von Zesen entlehnte Eröffnungsvers des unten analysierten Gedichts Liebe ist stärcker als tödtliche Schmertzen; vgl. XVI/114, 256 f., gegenüber Justus Georg Schottel: Ausführliche Arbeit von der Teutschen HaubtSprache [...]. Braunschweig 1663, S. 904).

10 Vgl. hierzu ausführlich Beck: Straßburger Eide in der Frühen Neuzeit (Anm. 4), S. 127-311.

11 Schottel: Ausführliche Arbeit (Anm. 9), S. 867; vgl. Justus Georg Schottel: Teutsche Vers- oder ReimKunst [...], Frankfurt/Main und Lüneburg 1656, S. 99.

12 Vgl. etwa das dreisilbig-trochäischen Beispielgedicht XVI/114, 254, dessen erste Hälfte aus Schottel: Ausführliche Arbeit (Anm. 9), S. 871, übernommen wurde. - Sehr wahrscheinlich hat Hieber Schottels Verskunst im Rahmen der Ausführlichen Arbeit konsultiert und nicht eine der älteren Separatausgaben (1645 und 1656; erstere war mir nicht zugänglich) verwendet: Bei der Übernahme jenes dreisilbig-trochäischen Beispielgedichts nämlich ist ihm wohl ein Lesefehler unterlaufen, eine Versauslassung, zu der der zweispaltige Satz des Gedichts in der Ausführlichen Arbeit verleitet, nicht aber der einspaltige der Einzeledition (vgl. Schottel: Vers- oder ReimKunst [Anm. 11], S. 104). Natürlich lässt sich streng genommen nicht ausschließen, dass Hieber absichtlich v. 3 f. des betreffenden Gedichts, in welcher VerskunstEdition auch immer, fortgelassen hat - aber es ist doch auffällig, dass im Parnassus Boicus just die Verse angeführt werden, die in der Ausführlichen Arbeit in der linken Spalte zu stehen kommen, und nur diejenigen wegfallen, die dort in die rechte Spalte ,abgewandert' sind. 
Alexandrinisch / nach unser Reimkunst aber Helden-art nennet ${ }^{\prime \prime}{ }_{13}$ und die der Parnassus Boicus aus seiner ,Lyrik' mit Hilfe von Ronsards Abbregé ausschließt - was wohl gezielt geschieht, nämlich im Hinblick auf eine weitere, inhaltliche Einschränkung: Schottels Exempla sind mehrheitlich, aber nicht sämtlich religiösen Inhalts, er bietet auch moralisch-didaktische und weltliche Beispielgedichte. ${ }^{14}$ Dieses Themenspektrum engt Hieber ein, er präsentiert ausnahmslos geistliche Kurzdichtungen. Und was hat das mit der ronsardisch-,lyrischen' Abkehr vom Alexandriner zu tun? Nun, der "teutsche[] Helden-Vers" hat „zwölff biß dreyzehen Sylben“ (XV/106, 166), und Dreizehnsilbler, die sich bei Hereinnahme des Alexandriners kaum hätten umgehen lassen,, ${ }^{15}$ sie hätten dem ,Lyriker' Hieber angesichts der religiösen Thematik seiner Gedichte ein zahlensymbolisches Problem bereitet.

Hierfür spricht der Schluss der Hieberschen Beispielreihe. Deren letztes Gedicht ist in "ZwölfFsylbige[N]“" Versen gehalten (XVI/114, 257) und umfasst zugleich, als einziges der Exempelgedichte, zwölf Verse: Es potenziert die heilige Zwölfzahl und bietet so, passend zum Ende einer Serie religiöser Gedichte, ein hundertvierundvierzigsilbiges poetisch-quadratisches Pendant zum Ende der Bibel, zur zwölflastigen Vision des himmlischen Jerusalem im vorletzten Kapitel der Offenbarung. ${ }^{16}$ Wohl kalkuliert reichen Hiebers ,lyrische' Beispiele nur bis zu zwölfsilbigen Versen und schließen - anders als Schottel, dem erst bei Vierzehn- bis Siebzehnsilblern unwohl wird ${ }^{17}$ - konsequent schon den womöglich dreizehnsilbigen Alexandriner aus.

13 Schottel: Ausführliche Arbeit (Anm. 9), S. 895 f.; vgl. Schottel: Vers- oder ReimKunst (Anm. 11), S. $142 \mathrm{f}$.

14 So begegnet etwa Schottel: Ausführliche Arbeit (Anm. 9), S. 875 f., ein Nebeneinander von moralischen und religiösen sowie ebd., S. 885 und S. 890, von religiösen und weltlichen Beispielgedichten; und die Schlusssequenz des Abschnitts der Ausführlichen Arbeit, an dem Hieber seine ,lyrischen' Exempel orientiert (Teutsche Verskunst, Lib. II, Cap. IV-IIX), endet mit ausschließlich moralischen bzw. weltlichen Gedichten, vgl. ebd., S. 909-913.

15 Entsprechend grenzt Hieber seine ,Lyrik' ja gegen "sowohl die Männlich / als Weibliche" Alexandriner ab (XVI/114, 253).

16 Vgl. Offb 21: „12. Und sie [die heilige Stadt Jerusalem] hatte eine grosse hohe Maur / die hatte zwölff Porten / und auf den Porten zwölff Engel [...]. 14. Und die Maur der Stadt hatte zwölff Gründ: und auf denselbigen waren die zwölff Namen der zwölff Apostlen deß Lamms. [...] 16. Und die Stadt ligt vierecket / und ihr Läng ist so groß / als groß ihre Breit ist. Und er maß die Stadt mit dem guldenen Rohr auf zwölff tausend Feldweegs: und ihre Länge / und Höhe / und Breite seynd gleich. 17. Und er maß ihre Maur / hundert und vier und viertzig Elen“; Biblia Sacra Vulgatæ Editionis [...] Volumen II. [...] Bibel Oder Heilige Schrifft. Zweyter Theil [...]. Übs. von Thomas Aquinas Erhard. 3. Auflage. Augsburg 1730, S. 731.

17 Vgl. Schottel: Ausführliche Arbeit (Anm. 9), S. 885: „Diese Sechs- und SiebenzehnSilbige Langkurtze / wie auch die Sechs- und Siebenzehnsilbigen Kurtzlange“ Verse „haben wegen jhrer gar zu weit lauffenden gedehnten auslänge / und wegen gar zu weiter Zurückweichung des Reimes / nicht eine gleiche Lieblichkeit und Wollaut mit den anderen etwas kürtzeren Trogaischen und Jambischen Reimarten: Wie sie denn auch der ungebundenen Rede fast ähnlich scheinen"; vgl. auch ebd., S. 898. Vgl. weiterhin ebd., S. 911, das Problem überlanger Anapäste und Daktylen: „Diese [...] vierzehnsylbig- und funfzehnsylbig Gekurtzlange Reimarten / wie auch [...] die dreyzehn- und vierzehnsylbig- Gekurtzlange [recte: Lang- 
Auch in anderer Hinsicht agiert Hieber hier geschickt. Sein Gedicht paraphrasiert „Rom. VIII. 35.“ (XVI/114, 257), ein berühmtes Pauluswort: „Wer will uns dan scheyden von der Lieb Christi? Trübsal? oder Angst? Hunger? oder Blösse? Gefahr? Verfolgung? oder Schwerd?" ${ }^{18}$ Eine rhetorische Frage eröffnet den Epistelvers; durch sie steht die Untrennbarkeit der Gläubigen von der Liebe Jesu von vornherein außer Frage, so dass sich die nachfolgend aufgelisteten Anfechtungen ohnmächtig ausnehmen. Hieber hingegen entfaltet anfangs ausladendwirkungsvoll - wirkungsvoll auch poetisch-stilistisch durch klangintensive Binnenreime - mögliche Anfechtungen:

Laß türmen / laß stürmen die feindliche Horden

Laß murren / laß kurren die höllische Porten /

Laß knallen / erschallen Stuck / Mörser / Carthaunen.

Laß Dröhnen / erthönen / Clärin vnd Posaunen /

Laß rühren / laß kürren / laß surren vnd brummlen /

Die heissere Paucken / vnd schnurrende Trum̃len /

Entzünden / entbünden das Krieges-Geschütze /

Laß glimmen / entbrinnen die feurige Blitze.

Laß toben die wogen der Winden vnd Wellen /

Und gleichsamb die Sternen am Himmel anbellen /

Diß alles vnd noch mehr / wird nimmermehr können /

Von Göttlicher Liebe mein Seele zertrennen.

(XVI/114, 257 f.; s. Abb. 1 und 2)

Zehneinhalb Verse entfalten die Kraft jener Widrigkeiten - woraufhin nur eineinhalb stilistisch merklich herabgestimmte Zeilen den Aufruhr jener geräuschvollen Wortmassen beruhigen. Eineinhalb schlichte Verse wiegen die poetische Last über ihnen auf, so dass die Überschrift, „UBER die Wort Rom. VIII. 35.“ (XVI/14, 257; Hervorhebung A.B.), hinsichtlich der Seitenfläche, auf der das Gedicht potentiell steht (wenn nicht, wie hier, ein kaum kalkulierbarer Seitenumbruch dazwischenkommt), ernst genommen werden kann. Die ersten zehneinhalb Verse paraphrasieren den Bibeltext sehr frei, erst der Gedichtschluss -

[...] vnd noch mehr / wird nimmermehr können /

Von Göttlicher Liebe mein Seele zertrennen. (XVI/114, 258)

- übersetzt recht genau den Schluss von Röm 8,39, einer Variation des Beginns von Röm 8,35: „neque creatura alia poterit nos separare à charitate Dei“. ${ }^{19}$

gekürzte, vgl. ebd., S. 905] Reimarten / sind im Teutschen etwas schwer zu machen / und scheinen auch wegen jhrer gar zuweitlauffenden Auslänge / nicht eine gleiche Lieblichkeit / mit den anderen etwas kürtzeren Reimarten zuhaben". Vgl. Schottel: Vers- oder ReimKunst (Anm. 11), S. 125 und S. 167.

18 Biblia Sacra / Heilige Schrifft II (Anm. 16), S. 599.

19 Biblia Sacra / Heilige Schrifft II (Anm. 16), S. 599. 
Bon Der Teut/क)en

Do Das mein Sdjifflein bald Dorten antents und Dort aud) wohne obn einţiges (End! izylffylbige.

qiebe ift ftárder als tỏotlicbe Sd)mersen giebe Die brinnet vno brennet im Soersen.

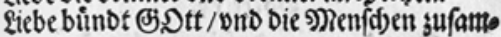
men

giebe balt bende in Sithe und Flammen.

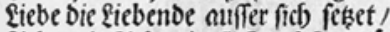

giebe mit Eieben in (S) Dtt fich ergóset.

Eiebe jerfibmerset Die Sersen ins gmein

Sis alle mur eins in GSOtt werben fenn.

$$
3 \text { wo̊lffylbige. }
$$

Utber bie Wert Rom. vint. 3 s.

Eas tilrmen/lak fturmen Die feind licbe Sorben

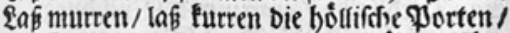

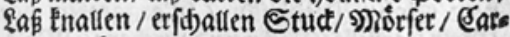
thaunen.

\&aß విróhnen ertbỏnen / తlårin und Pofats nen/

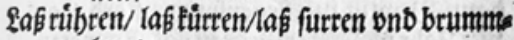
len /

Die beiffere \$auden/ ond fobnurtende Jumis len 7

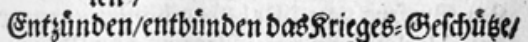

Ea a glimmen / entbrinnen Die feurige SOlise.

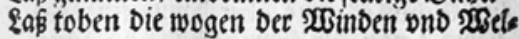
Ien!

Unb gleidffamb Die Sternen am Simmel ante bellen/

\section{Scunbert und I5.Det \$etid)t I}

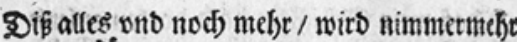
tơnnen/

Xon Bisttlidjer Siebe mein Seele zettrennen.

Govil bon ben vier Gattungen ber poeterey.

Sundert ond fünfisebender meridift.

23eiterer Betfolg Der Regenfputs gi(đ)en Şirdsen = Şiftori.

XXII. Chuno Plbbt von Sigberg tourDe 20ifd) off अlnno I 26. er bat bie ju feiner beit son Sిiedbolbo Grafen von 23od)burg/ ei= nem Ecbn \$iesboldi / S)arggrafen bot

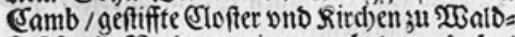
fadfen in Porbgau eingewenbet / ond bat felbit geftifftet bie Collegiat-Sirchen ju Et. Yos bann Saptift in Regenfpurg / ftarb / alš cr bier Tabr regieret/ wutbe зu St. Emmeran be graben.

XXIII. Henricus ein Sobn Othonis Deß erts

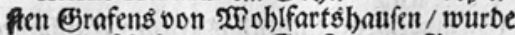
auff borfchub Friderici Brafens von 30 gen/ De $\bar{\beta}$ Sđus = Sherns úber Das Stift Fiegen. fpurg / von Der Geiftlichteit vno Surgers. fdafft wiber Den Willen Henrici Deß̧ boffárc

Abb. 1 und 2:

Parnassus Boicus XVI/114, 257 und 258; Reproduktion nach dem Exemplar der Bayerischen Staatsbibliothek München, Sign. Bavar. 2050a-3.

Derart schreibt Hieber tatsächlich „UBER die Wort“ der Paulinischen Epistel, er „türm[t]“ - so das erste Verb im Gedicht -, schriftbildlich-konkret vielfältige Widrigkeiten ,über' den entscheidenden Bibelworten, die sich ,unter' solchem Druck bewähren: und zwar nicht irgendwo, sondern hier und jetzt, an poetischem Ort und lyrisch wohldefinierter Stelle, mit dem zahlensymbolisch gewichtigen Übergang vom elften zum zwölften zwölfsilbigen Vers. Dadurch gewinnt das Gedicht performativen Charakter, es agiert in poetischer Praxis die Unbesiegbarkeit des amor Dei aus, von der seine Verse sprechen.

Wir haben es im Parnassus Boicus also mit einer poetischen Hauptgattung ,Lyrik' $^{\prime} \mathrm{zu}$ tun, die nicht para-, sondern orthodoxes religiöses Wissen transportiert - wobei die poetische Rede in Versen als solche, in ihrer spezifischen Differenz zur Prosa, die praktische Wirkmächtigkeit jenes traditionellen Wissens unter Be- 
weis stellt, es in seiner Gültigkeit modelliert. Hierin zeigt sich die epistemischdiskursive Relevanz solcher ,Lyrik', und zwar als einer Dichtung, in der der Vers, der sich Imitation und Variation verschreibt, nach wie vor entschieden "Ausdruck [...] , artistischer 'Anforderungen“" ist. Jene zwölf zwölfsilbigen Verse erlauben solche Folgerungen: Stellen sie doch keinen wenig aussagekräftigen Einzelfall dar, sondern das Ergebnis konzeptionsgeleiteter Poesieproduktion. Das zeigt das ähnlich gelagerte Gedicht, das dem eben analysierten vorhergeht:

Liebe ist stärcker als tödtliche Schmertzen

Liebe die brinnet vnd brennet im Hertzen.

Liebe bündt GOtt / vnd die Menschen zusammen

Liebe halt beyde in Hitze vnd Flammen.

Liebe die Liebende ausser sich setzet /

Liebe mit Lieben in GOtt sich ergötzet.

Liebe zerschmeltzet die Hertzen ins gmein

Biß alle nur eins in GOtt werden seyn. (XVI/114, 257; Abb. 1)

Auffällig ist zunächst die siebenfache Anapher in ihrer eindringlichen optischen und gegebenenfalls akustischen Präsenz - und komplementär hierzu, dass die „Liebe“ den letzten Vers dieses geistlichen Gedichts gerade nicht eröffnet, mehr noch, dass auch in dessen Fortgang diese christliche Haupttugend ,fehlt'. Eine irritierende Pointe, die sich wohl provokantem Kalkül verdankt, ${ }^{20}$ denn der ,lieblose' Schlussvers fällt auch anderweitig aus dem poetischen Rahmen: Er beginnt nicht, wie die übrigen Verse, mit einer betonten Silbe, so dass er tatsächlich einen „Eylffsylbige[N]“" „Anapæstische[n] Verß“ (XVI/114, 256 f.) vorstellen würde, ${ }^{21}$ den das Gedicht ja exemplifizieren soll, doch -

20 Es dürfte sich hierbei um einen gängigen Kunstgriff gehandelt haben; so versieht Schottel seine Ausführungen zur Anapher („Vornlauff“), „welche[] unterweilen / so es recht gemacht / nachdenklich und nicht ohn Zier ist", mit zwei sechsversigen Beispielgedichten, die in spannungsvollem Nebeneinander eine zur Gänze durchgeführte sowie eine mit dem letzten Vers abbrechende Anapher bieten: Im ersten Gedicht ist in sechsfacher Anapher davon die Rede, dass ,"Wenig sind / ach Gott / der Frommen / I Wenig in den Himmel kommen [...]" - während sich im zweiten Gedicht das Gros der um eine christliche Lebensführung Unbekümmerten mit einer nur fünffachen Anapher begnügen muss: „Viele leben wie sie wollen / I Viele thun nicht was sie sollen [...]" (Schottel: Ausführliche Arbeit [Anm. 9], S. 964). Das ist "nachdencklich und nicht ohn Zier", indem es poetisch demonstriert, dass jenes ,Wenige am Ende, mit dem letzten Vers beider Gedichte, doch mehr ist, als dieses ,Viele'.

21 Vgl. Schottel: Ausführliche Arbeit (Anm. 9), S. 906: Die anapästischen Verse „haben grosse Verwandtschaft [...] mit den Langgekurtzten oder Dactylischen / künnen auch leichtlich die einen in die anderen verändert werden / wenn nämlich zu den Langgekürtzten nur eine Sylb vorn angefüget / und also eine [...] Reimmaas [...] den Anfang machet / darauf denn die Gekurtztlangen oder Anapesten folgen" (vgl. Schottel: Vers- oder ReimKunst [Anm. 11], S. 158 f.). Ähnlich u. a. bereits Enoch Hanmann in seinen Anmerkungen (zuerst 1645) zu Martin Opitz' Buch von der Deutschen Poetery; vgl. Martin Opitz: Prosodia Germanica, Oder Buch von der Deutschen Poeterey [...]. Jetzo aber von Enoch Hannman an unterschiedenen Orten vermehret / und mit schönen Anmerckungen [...] verbessert. In ders.: Opera Geistund Weltlicher Gedichte [...]. Bd. 1. Breslau 1690, S. 1-266 [separate Paginierung], hier S. 190. 
$v-v v-v-v v-$

Biß alle nur eins in GOtt werden seyn. (XVI/114, 257)

- die dritte ,Reimmaas' bzw. der dritte ,pes ${ }^{\prime 22}$ weist nur zwei statt der zu fordernden drei Silben auf; eine Silbe fehlt, was leicht hätte vermieden werden können, wenn ,eines‘ anstelle von „eins“ gesetzt worden wäre:

$v-v \quad v-v \quad v-v v-$

,Biß alle nur eines in GOtt werden seyn.'

So jedoch haben wir einen ,hinkenden Vers' vor uns, ${ }^{23}$ oder aber eine jener metrischen Stolperfallen, wie sie sich häufig aus oberdeutscher Synkopierungs- und Apokopierungspraxis ergeben ${ }^{24}$ - eine weitere Auffälligkeit, durch die der letzte Vers den Rezipienten dazu anhält, der Faktur des Gedichts nachzuspüren.

Der Achtzeiler handelt von der Einswerdung der Menschen in Gott durch dessen Liebe sowie die Liebe zu ihm - oder besser: das Gedicht vollzieht in performativem artistisch-technischen Sprachhandeln zuletzt solche Vereinigung. Während das erste Verspaar ${ }^{25}$,nur' die Wirkung des amor Dei auf den Einzelnen schildert, spricht das zweite von der Verbindung, die solche Liebe zwischen Gott und den Menschen stiftet. Das dritte intensiviert dieses Thema: Es betont die Kraft des amor Dei, den Menschen aus seiner Ich-Befangenheit heraus "ausser sich“ zu „setze[n]“, ihn zu einem Sein „in Gott“ zu führen. Diese Liebe kennt kaum mehr ein von ihr trennbares Gegenüber, was die zweimalige figura etymologica „Liebe die Liebende [...] Liebe mit Lieben“ rhetorisch umsetzt; ihr Gleichklang macht erfahrbar, dass der amor Dei über eine bloße Verbindung hinaus eine Einheit der Liebenden stiftet.

Solche Einswerdung vollzieht nun das letzte Verspaar erstens: syntaktisch; zweitens: durch Synaphie; drittens: mittels der Verskadenz; und viertens: auf der Ebene einzelner Wörter. Zur Syntax: Bis einschließlich Vers sechs herrscht strenger Zeilenstil, jeder Vers ist als eigenständiger Hauptsatz von den anderen Versen syntaktisch unabhängig. ${ }^{26}$ Anders im letzten Verspaar: Zwar bietet auch der siebte Vers einen selbstständigen Hauptsatz, doch an ihn schließt der einzige Nebensatz des Gedichts an, so dass das Einswerden aller in Gott nicht in zwei

22 In Terminologie und metrischer Notation folge ich hier Schottel: Ausführliche Arbeit (Anm. 9), S. 833-835 und 906-911 (vgl. Schottel: Vers- oder ReimKunst [Anm. 11], S. 44-47 und S. 158-167).

23 „Die hinkenden Reime [= Verse] seynd, in welchen ein Theil oder Stükk des Pedis, oder der Reimmaas / mangelt und ausgelassen wird“; Schottel: Ausführliche Arbeit (Anm. 9), S. 970 f. (vgl. Schottel: Vers- oder ReimKunst [Anm. 11], S. 238); vgl. auch Georg Philipp Harsdörffer: Poetischer Trichter [...]. Erster Theil. 2. Auflage. Nürnberg 1650, S. 86.

24 Vgl. Beck: Straßburger Eide in der Frühen Neuzeit (Anm. 4), S. 239-243.

25 Die Gliederung des Gedichts nach Verspaaren empfiehlt sich, neben dem Paarreim, auf Grund der Zeichensetzung: Alle geraden Verse - und nur sie - schließen mit einem Punkt.

26 Entsprechend wären unter diesem Aspekt Versumstellungen denkbar, deren Beliebigkeit im Grunde nur das Pronomen ,beyde“ einschränkt. 
Einzelsätzen, sondern, sachlich angemessen, in nur mehr einem, zwei Verse vereinenden syntaktischen Gefüge zum Ausdruck kommt.

Dem korrespondiert die Gestaltung der Versgrenzen. Das metrische Schema der ersten drei Verspaare ist dieses:

$$
\begin{aligned}
& \text { x́xx|x́xx|x́xx|x́x^ } \\
& \text { x́xx|x́xx|x́xx|x́x^ }
\end{aligned}
$$

Die Pause von etwa einer Silbenlänge zwischen den Versen wird nicht durch Fugung, durch die unbetonte erste Silbe des Folgeverses gefüllt; die syntaktisch voneinander geschiedenen Verse erscheinen so auch metrisch klar voneinander getrennt. Im letzten Verspaar hingegen sieht das metrische Schema wie folgt aus:

$$
\begin{aligned}
& \text { x́xx|x́xx|x́xx|亡 }(\wedge) \quad \text { bzw. } \quad \text { x́xx|x́xx|x́xx|x́ } \wedge(\wedge)
\end{aligned}
$$

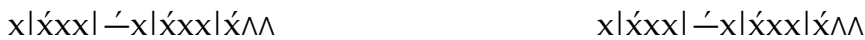

Den zweiten Vers eröffnet hier ausnahmsweise eine unbetonte Silbe, die ganz (oder zum Teil) die Pause am Ende des vorhergehenden Verses besetzt. Derart gehört sie gewissermaßen beiden Versen zu - als Bindeglied zwischen ihnen, die auf diese Weise sowohl syntaktisch als auch durch metrische Fugung miteinander verbunden sind.

Sehen wir uns die Verskadenzen an. Die beiden letzten, durch Synaphie verknüpften Verse, die die Einswerdung aller in Gott in einem Satzgefüge formulieren - sie zeigen folgerichtig männliche Kadenzen gegenüber den weiblichen der ersten sechs Verse: Deren Zweisilbigkeit erscheint im letzten Verspaar in Einsilbigkeit überführt, wodurch die poetische Aussageform ein weiteres Pendant zu jener Einswerdung bietet.

Vor der Folie all dessen erweisen sich auch die Auffälligkeiten auf der Ebene einzelner Wörter im letzten Verspaar als stimmig, etwa der ,lieblose‘ Abbruch der Anapher: Deren Fortführung im achten Vers hätte die auf Einheit gestellte elocutio des letzten Verspaars durch eine Dopplung, eine Spaltung der Liebe gestört die sich so indes, ihrer Wirkung gemäß, nur mehr als eine präsentiert. Ähnlich steht es mit jener metrisch fehlenden Silbe. Das korrekte ,eines‘ hätte einen performativen Widerspruch erzeugt: Im Kontext jener Fülle von einheitsorientierten Sprachgestaltungsstrategien hätte just dasjenige Wort ein zweisilbiges sein sollen, das die Einheit aller in Gott ausspricht? Hieber, in dessen Schriften bei diesem Thema sowohl ,eines' als auch ,eins seyn' vorkommt, ${ }^{27}$ dürfte sich hier mit gutem stilistischen Grund für die einsilbige Version samt sinntragender Störung des metrischen Schemas entschieden haben.

27 Sogar in einem Satz: „himmlischer Vatter! sende deinen H. Geist / daß sie eines seyn im Glauben und Liebe / wie wir eins seynd in der Natur und Weesenheit!" Gelasius Hieber: Gepredigte Religions-Histori [...]. Zweyter Theil [...]. Augsburg und Dillingen 1729, S. 689b, erklärende Paraphrase von Joh 17,22. - Ähnlich etwa auch Dominik Fleischmann: Schau-Bühne der Evangelischen Wahrheit [...]. Zweyter Theil [...]. München 1755, S. 104 f. (s. u. Anm. 36). 
Auch dieses Gedicht transportiert beziehungsweise modelliert mithin in performativer, artistisch-,lyrischer' Rede konventionelles religiöses Wissen in seiner Wirksamkeit; zudem erlauben hier intertextuelle Bezüge eine präzise Bestimmung der literar- und poetologiehistorischen Position von Hiebers epistemischdiskursiv beharrlicher ,Lyrik'.

Angeregt wurde jener Achtzeiler durch Schottels Ausführungen zu den deutschen ,Reimarten'. Hiebers "Liebe mit Lieben in GOtt sich ergötzet" verarbeitet den dort angeführten Vers "Mit Gott sich ergetzet" von "August[o] Buchner[o]", 28 dem Begründer deutscher Daktylen. ${ }^{29}$ Doch den inventorischen Nucleus des parnassidischen Beispielgedichts bildeten andere Verse auf derselben Seite:

Lieben ist stärker als tödtliche Schmertzen /

[...]

Funkelt und Flammet und glüet im Hertzen, ${ }^{30}$

heißt es da. Hieber variiert den dritten Vers und übernimmt den ersten fast unverändert:

Liebe ist stärcker als tödtliche Schmertzen

Liebe die brinnet vnd brennet im Hertzen.

Eine Adaption von Material „[A]Us Dem Hohen Liede [...] Cæxi[i]“, ${ }^{31}$ Philipps von Zesen, wo jene Verse Hld 8,6 umschreiben: „Liebe ist starck wie der Tod / [...] ihre Glut ist feurig / und eine []Flamme des HERRN“.32

Und wozu dient im Parnassus Boicus dieser über Schottel und Zesen vermittelte Hohelied-Bezug? Protestanten wie Katholiken, Zesen und Hieber lesen das Hohe

28 Schottel: Ausführliche Arbeit (Anm. 9), S. 904; vgl. Schottel: Vers- oder ReimKunst (Anm. 11), S. 156.

29 Schottel: Ausführliche Arbeit (Anm. 9), S. 899; vgl. Schottel: Vers- oder ReimKunst (Anm. 11) S. 147.

30 Schottel: Ausführliche Arbeit (Anm. 9), S. 904; vgl. Schottel: Vers- oder ReimKunst (Anm. 11), S. 156.

31 Schottel: Ausführliche Arbeit (Anm. 9), S. 904; vgl. Schottel: Vers- oder ReimKunst (Anm. 11), S. 156.

32 Biblia, das ist / die gantze Heilige Schrifft [...] / nach der Verdeutschung Doct. Martin Luthers [...]. Gotha 1712, Altes Testament, S. 698; zum Bezug der Zesen-Verse auf genau diesen Vers des Hohen Lieds vgl. Philipp von Zesen: Geistliche Wohl-lust oder Hohes Lied; in Palmen- oder dattel-reimen / mit [...] vom fürtreflichen J. Schopen gesetzten sang-weisen [...]. Amsterdam 1657, S. 109 f. und S. 114. Hieber hat diesen Bezug offenbar erkannt, denn die Verse „Liebe die brinnet vnd brennet im Hertzen. I [...] | Liebe halt beyde in Hitze vnd Flammen“, sie ähneln merklich einer Übersetzung von "Cant. VIII. 6“, die Hieber wenig später in seiner Gepredigten Religions-Histori bietet: „SEINe [...] LIEBE BRINNET UND BRENNEt wie FEuer und Flammen“; Hieber: Gepredigte Religions-Histori II (Anm. 27), S. 680b. - Zudem dürfte das brennende Herz an prominenter Stelle, direkt nach dem ersten erborgten Zesen-Vers, eine Art Autorsignatur des Augustiners Hieber vorstellen; vgl. sein Exlibris, das den Heiligen Augustinus als schreibenden Autor mit brennendem Herzen in der Linken zeigt (Abb. bei Beck: Straßburger Eide in der Frühen Neuzeit [Anm. 4], S. 308). 
Lied typologisch als eine Allegorie der Vermählung Christi mit seiner Kirche. ${ }^{33}$ Doch wer ist die Kirche Christi? Laut Lutheraner Zesen die „RECHT-GLÄUBIGE[] AusIerkohrne[] Gemeine Gottes / Dem Augspurgischen unver-Ifälschten Glaubensbekänntnüsse zugethan". ${ }^{34}$ Hieber zufolge indes ist "die wahre alleinseeligmachende Kirchen eine Allgemeine Kirchen", also eine, oder besser: die katholische, die „der abtrinnige Lutherus“ mit „seiner Winckel- und Affter-Kirch“ verlassen hat ${ }^{35}$ - und dieses dogmatische religiöse Wissen vermittelt Hiebers lyrische Rede durch entsprechende Gestaltung jenes typologischen Bezugs.

An die durch Zesen angeregte Hoheliedparaphrase der ersten vier Verse schließt die Entfaltung der liebenden Einheit aller in Gott an. Deren poetische Gestaltung kulminiert, wie beschrieben, im letzten Vers - auch dahingehend, dass besagte Einheit dort mit der des dreieinigen Gottes verknüpft erscheint: Bietet doch die Formulierung „eins in GOtt“ das durch Majuskeln hervorgehobene Wort "GOtt“ zum dritten und letzten Mal. Das Einssein aller in Gott durch die Liebe Gottes, kombiniert mit dessen mehrpersonaler Einheit, das verweist auf das siebzehnte Kapitel des Johannesevangeliums, wo allein im Neuen Testament sich genau dieser Themenkomplex findet:

11. [...] Heiliger Vatter / erhalte sie [die Apostel] in deinem Namen / [...] daß sie eins seyn / wie auch wir. [...] 20. Ich bitte aber [...] auch für diejenige / welche durch ihr Wort an mich glauben werden: 21. Auf daß sie alle eins seynd / wie du Vatter in mir bist / und ich in dir / daß sie auch also in uns eins seynd [...]. 22. Und ich hab jhnen die Herrlichkeit[] gegeben [...]: daß sie alle eins seynd / wie wir auch eins seynd. 23. Ich in ihnen / und du in mir: auf daß sie vollkommen seynd in einem: und die Welt erkenne / [...] daß du sie geliebet hast / gleichwie du mich hast geliebet. [...] 26. Und ich hab ihnen deinen Namen kund gemacht [...]: auf daß die Lieb / damit du mich geliebet hast / in ihnen sey / und ich in ihnen. ${ }^{36}$

33 Vgl. exemplarisch Zesen: Hohes Lied (Anm. 32), fol. Av; Gelasius Hieber: Gepredigte Religions-Histori [...]. Erster Theil [...]. Augsburg und Dillingen 1726, S. $141 b$.

34 Zesen: Hohes Lied (Anm. 32), fol. A ijr.

35 Hieber: Gepredigte Religions-Histori I (Anm. 33), S. 294a.

36 Biblia Sacra / Heilige Schrifft II (Anm. 16), S. 535 f. - Explizit ist an dieser Stelle zwar ,nur' von Gott Vater und Sohn die Rede, aber gerade Joh 17,26, der Schluss des Evangelienkapitels, der im Zeichen der Liebe die Einheit der Gläubigen mit der von Gott Vater und Sohn engführt, wurde wiederholt auf den Heiligen Geist als die Liebe zwischen letzteren gedeutet: Vgl. etwa Hieber: Gepredigte Religions-Histori II (Anm. 27), S. 690a (s. auch das Zitat Anm. 27), sowie eine Beuroner Predigt von Benedikt Schwank vom 20. Mai 2007 (URL: http://www. beitraege.erzabtei-beuron.de/ [3. 1. 2015]). Hierzu stimmt, dass Joh 17,20-26 seit dem zweiten Vatikanum im Lesejahr C als Perikope am letzten Sonntag vor Pfingsten vorgelesen wird (vgl. URL: http://www.perikopen.de/ [3. 1. 2015]). - Vgl. außerdem weitere verwandte frühneuzeitliche theologische Deutungen von Joh 17: Die von Noël Alexandre (1639-1724) sieht das Einssein der Gläubigen, die Trinität und die Liebe eng zusammen (vgl. Noël Alexandre: Theologia Dogmatico-Moralis Secundum Ordinem Catechismi Concilii Tridentini [...]. Tomus Secundus [...]. Paris 1759, S. 636b); und Fleischmann: Schau-Bühne der Evangelischen Wahrheit (Anm. 27), S. 104 f., führt in einer Predigt über den „Dreyeinigen GOtt“ nach Zitat 
Auf diesen Antitypus macht der Achtzeiler im Parnassus Boicus Zesens Hohelieddichtung transparent, denn Hieber versteht Joh 17 (bis heute gängig) ${ }^{37}$ als „Bitt [...] de[s] vermenschte[n] Sohn GOttes“ um „Einigkeit in seiner Kirchen“ ${ }^{38}$ - und so, zusammen mit dem Hohen Lied, als Mahnung, dass

die Kirch nur die eintzige Braut Christi ist: una est columba mea [...]: Cant. VI. 8. [...] Aus welchem die Ketzer und Spaltige gnugsam ersehen können, wie es bey ihnen, gleich von Hauß aus, gefehlet seye, daß sie von der Kirchen, die nit mehr als ein eintzige ist, und seyn kan [...], sich getrennet. ${ }^{39}$

Angesichts dessen liest sich jenes Gedicht als Angriff auf unkatholische Häretiker - und zwar, angesichts des vom Protestanten Zesen übernommenen Anfangsverses, als eine vom „Salomonische[n] Bräutigamb“ des Hohen Lieds aus über "Joan. XVII.“ geführte Attacke gegen „unsre [...] Protestanten die Lutheraner und Calvinisten " ${ }^{40}$ Eine weitere Pointe des Gedichtschlusses, und auch sie verdankt sich konventioneller Artistik: nämlich einer inventio, die fern von ,persönlichen Gefühlen' eine theologisch-dogmatisch gesicherte Prätextsuche darstellt, um anschließend durch Zitat, Variation und Neukombination des aufgefundenen Textmaterials eine katholisch-rechtgläubige Konversion protestantischer Dichtung und Poetologie des früheren 17. Jahrhunderts vorzunehmen. Schottel, Buchner und Zesen werden vor der Folie des Johannesevangeliums adaptiert, um die

von Joh 17,11 aus: „Wie sollen nun dise Wort eigentlich zu verstehen seyn, daß alle RechtGlaubige eines[!] seyn sollen, wie GOtt einig ist? [...] Sint unum. Hierauf antwortet kürtzlich der heilige Augustinus, daß solches durch Treu und Liebe beschehen müsse: Per charitatem. Wann ein Mensch dem anderen durch Liebe getreu ist, so wird er GOtt gleich. Sint unum per charitatem." Fleischmanns Berufung auf den Hl. Augustinus (auf dessen Auslegung von Joh 17 in De Trinitate IV/9, vgl. Aurelius Augustinus: Tomvs III. Opervm [...]. Paris 1586, S. 113 A/B) zeigt, dass es sich bei den referierten Positionen wohl kaum um vereinzelte theologische Stimmen handelt - vielmehr dürfte der Themenkomplex von amor Dei, mehrpersonaler Einheit Gottes sowie der Einheit der Gläubigen in Gott im Hinblick Joh 17 gelehrten zeitgenössischen Rezipienten bekannt gewesen sein, so dass sie ihn bei der Lektüre von Hiebers Gedicht an dieses herantragen konnten.

37 Vgl. die erwähnte Beuroner Predigt von Schwank (s. Anm. 36); außerdem die Predigt zum Himmelfahrtstag vom 24. Mai 2001 von Wolfgang Huber im Berliner Dom, URL: http:// www.ekd.de/glauben/feste/himmelfahrt/predigten/5576.html (1. 1. 2015).

38 Gelasius Hieber: Gepredigte Religions-History [...]. Dritter Theil [...]. Regensburg und Stadtamhof 1733, S. 19b, bezogen auf "Joan. XVII. 20. 21.“ (ebd.); auch hier kommt Hieber von Joh 17 aus auf den dort neben Vater und Sohn ,fehlenden' Heiligen Geist als denjenigen zu sprechen, der jene Bitte vollzieht.

39 Hieber: Gepredigte Religions-History III (Anm. 38), S. 19b-20a; ähnlich ebd., S. 184a, ebenfalls mit Kopplung von Joh 17 und Hld 6,8.

40 Hieber: Gepredigte Religions-History III (Anm. 38), S. 184a/b. - Vgl. auch die Predigt Hubers im Berliner Dom von 2001 (Anm. 37); sie zeigt, dass die Protestanten sich ob jener Einheitsforderung Jesu in Joh 17 noch immer ein wenig unter Druck fühlen; interessant in dieser Hinsicht Hubers Gedankengang, ob uns Häresien denn nicht bedeutend weiter gebracht hätten als die Befolgung jenes Einheitsgebots? 
Dichtkunst, die Opitz 1624 mit seinem Buch von der Deutschen Poeterey durch Lutherverse reformiert und begründet hatte, 1725 feindlich zu übernehmen.

Auch um Opitz geht es hier, denn Hiebers Gedichte stehen, was unerhört ist, unter dem Kolumnentitel „Von der Teutschen Poeterey“ (XVI/114, 257; s. Abb. 1). Kein postopitzianischer Poetologe wählte für seine Ausführungen diese Überschrift à la Opitz, der nicht ein, sondern das ,Buch von der Deutschen Poeterey verfasst hatte; Hieber ist meines Wissens der Erste (und wohl auch Einzige) der diesen Tabubruch wagt. ${ }^{41}$ Er führt, gerade auch mit seiner poetischen Hauptgattung ,Lyrik', die konventionelles religiöses Wissen nach überkommenen Mustern dichterischer Produktion technisch-artistisch modelliert, epistemisch-beharrlich jene in die Jahre gekommene ,Poeterey ${ }^{\prime}$ fort $^{42}$ - die auf protestantischer Seite, bereits historisch geworden, ${ }^{43} \mathrm{u}$. a. einer ,Lyrik' weichen mag, die in gefühlsinspirierten Versen subjektiv-,paradoxes' Wissen zum Ausdruck bringt und derart, teleologisch perspektiviert, den Keim unseres heutigen Verständnisses von Lyrik bildet.

Alternativlos war diese Entwicklung indes nicht. Dass Hiebers dezidiert technisch konzipierte ,Lyrik' für sich genommen ernst zu nehmen ist, hoffe ich gezeigt zu haben - woraus sich, wie ich glaube, auch deren literarhistorische Relevanz ergibt: Die artistischen Verfahren der Text- und Sinnproduktion, die sich an jener ,Lyrik' beobachten lassen, ihr Einsatz legt die Annahme nahe, dass sie im Hinblick auf ein Publikum Verwendung fanden, das solche Schreibstrategien ausmachen und verstehen konnte; also ist mit gelehrten Rezipienten zu rechnen,

41 Vgl. Beck: Straßburger Eide in der Frühen Neuzeit (Anm. 4), S. 196.

42 In der Diskussion wurde erwogen, ob Hiebers Poesie in ihrer Artistik nicht womöglich auch entschieden in genuin katholischer Tradition stehe? Franz Eybl verwies auf Paschasius' Pöesis artificiosa (1668, 1669 und 1674), Wolfgang Proß auf die Wirksamkeit italienischer kultureller Vorbilder gerade in Kurbayern. Freilich sind entsprechende Einflüsse wahrscheinlich - die ich bislang jedoch nicht nachweisen konnte. Zudem scheinen mir die poetisch-technischen Verfahren, die sich im Parnassus Boicus beobachten lassen, nicht auf prinzipielle konfessionelle bzw. regionale Eigentümlichkeiten hinzudeuten; es finden sich ja, wie immer wieder angemerkt, grundsätzliche Gemeinsamkeiten (etwa, was Quellen oder verstechnische Verfahren angeht) mit der protestantischen, mittel- und norddeutsch dominierten poetisch-poetologischen Tradition. Kurz: Hiebers ,Lyrik' dürfte eine übergreifende veraltende diskursive Tradition fortschreiben - übergreifend auch dahingehend, dass sie längst nicht nur den Bereich der Dichtung umfasst, vgl. Beck: Straßburger Eide in der Frühen Neuzeit (Anm. 4), S. 313-319.

43 Nach dem Erscheinen der von Hanmann nochmals (nach 1645, 1647 und 1650) erweiterten Ausgabe von Opitz' Buch von der Deutschen Poeterey (1658) geht dessen Primärrezeption zu Ende; erst 1689/90 wird diese extended version in Breslau wieder aufgelegt und, nachdem sie "lange den Laden gehütet hatte[]", zum einhundertsten Jahrestag des Buchs von der Deutschen Poeterey nochmals auf den Markt gebracht, „,mit einem neuen Titelblatte vom Jahr 1724 eingekleidet" (J[ohann] J[akob] Bodmer und J[ohann] J[Jakob] B[reitinger] [Hrsg.]: Martin Opitzens Von Boberfeld Gedichte. [...] Erster Theil. Zürich: 1745, fol. A2r ${ }^{\mathrm{r}}$ ). Seither ist die Opitzsche Dichtungslehre nicht mehr zusammen mit ihren Erweiterungen erschienen und nur mehr Gegenstand historisch-philologischen Interesses; Bodmer und Breitinger etwa arbeiten ab ca. 1724 an einer Art kritischen, von fremden Zusätzen ,gereinigten' Ausgabe der Deutschen Poeterey (vgl. die Selbstdarstellung der Herausgeber ebd., fol. A2 ${ }^{\mathrm{r}}-\mathrm{A} 3^{\mathrm{r}}$, sowie S. 3 f.). 
die zu kompetenter Lektüre jener Texte in der Lage waren. Das wiederum führt auf die Annahme einer eingespielten, intakten konservativen literarischen Kommunikationssituation im katholischen Süddeutschland der 1720er - und wohl auch bis zu drei Jahrzehnte danach. Daraus sollten sich literaturwissenschaftliche Konsequenzen ergeben: Eine Lyrikgeschichte sollte eingehend auch das katholisch-süddeutsche Komplement zur epistemisch bewegten, protestantischen Lyrik Mittel- und Norddeutschlands in den Blick nehmen; im Interesse einer angemessenen, gerade nicht problematisch-einseitigen Erforschung der literarischen Kultur des alten Reichs. 
(C) 2015, Otto Harrassowitz GmbH \& Co. KG, Wiesbaden ISBN Print: 9783447104975 — ISBN E-Book: 9783447194136 


\title{
Newton in der Dichtung
}

\author{
Simone De Angelis
}

In den letzten Jahren hat die Forschung ein besonderes Augenmerk auf die Bedeutung der Dichtung in der Debatte über den kulturellen Einfluss von Newton, seiner Ideen und Wissenschaft gelegt. Die lateinischen und englischen Gedichte, die von Patricia Fara und David Money behandelt wurden, prägen ein heroenhaftes Bild, in dem Newton als britischer Held gefeiert wird, als mathematisches Genie mit dem Status eines Halbgotts. ${ }^{1}$ In anderen Gedichten wird seine Himmelsmechanik, wie sie besonders die Principia entwerfen, gestützt oder kritisiert. In den Gedichten Alexander Popes und in denen des berühmten Schweizer Physiologen Albrecht von Haller, die hier im Fokus stehen sollen, wird Newton ähnlich dargestellt, jedoch mit etwas mehr Skepsis, vor allem gegenüber der mathematischen Methode seiner Naturphilosophie.

Die Forschung hat der Rolle der Dichtung in dieser skeptischeren Behandlung Newtons bislang wenig Beachtung geschenkt. Wenn die prominente Rolle der Dichtkunst in der Gestaltung der Rezeption von Newtons Ideen erklärt werden soll, kann allerdings der kulturelle Kontext weder auf Großbritannien noch auf die höfische Kultur beschränkt werden, sondern muss auch die grundsätzliche Debatte über die Natur des Menschen berücksichtigen, die innerhalb der bürgerlichen Kultur der Frühaufklärung geführt worden war. Die Funktion des Dichters und das Genre der Lehrdichtung, ${ }^{2}$ das die natürliche und die moralische Seite des Menschen anspricht, erscheint in diesem Kontext in einem neuen Licht.

Dieser Beitrag zeigt, wie sich die Auseinandersetzung mit der Erkenntnis der Natur in den 1720er Jahren in den Gedichten von Pope und Haller widerspiegelt.

1 Patricia Fara and David Money: Isaac Newton and Augustan Anglo-Latin poetry. In: Studies in History and Philosophy of Science 35 (2004), S. 549-571. Vgl. auch David K. Money: The English Horace. Anthony Alsop and the Tradition of British Latin Verse. Oxford 1998, S. 135-167 sowie Jean-François Baillon: Early eighteenth-century Newtonianism: the Huguenot contribution. In: Studies in History and Philosophy of Science 35 (2004), S. 533-548 (über John Theophilus Desaguiliers Gedicht The Newtonian system of the world, the best model of government, 1728).

2 Vgl. Wilhelm Kühlmann: Lehrdichtung. In: Reallexikon der Deutschen Literaturwissenschaft. Hrsg. von Harald Fricke u. a. Bd. 2. Berlin, New York 2000, S. 393-397 (über das Genre der Lehrdichtung in der deutschen Frühaufklärung); vgl. auch Rainer Baasner: Abraham Gotthelf Kästner: Aufklärer (1719-1800). Tübingen 1999, S. 243-260 (über Abraham Gotthelf Kästners Philosophische Gedichte von den Kometen, 1744) sowie Simone De Angelis: Von Newton zu Haller. Studien zum Naturbegriff zwischen Empirismus und deduktiver Methode in der Schweizer Frühaufklärung. Tübingen 2003, S. 109-113 (über das kosmologische Gedicht in der deutschen Frühaufklärung). 
Es ist dabei kein Zufall, dass es mit Haller ein Experimentalphysiologe war, der in seinen Gedichten epistemologische und methodologische Belange hinterfragte, denn es waren gerade die ,Wissenschaften vom Leben' des 18. Jahrhunderts, zu deren Etablierung Haller entscheidend beigetragen hatte, in denen die Grenzen der geometrischen, mathematischen Methode sichtbar geworden waren.

\section{Erkenntnis der Natur vs. menschliche Phantasie}

Die Einbettung von Newtons poetischer Rezeption im Kontext der Geschichte der Wissenschaften vom Menschen seit 1600 eröffnet eine interessante Perspektive. Es ist nämlich aus dieser Perspektive, aus der die Veränderungen in der Beziehung zwischen Geist und Körper, die sich um 1700 vollzogen und die auch einen Einfluss auf die Dichtkunst hatten, verstanden werden können. Diese Perspektive wurde auch von Henry St. John, Vicomte von Bolingbroke in seinen Letters or Essays Addressed to Alexander Pope eingenommen. Pope hatte unter dem Einfluss von Bolingbroke begonnen, seinen Essay on man (1733-34) zu schreiben. ${ }^{3}$ In den Works (1777) ist diesen Letters eine Einführung vorangestellt, in denen Bolingbroke seine philosophische Position darlegt.

In dieser Einführung grenzt Bolingbroke seine Auffassung von einer ,Ersten Philosophie' von der der Metaphysik als Seinswissenschaft oder Ontologie ab, ${ }^{4}$ die ihrerseits als Reaktion auf den Aristotelischen Naturalismus zu Beginn des 17. Jahrhunderts entstanden war. Das Problem, das durch die naturalistische Interpretation der Seele in ihrer Beziehung zum Körper aufgekommen und zu großen Debatten unter Philosophen und Theologen des 16. Jahrhunderts geführt hatte, war dadurch entstanden, dass Aristoteles die individuelle menschliche Seele innerhalb seiner Physik so diskutiert hatte, dass sie als sterblich erscheinen musste. ${ }^{5}$ Nach Bolingbroke erfanden die Metaphysiker die Hypothese von den zwei separaten Substanzen, was das System der Disziplinen grundlegend änderte: Die Disziplinen, die sich mit der immateriellen Seele (Metaphysik) beschäftigten, wurden von denjenigen Disziplinen getrennt, die sich mit den Körpern (Physik) beschäftigten. Letztere galten in der Philosophie als von untergeordnetem Status. ${ }^{6}$

Bolingbroke lehnte diese Hypothese eines Substanzendualismus ab, da Geist und Körper, wie er sagte, ,", are still united, and blended, as it were, together, in one human nature: and all natures, united or not, fall within the province of natural philosophy “. ${ }^{7}$ In seinem Konzept einer ,Ersten Philosophie', die eine andere Ord-

3 Brean S. Hammond: Pope and Bolingbroke. A Study of Friendship and Influence. Columbia 1984; Pope. Hg. v. Brean S. Hammond. London, New York 1996; The Complete Critical Guide to Alexander Pope. Hg. v. Paul Baines. London, New York 2001.

4 Lord Bolingbroke: The Works. Bd. 3. London 1777, S. 320.

5 Simone De Angelis: From text to the body: Commentaries on De Anima, anatomical practice and authority around 1600. In: Scholarly Knowledge. Textbooks in early modern Europe. Hrsg. von Emidio Campi u. a. Genf 2008, S. 205-227.

6 Bolingbroke: Works (Anm. 4), S. 326.

7 Bolingbroke: Works (Anm. 4), S. 326. 
nung der Wissenschaften vorsieht, gehört der erste Platz der Naturphilosophie, aus der "natural theology or theism and natural religion or ethics" ${ }^{\prime 8}$ entstehen.

Diese Kritik der Metaphysik impliziert bei Bolingbroke auch eine bestimmte Epistemologie und Methodologie als Reflexion über die Denkweise und die Wissensproduktion in den Naturwissenschaften. Prinzipiell ist Bolingbrokes Argument durch die Unterscheidung von natürlichem und unnatürlichem menschlichen Denken charakterisiert, wobei letzteres durch eine unangebrachte Verwendung des menschlichen Vorstellungsvermögens, der Phantasie, zustande kommt. Er behauptet, dass „hypothetical reasoning" und "systems and arguments à priori" - als eine Art von Philosophieren „out of the bounds of human knowledge“ - die natürliche Theologie und die natürliche Religion korrumpiert hätten. ${ }^{9}$

Für Bolingbroke hatte die Bildung von derartig hypothetischem Allgemeinwissen mit dem Stolz der Metaphysiker zu tun: „To consider, attentively, even the minutest phaenomena of body and mind mortifies their pride. Rather than creep up slowly, à posteriori, to a little general knowledge, they soare at once as far, and as high, as imagination can carry them ${ }^{10}{ }^{10}$ Das war nicht ironisch gemeint, da Bolingbroke Metaphysik als das Ergebnis eines „primitive error" ansah, der darin bestand, dass ",in the high opinion we are apt to entertain of the human mind, though it holds, in truth, a very low rank in the intellectual system" ${ }^{11}{ }^{11} \mathrm{Im}$ Hinblick auf Popes Portrait von Newton in seinem Essay on man, auf das noch zurückzukommen sein wird, sei hier schon angemerkt, dass auch Pope genau diese epistemologische Frage stellt:

The bliss of man (could pride that blessing find)

Is, not to act or think beyond mankind;

No pow'rs of body or of soul to share,

But what his nature and his state can bear.

Why has not man a microscopic eye?

For this plain reason - man is not a fly. $(1.189-194)^{12}$

Deshalb steht hinter der grundlegenden Unterscheidung zwischen einer natürlichen und einer vom Vorstellungsvermögen und von der Phantasie bestimmten Denkweise - nach Bolingbroke - die zu erörternde Frage: „what we can know of God, from what we cannot know ${ }^{\prime 13}$ Aus diesem epistemologischen Blickwinkel heraus fordert Bolingbroke eine Veränderung der Wissensordnung - weg von ei

8 Bolingbroke: Works (Anm. 4), S. 325.

9 Bolingbroke: Works (Anm. 4), S. 327.

10 Bolingbroke: Works (Anm. 4), S. 327.

11 Bolingbroke: Works (Anm. 4), S. 328.

12 Alexander Pope: The Works. 9 Bde. With his last Corrections, Additions, and Improvements; As they were delivered to the Editor a little before his Death; Together with the Commentaries and Notes of Mr. Warburton. London 1751, Bd. 3 [containing his Moral Essays].

13 Bolingbroke: Works (Anm. 4), S. 328. 
ner hierarchischen und hin zu einer psychogenetischen Ordnung, die in der Lage ist, zu demonstrieren, wie natürliches menschliches Wissen entsteht:

To cure this error, we need only turn our eyes inward, and contemplate impartially what passes there from the infancy to the maturity of the mind. Thus it will not be difficult, and thus alone it is possible, to discover the true nature of human knowledge, how far it extends, how far it is real, and where, and how it begins to be fantastical. ${ }^{14}$

Eine solche Untersuchung nimmt in nuce das epistemologische Programm der Aufklärung wieder auf, das John Locke in seinem Essay concerning human understanding (1689) initiiert und Etienne Bonnot de Condillac in seinem Essai sur l'origine des connoissances humaines (1746) weiterentwickelt hatte: „Locke pursued it. He grounded all he taught on the phaenomena of nature ${ }^{\prime \prime} .{ }^{15}$ Folglich müssen aus der Perspektive der Methode alle Naturwissenschaften

rise from below, and from our own level. [...] for all the knowledge that can be acquired about mind, [...], must be acquired, like that about body [...] within the bounds of their province, and by the means they employ, particular experiments and observations. ${ }^{16}$

Bolingbrokes Ansatz ist daher antimetaphysisch; er unterstützt den Empirismus und den Experimentalismus. Was aber in seiner Einleitung am meisten hervorsticht, ist, dass Bolingbroke in seiner Bestimmung der moralischen Seite von Mensch und Gesellschaft dieselben Unterscheidungskriterien angenommen hatte wie in seiner Kritik der Metaphysik - natürlich vs. ,phantasievoll'. Das ist kein Zufall und hat mit drei wichtigen Faktoren zu tun, die um 1670 zur Konfiguration einer neuen historischen Situation beitrugen und einen großen Einfluss auf das 18. Jahrhundert hatten: 1. Spinozas Konzept von Gottes Immanenz in der Natur; 2. die Newton'schen Naturgesetze; 3. die Naturrechtstheorie und ihr Konzept von Sittengesetz und bürgerlicher Gesellschaft. Es ist vor allem der dritte Faktor, der dabei hilft, Bolingbrokes Analyse des moralischen Verhaltens besser zu verstehen.

Die grundlegende Annahme der Naturrechtstheorien der zweiten Hälfte des 17. Jahrhunderts war, dass der moralische Bereich, sprich: der Bereich der menschlichen Handlungen, ebenso nach Gesetzen geregelt war wie der physische Bereich, also etwa die Bewegung der Körper. In De Legibus Naturae (1672) übernimmt Richard Cumberland (1623-1718) das Konzept des Naturgesetzes von Descartes und dem spätscholastischen spanischen Philosophen Francisco Suárez, indem er argumentiert, dass menschliches Handeln nach bestimmten Naturgesetzen abläuft, die vom Schöpfer festgelegt wurden, ohne dass dieser jedoch

14 Bolingbroke: Works (Anm. 4), S. 328.

15 Bolingbroke: Works (Anm. 4), S. 329.

16 Bolingbroke: Works (Anm. 4), S. 325-326. 
den freien Willen seiner Kreaturen und die Entfaltung der Fähigkeiten, mit denen diese ausgestattet wurden, behindert. ${ }^{17}$ Deshalb war für Cumberland, der auch die physiologischen und anatomischen Studien von Thomas Willis (Gehirn, Nerven) und Richard Lower (Herz) aus den 1660er Jahren kannte, die Ursache menschlichen Handelns der Geist und der Körper des Menschen (De Legibus Naturae, Proleg., §18). Die Prinzipien, die menschliches Handeln leiten, sind einerseits Selbstliebe oder Egoismus und andererseits Gefühle von ,mutual benevolence' oder Altruismus. Es gilt im gesellschaftlichen Leben zwischen diesen beiden Polen eine Balance zu finden (De Legibus Naturae, Kap. 2: De natura humana et recta ratio, $\S \S 17-30) .{ }^{18}$

In diesem Kontext ist Bolingbrokes moralisches Argument zu Beginn seiner Einleitung zu verstehen: Er beschuldigt seine Zeitgenossen, diese Balance zugunsten der Selbstliebe aufgegeben zu haben und - wiederum als Resultat einer verzerrten, falschen Vorstellung (,imagination“) - von der ,einfachen und wirklichen Natur' abgewichen zu sein:

When societies are once established, and governments formed, men flatter themselves that they proceed in cultivating the first rudiments of civility, policy, religion, and learning. But they do not observe that the private interests of many, the prejudices, affections, and passions of all, have a large share in the work, and often the largest. These put a sort of bias on the mind, which makes it decline from the straight course; and the further these supposed improvements are carried, the greater this declination will grows, till men lose sight of primitive and real nature, and have no other guide but custom, a second and a false nature. The author of one is Divine Wisdom, of the other, human imagination; and yet whenever the second stands in opposition to the first, as it does most frequently, the second prevails. From hence it happens, that the most civilised nations are often guilty of injustice and cruelty, which the least civilised would abhor, and that many of the most absurd opinions and doctrines, which have been imposed in the dark ages of ignorance, continue to be the opinions, and doctrines of ages enlightened by philosophy and learning. If I was a

17 Vgl. hierzu Simone De Angelis: Lex naturalis, Leges naturae, „Regeln der Moral“. Der Begriff des ,Naturgesetzes' und die Entstehung der modernen ,Wissenschaften vom Menschen' im naturrechtlichen Zeitalter. In: ,Natur', Naturrecht und Geschichte. Aspekte eines fundamentalen Begründungsdiskurses der Neuzeit (1600-1900). Hrsg. von Simone De Angelis u. a. Heidelberg 2010, S. 47-70; Robert Schnepf: Gottes Handeln und der Lauf der Natur. Probleme und Perspektiven der theologischen Vorgeschichte des neuzeitlichen Naturgesetzbegriffs im Mittelalter. In: Naturgesetze. Historisch-systematische Analysen eines wissenschaftlichen Grundbegriffs. Hrsg. von Karin Hartbecke und Christian Schütt. Paderborn 2006, S. 87-114; Jon Parkin: Science, Religion and Politics in Restauration England, Richard Cumberland's De Legibus Naturae, Suffolk 1999.

18 Vgl. auch De Angelis: Der Begriff des Naturgesetzes (Anm. 17), S. 52-69 sowie Simone De Angelis: Anthropologien. Genese und Konfiguration einer ,Wissenschaft vom Menschen' in der Frühen Neuzeit. Berlin, New York 2010, Kap. 6. 
philosopher, says Montaigne, I would naturalise art, instead of artilising nature. The expression is odd, but the sense is good, and what he recommends would be done, if the reasons that have been given did not stand in the way; if self-interest of some men, the madness of others and the universal pride of the human heart, did not determine them to prefer error to truth, and authority to reason. ${ }^{19}$

Bolingbroke fordert, das fehlerhafte Verhalten der Menschen zugunsten von deren moralischer Natur wieder auszubalancieren, entsprechend den Prinzipien des Naturrechts. Und dabei ist es gerade die Dichtung, die ein Gefühl für das Natürliche in der menschlichen Psyche wieder herstellen könne:

[...] let the generous muse resume her ancient dignity, re-assert her ancient prerogative, and instruct and reform as well as amuse the world. Let her give a new turn to the thoughts of men, raise new affections in their minds, and determine in another and a better manner the passions of their hearts. $^{20}$

Auf diese Weise machte Bolingbroke Pope auf die Rolle der Lehrdichtung in der modernen Welt aufmerksam und erinnerte an die ursprünglich religiöse und soziale Funktion von Kunst. Allerdings war die Aufgabe eines modernen Dichters schwieriger geworden als im Zeitalter vor der Aufklärung, da die Menschen ihr moralisches Defizit hinter dem Schleier der Zivilisation versteckten:

Poets, they say, were the first philosophers and divines, in every country; and in ours, perhaps, the first institutions of religion, and civil policy, were owing to our bards. Their task might be hard, their merit was certainly great. But if they were to rise now from the dead, they would find the second task, if I mistake not, much harder than the first, and confess it more easy to deal with ignorance than with error. ${ }^{21}$

Und Pope wusste, welche Art von moralischen Gefühlen er im modernen Bewusstsein bewegen musste:

Self-love forsook the path it first pursu'd, And found the private in the public good.

'Twas then the studious head, or gen'rous mind,

Follower of God, or friend of human kind,

Poet or patriot, rose but to restore

The faith and moral nature gave before;

Relum'd her ancient light, not kindled new; (3.281-287)

19 Bolingbroke: Works (Anm. 4), S. 315-316.

20 Bolingbroke: Works (Anm. 4), S. 314-315.

21 Bolingbroke: Works (Anm. 4), S. 315. 
Im Angesicht dieser Argumentation muss Popes Portrait von Newton in der zweiten Epistel seines Gedichts sowohl aus epistemologischer als auch moralischer Perspektive betrachtet werden.

\section{Popes Portrait von Newton}

In Popes Gedicht wird Newtons Wissenschaft und seine Entdeckung der Naturgesetze in die Debatte über die Wissenschaften vom Menschen eingebettet, wie die Verse 1-2 der Epistel II klar erkennen lassen: „Know then thyself, presume not God to scan! / The proper study of mankind is man." Das antike Diktum des Orakels von Delphi nosce te ipsum („Erkenne dich selbst“) war seit der Renaissance gewöhnlich in Studien zu finden, die die physische und/oder die moralische Seite der menschlichen Natur erforschten. Wenn wir nun diesen Eröffnungsversen Popes Bild von Newton gegenüberstellen, zeichnet sich die Absicht des Dichters klar ab: Der große Mathematiker soll als Halbgott erscheinen, dessen Intelligenz groß genug ist, um selbst Gott zu imitieren:

Go, wondrous creature! Mount where science guides,

Go, measure earth, weigh air, and taste the tides;

Instruct the planets in what orbs to run,

Correct old time, and regulate the sun;

Go, soar with Plato to th' empyreal sphere,

To the first good, first perfect, and first fair;

Or tread the mazy round his foll'wers trod,

And quitting sense, call imitating God;

As eastern priests in giddy circles run,

And turn their heads to imitate the sun.

Go, teach Eternal Wisdom how to rule -

Then drop into thyself, and be a fool

Superior being, when of late they saw,

A mortal man unfold all nature's law,

Admir'd such wisdom in an earthly shape,

And show'd a Newton as we show an ape. (2.19-34)

Das Bild von Newton in einem Käfig - „, a clever monkey, an exhibit for the angels to marvel at as we marvel at the semihuman intelligence of an ape ${ }^{\prime 22}-$ bekommt seine Bedeutung aus der oben erläuterten, natürlich verfahrenden Erkenntnis und der empirischen Methode. Denn, wie wir gesehen haben, hatte sich die epistemologische Situation seit dem Erscheinen von Newtons Principia im Jahre 1687 gewandelt. In den 1720er Jahren konnte das Natürliche nicht länger mit dem Mathematischen oder Metaphysischen identifiziert werden. Beide brachten nur ein abstraktes Wissen hervor, das in der praktischen und empirischen Welt, in der der Mensch die Welt durch die Sinne erkennt, nutzlos ist. Die neue, empirische

22 Hammond: Pope and Bolingbroke (Anm. 3), S. 83. 
Epistemologie betrachtete die Sinne als die Quelle allen menschlichen Wissens. Newton war zwar im Stande, die exzentrische Umlaufbahn eines Kometen nach den Kepler'schen Gesetzen und dem Gravitationsgesetz zu erklären, aber - fragt Pope -

Could he, whose rules the rapid comet bind,

Describe or fix one movement of his mind?

Who saw its fires here rise, and there descend,

Explain his own beginning, or his end? (2.35-38)

Mit anderen Worten: Newtons mathematische Modelle konnten keine Antworten auf Fragen geben, die die menschliche Natur und Existenz betrafen, wie Fragen der Psychologie oder was die Entstehung von Leben und den Tod betrifft.

Was jedoch wiederum interessant ist, ist die Tatsache, dass Pope zu Beginn seiner zweiten Epistel eine Doppelperspektive einnimmt, entsprechend der zwei beherrschenden Themen: Die natürliche Erkenntnis, die sich mit der physischen Welt beschäftigt (I.), und die Prinzipien des Naturrechts, die sich mit der moralischen Welt auseinandersetzen (II.). Sein Gedicht spiegelt daher die Doppelstruktur des Naturgesetzes wieder - das physische und das moralische Gesetz, wie sie oben bereits erwähnt wurden. Zwei Schlüsselkonzepte in seinen Texten sind denn auch ,Bescheidenheit' als Leitprinzip in den Naturwissenschaften, und ,Balance' als das lenkende Prinzip menschlichen Handelns.

Erstens, natürliche Erkenntnis:

Trace science, then, with modesty the guide;

First strip off all her equipage of pride;

Deduct what is but vanity, or dress,

Or learning' luxury, or idleness;

Or tricks to show the stretch of human brain,

Mere curious pleasure, or ingenious pain;

Expunge the whole, or lop th' excrescent parts

Of all our vices have created arts:

Then see how little the remaining sum,

Which serv'd the past, and must the times to come! (2.44-52)

Zweitens, moralische Natur:

Two principles in human nature reign;

Self-love to urge, and reason to restrain;

Nor this a good, not that a bad we call,

Each works its end, to move or govern all:

And to their proper operation still,

Ascribe all good; to their improper, ill.

Self-love, the spring of motion, acts the soul;

Reason's comparing balance rules the whole. (2.53-60) 
Dieser doppelte Blick sowohl auf die Natur als auch auf die Moral war grundlegend für das Denken der Aufklärung. Er konditionierte auch den poetischen Diskurs, aber nicht nur in England, sondern auch in Italien und in den deutschsprachigen Ländern am Ende des 17. und in der ersten Hälfte des 18. Jahrhunderts, als der junge Schweizer Physiologe Albrecht von Haller (1708-1777) sein poetisches Oeuvre schuf (1725-1748). ${ }^{23}$ Wie später noch zu zeigen sein wird, reflektiert seine Position als Dichter und als Wissenschaftler Aspekte genau der kulturellen Situation, die auch bei Pope und Bolingbroke zu beobachten waren. So hat etwa auch Haller ein Portrait von Newton in ein schon 1730 verfasstes Gedicht eingefügt. Bevor ich einige der Gründe analysiere, die Haller dazu gebracht haben, dieses Portrait zu verfassen, möchte ich aber Aspekte der Diskussion um einen natürlichen Stil skizzieren, die auch seine Dichtung betreffen.

\section{Der natürliche Stil}

Im Vorwort zur vierten Ausgabe seiner berühmten Gedichtsammlung Versuch Schweizerischer Gedichte (1748) schreibt Haller, dass er die englischen Dichter genau studiert habe und von ihnen „die Liebe zum Denken und den Vorzug der schweren Dichtkunst“ übernommen habe. ${ }^{24}$ Seiner Meinung nach sollte die Sprache der Dichtung prägnant, treffend und unerwartet sein, ihre Bilder und Figuren lebendig, um sicher zu gehen, dass sich der Leser nicht langweile. ${ }^{25}$ Ein englischer Dichter, an den Haller dabei wahrscheinlich dachte, war Jonathan Swift (1667-1745). Er wird in einer auf den 31. Juli 1727 datierten Notiz des Tagebuchs erwähnt, das Haller auf seiner Reise nach London führte, neben Joseph Addison und Adam Steele, den Verfassern des Spectator, Samuel Butler (1620-1680) und John Wilmot, Earl of Rochester (1647-1680). ${ }^{26}$ Haller schätzte Swifts satirischen Stil, was er in seiner Rezension von Swifts Tale of a Tub (publiziert 1704, geschrieben 1694), die er 1734 gelesen hatte, auch anmerkte. ${ }^{27}$ Besonders hob er die Lebhaftigkeit von Swifts allegorischer Erzählung und die Neuheit seiner Art, ein

23 Eric Achermann: Dichtung. In: Albrecht von Haller. Leben - Werk - Epoche. Hrsg. von Hubert Steinke, Urs Boschung und Wolfgang Pross. Göttingen 2008, S. 121-155 (der einen allgemeinen Überblick über Hallers Dichtung gibt).

24 Albrecht von Haller: Gedichte. Hrsg. von Ludwig Hirzel, Frauenfeld 1882, S. 248: „Ich hatte indessen die englischen Dichter mir bekannter gemacht und von denselben die Liebe zum Denken und den Vorzug der schweren Dichtkunst übernommen."

25 Haller: Gedichte (Anm. 24), S. 249: „Ein Dichter muß Bilder, lebhaffte Figuren, kurze Sprüche, starke Züge und unerwartete Anmerkungen auf einander häuffen oder gewärtig sein, daß man ihn weglegt."

26 Vgl. Albrecht Hallers Tagebücher seiner Reisen nach Deutschland, Holland und England, 1723-1727. Hg. von Erich Hintzsche und Heinz Balmer. Bern, Stuttgart, Wien 1971, S. 94 . Vgl. auch Barbara Mahlmann-Bauer: Albrecht von Haller, Satiriker auf den Spuren von Voltaire und Swift. In: Albrecht von Haller zum 300. Geburtstag. Pro Saeculo XVIII ${ }^{\circ}$ Societas Helvetica. Themenheft Nr. 1. Hrsg. von Jean-Daniel Candaux u. a. 2008, S. 7-43 (die Hallers Rezeption von Swift betont).

27 Vgl. Hallers Literaturkritik. Hrsg. von Karl Guthke. Tübingen 1970, S. 31. 
poetisches Urteil auszudrücken, hervor. Gleichzeitig mochte er allerdings die Grobheit von Swifts Bildern nicht. ${ }^{28}$

Haller glaubte, dass es möglich wäre, einen höheren Grad an natürlicher Schönheit zu erreichen, wenn man dem Witz mehr Sanftheit gab und Bilder verwendete, die sowohl angemessen als auch gefällig waren. ${ }^{29}$ In seinem Vorwort von 1748 war es Haller ein großes Anliegen, die Sprache seiner Dichtungen von derjenigen der deutschen Barockdichter abzusetzen, deren Wortwahl und Metaphern er als unnatürlich empfand, da sie ohne Realitätsbezug auf purer Imagination basierten. ${ }^{30}$ Hallers Kritik bezog sich damit auf eine europaweite Debatte über den natürlichen Stil, die bereits um 1700 entbrannt und mit der er offensichtlich vertraut war. Einer der Protagonisten dieser Debatte war der englische Dichter John Dryden (1631-1700), der das Werk von Vergil ins Englische übersetzt hatte (1697). ${ }^{31}$ Im Vorwort seines Gedichts Religio laici or a Lymans Faith (1682) fordert Dryden für das Genre der Lehrdichtung einen natürlichen Stil, den er ,legislativ` nannte:

The expressions of a poem designed purely for instruction, ought to be plain and natural, and yet majestic; for here the poem is presumed to be a kind of lawgiver, and those three qualities which I have named, are proper to the legislative style. The florid, elevated, and figurative way is for the passions; for love and hatred, fear and anger, are begotten in the soul, by showing their objects out of their true proportion, either greater than the life or less: but instruction is to be given by showing them what they naturally are. A man is to be cheated into passion, but to be reasoned into truth. ${ }^{32}$

28 "C'est [sc. Swift, SdeA] le Lucien de nos jours. Il a la raillerie universelle, le sel \& le piquant de cet ancien, mais il le surpasse sans doute par l'allegorie, par le vif de son sel, et par la nouveauté extraordinaire de la tournure de sa pensée. [...] Il y a d'ailleurs quelque chose de rude, et de grossier dans ses images, qui s'enfonce tantot dans l'obscène, et tantot dans le degoutant.“ Vgl. Hallers Literaturkritik (Anm. 27), S. 31-32.

29 „Si l'esprit consiste dans la facilité a trouver les raports des choses, jamais homme [sc. Swift, SdeA] n'en a tant $\mathrm{u}$, ni trouvé des raports plus cachez \& plus justes. S'il consiste a exprimer les degrez de beauté au naturel, il peut etre surpassé par ceux qui joignent plus de douceur au piquant, et qui presentent aux yeux des images en meme tems justes \& agréables." Vgl. Hallers Literaturkritik (Anm. 27), S. 33.

30 Haller erwähnt insbesondere Daniel Caspar von Lohenstein (1635-1683), einen Vertreter der ,Zweiten Schlesischen Dichterschule', vgl. Haller: Gedichte (Anm. 24), S. 248-249: „Die philosophischen Dichter, deren Größe ich bewunderte, verdrangen bald bey mir das geblähte und aufgedunsene Wesen dess Lohensteins, der auf Metaphoren wie auf leichten Blasen schwimmt."

$31 \mathrm{Zu}$ Dryden siehe auch Claude Rawson und Aaron Santesso: John Dryden (1631-1700). His Politics, His Plays, and His Poets. Newark, London 2004 sowie Wolfgang Pross: Haller und die Aufklärung. In: Albrecht von Haller (Anm. 23), besonders S. 436-442 (zur Debatte über den natürlichen Stil im europäischen wie auch im Haller'schen Kontext um 1730).

32 John Dryden: The Works. Bd. 2. Poems 1681-1684. Berkeley, Los Angeles, London 1972, S. 109. 
Drydens Unterscheidung zwischen Leidenschaft und Vernunft, die jeweils einen anderen poetischen Stil verlangten, nimmt die Unterscheidung Popes im Essay on man vorweg:

Modes of self-love the passions we may call;

$[\ldots]$

But what composes man, can man destroy:

Suffice that reason keep to nature's road,

[...]. (2.93/114-15)

In Drydens Begriff des natürlichen Stils avancieren die Vernunft oder der Verstand, die die Objekte in ihren wahren und natürlichen Proportionen zeigen, zum zentralen Kriterium eines stilistischen Konzepts, das Haller später als die Quelle seiner Dichtung betrachtete. ${ }^{33}$ Wie noch zu zeigen sein wird, hatte Hallers Vernunftdichtung auch einen bedeutsamen moralischen Anspruch.

Die poetologischen Reflexionen eines anderen Autors sind wichtig, um den Stil und den Gegenstand von Hallers wahrscheinlich berühmtesten Gedicht, Die Alpen, zu erklären, das er 1729, ein Jahr nach seiner Reise in die Schweizer Alpen, geschrieben hatte. In seiner Abhandlung Della perfetta poesia italiana aus dem Jahre 1706 unterscheidet Ludovico Antonio Muratori (1672-1750) den schwülstigen Stil, der überladen und metaphorisch ist, von dem einfachen, ausgereiften Stil, der die Wörter passend zum Thema verwendet. ${ }^{34}$ Der ausgereifte Stil ist von einem gewöhnlichen und natürlichen Ausdruck gekennzeichnet, der vom Leser problemlos verstanden werden kann und ihn in die Lage versetzt, abzuwägen, ob das, was die Wörter bedeuten, auch wahrscheinlich ist. Für Muratori ist die bukolische Dichtung, die das einfache Leben der Hirten zeigt, repräsentativ für diesen Stil. Die Darstellung der einfachen und bescheidenen Arbeit, die die Hirten im Umgang mit den Herden oder auf ihren Feldern verrichten, wird nach Muratori durch die Kunstfertigkeit des Dichters verschönert, die der Unterhaltung des Lesers dient. ${ }^{35}$

Allerdings wurde um 1700 diese Thematik wie auch die Frage nach dem natürlichen Stil mit dem moralischen Diskurs gekoppelt, der aus der Naturrechtstheorie hervorgegangen war. So transponierte Haller seine Landschaftsidylle in die Alpen und in das einfache und natürliche Leben von deren Bewohnern, das er idealisiert darstellte. Dieses Leben kontrastierte er mit den korrupten Gewohnheiten der Bevölkerung in modernen Städten. Vernunft und Natur, wie Haller es nennt, sind die Gesetze der Alpenbewohner:

33 Haller: Gedichte (Anm. 24), S. 249: „Hierauf entstund bei mir die neue Art zu Dichten, die so vielen Deutschen zu missfallen das Unglük gehabt hat, die ich aber so wenig bereue, daß ich es wünschen möchte, noch viel mehr Gedanken in viel mindre Zeilen gebracht zu haben."

34 Ludovico Antonio Muratori: Della perfetta poesia italiana. Hrsg. von Ada Ruschioni. 2 Bde. Milano 1971, Bd. 1, B. 2, Kap. 15, S. 472-73 u. S. 477.

35 Muratori: Della perfetta poesia (Anm. 34), S. 482. 
Glückseliger Verlust von schadenvollen Gütern!

Der Reichthum hat kein Gut, das eurer Armuth gleicht;

Die Eintracht wohnt bei euch in friedlichen Gemütern,

Weil kein beglänzter Wahn euch Zweytrachtsäpfel reicht:

Die Freude wird hier nicht mit ranger Furcht begleitet,

Weil man das Leben liebt, und doch den Tod nicht haßt;

Hier herrschet die Vernunft, von der Natur geleitet,

Die, was ihr nöthig, sucht, und mehrers hält für Last

$[\ldots]^{36}$

Und Haller schließt das Gedicht mit den Versen:

Bey euch, vergnügtes Volk, hat nie in den Gemühtern

Der Laster schwarze Brut den ersten Sitz gefaßt,

Euch sättigt die Natur mit ungesuchten Gütern,

Die macht der Wahn nicht schwer, noch der Genuß verhaßt:

Kein innerlicher Feind nagt unter euren Brüsten,

Wo nie die späte Reu mit Blut die Freude zahlt:

Euch überschwemmt kein Strom von wallenden Gelüsten,

Dawider die Vernunft mit eiteln Lehren prahlt.

Nichts ist, das euch erdrückt, nichts ist, das euch erhebet,

Ihr lebet immer gleich, und sterbet wie ihr lebet.

O selig! wer wie ihr mit selbst gezognen Stieren

Den angestorbnen Grund von eignen Aeckern pflügt:

Den reine Wolle deckt, belaubte Kränze zieren,

Und ungewürzte Speis' aus süsser Milch vergnügt:

Der sich bey Zephirs Hauch, und kühlen Wasser-Fällen,

In ungesorgtem Schlaf, auf weichen Rasen streckt:

Den nie ein hoher See das Brausen wilder Wellen,

Noch der Trompeten Schall in bangen Zelten weckt.

Der seinen Zustand liebt, und niemals wünscht zu bessern,

Das Glück ist viel zu arm sein Wohlseyn zu vergrössern. ${ }^{37}$

Haller projizierte damit auf die Alpenbewohner das Ideal des moralisch integren Menschen, der, wie der Dichter in seinen Versen auch behauptet, unter seinen Zeitgenossen nicht zu finden war. Tatsächlich stimmte die politische und soziale Situation in der Republik Bern, in der Haller gegen Ende der 1720er Jahre lebte, nicht mit seinem Ideal überein, vor allem was die Diskrepanz zwischen der Regierung einiger reicher aristokratischer Familien und dem Rest der Ge-

36 Albrecht von Haller: Versuch Schweizerischer Gedichte. Eilfte vermehrte und verbesserte Auflage. Bern 1777, S. 26 (ND Zürich, Hildesheim, New York 2006).

37 Haller: Versuch Schweizerischer Gedichte (Anm. 36), S. 57-58. 
sellschaft betraf. Die Arroganz der Aristokraten führte zu Korruption, Vetternwirtschaft und Oligarchie, was andere Bürger daran hinderte, unter ihnen auch Haller selbst, Mitglieder im sogenannten ,Rat der Zweihundert' ${ }^{\prime}$ u werden. ${ }^{38}$ Das war weder die Gesellschaft noch die Regierungsform, die sich Haller vorstellte. Eine Gesellschaft war für ihn eine Gemeinschaft von Menschen, die die gleichen Erfahrungen, Bedürfnisse und Pflichten hatte. Dieser Entwurf basierte auf den Prinzipien des Naturrechts, das im 18. Jahrhundert zur Entwicklung einer bürgerlichen Moraltheorie führte. Genau diese Prinzipien waren für Haller unter den günstigen Bedingungen der Alpenregion realisiert worden:

Und hier hat die Natur die Lehre recht zu leben

Dem Menschen in das Herz, und nicht ins Hirn gegeben. ${ }^{39}$

In seinem Gedicht Über den Ursprung des Übels (1734) bezieht sich Haller explizit auf das doppelte Konzept der Liebe, nämlich ,die Selbstliebe und die gesellige Liebe', die menschliche Handlungen leitet:

Er [sc. Gott, SdeA.] legte tief in uns zwey unterschiedne Triebe,

Die Liebe für sich selbst, und seines Nächsten Liebe.

[...]

Viel edler ist der Trieb, der uns für andre rühret,

$[\ldots]$

Sie, diese Liebe, war der Menschen erste Kette,

Sie macht uns bürgerlich, und sammelt uns in Städte;

$[\ldots]^{40}$

Auch Pope beschreibt im Essay on man eine Gesellschaft, in der ,die Natur Gesetz war', und wie dieses Gesetz durch Despotismus pervertiert wurde:

Great Nature spoke; observant man obey'd;

Cities were built, societies were made:

[...]

What war could ravish, commerce could bestow,

And he return'd a friend, who came a foe.

Converse and love, mankind might strongly draw,

When love was liberty, and nature law.

Thus states were form'd; the name of king unknown,

Till common int'rest plac'd the sway in one.

'Twas virtue only (or in arts or arms,

Diffusing blessings, or averting harms,)

38 Haller: Gedichte (Anm. 24), S. LXXXVII-III. Vgl. auch Mahlmann-Bauer: Albrecht von Haller, Satiriker (Anm. 26), bes. S. 14-19 (die Hallers Kritik jener Missstände in seinen satirischen Gedichten betont).

39 Haller: Versuch Schweizerischer Gedichte (Anm. 35), S. 28.

40 Haller: Versuch Schweizerischer Gedichte (Anm. 35), S. 178-179. 
The same which in a sire the sons obey'd,

A prince the father of a people made.

[...]

For nature knew no right divine in men:

$[\ldots]$

Who first taught souls enslav'd, and realms undone

Th' enourmous faith of many made for one;

That proud exception to all nature's laws,

$\mathrm{T}^{\prime}$ invert the world, and counter-work its cause?

Force first made conquest, and that conquest, law;

Till superstition taught the tyrant awe.

Then shar'd the tyranny, then lent it aid,

And gods of conqu'rors, slaves of subjects made:

[...] (2.200-214, 236-248)

Haller lernte diese politischen, ethischen und rechtlichen Lehren kennen, als er in Leiden die Vorlesungen von Willem Jacob 'sGravesande (1688-1742), dem wohl bekanntesten Interpreten von Newtons Naturphilosophie in Kontinentaleuropa, besuchte. In seinen Lehrbüchern erklärte 'sGravesande Newtons mathematischen Ansatz und seine Philosophie der Experimentalphysik. 'sGravesande, der seine Karriere als Anwalt begonnen hatte, zog dabei in seinen Schriften über ,moralische Evidenz' die Lehren eines wichtigen Naturrechtstheoretikers in Betracht, des Deutschen Samuel von Pufendorf (1623-1694), der 1673 ein Kompendium seines Hauptwerks De jure naturae et gentium (1672) unter dem Titel De officio hominis et civis juxta legem naturalem veröffentlicht hatte. Dieses Werk hatte einen großen Einfluss auf das politische und moraltheoretische Gedankengut des 18. Jahrhunderts. ${ }^{41}$ Hallers Jahre in Leiden (1725-27) waren deshalb sowohl für seine intellektuelle und wissenschaftliche Entwicklung als auch für die Interpretation Newtons in seinen Gedichten ausschlaggebend.

\section{Hallers Portrait von Newton}

Nachdem Haller seine ersten anatomischen Untersuchungen als Mitarbeiter von Johann Duvernoi in Tübingen durchgeführt hatte (1724-25), ging er im April 1725 nach Leiden, wo er bei Herman Boerhaave studierte und seine 1727 publizierte Dissertation über den Neuen Coschwiz'schen Speichelgang verfasste. ${ }^{42}$ Davor hatte Duvernoi in Tübingen im Rahmen einer Arbeit, in der es um dasselbe Thema ging und an der auch der sechszehnjährige Haller mitgearbeitet hatte, die

41 Simone De Angelis: Pufendorf und der Cartesianismus. Medizin als Leitwissenschaft und die Rolle der Bibelhermeneutik in Pufendorfs Verteidigung des Naturrechts um 1680. In: Internationales Archiv für die Sozialgeschichte der Literatur 29 (2004) 1, S. 129-172; vgl. auch De Angelis: Anthropologien (Anm. 18), Kap. 5.

42 Albrecht von Haller: Dissertatio Inauguralis sistens Experimenta et Dubia Circa Ductum Salivalem Novum Coschwizianum. Leiden 1727. 
Leistungen seines Schülers hervorgehoben. Es sei offensichtlich, so Duvernoi, dass Haller jene Methoden und wissenschaftlichen Herangehensweisen vertrat, die nicht auf Modellen oder Abbildungen, dem Wissen anderer oder auf Annahmen seines eigenen Denkens beruhten. Haller bevorzuge ein Wissen von der Natur, das auf genauen und oft wiederholten Experimenten beruhe, die von der Zuverlässigkeit der Natur und der Autopsie abhängig waren. ${ }^{43}$

Der Begriff der Zuverlässigkeit oder Vertrauenswürdigkeit, der im lateinischen Original des Textes verwendet wurde (,ex Naturae et $\dot{\alpha} v \tau o \psi \dot{i} \alpha \varsigma$ fide pen$\left.\operatorname{det}^{\prime \prime}\right){ }_{r}^{44}$ ist wichtig, um die epistemische Situation, auf die wir hier stoßen, zu verstehen: Der Begriff verweist darauf, dass sogar ein rigoroser experimenteller Ansatz nicht darum herum kommt, generelle Voraussetzungen über die Struktur der physischen Welt sowie über die Mittel, die dem Menschen zur Verfügung stehen, um diese Struktur zu erkennen, anzunehmen. In diesem Sinne basiert die Zuverlässigkeit der Natur auf der metaphysischen Annahme, dass die von Gott geschaffenen Naturgesetze unveränderlich sind. In Hallers Gedicht Gedanken über Vernunft, Aberglauben und Unglauben (1729) wird Newton als überirdische Figur, als der Moses der Naturphilosophie, der die Tafeln der Gesetze der Natur besitzt, dargestellt:

Ein Newton übersteigt das Ziel erschaffner Geister,

Find die Natur im Werk, und scheint des Weltbau's Meister;

Er wiegt die inn're Kraft die sich im Körper regt,

Den einen sinken macht, und den im Kreiß bewegt,

Und schlägt die Tafeln auf der ewigen Gesätze,

Die Gott einmal gemacht, daß er sie nie verletze. ${ }^{45}$

Die Zuverlässigkeit der Autopsie, die auf dem Sehen und der Sinneswahrnehmung basiert, wurde Teil des epistemologischen Konzepts der moralischen Evidenz oder moralischen Gewissheit, die Hallers Lehrer 'sGravesande in seiner Oratio de evidentia mathematica et morali (1724) erörterte. Dieser Text, der unter dem Titel Discours sur l'Evidence (1736) auch in französischer Übersetzung vorlag, wurde 1742 gemeinsam mit 'sGravesandes äußerst einflussreichem Hauptwerk über die Experimentalphilosophie Newtons - Physices Elementa Mathematica, experimentis confirmata. Sive Introductio ad Philosophiam Newtonianam (1720/21, ${ }^{2} 1725$, ${ }^{3} 1742{ }^{4} 1748$ ) - publiziert. 'sGravesandes Konzept der moralischen Evidenz, das auch in der Encyclopédie von Diderot und d'Alembert diskutiert wurde, war fundamental für die epistemologische Begründung der empirisch-experimentellen Naturwissenschaften um die Mitte des 18. Jahrhunderts. Es lag auch den methodologischen Überzeugungen des jungen Anatomen Albrecht von Haller Mitte

43 Thomas Breitbach: Albrecht Haller und der Coschwiz'sche Speichelgang. Die Entlarvung einer Fehlentdeckung. Unveröffentlichte Dissertation, Universität Bern 1991, S. 114-115.

44 Breitbach: Albrecht Haller (Anm. 43), S. 114-15 (der die Faksimile-Edition von 1725 wieder auflegt).

45 Haller: Versuch Schweizerischer Gedichte (Anm. 35), S. 63. 
der 1720er Jahre zugrunde. Außerdem war 'sGravesande überzeugt, dass es nicht möglich ist, sich von einem Objekt, das sich außerhalb unseres Körpers befindet, aufgrund von Wahrnehmung eine Idee zu bilden, da kein Objekt unmittelbar auf unsere Seele einwirken kann. Deshalb benötigen wir Mittel, die sich von diesen Objekten unterscheiden. Diese Mittel, mit denen der Schöpfer die Menschen ausgestattet hat, sind die Sinne, die Zeugenaussagen und die Analogie, die gemeinsam die moralische Evidenz konstituieren. Im Gegensatz dazu operiert der mathematische Beweis einzig vermittelst der Wahrnehmung von Ideen. ${ }^{46}$ Außerdem ist die moralische Evidenz die Grundlage für das Erkennen der Gesetze der physischen Welt und des Bereichs der menschlichen Handlungen, dem jede einzelne Gesellschaft ausgesetzt ist. ${ }^{47}$

Haller lernte von 'sGravesande vor allem, dass im Bereich der Naturphänomene nur eine moralische Gewissheit, die von der Erfahrung herrührt, erreicht werden kann, nicht jedoch eine mathematische Gewissheit. ${ }^{48}$ Haller glaubte einerseits, dass die Sinne die Quelle allen Wissens seien, andererseits war er davon überzeugt, dass die menschliche Natur durch eine fundamentale Schwäche (imbecillitas) charakterisiert sei, die mit der eingeschränkten Kapazität unserer Sinnesorgane zusammenhing. Deshalb war es für Haller unumgänglich, unterschiedliche Abstufungen von Gewissheit zu unterscheiden. Er benannte seine epistemologischen Prinzipien im Vorwort zur zweiten Auflage seiner Primae lineae physiologiae, das vom 24. April 1751 datiert ist. Dort macht er u. a. darauf aufmerksam, dass er überall, wo es darum gegangen war, das Ausmaß des physiologischen Wissens zu beschreiben, stets ehrlich angegeben hätte, was gewiss war, was wahrscheinlich und was noch nicht ausreichend bestätigt werden konnte. ${ }^{49}$

46 Willem Jacob 'sGravesande: Discours sur l'Evidence. In ders.: CEuvres Philosophiques et Mathématiques. Hrsg. von Jean Nicolas Sebastien Allamand. Zweiter Teil. Amsterdam 1774, S. 339: "Quand il est question de choses hors de nous, ce n'est pas point par la perception de ces choses, que nous en acquérons l'idée, aucun objet hors de nous ne pouvant agir immédiatement sur notre âme. [...] Il nous faut donc, pour acquérir l'idée des ces objets, des secours différents des objets mêmes. Ces secours, qui nous ont été fournis par le Créateur, son les Sens, le Témoignage \& l'Analogie, trois Fondemens de l'Evidence morale, pendant que l'Evidence mathématique n'en a qu'un seul, sçavoir la perception des idées."

47 'sGravesande: Discours sur l'Evidence (Anm. 46), S. 337-338: „[...] dès qu'il est question d'hommes, il faut, outre cela, que nous sçachions quels sont les secours mutuel dont des hommes, qui vivent en société, ont besoin; c'est à dire, il est nécessaire, que nous acquiérions l'idée de société entre des hommes sujets aux mêmes passions \& aux mêmes affections, auxquelles l'expérience nous apprend qu'ils sont réellement sujets. Si nous joignons à ces considérations celle de la société civile, comme cela se doit quand il s'agit des devoirs mutuels des hommes; il faudra, pour chaque société particulière, dont il sera question, sçavoir, où réside la puissance, dont doivent émaner les Loix, \& quelles Loix en sont émanées."

48 'sGravesande: Discours sur l'Evidence (Anm. 46), S. 338: „Nous n'avons aussi en Physique qu'une Evidence morale, au sujet des mouvemens des corps, dont l'assemblage forme cet Univers, \& des loix, auxquelles ces corps sont soumis."

49 Albrecht von Haller: Primae Lineae Physiologiae in usum Praelectionum Academicarum Aucta et Emendatae. Göttingen ${ }^{2} 1751$, Praefatio, S. 8: ,[...] narrare constitui ea omnia, quae ad rem physiologicam hactenus collata sunt, ut ea, quae vera sunt, quae probabilia, quae 
Als Experimentalphysiologe sezierte Haller lebende Tiere und verwendete Mikroskope, um die Bewegungen von deren Eingeweiden und Organen zu sehen, soweit diese außerhalb der Reichweite des Skalpells lagen. ${ }^{50}$ Trotz des empiristischen Ansatzes von Hallers Physiologie war er sich jedoch bewusst, dass er es auch mit Wissensansprüchen zu tun hatte, die wahrscheinlich, aber nicht absolut sicher waren.

Es ist aus dieser wissenschaftsmethodologisch reflektierten Perspektive heraus, aus der Haller in seinem Gedicht Die Falschheit menschlicher Tugenden (1730) ein ambivalentes Bild von Newton zeichnet: Auf der einen Seite lobt er das große mathematische Genie, auf der anderen weist er auf die Grenzen von dessen geometrischer Methode hin, die ,unfähig' ist, ,die Tiefen der Natur zu ergründen':

Versenkt im tiefen Traum nachforschender Gedanken, Schwingt ein erhabner Geist sich aus der Menschheit Schranken.

Seht den verwirrten Blick, der stäts abwesend ist, Und vielleicht itzt den Raum von andern Welten mißt;

Sein stäts gespannter Sinn verzehrt der Jahre Blüthe, Schlaf, Ruh und Wollust fliehn sein himmlisches Gemüthe.

Wie durch unendlicher verborgner Zahlen Reyh, Ein krumm=geflochtner Zug gerecht zu messen sey;

Warum die Sterne sich an eigne Gleise halten; Wie bunte Farben sich aus lichten Strahlen spalten; Was für ein inn'rer Trieb der Welten Wirbel dreht; Was für ein Zug das Meer zu gleichen Stunden bläht; Das alles weiß er schon: Er füllt die Welt mit Klarheit, Er ist ein stäter Quell von unerkannter Wahrheit. Doch ach, es lischt in ihm des Lebens kurzer Tacht, Den Milch und scharfer Witz zu heftig angefacht! Er stirbt, von Wissen satt, und einst wird in den Sternen Ein Kenner der Natur des Weisen Namen lernen. Erscheine grosser Geist, wann in dem tiefen Nichts Der Welt Begriff dir bleibt, und die Begier des Lichts, Und laß von deinem Witz, den hundert Völker ehren, Mein lehr=begierig Ohr die letzten Proben hören:

Wie unterscheidest du die Wahrheit und den Traum?

Wie trennt im Wesen sich das feste von dem Raum?

Der Körper rauhen Stoff, wer schränkt ihn in Gestalten,

Die stäts verändert sind, und doch sich stäts erhalten?

infirma, sincerus ubique indicem, quantum imbecillitas humana, meique inprimis ingenii limites permittunt.“

50 Hubert Steinke: Irritating Experiments. Haller's Concept and the European Controversy on Irritability and Sensibility, 1750-90. Amsterdam, New York 2005, Kap. 2 (über Hallers experimentelle Forschung im Göttinger Labor um 1750). 
Den Zug, der alles senkt, den Trieb, der alles dehnt, Den Reitz in dem Magnet, wonach sich Eisen sehnt,

Des Lichtes schnelle Fahrt, die Erbschaft der Bewegung,

Der Theilchen ewig Band, die Quelle neuer Regung,

Dieß lehre grosser Geist die schwache Sterblichkeit,

Worinn dir niemand gleicht, und alles dich bereut.

Doch suche nur im Riß von künstlichen Figuren

Beym Licht der Ziffer=Kunst, der Wahrheit dunkle Spuren;

Ins innre der Natur dringt kein erschaffner Geist,

$\mathrm{Zu}$ glücklich, wann sie noch die äußre Schale weis't;

Du hast nach reifer Müh, und nach durchwachten Jahren,

Erst selbst, wie viel uns fehlt, wie nicht du weist, erfahren. ${ }^{51}$

Hallers berühmte Verse - „Ins innre der Natur dringt kein erschaffner Geist“ sind emblematisch für die epistemische Situation, die oben beschrieben wurde. Das betrifft vor allem das Erkenntnisproblem im Bereich der ,Wissenschaften vom Leben' im 18. Jahrhundert, das im Schlussteil dieses Beitrags besprochen wird.

\section{Hallers Hypothese der ,Anziehungskraft' in den Lebenswissenschaften}

Die Schlussverse des Gedichts Die Falschheit menschlicher Tugenden weisen auf ein Erkenntnisproblem hin, mit dem sich Haller um 1750 konfrontiert sah, als im Bereich der lebenden Organismen neue Phänomene aufgetreten waren, besonders bei der Zeugung von Lebewesen. Dieses Problem hatte sowohl eine methodologische Seite, in der es um die Verwendung von Hypothesen in der experimentellen Physiologie ging, als auch eine ideologische Seite, in der es um Hallers Vorstellung vom sittlichen Menschen ging, mit der seine Physiologie eng verzahnt war.

Die ,Wissenschaften vom Leben' im 18. Jahrhundert wussten nichts über menschliche Zellen oder den genetischen Code im Sinne der heutigen Biologie. Die Diskussion war im Wesentlichen auf zwei embryogenetische Modelle fokussiert: einerseits die Epigenese (der zufolge die neuen Teile eines Lebewesen sich nacheinander ausbilden), andererseits die Präformation (der zufolge der Fötus schon im mütterlichen Ei präexistiert). Um 1750 zog Haller die Anziehungskraft nicht nur als Grundkraft der Reizbarkeit von Muskelfasern ${ }^{52}$ in Betracht, sondern auch als wahrscheinliche von Gott gelenkte Wirkursache der Embryogenese. In seiner Vorrede zum zweiten Band der deutschen Übersetzung von George Louis Le Clerc, Comte de Buffons Histoire naturelle (1750) maß Haller der Vorstellung,

51 Haller: Versuch Schweizerischer Gedichte (Anm. 35), S. 104-106.

52 Albrecht von Haller: Physiologie. In: Supplément à l’Encyclopédie, ou Dictionnaire raisonné des sciences, des Arts et des Métiers. Hrsg. von Fortunato Bartolomeo De Felice. Amsterdam. Bd. 4 (1777), S. 344b-365a, hier S. 358: „Le mouvement musculaire ne lui [Haller, SdeA] paroît qu'une attraction plus vive des élémens, excitée par le suc nerveux qui agit comme un stimulant." 
dass die gesamte Natur nur von wenigen allgemeinen Prinzipien gelenkt werde, unter diesen auch Newtons Anziehungs- und Abstoßungskräfte, große Plausibilität zu..$^{53}$

Selbst Buffon, dessen epigenetische Theorie Haller gegen die Angriffe der Theologen der Sorbonne verteidigt hatte, schien eine bildende Kraft der Materie vorauszusetzen, die Haller als den Newton'schen Grundkräften ähnlich ansah. ${ }^{54}$ Wichtig ist hier jedoch vor allem die Tatsache, dass Haller von Probabilität oder Wahrscheinlichkeit spricht - oder mit anderen Worten: über eine plausible Hypothese, deren Grad von Evidenz gemäß 'sGravesandes epistemologischen Kriterien mehr als wahrscheinlich war. Das bedeutete, dass die Hypothese in der Lage war, eine große Anzahl von Naturphänomenen zu erklären. ${ }^{55}$ Nach dem Vorbild seines ehemaligen Lehrers hatte Haller in der Vorrede zum ersten Band der deutschen Übersetzung von Buffons Histoire naturelle (1749) bereits ausführlich erklärt, welchen Nutzen die Verwendung von Hypothesen in der Naturerkenntnis haben könnte. ${ }^{56}$ Schließlich überprüfte Haller die Hypothese der Anziehungskraft in

53 Albrecht von Haller: Vorrede. In: [Georges Louis Leclerc, Count de Buffon] Allgemeine Historie der Natur nach allen ihren besonderen Theilen abgehandelt; nebst einer Besprechung der Naturalienkammer, Sr. Majestät des Königs von Frankreich. Mit einer Vorrede Herrn Doctor Albrecht von Haller, Zweyter Theil [Erster Band], Hamburg, Leipzig 1752, fol. a3v-a4r: „Es wäre ein Zeichen einer unverantwortlichen Verachtung gegen den Leser, wenn ich ihn belehren wollte, daß Hrn. v. B[uffons] Meynung [...] in Ansehung des Satzes einer allgemeinen gebildeten und bildbaren Materie, die gleichgültig ist, ein Mensch, ein Thier, oder ein Kraut zu werden, wieder etwas besonders hat, und von der durchgängig angenommenen Lehre von der Entwickelung [sc. die Präformation, SdeA] sich sehr weit entfernet. Ihre erste Wahrscheinlichkeit erhält diese Lehre [sc. Buffons epigenetische Theorie, SdeA] allerdings von der Übereinstimmung der ganzen Natur. Die weit herrschenden Gesetze der Schwere, der anziehenden Kraft und des federhaften Triebes scheinen bey der Natur eine große Geneigtheit zu beweisen, viele Körper mit gleichen Kräften zu versehen, und viele Wirkungen mit gleichen Gesetzen zu bewerkstelligen. Es scheint eine Spur eines unendlichen Verstandes in dieser Kunst zu liegen, so verschiedene, so widersprechende, und so zusammengesetzte Wirkungen durch einerlei Mittel zuwege zu bringen, und man findet in dieser sparsamen Weisheit einen Beweis der alles beherrschenden Weisheit, die vermuthlich in allen Thaten die kürzesten Mittel ergreift, und niemals zwey Gesetze brauchen wird, wo ein einziges zureicht."

54 Haller: Vorrede (Anm. 53), fol. b4r: „Gewisse Freunde der Vorsehung sehen das Lehrgebäude des Hrn. v. B[uffon] und des Hrn. Needham für gefährlich an. Die Materie hat bey diesen Gelehrten das Recht sich selbst zu bilden. Aus gewissen dehnenden und anziehenden Kräften entsteht der göttliche Bau einer Theresia oder eines Newton."

55 Willem Jacob 'sGravesande: Introduction à la Philosophie, contenant la Metaphysique et la Logique, Kapitel 17 (De la probabilité), S. 84: „On appelle Vraisemblance la Probabilité, qui surpasse la demi-certitude.“ Kap. 34 (De l'Usage des Hypothèses), S. 137: ,[...] il faut regarder l'Hypothèse comme incertaine, ou vraisemblable, suivant que la probabilité en est plus ou moins grande; ce qui dépend de la nature \& du nombre des phénomènes, qu'on explique." In ders.: CEuvres Philosophiques et Mathématiques (Anm. 45). Siehe auch Willem Jacob 'sGravesande: Introductio ad philosophiam. Metaphysicam et Logicam continens. Editio altera, Leiden: 1737, ND Hildesheim, Zürich, New York 2001, S. 185 u. S. 306.

56 Albrecht von Haller: Vorrede. In: [Georges Louis Leclerc, Count de Buffon] Allgemeine Historie der Natur nach allen ihren besonderen Theilen abgehandelt; nebst einer Besprechung der Naturalienkammer, Sr. Majestät des Königs von Frankreich. Mit einer Vorrede Herrn 
seinen embryologischen Studien (1755-57), indem er eine Reihe von Experimenten an bebrüteten Hühnereiern durchführte. ${ }^{57}$ Diese Studien waren das Resultat eines wichtigen epistemologischen Wandels. Denn im Umgang mit ungewissem oder nur probablem Wissen hatte sich die Verwendung von Hypothesen, die Newton aus seiner Naturphilosophie verbannt haben wollte, als ein unverzichtbares Werkzeug des experimentell verfahrenden Naturforschers erwiesen. ${ }^{58}$

Hallers Hypothese hatte allerdings auch noch eine andere wichtige Implikation, die in einigen Versen Alexander Popes deutlich wird, in denen dieser sich zur Omnipräsenz Gottes in der Welt äußert. Wie Pope in Epistel I seines Essay on man schreibt:

Just as absurd, to mourn the tasks of pains The great directing Mind of all ordains.

All are but parts of one stupendous whole,

Whose body nature is, and God the soul;

That, chang'd through all, and yet in all the same;

Great in the earth, as in th' ethereal frame;

Warms in the sun, refreshes in the breeze,

Glows in the stars, and blossoms in the trees;

Lives through all life, extends through all extent;

Spreads undivided, operates unspent;

Breathes in our soul, informs our mortal part,

As full, as perfect, in a hair as heart;

As full, as perfect, in vile man that mourns,

As the rapt seraph that adores and burns:

To him, no high, no low, no great, no small:

He fills, he bounds, connects, and equals all. (1.265-280)

In Popes Ausgabe der Works (1751) wurden diese Verse von William Warburton (1698-1779) detailliert kommentiert. Warburton legte die alten orphischen und stoischen Quellen offen und zeigte deren Übereinstimmung mit Passagen des Scholium generale in Newtons Principia sowie auch mit Paulus' Apostelgeschichte XVII, 27, 28, in der der Apostel den Anfang der Phainomena des griechischen Dichters Aratos von Soloi (4. Jh. v. Chr.) zitiert: „Denn in ihm leben und weben und sind wir". ${ }^{99}$ Das Problem dieser Verse liegt in ihrer Ambiguität, denn, wie der Kommentator anmerkt, ein Spinozist könnte sich in derselben Weise ausdrücken:

Doctor Albrecht von Haller, Erster Theil [Erster Band], Hamburg, Leipzig, 1751, S. XVII: „Doch die Hypothesen haben noch einen ernsthafteren Nutzen, [...]. Sie werfen nämlich Fragen auf, deren Beantwortung von der Erfahrung gefordert wird, und die ohne eine Hypothese uns nicht eingefallen wären, eine Wirkung, die ihren unsäglichen Vortheil in den Wissenschaften hat."

57 Albrecht von Haller: Commentarius de formatione cordis in ovo incubato. Hrsg. von Maria Teresa Monti. Basel 2000.

58 De Angelis: Von Newton zu Haller (Anm. 2), S. 417-438.

59 Pope: The Works (Anm. 12), Bd.3, S. 31-32 (Anmerkungen zu Vers 268). 
But now admitting, for argument's sake, there was an ambiguity in these expressions, so great, as that a Spinozist might employ them to express his own particular principles; and such a thing might well be, because the Spinozists, in order to hide the impiety of their principle, are used to express the Omnipresence of God in terms that any religious Theist might employ. In this case, I say, how are we to judge of the poet's meaning? Surely by the whole tenor of his argument. Now take the words in the sense of the Spinozists, and he is made, in the conclusion of his epistle, to overthrow all he has been advancing throughout the body of it: For Spinozism is the destruction of an Universe, where every thing tends, by a forseen contrivance in all its parts, to the perfection of the whole. But allow him to employ the passage in the sense of St. Paul, That we and all creatures live and move and have our being in God; and then it will be seen to be the most logical support of all that had preceded. For the poet having, as we say, laboured through his epistle to prove, that every thing in the Universe tends, by a foreseen contrivance, and a present direction of all its parts, to the perfection of the whole; it might be objected, that such a disposition of things implying in God a painful, operose, and inconceivable extent of Providence, it could not be supposed that such care extended to all, but was confined to the most noble parts of the creation. This gross conception of the First Cause the poet exposes, by shewing that God is equally and intimately present to every particle of Matter, to every sort of Substance, and in every instant of Being. ${ }^{60}$

In der Tat erwog auch Haller in einem Brief an seinen Freund Charles Bonnet vom 1. September 1757, dass Pope mit dem Prinzip des Optimismus (,tout est bien") zu weit gegangen sei. ${ }^{61}$ Aber die eigentliche Gefahr für Hallers Theismus bestand in der Tatsache, dass seine Hypothese der Anziehungskraft nicht nur mit dem antiken Monismus übereinstimmte, sondern auch mit dem sogenannten ,Neospinozismus', d. h. einer materialistischen Interpretation der Natur, die um 1750 von Diderot und sogar von Buffon vertreten wurde: Gott wird mit der Materie gleichgesetzt und die Natur ist, wie Gott selbst, causa sui, sprich: die Ursache ihrer selbst, d. h. autonom. ${ }^{62}$ Diese Vorstellung von Natur hatte für Haller Konsequenzen für den sittlichen Menschen: Sollten Experimente die Existenz einer bildenden Kraft der Materie beweisen, würde das für Haller bedeuten, dass die Menschen im Bereich der Moral, d. h. in ihrem Verhalten, autonom wären. Weder die säkulare Ethik des Naturrechts, noch die christliche Lehre würden die Menschen moralisch binden, sondern einzig das ,Recht der Natur' gemäß

60 Pope: The Works (Anm. 12), Bd.3, S. 33.

61 Vgl. The Correspondence between Albrecht von Haller and Charles Bonnet. Hrsg. von Otto Sonntag. Bern, Stuttgart, Wien 1983, S. 109-110.

62 Paul Vernière: Spinoza et la Pensée Française avant la Révolution. 2 Bde. Paris 1954, Bd. 2, S. 553. 
Spinoza und Hobbes. ${ }^{63}$ Aus diesem Grund ermahnte Haller den jungen Physiologen Caspar Friedrich Wolff, der glaubte, er habe experimentell bewiesen, dass seine ,vis essentialis' (Essentialkraft) für die Gefäßbildung verantwortlich sei, ${ }^{64}$ die theologischen Konsequenzen seiner Theorie zu bedenken. ${ }^{65}$

In größerer Sorge war Haller jedoch wegen der praktischen Konsequenzen von Atheismus und Unglaube. Er glaubte, dass Spinozas ,Recht der Natur', wenn es sich bei den Menschen durchsetzen sollte, soziale Institutionen wie Ehe, Familie, Freundschaft und das Band zwischen dem Fürsten und seinen Untertanen zerstören würde; eine Gesellschaft von Ungläubigen, so Haller, würde die vom Naturrecht begründeten sozialen Bande auflösen. ${ }^{66}$ Deshalb war das embryogenetische Modell der Präformation für Haller der einzige Weg geworden, um Gott als Schöpfer zu erhalten und die Menschheit vor einem Rückfall in den Hobbes'schen ,Naturzustand' zu bewahren. 1758 präsentierte Haller schließlich das Resultat seiner embryologischen Forschungsarbeit, die sich auf die ,Beweisfindung' der Präexistenz des Fötus in den Ovarien fokussierte. ${ }^{67}$

Der Bedeutungsverlust der Anziehungskraft in den ,Wissenschaften vom Leben' nach 1750 war ein Zeichen dafür, dass das Newton'sche Standardmodell der Interpretation der Natur nicht mehr länger aufrecht zu erhalten war. Zu Beginn der Goethezeit (1770-1830) war die Debatte über die Zeugungstheorien, vor allem in den Arbeiten von Kant und Goethe, denn auch vom Konzept des ,inneren Bildungstriebs' beherrscht, das von dem Göttinger Naturforscher Johann Friedrich Blumenbach in seiner Arbeit Über den Bildungstrieb $(1780,1781)$ entwickelt worden war. $^{68}$

63 Albrecht von Haller: Vorrede. In: [Jean Henry Samuel Formey:] Prüfung der Secte die an allem zweifelt. Mit einer Vorrede des Herrn von Haller, Göttingen 1751.

64 Caspar Friedrich Wolff: Theoria Generationis. Hrsg. von Robert Herrlinger, Halle 1759 (ND Hildesheim 1966), Pars II. De generatione animalium. Vis Vegetabilium essentialis. Et Viae Humorum in Animalibus, §168: „Embryonem hoc tempore ex substantia ovi nutriri, demonstrant illius volumen auctum, perfectiones acquisitae, absentia cujuscunque alius materiae, consumtio albuminis \& vitelli succedens, experimenta inferius recensenda, consequenter; Transire particulas nutrientes ex ovo ad embryonem; Et existere vim, qua id perficitur, quae non est systaltica cordis \& arteriarum, neque hinc facta pressio in venas vicinas, neque harum compressio a motu musculorum, dirigentem absque canalibus, viam determinantibus, adeo analogam illi, quam aeque vocabo essentialem."

65 Vgl. zu dieser Debatte Wolffs Brief an Haller, datiert vom 17. April 1767, der in Robert Herrlingers Einleitung zu Wolffs Theoria Generationis (Anm. 64), S. 17-18 zitiert wird. Vgl. auch Jacques Roger: Les sciences de la vie dans la pensée française du XVIII ${ }^{e}$ siècle. Paris 1963, S. 705-712 (über Hallers Kritik an Wolffs epigenetischer Theorie).

66 Haller: Vorrede (Anm. 63), S. 28: „Ich glaube, es ist genug erwiesen, daß diese neue Weisheit der Untergang des gesellschaftlichen Lebens seyn wird." Vgl. hierzu auch De Angelis: Von Newton zu Haller, S. 439-477.

67 Albrecht von Haller: Sur la Formation du Coeur dans le Poulet, Sur L'Oeil, sur la Structure du Jaune, \&c. Second Mémoire précis des Observations; suivi de Reflexions sur le Developement [...]. Bd.2. Lausanne 1758, XIII (Preuves de la préexistence du fetus dans l'oeuf), S. $186-192$.

68 Luigi Marino: I maestri della Germania. Göttingen 1770-1820. Torino 1975, S. 112-129; vgl. auch Jutta Heinz: „Unendlicher Bildungstrieb“ - Zu Blumenbachs „Bildungstrieb“ und sei- 
Auf der anderen Seite wurde auch die Naturrechtstheorie durch die Kritik Kants und den Kantianismus in den 1790er Jahren unterminiert, was Anzeichen dafür waren, dass sich die Welt und die Realitäten veränderten. ${ }^{69}$ Haller, der 1777 starb, wusste nichts von der Französischen Revolution, auch wenn er noch in den 1760er Jahren die sozialen Unruhen in der Republik Genf verfolgte und im Briefwechsel mit Bonnet mit Besorgnis kommentierte. ${ }^{70}$ Er hatte wohl eine Ahnung davon bekommen, wie sich die Dinge ändern konnten. Haller hatte vermutlich schon früh verstanden, dass ein radikaler Wechsel der sozialen Umstände und das Ende des aufklärerischen Absolutismus (,philosophische Monarchie'), den er unter den politischen Systemen stets bevorzugt hatte, für seine Vorstellung vom sittlichen Menschen verheerend sein würde. Gewiss hatte ihn seine moralische Empfindung dazu motiviert, als junger Mann Gedichte zu schreiben.

ner Rezeption in Philosophie und Literatur bis hin zu Friedrich Schlegel. In: Naturforschung und menschliche Geschichte. Hrsg. von Thomas Bach und Mario Marino. Heidelberg 2011, S. 175-203.

69 Simone De Angelis: Unbewusste Perzeptivität und metaphysisches Bedürfnis. Ernst Platners Auseinandersetzung mit Haller in den Quaestiones physiologicae (1794). In: Aufklärung Interdisziplinäres Jahrbuch zur Erforschung des 18. Jahrhunderts und seiner Wirkungsgeschichte 19 (2007), S. 243-273.

70 Haller an Bonnet, 7. Februar 1768: „Je suis desolé de tout cela. Vous allés vivre dans une Democratie, gouvernement orageux, foible et dur, et qui renverse toute subordination“. [,Das Ganze tut mir leid. Sie werden in einer Demokratie leben, unruhige, schwache und harte Regierungen, und die jede Unterordnung ablehnt"; dt. Übers. SdeA]. In: Correspondence between Albrecht von Haller and Charles Bonnet (Anm. 61), S. 725. 
(C) 2015, Otto Harrassowitz GmbH \& Co. KG, Wiesbaden ISBN Print: 9783447104975 — ISBN E-Book: 9783447194136 


\title{
Deistische Gotteserkenntnis, Poetik und Enthusiasmus
}

\author{
Der Hymnus an die Natur in Shaftesburys Moralists (1711)
}

\author{
Mark-Georg Dehrmann
}

1

Wie kann um 1700 Gotteserkenntnis im Gedicht inszeniert werden? Unter dieser Fragestellung wird im Folgenden ein Text betrachtet, der in der Geschichte der Dichtung nur selten Aufmerksamkeit erfährt: die Moralists (1709/1711) Anthony Ashley Coopers, des dritten Earl of Shaftesbury. ${ }^{1}$ Interessant sind die Moralists in Bezug auf eine Form der Dichtung, der in und seit der Frühaufklärung eine immense Bedeutung zukommt: das Gedicht, das in der Betrachtung der Natur und des menschlichen Selbst zur Erkenntnis Gottes vorstoßen will.

Dichtungen, die eine Gotteskenntnis aus der Natur und der Selbstbetrachtung des Menschen inszenieren, sind als Dichtungen auch theologische Stellungnahmen. Und theologisch gesehen kann dieser Gedichttypus ein erhebliches Provokationspotential bergen. Von den dogmatischen Fragen her kann Brisanz an all den Punkten entstehen, an denen sie auch in innertheologischen Streitigkeiten zutage tritt bzw. in den zeitgenössischen Debatten zwischen (offenbarungs-)theologischen und philosophischen Akteuren. Denn wenn sich Gott aus der Natur und aus dem Selbst des Menschen heraus erkennen lässt, dann kann dies die Geltung der Offenbarung in Frage stellen, also erstens die Heilige Schrift als Offenbarung des Heilsgeschehens, zweitens die zentrale Stellung von Christus als Mittler, drittens die Notwendigkeit der übernatürlichen Gnade, die sich im Glauben an das christliche Heilsgeschehen manifestiert.

Wenn sich aber Dichtung auf solche Fragen einlässt, dann geschieht dies in einem spezifisch poetischen Rahmen. Abgesteckt wird er vom zeitgenössischen Verständnis des Status poetischer Rede. Deren Sprechakte werden dadurch potentiell verkompliziert und mit einer gewissen Ambivalenz versehen, was ihren propositionalen Status und damit ihren diskursiven Geltungsanspruch betrifft. Poetische Sprache verfügt über gewisse Lizenzen, die sich aus der poetischen

1 Die Erstausgabe der Characteristicks erschien anonym s.l., s.n. [London] 1711. Eine erste, abweichende Fassung der Moralists wurde 1704 unter dem Titel The Sociable Enthusiast privat gedruckt, die Fassung der Characteristicks erschien separat erstmals 1709. Zitate werden im Folgenden direkt im Text nachgewiesen („,Moralists“ mit Seite), nach der Ausgabe: Anthony, Third Earl of Shaftesbury: Characteristicks of Men, Mannes, Opinions, Times. Hrsg. von Douglas Den Uyl. 3 Bde. Indianapolis 2001; die Moralists in Bd. 2, S. 101-247. 
Tradition herschreiben. Beispielsweise kann sie sich auf antike Gottheiten berufen, diese etwa in einer Apostrophe anreden, obwohl ihr Autor weder an deren Existenz glaubt, noch Abgötterei betreiben will. Sie bedient sich anderer Tropen und Figuren, ihre Rede kann also in bestimmten Beziehungen den Status einer ,uneigentlichen' Rede reklamieren. Sie beruft sich auf die Einbildungskraft, also die sinnliche Vergegenwärtigung und Kombination von Dingen, die nicht anwesend sind bzw. die in dieser Kombination auch historisch niemals existiert haben. Sie kann sich auf den Enthusiasmus beziehen, ohne sich unmittelbar dem Vorwurf von Schwärmerei auszusetzen. Ambivalent sind solche Lizenzen bzw. Besonderheiten der poetischen Rede aus verschiedenen Gründen. Dadurch, dass sie als uneigentliche Rede gelten können, ist ihr propositionaler Status oft unklar: Inwieweit behauptet sie das, was sie sagt, als Wahrheit? Als sinnlich eindrückliche Rede kann Dichtung sich als Vermittlerin von Wahrheiten geben, deren Wahrheit eigentlich nur von anderen Erkenntnisvermögen des Menschen eingesehen werden kann. Gleichzeitig mag die sinnliche Nachdrücklichkeit der Rede aber auch für sich reklamieren, etwas mitteilen zu können, was sich dem Menschen auf anderem Wege gerade nicht erschließt. Auch der Enthusiasmus kann mit einem neuen Ernst ausgestattet werden und damit eine Sonderstellung für den Dichter und die Dichtung beanspruchen.

\section{2}

Shaftesburys Moralists sind für alle diese Aspekte ein äußerst aufschlussreicher Text. Aus theologisch-dogmatischer Perspektive gesehen, inszenieren sie, ausgehend von der äußeren Natur, eine Gotteserkenntnis, die ohne Rekurs auf genuin christliche Dogmen auskommt. Gleichzeitig reflektieren sie - implizit wie explizit - eingehend über den besonderen Status von Dichtung in dieser Erkenntnisbewegung, und zwar bezogen auf die Gattung der Hymne, also den Lobgesang an eine Gottheit. Nicht zuletzt entfalten sie dabei eine Konzeption des Enthusiasmus, der sich ebenfalls nachzugehen lohnt.

Die Moralists sind nun allerdings kein Gedicht, sondern ein philosophischer Dialog. Aber am Höhepunkt dieses Dialogs beginnt einer der beiden Gesprächspartner mit einer hymnischen Anrufung der Natur und des Gottes, die von beiden wiederum im Gespräch reflektiert wird. Diese Konstellation eröffnet vielfältige Deutungsperspektiven: Die Moralists präsentieren das Modell einer Hymne und kommentieren es zugleich. Sie führen auf diese Weise paradigmatisch die hymnische Gotteserkenntnis vor und setzen diese poetische Leistung zum philosophischen Denken in Beziehung. Die Reflexionen über die Hymne lassen sich dabei geradezu als eine Poetik der Hymne lesen. ${ }^{2}$

2 Jüngst hat Rowan Boyson zutreffend festgestellt, dass die Bedeutung Shaftesburys für die Geschichte der Poesie in der Forschung noch kaum in den Blick genommen worden ist. Erstaunlicherweise umreißt selbst er dann Shaftesburys Begriff von Poesie, ohne auf die Moralists Bezug zu nehmen: Rowan Boyson: Poetical Stoical Shaftesbury. In: The Poetic Enlightenment. Hrsg. von Tom Jones und Rowan Boyson. London, Brookfield 2013, S. 89-103. 
Nicht nur die ungewöhnliche Anlage - gleichzeitig Dichtung und Reflexion über die Dichtung zu bieten - machen die Moralists zu einem besonderen Text für die Geschichte der Naturdichtung. Auch seine Rezeption in Deutschland trägt dazu bei - wenngleich dieser Aspekt hier nur sehr kurz angedeutet werden kann: Brockes $^{3}$ und Herder ${ }^{4}$ haben den Hymnus aufgegriffen und ihn - losgelöst von seinem Kontext im philosophischen Dialog - übersetzt. ${ }^{5}$ Auch bei Gottsched und Moses Mendelssohn kann eine Auseinandersetzung mit ihm nachgewiesen werden. ${ }^{6}$

Shaftesbury ist auch deshalb eine interessante und bedeutende Figur, weil er von den Zeitgenossen äußerst kontrovers diskutiert wurde, was die Frage seiner theologischen Orthodoxie angeht. Vielen erschien er als Deist und damit als Feind des Christentums. Anders als andere Deisten wie John Toland, Anthony Collins oder Matthew Tindal hatte Shaftesbury aber auch viele unverdächtige Verteidiger, die betonten, dass seine Philosophie mit einem recht verstandenen Christentum durchaus vereinbar sei. ${ }^{7}$ Insbesondere in der protestantischen deutschen Aufklärung sollte diese Möglichkeit einer Allianz weitreichende Folgen haben. ${ }^{8}$ Denn um 1750 wurden Shaftesburys Impulse unter anderem von dem jungen Theologen Johann Joachim Spalding entschieden aufgenommen. Dieser sollte wenige Jahre darauf eine der bedeutendsten Figuren innerhalb der Lutherischen Kirche in Preußen werden. Shaftesbury wird auf diese Weise eminent wichtig für die innere Reform der protestantischen Theologie in Deutschland. Sie führte in der zweiten Hälfte des 18. Jahrhunderts zu einer Reduktion des Dogmas und einer Akzentuierung des Christentums als Morallehre, kurz: zu einem Kli-

3 Die Übersetzung des ersten Teils des Hymnus eröffnet als „Einleitung“ den achten Band von Brockes' Irdischem Vergnügen (Hamburg 1746, S. [3]-6). Vgl. dazu Ida M. Kimber: Barthold Hinrich Brockes: Two Unacknowledged Borrowings. In: Modern Language Review 64 (1969), S. 806-808; Mark-Georg Dehrmann: Das „Orakel der Deisten“. Shaftesbury und die deutsche Aufklärung. Göttingen 2008, S. 395. Hier findet sich auch eine übergreifende Darstellung der deutschen Shaftesbury-Rezeption im 18. Jahrhundert.

4 Der erste Druck von Herders stark bearbeitender Übersetzung in: ders.: Gott. Einige Gespräche über Spinoza's System; nebst Shaftesburi's Naturhymnus. Gotha ${ }^{2} 1800$, S. 314-336. Dieser Druck basiert auf einer früheren Fassung, die Herder 1774/75 handschriftlich in das sogenannte Buch der Gräfin Maria (von Schaumburg-Lippe) eintrug; zu Herders ShaftesburyRezeption insgesamt vgl. Dehrmann: Orakel (Anm. 3), S. 341-387 und S. 409-411.

5 Übersetzungen liegen außerdem vor von Johann Joachim Spalding und Johann Lorenz Benzler, jeweils im Rahmen ihrer Übertragung der gesamten Moralists: Die Sitten-Lehrer oder Erzehlung philosophischer Gespräche, welche die Natur und Tugend betreffen. Aus dem Englischen des Grafen von Schaftesbury übersetzt [von J.J. Spalding]. Berlin 1745; Des Grafen von Shaftesbury philosophische Werke. Aus dem Englischen übersezt [von J.L. Benzler]. Bd. 2. Leipzig 1777. Vgl. zu den Übersetzungen Dehrmann: Orakel (Anm. 3), S. 394 und S. 406-408.

6 Vgl. Dehrmann: Orakel (Anm. 3), S. 187-193 (Gottsched) und S. 250-256 (Mendelssohn).

7 Vgl. vor allem die große Studie von Isabel Rivers: Reason, Grace, and Sentiment. A Study of the Language of Religion and Ethics in England, 1660-1780. Bd. 2: Shaftesbury to Hume. Cambridge 2000.

8 Das Folgende detailliert in Dehrmann: Orakel (Anm. 3), vor allem S. 89-155. 
ma, in dem die Streitigkeiten um Vernunft oder Offenbarung die Dringlichkeit verloren, die sie vorher besessen hatten.

Die folgende Interpretation wird sich insbesondere auf vier Punkte konzentrieren. Der erste betrifft die theologische Dimension der Hymne. Zweitens soll - damit zusammenhängend - genauer bestimmt werden, wie Shaftesbury das Verhältnis von Gotteserkenntnis und Naturerkenntnis gestaltet. Drittens gilt es zu skizzieren, welche Rolle dem Enthusiasmus zukommt. Viertens stellt sich die Frage, welche spezifische Leistung hier der Dichtung zugesprochen wird.

\section{3}

Zuvor aber muss rekapituliert werden, wie es überhaupt zu dieser hymnischen Dichtung im philosophischen Dialog kommt und auf welche Weise sie sich vollzieht. In den Moralists unterhalten sich - vereinfacht gesagt - der weise Philosoph Theocles und sein Freund Philocles, der einen heißen Drang zum philosophischen Denken hat, aber immer wieder an Punkte des Zweifels, der Unsicherheit und des Verdrusses über die Menschheit gerät. ${ }^{9}$ Die Grundfrage des Gesprächs ist die nach dem guten Leben, einem Leben in Übereinstimmung mit der Natur - und das bedeutet mit der Gottheit, mit den anderen Menschen und mit sich selbst. Schon diese Ausgangsfrage mit ihrer gewissermaßen antiken Zuspitzung verdeutlicht, dass Theocles seinem Freund nicht etwa die göttliche Offenbarung und den christlichen Glauben empfiehlt. Explizite Bezüge vermeidend, entfaltet Theocles eine Philosophie, die stark an der späten Stoa Marc Aurels und Epiktets orientiert ist. ${ }^{10}$ Ein Angelpunkt seiner Argumentation ist dabei die rechte Erkenntnis des Kosmos als einer Ordnung, die von der ordnenden Präsenz eines allumfassenden Geistes zeuge: eines Gottes, der sich im Kosmos und auch im Menschen manifestiere. Nach und nach gewinnt Philocles im Laufe des Gesprä-

9 Die Anlage des Dialogs ist komplizierter: Philocles berichtet brieflich an seinen Freund Palemon von seinen Gesprächen mit Theocles. Es handelt sich also um einen späteren Dialogbericht durch einen der Teilnehmer. An dem Gespräch nehmen zeitweise auch andere Personen teil.

$10 \mathrm{Zu}$ den stoischen Hintergründen von Shaftesburys Denken vgl. beispielsweise: Lawrence B. Klein: Shaftesbury and the Culture of Politeness: Moral discourse and cultural politics in early eighteenth-century England. Cambridge 1994; Laurent Jaffro: Les Exercices de Shaftesbury. Un stoïcisme crépusculaire. In: Cahiers de philosophie politique et juridique 25 (1994), S. 205-217; Friedrich A. Uehlein: „Stoisch, wahrhaft sokratisch“. Epiktet und Marc Aurel in der Philosophie Shaftesburys. In: Stoizismus in der europäischen Philosophie, Literatur, Kunst und Politik. Hrsg. von Barbara Neymeyr u. a. Berlin, New York 2008, Bd. 2, S. 10471062; Mark-Georg Dehrmann: „Virtue is the Good, and Vice the Ill of every-one“. Shaftesburys Humanismus und die Stoa. In: Genese und Profil des europäischen Humanismus im 18. Jahrhundert. Hrsg. von Hubert Cancik und Martin Vöhler. Heidelberg 2009, S. 35-55; ders.: Shaftesburys stoischer Sokratismus. In: Aufklärung 22 (2010), S. 77-103; Wolfram Benda, Christine Jackson-Holzberg, Patrick Müller, Friedrich A. Uehlein: Introduction. In: Anthony Ashley Cooper, Third Earl of Shaftesbury: Standard Edition. Complete Works [...]. Hrsg. von dens. Bd. II.6. Stuttgart-Bad Cannstadt 2011, S. 9-54; Boyson: Poetical Stoical Shaftesbury (Anm. 2). 
ches einen Begriff von diesem Gott und auch von seinem eigenen Selbst. Der Kosmos als Ordnung zeugt von einem intelligenten Prinzip, einem ,divine mind'.

Philocles bemerkt während des Dialogs aber immer wieder, dass das philosophische Gespräch zwar seine Ideen aufklärt, eines jedoch nicht leistet: Ihm fehlt die Gewissheit, von sich selbst her so denken und auch handeln zu können, wie er es eigentlich immer wieder als richtig erkannt hat (vgl. etwa Moralists, S. 134 f.). Daher begeben sich die beiden am Morgen des dritten Tages ihrer Unterredung in die Natur, die den Landsitz des Theocles umgibt. Hier setzt dieser nun zu einer neuen Form der Rede an. Er nimmt eine andere Positur ein, wendet seine Augen von Philocles ab, sinnt eine Weile, weist mit seiner Hand auf die Umgebung und beginnt zu sprechen: „Ye Fields and Woods, my Refuge from the toilsome World of Business, receive me in your quiet Sanctuarys, and favour my Retreat and thoughtful Solitude." (Moralists, S. 193) Der geänderten Redehaltung folgt ein Wechsel des sprachlichen Registers. Theocles' Rede richtet sich scheinbar nicht mehr an seinen Gesprächspartner, sondern sie apostrophiert die umliegende Natur. Die Anrede ist poetisch-archaisierend und jambisch rhythmisiert, obwohl der Text weiterhin als Prosa gesetzt ist. ${ }^{11}$ Es ist deutlich, was hier geschieht: Theocles hat die Rolle eines begeisterten Dichters angenommen, der die Natur preist.

Freilich kommt dieser Wechsel in den Moralists nicht überraschend. Beide Gesprächspartner haben sich eigens für diesen Morgen mit seinem Sonnenaufgang verabredet, ${ }^{12}$ damit Theocles seinem Freund die Schönheit und Ordnungshaftigkeit des Kosmos auf andere Weise zeige, als es vorher im diskursiven Gespräch geschehen war. Als sie sich am vorgesehenen Ort treffen, verweist Philocles scherzhaft auf den genius loci, der in dieser bukolischen Szene herrsche. Er bringt Vergil ins Spiel: Nun habe er Theocles dingfest gemacht, auf dass er ihm Rede stehe wie der gebundene und trunkene Silenus (vgl. Moralists, S. 192). Diese Anspielung auf die sechste Ekloge greift Theocles auf, aber er verwahrt sich gegen die Kosmogonie, die Silenus dort in einem Lied entfaltet. ${ }^{13}$ Zum Charakter des

11 Für die Zeitgenossen war das deutlich zu erkennen. Pope beispielsweise hat in den Anmerkungen zu seiner Dunciad Shaftesburys Prosa als Verse setzen lassen. Vgl. Alexander Pope: The Dunciad: Book the Fourth. With Illustrations of Scriblerus, and Notes Variorum. The Second Edition. London 1742, S. 34, Anm. zu Vers 480. Dies beobachtet und kommentiert: Pat Rogers: Shaftesbury and the Aesthetics of Rhapsody. In: British Journal of Aesthetics 12 (1972), S. 244-257, hier S. 250.

12 Die Verabredung: Moralists, S. 138. Zwischen Verabredung und Treffen fallen andere Gespräche der beiden, weshalb diese Stelle als Rahmen für den eigentlichen Hymnus meistens übersehen wird.

13 In der sechsten Ekloge heißt es (VV. 31-34): „namque canebat, uti magnum per inane coacta / semina terrarumque animaeque marisque fuissent / et liquidi simul ignis; ut his exordia primis / omnia et ipse tener mundi concreverit orbis;". In der Übersetzung von Johannes und Maria Götte: „Denn er sang, wie im leeren, gewaltigen Raum ineinander / wirbelten noch die Keime für Land und Luft und für Wasser / und für lauteres Feuer zugleich, wie aus diesen als Urstoff / alles entstand und sogar das zarte Gewölbe der Welt wuchs." Beides zitiert aus: Vergil: Landleben. Vergil-Viten. Hrsg. von Johannes und Maria Götte sowie Karl Bayer. München ${ }^{2} 1977$, S. 34 f. 
betrunkenen Gottes passe es wohl, dass er die Welt aus Chaos und ungeordneter Materie entstehen lasse. Für Theokles aber kann ein geordneter Kosmos nicht durch Zufall zustande gekommen sein. Er sei nicht zu denken ohne einen Geist, der ihn hervorbringe und organisiere, ohne "MIND" und „Thought" (ebd.), ohne bewusste Formung und Durchbildung. Schon Vergil habe in der Aeneis eine Gegenversion gedichtet, in den Versen, mit denen Anchises seinem Sohn Aeneas in der Unterwelt die Entstehung der Welt schildert: "The active Mind, infus'd thro' all the Space, / Unites and mingles with the mighty Mass: / Hence Men and Beasts. -“ (ebd.). In der Übersetzung von Dryden, ${ }^{14}$ die Theocles hier zitiert, sind Raum und Materie vom Geist durchwaltet; dieser bringt Tiere und Menschen hervor. Auch Theocles kündigt nun einen Gegengesang zu dem des Silenus an:

Here, Philocles, we shall find our sovereign Genius; if we can charm the Genius of the Place (more chaste and sober than your Silenus) to inspire us with a truer Song of Nature, teach us some celestial Hymn, and make us feel Divinity present in these solemn Places of Retreat. (Moralists, S. 193).

Diese Passage bietet ein argumentum des folgenden Gesangs und - gewissermaßen - eine Poetik der Hymne in Kurzfassung. Die Gattung wird angegeben, zunächst als "Song“ - in Anlehnung an das carmen ${ }^{15}$ des Silenus -, dann als „celestial Hymn“. Die adressierte Gottheit ist der "sovereign Genius", also der ,oberste Geist', der ,Mind' und Schöpfer des Kosmos. Zweck der Hymne ist es, diesen Geist „[h]ere", an diesem Ort, zu finden. Und auch den Weg, auf dem sich diese Gotteserkenntnis vollziehen soll, gibt Theocles an: Zum Genius des Ganzen führt der genius loci, also der Geist, der in der umgebenden Natur waltet. Ihn gilt es zu beschwören („,charm“) - so wie Silenus gebunden werden musste -, auf dass er dem Sänger sein Lied eingebe, wodurch am Ende die Anwesenheit der Gottheit an diesem Ort spürbar werden soll. ,[I]nspire", "teach" und „make us feel“ - der Hymne wird damit eine dreischrittige Struktur vorgegeben: Der Bitte um Inspiration folgen die Empfängnis einer Lehre, deren Entfaltung sowie schließlich die Erscheinung der Gottheit, indem sie ihre Anwesenheit und Wirklichkeit durch eine Gefühlserkenntnis evident werden lässt.

14 Die Verse 981-986 (in Drydens Zählung) des 6. Buches im Kontext zitiert: „Know first, that Heav'n, and Earth's compacted Frame, / And flowing Waters, and the starry Flame, / And both the Radiant Lights, one Common Soul / Inspires, and feeds, and animates the whole. / This Active Mind infus'd through all the Space, / Unites and mingles with the mighty Mass. / Hence Men and Beasts the Breath of Life obtain;“. The Works of Virgil: Containing His Pastorals, Georgics, and ÆEneis. Translated into English Verse; by Mr. Dryden. London 1697, S. 391. Bei Vergil lauten die Verse 724-728: „Prinicipio caelum ac terras camposque liquentis / lucentemque globum lunae Titaniaque astra / spiritus intus alit, totamque infusa per artus / mens agitat molem et magno se corpore miscet. inde hominum pecudumque genus [...]" Zitiert nach: P. Vergilius Maro: Aeneis. 5. und 6. Buch. Lateinisch/Deutsch. Übers. und hrsg. von Edith und Gerhard Binder. Stuttgart 22006, S. 136.

15 Sowohl die Ekloge selbst wird als „carmen“ (V. 5) bezeichnet als auch die Lieder („carmina“; V. 25) des Silenus; vgl. Vergil: Landleben (Anm. 13), S. 32-34. 
Und so beginnt Theocles mit der bereits zitierten Apostrophe an den genius loci, die umgebende Natur. ${ }^{16}$ Folgen wir, um uns Verfahren und Struktur zu vergegenwärtigen, dem ersten Teil des Gesangs: Die Anrufung der umgebenden Natur - „Ye Fields and Woods" - beginnt mit einer Bitte, dem Sänger günstig zu sein: „favour my Retreat and thoughtful Solitude." (Moralists, S. 193) In dieser Einsamkeit, angesichts der „Majestick Beautys of this Earth“ komme der Mensch zu seiner eigentlichen Bestimmung: „made for Contemplation, and to search his own and other Natures", sei dies der Ort, um "the Cause of Things" zu erwägen („meditate“) und die Werke der Natur näher zu betrachten (alles ebd.).

Ein vorläufiges Ziel findet der Aufschwung des Sängers in einer zweiten Apostrophe. Sie richtet sich nicht mehr an die Umgebung, sondern spricht nun die Natur als Ganze an: „O glorious Nature! Supremely Fair, and sovereignly Good! All-loving and All-lovely, All-divine!“ (ebd.). Natur - das meint hier nun ein Prinzip, in dem sich Schönheit und Güte vereinigen. Sie trägt die Attribute des Göttlichen an sich: ,supreme', ,sovereign', „All-divine“. Dieser zweiten Apostrophe an die göttliche Natur folgt unmittelbar eine dritte:

O mighty Nature! Wise Substitute of Providence! impower'd Creatress! Or Thou impowering DeITY, supreme Creator! Thee I invoke, and Thee alone adore. To thee this Solitude, this Place, these Rural Meditations are sacred; whilst thus inspir'd with Harmony of Thoughts, tho unconfin'd by Words, and in loose Numbers, I sing of Nature's Order in created Beings, and celebrate the Beautys which resolve in Thee, the Source and Principle of all Beauty and Perfection. (Moralists, S. 194)

Von der Natur richtet sich der Blick auf die Gottheit selbst. Diese Wendung vollzieht sich vermittels der einfachen Konjunktion „Or“. Die bevollmächtigte Schöpferin Natur und die bevollmächtigende Gottheit werden in diesem Zuge zwar unterschieden; aber mit höchster Selbstverständlichkeit geht Theocles von der einen zum anderen über. ${ }^{17}$ Dieser "supreme Creator" ist eigentlich das Ziel, zu dem die Erkenntnis des Sängers strebt. Zu ihm als dem „sovereign Genius“ (Moralists, S. 193) - wie es eingangs hieß - hat die invocatio des genius loci geführt. Die selbstreflexive, poetologische Wendung "I sing“ zeigt, dass die Bitte um Inspiration nun an ihren eigentlichen Adressaten gelangt ist und erfüllt wurde. Im selben Zug hat sich dem Sänger das Wissen erschlossen, dass die Schönheit und Ordnung der Natur von dieser Gottheit ausgehen.

Gleich darauf aber thematisiert Theocles ein Problem der Gotteserkenntnis, zu der er sich aufgeschwungen hat: „Thy Being is boundless, unsearchable, impene-

16 Seine Hymne ist dabei nicht überall streng metrisiert, aber durchgehend rhythmisiert. Er selbst gibt das, in einer selbstreflexiven Wendung der Hymne, zu verstehen: „,and in loose Numbers, I sing of Nature's Order in created Beings" (Moralists, S. 194).

17 Nicht zuletzt das "Or" wirkte provozierend auf die Zeitgenossen. Pope beispielsweise wirft Shaftesbury genau aufgrund dieser Passage vor, Natur und Gott zu identifizieren; vgl. ders. Dunciad (Anm. 11), S. 34. 
trable. In thy Immensity all Thought is lost; Fancy gives o'er its Flight: and weary'd Imagination spends it-self in vain" (Moralists, S. 194). Die Gottheit in ihrem Wesen erweist sich für Theocles als unbegreifbar. Hier scheitert das begriffliche Denken, und auch die bildlich vorstellende Phantasie versagt. Jeder Versuch, den „Abyss of Deıтү“ (ebd.) auf diese Weise zu ergründen, wirft den Sänger auf „,myself“ zurück, auf den "Sense of this so narrow Being“ (ebd.), also das Selbstbewusstsein kreatürlicher Beschränkung.

Aber gerade diese Rückkehr zu und Besinnung auf sich selbst weist den weiteren Weg für die Erkenntnis Gottes. Denn einerseits ist der Schöpfer in seinem Wesen für die Kreatur unbegreifbar. Aber als Geschöpf besitzt der Mensch andererseits Erkenntnisvermögen, die seinem Ort in der Schöpfung angemessen sind: „Yet since by Thee (O Sovereign Mind!) I have been form'd such as I am, intelligent and rational; since the peculiar Dignity of my Nature is to know and contemplate Thee; permit that with due freedom I exert those Facultys with which thou hast adorn'd me." (Ebd.) Theocles hat als Mensch eine seiner Natur entsprechende Einsicht in das Wirken des Schöpfers. Dem „MIND“, als der dieser hier angesprochen wird, korrespondiert die menschliche Geistnatur. Sie auszuüben und Gott in seinen Werken zu erkennen, konstituiert die Freiheit und die Würde (,Dignity") des Menschen. Mit der Bitte um Beistand und Leitung dabei endet der erste Teil von Theocles' Hymne.

\section{4}

Gehen wir damit von der Kommentierung der Hymne zu den vier Aspekten über, die näher betrachtet werden sollen. Als erstes stellt sich die Frage, welche theologischen Konsequenzen dieses Modell der Gotteserkenntnis birgt. Zunächst mag das, was Theocles hier vorführt, unspektakulär erscheinen. Der Mensch ist Teil eines geordneten, von einem gütigen Gott geschaffenen Kosmos. Und auch wenn er Gott selbst nicht erkennen kann, so spricht sich ihm die Existenz dieses Gottes doch deutlich genug in dessen Werken zu. Aber gerade diese Konzeption kann als hochbrisant verstanden werden. Sie verzichtet auf alle zentralen Elemente, die diese Gotteserkenntnis als spezifisch christliche ausweisen könnten: Es fehlt jeder Verweis auf die Schrift als Offenbarung Gottes. Der Mittler Christus, von dem die Offenbarung zeugt, wird nicht genannt; entsprechend ist nicht die Rede vom Glauben an das Offenbarungsgeschehen und an Gott, ebenso wenig von der Empfängnis der Gnade Gottes, wie sie sich auch im anglikanischen Kontext durch die Lektüre der Heiligen Schrift ergeben kann. Diese Gnade allein aber könnte den Menschen aus seinem natürlichen, verdorbenen Zustand befreien. Erst damit würde er gültiger Erkenntnisse und eines gottgefälligen Lebens fähig.

Provokant ist Theocles' Hymne nicht, weil sie natürliche Theologie betreibt. Sie ist es vielmehr, weil hier die natürliche Theologie absolut gesetzt wird. Die Erfahrung, dass Gott als Objekt der Erkenntnis nicht erfassbar ist, führt nicht zu Resignation, Hoffnung und Glauben, zu einer Wendung auf die Offenbarung. Vielmehr leitet sie zu der Einsicht, dass dieser Gott dem Menschen eine natür- 
liche Fähigkeit gegeben hat, sein Wirken in der Welt nachzuvollziehen und dadurch in ein rechtes Verhältnis zu ihm und zu sich selbst zu gelangen.

Der zweite Teil des Hymnus entfaltet diesen provokanten Gedanken noch weiter. Hier besingt Theokles, weiterhin die Gottheit apostrophierend, ihr Wirken im Gesamtsystem Kosmos. Dieses Wirken weise sich aus im alles belebenden „vital Principle“ (Moralists, S. 205), in Materie, Bewegung, Zeit und Raum, schließlich in "SENSE and Thought" (Moralists, S. $206 \mathrm{f}$.), also in Wahrnehmungsfähigkeit, Bewusstsein und Denken. Und wenngleich der Mensch alle diese Aspekte der Wirklichkeit in ihrem Wesen ebenso wenig zu begreifen vermag wie den Gott selbst - er hat doch mit "SENSE and Thought" einen privilegierten Zugang zu ihnen. Sie ermöglichen es ihm erstens, das göttliche Wirken in seinen Konkretionen zu beobachten, in den „Works of Nature“: „our weak Eyes, help'd by mechanick Art, discover in these Works a hidden Scene of Wonders" (Moralists, S. 206). Aber "SEnse and Thought" führen noch darüber hinaus. Zwar begreift der Mensch auch nicht, was diese beiden, ihm eigenen Vermögen in ihrem Wesen sind. Aber dass Reflexivität und Wahrnehmungsfähigkeit in ihm wirken, ist dem Menschen unmittelbar bewusst und gewiss, denn schließlich erkennt er durch sie die Welt und sich selbst. Diese Einsicht in seine eigene Natur führt Theocles zu einem weitreichenden Schluss: „Thus are we in a manner conscious of that original and eternally existent Thought, whence we derive our own" (Moralists, S. 207). Und entsprechend dankt er dem höchsten Wesen als demjenigen, „who hast thus communicated thy-self more immediately to us, so as in some manner to inhabit within our Souls; Thou who art Original Soul, diffusive, vital in all, inspiriting the Whole." (ebd., S. 207) ${ }^{18}$ Die reflexive Einsicht in seine Fähigkeit, Ordnung und Harmonie mit Freude zu erkennen, weist sich aus als substantielle Teilhabe an dem, was Ordnung und Harmonie stiftet. Dem Menschen selbst wohnen in gewisser Weise die göttliche Kraft und der göttliche Geist inne. Der Mind des Menschen ist ein Teil des göttlichen Mind, oder, stoisch-platonisch formuliert: Der menschliche nous hat Teil am göttlichen nous. ${ }^{19}$ Theocles' Formulierungen transformieren dabei christliches Vokabular: Die Mitteilung Gottes an den Menschen - „communicated“ - referiert auf ein Offenbarungsgeschehen; ,inspirit” wurde von zeitgenössischen Theologen mitunter für den der Heiligen Schrift einwohnenden Geist verwendet, der sich dem Menschen in einem übernatürlichen Akt der Gnade mitteile und ihm die Kraft zu einem gottgefälligen Leben verleihe. ${ }^{20}$

18 Während Theokles hier noch den göttlichen Mind apostrophiert, hat sich seine Rede in diesem Teil doch verändert. Denn die Ich-Form, in der sich die Bitte um Inspiration im ersten Teil vollzog, ist dem „we“ gewichen. Das Wissen, das sich dem Sänger erschließt, wird nun als paradigmatisches präsentiert, für den Zuhörer Philocles wie auch für die Gattung Mensch.

19 Vgl. dazu ausführlicher Dehrmann: Shaftesburys stoischer Sokratismus (Anm. 10), S. 94-96.

20 Vgl. etwa Richard Allestree, Regius Professor of Divinity in Oxford: „it has pleased God to inspirit and actuate all his Evangelical methods, by a concurrence of supernatural strength, makes it not only eligible but possible, I may say easie and pleasant for us to do whatever he commands us: and notwithstanding our natural debility, makes us through Christ 
All dies vollzieht sich hier durch die Betrachtung der Natur und des Selbst. Die Teilhabe am göttlichen Geist und die natürliche Fähigkeit, ihm handelnd und erkennend gerecht zu werden - darin liegt die "peculiar Dignity of my Nature" (Moralists, S. 194), wie es oben hieß. Gott zu dienen, bedeutet für den Menschen, der eigenen Natur und der Natur des Ganzen gerecht zu werden, also den ihm jeweils zukommenden Platz in der kosmischen Ordnung zu erkennen und einzunehmen. Was Shaftesbury hier aus stoischen und auch platonischen Traditionen heraus formuliert, kann als kompatibel mit christlichem Denken verstanden werden. Aber es lässt sich auch als Deismus reinsten Wassers interpretieren, wenn man in Rechnung stellt, dass Offenbarung, Erlösungsbedürftigkeit des Menschen, Eingriff der göttlichen Gnade, Glaube überflüssig würden.

\section{5}

Gehen wir zum zweiten Punkt über, der Frage, in welche Beziehung Naturerkenntnis und Gotteserkenntnis in diesem Modell treten. Das Ziel von Theocles' Hymnus war es, Gott in der Natur erfahrbar zu machen: „make us feel Divinity present in these solemn Places of Retreat." (Moralists, S. 193) In der Inszenierung seines Gedichtes scheint dies gelungen, bis hin zu einem transformierten, vernatürlichten Offenbarungs- und Gnadengeschehen. Natur- und Gotteserkenntnis kommen dabei aber in ein besonderes Verhältnis. Es kann nachvollzogen werden, wenn man sich verdeutlicht, dass Theocles' zitierte Zielbestimmung der Hymne mehrdeutig ist. ${ }^{21}$ Diese Mehrdeutigkeit aber illustriert gleichsam den Erkenntnisweg, der sich im Laufe des Gesangs ergibt.

Auf der ersten Ebene bezieht sich Theocles auf die spezifischen Voraussetzungen seines hymnischen Sprechens. „Divinity“ wird "present" vermittels des enthusiastischen Gesangs. Die Bitte des Sängers um Inspiration und Erscheinung des Gottes hat Gnade gefunden. Die Inspiration besitzt hier eine Bedeutung, die innerhalb der poetischen Sprache entweder esoterisch verstanden werden kann - als wirkliche Be-Geisterung - oder aber als uneigentlich. Sie lässt sich jedoch reformulieren, wenn man sie auf die Natur bezieht. Schließlich hat sich Gott „in these solemn Places of Retreat“ (Moralists, S. 193) offenbart als derjenige, der die ganze Natur belebt. Insofern kann von ihm generell gesagt werden, dass er auch an diesem spezifischen Ort in der Natur wirksam sei. Um ihn zu erkennen, braucht es kein enthusiastisches Wissen. An dessen Stelle tritt in dieser Auslegung die Beobachtung der Natur, einschließlich der Naturforschung - durch Instrumente geschärft, erblickt das schwache menschliche Auge „a hidden Scene of Wonders" (Moralists, S. 206), die von der kosmischen Ordnung zeugen. So

which strengthens us, able to do all things"; [Richard Allestree:] The Causes of the Decay of Christian Piety. Or an Impartial Survey Of the Ruines of Christian Religion, Undermin'd by Unchristian Practice. London 1667, S. 19. Die Passage wird zitiert im Wörterbuch von Samuel

Johnson: A Dictionary of the English Language [...]. 2 Bde. London ${ }^{6} 1785$, Bd. 1, s.p., sub verbo inspirit.

21 Vgl. die gesamte Passage oben, S. 208. 
verstanden, scheint Theocles in seiner Hymne eine physikotheologische Gotteserkenntnis in der Sprache der Dichtung vorzubringen. Aber angesichts des Gedankens der menschlichen Teilhabe am göttlichen nous gewinnt Theocles' Rede noch eine dritte Bedeutung. Die Bitte, „make us feel Divinity present“, erfüllt sich eigentlich erst, als der Sänger nicht mehr aus der äußeren Natur auf die Existenz und Präsenz Gottes schließt, sondern den Blick reflexiv auf sich selbst richtet. Die Gotteserkenntnis ergibt sich nicht aus einer Demonstration, die von wahrgenommenen Eigenschaften der göttlichen Werke auf die Existenz eines Schöpfers schließt. Evident wird sie vielmehr erst in der Selbsterkenntnis. Geist ist in der Natur, weil der menschliche Geist sich selbst in ihm und ihn in sich wiedererkennt. „Divinity“ ist also letztlich deshalb „present", weil sie im Menschen selbst immer schon wirksam ist.

Theocles' Hymne richtet sich also eigentlich auf Selbsterkenntnis bzw. erst in dieser kommt sie zu ihrem eigentlichen Ziel. Sie ist keine physikotheologische Dichtung, wenn damit gemeint ist, die Existenz Gottes aus der weisen Einrichtung der sichtbaren Natur zu demonstrieren. Eine solche Physikotheologie würde den entscheidenden Schritt verfehlen. Sie verstünde nicht, dass Ordnung und Schönheit in der Natur nur deshalb erkannt werden können, weil der menschliche Geist selbst Anteil hat an dem Prinzip, das Ordnung und Schönheit hervorbringt. Gerade darin, dass der Hymnus in diesem Sinne keine physikotheologische Dichtung ist, gründet auch seine Radikalität. Denn wenn beispielsweise William Derham 1711 und 1712 in den Boyle Lectures seine Physikotheologie vorträgt, dann zielt er zwar auf die vernunftmäßige Überzeugung vom Wirken Gottes in der Welt. Aber die Wirksamkeit dieser Überzeugung basiert letztlich auf „Fear and Obedience“ gegenüber der Natur wie der Offenbarung, auf „Thankfulness and Praise" gegenüber dem allmächtigen Gott. ${ }^{22}$ Derhams Physikotheologie hängt ab von der Offenbarung. Shaftesburys Gott aber offenbart sich dem natürlichen Menschen in unmittelbarer Evidenz. Die Natur ist für diesen Erkenntnisprozess ein Durchgangsraum, denn die entscheidende Einsicht in die Teilhabe des Menschen am göttlichen Geist ergibt sich durch Selbsterkenntnis.

\section{6}

Mit dem Verweis auf den Enthusiasmus wurde bereits auf die dritte Frage an die Moralists vorgegriffen: Was für eine Konzeption von Enthusiasmus ${ }^{23}$ wird hier vertreten, wenn sich Gott in dieser Weise dem Menschen offenbart?

Zunächst muss festgehalten werden, dass der Enthusiasmus mit dem Hymnus zu einem zentralen Thema der Moralists aufrückt. ${ }^{24}$ Er wird, wie oben schon ange-

22 William Derham: Physico-Theology: or, a Demonstration of the Being and Attributes of God, from his Works of Creation. [...] London ${ }^{2} 1714$, S. 443.

23 Zum Enthusiasmus vgl. die gründliche und umfassende Studie von Volkhard Wels: Der Begriff der Dichtung in der Frühen Neuzeit. Berlin, New York 2009, S. 179-333.

24 Der Enthusiasmus ist für Shaftesbury insgesamt ein wichtiges Thema. Im Letter Concerning Enthusiasm (zuerst 1708) rückt Shaftesbury eher vom Enthusiasmus ab, indem er ihn als Ur- 
deutet wurde, erstens als Modus hymnischer Dichtung inszeniert. Zweitens spielen die Moralists in der gesamten Anlage ihrer Szene auf den Platonischen Phaidros an; Sokrates begibt sich hier gemeinsam mit dem Titelcharakter in die Gegend außerhalb Athens, er stimmt im Laufe des Dialogs gleichfalls eine (ironische) enthusiastische Rede an. ${ }^{25}$ Drittens wird der Enthusiasmus diskursiv verhandelt (wie ebenfalls im Phaidros). ${ }^{26}$ Nur eines von vielen Beispielen bildet die Deutung von Vergils Ekloge über den betrunkenen Silen. Die Reflexion über den Enthusiasmus vollzieht sich aber auch formal. Denn Theocles trägt seine Hymne nicht in einem durchgehenden Raptus vor; vielmehr wird sie dreimal unterbrochen. ${ }^{27} \mathrm{Zu}$ nächst fällt Theocles selbst zweimal aus seiner Rolle, um mit Philocles die Inhalte des Gesangs zu rekapitulieren und zu erwägen (vgl. Moralists, S. 194 und S. 209). Diese Rückkehr in den Modus des Dialogs ermöglicht die Kommentierung und Auslegung des begeisterten Gedichts. Was der begeisterte Sänger dort in poetischer Rede vorgebracht hat, wird ,übersetzt' in einen Diskurs, der zur Normalität zurückkehrt ist. Schon diese Struktur wirft ein Licht auf den Enthusiasmus. Was er zutage fördert, muss im intersubjektiven Gespräch geprüft und gesichert werden können. ${ }^{28}$ Hier wird deutlich, was bereits die bewusste Inszenierung des enthusiastischen Zustandes durch Theocles nahelegt: Sein Enthusiasmus ist kein

sache für religiöses und politisches Schwärmertum bzw. Fanatismus identifiziert und ironisiert. Die Moralists bieten dagegen ein positives Verständnis des Enthusiasmus an, das allerdings - wie weiter unten deutlich werden wird - auf eine sehr spezifische Interpretation der ,göttlichen' Begeisterung zielt. Beide Positionen schließen einander nicht aus. Zur Enthusiasmuskritik vgl. etwa Hans-Jürgen Schings: Melancholie und Aufklärung. Melancholiker und ihre Kritiker in Erfahrungsseelenkunde und Literatur des 18. Jahrhunderts. Stuttgart 1977, S. 179-184 u. pass.; Michael Heyd: Be sober and reasonable: The Critique of Enthusiasm in the Seventeenth and Early Eighteenth Centuries. Leiden 1995; Albert Meier: Schwärmer auf dem Prüfstand. Shaftesburys, raillery` in der deutschen Moralphilosophie und Dichtung des 18. Jahrhunderts. In: Festschrift für Erich Trunz zum 90. Geburtstag. Vierzehn Beiträge zur deutschen Literaturgeschichte. Hrsg. von Dietrich Jöns u. Dieter Lohmeier. Kiel 1998, S. 55-74. Eine Interpretation beider Seiten des Enthusiasmus bieten Barbara Schmidt-Haberkamp: Die Kunst der Kritik. Zum Zusammenhang von Ethik und Ästhetik bei Shaftesbury. München 2000, S. 221-235 (mit einer Diskussion der Forschung); Günter Butzer: Soliloquium. Theorie und Geschichte des Selbstgesprächs in der europäischen Literatur. München 2008, S. 329-341.

25 Vgl. Platon: Phaidros, etwa 237a, 238c-d und 241e (Stephanus).

$26 \mathrm{Zu}$ Enthusiasmus bzw. manía vgl. ebd., 244a und den Fortgang des Dialogs. Zur Rezeption des Phaidros und des Symposion in der Frühen Neuzeit vgl. Wels: Begriff der Dichtung (Anm. 23), pass., beispielsweise bei Ficino: S. 198-205.

27 Der Hymnus wird dadurch in die vier Abschnitte geteilt, von denen oben bereits die Rede war. Wels geht in seiner Untersuchung zum Enthusiasmus (Begriff der Dichtung [Anm. 23], S. 224) auf den Dialog Naugerius, sive de poetica dialogus (1555) von Girolamo Fracastoro ein, der strukturelle Ähnlichkeiten zu haben scheint. Hier unterbreche der Dichter Naugerius den Dialog immer wieder, um begeistert Verse zu rezitieren. Zwar deutet Fracastoro den Enthusiasmus nach Wels als natürliche - nicht göttlich induzierte - Entrückung (vgl. ebd.); aber die Unterbrechung des Dialogs scheint hier nicht die Funktion der Enthusiasmus-Kontrolle zu haben, wie dies in den Moralists der Fall ist.

28 Vgl. dazu etwa Schmidt-Haberkamp: Kunst der Kritik (Anm. 24), S. 228-233. 
wirkliches Außer-sich-Sein, sondern ein bestimmter Modus der Rede, deren Inhalte sich auch vor dem abgekühlten Bewusstsein bewähren müssen.

Als Theocles sich zum zweiten Mal unterbricht, trägt er eine Bitte an seinen Gesprächspartner heran. Philocles möge über seinen Zustand wachen und ihn zur Raison rufen, wenn seine Rede sich in dunkle Tiefen oder zu luftige Höhen verliere (vgl. Moralists, S. 209 f.). Der Gedanke, dass der Enthusiasmus einer Kontrolle bedürfe, gewinnt hier eine neue Pointe. Denn Theocles fordert seinen Schüler gleichsam zu einem Lernprozess auf. Philocles soll sich den enthusiastischen Visionen nicht mehr einfach überlassen. Er selbst muss nun die Kontrollfunktion ausüben. Und das scheint ihm auch zu gelingen. Als Theocles das Element des Feuers besingt, unterbricht ihn Philocles ${ }^{29}$ und bittet um eine Deutung der dunklen Rede. Er hat den Eindruck, Theocles spiele auf die antike Vorstellung an, dass die Welt immer wieder von einem zyklischen Weltenbrand vernichtet würde. ${ }^{30}$ Mit dem Bild der Gottheit, das er gewonnen habe, könne er so etwas aber nicht vereinbaren. Theocles räumt ein, er sei, das Feuer besingend, selbst "too warm" (Moralists, S. 213) geworden. Künftig wolle er sich der Erde zuwenden (vgl. Moralists, S. 213 f.). Die Moralists führen hier einerseits den gelungenen Lernprozess von Philocles vor, der die nachdrückliche poetische Rede nun kritisch reflektiert. Daneben zeigt der Dialog auch, wie der Enthusiasmus sich spekulativ versteigen kann. Die Einbildungskraft kann überhand nehmen. Die erhitzte Rede ist dann gerechtfertigt, wenn sie zurückgebunden werden kann an die Natur und das für den Menschen Wesentliche: die Erkenntnis, dass sein Geist ein Teil des kosmischen Geistes ist und dass seine Bestimmung darin liegt, sein Denken und Handeln daran auszurichten.

Genau in dieser Möglichkeit, die enthusiastischen Gesichte an die Natur zurückzubinden, liegt aber eine der Pointen des enthusiastischen Hymnus in den Moralists insgesamt. Theocles agiert zwar als poeta vates, dem sich mit der Inspiration ein esoterisches Wissen erschließt. Aber gleichzeitig sind diese Lehren so gefasst, dass sie vor einer mit ruhiger Besonnenheit vorgenommenen Prüfung bestehen können. Was entweder esoterisch oder uneigentlich erscheint, lässt sich auch exoterisch und natürlich verstehen. Am Beispiel des Satzes „make us feel Divinity present" wurde diese kalkulierte Mehrdeutigkeit oben schon verdeut-

29 Wie sich diese Unterbrechung vollzieht, ist nicht ganz klar. Philocles beschreibt die Szene SO: „HERE Theocles stopt on a sudden, when (as he imagin'd) I was putting my Hand out, to lay hold of his Sleeve." (Moralists, S. 212) Es scheint, als würde Theocles sich den Vorgang nur einbilden; so deutet auch Schmidt-Haberkamp (Kunst der Kritik [Anm. 24], S. 229). Sie konzentriert sich in ihrer Interpretation auf Theocles und die Tatsache, dass er seinen Enthusiasmus selbst kontrollieren könne. Allerdings verdeutlicht der Text auch, dass hier ein Lerneffekt des Philocles vorliegt, denn dieser gibt gleich zu verstehen, dass ihm angesichts des Fortgangs des Hymnus unwohl geworden sei: „Indeed, said I, you might well expect the Fate of ICARUS, for your high-soaring. But this, indeed, was not what I fear'd. [...] I was afraid it might, in the issue, run to what they tell us of a universal Conflagration; in which I knew not how it might go, possibly, with our Genius." (Moralists, S. 213).

30 Vgl. das Zitat oben, in Anm. 29. 
licht. ${ }^{31}$ Nicht zuletzt gilt diese Reformulierbarkeit auch für den Enthusiasmus selbst. Als Beispiel sei eine Apostrophe aus dem Hymnus genannt, in der Theocles den Enthusiasmus thematisiert. Er wendet sich dort mit folgenden Worten an den Geist des Ganzen: „O mighty Genius! [...] Author and Subject of these Thoughts!“ (Moralists, S. 205) Als „Subject“ des Hymnus ist der Gott der Gegenstand der Rede. Indem Theocles ihn aber auch als „Author“ apostrophiert, gibt er der Vorstellung Ausdruck, dass er von dem Gott erfüllt sei und dieser nun aus ihm und durch ihn spreche. Was insofern wie ein wunderhaftes Geschehen - oder ein poetischer Topos - wirkt, hat aber einen doppelten Sinn. Denn wenn der menschliche Geist Teil des göttlichen Geistes ist, dann spricht der Mensch immer schon mit Gott, zumal wenn er dies erkennt - gerade das macht ja seine besondere Würde ${ }^{32}$ aus. Der „mighty Genius“ ist damit erstens in der enthusiastischen Sprache des Gedichtes der Gott, den Theocles anruft. Auf der zweiten Bedeutungsebene aber ist dieser Genius und Dämon identisch mit dem kosmischen nous, an dem der Mensch durch Bewusstsein und Denkfähigkeit teilhat. ${ }^{33}$

Was bedeutet diese kalkulierte Mehrdeutigkeit für den Enthusiasmus? Einerseits wird die Vorstellung einer übernatürlichen Begeisterung und Inspiration offensichtlich abgelehnt. Enthusiasmus ist weder Sonderoffenbarung noch Besessenheit. Der Mensch hat von seiner Natur her Anteil am göttlichen Geist, er bekommt ihn nicht erst durch eine besondere Bitte oder Gnade. Daher entsprechen die Erkenntnisse, zu denen der rechte Enthusiasmus führen mag, dem, was der Mensch auch ohne besondere Inspiration durch Selbstbetrachtung und Betrachtung des Kosmos erkennen kann. Zu deutlich ist es auch, dass Theocles die Haltung des poeta vates als eine Pose behandelt, die er bewusst verwendet, zumal er sie ja auch didaktisch einsetzt. Die enthusiastische Form der Rede ist kalkuliert. Die zahlreichen Verweise auf die Topoi des Enthusiasmus, den genius loci, die Nymphen (vgl. Moralists, S. 192), den Pegasus der Dichter oder den Hippogryphen Ariosts (Moralists, S. 214) - alles dies hat einen ironischen Unterton.

Aber diese Ironie zerstört doch diese Topoi nicht, sondern hält sie gewissermaßen in der Schwebe. Gleiches geschieht mit dem Enthusiasmus. Denn Theocles macht sich die Form der begeisterten, bewegenden Rede sehr wohl zunutze.

31 Vgl. oben, S. $212 \mathrm{f}$.

32 Vgl. oben, S. 210: „Dignity“.

33 Der Dämon ist für Shaftesbury ein äußerst bedeutungsträchtiger Begriff. Er ist nicht nur das griechische Pendant zum lateinischen Genius. Gleichzeitig bezieht er sich auf das daimónion des Sokrates und den daímon der späten römischen Stoiker Marc Aurel und Epiktet. Shaftesbury hat sich vor allem in den Jahren um und nach 1700 intensiv mit Sokrates beschäftigt und dabei eingehend Platon und Xenophon studiert. Er plante eine kommentierte, mit Übersetzungen versehene Edition der antiken Schriften über Sokrates; vgl. die umfangreichen Vorarbeiten in: Shaftesbury: Standard Edition. Bd. II.5: Chartae Socraticae. Design of a Socratick History. Hrsg. von Wolfram Benda, Christine Jackson-Holzberg und Friedrich A. Uehlein. Stuttgart-Bad Cannstadt 2008. Darin deutet er daimónion und daímon als natürliche Vernunft des Menschen, die Teil des göttlichen mind sei (vgl. dazu Dehrmann: Stoischer Sokratismus [Anm. 10], S. 91-96). 
Und insofern lässt sich für die Berechtigung des Enthusiasmus anbringen, was eben noch als Argument gegen ihn erschien: Er ist gerade deshalb gerechtfertigt, weil der Mensch von seiner Natur her Anteil am göttlichen Geist hat, er diesen also nicht erst durch eine besondere Bitte oder Gnade bekommt. Aus diesem Grund hat der Enthusiasmus in einer naturalisierten Auslegung einen genuinen Platz im Verhältnis des Menschen zur Welt und zu Gott. ${ }^{34}$ Wie dies gedacht ist, wird vollends deutlich, wenn sich Theocles und Philocles nach dem Hymnus über den Enthusiasmus unterhalten. ${ }^{35}$ Denn er sei die Liebe, die den Menschen zu dem hinziehe, was er als schön empfinde. Diese Liebe entzünde sich in der Regel an sinnlich erfahrbaren Dingen, die der Mensch heiß begehre. Nicht diese Liebe und nicht dieses Begehren seien dabei problematisch, wohl aber die Vorstellung, dass diese Liebe ihren adäquaten Gegenstand in den Objekten finde, auf die sie sich richte. Was der Mensch im sinnlich Schönen eigentlich liebe, was ihn eigentlich anziehe, sei nicht das schöne und begehrte Ding selbst, sondern das, was es schön mache, also letztlich der göttliche nous, der mit Bewusstheit die Harmonie und Ordnung geschaffen habe und sie durchwalte. ${ }^{36}$ Da der Mensch aber selbst nous sei, erkenne er in dieser Schönheit und Ordnung gleichsam auch sich selbst wieder. Enthusiasmus und Liebe sind Modi dieses Wiedererkennens. Recht verstanden, können sie den Menschen dazu führen, ja zunächst geradezu verführen, seine Liebe auf sich selbst zu richten, und das bedeutet für Shaftesbury, den eigenen mind, das eigene geistige Leitvermögen, dadurch zu ehren, dass man sich bemüht, ihn in Übereinstimmung mit dem ,general Mind' des Kosmos zu halten: „the particular Mind shou'd seek its Happiness in conformity with the general-one, and endeavour to resemble it in its highest Simplicity and Excellence." (Moralists, S. 201).

Offensichtlich haben wir hier einen Grundgedanken vor uns, der zum Teil eng an Platon angelehnt ist, an den Phaidros mit dem Gespräch über die Liebe und den Seelenmythos, an den Eros Diotimas aus dem Symposion: Liebe als Sehnsucht, die selbst als Leitfaden fungiert und den Liebenden aus dem Körperlichen zur Idee hinzieht. Zum Verhältnis Shaftesburys zu Platon muss es hier hinreichen, festzustellen, dass diese Platonische Konzeption in ein stoisches Denkmodell eingepasst wird, in dem die Bestimmung des Menschen in der Pflege seines Leitver-

34 Günter Butzer (Soliloquium [Anm. 24], insbes. S. 339 f.) kommt zu dem Schluss, Shaftesbury vertrete das Modell eines selbstinduzierten Enthusiasmus. Dem kann ich mich mit zwei Einschränkungen anschließen: Erstens gilt es diesen Enthusiasmus zu kontrollieren; zweitens zielt der Enthusiasmus am Ende gleichsam auf seine Überwindung, denn die Liebe zum Kosmos und zum mind, die den Enthusiasmus erregt, soll den Menschen am Ende auch im nüchternen Zustand leiten

35 Vgl. Shaftesbury: Moralists (Anm. 1), S. 220-232.

36 Vgl. etwa Shaftesbury: Moralists (Anm. 1), S. 226: "the Beautiful, the Fair, the Comely, were never in the Matter, but in the Art and Design; never in the Body it-self, but in the Form or forming Power." 
mögens liegt, das wiederum teilhat an der Geistnatur des Kosmos. ${ }^{37}$ Der Enthusiasmus ist für Shaftesbury die Liebe für das Schöne, das Gute und die Ordnung, die sich aus der Geistnatur des Menschen ergibt. Insofern, als die menschliche Natur Anteil am göttlichen Geist hat, spricht mit dem Enthusiasmus wirklich der Gott aus dem Menschen. Daher ist der Enthusiasmus - verstanden als Liebe für das Schöne - gerechtfertigt und wertvoll. Aber gleichzeitig führt diese Liebe, wenn sie sich selbst richtig versteht, weder ins Dunkle noch ins Esoterische, sondern zur Natur, also in die Selbsterkenntnis. Wenn sie geholfen hat, diesen Erkenntnisweg zu beschreiten, erweist sich das scheinbar Esoterische der Inhalte als Mittel, als besonderer und anziehender, damit aber in gewisser Weise auch uneigentlicher Ausdruck für etwas, was den Menschen eigentlich immer schon ausmacht, worüber der Mensch eigentlich immer schon verfügt.

\section{7}

Damit sind wir bei der vierten Frage angelangt: Welchen Sinn hat es dann, dass Theocles seine Lehren in der Form einer enthusiastischen Hymne vorträgt? Den Schlüssel hierzu bietet das Ende des Gesangs. Im vierten Teil seiner Hymne wendet sich Theocles der Erdkugel zu, die er imaginativ überfliegt. ${ }^{38}$ Sein Blick wandert zunächst durch die klimatisch extremen Regionen, den Nordpol, dann den Äquator, das fruchtbare Ägypten und die nahe Wüste. Aus der erhobenen, distanzierten Perspektive betrachtet, erregen alle evozierten Orte Staunen und Verwunderung, sie erweisen sich als schön oder - wie die Gebirge - als erhaben. Jeder Ort erscheint dabei als sinnvoller Teil in dem zusammenhängenden System des Ganzen, als das die Erde erscheint. Dieses Ganze jedoch besingt Theocles nicht vollständig. Sein imaginärer Flug erstreckt sich nur über einen Teil des Globus. Mittendrin bricht er ihn ab und beendet damit seinen Hymnus.

37 Der Hymnus in den Moralists und die anschließenden Diskussionen sind nicht zuletzt auch ein Kommentar zu Platon. Shaftesbury wurde vor dem Hintergrund dieser Passagen in der Forschung oft als Platoniker gesehen. Für ihn selbst allerdings ist nicht Platon entscheidend, sondern vielmehr Sokrates, der ein Leben nach der Natur lehre. Platon als Sokrates' Schüler sieht Shaftesbury überall dort am Werk, wo dessen einfache, auf die praktische Philosophie gerichteten Lehren ins Spekulative geführt werden (vgl. dazu Dehrmann: Stoischer Sokratismus [Anm. 10], pass.). Diesen ,Zusätzen' aber steht Shaftesbury überwiegend skeptisch gegenüber. Er präferiert Xenophon, Platon aber wird für Shaftesbury damit - in Übereinstimmung mit einem tradierten Platon-Bild (vgl. etwa Wels: Begriff der Dichtung [Anm. 23], pass.) - zum Repräsentanten des philosophischen Enthusiasmus par excellence. Mit seinem Hymnus greift Theocles dezidiert und bewusst diese spezifische Form der Philosophie auf, die auf besondere Weise die einfachen Lehren des Sokrates fortschreibe. Er nutzt und kritisiert sie. Am Ende führt er sie zurück zu einem natürlichen Verständnis ihrer Inhalte; darin liegt eine der Pointen des Hymnus. Zum Verhältnis Stoa und Platonismus bei Shaftesbury vgl. neben dem oben zitierten Aufsatz d. Vf. auch die in Anm. 10 genannte Literatur, ferner: Mark-Georg Dehrmann: Transition: „Pedagogy of the Eye“ in Shaftesbury's Second Characters. In: New Ages, New Opinions: Shaftesbury in his World and Today. Hrsg. von Patrick Müller. Frankfurt a.M. u. a. 2014, S. 45-60.

38 Vgl. Shaftesbury: Moralists (Anm. 1), S. 214-218. 
Dieses Detail ist entscheidend, um zu verstehen, welche Bedeutung Shaftesbury der Dichtung zuweist. Warum hört Theocles mitten in seinem Flug auf? Das mag sich nicht nur der Leser fragen, sondern auch Philocles ist verwundert: „I cannot help being concern'd for your breaking off just when we were got half the World over" (Moralists, S. 219). Und wenn nicht Europa, so führt Philocles aus, so hätte er doch gerne noch Amerika in das Bild der Welt eingefügt gesehen, Peru und Mexiko, die ganze Pracht dieser Länder mit ihren Tieren und Menschen, ihren Pflanzen und Wäldern, den Bergen und Flüssen, vor allem dem erhabenen Amazonas. All diese unterschlagene Pracht beschreibend, hält Philocles plötzlich inne, denn er bemerkt "so significant a Smile on Theocles's Face, that it stopt me, out of Curiosity, to ask him his Thought." (Moralists, S. 219) Natürlich lächelt Theocles, weil Philocles das, was er vermisst, selbst nachgetragen hat, unwillkürlich und ohne es zu bemerken. Damit aber habe, wie Theocles sagt, der „Spirit of this Sort of Prophecy“ (Moralists, S. 219) auch von Philocles Besitz ergriffen. Der Enthusiasmus ist gleichsam übergesprungen und hat ihn angesteckt, den abgebrochenen Gesang jetzt seinerseits fortzuführen. Erst damit, dass sein Zuhörer ergriffen worden ist, hat sich erfüllt, was Theocles als das Ziel seiner Hymne formuliert hatte: „make us feel Divinity present". ${ }^{39}$

Die Doppeldeutigkeit dieser Rede vom Enthusiasmus ist nun leicht zu erkennen und aufzuschlüsseln. Die Hymne als Lernprozess ist vollendet, weil Philocles selbst eine Perspektive einnehmen kann, aus der sich die Welt als harmonisches Ganzes offenbart. Der Gott spricht aus ihm, weil sein Geist jetzt in der Lage ist, die Ordnung und Harmonie des Kosmos aus eigener Kraft heraus zu erkennen. Er hat gelernt, selbsttätig aus dem intuitiven Wissen heraus zu operieren, dass sich in der Fähigkeit zur Wahrnehmung von Harmonie die Geistnatur ausspreche, die den Menschen als Teil eines harmonischen und geordneten Systems geschaffen habe.

Indem Philocles nun selbst die Welt und sich als durchwaltet vom nous begreifen kann, schließt sich eine große Klammer der gesamten Moralists. Denn den Anlass zu dem Hymnus hatte ursprünglich ein Zweifel gegeben, an dem Philocles zunächst unsicher zu werden drohte. Die Frage nach einem Leben, das der Natur entspreche, beantwortend, hatte Theocles entwickelt, dass dies für den Menschen bedeute, die menschliche Gattung insgesamt und den ganzen Kosmos als Objekte der Liebe und damit auch der Freude am Dasein begreifen zu können. ${ }^{40}$ Dann werde er erkennen, dass schlechtes menschliches Handeln nicht auf einem Missgriff Gottes in der Schöpfung beruhe, sondern auf einem Missverständnis des Menschen über sich selbst und über das, was in seinem wahren Interesse als Geistwesen liege. Dann werde er auch begreifen, dass Unglücksfälle nicht gegen die Harmonie des Kosmos zeugten, sondern vielmehr notwendige

39 Shaftesbury: Moralists (Anm. 1), S. 193; die Hervorhebung von M.G.D.

40 Vgl. Shaftesbury: Moralists (Anm. 1), S. 135-138. 
Bestandteile der Ökonomie des Ganzen seien. ${ }^{41}$ Nur eine sichere Vorstellung vom Kosmos als Ganzem könne zum Leitbild werden, um die Begegnisse des Lebens adäquat zu verstehen und zu beurteilen, und das bedeutet: sie als jeweils notwendige Konstellationen innerhalb einer kosmischen Harmonie zu bejahen. So sehr Philocles diese stark stoisch geprägte Lehre zu diesem Zeitpunkt des Gesprächs eingesehen hatte, so sehr war er doch im Zweifel, ob es überhaupt möglich sei, in sich selbst Vorstellungen der gesamten Menschheit und der Natur als Ganzer aufzubauen, die nicht abstrakt und damit wirkungslos blieben. Denn sie müssten ihm ja die Kraft verleihen, den Kosmos und die Menschheit beständig lieben zu können, die Kraft, scheinbare partikulare Störungen nicht als Irritationen dieser Liebe zu erfahren, sondern vielmehr als notwendige Ereignisse, die es dankbar im Interesse des Ganzen anzunehmen gelte. Entsprechend hatte Philocles seinen Freund mit folgenden Worten herausgefordert: „Indeed, [...] were it possible for me to stamp upon my Mind such a Figure as you speak of, whether it stood for Mankind or Nature, it might probably have its effect; and I might become perhaps a Lover after your way" (Moralists, S. 138). Nachdem Theocles mit dem Hymnus geantwortet und nachdem Philocles den Gesang gleichsam eigentätig weitergeführt hat, erinnert jener seinen Freund auch an die Herausforderung: "And thus we are return'd again to the Subject of our Yesterday's Morning-Conversation. [...] We then had prov'd the Force of Divine Beautr; and form'd in our-selves an Object capable and worthy of real Enjoyment." (Moralists, S. 223). ${ }^{42}$

Der Hymnus des Theocles' bietet Philocles also die Möglichkeit, sich ein anschauliches Bild vom Kosmos als System zu machen. Er evoziert eine phantasía, ein visum der gottdurchwalteten Welt, das affektiv besetzbar ist. Diese Vorstellungsbilder, denen der poetische Modus auch metrische und sprachliche Schönheit verleiht, besitzen eine größere Kraft als die Alltagssprache oder der dialogische philosophische Diskurs. ${ }^{43}$ Mittels der Phantasie kann die Dichtung scheinbar abstrakte Vorstellungen wie ,die Menschheit' oder ,die Natur' versinnlichen. Sie verleiht ihnen eine Anziehungskraft, die dem Abstraktum zunächst abgeht. Indem sie versinnlicht, stellt die Dichtung Objekte her, die den Zuhörer

41 Zum Theodizeeproblem, das einen Ausgangspunkt der Moralists bildet, vgl. Patrick Müller: „Dwell with honesty \& beauty \& order": The Paradox of Theodicy in Shaftesbury's Thought. In: Aufklärung 22 (2010), S. 201-231.

42 Auch früher im Text nimmt Philocles Bezug auf diese Szene, nämlich dort, wo er sich als Briefschreiber anschickt, seinem Adressaten Palemon von den Gesprächen mit Theocles zu berichten. Fast an der Aufgabe verzweifelnd, jenen Dialog über "the most difficult Subject" (Shaftesbury: Moralists [Anm. 1], S. 125) zu Papier zu bringen, vergegenwärtigt ihm sein Gedächtnis in einer fast traumhaften Vision den Lehrer Theocles inmitten der Natur, die er hymnisch besungen hatte. Dieses Vorstellungsbild gibt ihm dann eine "clear and perfect Idea of what I desir'd so earnestly to bring back to my Memory" (ebd., S. 126). Der Hymnus mit seiner versinnlichten Vorstellung des Kosmos hat sich so tief eingeprägt, dass die Erinnerung an ihn auch die leitenden Ideen, zu denen er hingeführt hat, wirksam reaktivieren kann.

43 Vgl. dazu Alexandra Kleihues: Figuren der Evidenz in Shaftesburys Moralists. In: Aufklärung 22 (2010), S. 41-57, insbes. S. $55 \mathrm{f}$. 
mittels ihres Zaubers ergreifen; sie erregt Liebe, und die Liebe des Hörers kann sich auf dieses Bild richten.

Diese Liebe hat aber eine besondere Pointe, die deutlich wird, wenn man sich an die unterschiedlichen Bedeutungsschichten erinnert, die Theokles' enthusiastische Rede barg. Denn der Erkenntnisprozess des Liebenden steuert auf die Erfahrung zu, dass die sinnlichen Objekte zwar seine Liebe erregen, aber nicht sie selbst dieser Liebe einen adäquaten Gegenstand bieten. Die Schönheit des Kosmos, die Anziehungskraft seines Vorstellungsbildes führen vielmehr zu der Erkenntnis, dass die Schönheit im mind ankert, der ihn hervorgebracht hat. Der mind selbst ist der Ursprung all der Bewunderung und Freude, die die phantasía erregt hat. Er ist der adäquate Gegenstand all der Bitten und Ehrenbezeugungen, die der enthusiastische Sänger anfangs einem Geist entgegenbrachte, den er erst herbeirufen zu müssen schien. Und er ist in jedem Menschen aktiv, so dass Liebe zu Gott und zum Kosmos letztlich bedeutet, der eigenen Geistnatur gerecht zu werden. Die Liebe, die die Dichtung erregt, hat eine Leitfunktion, die letztlich auf die Selbsterkenntnis zielt. ${ }^{44}$

Und insofern ist auch die Dichtung in den Moralists ein zunächst notwendiges Mittel, das sich am Ende aber wiederum selbst überwindet. Die verzaubernde Sprache der Poesie löst sich auf, wenn man von ihr zur Erkenntnis der Natur geleitet worden ist, und das heißt zu der Erkenntnis, dass Ursprung und Ziel jeder Liebe die Teilhabe des Menschen am göttlichen Geist ist.

44 In der ideengeschichtlichen Bewegung des Enthusiasmus-Denkens, die Wels (Begriff der Dichtung [Anm. 23], pass.] beschreibt, wäre Shaftesbury an einer interessanten Schlüsselposition anzusiedeln. Verknappt gesagt, beschreibt Wels zunächst die Entwicklung zu einer physiologischen Interpretation des Enthusiasmus - dieser biete also keine Sonderoffenbarung. Ab 1700 dann werde diese physiologische Sonderstellung des Dichters nach und nach emphatisch interpretiert; die besondere (physiologisch begründete) Begabung des Dichters lasse ihn zum Künder einer Sprache des Herzens werden. Shaftesbury naturalisiert den Enthusiasmus, ohne dabei jedoch im Falle des , positiven' Enthusiasmus auf die physiologische Dimension einzugehen. Gleichzeitig präsentiert er diesen Enthusiasmus als einen legitimen Leitfaden zu Einsichten, die sich dem Menschen aber auch im nüchternen Zustand erschlieBen sollen, da sie seine eigene Natur konstituieren. 
(C) 2015, Otto Harrassowitz GmbH \& Co. KG, Wiesbaden ISBN Print: 9783447104975 — ISBN E-Book: 9783447194136 


\title{
Zur religionshistorischen Verortung der "Naturlyrik' bei Barthold Heinrich Brockes
}

\author{
Volkhard Wels
}

Die Frage, die ich stellen möchte, lautet, welche Art von Frömmigkeit, Religion oder Glauben in Barthold Heinrich Brockes' Irdischem Vergnügen in Gott (17211748) zum Ausdruck kommt. Das ist alles andere als eine neue Frage. Zur Debatte gestellt worden sind bisher im Wesentlichen drei Optionen, nämlich ,orthodoxes' Luthertum, Deismus und Pantheismus. Ich möchte mich für keine dieser Optionen entscheiden und stattdessen dafür plädieren, vor allem „natürliche Religion“ und Teile der lutherischen Schultheologie in einen weniger radikalen Gegensatz zu bringen, als dies bisher geschehen ist. Dieses Plädoyer zielt vor allem darauf, den Übergang vom 17. Jahrhundert, also vom sogenannten ,Barock', zum 18. Jahrhundert, also zur sogenannten ,Aufklärung', weniger als einen Bruch denn als eine Entwicklung erscheinen zu lassen.

Was mit diesem ,Bruch' auf dem Spiel steht, ist offensichtlich. Wer die ,moderne Naturlyrik' als eine säkulare Erscheinung begreifen möchte, muss den Unterschied zwischen einem konfessionell geprägten, christlichen Weltbild und einer säkularisierten ,Aufklärung' möglichst scharf erscheinen lassen. Für das Werk von Brockes, das genau an der angeblichen Schwelle von ,Barock' und ,Aufklärung' steht, bedeutet dies, dass es entweder zum ,christlichen Barock' oder zur ,säkularen Aufklärung' geschlagen wurde.

Gegen diese binären Oppositionen möchte ich im Folgenden zeigen, dass das Werk von Brockes die Signatur einer spezifischen Epoche trägt, die sich nicht mit solchen trivialisierenden Schemata erfassen lässt. Weder gibt es ein in sich homogenes, christliches ,Barock', noch kann die ,Aufklärung' generell als ,Säkularisierung' verstanden werden. Statt dessen gilt es, die komplexe Frömmigkeitsgeschichte des 17. und 18. Jahrhunderts, wie sie sich im Werk von Brockes abbildet, deutlich zu machen. Dieses Werk steht mit seinen poetischen Formen in der Tradition der christlichen Erbauungs- und Andachtsliteratur, in seinen Inhalten aber vertritt es den Gottesbegriff der „natürlichen Religion“. Diese „natürliche Religion" ist weder eine ,säkulare' Erscheinung, noch ist sie auch nur eine Schwundstufe auf dem Weg vom Christentum zu einer ,säkularen Moderne'. Sie ist eine Transformation der christlichen Frömmigkeitspraxis, in der sich eine Religion herausbildet, die bis in die Gegenwart hinein eine gewisse Rolle spielt. 


\section{Anthropologischer Optimismus}

$\mathrm{Zu}$ den wenigen, in der Brockes-Forschung unumstrittenen Punkten gehört das Faktum, dass man den Gottesbegriff von Brockes überhaupt erschließen muss. Aus den neun Bänden des Irdischen Vergnügens in Gott wird nicht hinreichend deutlich, von was für einem Gott die Rede ist. ${ }^{1}$ Dies mag man bereits als Indiz dafür werten, dass es sich bei diesem Gott nicht um den Gott der lutherischen Schultheologie handelt. Hätte sich Brockes zu ihm bekennen wollen, wäre ihm dies nicht schwer gefallen.

Statt dessen herrscht im Irdischen Vergnügen eine gewisse Indifferenz, was zentrale Überzeugungen des Luthertums betrifft. Das ist insofern ein Argument für kryptoradikale Überzeugungen, als Hermann Samuel Reimarus dem unmittelbaren persönlichen Umfeld von Brockes angehört. Reimarus aber hat zeit seines Lebens den äußeren Eindruck eines kirchentreuen Lutheraners gewahrt, während er im Verborgenen an seiner Apologie für die vernünftigen Verehrer Gottes geschrieben hat, deren fragmentarische Veröffentlichung durch Lessing dann zu dem bekannten Streit mit Goeze geführt hat. Brockes gehörte zu den Wenigen, denen Reimarus diese Apologie mit ihrer Kritik der Bibel als göttlicher Offenbarung und ihrer Grundlegung einer „natürlichen Religion“ zu lesen gab. ${ }^{2}$ Zieht man außerdem das kryptoradikale Hamburger Umfeld in Betracht, wie es Martin Mulsow erschlossen hat, ist die Vermutung, dass wir es auch bei Brockes mit Heterodoxie zu tun haben könnten, alles andere als abwegig. ${ }^{3}$

Diesem Befund entspricht die Tatsache - deren Nachweis eines der zahlreichen Verdienste von Hans-Georg Kemper ist ${ }^{4}$-, dass zentrale Glaubensüberzeu-

1 Zitate aus dem Irdischen Vergnügen in Gott nach der Ausgabe von Jürgen Rathje, soweit bisher erschienen (Bd. 1 bis Bd. 2.2): Barthold Heinrich Brockes: Werke. Hg. u. komm. v. Jürgen Rathje. Göttingen 2012 ff. Alle anderen Zitate nach den Originalen oder der Reclam-Ausgabe von Hans-Georg Kemper (vgl. unten Anm. 4).

2 Gerhard Alexander: Einleitung. In: Hermann Samuel Reimarus: Apologie oder Schutzschrift für die vernünftigen Verehrer Gottes. Hg. v. Gerhard Alexander. Frankfurt/M. 1972, B. 1, S. 9-38, hier S. 17. Der Hinweis darauf bereits 1862 bei David Friedrich Strauß: Barthold Heinrich Brockes und Hermann Samuel Reimarus. In ders.: Kleine Schriften. Hg. v. Eduard Zeller. Leipzig 1862, S. 1-22, hier S. 9. Strauß war auch der erste, der aus dieser Nähe auf einen Deismus Brockes' geschlossen hat.

3 Vgl. Martin Mulsow: Monadenlehre, Hermetik und Deismus. Georg Schades geheime Aufklärungsgesellschaft 1747-1760. Hamburg 1998 und ders.: Moderne aus dem Untergrund. Radikale Frühaufklärung in Deutschland. 1680-1720. Hamburg 2002.

4 Die beste Gesamtdarstellung von Brockes ist die kommentierte Reclam-Ausgabe Barthold Heinrich Brockes: Irdisches Vergnügen in Gott. Naturlyrik und Lehrdichtung. Ausgewählt und hg. v. Hans-Georg Kemper. Stuttgart 1999. Eine ausführliche Interpretation im Kontext bietet Hans-Georg Kemper: Gottebenbildlichkeit und Naturnachahmung im Säkularisierungsprozeß. Problemgeschichtliche Studien zur deutschen Lyrik in Barock und Aufklärung. Tübingen 1981. Die Thesen zu Brockes präzise zusammengefasst in Hans-Georg Kemper: Norddeutsche Frühaufklärung. Poesie als Medium einer natürlichen Religion. In: Religionskritik und Religiosität in der deutschen Aufklärung. Hg. v. Karlfried Gründer und Karl Heinrich Rengstorf. Heidelberg 1989, S. 79-99; darüberhinaus die Darstellung in HansGeorg Kemper: Deutsche Lyrik der frühen Neuzeit. Bd. 5, Tübingen 1991 und seinen Beitrag in diesem Band. 
gungen des Luthertums im Irdischen Vergnügen keine Rolle spielen. Das beginnt bei Christus selbst, dessen namentliche Nennungen in den Tausenden von Seiten des Irdischen Vergnügens man vielleicht nicht an einer Hand abzählen kann, die sich aber in einem sehr überschaubaren Rahmen halten. Die schlechthin zentrale Botschaft Luthers, die Rechtfertigung allein aus dem Glauben an den Erlösungstod Christi, spielt keine Rolle, ebenso wenig wie die Erbsünde, die die Erlösung nötig macht. Gott erscheint im Irdischen Vergnügen nicht als Erlöser und Richter, nicht als strafender oder gnädiger Gott, sondern nur als Schöpfer in seiner Weisheit und Güte. Wie bei der Physikotheologie kann man deshalb auch bei Brockes von einem sapientalen Gottesverständnis sprechen. Der Gott der Physikotheologie ist der Schöpfergott, der die Welt nach Maß, Zahl und Gewicht (Buch der Weisheit 11,20) geordnet und in ihrer Schönheit geschaffen hat. Psalm 19 formuliert dieses Grundmotiv der gesamten Physikotheologie: „Die Himmel erzählen die Ehre Gottes, und die Feste verkündigt seiner Hände Werk“. Die Natur als solche ist gut, weil in ihr die Weisheit Gottes zum Ausdruck kommt. Dieser grundlegende Optimismus - der ein wichtiges Merkmal des Deismus darstellt - hat seinen berühmtesten Ausdruck in Alexander Popes Essay on Man (1732) gefunden, in dem es heißt: „One truth is clear; Whatever Is, is Right". Brockes ist der erste deutsche Übersetzer des Essay on Man. In seiner Fassung lautet diese Stelle, stilistisch nicht ganz geglückt: "So ist die Wahrheit offenbar: daß alles das, was ist, ist gut ${ }^{\text {. }}{ }$

Diesem optimistischen Schöpfungsverständnis entspricht eine optimistische Anthropologie. Auch das ist wiederum ein prägnantes Merkmal der „natürlichen Religion" des Reimarus. Der Mensch ist für Brockes kein schändlicher, fauler, stinkender und sündiger Madensack, wie es bei Luther immer wieder heißt, von der Erbsünde im Kern verdorben und nur durch den Glauben an Christus erlösungsfähig, sondern der Mensch ist gut, wie auch die Natur und die Schöpfung gut sind. Zu den Merkmalen dieser optimistischen Anthropologie gehört dabei an einer der ersten Stellen ein grundsätzliches Vertrauen in die menschliche Vernunft. Mit diesem Vertrauen bewegt sich Brockes in einem zumindest bedingten Gegensatz zu Luther. Luther war der Überzeugung, dass die menschliche Vernunft von sich aus nicht hinreichend ist, Gott zu erkennen. Dieser pessimistischen Einschätzung der Vernunft entspricht die Überzeugung von der Verborgenheit Gottes, wie sie Luther in De servo arbitrio entfaltet hatte. Die biblische Offenbarung ist notwendig, um die menschliche Vernunft soweit zu erleuchten, dass sie Gott im Glauben und in der Gnade erkennen kann. Die Ursache für diese Verschlossenheit der Schöpfung ist das für Luther schlechthin unhintergehbare Faktum der Erbsünde. Durch die grundlegende Korruption der menschlichen Vernunft ist eine von der göttliche Gnade unabhängige, selbständige Erkenntnis nicht möglich. In den Worten von Johann Anselm Steiger:

5 Alexander Pope: Versuch vom Menschen. Übers. v. Barthold Heinrich Brockes. Hamburg 1740, S. 31. 
Eine natürliche Gotteserkenntnis nach dem Sündenfall gibt es nach Luther nicht, jedenfalls nicht in dem Sinne, daß sie über eine bloße Ahnung hinaus zur Gewißheit des Glaubens führen könnte. Der sündige, gefallene Mensch ist wegen seiner verfinsterten Vernunft nicht fähig, Gott aus den Schöpfungswerken zu erkennen. ${ }^{6}$

Von einer solchen Heilsnotwendigkeit der biblischen Offenbarung kann bei Brockes aber keine Rede sein. Brockes versichert zwar immer wieder, dass die menschliche Vernunft nicht hinreichend sei, Gott zu erkennen. Das bezieht sich offensichtlich aber nicht auf die Erkenntnis Gottes aus der Natur, sondern nur auf die ,übernatürlichen' Qualitäten Gottes, wie die Trinität oder das Erlösungswerk. Diese sind nur aus der biblischen Offenbarung zugänglich und müssen im Glauben - und das heißt: nicht über die Vernunft - angenommen werden. Für die ,natürlichen' Qualitäten Gottes, wie sie sich in der Schöpfung offenbaren, gilt stattdessen, dass das ganze Irdische Vergnügen die Möglichkeit einer Erkenntnis Gottes aus der Natur von der ersten bis zur letzten Seite illustriert.

Mit dieser grundsätzlich positiven Bewertung der menschlichen Vernunft unterscheidet sich Brockes sicherlich von Luther. Das heißt aber nicht, dass Brockes mit dieser Bewertung auch außerhalb der protestantischen Theologie stünde. Insbesondere Melanchthon hatte mit seinen naturphilosophischen Schriften durchaus andere Akzente gesetzt als Luther, und damit auch eine eigene, wirkmächtige Tradition innerhalb des Luthertums begründet. Während Luther die von der Erbsünde grundsätzlich korrumpierte Vernunft eine „kleine Hure“ und die „Braut des Satans“ nennt und den Nachdruck allein auf die Gnade legt, die sich im Tod Christi offenbart, hat Melanchthon in seinen Logik-Lehrbüchern und in seinen naturphilosophischen Schriften der Vernunft einen sehr weiten Spielraum zugestanden. In seinen Loci communes rerum theologicarum (1521) hatte er schließlich sogar das getan, was Luther in seiner Disputatio contra scholasticam theologiam (1517) noch strikt abgelehnt hatte, nämlich die Glaubensinhalte einer logischen Deduktion und damit der Vernunft unterworfen. Ausgenommen davon hatte Melanchthon nur einige wenige, zentrale Mysterien wie die Trinität. In seinen Schriften zur Astronomie, Physik und Medizin hat Melanchthon die gesamte materielle Welt einer rationalen Analyse unterzogen, in der ausschließlich die natürlichen Ursachen, die causae naturales, relevant sind. ${ }^{7}$ Melanchthon hat dabei nirgendwo übernatürliche Ursachen ausgeschlossen, aber er ist offen-

6 Johann Anselm Steiger: Fünf Zentralthemen der Theologie Luthers und seiner Erben. Communicatio - Image - Figura - Maria - Exempla. Leiden u. a. 2002, S. 26.

7 Stellvertretend für die neuere Erforschung der Naturphilosophie Melanchthons vgl. Dino Bellucci: Science de la Nature et Reformation. Rom 1998 und Sachiko Kusukawa: The Transformation of Natural Philosophy: the Case of Philip Melanchthon. Cambridge 1995. Zur Anthropologie der Frühen Neuzeit insbes. Simone de Angelis: Anthropologien. Genese und Konfiguration einer ,Wissenschaft vom Menschen' in der Frühen Neuzeit. Berlin, New York 2010. 
sichtlich de facto davon ausgegangen, dass eine Kenntnis der causae naturales hinreichende Sicherheit beanspruchen kann.

Diese melanchthonische Wissensauffassung hatte sich an den Universitäten des protestantischen Raumes fest etabliert und eine Tradition herausgebildet, die etwa im sogenannten Helmstedter Philippismus zu Beginn des 17. Jahrhunderts zu einer manifesten Bewegung wird. Auf der Gegenseite, am anderen Ende des innerlutherischen Spektrums, steht eine Tradition, die insbesondere von Luthers frühen Schriften über Johann Arndt führt und am Ende des 17. Jahrhunderts in den Pietismus mündet. Während in der melanchthonischen Tradition die Logik als Grundlagendisziplin gilt, auch für die Theologie, steht auf dieser ,gnesiolutheranischen' Seite die gelebte Frömmigkeit, die praxis pietatis, im Mittelpunkt.

Im Verlauf des 17. Jahrhunderts wird der Spalt zwischen diesen beiden Traditionen zusehends größer. Die melanchthonische Naturphilosophie erweist sich sowohl als anschlussfähig an den Begriff der Natur als regelhaft-mechanische Ordnung, wie er sich im Gefolge von Descartes und dann den ,new sciences' herausbildet, als auch an den Rationalismus eines Christian Wolff oder Reimarus. Der physikotheologische Natur- und Gottesbegriff um 1700 kann sich deshalb - über diese melanchthonische Tradition - zurecht als Teil des Luthertums betrachten.

\section{Theologie und ,Naturwissenschaft'}

Das ist freilich alles grob vereinfacht und in dieser Zuspitzung problematisch. Die Zuspitzung ist aber insofern legitim, als Wolfgang Philipp in seiner leider immer noch vielzitierten Studie zur Physikotheologie diese als eine apologetische Reaktion von Seiten der protestantischen Theologie (die bei Philipp als monolithischer Block erscheint) auf die Erkenntnisse der ,new sciences' gedeutet hat. ${ }^{8}$ Die Physikotheologie wäre die Reaktion auf einen ,kopernikanischen Schock',

8 Wolfgang Philipp: Das Werden der Aufklärung in theologiegeschichtlicher Sicht. Göttingen 1957. In die Brockes-Forschung wurde diese Perspektive wirkmächtig übertragen von Uwe Karsten Ketelsen: Die Naturpoesie der norddeutschen Frühaufklärung. Poesie als Sprache der Versöhnung: alter Universalismus und neues Weltbild. Stuttgart 1974, der S. 177 etwa von den "reaktiven Bestrebungen der Physikotheologie" spricht, und diese in einem Gegensatzverhältnis zu den „,neuen Naturerkenntnissen“ sieht. Pointiert heißt es S. 86: „Brockes' Gedichte sind in ihrer Intention, diese Ordnung [Gottes] erkennbar zu machen, immer zugleich Kritik an der mechanistischen Theorie der neuen Naturphilosophie [...]." Diese Argumentation übernimmt etwa Heinz-Dieter Weber: Die Verzeitlichung der Natur im 18. Jahrhundert. In: Vom Wandel des neuzeitlichen Naturbegriffs. Hg. v. Heinz-Dieter Weber. Konstanz 1989, S. 97-141, der S. 98 bei Brockes eine „ästhetische Naturerfahrung“ erkennt, die sich "ihrer Differenz zur wissenschaftlichen Welterkenntnis“ vollauf bewusst sei. Das „Irdische Vergnügen“ sei „Korrelat“ „eines durch die wissenschaftlich-rationale Welterkenntnis eingetretenen Verlustes" (S. 104). In diesem Sinne auch Wolfgang Preisendanz: Naturwissenschaft als Provokation der Poesie. Das Beispiel Brockes. In: Frühaufklärung. Hg. v. Sebastian Neumeister. München 1994, S. 469-494 und zuletzt Alexander Kling in: Literatur und Wissen. Ein interdisziplinäres Handbuch. Hg. v. Roland Borgards u. a. Stuttgart u. a. 2013, S. 311-317. 
indem sie versuchen würde, die Erkenntnisse der entstehenden ,Naturwissenschaften' theologisch kompatibel zu machen. Auf den Punkt gebracht hat diese Interpretation Volker Meid in seiner Literaturgeschichte, wenn es dort heißt:

Die Modernität und Attraktivität dieser Denkweise [der Physikotheologie] lag vor allem darin, daß sie sich - anders als die religiöse Orthodoxie oder der Pietismus - neuen naturwissenschaftlichen Erkenntnissen nicht verweigerte, sondern sie vielmehr für die eigene Argumentation fruchtbar machte und sich damit zugleich den, gottlosen' Tendenzen eines mechanistischen Weltbilds entgegenstellte. ${ }^{9}$

Demgegenüber gilt es festzuhalten, dass weder die „Orthodoxie“ noch der Pietismus sich den naturwissenschaftlichen Erkenntnissen verweigerten noch das mechanische Denken als "gottlos" wahrgenommen wurde. Von einem ,kopernikanischen Schock' kann in der Physikotheologie, genauso wie bei Brockes, keine Rede sein. Die Erkenntnisse der ,new sciences' wurden - zumindest bis weit ins 18. Jahrhundert hinein - nicht als Herausforderungen der Theologie wahrgenommen im Sinne eines keimhaften Atheismus oder Materialismus, sondern als überwältigende Bestätigung einer göttlichen Ordnung der Welt. Auch für die Physikotheologie gilt, was Francis Bacon, der Prophet der ,new sciences', schon 1605 am Anfang von The Advancement of Learning geschrieben hatte: Dass nämlich eine Kenntnis der natürlichen Ursachen nicht zum Atheismus verleite, sondern im Gegenteil zur Erkenntnis Gottes als der übernatürlichen, ersten Ursache hinführe. ${ }^{10}$ Ähnlich heißt es bei dem Physikotheologen Lesser, der Theologe brauche Kenntnisse in "Natur-Wissenschaft", "denn ohne dieselbe wird er nicht im Stande seyn denen atheistischen Spöttern recht zu begegnen ". ${ }^{11}$

Die experimentelle Erforschung der Natur und die kausalmechanische Begründung aller natürlichen Vorgänge wurden als eine völlig neue Dimension der Erfahrung Gottes und seiner Schöpfung erlebt. Das ist auch die These von Udo Krolzig:

Ihnen [den Physikotheologen] geht es nicht um die Überwindung eines Gegenübers von Theologie und Naturwissenschaft, sondern um eine Vertiefung in die kausalmechanisch experimentell betrachtete und in Feldstudien erforschte Natur, wodurch neue Tiefen der Begegnung mit dem Schöpfergott erschlossen werden. ${ }^{12}$

9 Volker Meid: Die deutsche Literatur im Zeitalter des Barock. Vom Späthumanismus zur Frühaufklärung 1570-1740. München 2009, S. 322.

10 Francis Bacon: Über die Würde und die Förderung der Wissenschaften. Übers. v. Jutta Schlösser. Freiburg u. a. 2006, S. 17 f.

11 Friedrich Christian Lesser: Lithotheologie. Hamburg 1735, Vorrede S. XVII.

12 Udo Krolzig: Säkularisierung der Natur. Providentia-Dei-Lehre und Naturverständnis der Frühaufklärung. Neunkirchen-Vluyn 1988, S. 154. Eine Zusammenfassung bietet Udo Krolzig: Art. Physikotheologie. In: Theologische Realenzyklopädie Bd. 26, 1996, S. 590596. Höchst problematisch ist allerdings Krolzigs Begriff der Säkularisierung, vgl. dazu 
Das kausalmechanische Erklärungsmodell, wie es die Physikotheologie propagiert, steht weder in einem Widerspruch zur Anerkennung einer göttlichen Ordnung noch zur Teleologie, wie in der Folge von Philipps These behauptet worden ist. ${ }^{13}$ Es war genau im Gegenteil das kausalmechanische Erklärungsmodell, das als ein starkes Argument für den teleologischen ,Gottesbeweis' wahrgenommen wurde. ${ }^{14}$

Die biblische Offenbarung wurde nicht kausalmechanisch widerlegt, sondern erschien lediglich als eine zunehmend naive Formulierung derselben Erfahrung Gottes, die man aus der Natur in einer wesentlich deutlicheren und anspruchsvolleren Form machen konnte. Die ,Akkomodationstheorie', wie sie in der zweiten Hälfte des 18. Jahrhundert Johann Salomo Semler explizit formulieren wird - also die Annahme, dass Gott sich in der Bibel an die schwachen Verstandeskräfte der frühen Menschen angepasst und sich einer schlichten, bildlichen Ausdrucksweise bedient habe - kündigt sich bereits am Anfang des Jahrhunderts an. So heißt es bei Brockes schon im sechsten Band des Irdischen Vergnügens, wenn in der Bibel von Hölle, Drachen und Teufeln die Rede sei, gehe das auf die Vorliebe der „Orientalen“ für bildliche Ausdrücke zurück. Diese könnten aber „durch die vernünftigen Geistlichen“ auch „,vernünftig erklärt" werden. ${ }^{15}$ Die Bibel wird damit zu einem historischen Dokument, das in seinem historischen Kontext gelesen und verstanden werden muss. ${ }^{16}$ Auch hier wäre wieder auf Reimarus zu verweisen. ${ }^{17}$

unten. An Krolzig anschließend (mit überzogenem Anspruch, aber interessanten Einzelbeobachtungen) Paul Michel: Physikotheologie. Ursprünge, Leistung und Niedergang einer Denkform. Zürich 2008.

13 Manfred Büttner: Theologie und Klimatologie im 18. Jahrhundert. In: Neue Zeitschrift für systematische Theologie und Religionsphilosophie 6 (1964), S. 154-191; Manfred Büttner: Zum Übergang von der teleologischen zur kausalmechanischen Betrachtung der geographisch-kosmologischen Fakten. Ein Beitrag zur Geschichte der Geographie von Wolff bis Kant. In: Studia Leibnitiana 5 (1973), S. 177-195. Ähnlich Fritz Kraft: ,Denn Gott schafft nichts umsonst!' Das Bild der Naturwissenschaft vom Kosmos im historischen Kontext des Spannungsfeldes Gott - Mensch - Natur. Münster 1999, S. 81.

14 So schon Richard Toellner: Die Bedeutung des physikotheologischen Gottesbeweises für die nachcarthesianische Physiologie im 18. Jahrhundert. In: Berichte zur Wissenschaftsgeschichte 5 (1982), S. 75-82, der zeigt, wie das mechanistische Denken das physikotheologische Anliegen unterstützt. Vor allem aber Anne-Charlott Trepp: Von der Glückseligkeit alles zu wissen. Die Erforschung der Natur als religiöse Praxis in der Frühen Neuzeit. Frankfurt/M. u. a. 2009, S. 306-372.

15 Brockes: Irdisches Vergnügen in Gott. Hamburg 1740. Bd. 6, S. 580 („Gedanken über den Tod der Belise").

16 Zur Historisierung der Theologie im 18. Jahrhundert vgl. stellvertretend Walter Sparn: Auf dem Weg zur theologischen Aufklärung in Halle: Von Johann Franz Budde zu Siegmund Jacob Baumgarten. In: Zentren der Aufklärung. Bd. 1: Halle. Aufklärung und Pietismus. Hg. v. Norbert Hinske. Berlin 1989, S. 71-90.

17 Dirk Fleischer: Lebendige Geschichte: Hermann Samuel Reimarus und Johann Salomo Semler auf der Suche nach der biblischen Wahrheit. In: Aufgeklärtes Christentum. Beiträge zur Kirchen- und Theologiegeschichte des 18. Jahrhunderts. Hg. v. Albrecht Beutel u. a. Leipzig 2010, S. 75-92. 


\section{Kausale Ursachenforschung versus allegorische Exegese}

Wenn Brockes also - genauso aber Isaac Newton oder Robert Boyle - Gott aus und in den Ursache-Wirkungszusammenhängen der Natur erkennt, und zwar ohne dabei die christlichen Heilswahrheiten in irgendeiner Weise in Betracht zu ziehen, steht er damit nicht zwangsweise in einem Gegensatzverhältnis zum Luthertum, sondern kann in melanchthonischer Tradition der menschlichen Vernunft die Möglichkeit einer bedingt unabhängigen Naturerkenntnis zugestehen. Diese Tradition ist allerdings nicht mit der genuin lutherischen Deutung der Natur zu verrechnen. Der wichtigste Unterschied ist dabei, dass die Natur für Luther nur durch die biblische Offenbarung lesbar wird. Wenn die Natur zum Sprechen gebracht wird, dann allein durch die Heilswahrheiten der Bibel. Die Bibel ist der allegorische Schlüssel zum Buch der Natur:

Derjenige [jedoch], der durch die Predigt von Gesetz und Evangelium zum Glauben gekommen ist und die imputatio der fremden Gerechtigkeit Christi erlangt hat, beginnt, durch die Analogie des Glaubens (Röm 12,7) in den Schöpfungswerken die Inhalte der biblischen Verkündigung gespiegelt zu sehen und die wahre cognitio Dei naturalis wiederzugewinnen. ${ }^{18}$

Die Natur beginnt erst dann zum Menschen zu sprechen, wenn der Mensch das Wort Gottes vom Tod Christi im Glauben angenommen hat. Erst muss der Mensch zu glauben beginnen, dann kann er, noch einmal in den Worten Steigers, „mit den Augen des Glaubens per analogiam fidei die Sprache der Schöpfung als Verstärkung und Verlängerung des im Gottesdienst verkündeten Evangeliums verstehen lernen“.19 Selbstverständlich spricht eine solche durch die Heilswahrheiten der Bibel wahrgenommene Schöpfung nicht die Sprache der Naturphilosophie oder dessen, was man später ,Naturwissenschaft' nennen wird. Diese durch die Bibel wahrgenommene Schöpfung spricht nicht von irgendwelchen autonomen ,Naturgesetzen', von Kräften und Elementen der Materie, von Anziehung und Abstoßung, von organischen und anorganischen Prozessen der Bildung und Zersetzung, sondern die Schöpfung spricht, wie die Bibel, von Christus, von der Sünde und von der Erlösung, von der Fleischwerdung, dem Tod am Kreuz und vom kommenden Reich.

Steiger hat in mehreren Studien gezeigt, wie dieses lutherische Verständnis der Natur und der Schöpfung die geistliche Dichtung und Erbauungsliteratur des 17. Jahrhunderts beherrscht. Insbesondere sei hier auf seine Interpretation des "Sommerliedes“ von Paul Gerhardt verwiesen: „Geh aus mein Herz und suche Freud/ I In dieser lieben Sommerzeit I An deines Gottes Gaben“. Pointiert

18 Steiger: Zentralthemen (Anm. 6), S. 27.

19 Steiger: Zentralthemen (Anm. 6), S. 51. Vgl. dazu auch Johann Anselm Steiger: „Alles vol Bibel“. Die Predigt der Kreatur in der Theologie Martin Luthers. Oder: Die Sprachmacht des Gemachten. In: Scientiae et artes: Die Vermittlung alten und neuen Wissens in Literatur, Kunst und Musik. Hg. v. Barbara Mahlmann-Bauer. Wiesbaden 2004, Bd. 1, S. 189-214. 
gegen alle Versuche, dieses Kirchenlied in eine Vorgeschichte der ,Naturlyrik' zu stellen oder auch nur als Ausdruck ,naiver Naturfrömmigkeit' zu verstehen, zeigt Steiger, dass es sich um eine genuin lutherische Interpretation der Schöpfung handelt, in der die ganze Natur von den Wahrheiten der Offenbarung spricht. Der Sommer bezeichnet darin keineswegs nur eine Jahreszeit, sondern steht für das jenseitige Paradies. Steiger spricht von einer „emblematischen Wiedergewinnung der Wirklichkeit" - und das heißt: der biblischen Heilswahrheiten - im Bild der Natur. ${ }^{20}$

Maria Marten hat in ihrer Studie zur Pflanzenallegorese in der protestantischen Predigtliteratur eine eindrückliche Illustration dieser lutherischen Tradition geliefert. Hier wird auch sehr anschaulich, was genau es bedeutet, die Natur mit dem allegorischen Schlüssel der Bibel zu lesen. So bezeichnet die niedrig am Boden wachsende Erdrose den sündigen Menschen, der, ursprünglich als Gottes Ebenbild erschaffen, vom Teufel niedergetreten worden ist. Die drei Blätter des Stiefmütterchens verweisen auf die göttliche Trinität, der Ölbaum mit seinen vielen Äste auf die Ausbreitung der Kirche, die purpurne Farbe des Veilchens auf das Leiden Christi, die roten Blüten der Pfingstrose auf das blutige Haupt Christi. ${ }^{21}$ Gott spricht überall in der Natur zum Menschen, und der Mensch kann diese Sprache im Glauben und im Licht des Evangeliums verstehen. Die Natur ist keine autonome Größe, sondern eine „Maske Gottes“ („larva dei“), ${ }^{22}$ in der der Gläubige die Heilswahrheiten der Bibel wiederfindet.

Diese genuin lutherische Tradition findet um 1600 eine äußerst einflussreiche Reformulierung und Transformation in Johann Arndts Vier Büchern vom wahren Christentum (1605 ff.). Dieses wohl meistgedruckte Buch des 17. Jahrhunderts propagiert eine Reformation der individuellen Frömmigkeit. Die praxis pietatis soll der von Luther vollzogenen Reformation der Theologie als der Theorie des Glaubens an die Seite treten. ${ }^{23}$ Frömmigkeit als gelebte Praxis auf der einen Seite und Theologie als ,bloße Theorie' auf der anderen Seite erscheinen als Gegensatz, wie er etwa schon die mittelalterliche, klösterliche Mystik im Gegensatz zur akademischen Scholastik bestimmt hat. Das vierte der Vier Bücher Arndts ist das Buch der Natur. Dieses vierte Buch vermittelt die lutherische Konzeption der Natur als einer Anrede Gottes, die erst im Glauben verständlich wird, an die Erbauungsliteratur und die geistliche Dichtung des 17. Jahrhunderts. Die geistliche Dichtung von Andreas Gryphius, Johann Rist, Sigmund von Birken oder Catharina Regina

20 Johann Anselm Steiger: „Geh' aus, mein Herz, und suche Freud.“ Paul Gerhardts Sommerlied und die Gelehrsamkeit der Barockzeit (Naturkunde, Emblematik, Theologie). Berlin 2007, S. 33. Vgl. zum „Sommerlied“ auch den Beitrag von Kemper in diesem Band.

21 Maria Marten: Buchstabe, Geist und Natur. Die evangelisch-lutherischen Pflanzenpredigten in nachreformatorischer Zeit. Bern u. a. 2010. Die Beispiele dort S. 127, 129, 113 und 105.

22 Vgl. Steiger: Zentralthemen (Anm. 6), S. 28.

$23 \mathrm{Zu}$ Johann Arndt vgl. stellvertretend Hanns-Peter Neumann: Natura sagax - die geistige Natur: zum Zusammenhang von Naturphilosophie und Mystik in der frühen Neuzeit am Beispiel Johann Arndts. Tübingen 2004 und Hans Schneider: Der fremde Arndt. Studien zu Leben, Werk und Wirkung Johann Arndts. Göttingen 2006. 
von Greiffenberg, die Meditationsliteratur eines Johann Gerhard, die Erbauungsliteratur eines Christian Scriver, Joachim Lüdkemann und Heinrich Müller, genauso wie die geistliche Emblematik eines Johann Saubert oder Johann Michael Dilherr gehören in diese Tradition eines Ideals von gelebter Frömmigkeit.

Bei der Physikotheologie um 1700 im Allgemeinen und bei Brockes im Besonderen kann dagegen - soweit die Forschungslage ein solches Urteil zulässt ${ }^{24}$ - von einem solchen lutherischen Begriff der Natur keine Rede sein. Die Natur wird im Irdischen Vergnügen nicht durch die Heilswahrheiten der Bibel verständlich, sondern sie wird in und durch die ,natürlichen Ursachen', die causae naturales, als göttliche Ordnung verständlich. Das heißt aber nicht, dass Brockes damit außerhalb des kirchlichen Luthertums stehen muss, denn mit Melanchthon gibt es die Tradition eines solchen sapientalen Schöpfungsverständnisses eben auch innerhalb des Luthertums. Für Melanchthon, genauso wie für Brockes, erscheint die Schöpfung als Ausdruck der Weisheit Gottes, im Gegensatz zu Luther, für den die ganze Natur nur vom Heilshandeln Gottes spricht. Im Unterschied zu einem sapientalen Schöpfungsverständnis bei Melanchthon könnte man bei Luther deshalb von einem soteriologischen Schöpfungsverständnis sprechen.

Was mit diesem Unterschied für die Naturdeutung auf dem Spiel steht, illustrieren zwei Beispiele. Sigmund von Birken schreibt 1669 über die Passionsblume:

Sie ist eine Wunderblume/ eine stumme Predigerinn des Jesus-Leidens/ und ruffet uns gleichsam zu: Haltet im Gedächtnis Jesum den Gekreuzigten! dannenhero sie die Jesus Blume heisen möchte/ und der zeit in unsern Herzen wachsen und blühen soll. ${ }^{25}$

Die Passionsblume - sie trägt bis heute diesen Namen - zeugt durch ihre Form und die Zahl ihrer Blütenblätter von der Passion Christi. In der Folge des zitierten Gesprächs werden ihre Eigenschaften systematisch auf die Details der Passionsgeschichte bezogen: auf das Kreuz, auf die Lanze, mit der Christus verletzt wurde, auf die Farbe des Blutes usw. Die natürlichen Eigenschaften der Passionsblume spielen dagegen keine Rolle. Ein zweites Beispiel für eine solche allegorische Naturdeutung ist Johann Rist, der angesichts des Wachstums der Pflanzen in seinem Garten eben nicht nur an „die herliche Würkungen der Natur" gemahnt wird, sondern in diesen „etwas übernatürliches“ erkennt, nämlich die „Aufferstehung der Todten":

24 Es fehlt vor allem an gezielten Studien zu einzelnen Autoren, wie sie Trepp: Glückseligkeit (Anm. 14) für Lesser und Krolzig: Säkularisierung (Anm. 12) für Fabricius vorgelegt haben.

25 Sigmund von Birken: Himmel-klingendes Schäferspiel dem Nachruhme [...] Johann Michael Dilherrns [...] 1669 [...] gewidmet von der Blumen-Genosschaft an der Pegnitz. [Nürnberg 1669], hier S. 5. Auf die Stelle hingewiesen hat Trepp: Glückseligkeit (Anm. 14), S. 257. 
sintemahl ich so wohl aus dem Natur- als Schriftbuch nunmehr vollenkommen bin vergewißert/ das/ so wahr als Gott unser Schöpfer lebet/ der alle Jahr der Welt gleichsahm ein neues Leben wiedergiebet/ auch wir/ sein Geschöpfe nach dem Tode widrum leben werden. ${ }^{26}$

Der Frühling zeugt nicht von der Weisheit Gottes, der die Jahreszeiten einander abwechseln lässt, sondern von der kommenden Auferstehung nach dem Tod. Eine solche soteriologische Interpretation von Erscheinungen der Natur wird man bei Brockes vergeblich suchen. Für Brockes' sapientales Schöpfungsverständnis zeugen die Blumen nicht vom Heilshandeln Gottes, sondern mit ihren Farben und Formen, mit ihrer biologischen Funktionalität von der Weisheit Gottes, die in der Ordnung und Schönheit der Welt zum Ausdruck kommt. Für Brockes und die Physikotheologie dient der ,naturwissenschaftliche' Nachweis der Kausalzusammenhänge dem Nachweis einer göttlichen Ordnung. Für die lutherische Tradition ist die Natur dagegen eine Allegorie, die vom Heilshandeln Gottes in der Schöpfung zeugt. ${ }^{27}$ Das sind zwei ganz unterschiedliche Naturbegriffe. Sie müssen allerdings keinesfalls gegensätzlich sein, sondern können durchaus komplementär sein. Auch hier gilt, dass man sich vor dichotomischen Vereinfachungen hüten sollte.

Brockes illustriert diesen Vorbehalt, wenn er sich mit seiner Naturdichtung in die Tradition von Paul Gerhardt ${ }^{28}$ stellt oder in einer Liste mit Lektüreempfehlungen, die im Patrioten erschien, an erster Stelle die Klassiker der lutherischen Erbauungsliteratur nennt: Luther, Scriver, Lüdkemann, Lassenius, Arndt, Gerhard..$^{29}$ Sein Freund und Hamburger Kollege Johann Albert Fabricius stellt seiner Brockes gewidmeten Übersetzung von William Derhams Astrotheologie eine lange Literaturliste voraus, die von den Kirchenvätern über das katholische Mittelalter bis hin zu Melanchthon, Scriver, Dilherr und Arndt führt. ${ }^{30}$ Auch Robert Boyle wird dort prominent hervorgehoben. Brockes und Fabricius haben sich in einer kontinuierlichen, christlichen Tradition gesehen, nicht als Vertreter eines neuen, ,säkularen' Naturbegriffs.

26 Johann Rist: Das Alleredelste Nass. In ders.: Sämtliche Werke. Hg. v. Eberhard Mannack. Bd. 4, S. 1-120, hier S. 30 f. Auch dieses Beispiel nach Trepp: Glückseligkeit (Anm. 14), S. 113.

27 Zum damit verbundenen Funktionswandel der Allegorie vgl. Peter-André Alt: Begriffsbilder. Studien zur literarischen Allegorie zwischen Opitz und Schiller. Tübingen 1995, S. 468-486.

28 Vgl. das Gedicht „Unbegreiffliche Gleichgültigkeit“ in der Reclam-Ausgabe von Kemper (Anm. 4), S. 217 ff. und Brockes: Irdisches Vergnügen in Gott. Hamburg 1740. Bd. 6, S. 279 f.

29 Brockes: Achtes Stück. Donnerstag, den 24. Febr. 1724. In ders.: Werke Bd. 1 (Anm. 1), S. 430 437. Vgl. auch: Der Patriot. Hg. v. Wolfgang Martens. Berlin u.s. 1969, Bd. 1, S. 67.

30 William Derham: Astrotheologie, oder Himmlisches Vergnügen in Gott. Übers. v. Johann Albert Fabricius. Hamburg 1728 („Verzeichnis der alten und neuen Scribenten, die sich haben lassen angelegen seyn, durch Betrachtung der Natur, und der Geschöpffe, die Menschen zu Gott zu führen", S. XIII-LXIV). 


\section{Das Irdische Vergnügen als religiöse Praxis}

Brockes steht zwar nicht mit seinem Naturbegriff in der Tradition der Erbauungsliteratur, wohl aber mit der religiösen Praxis, als die er seine Arbeit am Irdischen Vergnügen in Gott begreift. Dass es sich bei dieser unermüdlichen, über fast dreißig Jahre und neun Bände erstreckenden Arbeit seinem eigenen Verständnis zufolge um eine religiöse Tätigkeit, eine Frömmigkeitsübung und -ausübung, also eine praxis pietatis handelt, dokumentieren die zahllosen Versicherungen von Brockes selbst, die sich fast in jedem seiner Gedichte finden. In seiner Lebensbeschreibung heißt es, er habe mit dem Irdischen Vergnügen begonnen, „um den Schöpfer zu besingen":

Wozu ich mich um so viel mehr verpflichtet hielte, als ich eine so große und fast unverantwortliche Nachlässigkeit, Unempfindlichkeit, und dem daraus folgenden Undanck gegen den Allmächtigen Schöpfer für höchst sträflich und dem Christenthum gantz unanständig hielte. Verfertigte demnach [...] eintzelne Stücke [...] um so wol mich selbst als andere zu des weisen Schöpfers Ruhm [...] anzufrischen [...]. ${ }^{31}$

Brockes praktiziert damit in formaler Hinsicht genau das, was auch die Erbauungsliteratur als Frömmigkeitsübung praktiziert hat. Günther Butzer hat das Wesen dieser Erbauung und Andacht sehr treffend als „Psychagogik“ beschrieben, als "Seelenführung“. ${ }^{32}$ Erbauungsliteratur ist in diesem Sinne Meditationsliteratur, indem sie sowohl den Verfasser wie den Leser dazu anleitet, seine Aufmerksamkeit auf Gott zu richten. Die rhetorischen Stilmittel und die poetische Form der geistlichen Dichtung und der Erbauungsliteratur bekommen von hier aus ihre Legitimation: sie dienen der Aufmerksamkeitssteuerung, der Verdeutlichung, der Einprägung eines religiösen Wissens. ${ }^{33}$ Sie sind eine Form religiöser Übung und Praxis.

Diese Beschreibung der Erbauungsliteratur als religiöser Übung ergänzt sich mit der These von Anne-Charlott Trepp, deren Studie zur Naturerfahrung in der Frühen Neuzeit den Untertitel „Die Erforschung der Natur als religiöse Praxis“ trägt. ${ }^{34}$ Trepp verortet die geistliche Dichtung eines Johann Rist, die InsektenStudien der Maria Sibylla Merian und die physikotheologischen Werke von Friedrich Christian Lesser nicht innerhalb einer Alternative von Dichtung oder ,Naturwissenschaft', sondern beschreibt sie aus ihrem zeitgenössischen Kontext

31 Brockes: Selbstbiographie. In ders.: Werke Bd. 1 (Anm. 1), S. 1-40, hier S. 25.

32 Günter Butzer: Psychagogik in der Frühen Neuzeit. In: Diskurse der Gelehrtenkultur in der Frühen Neuzeit. Ein Handbuch. Hg. v. Herbert Jaumann. Berlin, New York 2010, S. 715746. Vgl. dazu auch den Beitrag von Butzer in diesem Band. Wenig aussagekräftig dagegen Henrik Petersen: B. H. Brockes, J. A. Fabricius, H. S. Reimarus: Physikotheologie im Norddeutschland des 18. Jahrhunderts zwischen theologischer Erbauung und Wissensvermittlung. Diss. Kiel. Digital zugänglich unter: urn:nbn:de:gbv:8-diss-20408 (07.04.2015).

33 Vgl. dazu den Beitrag von Franz Eybl in diesem Band, mit ausführlichen Angaben zu weiterer Literatur.

34 Trepp: Glückseligkeit (Anm. 14). 
heraus als Teil einer religiösen Praxis. Diese Praxis äußert sich gleichermaßen etwa in den Predigten, die Lesser unter freiem Himmel abgehalten hat, wie in den Naturalienkabinetten der Zeit - also in zwei Bereichen, die man heute als religiöse und wissenschaftliche Praxis unterscheiden würde. Die Leidenschaft, mit der in diesen Kabinetten Versteinerungen, Muscheln, Skelette, Mineralien usw. gesammelt und beschrieben werden, ist Ausdruck derselben Hinwendung zur Natur als göttlicher Ordnung, wie sie Brockes' Irdisches Vergnügen auszeichnet.

Dass es sich bei Brockes' Erforschung der Natur um eine religiöse Praxis handelt, findet ein weiteres Argument in der Tatsache, dass sich das gesamte Irdische Vergnügen als Lob- und Dankgebet versteht. Gerade als Lob- und Dankgebet, als Vergegenwärtigung göttlicher Weisheit und Macht in der Schöpfung, steht das Irdische Vergnügen aber wiederum klar in der Tradition der Erbauungsliteratur und eines christlichen Gottesbegriffes. Das Gebet als solches erfordert die Annahme eines persönlichen Gottes, der in das Geschehen dieser Welt eingreift. Wenn eine göttliche Providenz bestritten wird - etwa im Sinne eines spinozistischen Pantheismus, der Gott mit der Natur identifiziert, oder im Sinne eines mechanistischen ,Uhrmacher-Gottes', der den Lauf der Welt von der Schöpfung an festgelegt hat - dann hat das Gebet keinen Sinn. Wenn Gott die Welt wie ein Uhrwerk in Gang gesetzt hat, das dann ohne weitere Eingriffe abläuft, ${ }^{35}$ dann braucht man zu diesem Gott nicht zu beten, genauso wenig, wie man zu einem Gott beten muss, der mit der Natur identisch ist.

Dem gegenüber gilt es festzuhalten, dass nahezu jedes zweite Gedicht des Irdischen Vergnügens sich als Dankgebet versteht oder zumindest mit einer Dankesformel schließt. Das mag trivial erscheinen, ist aber ein gewichtiges Argument dafür, dass es sich bei dem Gott von Brockes nicht um einen pantheistisch oder spinozistisch gedachten Gott handelt, sondern um einen persönlichen Gott, der in seine Schöpfung eingreift und sich am Lob und Dank seiner Geschöpfe erfreut. Dies wird im Irdischen Vergnügen ausdrücklich bestätigt, wenn Gott dort zu erkennen gibt, dass er aus Liebe zu seinen Geschöpfen an deren Gebeten Gefallen findet. ${ }^{36}$ Programmatisch zeigt der Titelkupfer zum fünften Band des Irdischen Vergnügens, wie das Lob der Schöpfung als Dankopfer in den Himmel steigt. Wenn Immanuel Kant am Ende des Jahrhunderts in seiner Schrift Die Religion innerhalb der Grenzen der bloßen Vernunft (1793) das private Gebet als „,bloßen Re-

35 Die Uhrwerksmetapher als solche impliziert dabei keineswegs, dass das Uhrwerk keine weiteren Eingriffe Gottes erlauben würde. Deswegen können sich auch Brockes und die anderen Physikotheologen der Metapher bedienen, ohne damit theologisch gesichertes Gebiet $\mathrm{zu}$ verlassen. Lesser geht in seiner Lithotheologie ausführlich auf diesen Punkt ein, indem er zeigt, wie Gott „die natürlichen Ursachen auf eine ausserordentliche Art zur Ausführung seines Vorhabens" - also im Gegensatz zur ,ordentlichen' Art der providentia generalis, vgl. dazu unten - gebrauchen kann und das Erdbeben etwa so einsetzt, dass die göttliche Strafe den Richtigen trifft, also im Sinne der providentia specialis. Lesser: Lithotheologie (Anm. 11), S. 25.

36 Brockes: Irdisches Vergnügen (ed. Rathke, Anm. 1) Bd. 2.1, S. 391-395 („Der Zweifel“). 
ligionswahn und Afterdienst Gottes" bezeichnet, ist das deshalb sicher nicht die Überzeugung von Brockes. ${ }^{37}$

Damit ist auch gesagt, dass ich - im Gegensatz zu Hans-Georg Kemper ${ }^{38}$ keine Kontinuität zwischen der ,Naturlyrik' eines Brockes und derjenigen etwa Goethes erkennen kann. Der Naturbegriff von Brockes und den Physikotheologen ist Ausdruck eines mechanistischen und rationalistischen Denkens und steht also solcher - tendenziell ${ }^{39}$ - in einem Gegensatz zu hermetisch-spiritualistischen Positionen, wie sie später bei Goethe zum Tragen kommen. Die pantheistische Naturlyrik Goethes versteht sich nicht als Dankgebet, sondern ist Ausdruck eines dynamisch-vitalistischen Naturbegriffs, einer Einheit von Mensch und belebt gedachter Natur. ${ }^{40}$ Mit dem Natur- und Gottesbegriff von Brockes ist eine solche Einheit nicht zu haben.

37 Immanuel Kant: Die Religion innerhalb der Grenzen der bloßen Vernunft. Viertes Stück, zweiter Teil §2: „alles, was, außer dem guten Lebenswandel, der Mensch noch tun zu können vermeint, um Gott wohlgefällig zu werden, ist bloßer Religionswahn und Afterdienst Gottes".

38 Kemper sieht eine solche Kontinuität, weil er die "natürliche Religion“ eines Brockes als Ausdruck einer hermetisch-neuplatonischen Tradition deutet und gerade in Gegensatz zum Deismus und Mechanismus bringt. Vgl. z. B. Kemper: Norddeutsche Frühaufklärung (Anm. 4), S. 93: „Es ist sein [Brockes'] Verdienst, daß er die Poesie zum priesterlichen Medium einer Naturreligion erhob, die sich auf einen in der Auseinandersetzung mit dem Cartesianismus entwickelten, religiös fundierten Naturbegriff stützen konnte und die im Unterschied zur deistischen Vernunftreligion, deren Glaubensgrundsätze Brockes freilich ebenfalls zitieren konnte, auch die Sinne und das Gefühl ansprach und befriedigte. Damit verwirklichte er in der Frühaufklärung mit Hilfe seiner Poesie wichtige Aspekte, Tendenzen und Funktionen auf der Grundlage einer Weltanschauung, welcher auch die Sturmund-Drang-Generation zentrale Ideen und Impulse verdankt." Ähnlich Kemper in seiner Brockes-Ausgabe (Anm. 4), S. 215 f. und in ders.: Deutsche Lyrik der Frühen Neuzeit Bd. 5/2 (Anm. 4), S. 47-75. Ausführlich und mit zahlreichen neuen Argumenten sein Beitrag in diesem Band.

39 Diese Einschränkung ist wichtig, denn grundsätzlich scheint es um 1700 keinen strikten Gegensatz zwischen einem hermetisch-spiritualistischen und einem mechanistischen Naturbegriff zu geben. Der "Geist"-Begriff, auf den sich Kempers Argumentation vor allem stützt, belegt dies paradigmatisch. Die spiritus-Theorie, die damit angesprochen ist, kann durchaus mechanistisch gedacht werden, wenn die spiritus als kleinste materielle Einheiten gelten. Insbesondere in Hinblick auf Thomasius' Versuch von Wesen des Geistes, auf den sich auch Kemper beruft, verdiente das Thema dringend weitere Aufmerksamkeit. Auf den Eklektizismus von Brockes gerade hinsichtlich hermetischer Elemente hat auch Wolfram Mauser: Die „Balsam=Kraft" von innen. Dichtung und Diätetik am Beispiel des B.H. Brockes. In ders.: Konzepte aufgeklärter Lebensführung. Literarische Kultur im frühmodernen Deutschland. Würzburg 2000, S. 244-274, hier S. 247 f. hingewiesen.

40 In diesem Sinne schon Wolfgang Martens: Erbauliche Naturlyrik eines Aufklärers (B. H. Brockes). In ders.: Literatur und Frömmigkeit in der Zeit der frühen Aufklärung. Tübingen 1989, S. 261-275. 


\section{Mechanische Erklärungen und göttliche Providenz}

Auf der anderen Seite gilt wieder, dass die atheistischen, materialistischen Konsequenzen, die später mit dem mechanistischen Denken verknüpft werden, nicht auf die Zeit von Brockes zurückprojiziert werden dürfen. Das aber geschieht, wenn man die Vorstellung eines Gottes, der die Schöpfung analog zu einem mechanischen Uhrwerk geschaffen hat, mit dem Deismus identifiziert. Diese Vorstellung impliziert, Gott hätte dieses Uhrwerk der Schöpfung einmal geschaffen und in Gang gesetzt, ohne dann selbst noch in den Ablauf eingreifen zu können und zu müssen. Eine solche Schöpfungsvorstellung würde auf moralischer Ebene einen Fatalismus implizieren und sich damit in radikalem Widerspruch zu jeder christlichen Ethik befinden.

Ein so verstandener Deismus ist immer wieder zum theologischen Überbau der neuen mechanischen Modelle und der ,new sciences' erklärt worden. An die Stelle des persönlichen, ,lebendigen' Gottes der christlichen Theologie wäre der ,tote' Gott der Moderne getreten, der durch Gebete nicht ansprechbar ist und in seine Schöpfung nicht mehr eingreift. An die Stelle einer göttlichen Providenz, die jedes individuelle Leben im Blick hat, wäre die blinde mechanische Notwendigkeit getreten.

Gegen solche simplifizierenden Vorstellungen haben jedoch Günter Gawlick und Winfried Schröder gezeigt, dass es diesen Gegensatz für das 17. und frühe 18. Jahrhundert nicht gibt. ${ }^{41}$ Der sogenannte Deismus als die theologische Strömung, die die neuen naturwissenschaftlichen Erkenntnisse und damit das mechanische Erklärungsmodell als seine Grundlage versteht, haben die Existenz einer göttlichen Providenz nie und nirgends geleugnet. Auch wenn es der ,großen Erzählung' vom Aufstieg der modernen ,Naturwissenschaften', die die alte, christliche Theologie herausfordern und schließlich zerstören, zuwiderläuft, lässt der historische Befund, folgt man Winfried Schröder, keinen Zweifel zu: Keiner der sogenannten Deisten hat eine göttliche Providenz bestritten. ${ }^{42}$ Damit

41 Vgl. v. a. Winfried Schröder: Der Deismus in der Philosophie der Neuzeit. In: Gestalten des Deismus in Europa. Hg. v. Winfried Schröder. Wiesbaden 2013, S. 7-27, der damit die Arbeiten von Günter Gawlick aufnimmt, vgl. darunter insbes. Günter Gawlick: Christian Wolff und der Deismus. In: Christian Wolff 1679-1754. Interpretationen zu seiner Philosophie und deren Wirkung. Hg. v. Werner Schneiders. Hamburg 1983, S. 139-147 und ders.: Reimarus und der englische Deismus. In: Religionskritik und Religiosität in der deutschen Aufklärung. Hg. v. Karlfried Gründer und Karl Heinrich Rengstorf. Heidelberg 1989, S. 43 54. Zur Rezeption des englischen Deismus vgl. Christopher Voigt: Der englische Deismus in Deutschland. Tübingen 2003 und Mark-Georg Dehrmann: Das „Orakel der Deisten“. Shaftesbury und die deutsche Aufklärung. Göttingen 2008.

42 Wenn Christian Wolff in seiner Theologia naturalis (1737) den Deismus genau in diesem Sinne definiert, nämlich als Leugnung göttlicher Providenz - „Deista a nobis dicitur, qui Deum existere concedit, cum tamen res humanas curare negat, seu providentiam negat.“ (Theologia naturalis II.2, §529) - ist mit dem Begriff des Deismus hier wohl eher ein spinozistischer Pantheismus gemeint. Die Verallgemeinerung dieser Stelle hat in der Forschung zu zahlreichen Fehlurteilen geführt, vgl. z. B. Krolzig: Säkularisierung der Natur (Anm. 12), S. 168. Die Definition könnte sich auch apologetischen Tendenzen in eigener Sache verdanken: Wolff 
aber fällt einer der wichtigsten und größten Unterschiede zur lutherischen Theologie weg. Denn auf der anderen Seite gilt, dass diese lutherische Theologie sehr wohl einen providentia-Begriff entwickelt hatte, der den Herausforderungen der ,neuen Naturwissenschaften' mit ihren mechanischen Erklärungsmodellen gewachsen war.

Mit dem Begriff eines concursus dei, einer "göttlichen Mitwirkung“ hatte die protestantische Schultheologie - es handelt sich wiederum um eine melanchthonische Tradition - das Wirken Gottes auch nach Beendigung der Schöpfung bezeichnet und damit ein mechanisch ablaufendes Naturgeschehen mit der Möglichkeit direkter Eingriffe Gottes verträglich gemacht. ${ }^{43}$ Der Begriff des concursus richtet sich gegen die Möglichkeit eines Fatalismus in dem Sinne, dass Gott nach Vollendung der Schöpfung nicht mehr in den Lauf der Welt eingreifen würde. Wichtig ist dabei die Unterscheidung zwischen einer providentia generalis und einer providentia specialis. Während die providentia generalis im Sinne einer creatio continua, einer fortwährenden Schöpfung, für den allgemeinen Ablauf des Weltgeschehens verantwortlich ist, betrifft die providentia specialis das, was dem einzelnen Menschen zustößt.

Eine besonders anschauliche und deutliche Formulierung dieser concursusVorstellung findet sich in der Lithotheologie des Pfarrers und Physikotheologen Lesser, wenn es dort heißt, „daß Gott bey allen Bewegungen derer natürlichen Dinge concurriere." Auch wenn „die natürlichen Ursachen ihre eigene mitgetheilte Krafft, etwas zu thun, haben; so trägt doch Gott zugleich bey allen ihren Bewegungen das Seinige bey." ${ }^{44}$ Auch wenn etwa bei einem Erdbeben alles „natürlicher Weise", also kausalmechanisch zuginge, würden

diese natürlichen Ursachen von Gottes, des Werck-Meisters und Regierers der Natur, weiser Regierung und straffenden Gerechtigkeit so geleitet, daß er sie zu gewisser von ihm bestimmter Zeit zu seinen Straff-Gerichten brauchet. [...] Gott giebt nemlich in der Natur nicht einen bloßen Zuschauer ab, der alles gehen lässet, wie es gehet; sondern seine Fürsehung schläget sich gar offt ins Mittel, und richtet den ordentlichen Lauff derer natürlichen Ursachen zu ihrem Endzweck, daß man ihren allmächtigen Finger leicht sehen kan. ${ }^{45}$

definiert den Deismus über die Leugnung göttlicher Providenz, um seine eigene „Theologia naturalis" von solchen Vorwürfen abzugrenzen.

43 Vgl. allgemein Hermann Deuser: Art. Vorsehung. In: Theologische Realenzyklopädie Bd. 35. Berlin, New York 2003, S. 302-323, bes. S. 319-321; außerdem Reinhold Bernhardt: Was heißt „Handeln Gottes“? Eine Rekonstruktion der Lehre von der Vorsehung. Münster u. a. 2008, S. $111 \mathrm{ff}$.

44 Lesser: Lithotheologie (Anm. 11), S. 196 (Kapitel III.1.2, §142). Vgl. Trepp: Glückseligkeit (Anm. 14), S. 455.

45 Lesser: Lithotheologie (Anm. 11), S. 22 f. 
Mechanisches Denken und protestantische Providenz-Vorstellungen schlieBen sich damit keineswegs aus. ${ }^{46}$ Die neue ,naturwissenschaftliche' Vorstellung von einem geschlossenen Kausalnexus der Natur kann durchaus mit einem unmittelbaren Wirken Gottes in der Welt vermittelt werden. ${ }^{47}$

Die Unterscheidung zwischen providentia generalis und providentia specialis überbrückt den Gegensatz zwischen dem Wirken allgemeiner, mechanisch gedachter Naturgesetze und der Möglichkeit unmittelbarer Eingriffe Gottes in das Leben des Einzelnen. Die Natur gehorcht im Sinne der providentia generalis allgemeinen Naturgesetzen, wie sie von den Botanikern, Physikern und Chemikern erschlossen werden, gleichzeitig aber werden diese Naturgesetze nur durch die Mitwirkung Gottes in ihrer Gültigkeit erhalten. Der Verweis auf die Botaniker, Physiker und Chemiker ist dabei nicht zufällig, denn es sind gerade die Vertreter dieser ,new sciences', die sich ausdrücklich auf die protestantische concursusVorstellung berufen - so etwa der Chemiker Robert Boyle in seinem Inquiry into the vulgarly received notion of nature (1686). ${ }^{48}$ Bei Boyle reicht die Vorstellung einer göttlichen Allgegenwart sogar bis in die atomare Struktur der Elemente hinein. Dass Isaac Newtons mechanistische Kosmologie die Möglichkeit eines unmittelbaren Eingriffs Gottes in das Weltgeschehen bestritten hätte, gehört zu den großen ätiologischen Mythen der Moderne. Das Gegenteil ist richtig:

The typical picture of Isaac Newton as the paragon of Enlightenment deism - responsible for recasting God as a divine clockmaker with nothing more to do once he had completed his creation - is more than just badly mistaken: it is precisely the opposite of the truth. It cannot simply be corrected; it must be utterly repudiated. ${ }^{49}$

In der 1715 ausgetragenen Auseinandersetzung zwischen Isaac Newton, Samuel Clarke und Gottfried Wilhelm Leibniz bekennen sich sowohl Leibniz wie Newton und Clarke zu einer göttlichen Providenz. ${ }^{50}$ Obwohl die Naturphilosophie sowohl Newtons wie Leibnizens auf mechanischen Gesetzmäßigkeiten beruht, begreift keiner von beiden diese Providenz im Sinne eines mechanischen Fata-

46 Vgl. Trepp: Glückseligkeit (Anm. 14), S. 454. Den vielzitierten Vers von Brockes - „Gott ist kein alter Mann [...]. Er ist ein ewiges allgegenwärtges All“ (Irdisches Vergnügen, ed. Rathje, Bd. 2.1, „Das, durch die Betrachtung der Grösse Gottes, verherrlichte Nichts der Menschen“ S. 343) muss man deshalb auch nicht als pantheistisches Bekenntnis lesen, sondern kann ihn im Sinne der lutherischen concursus-Vorstellung verstehen - also bezogen auf die Allgegenwart Gottes, nicht als Identifikation von Gott und All.

47 Vgl. Bernhard: Handeln Gottes (Anm. 43), $111 \mathrm{ff}$.

48 Vgl. Robert Boyle: A Free Enquiry Into the Vulgarly Receiv'd Notion of Nature. In ders.: Works. Hg. v. Michael Hunter u. Edward B. Davis. London 2000, Bd. 10, S. 437-571.

49 Edward B. Davis: Myth 13: That Isaac Newton's Mechanistic Cosmology Eliminated the Need for God. In: Galileo Goes To Jail and Other Myths about Science and Religion. Hg. v. Ronald L. Numbers. Cambridge, Mass.; London 2009, S. 115-122, hier S. 116.

50 Krolzig: Säkularisierung der Natur (Anm. 12), S. 99-132 zu Natur und providentia bei Newton und Leibniz. Vgl. auch Ulrich L. Lehner: Kants Vorsehungskonzept auf dem Hintergrund der deutschen Schulphilosophie und -theologie. Leiden u. a. 2007, S. 31-58. 
lismus, sondern beide sehen sich auf dem Boden der protestantischen Schultheologie. ${ }^{51}$ Das wiederum heißt: es gibt keinen radikalen Gegensatz zwischen den ,neuen Naturwissenschaften' und der ,alten', christlichen Theologie.

Dieser Punkt ist vor allem deshalb von Interesse, als in der zweiten Hälfte des 18. Jahrhunderts, prominent etwa mit d'Holbachs Systeme de la nature oder de La Mettries L'homme machine mechanistisches Denken tatsächlich mit Atheismus und Materialismus identifiziert zu werden beginnt. Davon aber kann zu Beginn des 18. Jahrhunderts noch keine Rede sein. Das Irdische Vergnügen in Gott demonstriert mit seiner überwältigende Präsenz von Lob- und Dankesformeln, dass die christliche Vorstellung eines persönlichen Gottes sich hervorragend mit den neuen ,naturwissenschaftlichen' Erkenntnissen vermitteln ließ.

Dass Brockes aber auch im Sinne einer providentia specialis vom concursus dei in seinem eigenen Leben überzeugt war, dokumentiert die von ihm selbst verfasste Lebensbeschreibung. Diese Lebensbeschreibung dient im Grunde nur und ausschließlich der Dokumentation des göttlichen Wirkens im eigenen Lebenslauf, illustriert mithin das Wirken der providentia specialis. Brockes listet Jahr für Jahr die Punkte auf, an denen Gott unmittelbar in sein Leben eingegriffen hat: Gefahren, denen er auf Reisen entronnen ist, Unglücksfälle, Naturkatastrophen wie Brände und Überschwemmungen, Krankheiten, Geburten und Todesfälle, aber auch sein politischer Aufstieg in Hamburg. Die Lebensbeschreibung beginnt mit zwei Sätzen, in denen diese Vorstellung ausdrücklich benannt wird:

Anno 1724. d. 12 Aug. habe ich diese meine Lebens Beschreibung in Gottes Nahmen zu entwerffen angefangen, nicht aus eitler Ehre oder andern Absichten, welches ich vor Gott bezeuge, sondern blos um mich einiger von den unzähligen Wolthaten Gottes die er mir zeit meines Lebens erwiesen, mit froher Danckbarkeit zu erinnern. Denselben allerweisesten allermächtigsten und liebreichsten Vater innbrünstig anflehend dass er die übrige Zeit meines Lebens mir ferner gnädig seyn und vor allen bösen so wol mich als die meinen gnädiglich behüten wolle. ${ }^{52}$

Wollte man allerdings aus diesem Glauben an eine göttliche Providenz auf einen schultheologischen, lutherischen Gottesbegriff zurückschließen, wäre dies wiederum eine Vereinfachung. Auch der Gott der „natürlichen Religion“ sorgt sich um seine Geschöpfe und erfreut sich an deren Dank.

51 Krolzig: Säkularisierung der Natur (Anm. 12), S. 132.

52 Brockes: Selbstbiographie (Anm. 31), S. 3. 


\section{Das Irdische Vergnügen in Gott als „natürliche Religion“ in poetischer Form}

Gawlick und Schröder bestimmen den Deismus über zwei Merkmale. Erstens über die Suffizienz einer „natürlichen Religion“, das heißt die Überzeugung, dass das aus bloßer Vernunft erreichbare Wissen von Gott und unseren Pflichten ihm gegenüber hinreicht, um ein gottgefälliges Leben $\mathrm{zu}$ führen. ${ }^{53}$ Zweitens ist mit dieser Suffizienz eine übernatürliche Offenbarung wie die Bibel unnötig geworden, auch wenn ihr eine pädagogische Funktion zugesprochen werden kann, wie prominent etwa später bei Lessing in der Erziehung des Menschengeschlechts.

Übernimmt man diese beiden Kriterien, fallen die Übereinstimmungen zum Werk von Brockes sofort in die Augen. Das Irdische Vergnügen in Gott ist Ausdruck einer „natürlichen Religion“, insofern eigentlich jedes Gedicht aus Vorgängen und Erscheinungen der Natur mittels eines Vernunftschlusses - und das sind auch Analogieschlüsse - auf die Existenz Gottes zurückschließt oder daraus Konsequenzen für die Bedingungen menschlichen Daseins ableitet. Der biblischen Offenbarung widerspricht Brockes zwar nicht explizit, sie spielt aber de facto keine Rolle.

Besonders auffällig ist dabei die Analogie zu Reimarus. Wie sein Freund Reimarus, der sich zeit seines Lebens nicht als Kritiker der christlichen Theologie zu erkennen gegeben hat, gleichzeitig aber in seinen Vornehmsten Wahrheiten der natürlichen Religion den Versuch gemacht hat, diese Wahrheiten allein mittels Vernunftschlüssen und ohne Rekurs auf die biblische Offenbarung zu ermitteln, so ist auch das Irdische Vergnügen in Gott allein dem positiven Aufweis dieser Wahrheiten der „natürlichen Religion“ gewidmet. ${ }^{54}$ Biblische Motive sind im Irdischen Vergnügen eher selten anzutreffen und die theologischen Grundüberzeugungen, die für eine biblische Theologie charakteristisch sind - Trinität, Erbsünde, Erlösung, Sakramente, Apokalypse, Höllenstrafen usw. - tauchen, wie eingangs bereits bemerkt, bei Brockes gar nicht auf. Vor allem aber hat Reimarus eine göttliche Providenz nie und nirgends bestritten, sondern nachdrücklich bejaht. Die Überzeugung eines göttlichen Wirkens in der Natur und im Leben des Einzelnen - also im Sinne einer providentia generalis und specialis - steht für ihn geradezu im Mittelpunkt seines Glaubens.

53 Schröder: Deismus in der Philosophie der Neuzeit (Anm. 41), S. 8. Mark-Georg Dehrmann hat in der Diskussion dagegen darauf hingewiesen, dass der Deismus nicht allein über bestimmte theoretische Positionen bestimmt werden kann, sondern immer auch als ,diskursives Phänomen' verstanden werden müsse. So könne auch ein lutherischer Christ natürliche Theologie betreiben, ohne deswegen als Deist gelten zu müssen, weil seine Vernunft eben durch seinen Glauben erleuchtet ist. Betriebe auf der anderen Seite jemand natürliche Theologie, der gleichzeitig provokativ die Offenbarung ablehnte, würde er von theologischer Seite als ,Deist' identifiziert und angegriffen. Entscheidend wäre damit eher die Frage, welches provokatorische Potential jemand entfaltet als die Frage, welche möglicherweise deistischen Positionen er vertritt. Zum Hintergrund dieses Einwandes, der gerade hinsichtlich Brockes interessant ist, vgl. Dehrmann: Orakel der Deisten (Anm. 41), bes. S. 107 f.

$54 \mathrm{Zu}$ Reimarus jetzt stellvertretend Dietrich Klein: Hermann Samuel Reimarus (1694-1768). Das theologische Werk. Tübingen 2009. 
Wenn Christus im Irdischen Vergnügen keine nennenswerte Rolle spielt, entspricht dies bei Reimarus der Tatsache, dass dieser Christus nicht für den Sohn Gottes hielt, sondern nur für eine Art antiken Weisheitslehrer, ähnlich Sokrates. In seinen physikotheologischen Allgemeinen Betrachtungen über die Triebe der Thiere (1760) vertritt Reimarus eine optimistische Anthropologie, indem er gerade an den „Trieben der Thiere“ deren Funktionalität in der Natur aufweist. Vor allem aber äußert sich Reimarus' optimistische Anthropologie in der Hochschätzung der menschlichen Vernunft, wie sie in einem Lehrbuch der Logik zum Ausdruck kommt (Vernunftlehre, 1756). In der Apologie erklärt Reimarus die Vernunft zum „Prüfe-Stein“ der Offenbarung, setzt also im Gegensatz zu Luther nicht den Glauben an die erste Stelle, sondern die Vernunft:

Eine vernünftige Religion muß vor allen Dingen in jeder sogenannten Offenbarung der Grund- und Prüfe-Stein werden, als welche gewiß durch die Natur von Gott abstammet. Mithin muß uns auch ein ungehinderter Gebrauch der gesunden Vernunft und ihrer Regeln leiten. Ohne Vernunft und deren Gebrauch wären wir, wie das Vieh, gantz und gar keiner Religion fähig $[\ldots] \cdot{ }^{55}$

Analog heißt es im „Glaubensbekenntnis“ von Brockes:

Vom Glauben mach ich, demuthvoll, I Hier mein Bekenntniß offenbar: I Ich glaub, und halte das vor wahr, | Was Gott will, daß ich glauben soll. I Doch giebet die Vernunft mir ein: I Ich müsse dessen, was Gott wolle, | daß man es völlig glauben solle, I ganz überzeugt versichert seyn. ${ }^{56}$

Dieses Glaubensbekenntnis hatte der Patriot - die Hamburger Variante der ,moralischen Wochenschriften', zu deren Mitarbeitern Brockes gehörte - in seinem vierten Stück (1724) formuliert, wenn der ,Patriot' dort als ,vernünftiger Christ' beschrieben wird, der glaubt, „daß die wahre Gottes-Gelahrtheit gar wohl eine kluge aus der gesunden Vernunfft einfliessende Sitten-Lehre, als eine nutzbare Dienerin, hinter sich möge hertreten lassen. " ${ }^{57}$ Wenn Brockes wiederholt versichert, die Offenbarungswahrheiten würden nur deshalb in seinem Werk keine Rolle spielen, weil es ihm eben um die Schöpfung und die Natur ginge, und nicht um die Offenbarungswahrheiten der Theologie und letztere zu verkündigen sei Aufgabe des Pfarrers, ${ }^{58}$ mag man das ernst nehmen oder für einen bloßen Vorwand halten: in jedem Fall bestätigt es die Tatsache, dass die biblische Offenbarung nicht notwendig ist, um Gott zu erkennen.

Die negative, bibelkritische Seite, wie sie Reimarus in der apokryphen Apologie entwickelt, fehlt bei Brockes allerdings. Indem Reimarus seine Apologie aber

55 Reimarus: Apologie (Anm. 2), §10, S. 54.

56 Brockes: Irdisches Vergnügen. Hamburg 1748, Bd. 9, S. 415. Abdruck bei Kemper in der Reclam-Ausgabe (Anm. 4), S. 232.

57 Der Patriot (Anm. 29), S. 27.

58 Vgl. das Zitat unten Anm. 64. 
nie publiziert hat, ist das Fehlen einer explizit deistischen Argumentation bei Brockes kein starkes Gegenargument. Viel wichtiger scheint die Tatsache des öffentlichen Schweigens, die Reimarus und Brockes damit verbindet. Reimarus hat seine Apologie, wie er in deren ersten Sätzen versichert, nicht aus Angst vor Verfolgung nicht publiziert, sondern weil er keinen Anlass zu Streitereien geben wollte:

Lieber mag der gemeine Hauffe noch eine Weile irren, als daß ich ihn, (obwohl es ohne meine Schuld geschehen würde) mit Wahrheiten ärgern, und in einen wütenden Religions-Eiffer setzen sollte. Lieber mag der Weise sich, des Friedens halber, unter den herrschenden Meynungen und Gebräuchen schmiegen, dulden und schweigen, als daß er sich und andere, durch gar zu frühzeitige Äußerung, unglücklich machen sollte. ${ }^{59}$

Dieses irenische Bekenntnis findet seine Analogie bei Brockes, der in den Anhang seiner Pope-Übersetzung folgenden „Sinn-Spruch“ gesetzt hat: „Der Socrates um Rat gefraget: Wie man die Götter bestens preise, I Und ihnen sich gefällig mache? Sprach: folget eures Landes-Weise. ${ }^{\prime 60}$ Das ist genau die ,politische' Haltung gegenüber Glaubensfragen, die die Hamburger Geistlichkeit so scharf kritisiert.

\section{Dichtung als überkonfessionelle Frömmigkeit}

Diese ,politische' Haltung verweist auf einen Punkt, der für alle Anhänger der „natürlichen“ und damit ihrem Selbstverständnis zufolge nach auch „vernünftigen Religion“ von größter Bedeutung ist, nämlich auf den Irenismus als Gegensatz zum dogmatischen Gezänk der christlichen Konfessionen. ${ }^{61}$ Gerade dagegen aber richtet sich die „natürliche Religion“ grundsätzlich und in allen ihren Formen: Mit den konfessionellen Fanatikern, den Glaubenseiferern will man nichts zu tun habe. Auch hier stehen Reimarus und Brockes in einer breiten protestantischen Tradition, die mindestens zurückgeht auf Hugo Grotius De veritate religionis christianae (1622), den ,Klassiker' der irenischen Frömmigkeit, wenn nicht weiter bis auf Erasmus und Melanchthon. Ernst Fischer hat diese Frömmigkeit des Irdischen Vergnügens sehr treffend beschrieben:

Das IVG [also das „Irdische Vergnügen in Gott“] als geistliche Dichtung neuen Zuschnitts zielte darauf ab, einer einfachen, allgemein nachvollziehbaren Frömmigkeit den ,Sitz im Leben' zurückzuerobern, einer Frömmigkeit, die einen christlichen Grundcharakter wahrte, zugleich aber vom Abbau aller im engeren Sinn konfessionellen Elemente geprägt war: Mit Rechtfertigungs- und Gnadenlehre, mit dem gesamten christologisch-

59 Reimarus: Apologie (Anm. 4), Vorbericht §1, S. 41.

60 Brockes: Einige lehrreiche zum Teil eigene, zum Teil übersetzte Sinn-Sprüche. In Pope: Versuch vom Menschen (Anm. 5), S. 203.

61 In diesem Sinne richtungsweisend Ernst Fischer: Brockes' didaktische Poesie als Medium der Orthodoxiekritik, oder: Ursprünge der Aufklärung in Deutschland. In: Beiträge zu Komparatistik und Sozialgeschichte der Literatur. Hg. v. Norbert Bachleitner u. a. Amsterdam 1997, S. 657-681. 
soteriologischen Moment bleiben Kernbereiche genuin lutherischer Glaubensauffassung ausgespart, an die Stelle von Erbschuld, Sündenbewußtsein und Bußgesinnung treten Schöpfungsoptimismus, positive Anthropologie und innerweltlich-eudämonistisches Denken; Natur löst als universelle Legitimationsformel die Bibel ab. ${ }^{62}$

Im selben Sinne hat Hans-Georg Kemper das Irdische Vergnügen als Ausdruck eines „allgemeinen Christentums“ bezeichnet, „das sich im wesentlichen durch eine aus dem ersten Artikel (dem Glauben an den Schöpfer) entwickelte natürliche Religion geeint und befriedet wissen soll." Widersprechen würde ich Fischer und Kemper nur darin, dass dieses „allgemeine Christentum“ sich als ein „Alternativprogramm zur Orthodoxie" versteht. ${ }^{63}$

Reimarus und Brockes verstehen die „natürliche Religion“ nicht als Gegensatz oder auch nur Alternative zur christlichen Glaubenspraxis, sondern als Gegensatz zu den unvernünftigen, aus der Bibel abgeleiteten Überzeugungen der christlichen Dogmatik. Aber diese aus der Bibel abgeleiteten theologischen Überzeugungen waren für sie eben nicht mit der christlichen Glaubenspraxis identisch. Praktizierte Frömmigkeit und theoretische, dogmatische Theologie sind für sie zwei grundsätzlich verschiedene Dinge. Berühmt geworden ist Reimarus' Unterscheidung zwischen der Religion Christi mit ihrem zentralen Gebot der Nächstenliebe und dem Christentum als der korrumpierten, institutionellen Form, die die Apostel aus ihrem Streben nach weltlicher Macht heraus dieser Religion Christi gegeben haben. Die praktizierte Frömmigkeit Christi hat mit der Theologie der christlichen Kirche nicht nur nichts zu schaffen, sie steht in direktem Gegensatz zu dieser. Ganz analog schreibt Brockes, Kern des „vernünftigen Gottesdienstes" sei das Gebot der Nächstenliebe. An derselben Stelle heißt es weiter, über die "Geheimnisse" des Glaubens wolle er, Brockes, dagegen nicht sprechen. Das überlasse er denen, „die sonderlich dazu bestellt, und die, mit mehr geübten Händen, I Die Schätze der Geheimnisse, vermögend, auszuspenden", also den studierten Theologen. ${ }^{64}$

Reimarus hat sich in einem radikalen Widerspruch zu diesem institutionalisierten Christentum gesehen, aber keinesfalls in einem Widerspruch zu dem, was er als den Kern und die eigentliche Praxis der christlichen Frömmigkeit gesehen hat, nämlich das Gebot der Nächstenliebe. Die Ablehnung der christlichen Theologie bedeutet nicht die Ablehnung der richtig verstandenen christlichen Glaubenspraxis. Darin unterscheidet sich Reimarus nicht von seinen zahlreichen

62 Ernst Fischer: Patrioten und Ketzermacher. Zum Verhältnis von Aufklärung und lutherischer Orthodoxie in Hamburg am Beginn des 18. Jahrhunderts. In: Zwischen Aufklärung und Restauration. Sozialer Wandel in der deutschen Literatur (1700-1848). Hg. v. Wolfgang Frühwald u. Alberto Martino. Tübingen 1989, S. 17-47, hier S. 34.

63 Kemper: Nachwort. In: Brockes: Irdisches Vergnügen in Gott (Anm. 4), S. 259-297, hier S. 270.

64 Brockes: Irdisches Vergnügen in Gott. Hamburg 1746, Bd. 8, S. 619 und 620 („Der vernünftige Gottesdienst"). Teilabdruck in der Ausgabe von Kemper (Anm. 4), S. 221-223. 
Nachfolgern im weiteren Verlauf des 18. Jahrhunderts, bis hin zu Immanuel Kant, dessen „kategorischer Imperativ“ auch nichts anderes ist als eine philosophische Reformulierung des christlichen Gebots der Nächstenliebe.

Gerade weil es ihm um eine „natürliche Religion“ als praktizierte, im alltäglichen Leben verwirklichte Frömmigkeitspraxis ging, ist es keine Heuchelei, wenn Reimarus bis an sein Lebensende nach außen hin den Schein eines gläubigen Christen aufrecht erhalten hat. Die richtig verstandene, christliche Frömmigkeitspraxis war identisch mit der Ethik, die aus seiner „natürlichen Religion“ folgte. Das aber heißt, dass Deismus und christliche Frömmigkeit - im Unterschied zu Deismus und dogmatischer Theologie - nicht als Gegensätze verstanden werden dürfen.

Die neun Bände des Irdischen Vergnügens in Gott mit ihren Hunderten von Gedichten, manche sicherlich von zweifelhafter poetischer Qualität, haben immer wieder viel Anlass zu Spott und Ironie gegeben. Versteht man das Irdische Vergnügen in Gott aber nicht als ein im modernen Sinne literarisches Werk, im Sinne eines emphatischen ,Kunst' oder ,Literatur'-Begriffs, sondern als Ausdruck einer religiösen Praxis, als Dokument einer gelebten Frömmigkeitsübung und -ausübung, dann würden diese neun Bände in ihrer Massivität vielleicht etwas verständlicher. Das Irdische Vergnügen in Gott ist Ausdruck einer Meditationspraxis, die selbst wieder Anlass zu einer solchen Meditation geben will. Das Irdische Vergnügen in Gott ist eine Übungsform, mit der eine bestimmte, überkonfessionelle Frömmigkeit gleichermaßen ausgedrückt wie vermittelt und eingeübt werden soll. Die poetische Form - also die Versform, die Reimbindung, die rhetorischen Stilmittel usw. - sind, wie in der Erbauungsliteratur des 17. Jahrhunderts, vor allem als Medium der Vergegenwärtigung und Veranschaulichung zu verstehen. Statt in das Leiden Christi vertiefen Brockes und seine Leser sich allerdings in die Wunder der Schöpfung. Statt den Katechismus auswendig zu lernen, studiert man die Offenbarung Gottes in der Natur. Die meditative Versenkung in die Natur und in die mechanischen, physikalischen, chemischen und biologischen Prozesse, die ihr zugrundeliegen, ist eine religiöse Praxis in dem Sinne, dass hier aus der Natur auf die Bedingungen der Menschlichkeit zurückgeschlossen wird. Aus der Natur - und nicht aus der Bibel - erfahren Brockes und seine Leser, was es heißt, Mensch zu sein, wenn die Natur eine Schöpfung Gottes ist.

\section{8 ,Orthodoxie' zwischen „natürlicher Religion“ und Pietismus}

Die öffentliche Diskussion um 1700 wird nicht im Sinne einer wie auch immer gearteten ,Säkularisierung' als Auseinandersetzung zwischen einer konservativüberkommenen, protestantischen ,Orthodoxie' des ,Barock' und einer liberalprogressiven, ,natürlichen Religion’ der ,Aufklärung' wahrgenommen, sondern als Auseinandersetzung um die Deutung und Begründung bestimmter Glaubensinhalte. Es geht etwa um den Status der Vernunft in ,Religionssachen' überhaupt, um den Status der biblischen Offenbarung (literales Verständnis versus Annahme einer ,Akkomodation' Gottes), um die Deutung ,mythischer' Elemente 
der Bibel (Gottessohnschaft Christi, Trinität, Erbsünde, Ewigkeit der Höllenstra-

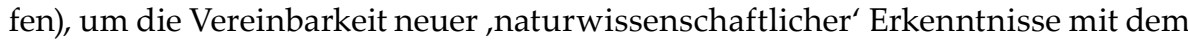
biblischen Wissen (Heliozentrismus) oder etwa um den Status der sogenannten Adiaphora (Spiel, Tanz, Musik, weltliche Dichtung). Der grundlegende Charakter der christlichen Religion im Sinne einer ,Säkularisierung' stand dabei nicht zur Debatte. Bis weit ins 18. Jahrhundert hinein gilt vielmehr der Befund von Ulrich Barth:

Es ist unsachgemäß, die Aufklärungsepoche in pauschaler Form für die Säkularisierung oder Dechristianisierung Europas haftbar zu machen. Die religions- oder christentumsfeindliche Globaltendenz, die ihr von orthodoxen Kritikern und halbgebildeten Bewunderern zugeschrieben wird, läßt sich nur partiell auf das tatsächliche geschichtliche Profil abbilden. ${ }^{65}$

Befreit man sich von den teleologischen Perspektivierungen, die mit den Begriffen der Säkularisierung und der ,Aufklärung' verknüpft sind, erscheint das Irdische Vergnügen von Brockes weniger am Schnittpunkt von ,Barock' und ,Aufklärung', als vielmehr innerhalb einer komplexen theologischen Problemlage, die ihren historisch prägnantesten Ausdruck in den sogenannten , pietistischen Streitigkeiten' gefunden hat. Verortet man das Werk von Brockes im Kontext der theologischen Fragen, die hier verhandelt wurden, springen die Verbindungen ins Auge. Dem strikten Sündenbewusstsein des Pietismus, das in letzter Instanz mit der Erbsünde begründet wird, steht die optimistische Anthropologie der „natürlichen Religion" diametral gegenüber. Der gesamte theologische Nachdruck liegt im Pietismus auf der Gnade Gottes, wie sie sich im Tod Christi offenbart. Der Gläubige ist deshalb aufgefordert, sich in die Wunden Christi zu vertiefen, und nicht in die Wunder der Schöpfung. Das zeitgleich entstandene, poetische Werk des Grafen Zinzendorf, in dessen Aberhunderten von geistlichen Liedern Christus mehr oder weniger in jedem einzelnen Vers beschworen wird, verhält sich komplementär zum Werk von Brockes, in dem der Name Christi kaum einmal genannt wird.

Auch das bestätigt noch einmal die Differenz zwischen einer Theologie, die in der Tradition Luthers den Nachdruck auf die Soteriologie legt, und der Tradition Melanchthons mit ihrem sapientalen Schöpfungsverständnis. Melanchthon jedenfalls gehört für einen Radikalpietisten wie Gottfried Arnold zu den meistgehassten Autoren. Er wurde wesentlich für die Fehlentwicklung der protestantischen Theologie - so jedenfalls stellte es sich für die Pietisten dar - nach dem Tod Luthers verantwortlich gemacht. ${ }^{66}$ Der positiven Bewertung der menschlichen

65 Ulrich Barth: Gott als Projekt der Vernunft. Tübingen 2005, S. 142. Grundsätzlich zur Säkularisierungsthese vgl. Ulrich Barth: Art. „Säkularisierung I“. In: Theologische Realenzyklopädie Bd. 29, S. 603-634.

66 Johannes Wallmann: Das Melanchthonbild im kirchlichen und radikalen Pietismus. In: Melanchthonbild und Melanchthonrezeption in der lutherischen Orthodoxie und im Pietismus. Hg. v. Udo Sträter. Wittenberg 1999, S. 11-24. 
Vernunft in dieser melanchthonischen Tradition steht das Verdikt eines Zinzendorf entgegen, der 1725 eine Begründung der Religion auf der „bloßen Empfindung" fordert, mithin auf der Stimme Gottes im eigenen Inneren:

Die Religion kan ohne Vernunfft-Schlüsse gefaßt werden, sonst könnte niemand eine Religion haben, als der einen aufgeklärten Kopf hätte, und die wären die besten Gottesgelehrten, die am meisten Vernunfft hätten, jenes aber ist nicht glaublich, und auch dieses streitet mit der Erfahrung.

Deswegen gilt: „Die Religion muß eine Sache seyn, die sich ohne alle Begriffe, durch bloße Empfindung erlangen lässet [...]." ${ }^{17}$ Diese Behauptung steht den oben zitierten Äußerungen von Brockes und Reimarus, in denen die Vernunft zur Grundlage der Religion erklärt wird, diametral entgegen. „Der Vernünftige Gottes-Dienst" lautet programmatisch der Titel eines Gedichts im achten Teil des Irdischen Vergnügens. ${ }^{68}$ Im Grunde aber ist das ganze Irdische Vergnügen ein „vernünftiger Gottesdienst".

Ähnlich gegensätzlich verhält es sich mit dem Naturbegriff. In einem Lied Gottfried Arnolds, dessen thematische Nähe zu Brockes nicht größer sein könnte - ein Spaziergang im Garten - führt die Wahrnehmung der Natur nicht zur Erkenntnis der Weisheit und Liebe des Schöpfers, sondern zurück zu Christus:

Es ist ja wahr, im Feld siehts lieblich aus, I Wo alles sich mit Blumen kann bezieren; I Ich aber geh auch hier in meinem Haus I In aller Still mit meinem Lamm spazieren. I Da scheint die Sonn, da singt die Nachtigall, I Da grünts und blühts, da rauschen frische Quellen; I Ich seh da nichts, als Jesum überall, I Sein Engel=Chor erfüllet alle Stellen. I Er ist die Sonn, die Liebe, der Gesang, I Dabei die Hoffnung grünt und reine Wasser springen, I Ist das nicht gnug bei meinem schönen Gang? I Er soll mich ja zum Paradiese bringen. ${ }^{69}$

Dem lässt sich bei Brockes nichts an die Seite stellen. Brockes sieht in seinem Garten weder Jesus, noch hört er Engelschöre. Ausgerechnet der Vergleich des Gartens mit dem Paradies, die bildmächtigste Gartenmetapher der christlichen Tradition, spielt im Irdischen Vergnügen in Gott eine höchst untergeordnete Rolle gerade weil es eben um das „,irdische Vergnügen“ geht, und nicht um das „überirdische“. Auf der anderen Seite sind Zinzendorf oder Arnold nicht an den neuen naturwissenschaftlichen Erkenntnissen interessiert, die für dieses „irdische Vergnügen" eine so große Rolle spielen. Was man über die Natur lernen kann, steht für Zinzendorf und Arnold in der Bibel.

67 Nikolaus Ludwig von Zinzendorf: Der Teutsche Sokrates. In ders.: Hauptschriften. Bd. 1: Schriften des jüngeren Zinzendorf. Hildesheim 1962, S. 289 („,Anhang zum Socrate“).

68 Brockes: Irdisches Vergnügen in Gott. Hamburg 1746, Bd. 8, S. 614-620. Teilabdruck in der Ausgabe von Kemper (Anm. 4), S. 221-223.

69 Gottfried Arnold: Sämmtliche geistliche Lieder. Hg. v. Karl C. Ehmann. Stuttgart 1856, hier S. $281 \mathrm{f}$. („Spaziergang mit Jesu“). 
Es wäre allerdings falsch, dem Pietismus per se ein Desinteresse an der Natur und dem Naturwissen zu unterstellen. Udo Sträter hat im Gegenteil das rege Interesse des Halleschen Pietismus an der Natur aufgezeigt, aus dem im Übrigen ja auch der Physikotheologe Lesser hervorgegangen ist. ${ }^{70}$ Auch hier wird man also differenzieren müssen zwischen den verschiedenen Formen des Pietismus. Brockes, der 1700 in Halle studiert hat, war mit diesen Differenzierungen genauso wie mit den Konflikten zwischen der sogenannten ,Orthodoxie' - wie die protestantische Schultheologie von pietistischer Seite genannt wurde ${ }^{71}$ - und den pietistischen Frömmigkeitsformen zwangsweise schon von dieser Zeit an vertraut.

Insbesondere Hamburg hatte in den Auseinandersetzungen um den Pietismus eine große Rolle gespielt. 1677 bis 1688 hatte in Hamburg der sogenannte erste Theaterstreit getobt, in dem es ursprünglich um die Legitimität geistlicher Stoffe auf der Opernbühne gegangen war. ${ }^{72}$ Ausgangspunkt war die Aufführung eines geistlichen Singspiels zur Eröffnung der Hamburger Oper 1678 gewesen. Auch der erste große Erfolg von Brockes ist ein geistliches Singspiel: Der für die Sünden der Welt gemarterte und sterbende Jesus. Eine Aufführung solcher geistlichen Singspiele in der Kirche war nicht durchzusetzen. Noch 1712 lässt Brockes es privat in seinem Hause aufführen. ${ }^{73}$ Dabei ist die Hamburger Geistlichkeit durchaus gespalten, denn die sogenannten ,Orthodoxen' stehen den geistlichen Singspielen liberal gegenüber. Der Hamburger Pietist Anton Reiser dagegen hatte 1681 in seiner Theatromania das ganze Theater zu einem „Werk der Finsternis“ erklärt. ${ }^{74}$

Grundsätzlich geht es bei den Streitereien um das Theater um die Frage der sogenannten ,Adiaphora' als der ,Mitteldinge', die für sich genommen weder gut noch böse sind und erst im Gebrauch oder Missbrauch gut oder böse werden. ${ }^{75}$ Nach schultheologischer Überzeugung gehören dazu etwa Tanz, Spiel und weltliche Musik, nach pietistischer Überzeugung gibt es diese Adiaphora dagegen nicht. Tanz, Spiel und weltliche Musik sind immer Fallstricke des Teufels. Das

70 Udo Sträter: Zum Verhältnis des frühen Pietismus zu den Naturwissenschaften. In: Pietismus und Neuzeit 32 (2006), S. 79-100. Zu Lesser insbes. Trepp: Glückseligkeit (Anm. 14), S. 372-465.

71 Zur Problematik des ,Orthodoxie'-Begriffs, der erst von Gottfried Arnold aus pietistischer Perspektive geprägt wird, vgl. Theodor Mahlmann: Art. Orthodoxie II. In: Historisches Wörterbuch der Philosophie. Darmstadt 1984, Bd. 6, Sp. 1382-1385.

72 Präzise Zusammenfassung der Ereignisse bei Johannes Geffcken: Der erste Streit über die Zulässigkeit des Schauspiels, 1677-1688. In: Zeitschrift des Vereins für Hamburgische Geschichte 3 (1851), S. 1-33.

73 Vgl. den Überblick von Harold P. Fry: Barthold Heinrich Brockes und die Musik. In: Barthold Heinrich Brockes (1680-1747). Dichter und Ratsherr in Hamburg. Hg. v. Hans-Dieter Loose. Hamburg 1980, S. 71-104.

74 Anton Reiser: Theatromania, oder Die Wercke der Finsterniß. Nissen, Ratzeburg 1681.

75 Reimund B. Sdzuj: Adiaphorie und Kunst. Studien zur Genealogie ästhetischen Denkens. Berlin 2005 hat gezeigt, dass in und mit dieser Adiaphora-Diskussion sich das entwickelt, was später die Ästhetik als Disziplin beanspruchen wird: ein theologisch und moralisch ,wertneutraler' Raum. Genau in diesem Sinne, so meine These, ist die Funktion der Dichtung in der "natürlichen Religion“ von Brockes zu verstehen: als überkonfessionelles, irenisches Medium. 
gesamte Irdische Vergnügen in Gott muss aus dieser Perspektive - eben als ,irdisches Vergnügen' - schon als ein zumindest latent antipietistisches Manifest erscheinen.

Ralph Häfner hat gezeigt, wie Brockes' Preislied auf den Tokayer Wein im Kontext einer Geselligkeitskultur zu verorten ist, die in letzter Instanz auf naturrechtliche Vorstellungen zurückzuführen ist, mithin auf eine optimistische Anthropologie. In geradezu programmatischer Weise übergeht Brockes in diesem Preislied die gesamte religiöse und mythische Dimension, wie sie sich gerade beim Wein aufdrängt. Weder gibt es Anspielungen auf die Bedeutung des Weins im Abendmahl, noch auf Dionysos und die antike Mythologie. Stattdessen wird der Wein zum Symbol für die "Schönheit irdischer Genüsse“, in denen die angeborene sittliche Güte des Menschen zur Erscheinung kommt. ${ }^{76}$ Auch das steht in maximaler Opposition zur pessimistischen Anthropologie des Pietismus - einmal ganz abgesehen vom moralischen Fundamentalismus der Pietisten, der den Genuss von Alkohol per se verbietet und dieses Gedicht von Brockes zu einer Provokation macht. Analog hat Häfner für die Hydrotheologie von Fabricius gezeigt, dass sie als eine "philologische Festkultur" ein conviviales Spiel im Sinne eines grotianischen Irenismus darstellt. ${ }^{77}$

Derselbe Irenismus als Ablehnung von jedem Glaubenseifer und Fanatismus dürfte auch dafür verantwortlich sein, dass sich bei Brockes kaum eine unmittelbare Auseinandersetzung mit dem Pietismus finden lässt. Umso mehr Aufmerksamkeit verdienen deshalb die Verse in einem "Der Atheist“ betitelten Gedicht, in denen Brockes sich die ,orthodoxe' Polemik zu eigen macht. Gegen die pietistischen Weltverächter heißt es dort:

Zum andern, daß man, sonder Grund, uns manche Wollust in der Welt, I Die uns erlaubt, ja gar gebothen, mehr als unchristlich vorenthält, I Wie sonderlich die Pietisten hierin am allermeisten fehlen, I Die, durch die Mischungen des Cörpers und bittere Melancholey I verführet, allenthalben lehren, daß alle Lust verboten sey, I Wodurch sie nicht nur sich und andre, mit stetiger Betrübniß quälen; I Nein, noch dazu, so viel an ihnen, dem Schöpffer Güt und Liebe stehlen I Die doch sein wahres Wesen ist. Es zeiget Schrift, es zeigt Natur, I Daß göttliche Vollkommenheit nur dieß am allermeisten wolle, I Daß man sich, hier sowohl auf Erden, als ewig dort, vergnügen solle, I (Wie hier Geschöpf und Sinne zeigen, der Himmel dort) die klarste Spur. I Der Schöpfer wollte seinen Ruhm, o Lieb! an

76 Ralph Häfner: Bukolik, Physikotheologie, Antimachiavellismus. Barthold Heinrich Brockes' Preislied auf den Tokayer Wein. In: Literatur und Theologie im 18. Jahrhundert. Konfrontationen - Kontroversen - Konkurrenzen. Hg. v. Hans-Edwin Friedrich u. a. Berlin, New York 2011, S. 199-212, hier S. 212.

77 Ralph Häfner: Philologische Festkultur in Hamburg im ersten Drittel des 18. Jahrhunderts: Fabricius, Brockes, Telemann. In: Philologie und Erkenntnis. Beiträge zu Begriff und Problem frühneuzeitlicher ,Philologie'. Hg. v. Ralph Häfner. Tübingen 2001, S. 349-378. 
unsre Freude fügen, I Und ist der beste Gottesdienst, sich Gott zu Ehren, $\mathrm{zu}$ vergnügen. ${ }^{78}$

Diese ,physiologische' Pathologisierung des Pietismus - es handelt sich beim Pietismus im Grunde nicht um eine theologische Überzeugung, sondern um ein medizinisches Krankheitsbild, das man heute als Depression bezeichnen würde - ist für jeden Leser der Zeit eine deutliche Parteinahme. Sie entspricht genau der Kritik des Pietismus, die schon 1699 Friedrich Christian Bücher aus ,orthodoxer' Perspektive in seinem Plato mysticus in Pietista redivivus vorgebracht hatte, wenn dort der ganze Pietismus ebenfalls auf eine melancholische Erkrankung zurückgeführt wurde. ${ }^{79}$ Als Therapeutikum gegen solche Formen der Depression gelten - damals wie heute - Musik, Spiel, geselliges Beisammensein und andere Formen der ,irdischen Vergnügen'. Wer dagegen alleine zu Hause sitzt und nur über seine Sündhaftigkeit meditiert, wird depressiv. Das ganze Irdische Vergnügen in Gott erscheint aus dieser Perspektive als eine diätetische Maßnahme, die geradezu auf Melancholie-Vermeidung abzielt und als solche im Kontext der anthropologischen Psychomedizin der Zeit gesehen werden muss. ${ }^{80}$

Diese Kultur der Geselligkeit, in der Musik, Gesang, Spiel und Scherz eine große Rolle spielen, ist symptomatisch auch für die fast zeitgleich einsetzende Anakreontik, die in der Brockes-Forschung eine merkwürdig geringe Rolle spielt. Deren theologisches, frömmigkeitsgeschichtliches Profil dürfte dem des Irdischen Vergnügens zumindest verwandt sein. Friedrich von Hagedorn lebt in unmittelbarer Nähe zu Brockes und ist mit ihm befreundet. 1747 richtet er ein „Anakreon" betiteltes Gedicht gegen diejenigen Anakreontiker, die in ihren Scherzen zu weit gegangen waren und die Religion verächtlich gemacht hatten. ${ }^{81}$ Gegen sie heißt

78 Brockes: Irdisches Vergnügen in Gott. Hamburg 1740, Bd. 6, S. 373 f. („Der Atheist“). Auf die Stelle und ihre Bedeutung aufmerksam gemacht hat Kemper: Deutsche Lyrik (Anm. 4), Band 5/1, S. 68. Dort in der Folge auch eine historische Einordnung des Melancholie-Vorwurfs.

79 Friedrich Christian Bücher: Plato mysticus in Pietista redivivus. Danzig 1699, S. 9. Zu diesem Kontext nach wie vor grundlegend Hans-Jürgen Schings: Melancholie und Aufklärung. Melancholiker und ihre Kritiker in Erfahrungsseelenkunde und Literatur des 18. Jahrhunderts. Stuttgart 1977. Dort S. 153-155 zu Bücher.

80 Auf diesen diätetischen Kontext hingewiesen hat Mauser: Balsam=Kraft (Anm. 39). Mauser hat denselben Kontext auch schon für die anakreontische Dichtung namhaft gemacht, vgl. Wolfram Mauser: Anakreon als Therapie? Zur medizinisch-diätetischen Begründung der Rokokodichtung. In ders.: Konzepte aufgeklärter Lebensführung. Literarische Kultur im frühmodernen Deutschland. Würzburg 2000, S. 301-329. Zur Anthropologie und Psychomedizin der Zeit vgl. stellvertretend den Band: „Vernünftige Ärzte“. Hallesche Psychomediziner und die Anfänge der Anthropologie in der deutschsprachigen Frühaufklärung. Hg. v. Carsten Zelle. Tübingen 2001.

81 Zum Kontext vgl. Ernst Fischer: „Er spielt mit seinen Göttern“. Kirchen- und religionskritische Aspekte der anakreontischen Dichtung in Deutschland im 18. Jahrhundert. In: Der Kampf der Aufklärung. Kirchenkritik und Religionskritik zur Aufklärungszeit. Hg. v. Jean Mondot. Berlin 2004, S. 71-85. Allgemein zum theologischen Konfliktpotential der Anakreontik vgl. Theodor Verweyen: „Halle die Hochburg des Pietismus, die Wiege der Anakreon- 
es: „Doch höhnt ich nicht die Götter, I Auch nicht der Götter Diener, I Auch nicht der Götter Tempel“:

In Tejos und in Samos I Und in der Stadt Minervens | Sang ich von Wein und Liebe, I Von Rosen und vom Frühling, I Von Freundschaft und von Tänzen; | Doch höhnt ich nicht die Götter, I Auch nicht der Götter Diener, | Auch nicht der Götter Tempel; I Wie hieß ich sonst der Weise? I Ihr Dichter voller Jugend, I Wollt ihr bei froher Muße I Anakreontisch singen, I So singt von milden Reben, I Von rosenreichen Hecken, I Vom Frühling und von Tänzen, I Von Freundschaft und von Liebe; I Doch höhnet nicht die Gottheit, I Auch nicht der Gottheit Diener, I Auch nicht der Gottheit Tempel. | Verdienet, selbst im Scherzen, | Den Namen echter Weisen. ${ }^{82}$

Das „irdische Vergnügen“ musste in einem religiös akzeptablen Rahmen bleiben, und gerade in diesem Punkt waren die ,jungen Wilden' der Anakreontik mit ihrer Religionsspötterei einen Schritt zu weit gegangen - jedenfalls aus der Perspektive der älteren Generation von Hagedorn und Brockes.

\section{Galante ,Orthodoxie': Erdmann Neumeister}

Noch wichtiger als die Anakreontik ist aber für das Werk von Brockes die sogenannte galante Dichtung, die in vielen Punkten der Anakreontik vorausgeht und den unmittelbaren zeitgeschichtlichen Hintergrund des Irdischen Vergnügens bildet. Erdmann Neumeister, der in der Brockes-Forschung immer nur als Theologe und Hamburger Hauptpastor in Erscheinung tritt, teilweise sogar als „,ultraorthodoxer Gegenspieler" von Brockes bezeichnet wird, hatte seine Karriere als galanter Dichter begonnen. 1695 hatte er seinem kritisch kommentierten Verzeichnis deutscher Dichter (De poetis germanicis) und mit seiner Allerneuesten Art zur reinen und galanten Poesie zu gelangen (1695, Druck 1707) zwei wichtige Programmschriften der galanten Dichtung verfasst. ${ }^{83}$ Seine eigenen galanten Gedichte erschienen unter anderem in den ersten Bänden der "Neukirchschen Sammlung", also der programmatischen Sammlung der ganzen Bewegung. In dieser Sammlung sind auch die erotischen Dichtungen Hoffmannswaldaus zu finden, in denen die galante Sinnlichkeit ihre sicherlich radikalste Ausprägung gefunden hat. Nach Franz Heiduk hatte Neumeister sogar entscheidenden Anteil an der Redaktion dieser Bände. ${ }^{84}$ In dem Artikel, den Neumeister Hoffmannswaldau in De poetis

tik“. Über das Konfliktpotential der anakreontischen Poesie als „Kunst der sinnlichen Erkenntnis". In: Zentren der Aufklärung I: Halle. Aufklärung und Pietismus. Hg. v. Norbert Hinske. Berlin 1989, S. 208-238.

$82 \mathrm{Zu}$ Hagedorns Religiosität vgl. Steffen Martus: Friedrich von Hagedorn. Konstellationen der Aufklärung. Berlin, New York 1999, S. 323-415.

83 Helmut K. Krausse: „Die unverbotne Lust“. Erdmann Neumeister und die galante Poesie. In: Daphnis 9 (1980), S. 133-161. Zu Neumeister und der galanten Dichtung vgl. auch den Beitrag von Stefan Elit in diesem Band.

84 Franz Heiduk: Nachwort. In: Erdmann Neumeister: De Poetis Germanicis. Hg. v. F. Heiduk in Zusammenarbeit G. Merwald. Bern, München 1978, S. 505-512, hier S. 509. 
germanicis gewidmet hatte, wird die „ausgesuchte Feinheit“ („elegantia exquisita $^{\prime \prime}$ ) dieser "erotischen Oden“ sogar ausdrücklich hervorgehoben. ${ }^{85}$

Es ist genau diese erotische Lyrik Hoffmannswaldaus, für die Anselm Schubert gezeigt hat, dass in ihr eine optimistische Anthropologie zum Ausdruck kommt, die mit der traditionellen Erbsündenlehre der lutherischen ,Orthodoxie in zentralen Punkten gebrochen hat. ${ }^{86}$ Schubert hat allerdings auch gezeigt, dass diese Auflösung der pessimistischen, christlichen Anthropologie kein Ergebnis der ,Aufklärung' ist, sondern sich aus der protestantischen ,Orthodoxie' heraus entwickelt hat:

Die Kritik an der Erbsündenlehre ist weder eine Erfindung der Aufklärungsphilosophie noch der Aufklärungstheologie des 18. Jahrhunderts, sondern hat eine lange und komplizierte Vorgeschichte in den theologischen Debatten des 17. Jahrhunderts. Die Aufklärung war bei weitem nicht so ,aufgeklärt' und die Orthodoxie bei weitem nicht so ,orthodox', wie die Aufklärer selbst behaupteten. ${ }^{87}$

Dieser Punkt ist für die Einschätzung des „ultraorthodoxen“ Erdmann Neumeister von herausragender Bedeutung. 1697 wird Neumeister als Pfarrverweser in Bad Bibra bestellt, 1715 als Hauptpastor nach Hamburg berufen. Im geistlichen Amt muss Neumeister natürlich mit der weltlichen Dichtung aufhören. Aber dafür, dass Neumeister mit Amtsantritt auch seine Überzeugungen radikal geändert hätte - mithin ein früher, ,galanter` Neumeister von einem späten, ,orthodoxen' Neumeister zu unterscheiden wäre -, gibt es bisher keine Indizien. Im Gegenteil: Die grundlegende Reform der Kirchenkantate, die mit dem Namen Neumeisters verknüpft ist („die Geschichte der Kirchenkantate im 18. Jahrhundert [ist] die Geschichte der Kantate Neumeisterscher Prägung “) ${ }^{88}$ besteht gerade darin, dass Neumeister die Prinzipien der höfischen Oper (die Abfolge von Arie und Rezitativ) auf die Kirchenkantate überträgt. Neumeister gestaltet die Kirchenkantate damit nicht nur nach dem Modell weltlicher Formen, sondern nach dem Modell der Oper als höfisch-galanter Form par excellence. Gerade die Oper, die Neumeister zum Modell der Kirchenkantate gemacht hatte, war in der Debatte zwischen Gottfried Vockerodt und Johann Beer der Stein des Anstoßes für den sogenannten zweiten adiaphoristischen Streit gewesen. Neumeister übernimmt

85 Neumeister: De Poetis Germanicis (Anm. 84), S. 55 (Übersetzung S. 191).

86 Anselm Schubert: Auf der Suche nach der menschlichen Natur. Zur erotischen Lyrik Hoffmannswaldaus. In: Daphnis 25 (1996), S. 423-465.

87 Anselm Schubert: Das Ende der Sünde. Anthropologie und Erbsünde zwischen Reformation und Aufklärung. Göttingen 2002, S. 230 f. Vgl. dagegen den Befund von Dehrmann: Orakel der Deisten (Anm. 41), S. 107, Anm. 82.

88 Alfred Dürr: Die Kantaten von Johann Sebastian Bach. München u. a. 1985, Bd. 1, S. 22. Zu Neumeisters Kantatenform vgl. Irmgard Scheitler: Deutschsprachige Oratorienlibretti von den Anfängen bis 1730. Paderborn u. a. 2005, S. 133-155. 
dabei in vielen Punkten die Position Beers, mit dem er auch persönlich bekannt war. $^{89}$

Diese Neugestaltung der Kirchenkantate hat im sogenannten „Kantatenstreit“ um 1726 zu schwersten Auseinandersetzungen mit dem Pietismus geführt. Nach Vorstellung der Pietisten sollte das kirchliche Lied so schlicht wie möglich gehalten sein, auf jeden Fall aber die Musik allein im Dienst des göttlichen Wortes stehen. Radikal pietistische Forderungen gingen soweit, jede Instrumentalbegleitung oder Instrumentalmusik überhaupt abzulehnen und allein einen möglichst schlichten Kirchengesang zu erlauben. Die hochartifiziellen Formen von Arie und Rezitativ, wie sie Neumeister in die Kirchenkantate eingeführt hat, erschienen aus dieser Perspektive als unverantwortliche ,Spielerei' mit dem Wort Gottes. Es waren dabei unter anderem Bach und Telemann, die die Kantaten Neumeisters vertont haben. Mit Telemann, für dessen Berufung nach Hamburg er zusammen mit Brockes verantwortlich gewesen sein dürfte, arbeitete Neumeister über einen Zeitraum von 35 Jahren zusammen.

Aber nicht nur mit seinen poetischen Werken, sondern vor allem als Theologe gehört Neumeister zu den schärfsten Gegnern der Pietisten. Zahlreiche Predigten, Traktate und Polemiken hat er ihnen gewidmet..$^{90}$ Seine mehrfach aufgelegte Idea Pietismi (zuerst 1712) ist eine Art Index der antipietistischen Polemik in Versform. ${ }^{91}$ Mit genauen bibliographischen Nachweisen belegt Neumeister, wer die zahlreichen pietistischen Irrtümer an welcher Stelle widerlegt hat. Wie Brockes (und später Karl Philipp Moritz im Anton Reiser) macht auch er dem Pietismus zum Vorwurf, dass dessen Erbsünden- und Gnadenlehre zur melancholischen Depression prädisponiere. Mit einer "pessimistischen menschlichen Selbstdeutungspraxis", wie sie Ernst Fischer grundsätzlich dem „orthodoxen Protestantismus“ attestiert, ist diese Polemik - vorsichtig ausgedrückt - schwer zu vermitteln. ${ }^{92}$

Wenn Neumeister ein "Ultraorthodoxer" war, dann muss man im Auge behalten, dass diese "Ultraorthodoxie“ mit der Adiaphora-Lehre äußerst liberale Positionen vertrat, wie man das heute nennen würde. ,Orthodox'-konservativ war man gegenüber den anderen Konfessionen und den innerprotestantischen, pietistischen Tendenzen - also dort, wo es die Reinheit der lutherischen Lehre betraf. Aber zu dieser ,orthodoxen' Lehre gehörte eben auch, dass „,irdische Vergnügen" nicht generell verboten waren. Musik, Spiel und Tanz, Alkoholgenuss und sogar sexuelle Bedürfnisse (die auch Luther selbst ja keineswegs verdammt hatte) waren legitim, solange sie nicht zum Selbstzweck wurden. Von der ,ein-

89 Vgl. Wolfgang Miersemann: Erdmann Neumeisters „Vorbericht" zu seinen „Geistlichen Cantaten“ von 1704: ein literatur- und musikprogrammatisches „Meister-Stück“. Erdmann Neumeister (1671-1756). Wegbereiter der evangelischen Kirchenkantate. Hg. v. Henrike Rucker. Rudolstadt 2000, S. 51-74. Vgl. dort auch den Beitrag von Christian Bunners: Musiktheologische Aspekte im Streit um den Neumeisterschen Kantatentyp, S. 39-50.

90 Zur genaueren Einordnung seiner Polemik vgl. Johannes Wallmann: Erdmann Neumeister der letzte orthodoxe Gegner des Pietismus. In: Erdmann Neumeister (Anm. 89), S. 27-37.

91 Erdmann Neumeister: Idea Pietismi. Frankfurt, Leipzig 1714, S. 56.

92 Fischer: Brockes' didaktische Poesie (Anm. 61), S. 680. 
gebildeten Heiligkeit' und den mystischen, weltfremden Forderungen radikaler Pietisten mit ihrer Verteufelung aller weltlichen Vergnügungen wollten gerade die ,Orthodoxen' nichts wissen. Der ,orthodoxe' Lutheraner hatte seinen Platz und seine ,Berufung' vielmehr in der Welt. Mit den Worten von Brockes:

Sich unsern Erdkreis vorzustellen, I Als wie ein Vorgemach der Höllen, | Und wenigstens, als einen Kerker, den lauter Missethäter füllen, | So alle schmerzlich abzuthun [also verdammt sind]; sind schwarze schwärmerische [also melancholische, pietistische] Grillen. [...] Gedenken, daß der Erdenkreis, zusammt den Menschen und den Thieren, I Sich, nach des weisen Schöpfers Willen, beständig in der Ordnung führen, I Und das seyn, was sie sollen seyn, ist, wie man denken soll, gedacht. ${ }^{93}$

Mit dieser klar gegen den Pietismus gerichteten Vorstellung von einer Schöpfung, in der alles so, wie es ist, seine Ordnung hat, stehen Brockes und seine „natürliche Religion“ sicherlich nicht in einem Gegensatz zur protestantischen ,Orthodoxie'. Im Gegenteil: die zitierten Verse sind ein Bekenntnis zu dieser ,Orthodoxie'.

\section{Politische Gegensätze}

Was auf der anderen Seite aber auch außer Zweifel steht, ist die Tatsache, dass zwischen dem Hamburger Rat, dem Brockes angehörte, und der Geistlichkeit der Stadt ein schwieriges Verhältnis herrschte, das bis weit ins 17. Jahrhundert zurückreichte. Hamburg unterschied sich damit nicht von anderen Städten. Der Rat musste die politischen und ökonomischen Interessen der Stadt im Auge haben, die Geistlichkeit das Seelenheil der Gläubigen. Das einfache Kirchenvolk stand dabei auf Seiten der Geistlichkeit. In diesem politischen Sinne war Neumeister sicherlich kein Ireniker. Vielmehr versuchte die lutherische Geistlichkeit der Stadt die anderen Konfessionen, die in Hamburg sowieso schon eine kleine Minderheit war, mit allen Mitteln zu bekämpfen. Vor allem aber tobte innerhalb der Hamburger Geistlichkeit ein Kampf zwischen ,Orthodoxen' und Pietisten.

Was diese Auseinandersetzungen betraf, war Neumeister ein „ultraorthodoxer" $^{\text {" }}$ Lutheraner. ${ }^{94} 1719$ war es - wohl im Anschluss an eine Predigt Neumeisters - zu Ausschreitung gekommen, bei denen der ,orthodoxe“ „Pöbel“ die katholische Privatkapelle des österreichischen Gesandten zerstört hatte. ${ }^{95}$ Der Kaiser forderte eine kniefällige Entschuldigung des Rates und eine hohe finanzielle Entschädigung. Indem die kaiserliche Protektion für die Stadt von enormer

93 Brockes: Irdisches Vergnügen in Gott. Hamburg 1740, Bd. 6, S. 325 („Eigentlicher Zustand auf Erden").

94 Vgl. Fischer: Patrioten und Ketzermacher (Anm. 62), S. 35-40.

95 Den Begriff „Pöbel“ verwendet Brockes: Irdisches Vergnügen (ed. Rathje, Anm. 1) Bd. 2.1 S. 358 in seiner Rückerinnerung an das Ereignis: „da mich mein Vater-Land I Zum grossen Carl nach Wien gesandt, I Um die, durch unsers Pöbels Schuld, I (So alle Schrancken überschritten) I Mit Recht' verlohr'ne Gnad' und Huld I Uns wieder helffen zu erbitten“. 
Wichtigkeit war, entsandte der Rat eine Gesandtschaft nach Wien, zu der auch Brockes gehörte. Unter anderem durch ein Gedicht von Brockes gelang es dieser Gesandtschaft, den Kaiser zu versöhnen. ${ }^{96}$ Angesichts eines solchen ,Fanatismus dürfte Brockes also durchaus auch an Neumeister gedacht haben, als er 1740 in den Anhang seiner Pope-Übersetzung („Einige lehrreiche zum Teil eigene, zum Teil übersetzte Sinn-Sprüche“) folgende Verse gesetzt hat: „Wenn nicht die Obrigkeit gelindre Triebe nährte, | Und vielen Geistlichen den heilgen Eifer wehrte; | Es würde, dem zu Ehr, der diese Welt gemacht, I Der grosse Theil der Welt, gelassen, umgebracht. ${ }^{\prime 97}$

Was aber in den Hamburger Konflikten zu Tage tritt, ist in erster Linie ein politischer Gegensatz zwischen ,Obrigkeit' und Geistlichkeit, kein theologischer. Der Rat musste ,politisch' handeln und warf der Geistlichkeit dogmatischen Starrsinn vor. Die Geistlichen dagegen warfen dem Rat vor, nur die ökonomischen Interessen zu vertreten und das Seelenheil der Gläubigen aufs Spiel zu setzen. „Geld ist der Hamburger ihr Gott" hat Neumeister an seinen ,orthodoxen' Kollegen Valentin Ernst Löscher geschrieben. ${ }^{98}$ Im Briefwechsel mit Ernst Salomo Cyprian, einem weiteren ,Orthodoxen', findet sich die vielzitierte Stelle, in der sich Neumeister über das „heillose Patriotenkollegium“ beschwert, das aus lauter „Thomasianern“ bestünde, die „der Reinheit der Lehre“ zu nahe treten wollten. ${ }^{99}$

„Thomasianer" bezeichnet die Anhänger von Christian Thomasius, der zu diesem Zeitpunkt wie kein anderer mit weltlich-politischen Klugheitslehren assoziiert wurde. Brockes hat um 1700 ein Jahr bei ihm studiert. Mit ,Patrioten' sind die Herausgeber der gleichnamigen Wochenschrift gemeint, zu denen Brockes gehörte. Wolfgang Martens hat die Frömmigkeit, wie sie der Patriot vertritt, prägnant charakterisiert:

96 Vgl. Fischer: Patrioten und Ketzermacher (Anm. 62), S. 26 ff.; Jürgen Klein: Barthold Heinrich Brockes als Politiker. In: Barthold Heinrich Brockes (1680-1747). Dichter und Ratsherr in Hamburg. Neue Forschungen zu Persönlichkeit und Wirkung. Hg. v. Hans-Dieter Loose. Hamburg 1980, S. 11-44. Dort S. 31 f. zu Brockes' Gesandtschaftsreise 1721 nach Wien in Folge der Unruhen. Außerdem Franklin Kopitzsch: Grundzüge einer Sozialgeschichte der Aufklärung in Hamburg und Altona. Hamburg 1982. Teil 1, S. 297 ff. zu Neumeisters Auseinandersetzung mit dem Rat und dem Patrioten.

97 Barthold Heinrich Brockes: Einige lehrreiche zum Teil eigene, zum Teil übersetzte SinnSprüche. In Pope: Versuch vom Menschen (Anm. 5), S. 202. Auf die Verse aufmerksam gemacht hat Kemper, der sie S. 231 in seine Reclam-Ausgabe (Anm. 4) übernommen hat. Dort im Nachwort S. 265 ff. eine abweichende Darstellung des Verhältnisses von Brockes und Neumeister.

98 „Geld ist der Hamburger ihr Gott“. Erdmann Neumeisters Briefe an Valentin Ernst Löscher. Hg. v. Herwarth von Schade. Herzberg 1998.

99 Erdmann Neumeisters Briefe an Ernst Salomo Cyprian. Hg. v. Thomas Wotschke. 3 Teile. In: Zeitschrift des Vereins für Hamburgische Geschichte Bd. 26 (1952), S. 107-146; Bd. 30 (1929), S. 136-161; Bd. 31 (1930), S. 161-197. Dort Bd. 31 (1930), S. 181. 
Mit Nachdruck wird beteuert, zu den Pflichten eines rechten Patrioten gehöre es auch, seinen Gott recht zu erkennen und das Predigtamt zu ehren, zugleich aber wird eine Abgrenzung der Funktionen des weltlichen Sittenlehrers von denen des geistlichen Amts vorgenommen. Dabei wird dem geistlichen Amt respektvoll der höherer Rang eingeräumt und das eigene Verfahren bescheiden der kirchlichen Verkündigung und Lehre nachgeordnet: die vernünftige Moral sei eine nützlicher Dienerin $(27,14)$, die der Theologie nachfolge. ${ }^{100}$

Es gibt keinen Grund, diese Überordnung der kirchlichen Verkündigung gegenüber der vernünftigen Moral, wie sie der Patriot predigt, für einen Vorwand zu halten, der letztlich der Abwertung des geistlichen Amtes diente. Sie entspricht genau der Haltung, wie sie Brockes in seinem Irdischen Vergnügen praktiziert. Die Verkündigung der Heilswahrheit obliegt der Geistlichkeit, die vernünftige Moral, das ,Gesetz der Natur ' dem „weltlichen Sittenlehrer“. Zwischen beiden gibt es zu diesem Zeitpunkt keinen grundsätzlichen Gegensatz, sondern ein komplementäres Verhältnis.

Das aber spricht nicht dafür, dass zwischen Brockes und Neumeister ein Missverhältnis herrschte, im Sinne von ,christlichem Barock' versus ,säkularer Aufklärung'. Bisher gibt es für ein solches Missverhältnis keine Belege. ${ }^{101}$ Im Gegenteil: 1727 erscheint im zweiten Teil des Irdischen Vergnügens eine „Aufmunterung an andere, zu gleichmäßiger Betrachtung der Werke Gottes", in der an einer der ersten Stellen Neumeister als „,heller Kirchen-Stern“ gepriesen wird. Das Lob des „Erlösungs-Werks“, heißt es dort, ließe sich sehr gut mit dem Lob der Schöpfung verbinden. ${ }^{102}$ Das mag man als kleine Spitze gegen die Geistlichkeit werten, ähnlich dem folgenden Lob der „tapfren Gottes-Helden“ Löscher und Wolf, die „von dem Buch der Welt erstaunten Hörern melden“ ${ }^{103}$ „Erstaunt" sind die Hörer of-

100 Der Patriot. Hg. v. Wolfgang Martens. Bd. 4: Kommentarband. Berlin, New York 1984, S. 37, hier mit Bezug auf das 4. Stück des „Patrioten“. Vgl. auch Wolfgang Martens: Die Botschaft der Tugend. Die Aufklärung im Spiegel der deutschen Moralischen Wochenschriften. Stuttgart 1968, S. 198-217: „Zum Religionsbegriff der Wochenschriften: Die vernünftige Religion“. Zur Gegenposition Neumeisters vgl. Fischer: Patrioten und Ketzermacher (Anm. 62), S. $41 \mathrm{ff}$.

101 Das könnte freilich auch an der Quellenlage liegen. Das umfangreiche theologische Werk Neumeisters, insbesondere die Predigten, harren noch der Erschließung, von archivalischen Quellen ganz abgesehen. Carsten Zelle: Anakreontik und Anthropologie - Zu Johann Arnold Eberts ,Das Vergnügen' (1743). In: Anakreontische Aufklärung. Hg. v. Manfred Beetz und Hans-Joachim Kertscher. Tübingen 2005 rekonstruiert die Auseinandersetzung um eine Serenade Eberts, in der sich ebenfalls ein Konflikt von Rat und Geistlichkeit abzeichnet.

102 Brockes: Irdisches Vergnügen in Gott (ed. Rathje, Anm. 1) Bd. 2.2, S. 858. Zu dem an die Geistlichkeit gerichteten Vorwurf, sie vernachlässige über dem Erlösungswerk das Werk der Schöpfung vgl. auch Fischer: Brockes' didaktische Poesie (Anm. 61), außerdem der Beitrag von Kemper in diesem Band.

103 Brockes: Irdisches Vergnügen in Gott (ed. Rathje, Anm. 1) Bd. 2.2, S. 864. 
fensichtlich, weil sie von Theologen ein solches Lob der Schöpfung nicht erwartet hätten.

Erstaunlich aus heutiger Perspektive aber ist die Tatsache, dass die „ultraorthodoxen" Neumeister, Löscher und Wolf dort in einer Reihe stehen mit Besser, Gottsched, König, Hagedorn, Haller und Richey: also dem, was zu diesem Zeitpunkt die ,Aufklärung' heißt. Das kann nicht nur Heuchelei gewesen sein, denn noch 1756 führte ausgerechnet Gottsched den Vorsitz bei der Trauerfeier Neumeisters. Auch das ist abschließend noch einmal eine Warnung, den Konflikt, der 1774 mit Lessings Veröffentlichung der „Fragmente“ aus Reimarus' Apologie anhebt, auf die Zeit von Brockes und Neumeister zurückzuprojizieren.

Im Gegensatz zu Lessing weiß Brockes noch nicht, dass er der ,säkularen Aufklärung' angehört und Neumeister dem ,christlichen Barock'. 
(C) 2015, Otto Harrassowitz GmbH \& Co. KG, Wiesbaden ISBN Print: 9783447104975 — ISBN E-Book: 9783447194136 


\title{
Un-/Biblischer Schöpfungsgesang \\ Psalm 8 und die Anfänge der deutschen Naturlyrik
}

\author{
Hans-Georg Kemper
}

\section{1 ,Paradoxieentfaltung': ,Vorgeschichte' moderner Naturlyrik mit ,heidnischem' Schöpfungspsalm}

1. Für die deutsche Lyrik der Frühen Neuzeit ist der dominante religionsgeschichtliche Diskurs vielfach gattungskonstitutiv. ${ }^{1}$ So führt die Frage, ob die Naturlyrik in der von Goethe geprägten subjektbezogenen und pantheisierenden Gestalt eine ,Vorgeschichte' im 17. Jahrhundert habe, ${ }^{2} \mathrm{zu}$ einer paradoxen Antwort: Der religionsgeschichtliche Kontext verhindert eine gattungsbildende ,Vorgeschichte', weist aber selbst eine kontinuierliche pantheisierende kosmotheologische Religiosität auf, und zwar insbesondere in den Aneignungen hermetischer Tradition. ${ }^{3}$ Diese wurde in der vormodernen Lyrik vereinzelt, verschieden und

1 Dies habe ich vor allem in meiner Habil.-Schrift und meiner Lyrik-Geschichte nachzuweisen versucht: Hans-Georg Kemper: Gottebenbildlichkeit und Naturnachahmung. Problemgeschichtliche Studien zur deutschen Lyrik in Barock und Aufklärung. 2 Bde. Tübingen 1981. Ders: Deutsche Lyrik der frühen Neuzeit. 10 Bde. Tübingen 1987-2006. Die einzelnen Bände werden nur mit Band- und Seitenzahl sowie Erscheinungsjahr zitiert. Zuletzt zusammenfassend: Hans-Georg Kemper: Geschichte der deutschen Lyrik. Bd. 2: Von der Reformation bis zum Sturm und Drang. Stuttgart 2012.

2 Aufschlussreich im vorliegenden Zusammenhang ist vor allem Volkhard Wels, der sich unter dieser Fragestellung kritisch mit meiner Lyrik-Geschichte auseinandersetzt: Volkhard Wels: Zwischen Spiritualismus, Hermetik und lutherischer „Orthodoxie“. Zu Hans-Georg Kempers Vorgeschichte der Naturlyrik. In: Zeitsprünge. Forschungen zur Frühen Neuzeit 16 (2012), H. 3/4, S. 243-284. Wels kritisiert vor allem das Gewicht, das ich der hermetischen Tradition für diese Entwicklung beimesse, und bringt stattdessen den Einfluss der Melanchthonschen Naturphilosophie und der lutherischen Erbauungsliteratur ins Gespräch. Für diesen als Einladung zu einer allgemeinen Diskussion der Genese deutschsprachiger Naturlyrik gedachten Beitrag bin ich Wels dankbar und möchte mich an der Diskussion beteiligen, zum einen in den Zeitsprüngen selbst, zum anderen in dem vorliegenden Vortrag (die Vortragsform wurde beibehalten), der meine Position exemplarisch an einem rezeptionsgeschichtlichen Beispiel erläutert. - Wels' Begriff der ,Vorgeschichte' verstehe ich - zur Vermeidung impliziter lyrikgeschichtlicher Vorurteile - hier neutral im Sinne von ,Anfängen der deutschen Naturlyrik'. Zu dieser gehören natürlich auch die im Folgenden behandelten Lieder Gerhardts und Gellerts.

3 Zur Diskussion um die Definierbarkeit der vielgestaltigen frühneuzeitlichen Hermetik und ihre Beziehung zur Esoterik vgl. u. a. zuletzt: Kemper: Deutsche Lyrik (Anm. 1) Bd. 4/I (2006), S. 56-65. - Ferner folgende Forschungsberichte: Monika Neugebauer-Wölk: Aufklärung - Esoterik - Wissen. Transformationen des Religiösen im Säkularisierungsprozess. Eine Einführung. In: Aufklärung und Esoterik. Rezeption - Integration - Konfrontation. 
gattungsinhomogen rezipiert, verhalf dann aber den Lyrikern des Sturm und Drang zur Herausbildung ihrer ,Naturlyrik'.4

2. Diese Thesen konkretisiere ich an einem Exempel aus den Psalmenparaphrasen. Diese sind vor allem im Luthertum, dem die wichtigsten deutschsprachigen Autoren der Frühen Neuzeit angehören, zu größter Bibel- und Dogmentreue ver-

Hg. v. ders. unter Mitarbeit von André Rudolph. Tübingen 2008, S. 5-28. - Peter-André Alt: Hermetismus und frühneuzeitliche Literatur. Zur Forschungslage. In ders.: Imaginäres Geheimwissen. Untersuchungen zum Hermetismus in literarischen Texten der Frühen Neuzeit. Göttingen 2012, S. 11-24. - Kristine Hannak: Geist=reiche Critik. Hermetik, Mystik und das Werden der Aufklärung in spiritualistischer Literatur der Frühen Neuzeit. Berlin, Boston 2013, S. 16-36. - Aufschlussreich für den hermetischen Anteil am Naturbegriff der Frühen Neuzeit sind die Beiträge in dem Sammelband: Der Naturbegriff in der Frühen Neuzeit. Semantische Perspektiven zwischen 1500 und 1700. Hrsg. von Thomas Leinkauf unter Mitwirkung von Karin Hartbecke. Tübingen 2005. Einschlägig und ergiebig in unserem Zusammenhang insbesondere Barbara Mahlmann-Bauer: Poetische Darstellungen des Kosmos in der Nachfolge des Lukrez. Bruno - Kepler - Goethe. Ebd., S. 109-186. - Anregend für den vorliegenden Zusammenhang auch Jan Assmann: Moses der Ägypter. Entzifferung einer Gedächtnisspur. Darmstadt 1998. Seine Beobachtungen zur frühneuzeitlichen Rehabilitation des Corpus Hermeticum seit der Renaissance im Kontext einer zur ,natürlichen Religion' der Aufklärung führenden ägyptologischen Moses-Debatte kann ich hier leider nur sporadisch berücksichtigen. Mein Beitrag zeigt, dass sich die Entwicklung zur Konzeptualisierung einer ,natürlichen Religion' im Rückgriff auf die Hermetik unabhängig von der ,Moses-Debatte' auch in anderen - religionsgeschichtlichen sowie naturwissenschaftlichen - Diskursfeldern und von daher auch in literarischen Texten und Positionen vollzieht.

4 Im Sturm und Drang ergeben sich allerdings neue Gattungsprobleme. Herders ,holistische' Begründung der Naturpoesie richtete sich gegen die ,gedrechselte' humanistische und poetik- sowie rhetorik-orientierte ,Letternkultur'. Naturpoesie war für ihn eine sinnliche, aus dem ,Herzen' stammende und für die ,Herzen' verfasste orale Poesie, wie sie als nationale Volkspoesie überliefert war und erneuert werden sollte. Daraus entstehende Gattungen wie das Erlebnisgedicht oder die Natur- und Liebeslyrik waren deshalb oft komplex verschwistert (wie sich am Schluss noch zeigen wird). Im Übrigen ist vor allem beim Typ des Erlebnisgedichts die Fixierung auf Herder problematisch; denn neben ihm (und seiner frühen Rigaer Lyrik) haben auch Lavater und Lenz unabhängig und z. T. vor Goethe diesen "Typ' geschaffen. Und keiner dieser Autoren beruft sich im Zusammenhang mit deren Entstehung auf Herder, sondern alle weisen auf denselben pietistisch-hermetischen Kontext hin, dem sie selbst - auch in ihrer biographischen Konstellation - entstammen. Vgl. dazu Kemper: Deutsche Lyrik (Anm. 1). Bde. 6/II u. 6/III (2002). - Generell ist es problematisch, moderne Begriffe von Lyrik oder deren Teilgattungen ungeprüft als Orientierungs- und OrdnungsKategorien auf die Lyrik der Frühen Neuzeit zu übertragen. Dafür bietet gerade die Naturlyrik eindrucksvolles Anschauungsmaterial. Aber auch umgekehrt erfasst eine in der Frühen Neuzeit verbreitete Teilgattung aus der Geistlichen Poesie wie die Psalmenparaphrase bei zu enger Orientierung an den biblischen Gattungsvorgaben gerade nicht die entscheidende Innovation individueller Abwandlung: Wie sich zeigen wird, bleibt oftmals der Kerninhalt des Prätextes als Hauptstimulans der poetischen Rezeption erhalten, diese selbst wandert aber in der subjektiven Aneignung und deren dichterischer Form aus der engen Paraphrasentradition aus. Im Übrigen aber eignet sich diese Gattung der Bibelpoesie und ihre Entwicklung als historischer Wegweiser zu Herders neuem Lyrik-Verständnis. Denn: „Alle wichtigen Merkmale der ,Naturpoesie' leitet er aus der ,Bibel-Poesie' her" (Kemper: Deutsche Lyrik [Anm. 1] Bd. 6/II (2002), S. 153. Vgl. dazu ebd., S. 252-277). 
pflichtet, denn der $P_{s a l t e r}{ }^{5}$ repräsentiert neben dem Hohenlied ${ }^{6}$ die Bibelpoesie und damit die vom Heiligen Geist selbst inspirierten Vorbilder der im Luthertum gattungsreich gepflegten geistlichen Poesie. Indessen lädt der Psalter paradoxerweise wiederum vor allem mit seinen Schöpfungsliedern ${ }^{7}$ auch zur Aneignung her-

5 Insgesamt besaßen die 150 meist David zugeschriebenen Gesänge gerade als biblische Liedsammlung auch im Calvinismus mit seinem (Hugenotten)-Psalter eine exzeptionelle Vorbildfunktion. Vgl. dazu: Luther, Zwingli, Calvin in ihren Liedern. Hrsg. v. Markus Jenny. Zürich 1983, S. 279. Luther wählte aus dem Psalter als Vorlagen für seine aktualisierenden Bekenntnis- und Verkündigungs-Lieder bezeichnenderweise keine Schöpfungs-, sondern sieben Bußpsalmen und den ,Anti-Welt'-Psalm 46 („Ein feste burg ist vnser Gott“) mit dem berühmt-berüchtigten „Las faren dahin“. Vgl. Martin Luther: Die deutschen geistlichen Lieder. Hrsg. von G. Hahn. Tübingen 1967, S. 62 f. - Wegen des hohen Stellenwerts des Psalters im protestantischen kirchlichen Kultus und in der geistlichen Poesie gab es in der Frühen Neuzeit eine intensive poetologische Diskussion über diese Bibelpoesie: von ihren stilistischen und rhetorischen Qualitäten im 17. Jahrhundert bis zu ihrer Einschätzung als ,einfältiger “ „Erlebnislyrik“, als Modell der Oden und Medien der Ausdrucksästhetik sowie inspirationsgeleitetem Inbegriff der Poesie im 18. Jahrhundert. Vgl. den Überblick von Dietmar Till: Die Psalmen als Modell poetischer Rede. Umrisse eines Diskurses, ca. 1650 - 1850. In: Morgen-Glantz 22 (2012), S. 35-54. - Einen Gesamtüberblick bieten Inka Bach/Helmut Galle: Deutsche Psalmendichtung vom 16. bis zum 20. Jahrhundert. Untersuchungen zur Geschichte einer lyrischen Gattung. Berlin New York 1989. - Zur poetischen Psalmenrezeption im 17. Jahrhundert vgl. Irmgard Scheitler: Das Geistliche Lied im deutschen Barock. Berlin 1982, S. 155 ff., u. a. auch zu Opitz' Übersetzungen von 61 Psalmen (darunter nicht Psalm 8) und zu Weckherlins kompletter umfangreicher Vers-Übertragung. Weitere Psalmenparaphrasen von Autoren des 17. und 18. Jahrhunderts behandeln die Bände 4 und 6 der Deutschen Lyrik (Anm. 1). - Von zentraler Bedeutung für das Lyrik-Verständnis des Sturm und Drang ist Herders große Abhandlung Vom Geist der Ebräischen Poesie mit zahlreichen poetischen Translationen von Psalmen: Johann Gottfried Herder: Vom Geist der Ebräischen Poesie. In ders.: Schriften zum Alten Testament. Hrsg. von Rudolf Smend. Frankfurt a. M. 1993, S. 661-1301. Zu den Psalmen ebd., S. 1189 ff., 1246 ff.

6 Vgl. dazu u. a. Kemper: Deutsche Lyrik (Anm. 1) Bd. 4/II (2006), S. 62 ff., 166 f. u. ö. Ders.: Hermetisch-poetischer Liebeszauber. Von der mystischen "Jeßus-wollust" zur "Passion' der Liebesehe. In: Konzepte des Hermetismus in der Literatur der Frühen Neuzeit. Hrsg. v. Peter-André Alt u. Volkhard Wels. Göttingen 2010, S. 393-432, hier S. 407 ff. (mit weiterer Lit.). Unter dem Stichwort ,Traditionsbildungsfunktion' zeigt Rüdiger Zymner in einer Fallstudie auch an der poetischen Rezeption des Hohenliedes eine Entwicklung auf, die von der Traditionsaneignung bis zur Traditionssubversion führt: Rüdiger Zymner: Funktionen der Lyrik. Münster 2013, S. 150-165.

7 Unter den Hymnen, Klagen und Dankliedern finden sich auch einige Schöpfungspsalmen. Im engen Sinne zählen dazu nur vier Lieder (Ps. 8, 19A, 104, 148), die zur Gattung des Hymnus gehören. Da dieser schon im Psalter in seinem Hauptteil die ruhmwürdigen Taten Gottes aus Natur und Geschichte ,erzählt', enthalten auch weitere Psalmen größere oder kleinere Passagen über Jehovas Wirken in seiner Schöpfung (z. B. Ps. 33, 6 ff.; 65, 7 ff.; 95, 4 ff.; 95, 4 ff.; 135, 6 ff.; 136, 5 ff.; 146, 6 ff.). Vgl. dazu Arthur Weiser: Die Psalmen übersetzt und erklärt. 6. Aufl. Göttingen 1963, S. 40. Vor allem den Psalmen 8, 19A (V. 1-7) und 104 werden Übernahmen aus altägyptischen Weisheitssprüchen und Schöpfungsmythen attestiert (ebd., S. 40 f.; Kurt Galling: Psalmen. I. Im AT. In: RGG 3. Aufl. Bd. 5, Sp. 672-686, hier Sp. 673, 676 f.). Für Assmann und andere Ägyptologen gilt Psalm 104, V. 20-30 sogar als Übersetzung des Großen Hymnus Echnatons, des berühmten revolutionären Stifters eines streng monotheistischen Kults um einen neuen Gott des Lichts (Echnaton wurde deshalb auch als ,„ägyptischer Moses" bezeichnet). Nachweis der Parallelstellen bei Assmann (Anm. 3), S. 255-259. Der ge- 
metischer Naturauffassungen ein. Als Beispiel dazu dient im Folgenden der von altägyptischer Weisheit und lyrischer „Paradoxieerwartung“ geprägte Psalm $8 .^{8}$

2. Herr, unser Herrscher, wie herrlich ist dein Name in allen Landen, du, den man lobet im Himmel! [der du zeigst deine Hoheit am Himmel!]

3. Aus dem Munde der jungen Kinder und Säuglinge hast du eine Macht zugerichtet um deiner Feinde willen, dass du vertilgest den Feind und den Rachgierigen.

4. Wenn ich sehe die Himmel, deiner Finger Werk, den Mond und die Sterne, die du bereitet hast;

5. was ist der Mensch, dass du seiner gedenkst, und des Menschen Kind, dass du dich seiner annimmst?

6. Du hast ihn wenig niedriger gemacht denn [als] Gott, und mit Ehre und Schmuck hast du ihn gekrönt. [mit Ehre und Herrlichkeit hast du ihn gekrönt.]

7. Du hast ihn zum Herrn gemacht über deiner Hände Werk; alles hast du unter seine Füße getan:

8. Schafe und Ochsen [Rinder] allzumal, dazu auch die wilden Tiere,

9. die Vögel unter dem Himmel und die Fische im Meer und was im Meer geht [alles, was die Meere durchzieht].

10. Herr, unser Herrscher, wie herrlich ist dein Name in allen Landen!

Der Mensch also - ein Nichts und ein Gott im Angesicht der Schöpfung! ${ }^{9}$ Seine ,Würde ${ }^{10}$ erscheint als paradoxale Einheit von nichtigem Wesen und Gottes Eben-

samte Wortlaut des auch Sonnengesang Echnatons genannten Hymnus aus der Zeit um 1350 v. Chr. in: Altägyptische Dichtung. Ausgewählt, übersetzt. u. erläutert von Erik Hornung. Stuttgart 1996, S. 129-133. Vgl. dazu ebd., S. 183. Zu Übernahmen der altägyptischen Weisheit im AT vgl. auch die Zusammenfassung in: Altägyptische Weisheit. Lehren für das Leben. Eingeleitet, übersetzt u. erläutert von Hellmut Brunner. Zürich und München 1988, S. 88 f.

8 Vgl. dazu Weiser (Anm. 7), S. 94 ff. - Zum Begriff „Paradoxieerwartung“ als Spezifikum vor allem epigrammatisch-arguten, widersprüchlichen Sprechens in hermetik-affiner Poesie vgl. Peter-André Alt: Imaginäres Geheimwissen (Anm. 3), S. 181 ff. Der Wortlaut von Psalm 8 wird zitiert nach der Übersetzung Martin Luthers in der revidierten Fassung von 1953 [in eckigen Klammern Abweichungen in der aktuellen revidierten Fassung von 1984].

9 Dieses schöpfungstheologische Paradox steht in keinem Zusammenhang mit Luthers soteriologischem Paradox des Menschen als eines "simul iustus et peccator“.

10 Giovanni Pico della Mirandola hatte in der Renaissance in seiner berühmten Rede Über die Würde des Menschen ein in freier Selbstbestimmung erreichbares Menschenbild mit der Alternative zwischen ,Nichts' und ,Göttlichkeit' entworfen. Als Ziel proklamierte er, „unter Anspannung aller Kräfte“ "das Höchste zu erreichen“ und „in die Nähe der erhabenen Gottheit zu eilen." Giovanni Pico della Mirandola: De dignitate hominis. Lateinisch und Deutsch. Eingeleitet von Eugenio Garin. Bad Homburg v. d. H., Berlin, Zürich 1968, S. 28 f. Gleich zu Beginn berief sich Pico auch auf Hermes Trismegistus. Dieser habe den Menschen wegen seiner Sonderstellung unter allen erschaffenen Wesen ein "magnum miraculum" genannt. Ebd., S. 26. Tatsächlich heißt es im Corpus Hermeticum: „Denn der Mensch ist ein göttliches Lebewesen und lässt sich auch nicht mit den anderen Lebewesen vergleichen, die auf der Erde leben, sondern nur mit denen oben im Himmel, die Götter genannt werden. [...] Deshalb muß man es auszusprechen wagen, dass der irdische Mensch ein sterblicher Gott 
bild. Rezeptionsgeschichtlich überforderte dieses Paradox das dem kirchlichen Kultus nahe stehende geistliche Lied (Kap. 2), inspirierte aber in der privaten Lese- und Erbauungspoesie Autoren zur subjektiven Auslegung, die zu Varianten moderner Naturlyrik führt (Kap. 3 und 4). Dazu regt der Psalm auch mit wichtigen Konstitutionsbedingungen an: Er praktiziert mit dem Lobpreis Gottes „in allen Landen“ und damit auch über die Glaubens- und Konfessionsgrenzen hinweg, eine ,natürliche Theologie' als Gottes-Dienst in der Natur durch ein reflektierendes und emotionales Ich, das sich in Gottes Natur als deren Objekt und Subjekt ohne Angst vor der christlichen Todsünde des,eritis sicut Deus' in Vers 6 [Gen. 3, 5]) erkundet.

\section{Lutherische Natur-Allegorese und Schöpferverehrung (Luther, Gerhardt, Gellert)}

1. Die kosmotheistischen Häresien dieses Psalms forderten zu seiner Umdeutung heraus, und dies schon im Neuen Testament. Jesus selbst berief sich im Anschluss an die Tempelreinigung und die ersten Wunder, die auch Kinder zur Huldigung: „Hosianna dem Sohn Davids!“ veranlassten, zur Rechtfertigung gegenüber den zürnenden Hohenpriestern auf Ps. 8, 3 und verstand sich damit als göttlichen Adressaten des Psalms (Mt. 21, 15 f.). Paulus wiederum, der zugleich die ,natürliche Theologie' scharf kritisiert, ${ }^{11}$ wie auch der Autor des Hebräerbriefes bezie-

und der Gott am Himmel ein unsterblicher Mensch ist.“ Das Corpus Hermeticum Deutsch. Übersetzung, Darstellung und Kommentierung in drei Teilen. Im Auftrag der Heidelberger Akademie der Wissenschaften bearbeitet $u$. hrsg. von Carsten Colpe $u$. Jens Holzhausen. Teil I: Die griechischen Traktate und der lateinische ,Asclepius'. Übersetzt. u. eingeleitet von Jens Holzhausen. Stuttgart-Bad Cannstatt 1997, S. 113. Diese Sammlung wird im Folgenden mit den Titel-Initialen CHD und der jeweiligen Seitenzahl zitiert. - Vielleicht nicht zufällig treffen also im Psalm 8 und im Corpus Hermeticum zwei ursprünglich aus Ägypten stammende Weisheiten zusammen. Jedenfalls bleibt die von Moses verdrängte kosmotheistische Alternative der altägyptischen Religion - wie auch dieser Text zeigt - an einigen Stellen des AT präsent, vielleicht weil Jahwe bei seiner Aufwertung vom nationalen Geschichts-Gott Israels zum höchsten Welt-Wesen auch die Funktion des Herrschers über den Kosmos übernehmen musste. Assmanns Folgerung indes, Gott müsse dann auch „seine transzendente Außerweltlichkeit aufgeben und eine immanente kosmische Gottheit werden" (Assmann [Anm. 3], S. 79), ist nicht zwingend. Gerade wenn Gott wie in Psalm 8 einen irdischen Stellvertreter einsetzt, kann er seine Transzendenz bewahren. Diese Lösung fand auch Echnaton, der sich allein als irdischer Stellvertreter des Sonnengottes Aton verstand und damit wie sein ,konträrer Nachahmer' Moses jeglichen Polytheismus und alle Idolatrie unterband. Wie bei Echnaton, aber auch in der vorausgehenden und folgenden altägyptischen Religiosität fehlt in Psalm 8 überdies ein Sündenbewusstsein und das „Leiden an der Sünde“, das nach Assmann als "wichtigstes Motiv" den biblischen Offenbarungs-Monotheismus kennzeichnet (Assmann [Anm. 3], S. 282).

11 Die Möglichkeit einer, natürlichen Theologie' wurde einerseits in der Bibel - vor allem wieder in den Schöpfungspsalmen - praktiziert: „Herr, wie sind deine Werke so groß und viel! Du hast sie alle weislich geordnet, und die Erde ist voll deiner Güter." (Ps. 104, 24). Oder: „Die Himmel erzählen die Ehre Gottes [...] Es ist keine Sprache noch Rede, da man nicht ihre Stimme höre." (Ps. 19, 2, 4). Danach hatten also auch die Heiden in ihren Naturreli- 
hen ihrerseits den „Menschen“ im ,sensus litteralis' des Gesangs allein auf den „Menschensohn“ Christus (1. Kor. 15, 27; Hebr. 2, 6-9), den Gott hier erhöht und als Schöpfer und Erhalter der Welt eingesetzt habe. Martin Luther nutzte diese Umdeutung in seiner Übersetzung (1545) zum neuen christologischen Wortsinn: „6. Du wirst jn lassen eine kleine zeit von Gott verlassen sein/ Aber mit ehren vnd schmuck wirstu jn krönen. 7. Du wirst jn zum Herrn machen vber deiner hende werck/ Alles hastu vnter seine Füsse gethan. “ ${ }^{12}$ Damit war der Psalm in die Soteriologie integriert, und sie bestimmte auch Luthers Gesamtdeutung des Psalters als einer „kleinen Biblia“: „VND solt der Psalter allein deshalben theur vnd lieb sein/ das er von Christus sterben vnd aufferstehung/ so klerlich verheisset/ vnd sein Reich und der gantzen Christenheit stand vnd wesen furbildet." ${ }^{13}$ Philipp Melanchthon hat in seiner Paraphrase des achten Psalms die Kirche als sprechendes Subjekt eingesetzt und zugleich ebenfalls auf „Christus exaltatus [...] super omnes creaturas" bezogen. ${ }^{14}$ - Auch die "Psalmenexegeten des 17. Jahrhunderts" „betonen“ bei Psalm 8 „immer die Funktion von Christi Erlösungswerk: denn nur durch die redemptio könne der Schöpfer überhaupt die schwachen Menschen nach dem Sündenfall zu sich und seiner Erkenntnis hinaufziehen." ${ }^{15}$

Selbst Johann Arndt, der bedeutendste und einflussreichste Erbauungsschriftsteller des Luthertums in der Frühen Neuzeit, in dessen Wahrem Christentum der Natur immerhin ein Heilsweg zu Gott zugestanden wird, insistiert in seinem Gantzen Psalter Davids bei der Auslegung von Psalm 8 in drei Predigten auf dessen strikt christologischer und ekklesiologischer Deutung, ja die Predigten II und

gionen eine Gotteserkenntnis. Das war für den Alleinvertretungsanspruch der jüdischen und christlichen Soteriologie gefährlich. Deshalb machte Paulus dieser Art von natürlicher Gotteserkenntnis den Heiden zum doppelten Vorwurf. „Denn was man von Gott weiß, ist ihnen offenbar", „nämlich an der Schöpfung der Welt; also dass sie keine Entschuldigung haben." (Rm 1, 19 f.). Sie hätten sich von daher zu jener Wahrheit bekehren lassen müssen, die in der Natur nicht zu finden ist, sondern nur in der Heilslehre von Christus. Weil sie aber in ihrer scheinbaren „Weisheit" verharrten, so Paulus, „sind sie zu Narren geworden und haben verwandelt die Herrlichkeit des unvergänglichen Gottes in ein Bild gleich dem vergänglichen Menschen und der Vögel und der vierfüßigen und der kriechenden Tiere", womit auch an das Goldene Kalb und die ägyptische Idolatrie erinnert sein mag ( $\operatorname{Rm~1,~22~f.)~}$ Gotteserkenntnis aus der Natur ist so allenfalls im Vorhof des Tempels geduldet und verfälscht ohne die in der Schrift offenbarte heilsgeschichtliche Wahrheit Gott zu einem in den mosaischen Geboten untersagten ,Bild' aus der Natur und verführt damit zu Selbstvergottung und mythologischer Abgötterei. Von daher und vom hohen Stellenwert des Römerbriefes in der lutherischen Theologie erklärt sich die besondere Wachsamkeit der Orthodoxie gegenüber allen Versuchen, Gott auch aus der Natur oder gar nur aus der Natur zu erklären oder gar zu verherrlichen.

12 Martin Luther: Biblia. Das ist die gantze Heilige Schrifft Deudsch auffs new zugericht. Wittenberg 1545. Hrsg. von Hans Volz unter Mitarbeit von Heinz Blanke. Textredaktion Friedrich Kur. 3 Bde. München 1974. Hier Bd. 2, S. 972 f.

13 So in seiner Vorrede auf den Psalter. Luther: Biblia (Anm. 12), S. 964. Der Psalter sei auch „ein Exempelbuch von der gantzen Christenheit oder allen Heiligen zusamen" (ebd.).

14 Zit. in: Mahlmann-Bauer (Anm. 3), S. 165. Zu Calvin ebd.

15 So-mit Kommentarbeispielen aus lutherischer und calvinistischer Feder - Mahlmann-Bauer (Anm. 3), S. $165 \mathrm{f}$. 
III behandeln eigens und in systematischer Form alle wichtigen Lehrstücke der lutherischen Christologie. ${ }^{16}$ Und im Bezug darauf gibt Arndt auch in seiner ersten Predigt (zu Ps. 8, 4) die grundsätzlich allegorische Naturbetrachtung in Erbauungsschrifttum und Kirchenlied vor: „Der natürliche Himmel ist ein schön Bilde des geistlichen Himmels/ der heiligen Christlichen Kirchen. ${ }^{17} \mathrm{Im}$ Zusammenhang damit erläutert ein weiterer Abschnitt im Blick auf Ps. 8, 5 die Lehre von der ,vanitas vanitatum': „Die gantze H. Schrifft ist gerichtet auffs Erkäntniß unseres Elendes und Nichtigkeit/ und auffs Erkäntniß der Gnaden Gottes." ${ }^{18}$ - Dies illustriert exemplarisch die Schwierigkeiten für Autoren innerhalb des Luthertums, nicht etwa nur die als „heidnisch“ verworfenen kosmotheistischen Anschauungen, sondern auch unverstellte Naturwahrnehmungen oder selbst christliche Schöpfungslehren gegenüber der zentralen Stellung der Heilslehre zu ,Wort’ zu bringen.

2. In Paul Gerhardts Schöpfungsliedern „Die güldne Sonne“ und „Sommergesang“ („Geh aus mein Herz und suche Freud“) ${ }^{19}$ meldet sich nach dem Ende des Dreißigjährigen Krieges ein positives lutherisches Naturgefühl zu Wort. ${ }^{20}$ Aber in dem streng bibelbezogenen Typ des Gerhardtschen ,Frömmigkeitsliedes dienen die Schöpfungspsalmen ganz im Sinne Luthers und Arndts nur als Signaturen und Evidenz-Exempel für soteriologische Hoffnungen. ${ }^{21}$ In dem „Mor-

16 Johann Arndts Auslegung des gantzen Psalters Davids (zuerst 1617) wird hier nach der FolioAusgabe Der gantze Psalter Davids, des H. Königs und Propheten, in 462. Predigten außgelegt und erkläret (Frankfurt a. M. 1701) zitiert. Die drei Predigten über Psalm 8 ebd., S. 62-70. Ich danke Wolfgang Sommer, Neuendettelsau, herzlich für die Übermittlung ihres Wortlauts. - Selbst in den späteren revidierten Fassungen der Lutherbibel mit dem eingangs zitierten korrekten Wortlaut hat sich in den Überschriftskolumnen noch die christologische Deutung gehalten: "Gottes Größe in der Schöpfung. Des Menschensohnes Niedrigkeit und Hoheit." So in der Ausgabe von 1953. Immerhin hat sich in den neueren Bibelausgaben der Wortsinn durchgesetzt, auch in der Zürcher Bibel. Psalm 8, 6 lautet hier: „,Du hast ihn wenig geringer gemacht als Gott, mit Ehre und Hoheit hast du ihn gekrönt. Du hast ihn zum Herrscher gesetzt über die Werke deiner Hände."

17 Arndt: Der gantze Psalter (Anm. 16), S. 64.

18 Arndt: Der gantze Psalter (Anm. 16), S. 62.

19 Ulrich Kittstein gelangt bei diesem Lied zu dem Resultat: „So fügt sich die anfangs so breit ausgemalte schöne Natur letztlich in eine hierarchische Ordnung ein, die dieser Natur als einer vergänglichen, bloß irdischen Erscheinung lediglich einen untergeordneten Rang zugesteht." Ulrich Kittstein: Deutsche Naturlyrik. Ihre Geschichte in Einzelanalysen. 2. Aufl. Darmstadt 2012, S. 27. Aber auch in allen anderen von ihm kurz behandelten Naturgedichten des Zeitraums bestätigt sich für Kittstein stereotyp die ,vanitas'-Erfahrung des ,Barock'

20 Auch wo der Schöpfer in den Katastrophenjahrzehnten um 1600 zornig und drohend in seiner Schöpfung agierte, da deuteten die lutherischen Kirchenlieder dies als göttliches Heilshandeln, womit er seine Lutheraner strafend zur Buße bewegen wollte. Vgl. Kemper: Deutsche Lyrik (Anm. 1) Bd. 2 (1987), S. $227 \mathrm{ff}$.

21 Die erste Strophe von "Die güldne Sonne“ spielt auf den Sonnenhymnus von Psalm 19A an, der im ptolemäischen Sinne den Umlauf der Sonne um die Erde beschreibt (Ps. 19, 7) und zugleich allegorisch heidnisch-ägyptische Sonnengott-Bilder verwendet („und dieselbe geht heraus wie ein Bräutigam aus seiner Kammer und freut sich wie ein Held zu laufen den Weg“; Ps. 19, 6; vgl. Weiser [Anm. 7], S. 134 f.). Doch vermeidet Gerhardt jeden mythologischen Zungenschlag und einen eindeutigen Bezug zum ptolemäischen Weltbild 
genlied“ („Die güldne Sonne / Voll Freud und Wonne / Bringt unsern Grenzen/ Mit ihrem Glänzen / Ein herzerquickendes liebliches Licht." ${ }^{22}$ überblendet sich im Anschauen des "lieblichen Lichts" der "güldnen Sonne“ von Anfang an der ,natürlich-mimetische' Blick auf den zentralen Planeten mit seiner geistlichen - und eigentlichen - Bedeutung, dem ,sensus mysticus' des ,Buchs der Natur'; denn Christus sagt bekanntlich, er sei „das Licht der Welt" und wer ihm nachfolge, werde „das Licht des Lebens haben.“ (Joh. 8, 12) In diesem Sinne legt sich dieses ,geistliche Natur-Gedicht" bis zur letzten Strophe auf die "wahre Sonne" hin selbst aus. Die typologische Form des Liedes prägt schon die zweite Strophe. Deren Aufgesang, psalmodiert' mit Bezug auf Psalm 8, 2-4, überbietet ihn im Abgesang aber dann heilsgeschichtlich und zeigt damit exemplarisch die figurale Allegorisierung der Natur (VALG, S. 132):

Mein Auge schauet,

Was Gott gebauet

Zu seinen Ehren

Und uns zu lehren,

Wie sein Vermögen sei mächtig und groß,

Und wo die Frommen

Dann sollen hinkommen,

Wenn sie mit Frieden

Von hinnen geschieden

Aus dieser Erden vergänglichem Schoß.

Strophe 7 steigert die Spannung von Natur-Betrachtung und Heilserwartung mit Bezug auf Psalm 8, 5 wie bei Arndt zur ,barocken' ,vanitas'-Vorstellung (ebd., S. 133):

Menschliches Wesen,

Was ists? Gewesen.

In einer Stunde

Geht es zu Grunde

Sobald das Lüftlein des Todes drein bläst.

Alles in allen

Muß brechen und fallen,

Himmel und Erden

Die müssen das werden,

Was sie vor ihrer Erschöpfung gewest.

durch Einbezug von unverfänglichen Einzelmotiven aus dem Schöpfungspsalm 104 und ignoriert zugleich dessen ägyptisch-,heidnisches', panentheistisches Bedeutungspotential (V. 2: „Licht ist dein Kleid, das du anhast“; stattdessen V. 9: „Du hast eine Grenze gesetzt“"). Vgl. dazu Anm. 7.

22 Paul Gerhardt: Wach auf, mein Herz, und singe. Vollständige Ausgabe seiner Lieder und Gedichte. Hrsg. von Eberhard von Cranach-Sichart. 4. Aufl. Wuppertal 2007, S. 132.-135, hier S. 132. Die Ausgabe im Text abgekürzt als VALG mit Seitenzahl. 
Nach der Evokation der Bildwelt der Schöpfungspsalmen überbietet und vereinseitigt Gerhardt deren Gottes-, Schöpfungs- und Menschenbild im auch durch den Fragegestus („Menschliches Wesen, / Was ists? Gewesen.“) verdeutlichten Bezug auf Psalm 8, 5. Die Göttlichkeit des Menschen gilt indirekt nur als VerheiBung für das Jenseits. Denn das Lied endet mit der Lutherschen Fokussierung auf Christus, der wahren „Sonnen gewünschtes Gesicht", als Garanten einer künftigen über-irdischen Herrlichkeit (VALG, S. 135): „Freude die Fülle / Und selige Stille / Hab ich zu warten / Im himmlischen Garten;/ Dahin sind meine Gedanken gericht." Im Diesseits dagegen müssen Schöpfung und Mensch doch wieder „das werden", „Was sie vor ihrer Erschöpfung gewest“ (nämlich ,Nichts').

3. Mitte des 18. Jahrhunderts, als das Luthertum mit neuen Religionsfeinden Gottesleugnern, Naturalisten und Deisten - zu kämpfen und den physikotheologischen Gottesbeweis als apologetische Waffe zu schätzen gelernt hatte, galt es, die dem biblisch-ptolemäischen Weltbild entsprungene Schöpfung gleichwohl als Werk eines immer noch theistisch-transzendenten Schöpfers zu verteidigen. Berühmt ist dabei der von Psalm 8 inspirierte sechsstrophige „Preis des Schöpfers" von Christian Fürchtegott Gellert (Str. 1): ${ }^{23}$

Wenn ich, o Schöpfer! Deine Macht,

Die Weisheit deiner Wege,

Die Liebe, die für alle wacht,

Anbetend überlege:

So weis ich, von Bewundrung voll,

Nicht, wie ich dich erheben soll,

Mein Gott, mein Herr und Vater!

Hier schiebt sich das Ich nicht nur grammatikalisch vor den Schöpfer und „überlegt " "anbetend" - also in der empfindsamen Kombination von ,Kopf und Herz' - dessen Weisheit, Liebe und Macht, es begründet sich auch selbst - allerdings nicht als individuelles, sondern als gnomisches Kirchenlied-Ich - aus dieser Betrachtung, die sich mit Beispielen für die Schöpfer-Herrlichkeit aus verschiedenen Schöpfungspsalmen in den folgenden drei Strophen fortsetzt. Strophe 5 resümiert aposteriorisch aus der Güte des Schöpfers und der Herrlichkeit der Schöpfung den Standort des Menschen. Erneut wird dabei die Paradoxie des Psalms aufgelöst, diesmal - im Gegensatz zu Gerhardt - ohne Beachtung der

23 Zugleich bot Gellert mit der poetischen Übersetzung des Schöpfungshymnus Psalm 19, V. 1-7 („Die Himmel rühmen des Ewigen Ehre“) unter dem Titel „Die Ehre Gottes aus der Natur" eine Quintessenz des aposteriorischen Gottesbeweises im rhetorischen Fragegestus: „Verkündigt Weisheit und Ordnung und Stärke / Dir nicht den Herrn, den Herrn der Welt?" Christian Fürchtegott Gellert: Geistliche Oden und Lieder. In ders.: Sämmtliche Schriften. 10 Teile in 5 Bänden. Erster und Zweiter Teil. Reprograf. Nachdr. d. Ausgabe Leipzig 1769. Hildesheim 1968, S. 145 f., hier S. 145. 
Niedrigkeit zugunsten der Hoheit des sich als Wunderwerk bestaunenden Menschen (nach Psalm 8, 6 f.):

Der Mensch, ein Leib, den deine Hand

So wunderbar bereitet;

Der Mensch, ein Geist, den sein Verstand,

dich zu erkennen, leitet;

Der Mensch, der Schöpfung Ruhm und Preis,

Ist sich ein täglicher Beweis

Von deiner Güt und Größe.

Daraus resultiert dann der Aufruf zum ,Gottes-Dienst' am Schluss. Der von christologischer Deutung des Psalms befreite Mensch feiert sich in diesem geistlichen Lied selbst als „der Schöpfung Ruhm und Preis“, er konstituiert und spiegelt sich im „Ruhm des Schöpfers“ und damit zumindest indirekt auch im Schöpfer selbst als dessen höchstes ,Kunst-Werk'. Aber dieses Selbst-Lob soll doch wiederum nur dem Schöpferlob dienen. Mit dem Luthertum konform bleibt Gellert, indem er am Begriff des theistisch-transzendenten Schöpfers festhält, diesen also nicht kosmotheistisch mit seiner Schöpfung vermengt. ${ }^{24}$ Weil die Natur als Werk Gottes unbeseelt bleibt, kommt es zu keiner identitätsstiftenden Kommunikation mit ihr - und deshalb auch lyrikgeschichtlich zu keiner Kommunikation mit dem jungen Goethe, der den Leipziger Lehrer nur als Beckmesser seines Stils wahrnahm. ${ }^{25}$

\section{Hermetisch ,tingiertes' Luthertum -} "Wunder"-,"All" und „erhöhtes" Ich (Greiffenberg)

1. Wie für Gerhardt wird für Catharina Regina von Greiffenberg die Nichtigkeit des Menschen zum Schlüssel für ihr Gottes- und Menschenbild und ihre Naturanschauung, aber eben daraus leitet sie auch den göttlichen Status des Menschen und des Ichs ihrer Texte ab. In einem „Kunst=Gedanken ${ }^{\prime 26}$ mit dem Titel „Was ist der Mensch! daß du sein gedenkest. Ps. 8. V. 4.“ (!) aus ihrer Sammlung Geistlicher

24 Eine interessante Übergangsfigur ist in dieser Hinsicht Klopstock mit seiner sprachgewaltigen, das nachkopernikanische Weltbild bestaunenden Naturdichtung. Innovativ geschult an der Psalmensprache agiert in seiner Hymne ,Die Frühlingsfeier/ Die Frühlingsfeyer zunächst der angebetete „Allmächtige“ und „Unendliche“ im grenzenlosen All als seiner Hände Werk und wird am Schluss als "Vater" und "Jehova“ fast alttestamentlich personhaft in den vormodernen Erfahrungs-Horizont des erlebenden ,Ich' zurückgeholt. Friedrich Gottlieb Klopstock: Oden. Auswahl u. Nachwort v. Karl Ludwig Schneider. Stuttgart 1980, S. 58-67.

25 Vgl. dazu Kemper: Deutsche Lyrik (Anm. 1) Bd. 6/II (2002), S. 293, 311.

26 Catharina Regina von Greiffenberg: Geistliche Sonette, Lieder und Gedichte. Mit e. Nachwort zum Neudruck von Heinz-Otto Burger. Darmstadt 1967, S. 251. Kunst-Gedanken nennt Greiffenberg die zwischen ihre Lieder eingestreuten epigrammartigen, aber längeren Meditations-Gedichte. Der Band wird im Folgenden mit den Titel-Initialen GSL zitiert. 
Sonette / Lieder und Gedichte (1662) erklärt sie sich die Zuwendung zu dem hilflosen Menschen aus Gottes Haupteigenschaft, der Liebe (GSL, S. 345):

Kann aus diesem Gnaden=Werk/ wie aus einem Büchlein lesen deiner Gottheit Eigenschafft/ Art/ und recht selbständigs Wesen: dass du gütig/ liebreich/ heilig/ und derwegen Gott must seyn. Aus der unergründten Liebe/ leucht der Gottheit heller Schein.

Diese allen Verstand übersteigende göttliche Liebe zeigt sich für sie grundlegend in zwei "Wunder=Proben", nämlich dem zweifachen Eingehen in die Kreatürlichkeit der Welt, zuerst als Vater und Schöpfer - das ist Thema der ersten 100 Sonette ihrer Sammlung -, dann nochmals als Sohn und Erlöser - dies in den nachfolgenden 85 Sonetten auf Christus. ${ }^{27}$ Im Gegensatz zur calvinistischen Prädestinationslehre ${ }^{28}$ und zur dominanten Soteriologie des Luthertums handelt Gott für Greiffenberg in beiden Offenbarungsquellen gleich gütig und will daher sein Ziel, die Erhöhung des Menschen, auch mittels seiner Schöpfung erreichen.

Mit der ersten „Wunderprobe“, nämlich der Kosmogonie, gelangt neben Gen. 1, $27 \mathrm{f}$. wieder Psalm 8 in den Fokus der Autorin. In vier Alexandriner-Sonetten begründet sie die Kosmogonie nämlich mit Gottes in der Prädestination gefassten Absicht: „daß du uns schuffst/ geschah allein uns zuerhöhen" (GSL, S. 10). ${ }^{29}$ Für ihre argute Argumentation verbindet sie christlich-lutherisches Glaubensgut mit

27 Der erste und wichtigste Teil der Lyrik-Sammlung mit zweihundertfünfzig Sonetten auf die Trinität folgt den Artikeln des ,Apostolischen Glaubensbekenntnisses'. Die ersten hundert Sonette thematisieren vorrangig den ,Vater ${ }^{\prime}$ als Schöpfer und bedenken sein Wirken von der Kosmogonie über zahlreiche Beispiele seines Handelns im AT bis zu den Glücks- und Unglücksfällen seiner Schöpfungserhaltung in der Gegenwart. Das zweite Hundert widmet sich dem Erlöser und damit seinem im Neuen Testament bezeugten Lebens-Lauf von der Geburt über wichtige Wunder, den Leidensweg, Auferstehung und Himmelfahrt sowie seine Abendmahlsstiftung. Die letzten 15 Sonette des zweiten Hunderts sind dem Heiligen Geist gewidmet. Eine weitere Zugabe von 50 ,Klinggedichten' bezieht dann wichtige Stationen von Kirchen- und Kalenderjahr mit ein, ferner Aufmunterungen zu christlichen Tugenden sowie Landschafts- und allein 15 Frühlings-Gedichte mit einer auf Christus als Schöpfer bezogenen Naturlyrik.

28 Diese hält Greiffenberg für Gotteslästerung. Catharina Regina von Greiffenberg: Sämtliche Werke in 10 Bänden. Hrsg. von Martin Bircher u. Friedhelm Kemp. Millwood N.Y. 1983, hier Bd. VIII, S. 529 ff. Die Bände werden im Folgenden mit SW abgekürzt sowie mit Band- und Seitenzahl zitiert. Vgl. dazu auch das Kapitel Kleine Konfessionskunde: Die wichtigsten Glaubensartikel und Lehrdifferenzen. In: Kemper: Deutsche Lyrik (Anm. 1) Bd. 4/I (2006), S. 353-364; zum calvinistischen und lutherischen Verständnis der Prädestination ebd., S. $361 \mathrm{ff}$.

29 Greiffenberg ist eine von den Autoren, die Wels zu den „theologisch unauffälligen Protestanten“ zählt, die auf Grund des "theologie- und sozialhistorischen Befundes" Vertreter einer "lutherischen Religiosität" seien. Die von mir herausgestellten Bezüge zur Hermetik seien deshalb ungerechtfertigt und problematisch. Wels: Zwischen Spiritualismus, Hermetik und lutherischer „Orthodoxie“ (Anm. 2), S. 259. Die „Indizien, an denen Kemper seine Interpretationen festmacht, im Detail zu überprüfen“, sei „hier nicht der Ort", „obwohl das natürlich die eigentliche Herausforderung wäre." Ebd. Für die Diskussion biete ich im Folgenden weiteres Material. 
hermetischen Vorstellungen. ${ }^{30}$ Dies verdeutlicht auch das dritte Sonett „Uber Gottes gnädige Vorsorge“. Es ist unausgesprochen eine kühne Meditation über Psalm 8. Diese versucht, die christlich-lutherische Sicht von Schöpfung und Mensch als einem göttlichen Werk ,aus Nichts' und ,als Nichts' zu einer paradoxen Deifizierung des Menschen umzudeuten. Letztere erfolgt allerdings am Schluss vorsichtshalber nur in einer rhetorischen Frage, weil diese ,conclusio' noch kühner ist als der Psalm selbst, wonach der Mensch immerhin „wenig niedriger denn Gott" sei (SWL, S. 12):

Ach hoher Gott/ vor dem die Sternen gleich dem Staube/ die Sonn' ein Senffkorn ist/ der Mond ein Körnlein Sand/ der ganze Erden Ball ein Pflaumen auf der Hand. Verwunderns voll hierob/ ich mich schier ganz betaube.

Wann deine Haubtobacht'/ auf mich ein nichts/ich glaube/ Ja! Reich erfahrner spür'/ im Tausendschickungs=Stand: So scheints/ auf mich allein sey all dein Fleiß gewandt, nur dieses Wunders Art zu preißen mir erlaube.

Ich bin ein Nichts/ aus nichts: durch deine Gnad so viel/ dass deiner Güte Mäng' ich ein eintreffends Ziel.

30 Das erste Sonett „Von der hohen Erschaffungs Gnade“ eröffnet mit der hermetischen, auf Böhmes Kosmogonie verweisenden Vorstellung, Gott habe in der Sehnsucht nach SelbstBeschauung Welt und Mensch als einen „Spiegel“ seiner selbst magisch erzeugt („Herr/ deine Heiligkeit/ sich selber zu besehen // hatt' eine Gottes-Lust, die Allheit fund' in ihr // ein reichs Ergötzungs=Feld/ betrachtend ihre Zier.") und endet mit der Bitte um Rückkehr in die göttliche Licht-Welt („,daß du uns schuffst/geschah allein uns zuerhöhen. [...] Wir und das ganze Seyn/ seyn deine Wunder=Proben. // Wann deine Gnad nicht wär/ wir wären alle nicht. Gib/ dass/ als Strahlen / wir gehn lobend in ihr Liecht!“ (GSL; S. 10) Im „Wunder“ der Kosmogonie und mit ihr der Erschaffung des Menschen als Ausfluss der göttlichen Gnade und Liebe und der Rückkehr in die transzendente göttliche „Liecht"-Welt deutet sich ein eigener Heilsweg über das ,Buch der Natur' an. - Das zweite Kosmogonie-Sonett verlagert den Grund-Gedanken von der Erschaffung der Welt hin zur Erhaltung, und der abstrakte theologische Sachverhalt wird originell alchimistisch-naturkundlich versinnlicht: Gottes Erhaltungs-Gnade erscheint als über die Sterne wirkende "Feuchtigkeit", womit der an Gen. 1, 2 anknüpfende ,essentialische Mercurius' oder das „UniversalSperma“ der Alchimie gemeint sein dürfte. (Vgl. zu diesem Barthold Heinrich Brockes: Irdisches Vergnügen in Gott. Naturlyrik und Lehrdichtung. Ausgewählt u. hrsg. von Hans-Georg Kemper. Stuttgart 1999, S. 136. Künftig abgekürzt als IVG-R.) Dieses wird zum „Lebens=Safft“ und "pflegt in die Edlen theil der Edlesten zu sinken.“ Das Gedicht endet mit der das „ex nihilo“ der Anfangszeile aufgreifenden Pointe: „Gar gern will ich gestehn/ dass ich nur Staub und Erd: // auf dass dein' Herrlichkeit in mir erfunden werd." (SWL, S. 11) Zur Bedeutung alchimistischer Bildlichkeit und der "Fließ"- und „Thau-,Vorstellungen für die (auch erotisch fundierte) Synchronisierung von Text- und Körper-„,Verflüssigungen“ im Prozess komplexer ,unio'-Erfahrungen vgl. jetzt auch Franz M. Eybl: „Den Himmel auf der Zung', im Munde die Sonne.“ Die Einverleibungen der Catharina Regina von Greiffenberg. In: Scharfsinn und Frömmigkeit. Zum Werk von Catharina Regina von Greiffenberg (1633-1694). Hrsg. v. Gesa Dane. Frankfurt a.M. u. a. 2013, S. 39-77, hier S. 42 ff., 54 ff., 58 f. Zum „Tröpflein“ als Bild alchimistischer "putrefactio“ vgl. auch Jörg Jungmayr: Mystische Traditionen bei Catharina Regina von Greiffenberg. Ebd., S. 79-100, hier S. 80 f. 
der Menschen bößer Sinn möcht' diß vor Hoffart achten.

Doch ists der Demutgrund/ Gott/ deine Werk betrachten.

Ich bin/ wie ich gesagt/ ein Nichts: mein Alles du.

Hat (Wunder!) Allheit dann in Nichtes ihre Ruh?

Dieser Schluss ist zunächst eine Anspielung auf das Sechs-Tage-Werk der Genesis - Gott "ruhte" "am siebenten Tage von allen seinen Werken“ - und erinnert daran, dass Gott im ersten (jahwistischen) Schöpfungsbericht vornehmlich und zuletzt den Menschen vor dessen Sündenfall als sein Ebenbild und seinen Stellvertreter auf Erden eingesetzt hat. Davon handelt ja auch Psalm 8, der den Sündenfall jedoch ebenso wenig erwähnt wie Greiffenbergs Text (vgl. Gen. 1, 26 ff.; Gen 2, 1 f., 15). Indessen transformiert die Autorin hier offenkundig die biblischchristliche in die hermetische Kosmologie, und zwar in der Konstellation von "Allheit" und „Ruh“. ${ }^{31}$ Bereits das erste Sonett beginnt mit der Anrede: "Ach Allheit" (SWL, S. 1), und diese Apostrophierung Gottes und Christi durchzieht den ganzen Lyrik-Band und das übrige Werk der Greiffenberg. Damit überschreitet sie das theistisch-personale christliche Gottesbild. Im Corpus Hermeticum ist Gott ein stets tätiges Wesen, Urheber von ,Allem', ruht aber selbst als das „Eine“ in sich: „Von einem einzigen Anfange hängt das All ab, der Anfang aber hängt von Einem und Einzigem ab, und der Anfang bewegt sich, damit er wieder zum Anfang wird, das Eine und Einzige aber steht fest und bewegt sich nicht." (CHD, S. 107) Da Gott selbst und allein unbeweglich in sich ruht, aber alles als sein Abbild schafft, hat dieses das letzte Ziel, wieder tätig zu Gott zurückzustreben, um in seiner Ruhe auch in Ewigkeit die eigene zu finden (CHD, S. 298 f.). ${ }^{32}$ Aber schon in der Gotteserkenntnis selbst "findet der Mensch die Ruhe, die er gesucht hat" (CHD, S. 170). - Diese Funktion des meditativen ,Betrachtens' der schöpferischen Tätigkeit der Allheit gilt auch für das Ich des Sonetts. In den Nöten des „Tausendschickungs=Standes" gelangt es mit dem „Demutsgrund/ Gott/ deine Werk betrachten“ zur Ruhe in der Gewissheit, selbst auserwähltes Ziel des göttlichen Schöpfungs-Handelns zu sein. Damit kehrt sich die Bewegung von ,Allem in Eines' um, und das Eine als All vereinigt sich mit dem scheinbaren Nichts des Einzel-Ichs, weil dieses selbst göttlichen Ursprungs und damit göttlicher Natur ist. Im folgenden Sonett erblickt sich das Ich ohne rhetorisches Fragezeichen in paradoxaler Selbstbestimmung als ein „Stäublein“ im All und zugleich als „der

31 Und wenn Greiffenberg auch am Geozentrismus festhält (die Sonne laufe mit einer Geschwindigkeit von 114.000 Meilen pro Stunde um die Erde; SW V, S. 27), so sind ihr doch die riesigen astronomischen Dimensionen des Weltraums bewusst, um Gott nicht nur metaphorisch als „Allheit“ zu verstehen: „Hundert sechs und sechzig mal/ größer als der Erden=kreis/ ist die Sonn/ des Himmels=preis" (SW IX, S. 326).

32 Diese Lehre vertritt auch Daniel von Czepko in seinem hermetischen Weltbild, hier in seinem Epigramm Ruh: „Mensch, der Bewegung Quell und Ursprung ist die Ruh./ Sie ist das best. Ihr eilt die gantze Schöpfung zu." Daniel von Czepko: Sexcenta Monodisticha Sapientum. In ders.: Geistliche Schriften. Hrsg. von Werner Milch. Unveränd. fotomechan. Nachdruck der Ausgabe Breslau 1930. Darmstadt 1963, S. 201-277, hier S. 238. 
Allmacht Pracht=geschöpff“, weil es sich erneut zum „höchsten EhrenZiel“ - der Vereinigung mit Gott - auserwählt weiß (GSL, S. 13).

2. Der Sonneten/ Andres Hundert auf Christus beginnt bis in die Wortwahl mit derselben Paradoxie (so „Auf Christus Wunder=Geburt“): „WIe? Hat die Allheit sich in dieses Nichts begeben! // Die Vnaussprechlichkeit so alles sprichet aus // Macht sie die Schwachheit dann zu ihrer Allmacht Haus? // [...] Gott wird ein Mensch/ auf daß der Mensch sey unverlohren." (GSL, S. 103) Hier deutet sich bereits die von Spiritualisten und Hermetikern geteilte und bis zum jungen Goethe wirkende Überzeugung an, die Menschwerdung und nicht der für die Doppelnatur problematische Opfertod des Gottessohns sei das Entscheidende, denn Christus sei nur Mensch geworden, um diesen als höchste Repräsentation der (gefallenen) Schöpfung und damit diese selbst aus der Defizienz der Materie zu befreien und die Rückkehr ins Göttliche zu ermöglichen. ${ }^{33}$ Die Christologie erhält so eine schöpfungstheologische Dimension.

Auch als Mensch war Christus für die Freifrau eine "Vermenschte GOttheit" (GSL, S. 102). Dazu stützte sie sich auf eine - schon von Melanchthon und seinen Anhängern nicht geteilte, von den anderen Konfessionen als Häresie verurteilte, aber wiederum von Johann Arndt mit Nachdruck vertretene - Sonderlehre Luthers, der auch der menschlichen Natur Christi die göttlichen Eigenschaften der Allgewalt und Ubiquität zugesprochen hatte. ${ }^{34}$ Diese habe der Gottessohn, so war sie überzeugt, auf Erden nur verborgen, aber im Geheimen ausgeübt (vgl. SW III, S. 357 ff. u. ö.). Nach seiner Auferstehung brauchte er wegen der Ubiquität seiner psychosomatischen „Subtiligkeit“ (SW III, S. 30) auch nicht zum Himmel aufzufahren: „kurz! Das zwey Naturte Wunder/ das recht unbeschreiblich All/ [...] Bleibt doch noch im Erdenball!“ jubiliert sie in einem Sonett (GSL, S. 176). So blieb Christus als Pantokrator, "himmlischer Chymist" (V, S. 483) und "göttliches Universal“" (SW VI, S. 804, 838, 1216) kraftvoll und nicht nur als Geist in der Schöpfung anwesend. Er bot dem „Nichts" seine „Allheit" vor allem im Abendmahl als Vergottungsmittel an (SW VIII, S. 822), aber auch in den Naturerscheinungen, und von daher entwickelte Greiffenberg eine christologische Naturlyrik um ihren „Jesus-Frühling“. ${ }^{35}$

33 Vgl. zur Entwicklung und Begründung dieses Gedankens im Anschluss an das Corpus Hermeticum und die Rezeption der platonischen ,anima mundi'-Lehre schon bei Cusanus Burkhard Dohm: Die Unsterblichkeit der Tierseele im Denken des Nicolaus Cusanus. In: The Animal Soul und the Human Mind. Renaissance Debates. Hrsg. von Cecilia Muratori. Pisa, Rom 2013, S. 27-43, bes. S. 28 ff., 37 ff. - Zu Goethe vgl. (mit weiterer Lit.) Hans-Georg Kemper: Bildung zur Gottähnlichkeit. Transformationen pietistischer und hermetischer Religiosität zur klassischen Kunst-Religion in Goethes Wilhelm Meisters Lehrjahren. In: GoetheJahrbuch 130 (2013 [Ersch. 2014]), S. 75-92, hier S. 85 f.

34 Vgl. dazu die Kleine Konfessionskunde. In. Kemper: Deutsche Lyrik (Anm. 1) Bd. 4/I (2006), S. 355 ff. Johann Arndt in seinen Predigten zu Psalm 8 (vgl. Anm. 16), S. 67 ff.

35 Vgl. dazu Kemper: Hermetisch-poetischer Liebeszauber (Anm. 6), S. 410 ff. 
3. In solcher schöpfungstheologisch grundierten, „erstaunlich ich-starken“ Poe$\mathrm{sie}^{36}$ konstituiert sich die Sprechinstanz gleichwohl, wie es scheint, als eine ,heterologe' Subjektivität, die sich an vorgegebenen Traditionen - biblischen, lutherisch-dogmatischen, gelehrten und poetologischen Vorgaben und kirchlichen Riten - sowie am göttlichen Adressaten orientiert, vor dem sie sich im Kontext des Psalms als ,Nichts' begreift. Damit erringt das Ich - so Eva Kormann - „ein Bewusstsein seiner selbst gerade durch die Demut gegenüber Gott und die Unterwerfung unter seinen Willen". ${ }^{37}$ Aber dadurch erlangt es eben auch seine absolute Selbst-Gewißheit und das Bewusstsein der eigenen Geborgenheit, Unverlierbarkeit und maximalen Ich-Stabilität, die es wiederum aus Dankbarkeit dem Lob des Schöpfers im poetischen Gottesdienst widmet. Gerade weil das Ich sich letztlich aber mithilfe einer arguten Umdeutung der Tradition so ausschließlich aus Gott und auf Gott hin als ihr ,Ein und Alles' begründet, übersteigt es die Grenzen der heterologen Subjektivität und verlässt zugleich mit der Exklusivität des Erlöstheitsbewusstseins die konfessionelle Gemeinsamkeit mit der Leserschaft. ${ }^{38}$

36 Vgl. Eva Kormann: Heterologie und geistliche Virtuosität. Zur Ich-Konzeption in Greiffenbergs Gedichten. In: Scharfsinn und Frömmigkeit (Anm. 30), S.145-162, hier S. 152. Kormann zählt im Kontext neuerer Lyrik-Theorien die Lyrik pauschal zu den „fiktionalen Textsorten“ (ebd., S. 146). Dem widerspricht mit guten Gründen - ebenfalls im Kontext neuerer Theorien - Rüdiger Zymner: Lyrik. Umriss und Begriff. Paderborn 2009, S.10 ff. Nach Zymner kann Lyrik fiktional oder nicht-fiktional sein, nach meiner Ansicht $u$. U. sogar beides zugleich, nämlich dann, wenn über die Form ein fiktiver Zusammenhang hergestellt wird, in der gleichwohl ein Autor selbst ,spricht' und eine eigene Erfahrung mitteilt. Dies ist - wie sich zeigen wird - in Brockes' Gedichten der Fall. Bei Greiffenberg handelt es sich um ein gnomisches Ich, das die pointierte Wahrheit seiner Aussage aber nur durch die Authentizität der im Ich sich artikulierenden eigenen Glaubenserfahrung der Autorin verbürgen kann. Es ist kein Zufall, dass gerade geistliche Dichter Batteux widersprachen, als dieser den Grundsatz der ,Nachahmung der Natur' auch für die Lyrik beanspruchte; denn, so betonte der BatteuxÜbersetzer Johann Andreas Cramer, die der „Begeisterung“ und dem „Enthusiasmus“ entsprungenen geistlichen Lieder drückten "wirkliche“ und keine nachgeahmten Empfindungen aus (vgl. Kemper: Deutsche Lyrik [Anm. 1], Bd. 6.I (1997), S. 216 ff., 222 ff.).

37 Kormann: Heterologie (Anm. 36), S. 149.

38 Zwar bezieht das ,Ich' auch die fromme Leserschaft explizit durch ,Wir' und ,uns' ein (,,daß du uns schuffst / geschah allein uns zuerhöhen"), doch sprengt die eigenständige subjektive Umdeutung und Aneignung einer vorgegebenen Deutungstradition und die argute, zugleich hochemotionale Feier des mit Gott vereinten ,Nichts' die Grenzen lutherischen Glaubens und führt - dies gegen Kormann (ebd., S. 161) - zur Nichtidentifizierbarkeit jedes Lesers mit diesem ,Ich', der sich noch in den Nöten des diesseitigen „TausendschickungsStandes" als ,simul iustus et peccator' fühlen musste. Diese These wird auch durch die von Franz H. Eybl entdeckte und analysierte entschärfende poetische Überarbeitung von 10 Liedern und 13 Sonetten aus Greiffenbergs Passionsandachten mit der "Tilgung“" "sprachlicher Erscheinungsweisen mystischer Repräsentation durch den weiblichen Körper" durch den Stuttgarter Hofprediger Johann Reinhard Hedinger (1702) unterstützt. Eybl: „Den Himmel auf der Zung', im Munde die Sonne" (Anm. 30), S. 65 ff. In ihrer frommen poetischen Radikalität war die Freifrau für das lutherische Publikum offenbar nicht, anschlussfähig. Ihr Werk blieb den Zeitgenossen daher auch weitgehend - überdies wegen seines alsbald in Verruf geratenen ,manieristischen Stils' - unbekannt. - Gerade die im Protestantismus geforderte religiöse Selbstverantwortung des Einzelnen, auch in Glaubensfragen zu prüfen und „das Richtige zu wählen", hat immer wieder zu spiritualistischen, mystischen und radikalpietis- 
Indem es sich in dem einen ,Anderen' und diesen als das Andere seiner selbst begreift, begibt es sich auf den Weg in die Moderne, denn auch das neuzeitliche Individuum, wie es sich in der Naturlyrik des Sturm und Drang exemplarisch artikuliert, konstituiert sich - und wird seiner selbst erst gewahr und gewiss - in der Begegnung mit einem oder einer Anderen (sei es bei Goethe polemisch wie in "Prometheus" oder identifikatorisch wie in "Ganymed“), mit dem (makrokosmischen) All, in dem es seine (mikrokosmische) Ebenbildlichkeit entdeckt, oder auch mit der entmythologisierten, vielerlei (Selbst-)Projektionen ermöglichenden ,Geliebten' oder ,Mutter' Natur.

In Greiffenbergs geistlicher Poesie vermag sich das Ich im persönlichen, emotionalen lyrischen Lobpreis der "Allheit“ die eigene Göttlichkeit zu erschreiben. Das ist auch die im Kern immer noch religiöse und nicht nur ästhetische Grundkonstellation von Ich und Natur zu Beginn der modernen Naturlyrik. „So schwinge dich dann hin/ mein Herz! In dein Vergnügen in Gott!“ (SW VII, S. 437), ruft die vom Geist inspirierte Autorin in einem Sonett und sucht diese Freude auch zu verbreiten (SW I, S. 442): „Die schönste Kunst im Schreiben // ist/ unvermerkt der Erd' den Himmel einverleiben."

\section{Gottebenbildlichkeit des Ich aus der ,Betrachtung' des All (Brockes)}

1. Die Zitate wirken schon wie eine Vorausdeutung auf Barthold Heinrich Brockes. Dieser eröffnet 1721 den ersten Band seines Hauptwerkes Irdisches Vergnügen in Gott mit der Absicht, zu zeigen, wie leicht der "schöne Bau der Erden“, den die Menschen sich selbst zur Hölle machen, „Euch allen könn’ ein [also nicht mehr der] Himmel werden! “ ${ }^{39}$ Das anschließende erste und damit programmatische, vielleicht mit dem Teleskop vollführte ,Erlebnis'-Gedicht liest sich als Emanzipa-

tischen Abweichungen und anderen Heterodoxien geführt, die das Bewusstsein selbstverantwortlicher Individualität hervorgerufen haben.

39 Das einleitende Titel-Kupfer zeigt denn auch eine sitzende weibliche Figur, die im Gegensatz zur Muse in Greiffenbergs Titelkupfer nicht mehr zum Himmel aufblickt, sondern in einem umgrenzten ,barocken' Garten ein vis-à-vis aufgestelltes Blumen-Arrangement bewundert, während der Himmel teilweise ostentativ durch einen baldachinartig geschwungenen Vorhang verdeckt wird. „Freuen wir uns nicht des Schöpffers in der Creaturen Pracht", lautet die ironisch-polemische ,subscriptio', "So ist, wenigstens für uns, diese Welt umsonst gemacht." Barthold Heinrich Brockes: Irdisches Vergnügen in Gott. Erster und Zweiter Theil. Hrsg. u. kommentiert von Jürgen Rathje. Göttingen 2013. (= B.H.W. Werke Bd. 2.1), VorsatzBlatt. Diese noch unabgeschlossene neue Werk-Ausgabe wird nachfolgend zitiert als W mit Band- und Seitenzahl. - Der beharrlich beibehaltene Obertitel des neunbändigen Werkes kann diese Aufwertung des Diesseits bestätigen: ,Irdisches Vergnügen in Gott', wobei „Vergnügen“ mit dem Hauptaffekt der „Freude“ aus der ,subscriptio' übersetzt werden kann (so auch Rathje im Vorwort; ebd., o. S.). Und der oft überlesene Zusatz bestehend in Physicalischund Moralischen Gedichten betont den Zusammenhang von Ästhetischem und Ethischem als Programm einer ,Kalokagathie' - und dies oft (zum Missvergnügen des modernen Lesers) auch in den naturbeschreibenden Gedichten selbst - und verleiht der Brockesschen Poesie einen komplexen Sinnzusammenhang, den von vornherein verfehlt, wer nur die Naturmalereien als das literarhistorisch Innovative dieses Autors für wichtig hält. 
tion aus der Paraphrasen-Tradition, als Transformierung zentraler Aussagen von Psalm 8 in eine irritierende Begegnung mit der Pluralität der Welten (W 2.1, S. 9):40

Das Firmament.

Sir. XLIII, 1.

Man siehet seine Herrlichkeit an der mächtigen grossen Höhe, an dem hellen Firmament, an dem schönen Himmel.

Als jüngst mein Auge sich in die Sapphirne Tieffe, Die weder Grund, noch Strand, noch Ziel, noch End' umschrenckt, Ins unerforschte Meer des holen Luft-Raums senckt', Und mein verschlungner Blick bald hie- bald dahin lieffe, Doch immer tieffer sanck; entsatzte sich mein Geist, Es schwindelte mein Aug', es stockte meine Seele $\mathrm{Ob}$ der unendlichen, unmäßig-tieffen Höle, Die, wol mit Recht, ein Bild der Ewigkeiten heisst, So nur aus Gott allein, ohn' End' und Anfang, stammen. Es schlug des Abgrunds Raum, wie eine dicke Fluth Des Boden-losen Meers auf sinckend Eisen thut, In einem Augenblick, auf meinen Geist zusammen. Die ungeheure Gruft voll unsichtbaren Lichts, Voll lichter Dunckelheit, ohn' Anfang, ohne Schrancken, Verschlang sogar die Welt, begrub selbst die Gedancken; Mein gantzes Wesen ward ein Staub, ein Punct, ein Nichts, Und ich verlohr mich selbst. Diß schlug mich plötzlich nieder; Verzweiflung drohete der ganz verwirrten Brust: Allein, o heylsams Nichts! glückseliger Verlust! Allgegenwärt'ger Gott, in Dir fand ich mich wieder.

Die epochale Bedeutung dieses Gedichts unterstreicht Brockes durch ein 30seitiges Neujahrsgedicht in der religionsphilosophischen Tradition des Lehrdialogs. ${ }^{41}$ Darin begründet er das ästhetisch-religiöse ,Erlebnis' im „Firmament“ rational als Anwalt der ,new science' gegenüber einem Zweifler, der die ,barocke' ,vanitas' wegen der Nichtigkeit des Menschen nihilistisch zuspitzt, und greift die paradoxale Schlusspointe des „Firmaments“ schon im Titel auf: „Das, durch die Betrachtung der Grösse GOttes, verherrlichte Nichts der Menschen. In einem Ge-

40 Vgl. zu diesem Gedicht auch den Beitrag von Jörg Robert im vorliegenden Band.

41 In Form von Lehrdialogen ist $\mathrm{u}$. a. auch das Corpus Hermeticum gestaltet, von dem eine deutsche Übersetzung 1706 in Hamburg erschien. Vgl. dazu Kemper: Deutsche Lyrik (Anm. 1), Bd. 5.1 (1991), S. $108 \mathrm{ff}$. 
spräche. Auf das Neue Jahr, 1722 “. ${ }^{42}$ Dieser Lehrdialog entwickelt zugleich physikotheologisch den Kern von Brockes' ,natürlichem Gottesdienst'. ${ }^{43}$

Die Einführung in das neue Weltbild vollzieht sich zunächst auch in der Form des „Firmaments“. So nutzt Brockes zwar den ,barocken' Alexandriner-Vers, die quartettartige Gestaltung des Sonetts oder Epigramms und die von diesem geforderte , argut'-paradoxale Schlusspointe. Gleichzeitig ,wandert' er aber aus diesen Traditionen aus, indem er die von Greiffenberg zur meditativen Pointierung kreativ genutzte Enge der Sonett- und Epigramm-Form zu einem Gedicht mit zwanzig Versen erweitert. In ihm gewinnt nun das Ich buchstäblich ,Raum', um die ,Enge' des alten, im Bibelzitat erinnerten Weltbildes in einem hochemotionalen optischen ,Höhenflug' zu transzendieren und mit Hilfe auch von Oxymora zu einer Ästhetik des Erhabenen vorzustoßen. ${ }^{44}$ Dies geschieht durch die Introduktion eines für Brockes' Gedichte konstitutiven Ich, das neben autorfiktionaler

42 W 2.1, S. 331-360. Im Folgenden zitiert als "Neujahrsgedicht auf 1722“.

43 Zur Physikotheologie vgl. zuletzt umfassend Anne-Charlott Trepp: Von der Glückseligkeit alles zu wissen. Die Erforschung der Natur als religiöse Praxis in der Frühen Neuzeit. Frankfurt, New York 2009, S. 306 ff. u. ö. - Wels' Zuordnung von Brockes zur lutherischen Physikotheologie und deren Herleitung aus der rationalen melanchthonschen Naturphilosophie führt ihn zu dem Urteil (über Brockes): „,Paradoxieerfahrung' ist von dieser Lehrdichtung deshalb nicht zu erwarten, genauso wenig wie eine unmittelbare Ansprache Gottes in der Natur". Diese Ansicht wird allerdings schon von diesem Eröffnungsgedicht des Hauptwerkes widerlegt, ebenso die weitere These, die „Bewunderung des Betrachters“ trete noch nicht wie bei Klopstock oder Goethe „in der lyrischen Form selbst in Erscheinung.“ Wels: Zwischen Spiritualismus, Hermetik und lutherischer „Orthodoxie“ (Anm. 2), S. 282 f. - Nicht zu übersehen ist auch der Rekurs auf die altehrwürdige, vor allem im Katholizismus gepflegte, von Arndt zum Teil übernommene und zur Begründung und Entstehung der Physikotheologie ebenfalls beitragende ,Wege'-Theologie, zum einen in Gestalt theoretischer Diskussion in einem dialogartigen Lehrgedicht „Die erste Staffel zur Gottheit“ (Barthold Heinrich Brockes: Land-Leben in Ritzebüttel, als des Irdischen Vergnügens in GOTT Siebender Theil. Von neuem aufgelegt. Tübingen 1746, S. 638-641: im Folgenden werden die Bände III bis VII des Irdischen Vergnügens in Gott unter der Sigle IVG sowie Band- und Seitenzahl zitiert), zum anderen in naturbetrachtender Poesie wie im Gedicht Das Große und Kleine. In letzterem ersetzen die neuen Erfindungen von Teleskop und Mikroskop realitätsaffin ein Itinerarium mentis in Deum wie bei Bonaventura oder eine Ascensio mentis in Deum per scalas rerum creatarum bei Bellarmin (vgl. dazu Kemper: Gottebenbildlichkeit [Anm. 1], Bd. I, S. 164, 169 ff.) Und statt eines allwissenden Engels namens Kosmiel in Athanasius Kirchers geträumtem Himmelsflug Iter ecstaticum (Würzburg 1671) reist ein Licidas per Fernrohr weiter und weiter in den Weltraum, dessen „Tieffen“ er nicht ergründen kann, selbst wenn er seine "Himmel-Fahrt' „bis in Ewigkeit“ fortsetzen würde (Barthold Heinrich Brockes: Auszug der vornehmsten Gedichte aus dem Irdischen Vergnügen in Gott. Faksimile-Druck nach d. Ausg. v. 1738. Mit einem Nachwort von Dietrich Bode. Stuttgart 1965, S. 242-247, hier S. 244. Dieser Band wird nachfolgend mit der Sigle A u. Seitenzahl zitiert). Aber Licidas darf sich auch mit der naturmystischen Schlusspointe des Firmaments trösten: Er fände „nie ein Ziel, weil er GOtt immer fünde" (ebd.). Das stellt das katholische und mystische, an das alte hierarchisch gestufte Weltbild gebundene Aufstiegsdenken mit der schließlichen Vereinigung der Seele mit dem transmundanen Gott pointiert, auf den Kopf “". Vgl. dazu auch Anm. 57.

$44 \mathrm{Vgl}$. dazu auch die detaillierte Interpretation dieses Gedichts in: Josef Billen u. Friedhelm Hassel: Undeutbare Welt. Sinnsuche und Entfremdungserfahrung in deutschen Naturgedichten von Andreas Gryphius bis Friedrich Nietzsche. Würzburg 2005, S. 38-49, hier S. 44. 
formaler Fingierung des ,Erlebnisses' autorfaktuale, ja autobiographische Züge aufweist, welche letztlich die ,Wahrheit' der Schlusspointe beglaubigen. ${ }^{45}$ Das Ich selbst und keine theologische Norm verbürgt nun mit der zugleich astronomisch gesicherten Wahrnehmung die Authentizität des ,Erlebten' und damit die Transformation traditionellen Wissens im experimentellen Akt der Welt- und Selbsterkundung.

Inhaltlich beruft sich Brockes mit Titel und Bibelzitat zunächst auf eine zentrale Vorstellung des alten ptolemäischen Weltbildes, auf die "Himmelsfeste“ als achte Sphäre oberhalb des Umlaufs der sieben Planeten, jenseits derer die Sphäre der Transzendenz begann. ${ }^{46}$ Die Dimensionen dieses Weltbildes werden durch den als grenzenlos erfahrenen Weltraum augenscheinlich widerrufen, die visuelle ,Raum-Fahrt' ist also zugleich eine ,Zeit-Reise' von einem Weltbild zum anderen, der "schöne Himmel“ des apokryphen (von altägyptischer Weisheit geprägten ${ }^{47}$ Jesus Sirach erweist sich für das - wie das "Neujahrsgedicht auf 1722 " nahe legt ${ }^{48}$ - ohnehin noch von ,barocken' Welt- und ,vanitas'-Ängsten bedrängte Ich als erhaben und "ungeheuer" und spiegelt sich in seiner "Verzweiflung", und doch ereignet sich am Schluss eine paradoxe, ,barockmystisch' gestaltete Erfahrung des Einsseins des zum "Nichts“ ,vernichtigten' Ich mit einem in der Natur nahen Gott - ein Einssein, das ganz im Sinne von Psalm 8 die Gott-Nähe des Ich impliziert.

2. Berufung auf die Bibel, ,erlebter' Widerruf ihres Weltbildes und Erreichen der Vereinigung mit Gott - wie passt das zusammen? Hier sucht offenbar ein Sprecher sich und seinen Glauben in einer Art ,Mystik mit offenen Augen' im neuen Weltbild zu ,verorten'. Dazu sind vorrangig drei Aspekte zu klären: das Verhältnis von Bibel und ,Buch der Natur', die Verarbeitung der ,Pluralität der Welten' und die Plausibilisierung eines damit zu vereinbarenden Gottesbegriffs. Erstens

45 Vgl. dazu auch Anm. 36. - Der Eindruck des Autobiographischen wird durch die alle Bände durchziehenden, stets umfangreichen Neujahrsgedichte verstärkt, in denen Brockes nach Abhandlung eines Themas am Schluss die wichtigsten familiären Ereignisse des Jahres zusammenfasst. So beim Neujahrsgedicht auf 1722 u. a. seine wichtige Mission als Rats-Mitglied zum Hof nach Wien, um den Kaiser auch durch eine poetische Huldigung wieder versöhnlich zu stimmen, nachdem ein von der Geistlichkeit aufgehetzter Pöbel ein katholisches Gotteshaus in Hamburg verwüstet hatte (W 2.1, S. 358 f.). In den Lehrdialogen kennzeichnet der Autor die eigenen Position stets durch die vorangestellte Initiale „B.“ (= Brockes).

46 Vgl. Billen/Hassel: Undeutbare Welt (Anm. 44), S. 10 f., 43.

47 Vgl. Brunner: Altägyptische Weisheit (Anm. 7), S. 89.

48 Eine nahezu komplette Vergegenwärtigung der ,barocken',vanitas'-Vorstellungen bietet der ,gegnerische' Gesprächspartner „A.“. W 2.1, S. 344 ff. Brockes nutzt diese eindrucksvolle Aufstellung aller Argumente für die Nichtigkeit und Vergänglichkeit des Menschen zur Zuspitzung hin zum Nihilismus, der sich hier als konsequent erweist, wenn die Soteriologie als ,Antwort' auf die ,vanitas' - wie hier bei „A.“ - völlig ausfällt. Dieser verleugnet deshalb auch ein Fortleben nach dem Tod: „Es scheint, dass Tod und Nichts bey Menschen einerley,/ Und dass die Hoffnung jenes Lebens/ Ein Kind der Eitelkeit, des Hochmuths Frucht nur sey.“ W 2.1, S. 345. Oder: „Was ich, den Augenblick vor meinem Leben, war, / Werd' ich, den Augenblick nach meinem Leben, werden." Ebd., S. 348. 
möchte der Hamburger Ratsherr grundsätzlich einen sinnlich-natürlichen, auf den ersten Glaubensartikel gestützten Gottesdienst etablieren und nutzt dazu viele - vor allem alttestamentliche - Bibelstellen, darunter bemerkenswerterweise auch die von altägyptischer Weisheit geprägten Schöpfungspsalmen 104 und 148 sowie Sapientia Salomonis Kap. 11, 22 ff. und Jesus Sirach Kap. 28 als Beweis für die Schöpferverehrung in der Bibel selbst. ${ }^{49}$ Den Theologen wirft er die mit Weltverachtung verbundene Verabsolutierung des soteriologischen 2. Artikels ${ }^{50}$ sowie „Hass“ auf die Verehrer Gottes aus der Natur vor ${ }^{51}$ und beruft sich bei der deistischen Begründung für seinen „Ältesten Gottesdienst“, den schon Adam und Eva im Paradies ausgeübt hätten, wo es noch gar keine Bibel gegeben habe, ${ }^{52}$

49 Vgl. den ,Anhang verschiedener Uebersetzungen' in W 2.2, S. 869-873.

50 Dies exemplarisch in dem langen, effektvoll an den Schluss des Zweiten Theils gerückten Gelegenheitsgedichts „Aufmunterung an andere, zu gleichmäßiger Betrachtung der Werke Gottes" (W 2.2, S. 856-865). Der Aufruf richtet sich an 50 namentlich genannte Adressaten, darunter zeitgenössische Theologen. Das Gedicht wendet sich zunächst an Gott selbst mit der Bitte um Beistand: „Unwandelbares All! Allgenwärtigs Wesen, / Selbständigs, ewigs Licht, / Erleuchte doch derjenigen Gesicht, / Die irgend diese Blätter lesen!“ Den Hamburger Theologen, Reformer des Kirchengesangs und Poetologen Erdmann Neumeister lockt Brockes mit der prätendierten ,Harmonie' von Bibel und Buch der Natur: „Laß auch vom Schöpfer einst dein Saitenspiel erklingen! / Bey dem Erlösungs-Werk die Schöpfung zu besingen, / Kann wohl beysammen stehn, und stimmt gut überein." Ebd., S. 858. Dann aber spart er mit Berufung auf die heilsame Wirkung von Schöpfungsliedern im lutherischen geistlichen Lied nicht mit Vorwürfen gegenüber den Geistlichen. Dieses Schöpfungs- und Schöpferlob bleibe „fast uns ganz verborgen“, „Und es ist gar dahin gebracht, / Daß fast kein Geistlicher des Schöpfers Wunder-Macht / In seiner Creatur in Predigten erhöhn / Und von den Kanzeln Gott in seinem Werk zu sehn, / (Will er kein Neuling seyn) sich unterstehen darf." "Wie viele tausend Christen" seien schon "gestorben", ohne von des "Schöpfers Herrlichkeit" auch nur die geringste "Spur" „verspüret" zu haben, weil sie nicht „darauf geführet" worden seien. Ebd., S. 86. Dann lobt Brockes wiederum Valentin Ernst Löscher und den Hamburger Pastor Johann Christoph Wolf als „tapfre Gottes-Helden“ für ihren Einsatz, „dass man zum Schöpfer auch auf Leitern müsse steigen / Von seiner Creatur. Ihr beyde zeigt den Frommen / Den Vorhof, der, um recht ins Heiligste zu kommen, / Ganz unumgänglich ist." (Ebd., S. 864) In dieser Spannung zwischen „Vorhof" und „unumgänglich“ liegt - mit wechselnden Akzenten - der theologische Anspruch, den Brockes selbst mit seinem Irdischen Vergnügen in Gott erhebt.

51 Ähnliche Vorwürfe beherrschen auch den Anfang des „Neujahrsgedichts auf 1722“: „Es ist Bedaurens wehrt, dass auch Theologi / (Denn viele nehm' ich aus, und spreche nicht von allen) / Sich um des Schöpfers Werck nicht die geringste Müh / zu nehmen angewöhnt. [...] Ja, welches schrecklich ist, diejenigen noch hassen, / die in Geschöpfen Gott zu sehn, / Und Seiner Weisheit Macht und Wesen zu erhöhn, / Sich etwan unterstehn und sich gelüsten lassen." (W 2.1, S. 335)

52 Im Gefolge des Ursprungsdenkens der Renaissance entwickelt Brockes die These, der "älteste GOttes=Dienst", nämlich der von Adam und Eva im Paradies, sei eine von göttlicher Schrift-Offenbarung und kirchlicher Autorität noch freie Verehrung Gottes in der Natur gewesen (IVG VI, S. 245 f.; V, S. 149; A, S. 550) und diese sei deshalb auch heute noch die beste Übung der Frömmigkeit: „Denn nichts so sehr, als dieß, kann unsre Seelen leiten / Zu den verlohr'nen Herrlichkeiten." (Ebd.) Verloren waren diese nicht durch den Sündenfall, wie die Theologen lehrten, sondern durch deren spitzfindig argumentierendes (also selbst die Vernunft - allerdings unvernünftig - in Anspruch nehmendes) „Ketzermachen“ (IVG VI, S. 623) und durch uneinsichtige Lehren. 
sogar auf Christus selbst: „Denn also lehrt er öffentlich: // Wer meinen Vater ehrt, der ehret mich!" (W 2.2, S. 865, Hervorhebung von Brockes.) Dieser Spruch ist aber dem Wortlaut und der Sache nach in der Bibel nicht zu finden. Im Gegenteil sagt Jesus zu seinen Jüngern: „Wer den Sohn nicht ehrt, der ehrt den Vater nicht, der ihn gesandt hat." (Joh. 5, 23) ${ }^{53}$ Diese Sinn-Verkehrung zeigt den Ernst, mit dem der frühere Autor des Passions-Oratoriums, der Christus auch leicht als Pantokrator in sein Schöpferlob hätte einbeziehen können, nun einen trinitarischen Gottesbegriff ablehnt. ${ }^{54}$ Als Prophet eines allgegenwärtigen Gottes verabschiedet er

53 Analog 1. Joh. 2, 23; Joh. 15, 23. Sachlich analog der soteriologische Zentralsatz Jesu: „Ich bin der Weg und die Wahrheit und das Leben; niemand kommt zum Vater denn durch mich." Joh. 14, 6; vgl. Joh. 14, 13. - Warum Brockes in diesem - schon in Anm. 50 zitierten - Gelegenheitsgedicht eine solche provozierende Falsch-Aussage riskiert, bleibt rätselhaft. Vielleicht hielt er seine kühne Umkehrung für eine konsequente Folgerung aus diesem Jesus-Wort, vielleicht wollte er mit seinem Zitat wenigstens den Lesern ein trinitarisches Verständnis seiner Gottes-Feier ermöglichen. Jedenfalls hätte er wie sein Freund Hermann Samuel Reimarus einfacher auf Mt. 22, 37 ff. verweisen können, um die Verehrung des ,Vaters' als wichtigste Verpflichtung durch Jesus selbst zu begründen. Von einem Pharisäer nach dem „vornehmsten Gebot im Gesetz gefragt“ antwortet dieser: „37. Du sollst lieben Gott, deinen Herrn, von ganzem Herzen, von ganzer Seele und von ganzem Gemüte. 38. Dieses ist das vornehmste und größte Gebot. 39. Das andere aber ist ihm gleich: Du sollst deinen Nächsten lieben wie dich selbst. 40. In diesen zwei Geboten hanget das ganze Gesetz und die Propheten.“ Diese Stelle war für Reimarus der „Kern“ der von Jesus - der sich nie selbst als Gott verstanden habe - gepredigten praktischen Religion, die mit der Vernunft und natürlichen Religion völlig übereinstimme: Hermann Samuel Reimarus: Apologie oder Schutzschrift für die vernünftigen Verehrer Gottes. Hrsg. von Gerhard Alexander. 2 Bde. Frankfurt a. M. 1972, hier Bd. II, S. 25, 30. Bd. I, S. 69, 99, 113, 126 u. ö.

54 So auch im "Neujahrsgedicht auf 1722“. In der Tübinger Ausgabe lautet die Passage: „Ein Bettler, der nie eines Thalers wehrt /In seinem Bettelsack gesehen, / Kann weder Wehrt noch Zahl verstehen, / Wenn er von Millionen hör't. So können auch wir armen Hörer, / So lange wir durch uns'rer Schulen Lehrer / Theils gar zu allgemein, theils gantz verwirret, / Theils Dreylings=förmige / Gedancken und Ideen / Von Gottes Majestät bekommen, nichts verstehen.“ (IVG I, S. 340-379, hier S. 344) Das Wort „Dreylings=förmig“ findet sich in der 2. Aufl. 1724 der Hamburger Ausgabe und wurde von da in die Tübinger Ausgabe übernommen. "Dreyling" - das heutige "Drilling" - wurde laut Grimms ,Deutschem Wörterbuch' auch als Bezeichnung für die Trinität benutzt (Deutsches Wörterbuch von Jacob und Wilhelm Grimm. Bd. 2. Nachdr. München 1984, Sp. 1386), bezeichnete im 18. Jahrhundert aber auch „ein dreiheller- oder dreipfennigstück, wie dreier, drilling oder dreiling" (so auch von J. E. Schlegel oder Lessing benutzt; ebd., Sp. 1387). Von daher versteht sich, warum Brockes in der von Rathje offenbar herangezogenen Version der siebenten und letzten Ausgabe des Ersten Theils der Hamburger Ausgabe "dreylings=förmige" in "Pfennings-förmige“ verwandelt (W 2.1, S. 335. Vgl. ebd., S. 934) - ein Wort, das Grimm als Unikat nur bei Brockes nachweist (Deutsches Wörterbuch von Jacob und Wilhelm Grimm. Bd. 13. Nachdr. München 1984, Sp. 1668). Den zeitgenössischen Lesern dürfte vom Kontext her - angefangen von dem dem Bettler unbekannten „Thaler" bis hin zur Kritik am Gottesbegriff - auch bei dieser Änderung die Kritik am Trinitätsbegriff bewusst geblieben sein, und dies mit der zusätzlichen Konnotation, dass der Gottes-,,Thaler" durch den "Pfennings“-,Dreyling' nur verkleinert und herabgesetzt wird. Am Trinitätsbegriff übte auch Reimarus in seiner ,Apologie', die er freilich zu Lebzeiten erst gar nicht zu veröffentlichen wagte, heftige Kritik (Reimarus: Apologie [Anm. 53]. Bd. I, S. 48 f. Bd. II, S.46 ff., 73 ff.), ebenso an einem theistisch-personalen Gottesbegriff (ebd. Bd. I, S. 74, 179 ff. u. ö.). Auch in diesem Punkt stimmt Brockes - wieder öf- 
die „Sonne“ lutherischer Frömmigkeit aus seinem poetischen ,Gottes-Dienst", das ,Buch der Natur' wird für ihn zur entscheidenden Offenbarungsquelle, von der her das Weltbild der Bibel weitreichend zu korrigieren ist.

Im Zusammenhang damit führt „Das Firmament “ zweitens den „Schock“ über die astronomischen Einsichten in eine Vielzahl von Welten, über die stellare Bedeutungslosigkeit der Erde und den Verlust der Anthropozentrik des biblischen Weltbildes vor, was Psalm 8, 5 eine neue „Tiefen“-Dimension verleiht. „Denn was ist unsere ganze Erdkugel“, klagte auch William Derham in seiner Astrotheologie, ,"anders als ein Punct; ein Nichts gegen das ganze Weltgebäude“ ${ }^{55}$ Aber aus dieser „Kränkung" ging die Vernunft gestärkt hervor; denn sie holte in der Erkenntnis des Alls, seiner Größe und naturgesetzlichen Ordnung gleichsam die Dimensionen eines nun nicht mehr unberechenbar und zornig handelnden, sondern allweisen göttlichen „architectus mundi“ ein, und schon Johannes Kepler hatte am Schluss seines Mysterium cosmographicum (1592) in einer enthusiastischen poetischen Paraphrase von Psalm 8 Gott dafür gerühmt, dass er das „Ingenium“ des Astronomen gewürdigt habe, die „Planetenbahnen“ in ihrer „fünffachen Norm“ zu errechnen (wie er V. 4 erweiterte); er habe ihn so zum göttlichen Geist emporgehoben; „nur zum Göttergeschlecht gehört er nicht", hatte Kepler Vers 6 mythologisierend entschärft. ${ }^{56}$ Auch Brockes, der auf seinen „Sternen-Reisen“ ${ }^{57}$ vom „Seelen=Schwindel“ erfasst

fentlich - mit Reimarus überein (vgl. Anm. 58). Gott ist allein der "Schöpfer“, auch in seinen soteriologischen Aktivitäten. Christus wird auch im "Neujahrsgedicht auf $1722^{\prime \prime}$ nur von dem Dialogpartner „A.“ ins Gespräch gebracht, der die Existenz der Pluralität der Welten vom biblischen Weltbild her ablehnt und ironisch fragt, ob es schriftgemäß sei zu glauben, der Erlöser könne auch für die Bewohner einer Vielzahl anderer Welten gestorben sein, was „B." bejaht, falls die Bewohner anderer Planeten, wie er seinerseits ironisch kontert, „Auch etwa, durch uns gleiche Thaten, / In gleichen Stand mit uns gerahten" (W 2.1, S. 342).

55 William Derham: Astrotheologie oder Anweisung zu der Erkenntnis GOTTES aus der Betrachtung der Himmlischen Körper, aus der 5. Engl. Ausgabe übersetzet. 4. Aufl. v. Jo. Alberto Fabricio, nebst dessen Pyrotheologie, oder Anweisung zur Erkenntnis Gottes aus Betrachtung des Feuers. Hamburg 1745, S. 235. Fabricius hatte seine Übersetzung Brockes gewidmet.

56 Text, Übersetzung und einlässliche Interpretation von Keplers Psalmenparaphrase in Mahlmann-Bauer (Anm. 3), S. 159 ff. Zur Verarbeitung der Pluralität der Welten zu Beginn der Aufklärung vgl. auch Karl S. Guthke: Der Mythos der Neuzeit. Das Thema der Mehrheit der Welten in der Literatur- und Geistesgeschichte von der Kopernikanischen Wende bis zur Science Fiction. Bern, München 1983, S. 180 ff.; Billen/Hassel: Undeutbare Welt (Anm. 44), S. 42 f. Im Sinne Keplers aktualisiert auch Gottsched 1733/34 im Titelkupfer zu seinen Ersten Gründen der gesammten Weltweisheit Psalm 8: „Hier starret Sinn und Witz, der Geist verliert sich gantz, / In aller Welten Heer, Pracht, Ordnung, Lauf und Glantz. / O! was ist hier der Mensch? Er wäre nichts zu nennen, / Könnt er am Werke nicht, des Meisters Größe kennen." Johann Christoph Gottsched: Erste Gründe Der Gesammten Weltweisheit, Darinn alle Philosophische Wissenschaften in ihrer natürlichen Verknüpfung abgehandelt werden. 2 Theile. Leipzig 1732/33. Unveränd. Nachdruck in einem Bd. Frankfurt/M. 1965, unpag.

57 Vgl. z. B. A, S. 677 ff. Vgl. auch Anm. 43. - Zugleich sprengt die dem neuen Weltbild injizierte Allgegenwart Gottes - dies gegen die Vorstellung von einem deistisch in die Ferne gerückten ,Uhrmacher'-Gott, wie sie auch Fénelon gestattet - die Vorstellung von einem biblisch-christlichen, personhaft handelnden theistischen Gott der traditionellen lutherischen Physikotheologie. - Dieser Begriff, kritisiert Brockes, sei aus der Bibel - und zumal dem $\mathrm{AT}$ - übernommen und kanonisiert worden, dessen Anthropomorphisierung sei durch das 
wird und öfter das "Nichts" des Menschen vor der göttlichen Allmacht betont, ${ }^{58}$ findet im „Neujahrslied auf 1722“ diesen Trost (W 2. 1, S. 357):

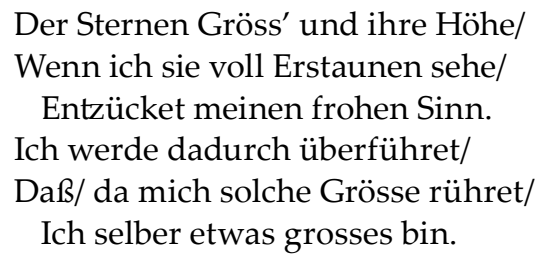

Und das ist für Brockes eigentlich der entscheidende, im „Firmament“ sinnlichemotional vollführte, im "Neujahrsgedicht auf 1722" aposteriorisch bewiesene „Lehr=Satz", dass man von Gott stets das „Größte“ denken müsse - „denn mich bedünckt: es sey / Ein kleiner Gott und kein Gott einerley“ (W 2.1, S. 334), ein "Lehr=Satz", „Der uns der Gottheit Gröss' recht anzusehn verbindet; / Da ja die Seele selbst, wenn ich es recht ermesse, / In Gottes Gröss' ihr eigne Grösse, ihr Heyl, ihr ewigs Wohl, ganz überzeugend findet." (W 2.1, S. 355 f.) ${ }^{59}$

Was also ist das - drittens - für ein Gott, der im ,Großen' der „ungeheuren Gruft" „ohn' Anfang, ohne Schrancken“, aber auch im ,Kleinen' und im Menschen „allgegenwärtig“ ist? Das „Neujahrsgedicht auf 1722“ bietet eine für „Das Firmament“ gültige Definition (IVG I, S. 353):

Gott ist kein alter Mann, kein Geist, wie and're Geister,

Er ist ein ewiges allgegenwärtigs All,

Ein unermesslich's Gantz, in dem, als wie ein Ball

Im weiten Ocean, nicht nur die Erd' allein,

menschlich-,,figürlich“-,,morgenländische“ Reden der Juden entstanden und „Der Gottheit unanständig“ (IVG VI, S. 288). Vgl. dazu auch Brockes' Gedicht „Gottes Allgegenwart“; A, S. $531 \mathrm{f}$. So polemisiert auch der Sprecher „B.“ im „Neujahrsgedicht auf 1722“: "An statt uns recht zum Schöpfer zu erheben, / Der aller Ewigkeit Unendlichkeiten füllt, / In dem wir weben, sind, und leben; / So stellen wir / Uns einen alten Greisen für, / Und einen solchen nicht einmal, / Als gegenwärtig hier auf Erden, / Nein! Er muß in des Himmels Saal / Noch allererst gesuchet werden." W.2.1, S. 336.

58 So auch eindrucksvoll im „Neujahrsgedicht auf 1722“ (W 2.1, S. 344 ff.). Das gilt erst recht, wenn Gott seine Allgewalt in Naturkatastrophen demonstriert. Vgl. den "Gesang zur Zeit des Ungewitter“: A, S. 277-280, hier Str. 14, S. 279: „Von unserm Nichts kann nichts so klar uns überführen, / Als wenn wir die Gewalt der Elementen spüren. / Die ungeheure Macht erweiset, wie so klein, / So elend, so gering und arm wir Menschen seyn."

59 Ferner überwindet das Subjekt den "Schock“ durch eine zunächst paradox anmutende neue, vertiefte Anthropo- und Geozentrik, eine Konzentration auf die vom Menschen allein überschaubare und beherrschbare Erde, die es nun genauestens zu erkunden und zu ,betrachten' gilt. Der Mensch sieht sich von daher neu berufen zum „Gott der Erde“ (Ps. 8, 6 f.). - Im „Firmament“ aber führt das Keplersche „ingenium“ nicht zur Selbsterhöhung, sondern wird in gleichsam ,barocker' Überwältigung „,begraben“ und in den Seelenschwindel und das Gefühl völliger Ohnmacht und Nichtigkeit hineingezogen. Und ähnlich wie im Kosmogonie-Sonett Greiffenbergs schlägt gerade dies in das Erlebnis der Gottesgewissheit um. In der völligen Selbstpreisgabe findet sich das Ich in mystischer Paradoxie im „allgegenwärt'gen Gott" wieder. 
Nein, ein unzählbar Heer von Sonnen, Sternen, Erden, Die bloß durch ihn umringt, erfüllt, erhalten werden, In stiller Majestät, in reger Ruhe schwimmt.

Bis ins Detail entspricht dieses panentheistische Gottesverständnis dem des Corpus Hermeticum und auch Greiffenbergs. Gott ist ein „unermesslich's Gantz“, also ein ,Hen', und ein ",allgegenwärtigs All“, ein ,Pan', er "umringt“ das gesamte Universum, „erfüllt" und „erhält" es, und das „Heer" der Welten „schwimmt" in ihm „in reger Ruhe“. Diese schon bei Greiffenberg thematisierte Paradoxie verweist auf die schöpferische Vitalität im Universum, das gleichwohl in Gott „ruht“. Dies impliziert - wie das „Schwimmen im Meer" auch im Firmament illustriert -, dass Brockes sich wie das Corpus Hermeticum keinen pneuma- oder luftleeren Raum im Kosmos vorstellen konnte, obwohl die Pluralität der Welten dies erforderte. ${ }^{60}$ Das Ich erlebt im Gedicht also keinen „horror vacui“, wie jüngst interpretiert, ${ }^{61}$ sondern das "Auge " "senckt“ sich „Ins unerforschte Meer des holen (= verborgenen, gekrümmten) Luft-Raums“; denn sonst würde Gott ja nicht „,allgegenwärtig“ sein, „alles erfüllen“ können und wäre nicht ,jederzeit" und überall zu finden und sinnlich zu erfahren. Er ist „kein Geist, wie and're Geister", kein reiner "Spiritus', der nur die "sensus interiores“ tingiert, sondern ein mit allen äußeren Sinnen spür- und erfahrbares Wesen. ${ }^{62}$ Darauf beruht Brockes'

60 Im Abschnitt über, die Leere' heißt es im CHD, S. 303: „etwas Leeres gibt es nicht, konnte es niemals und wird es niemals geben." „,...] denn auch wenn es möglich ist, das zu sehen, was an derartigen Dingen leer sein kann, so kann dennoch das, was als leer erscheint, - mag es nun klein oder groß sein, an Pneuma und Luft nicht leer sein." Ebd., S. 304. Das Pneuma wird allem Lebendigen von Gott eingehaucht (ebd., S. 274). „Das Pneuma, von dem alles erfüllt ist, mischt sich mit allen Dingen und belebt so alles, und dem Menschen ist der Geist zur Erkenntnis [= ,Gnosis'] gegeben, der - und das gibt es nur in diesem Fall - als fünfter Teil dem Menschen aus dem Äther zugestanden wird.“ Ebd., S. 260 f. „Die Luft aber ist das Werkzeug oder Hilfsmittel für alles, mittels dessen alles geschieht" (ebd., S. 278). Auch im „Neujahrsgedicht auf 1722“ spricht „B.“ von „der holen Lüfte weitem Kreis“ und wiederholt das „Grauen“ „vor solcher Tieffe," in prosanahen Madrigalversen: „Da denn dieß Grundund Grentzenlose Meer, / Das ungemessene Welt-Stern und Sonnen-Heer / Ihn, samt der gantzen Welt, zum Punct, zu nichtes machte. / Denn, dacht' er, wenn in solchen Gründen / Sich tausend tausend Welten finden, / Und in des Luft-Raums Abgrunds-Thal / Viel Sonnen ohne Mas' und Zahl; / So find' ich, dass der Raum so ungeheuer groß, / Daß gegen ihn die Welt ein kleiner Erden-Kloß, / Ein' Erbs, ein Senf- ein Sand-Korn scheint." W 2.1, S. 338 f.

61 Vgl. Billen/Hassel: Undeutbare Welt (Anm. 44), S. 46 ff.

62 Grundbedingung für die Vorstellung einer wechselseitigen Durchdringbarkeit von Geist und Materie ist die Überzeugung vom Kosmos als einem Lebewesen. Vgl. CHD, S. $154 \mathrm{f}$.: „Denn weder gab es im Kosmos etwas Totes, noch gibt es dies noch wird es künftig geben. Der Vater wollte nämlich, dass der Kosmos ein Lebewesen sei, solange er besteht. Deswegen muß er notwendigerweise auch ein Gott sein." Von daher ergeben sich Gradationen zwischen den ,Welten' von Geist und Materie (ebd., S. 153 f.): „Der Logos ist nun Abbild und Geist Gottes; der Körper Abbild der Idee und die Idee Abbild der Seele. Der feinste Teil der Materie ist die Luft, der feinste Teil der Luft die Seele, von der Seele aber der Geist und vom Geist Gott. Und Gott ist um alles und durchdringt alles, der Geist aber ist um die Seele, die Seele um die Luft, die Luft aber um die Materie.“ Auf Hermes' Aussage: „Und es gibt nichts 
unentwegter "sinnlicher Gottesdienst". Das die kosmische "Gruft" erfüllende „unsichtbare Licht" und die „lichte Dunkelheit" verweisen auf die hermetische Vorstellung, dass sich im göttlichen Licht, im Äther oder in der ,quinta essentia' die göttlichen Kräfte verbergen und all-wirksam in den Kosmos und mit der Luft auch auf die Erde übertragen. ${ }^{63}$ So begleiten Gottes Kräfte im ,Flug' bereits das Ich und plausibilisieren die Schlusspointe. ${ }^{64}$ Mit ihr begründet das „Neujahrsgedicht auf 1722“ auch seine nicht mehr aus der göttlichen Vorsehung, sondern aus der intellektuellen Verwandtschaft mit Gott hergeleitete Soteriologie (W 2.1, S.355):

Denn weil Gott selbst die Fähigkeit,

Von Seiner Grösse was zu dencken,

Und also fast Sich Selbst in unsern Geist zu sencken,

So wunderbar gewürdigt hat,

Wodurch sie gleichsam in der That

Mit Gott verbunden ist; so ist ja nicht zu glauben,

Daß, was mit Gott vereint vernichtigt werden kann.

Hieß dies der Gottheit nicht was von der Gottheit rauben?

Werdendes oder Gewordenes mehr, wo Gott nicht ist", fragt sein Sohn Tat zurück: „Also ist er in der Materie, mein Vater?" Hermes antwortet: "Ja, denn ist die Materie getrennt von Gott, welchen Platz willst du ihr dann zuteilen. [...] Magst du von Materie, Körper oder Sein sprechen, wisse, dass auch dies Wirkungen Gottes sind. Die Wirkkraft, die die Materie entstehen lässt, ist die Materialität; die Wirkkraft, die die Körper entstehen lässt, ist die Seinshaftigkeit. Und dies ist Gott, das All. Im All ist nichts, was nicht Gott ist." CHD, S. 158. Diese Vorstellung vom Kosmos als einem lebendigen Wesen und von dem Durchwirktsein der Materie, ja der Atome von Gott bzw. göttlichen Kräften hat auch Brockes expressis verbis vertreten. Vgl. IVG IV, S. 132 f.: „Durchdringt hingegen eine GOTTHEJT (so wie sie ja unstreitig thut, / Da Sie allgegenwärtig ist) an allen Orten alle Dinge, / So ist kein Cörperchen so klein, und kein Geschöpffe so geringe, / Das Sie nicht durch und durch erfüllt; in welchem Sie nicht würckt und ruht." Vgl. dazu Hans-Georg Kemper: Norddeutsche Frühaufklärung. Poesie als Medium einer natürlichen Religion. In: Religionskritik und Religiosität in der deutschen Aufklärung. Hrsg. v. Karlfried Gründer u. Karl Heinrich Rengstorf. Heidelberg 1989, S. 79-99, hier S. 85 ff.

63 So auch im „Neujahrsgedicht auf 1722“: „Der Gottheit nahe Majestät, / Die in und durch und über alles geht, / Scheint sich im Licht der Sonnen-Strahlen / Fast augenscheinlich abzumahlen, / Das Licht füllt alle Ding'; und nichts / Vergleicht an Grösse sich der Gröss' und Kraft des Lichts.“ W 2.1, S. 337. Vgl. ferner Brockes' Lehrgedicht „Die Luft“: IVG-R, S. 126ff).

64 Sie wird zugleich - analog zur Greiffenberg - bewirkt durch die von Brockes oft gepriesene wichtigste göttliche „Kraft“, nämlich „unsers Schöpfers Liebe, / Die eintzig Ihn, die Welt so schön zu machen, triebe“. So im Gedicht „Der weisse Schmetterling“ (W 2.1, S. 176-178, hier S. 176). Vgl. zu diesem problemgeschichtlich aufschlussreichen Gedicht Kemper (wie Anm. 62). Auf diese Liebe war eine Reihe von Traditionen und Naturphänomenen beziehbar: die stoisch-hermetische ,Sympathie', der durch Ficino hermetisch interpretierte platonische ,Eros', der als Liebes- und Schöpfungskraft wirkte (vgl. Kemper: Deutsche Lyrik [Anm. 1]. Bd. 3 [1988], S. 131 ff.), sowie die von Newton mathematisch errechnete, aber erst nach ihm mechanistisch verstandene Schwerkraft, die für Newton noch Zeichen der „Vergöttlichung des Universums" war. Vgl. dazu Billen/Hassel: Undeutbare Welt (Anm. 44), S. 13 f. Diese Universal-Liebe durchzieht - auch bei Greiffenberg (SW V, S. 461) - die ,Kette der Wesen' und garantiert die Unsterblichkeit des Universums und aller Lebewesen. Vgl. W 2.1, S. 177; IVG VIII, S. 314, 554; CHD, S. 144, 155. 
Hierin liegt auch der Grund für die Vorstellung einer psychophysischen ,Wiedergeburt' aller Lebewesen, wie sie auch dem Corpus Hermeticum, aber nicht dem lutherischen Dogma entspricht. ${ }^{65}$ Die Schlusspointe des „Firmaments“ wirkt so wie die ,epochale' sinnbildliche ,renovatio' des Ich von der ,barocken ,vanitas' zur Selbsterhöhung seiner - zugleich gegenüber dem „horror vacui“ schützenden - pantheistisch abgesicherten Gottähnlichkeit. ${ }^{66}$

\section{Wenn Brockes Gott abschließend als „Allgegenwärtiger Herr Zebaoth“ apost- rophiert (W 2.1, S. 359), so verweist dies auf die semantische Umcodierung und}

65 Jedenfalls trifft auf Brockes hier die Definition eines „Naturalisten“ oder „Deisten“ aus der auf den englischen Deismus bezogenen Sicht des Lutheraners Johann Georg Walch zu: „,da man der Natur mehr beylege; als sich's gebühre“ und „meinet, man könne durch die Vernunft alles dasjenige erkennen, was man zur Seligkeit zu wissen, nöthig habe, und brauche also die Offenbarung heiliger Schrift nicht.“ Johann Georg Walch: Historische und Theologische Einleitung in die Religions-Streitigkeiten, welche sonderlich ausser der EvangelischLutherischen Kirche entstanden. 5 Bde. 3. Aufl. Jena 1733-1736. Hier Bd. V/2, S. 176 f. - Im Zusammenhang mit der Lehre von der Lebendigkeit des Kosmos (vgl. Anm. 62) begründet Hermes auch die Wiedergeburt (CHD, S. 158): „Denn die Lebewesen sterben nicht, mein Sohn, sondern als zusammengesetzte Körper lösen sie sich auf. Ihre Auflösung aber ist kein Tod, sondern die Trennung einer Verbindung. Sie lösen sich aber nicht auf, um zugrunde zu gehen, sondern um von neuem zu werden. Denn worin besteht die Kraft des Lebens? Nicht in der Bewegung? Und was ist im Kosmos unbewegt? Nichts, mein Sohn!“ Die Wiedergeburt ist das Schwerpunktthema von Traktat XIII, der mit Hymne und Gebet endet (ebd., S. 159-188). Brockes entwickelt im "Neujahrsgedicht auf $1722^{\prime \prime}$ die Wiedergeburt zunächst aus einer Analogie der Jahreszeiten. Des „Cörpers Hässlichkeit im Alter" korrespondiert mit „unsrer Erden / Verächtlicher Gestalt im Frost“, die aber im Frühling zu neuem Leben erwacht. „So wird auch unser Leib, / Nachdem des Alters Frost ihn hier versehret, / Im ew'gen Frühling leicht verjünget und verklähret.“ (W 2.1, S. 352) Den Einwand von „A.“, Mutationen in der Natur könnten kein Analogie-Beweis für den Menschen sein (ebd., S. 353), wischt „B.“ beiseite, es verkleinere Gottes Schöpfermacht, ihm diese Veränderung im Bereich des Menschen nicht auch zuzutrauen. „Draus folget nun: dass Gott zwar die Veränderung, / Doch nicht den Untergang und die Vernichtigung, / So herrlicher Geschöpfe könne wollen. [...] Zumalen da wir überführet / dass die Vernichtigung nicht einst die Cörper rühret, / Weil ja bekannt, dass unser Leib zu Erde, / Nicht aber, wie du schwärmst, zu nichte, werde. [...] Nichts wird zu nichts, und alle Dinge bleiben / Im allgemeinen Raum, in Gottes Händen, stehn." (Ebd., S. 354) Im Zusammenhang mit der Wiedergeburt thematisiert Brockes das ihn auch sonst ungemein faszinierende Geheimnis des Samens, weil sich in ihm Geist und Materie unmittelbar zu verbinden scheinen und im Samen als entscheidender Wirkkraft des Lebens Gottes Wirkung unmittelbar spürbar ist: „Es stammet bloß aus Dir allein / Das worin sich, so wie es scheint, / Der Cörper und der Geist vereint, / Das unbegreifliche Geheimniß aller Saamen, / Und deren, allen Witz verwirrend Eigenschaft.“ Ebd., S. 358.

66 Brockes' eklektisch tätige Vernunft prüft in der Verarbeitung des neuen Weltbilds auch hermetische Vorstellungen und konserviert sie, wo sie ihr noch evident erscheinen. Analog deutet auch Hans Joachim Kreutzer im Blick auf Newton, der alchimistische Studien betrieb, auf Brockes und Johann Sebastian Bach den „,außerordentlich hohen Anteil“ der "Geheimwissenschaften in Bildung und Lektüre der Zeit“: „Der Weg der Erkenntnis führt nicht ins Grenzenlose schlechthin, der Mensch bleibt aufgehoben in einem von der Kraft Gottes bestimmten All." Hans Joachim Kreutzer: Weltalldichtung und Vollendung der Natur. Literaturtheorie im Umkreis Johann Sebastian Bachs. In ders.: Das zweite Leben der Künste. Literatur und Musik. Würzburg 2014, S. 9-35, hier S. 24, 26. 
damit auf die Gleich-Gültigkeit aller alten und neuen Namen für den „Unaussprechlichen" ${ }^{67}$ Diese Personalisierung des ,Pan' hat ihren religionsphilosophischen und zugleich psychologischen Grund in der in den Handlungen dieses All erfahrenen Kern-Kraft der ,Sympathie'. Und sie erweckt die preisende GegenLiebe der durch sie hervorgerufenen Kreaturen, die sich nach ,Analogie' ihrer Empfindungen auf etwas Persönliches richten muss. Denn der Mensch, so erklärt Herder in seiner Schrift Vom Geist der Ebräischen Poesie, kann nur zu einem ihm ähnlichen oder als persönlich-lebendig empfundenen Wesen (wie auch zur ,Mutter Natur') überhaupt eine Beziehung aufbauen. ${ }^{68}$ - Noch in Herders Gott-Gesprächen von 1800 erscheint die Angleichung als „das heiligste und gewiß göttliche

67 So ruft auch Klopstock Gott in der „Frühlingsfeier“ an, den er zugleich den „Namenlosesten" nennt, vgl. Klopstock: Oden (Anm. 24), S. 62, 66 f. Zugleich entspricht dies dem Wortgebrauch des Corpus Hermeticum, in dem ,der' Eine auch als, der' Schöpfer bezeichnet und zugleich als ,All' angebetet wird. Zur Erklärung heißt es im Asclepius: „[...] ich habe keine Hoffnung, daß man den Schöpfer der gesamten Erhabenheit und Pracht, den Vater und Herrn aller Dinge, mit einem Namen, sei er auch aus vielen zusammengesetzt, bezeichnen kann, ihn, der namenlos ist oder eher jeden Namen trägt, weil er ja einer und alles ist, so daß man entweder alles mit seinem Namen oder ihn selbst mit dem Namen von allem benennen muß." CHD, S. 280. Auf diese Passage beziehen sich mehrere an der Rehabilitation der altägyptischen Weisheit interessierte frühneuzeitliche Autoren. Vgl. Assmann: Moses der Ägypter (Anm. 3), S. 77, 179 ff. Vgl. dazu auch Goethes Schlussgedicht des Buchs Suleika aus dem Westöstlichen Divan, in dem die Geliebte mit „Allahs Namenhundert“ ausgeschmückt wird. Johann Wolfgang Goethe: West-östlicher Divan. In ders.: Gedichte und Epen. Bd. II. 9. Aufl. Textkrit. durchges. u. kommentiert v. Erich Trunz. München 1972, S. 88.

68 Aus ihr erwächst eine „freundschaftliche Vertraulichkeit“ als „Grund aller Beziehungen des Menschen zu Gott und Gottes zum Menschen“. Herder: Vom Geist der Ebräischen Poesie (Anm. 5), S. 968. - Noch in Herders klassischem Hauptwerk Ideen zur Philosophie der Geschichte der Menschheit (1784 ff.) gilt die hermetische Kraft der "Sympathie“ nicht nur als Ursache für die göttliche Emanation in die Welt („Eins in All!“), sondern auch umgekehrt wie bei Brockes für die erneute Rückkehr ins Göttliche („,All in Eins!“), wobei auch für Herder die vitalen Höherentwicklungen in der "grossen Lebenskette" als Beweise nach ,Analogie der Natur' dienen (vgl. CHD, S. 255 ff.): Johann Gottfried Herder: Ideen zur Philosophie der Geschichte der Menschheit. Hrsg. von Martin Bollacher. Frankfurt/M. 1989, S. 193. - Bereits in seinem frühen Rigaer Hymnus Fragment eines Lobgesanges an die menschliche Seele hat Herder unter deutlichem Rückbezug auf Psalm 8 die von Brockes erreichte Position der Erhöhung des Menschen in der Betrachtung der Größe Gottes dahingehend radikalisiert, dass die menschliche Seele selbst als Mikrokosmos in Analogie zum makrokosmischen Schöpfer das ,All' als ihr ,All' aus sich selbst schöpft und damit sich zur ,anima mundi' vergottet: Johann Gottfried Herder: Volkslieder. Übertragungen. Dichtungen. Hrsg. von Ulrich Gaier. Frankfurt a. M. 1990, S. 786-789. - Ein - allerdings die Existenz des Makrokosmos voraussetzendes - "Gleiches" gestaltet noch der späte Goethe im Zyklus Gott und Welt mit dem „Prooemion“ (,So weit das Ohr, so weit das Auge reicht / Du findest nur Bekanntes das Ihm (= Gott) gleicht, / Und deines Geistes höchster Feuerflug / Hat schon am Gleichnis, hat am Bild genug; [...]", und den anschließenden vier ,kosmologischen' Gedichten „Wiederfinden“, „Weltseele“, „Dauer im Wechsel“ sowie „Eins und Alles“ (Johann Wolfgang Goethe: Gedichte 1800-1832. Hg. v. Karl Eibl. Darmstadt 1998 (= Sämtliche Gedichte Bd. II), S. 489-495). In ihnen werden, so Eibl zutreffend, „die Gesetze des Makrokosmos immer aus ihrem Walten im erfahrbaren Mikrokosmos bedacht“. Kommentar, ebd., S. 1074. Vgl. zu diesem Zyklus auch Mahlmann-Bauer (wie Anm. 3), S. 172 ff. 
Gesetz": „Alles, was sich liebt, verähnlichet sich einander" ${ }^{\prime 69}$ Deshalb erblickt sich auch der Mensch, das geliebte würdigste Geschöpf, im Spiegel der göttlichen Natur als „wenig niedriger" "denn Gott“.

Und deshalb „verähnlicht" sich auch - poetologisch gewendet - in der Lyrik so oft Natur- und Liebespoesie, deshalb "leuchtet / Mir die Natur" so "herrlich" in Goethes „Mailied“, deshalb „lacht die Flur", deshalb erscheinen Natur und Liebe im „Mädchen" und dieses als ebenbildlicher "Spiegel“ der göttlichen Natur. ${ }^{70}$ Das hermetische Gottes- und Menschenbild prägt nun auch den Beginn der goethezeitlichen Lyrik und wird in ihr die mechanistische und nihilistische Entgötterung der Welt und des Menschen überleben. Nach dem hermetischen ,Spiegelgesetz' von Anziehung und Angleichung ist es kein Wunder, dass gerade ein Psalm mit ägyptischer Weisheit auch die aus Ägypten stammende Weisheit des Hermes angezogen hat und so als ,Bote' zur Einsicht in die Anfänge einiger hermetisch tingierter Kontexte und Texte frühneuzeitlicher Naturlyrik führen konnte.

69 Johann Gottfried Herder: Gott. Einige Gespräche. In ders.: Schriften zu Philosophie, Literatur, Kunst und Altertum. 1774-1787. Hrsg. von Jürgen Brummack u. Martin Bollacher. Frankfurt a. M. 1994, S. 785.

70 Johann Wolfgang Goethe: Mailied. In ders.: Gedichte 1756-1799. Hg. v. Karl Eibl. Darmstadt 1998 (= Sämtliche Gedichte Bd. I), S. 287 f. 


\section{„Des Abgrunds Raum" \\ Lyrische Ekstase(n) bei Barthold Heinrich Brockes}

Jörg Robert

\section{Ekstase als lyrische Form}

Einer viel zitierten Definition Martin Bubers zufolge bezeichnet der Begriff ,Ekstase' im Allgemeinen

[d]ie elementare Vorstellung [...] einer - mehr oder minder gedachten Vereinigung mit Gott. Ekstasis ist ursprünglich: Eingehen in den Gott. Enthusiasmos: Erfülltsein vom Gotte. Essen des Gottes, Einatmen des göttlichen Feuerhauchs, Liebeseinigung mit dem Gott (diese Grundform ist aller späteren Mystik eigen geblieben), Neugezeugtwerden, Wiedergeburt durch den Gott, Auffahrt der Seele zum Gotte, in den Gott [...]".

Buber betont entschieden den religiösen Erfahrungsgehalt des mystischen Erlebens, den Aspekt der unio mystica, die erotisch-ästhetische Erlebnis- und Ausdruckskomponenten eröffnet. Hier wirkt Thomas von Aquins bekannte Bestimmung der Mystik als cognitio dei experimentalis („erfahrende Gotteserkenntnis“) nach. Sie zeichnet sich dadurch aus, dass das Subjekt „,in sich den Geschmack der göttlichen Süße und das Wohlgefallen des göttlichen Willens wahrnimmt“. ${ }^{2}$ Für diese so genannte ,Erlebnis-' oder Erfahrungsmystik ist (etwa bei Meister Eckhart $^{3}$ ) das griechische Fremdwort „extasis mentis“ eingeführt; geläufige Alternativbegriffe sind ",alienatio“" oder „excessus mentis“, im Deutschen „Entrückung“, „Ver-“ oder „Entzückung.“ ${ }^{4}$ Ekstase bedeutet also „Austritt der Seele aus dem Körper" in einem „Erlebnis extrem intensiver Ergriffenheit bei gleichzeitigem Verlust der Körperempfindung und des Realitätsbezuges zur Umwelt“ ${ }^{5}{ }^{5}$ Dabei

1 Martin Buber: Werkausgabe. Bd. 2.2: Ekstatische Konfessionen. Hrsg., eingel. und kommentiert von David Groiser. Gütersloh 2012, S. 52 f.

2 Thomas von Aquin: Summa theologiae: Die deutsche Thomas-Ausgabe Bd. 18. Heidelberg 1953, II-II, 97, 2 ad 2.

3 Meister Eckhart: Lateinische Werke. Bd. 5. Hrsg. von Josef Koch, Bernhard Geyer und Erich Seeberg. Stuttgart 1936, S. 94.

4 Bei Guigo von Kastell (1088-1137) meint ,E.' die Lösung der Diener Gottes vom Irdischen durch Ekstase des Geistes (a terrenis per mentis excessum alienare), die zur Enthüllung der Geheimnisse Gottes führt. Guigo I. von Kastell: Consuetudines. Parisiis 1854. Capitulum LXXIX: De commendatione solitariae vitae, Abs. 4.

5 Wörterbuch der Mystik. Hg. v. Peter Dinzelbacher. 2. ergänzte Auflage. Stuttgart 1998, Art. Ekstase, S. 132. 
lässt sich mit Kurt Ruh zwischen Ekstase, Vision und Offenbarung unterscheiden:

Wie in der Ekstase (extasis, excessus, raptus) die visio erfolgt, so in der visio die Offenbarung (revelatio) [...] Die Ekstase ist der Akt, der die Bedingungen der leiblichen Existenz aufhebt, die visio die übersinnliche Erkenntnisund Erfahrungsform der visionären Person, die Offenbarung die Kundgebung der Überwelt. ${ }^{6}$

So präsent die Mystik gegenwärtig in ethno-anthropologischen, religions- und kulturwissenschaftlichen, aber auch in ästhetischen Debatten ist, ${ }^{7}$ so sehr fehlt es doch weiterhin an einer eigentlichen Literaturgeschichte der Ekstase. ${ }^{8}$ Dies gilt weniger für die mittelalterliche Mystik, die gerade in den letzten zwei Dekaden intensiv neu erschlossen wurde, ${ }^{9}$ als vielmehr für deren Rezeption und Transformation zwischen Spätmittelalter und ,Sattelzeit' - und darüber hinaus. ${ }^{10}$ Hier setzen die folgenden Überlegungen an. Sie widmen sich der Mystik nach und jenseits der Mystik. Im Mittelpunkt stehen lyrische Formen. In den lyrischen Ekstasen des 17. und 18. Jahrhunderts manifestiert sich ein doppelter Prozess: Einerseits eine dichte Rezeption semantischer Ressourcen mystischen Erlebens und Sprechens, andererseits deren Transfer auf Felder, in denen der Transzendenzbezug mehr und mehr zurücktritt gegenüber innerweltlichen Erschließungs- und Erfahrungsweisen. Formal aber bleiben die Komponenten ekstatischer Rede erhalten. Lyrische Ekstasen sind Texte über Gesichte, die den Versuch unternehmen, das Erlebnis narrativ und performativ nachzuvollziehen. ${ }^{11}$

6 Kurt Ruh: Geschichte der abendländischen Mystik. 2. Bd. Frauenmystik und Franziskanische Mystik der Frühzeit. München 1993, S. 78.

7 Einen aktuellen Überblick bieten etwa Volker Leppin: Die christliche Mystik. München 2007; Uta Störmer-Caysa: Einführung in die mittelalterliche Mystik. Stuttgart 2004; Deutsche und niederländische Texte des Mittelalters. Hg. v. Peter Dinzelbacher. Berlin, Boston 2012. Unüberholt bleibt Kurt Ruh: Geschichte der abendländischen Mystik. 5 Bde. München 1990-1999.

8 Eine wichtige Vorarbeit leistet eine komparatistische Studie von Christiane Augner, die "Gedichten der Ekstase in der Literatur des 16. und 17. Jahrhunderts" gewidmet ist und in diesem Zusammenhang neben der französischen, spanischen und englischen auch die deutsche Tradition in Gestalt Friedrich Spees, Johannes Schefflers / Silesius, Catharina Regina von Greiffenbergs und Quirinus Kuhlmanns einbezieht. Christiane Augner: Gedichte der Ekstase in der Literatur des 16. und 17. Jahrhunderts. Tübingen 2001, hier S. 9: „Nur in Ansätzen hat die literaturwissenschaftliche Forschung sich bisher mit der Problematik einer literarischen Darstellung der Ekstase auseinandergesetzt". Das Leitzitat dieses Beitrages entlehne ich einer 2011 erschienenen Studie von Julia Weitbrecht zum Thema „Reise und Heiligung in Legenden und Jenseitsreisen der Spätantike und des Mittelalters".

9 Deutsche Mystik im abendländischen Zusammenhang: neu erschlossene Texte, neue methodische Ansätze, neue theoretische Konzepte. Hg. v. Walter Haug. Tübingen 2000.

10 Zur europäischen Wirkung Jakob Böhmes im 17. und 18. Jahrhundert. Hg. v. Wilhelm Kühlmann und Friedrich Vollhardt. Berlin, Boston 2012.

11 Vgl. die Einteilung von Löser in „praktische (Erlebnis-) und spekulative (theoretisch-philosophische) Mystik“. Literaturwissenschaftliches Lexikon. Hg. v. Horst Brunner, Rainer Moritz. 2. Auflage. Berlin 2006, Art. Mystik, S. 285. 
Lyrische oder poetische Ekstasen in diesem Sinne stehen an einer Medienbzw. Gattungsgrenze: Sie übertragen das Schauen ins Erzählen und implementieren der Lyrik eine biographische Dimension, die immer wieder topische Narrative oder narrative Topiken bemüht: Seelen- und Himmelsreise, Vision und Unterweltsfahrt, Ertrinken und Versinken. ${ }^{12}$ Ausgenommen aus dem Untersuchungskorpus sind damit jene Texte, die sich der Ekstase in theoretisch-reflektierender Weise nähern - darunter die meisten Epigramme in Angelus Silesius' Cherubinischem Wandersmann ${ }^{13}$ oder jene Stücke der Spee'schen Trotznachtigall, deren brautmystische Konstellation in der petrarkistischen Tradition der reflektierenden Distanzliebe steht. ${ }^{14}$ Überhaupt wird die eigentlich erotische, bernhardinische Linie hier eine untergeordnete Rolle spielen. Lyrische Ekstasen sind performative Texte, weniger Meditationen als poetisch-mimetische Vollzüge religiösen Wissens und Handelns. Als religiöses Wissen in actu diskursivieren sie Grenzgänge, liminale Erfahrungen. Das Element der Narration und Transgression ist ihnen inhärent: Lyrische Ekstasen sind daher - im Sinne der Thomas'schen cognitio dei experimentalis - präadaptive Formen von Erlebnis- und Erlebenslyrik. Eine biographische Dimension ist ihnen inhärent. Lyrische Ekstasen sind Grenzfälle ästhetischer Kommunikation, für das Subjekt der Aussage ebenso wie für den Rezipienten. Die Reflexion auf die Grenzen des Darstellbaren ist den Texten daher eingeschrieben. ${ }^{15}$

Von den lyrischen Ekstasen des 17. und 18. Jahrhundert lassen sich die bekannten Makrothesen zur Geistes- und Ideengeschichte der Frühen Neuzeit neu reflektieren. Das religiöse Wissen der Lyrik hat symptomatische Qualität. Seit langem scheint ausgemacht, dass sich in der Frühen Neuzeit eine Literarisierung und Profanierung der Mystik vollziehe. Zudem wird eine „Tendenz zur Subjektivierung“ konstatiert, sofern „mit dem Zustand der Ekstase das menschliche

12 Maximilian Benz, Julia Weitbrecht: Die Formierung des Jenseits als Bewegungsraum in Jenseitsreisen der Spätantike und des Mittelalters (,Paulus-Apokalypse', ,Visio Pauli', ,Visio Tnugdali'). In: Mittellateinisches Jahrbuch 46 (2011), S. 229-243; weiterhin: Julia Weitbrecht: Aus der Welt. Reise und Heiligung in Legenden und Jenseitsreisen der Spätantike und des Mittelalters. Heidelberg 2011; Brigitte Pfeil: Mittelalterliche Jenseitsvorstellungen und Jenseitsreisen mit besonderer Berücksichtigung des Mönches Alber von Windberg. In: Jahresbericht des historischen Vereins für Straubing und Umgebung 102 (2002), S. 133-173, hier S. 133 f.; Peter Dinzelbacher: Vision und Visionsliteratur im Mittelalter. Stuttgart 1981; Mittelalterliche Visionsliteratur. Eine Anthologie. Hg. v. Peter Dinzelbacher. Darmstadt 1989. Zur Tradition der Unterweltsfahrten (descensus, Nekyia) von der Antike bis in die Neuzeit vgl.: Unterwelten - Modelle und Transformationen. Hg. v. Jörg Robert und Joachim Hamm. Würzburg 2014.

13 Nicht aber seine Heilige Seelen-Lust Oder Geistliche Hirten-Lieder der in Ihren Jesum verliebten Psyche (Breßlau 1657, 2., um 5 Bücher vermehrte Aufl. 1668).

14 Cornelia Rémi: Philomela mediatrix. Friedrich Spees Trutznachtigall zwischen poetischer Theologie und geistlicher Poetik. Frankfurt/M. 2006.

15 Vgl. Daniel Kazmeier: Poetik des Abbruchs: Literarische Figurationen von Negativität im 17. und 18. Jahrhundert (Pascal - Greiffenberg - Pyra). Erscheint Würzburg 2015; zur Tradition der via negativa vgl. Denys Turner: The Darkness of God, Negativity in Christian Mysticism. Cambridge 1995. 
Subjekt in den Mittelpunkt der Darstellung rückt. ${ }^{16}$ Die religiöse Erfahrung des Subjekts, so die These, verschiebt sich. Sie ist nicht mehr Erfahrung im Subjekt, sondern (Selbst-)Erfahrung des Subjekts, das sich seiner Teilhabe am Göttlichen bewusst wird. Damit ist jene Tendenz zur ,Selbstvergottung' („Vergöttung in GOtt“ bei Silesius) angesprochen, die Hans-Georg Kemper in seiner Habilitationsschrift und in seiner Geschichte der Lyrik in der Frühen Neuzeit als Tendenz der Barockmystik beschrieben hat. ${ }^{17}$ In der Identifikation von Gott und Subjekt, wie sie etwa bei Angelus Silesius vollzogen wird ${ }_{1}^{18}$ gelange die genuin vormoderne Mystik an einen Endpunkt. Literarisierung, Subjektivierung und Profanierung (bzw. Säkularisierung) sind demnach nur unterschiedliche Facetten eines Prozesses semantischer Umcodierung und Übertragung. Literatur und religiöses Wissen - die Seite der praxis pietatis - scheinen sich im Sog frühneuzeitlicher Ausdifferenzierungsdynamiken zu scheiden. Wo genuin religiöse Erfahrung war, emergiert nun die Religion des Subjekts.

Dass diese De- und Repotenzierung mystischer Semantiken jedoch ein widersprüchlicher und vielschichtiger, keineswegs einsinnig verlaufender Prozess ist, hat zuletzt die in der Frühneuzeitforschung auflebende Debatte um den Säkularisierungsbegriff gezeigt. ${ }^{19}$ Bei aller Skepsis gegen teleologische Verlaufsbegriffe und ,große Erzählungen' insgesamt zeigt die aktuelle Debatte doch ein differenziertes Bild. Es geht weniger darum, Säkularisierung als Konzept zu verabschieden als vielmehr darum, die ganz unterschiedlichen Dynamiken, Felder und Reichweiten exakt zu fassen, in denen sich Tendenzen der systemischen Entkopplung und semantischen Umcodierung religiöser Rede- und Empfindungsweise vollziehen. Auch im Bereich einer Mystik nach der Mystik wirken Kräfte

16 Augner: Gedichte der Ekstase (Anm. 8), S. 43.

17 Hans-Georg Kemper: Gottebenbildlichkeit und Naturnachahmung im Säkularisierungsprozess. Problemgeschichtliche Studien zur deutschen Lyrik in Barock und Aufklärung. 2 Bde. Tübingen 1981.

18 Winfried Freund: Sinnsuche - der Weg nach innen: Jakob Böhme, Angelus Silesius und die barocke Mystik. In: Annäherungen (2003), S. 48-58; Michael Fischer: „Du bist gantz schön“: das Motiv von der Schönheit Christi bei Angelus Silesius und seinen Zeitgenossen. In: Jahrbuch für Liturgik und Hymnologie 45 (2006), S. 193-213; Cezary Lipiński: Angelus Silesius: im Spannungsfeld zwischen "GOtt leben“ und „Selbst=vernichtigung“. In: Zwischen Verlust und Fülle. Studien zur Literatur und Kultur. Festschrift für Louis Ferdinand Helbig. Wrocław 2006, S. 133-174; Jan Mohr: Die zwei Füße des Mystikers: Spekulation und Andachtsübung in Angelus Silesius' "Cherubinischer Wandersmann“. In: Daphnis 36 (2007), 3-4, S. 539-564; Jan Mohr: Epigramm und Aphorismus im Verbund: Kompositionen aus kleinen Textformen im 17. und 18. Jahrhundert (Daniel Czepko, Angelus Silesius, Friedrich Schlegel, Novalis). Frankfurt/M. 2007; Angelus Silesius: Angelus Silesius: [der Mystiker]. Hrsg., ausgewählt und kommentiert von Gerhard Wehr. Wiesbaden 2011; Helen WatanabeO'Kelly: Ways of knowing. Blaise Pascal, Angelus Silesius and Catharina Regina von Greiffenberg. In: The present word (2013), S. 92-101.

19 Charles Taylor: Ein säkulares Zeitalter. Frankfurt/M. 2009 (zuerst engl.: A secular Age. Cambridge 2007); Literarische Säkularisierung im Mittelalter. Hg. v. Susanne Köbele u. Bruno Quast. Berlin 2014 (hier bes. die Einleitung der Herausgeber, S. 9-20). 
der Pluralisierung, wie sie die frühe Neuzeit insgesamt kennzeichnen. ${ }^{20}$ Keinesfalls nämlich erschöpft sich die Transformation mystischer Rede allein in einer Autonomisierung des profanen Eros (wie in der Brautmystik Spees oder des Angelus Silesius' mit ihren petrarkistischen Basiselementen und -konstellationen). Funktionen und Einsatzfelder mystischer Rede vervielfältigen sich überhaupt: Im Horizont der new science können Elemente mystischer Seelenerfahrung zur semantischen Ressource für naturphilosophisch-kosmologische Erfahrungen werden. Die cognitio dei experimentalis wird zum Medium kosmologischer Erkenntnis, bei der jedoch - darin liegt die Pointe - auch die Gefahren und die Abgründe der curiositas stets präsent bleiben. Die Versenkung in die Schöpfung - statt in den Schöpfer - ist der wunde Punkt einer kosmologischen Wende der Mystik am Ende der Vormoderne.

Am Beginn dieser Überlegungen steht eine kursorische Übersicht über Formen und Themen lyrisch-literarischer Himmelsreisen. Nach einem Blick auf verschiedene frühneuzeitliche Variationen der Seelenreise und des Enthusiasmus' (2.) soll die Ambivalenz mystischer Rede an einem Zyklus gezeigt werden, der zutiefst durch das Problemdreieck von Theologie, Naturwissenschaft und Literatur konfiguriert wird (3.). Das Eröffnungsgedicht von Barthold Hinrich Brockes Irdischem Vergnügen in Gott mit dem Titel „Über das Firmament" (1721) belegt die fortwirkende Symbiose religiösen Erlebens, naturwissenschaftlicher Erkenntnis und Selbsterfahrung des Subjekts. Der Blick in die Tiefe des Kosmos führt bis an die Grenze des Selbstverlusts. Die lyrische Selbsterfahrung wird zur Grenz- und Nahtoderfahrung (4.), die erst durch die Wiedergeburt in Gott wieder aufgehoben wird. Das Einleitungsgedicht lässt sich damit als Warnung aus dem Geist der curiositas-Kritik verstehen, mit der die Grenzen der Naturerkenntnis programmatisch gesteckt werden.

\section{Iter exstaticum - Mystiker und Kosmonauten}

In form- und literaturgeschichtlicher Hinsicht müsste eine Geschichte der lyrischen Ekstase eine Reihe poetologischer Leitbegriffe und Topoi bedenken. Sie müsste die Rezeption der Bacchus-Oden des Horaz (c. 2,19; bes. 3,25: "Quo me, Bacche, rapis“), die Theorie des dichterischen Enthusiasmus ${ }^{21}$ und der Inspiration, die Figuren des poeta vates und die Erfahrung des Erhabenen einschließen. Stofflich-thematisch gehören in dieses Feld die Visionen, Jenseits-, Unterweltsoder Himmelsreisen, die Levitationen und Himmelfahrten, die in der Form des Enthusiasmus bei Sarbiewski, Balde ${ }^{22}$ oder - davon abhängig - in Gryphius'

20 Pluralisierungen. Konzepte zur Erfassung der Frühen Neuzeit. Hg. v. Jan-Dirk Müller, Wulf Oesterreicher, Friedrich Vollhardt. Münster u. a. 2010; zur Frage des religiösen Wissens: Religiöses Wissen im vormodernen Europa (800-1800). Transfers und Transformationen. Hg. v. Annette Gerok-Reiter, Volker Leppin, Andreas Holzem. Tübingen 2015.

21 Volkhard Wels: Der Begriff der Dichtung in der Frühen Neuzeit. Berlin 2009, S. 179-194.

22 Eckart Schäfer: Deutscher Horaz. Conrad Celtis - Georg Fabricius - Paul Melissus - Jacob Balde. Die Nachwirkung des Horaz in der neulateinischen Dichtung Deutschlands. Wiesbaden 
Kirchhofsgedanken ${ }^{23}$ ein eigenes Subgenus ausbilden. Balde vergleicht seine Enthusiasmen mit Somnambulismus ${ }^{24}$ und Opium-Genuss. ${ }^{25}$ Die Enthusiasmen versetzen den Dichter bei der Bibellektüre ins Paradies, ${ }^{26}$ auf die Spitze der Pyramiden von Gizeh ${ }^{27}$ oder nach Konstantinopel und wieder zurück. ${ }^{28}$ Der poetische raptus dient hier nicht mehr der Erweiterung des religiösen Erlebens, sondern des Welterlebens schlechthin: Das berühmte Melancholia-Gedicht thematisiert den Drang der "libera mens" den topographischen ,Kerker' zu durchbrechen und auf den Flügeln der „divina poesis“ die Welt zu erkunden:

Semper ego inclusus Germanae finibus orae in Bavara tellure senescam [...]

libera mens tamen est: ubi vult, habitatque volatque. in pelago non impedit Auster,

in terris non tardat obex, transcendit et Alpes nubiferas ac sidera pulsat.

accedit Phoebi donum, divina poësis.

hac fretus velocior Euro

Euri nascentis patriam cunasque videbo, Aurorae rapiendus in ortum. ${ }^{29}$

Ewig bleib ich beschlossen in Deutschlands Grenzen, und altern muß ich im bayrischen Land. [...]

doch ist mein Geist frei: er wohnt und er fliegt, wo's ihm gutdünkt.

Nicht behindert Südsturm auf See ihn,

1976, S.178-195; Beate Promberger: Die ,Enthusiasmen` in den lyrischen Werken Jacob Baldes von 1643. Diss. München 1998. Bereits Eckart Schäfer hat (S. 178 f.) die 16 mit diesem Titel versehenen poetischen Ekstasen auf das rhetorische Verfahren der ,evidentia' bezogen und auf Berührungspunkte zwischen ihnen und der Meditationstechnik der Exercitia spiritualia hingewiesen.

23 Nach Jacobii Balde: Lyricorum Libri. Liber II. 39. Coloniae 1706; ders.: Silvarum Libri. Liber VII.8. Coloniae 1706.

24 Jacob Balde S.J.: Opera Poetica omnia (= OPO). Ndr. der Ausg. München 1729. Hrsg. und eingel. von Wilhelm Kühlmann und Hermann Wiegand. 8 Bde. Frankfurt/M. 1990, Bd. 2, S. $103 \mathrm{f} .:$ "Nimirum in speculationes Apollineas defixo, haut difficiliores sunt ascensus isti, quàm in somnambulantibus discursus per tecta."

25 Balde, OPO VII (Anm. 24), S. 12: „Quemadmodum Turcicum semen, quod opium vocant, praemorsum continuò mentem efferat, dum oblectat palatum: ita sensus istos, qui instar spirituum super aquam Pegaseam feruntur, Poëmati inspersos, vim habere titillandi ingenium, rapiendique cum voluptate, quò feruntur."

26 Balde: Silv. VII (Anm. 23), 6.

27 Balde: Lyr. IV (Anm. 23), 47.

28 Balde: Lyr. IV (Anm. 23), 37 bzw. IV, 39.

29 Balde: Melancholia - Schwermut. In: Lateinische Gedichte deutscher Humanisten: lateinisch und deutsch. Ausgew., übers. und erl. von Harry C. Schnur. Stuttgart 1967, S. 4 f. (v. 1 f.; 12-20; Übers. H.C. Schnur, an einer Stelle korrigiert). 
keine Schranke zu Land; selbst die Alpen, die wolkengekrönten, überfliegt er und pocht an die Sterne.

Ihm gesellt sich des Phoebus Gabe, die göttliche Dichtkunst.

Ihr vertrauend, wird schneller als Ostwind

ich des Ostwinds Ursprungsland und Wiege erblicken,

hingerissen zum Aufgang Auroras.

Eine nicht weniger bemerkenswerte Transformation mystisch-ekstatischer Seelen- und Himmelsreisen stammt von Athanasius Kircher. Schon der Titel seines Iter exstaticum, das 1656 erschien und seine endgültige, höchst erfolgreiche Endversion im Druck von 1671 fand, ${ }^{30}$ verweist auf die mystische Tradition, etwa Bonaventuras itinerarium mentis in Deum. ${ }^{31}$ Inhalt des Werkes ist eine geträumte Reise durch den Kosmos in Form eines dreiteiligen Dialoges zwischen zwei Figuren: dem Gottesschüler Theodidactus und seinem himmlischen Führer Cosmiel. Vermittelnd tritt ein Ich-Erzähler auf. Ein zweiter Teil (Iter exsctaticum II, zuerst 1657 erschienen) ist überschrieben ,iter exstaticum in Mundum subterraneum“ und widmet sich der Darstellung des Erdinneren und des Meeresgrundes.

Kirchers Umdeutung der mystischen Seelen- und Himmelsreise zur Imagination einer realen Expedition zeigt eine Transformation der religiösen Ekstase am Ende des 17. Jahrhunderts: „Die Profanierung der mystischen Ekstase hat also im deutschen Barock ein extremes Ausmaß angenommen“.32 Doch diese ,Profanierung' ist weder als einzige und endgültige Transformation, noch als Krisen- und Auflösungserscheinung zu sehen. Die de-sakralisierte Ekstase wird vielmehr frei und fungibel für epistemologische Erschließungsprojekte im zerdehnten Newton'schen Kosmos mit seiner Pluralität bewohnter Welten. Die Seelen- und Himmelsreise bietet sich als literarisches Erkundungsmedium für das „innerweltlich Unsichtbare“33 an. Aus Visionen werden im 18. Jahrhundert Visitationen, aus spirituellen Entzückungen Entrückungen zu fremden Welten, aus Jenseitsfahrten imaginierte Weltraumexpeditionen.

In den 1740er Jahren erscheinen zwei Texte, in denen sich die topischen Narrative der Unterwelts- und der Himmelsfahrt in ironischer Weise in pseudo-Itinerare verwandeln. Der descensus ad inferos in Ludvig Holbergs neulateinischem Roman Nicolai Klimii iter subterraneum (1741), der die Reise eines norwegischen Bacchalaureus gleichen Namens zum Mittelpunkt der Erde schildert - eine ironische Auseinandersetzung mit dem kosmologischen Schrifttum und den von Edmond Halley ausgehenden Hohlerde-Spekulationen des ausgehenden 17. Jahrhunderts. Auf der anderen Seite, der des ascensus, Die Geschwinde Reise auf dem

30 Harald Siebert: Die große kosmologische Kontroverse: Rekonstruktionsversuche anhand des Itinerarium exstaticum von Athanasius Kircher SJ (1602 - 1680). Stuttgart 2006.

31 Kemper: Gottesebenbildlichkeit Bd. 1 (Anm. 17), S. 163-180.

32 Kemper: Gottesebenbildlichkeit Bd. 1 (Anm. 17), S. 199.

33 Hans Blumenberg: Das Interesse am innerweltlich Unsichtbaren. In: Die Legitimität der Neuzeit. Erneuerte Ausgabe. Frankfurt/M. 1996, S. 422-439. 
Lufft-Schiff nach der obern Welt, welche jüngstlich fünff Personen angestellt (1744). ${ }^{34}$ Sie stammt aus der Feder des Leipziger Astronomen Eberhard Christian Kindermann, den Martin Mulsow zuletzt als einen ,Freigeist' im akademischen Kreis um Gottsched, Mylius und Kästner gewürdigt hat. ${ }^{35}$ Seine Geschwinde Reise baut auf einem Vorgängerwerk Reise in Gedanken durch die eröffneten allgemeinen Himmelskugeln (1739) auf, das schon im Titel an die Tradition des Kircher'schen Iter ecstaticum anschließt. Der Roman von 1744 hat eine allegorische Struktur: Die fünf Kosmonauten, die sich anschicken, „eine Reise von der Unter- nach der Oberwelt anzustellen“ (S.40), sind die fünf Sinne. ${ }^{36}$ Auf der Rückreise von einem neu entdeckten Marsmond bemerken sie einen Kometen, dessen Bewohner mit „elastischen“, d. h. „,̈therische[n] Cörper[n]“ ausgestattet sind und der auf die Sonne zurast. Dies eröffnet den Reisenden Gelegenheit, Thesen über abgeschiedene Seelen und ihre feinstoffliche Natur zu entwickeln. Kindermann schließt dabei an hermetische Spekulationen innerhalb des Gottsched-Umfelds an. Gottsched selbst hatte im Rahmen seiner Societas Conferentium in den Jahren 1732-1734 eine Abhandlung mit dem vielsagenden Titel Philosophische Mutmaßungen von dem Aufenthalte der abgeschiedenen Seelen verfasst. ${ }^{37}$ Kindermanns Geschwinde Reise ist die narrative Umsetzung dieser säkularen, hermetisch-alchemistisch geprägten Jenseitsspekulation. Zugleich verweist die allegorische Einkleidung - die fünf Sinne reisen zum Mond - auf den epistemologischen Charakter dieser Phantasie: Die Reise zum Mond ist eine Reflexion auf Reichweiten und Grenzen sinnlicher Erkenntnisse über das Weltall. An den Grenzen des Wissens, in der Grauzone des Zweifelhaften, findet die Literatur ihre epistemologische Zuständigkeit und Legitimation.

Von hier aus ist es nur ein Schritt zu Barthold H. Brockes. ${ }^{38}$ Dass auch er lebhaft an den seit Fontenelle prosperierenden Spekulationen um die ,Pluralität der

34 Eberhard Christian Kindermann: Die geschwinde Reise. (o. Hg.) Zürich 2006, S. 37-87; Frank Baudach: Planeten der Unschuld - Kinder der Natur. Die Naturstandsutopie in der deutschen und westeuropäischen Literatur des 17. und 18. Jahrhunderts. Tübingen 1993, S. 232 250 .

35 Martin Mulsow: Freigeister im Gottsched-Kreis. Wolffianismus, studentische Aktivitäten und Religionskritik in Leipzig 1740-1745. Göttingen 2007, S. 100-103.

36 Vgl. Jakob Balde: Urania victrix. liber I - II = Die siegreiche Urania. Hrsg., übers. u. komm. v. Lutz Claren, Wilhelm Kühlmann, Wolfgang Schibel, Robert Seidel und Hermann Wiegand. Tübingen 2003; Wilhelm Kühlmann, Robert Seidel: Askese oder Augenlust? Sinnesvermögen und Sinnlichkeit bei Jakob Balde SJ und Barthold Heinrich Brockes. In: Iliaster. Literatur und Naturkunde in der frühen Neuzeit. Festgabe für Joachim Telle zum 60. Geburtstag. Hrsg. von Wilhelm Kühlmann und Wolf-Dieter Müller-Jahncke. Heidelberg 1999, S. 131-166.

37 Mulsow: Freigeister im Gottsched-Kreis (Anm. 35), S. 102.

38 Das literaturwissenschaftliche Interesse an Brockes' physikotheologischer Naturlyrik und ihren epistemologischen Fundamenten scheint ungebrochen. Im Folgenden eine Auswahl der wichtigsten und neuesten Arbeiten: Natalie Binczek: Mikroskopie des Sandes. Zu Christian Wolff und Barthold Heinrich Brockes. In: Biologie, Psychologie, Poetologie. Verhandlungen zwischen den Wissenschaften. Hrsg. von Walburga Hülk und Ursula Renner. Würzburg 2005, S. 201-219; Roland Borgards: Poetik des Schmerzes. Physiologie und Literatur von Brockes bis Büchner. München 2007, S. 63-82; Bettina Clausen: „Sie kam mir für, 
Welten' und deren Bewohner partizipierte, ist längst gesehen worden. ${ }^{39}$ Brockes' „Faszination vom Motiv der Weltraumreise ${ }^{40}$ ist im Irdischen Vergnügen überall greifbar. Im langen, erzählenden Gedicht Traum-Gesicht ${ }^{41}$ sieht sich Brockes in der Tradition von Keplers Somnium während einer kosmologischen Traum-Reise zu einem unbekannten Planeten entführt, der von exotischen Wohlgerüchen, aber auch von „ewge[r] Dämmrung“ erfüllt ist (161). Dort sieht er sich plötzlich einer „ungezehlten Schaar / Besonderer Geschöpf“ (162) gegenüber, die wegen des dämmrigen Lichts mit sechs Augen ausgestattet sind und sich aufgrund ihrer ätherischen „Flüchtigkeit“ schwebend fortbewegen - auch dies Reflex der eben angesprochenen, hermetischen Spekulation über die ätherischen Körper der Abgeschiedenen. Was an den rätselhaften Wesen auffällt, ist ihre gleichsam hyperästhetische Sensibilität, z. B. für alle olfaktorischen Reize: „Diß scheinen Seelen, / Die bloß durch einen Sinn sich mit der Welt vermählen“. Dies gilt auch für die Bewohner eines weiteren Planeten, der zweiten Station der Traum-Reise,

wie eine Königin“. Zur Naturlyrik des Ratsherrn Barthold Heinrich Brockes (1680-1747). In: Hamburg im Zeitalter der Aufklärung. Hrsg. von Inge Stephan und Hans-Gerd Winter. Berlin, Hamburg 1989, S. 161-184; Harold P. Frey: Gleich einem versificierten Buffon. $\mathrm{Zu}$ Chronologie und Quelle von Brockes' Betrachtungen über die drey Reiche der Natur. In: Natura loquax. Naturkunde und allegorische Naturdeutung vom Mittelalter bis zur frühen Neuzeit. Hrsg. von Wolfgang Harms und Heimo Reinitzer. Frankfurt/M. 1981, S. 257-276; Harold P. Frey: Die Betrachtungen über die drey Reiche der Natur als Schlüssel zu einer neuen Brockes-Deutung. In: Lessing-Yearbook 11 (1979), S. 142-164; Barbara Hunfeld: Der Blick ins All. Reflexionen des Kosmos der Zeichen bei Brockes, Jean Paul, Goethe und Stifter. Tübingen 2004; Hans-Georg Kemper: Naturkräfte. In: Barthold Heinrich Brockes: Irdisches Vergnügen in Gott. Naturlyrik und Lehrdichtung. Hrsg. und ausgewählt von Hans-Georg Kemper, Stuttgart 1999, S. 148-152; Uwe-Karsten Ketelsen: Die Naturpoesie der norddeutschen Frühaufklärung. Poesie als Sprache der Versöhnung: alter Universalismus und neues Weltbild. Stuttgart 1974; Jörg Kreienbrock: „Merk's! Merk's!“ Aufmerksamkeit als Medium experimenteller Wahrnehmung bei Barthold Heinrich Brockes. In: „Es ist nun einmal zum Versuch gekommen“. Hrsg. von Michael Gamper, Martina Wernli und Jörg Zimmer. Experiment und Literatur I. 1580-1790. Göttingen 2009, S. 241-254; Günter Peters: Blumenblitze. Lektüre und Konstruktion der Natur in der physikotheologischen Ästhetik von Brockes zu Goethe. In: Ästhetik und Naturerfahrung. Hrsg. von Jörg Zimmermann. Stuttgart-Bad Cannstatt 1996, S. 195-222; Günter Peters: Die Kunst der Natur. Ästhetische Reflexion in Blumengedichten von Brockes, Goethe und Gautier. München 1993; Wolfgang Preisendanz: Naturwissenschaft als Provokation der Poesie. Das Beispiel Brockes. In: Frühaufklärung. Hrsg. von Sebastian Neumeister. München 1994, S. 469-494; Klaus Weimar: Gottes und der Menschen Schrift. Zum vollkommenen Gedicht des Barthold Hinrich Brockes. In: Merkur 45 (1991), S. 1089-1095; Carsten Zelle: Das Erhabene in der deutschen Frühaufklärung. Zum Einfluß der englischen Physikotheologie auf Barthold Heinrich Brockes' Irdisches Vergnügen in Gott. In: Arcadia 25 (1990), S. 225-240.

39 Karl Siegfried Guthke: Der Mythos der Neuzeit. Das Thema der Mehrheit der Welten in der Literatur- und Geistesgeschichte von der kopernikanischen Wende bis zur Science Fiction. Bern, München 1983, S. 274-278; Karl Richter: Literatur und Naturwissenschaft. Eine Studie zur Lyrik der Aufklärung. München 1972, S. 170 ff.

40 Guthke: Mythos der Neuzeit (Anm. 39).

41 B. H. Brockes: Irdisches Vergnügen in GOTT. 4. Teil. Tübingen 1753, S. 160-166. 
die "gleichsam Geister waren“ und nur für akustische Sensationen empfindlich sind. Dies führt Brockes zu der Spekulation, ob

nicht noch verschiedne Erden

Im Reiche der Natur vielleicht gefunden werden,

In welchen den Bewohnern nicht allein

Fünf Sinnen, noch vielmehr, vielleicht geschencket seyn. (IVG IV, 1753, 166)

Brockes setzt solche Spekulationen, die immer wieder der "philosophischen Frage nach dem Rang des Menschen im belebten Kosmos ${ }^{\prime 42}$ gelten, in zahlreichen weiteren Texten, z. B. in einer Fortsetzung "Zum Traum-Gesicht" oder in den Gedichten "Vier Welten" und "Vergleichung", fort. Auch sie sind in der Forschung stets im Hinblick auf das Thema der Pluralität der Welten behandelt worden. Ihre formgeschichtliche Position in einer Geschichte lyrischer Ekstasen ist jedoch nirgends thematisiert worden. Und doch erweist sich gerade das Gedicht „TraumGesicht" als kosmologisch-spekulative Fortführung des alten Visions- und Jenseitsreise-Narrativs: Von der Entrückung über den Seelenflug bis hin zur Vision ätherischer und hyperästhetischer Aliens, die in ihrer „ungemeine[n] Flüchtigkeit", zumal mit ihren „Schwanen-Federn" (162), entweder wie abgeschiedene Seelen oder Engel wirken, sind die christlich-religiösen Bildresiduen nicht zu übersehen. Kosmologie und extraterrestrische Spekulation kleiden sich in älteste religiöse Narrative und Topiken - die der Visions- und Jenseitsfahrten, der mystisch-ekstatischen Trancen und Enthusiasmen. Dieser Vorgang ist mit dem Begriff ,Säkularisierung' nur unzureichend umschrieben. Es handelt sich vielmehr um eine Verschiebung religiöser Rede in einen neuen Kontext, der gleichwohl von religiösen Sinnerwartungen und Energien durchzogen ist und bleibt. Die Entkopplung der Wissensbereiche ist also nur eine relative. In Brockes' Fall erfüllt die alte Form des iter extaticum den Zweck, die Grenzen des „innerweltlich Unsichtbaren", hier den fernen Rand des Kosmos, wenigstens in der TraumImagination sichtbar zu machen. Form- und Funktionsgeschichte bedingen sich also wechselseitig. Das iter extaticum soll die Tiefen des Kosmos ausleuchten und erhellen. Noch in diesem Extremfall erweist sich Brockes' Dichtung als „Perspectiv $^{\text {“43 }}$ der Naturerkenntnis, als Wahrnehmungsexperiment.

\section{Glückseelige Ertrinkung - Brockes am Abgrund}

Auch andere Texte des Irdischen Vergnügens in Gott lassen sich in die Tradition der lyrischen Ekstasen, der Jenseitsreisen, Visionen, Traumgesichte und Himmelsflüge einreihen. Welche Bedeutung diese Form insgesamt für den Zyklus besitzt, zeigt bereits das Eröffnungsgedicht mit dem Titel „Das Firmament“,

42 Guthke: Mythos der Neuzeit (Anm. 39), S. 277.

43 Martina Wagner-Egelhaaf: Gott und die Welt im Perspektiv des Poeten. Zur Medialität der literarischen Wahrnehmung am Beispiel Barthold Hinrich Brockes'. In: Deutsche Vierteljahrsschrift für Literaturwissenschaft und Geistesgeschichte 71 (1997), S. 183-216.

44 Die beste und einlässlichste Interpretation bietet Hunfeld: Blick ins All (Anm. 38), S. 63-70. 
interessante Variation der eben dargestellten Himmelsreisen bietet. In zwanzig Alexandrinerversen schildert der Autor ein prekäres Ekstase-Erlebnis, das die Form des iter extaticum und des Visionsberichts aufgreift. Seiner Position in der Sammlung entsprechend hat das Gedicht proömialen Charakter, denn „,[n]icht allein der Himmel, sondern das Projekt des Irdischen Vergnügens selbst wird hier ausgelotet." ${ }^{45}$

Das Firmament.

Sir. XLIII, 1

Man siehet seine Herrlichkeit, an der mächtigen grossen Höhe, an dem hellen Firmament/ an dem schönen Himmel

$+++$

Als jüngst mein Auge sich in die Sapphirne Tieffe,

Die weder Grund, noch Strand, noch Ziel, noch End' umschrenckt,

Ins unerforschte Meer des holen Luftraums, senckt',

Und mein verschlungener Blick bald hie- bald dahin lieffe,

Doch immer tieffer sank; entsatzte sich mein Geist,

Es schwindelte mein Aug', es stockte meine Sele

Ob der unendlichen, unmäßig-tieffen Höle,

Die, wol mit Recht, ein Bild der Ewigkeiten heißt,

So nur aus GOtt allein, ohn' End' und Anfang, stammen.

Es schlug des Abgrunds Raum, wie eine dicke Flut

Des Boden-losen Meers auf sinckend Eisen thut,

In einem Augenblick, auf meinem Geist zusammen.

Die ungeheure Gruft voll unsichtbarem Lichts,

Voll lichter Dunckelheit, ohn' Anfang, ohne Schranken,

Verschlang sogar die Welt, begrub selbst die Gedanken;

Mein ganzes Wesen ward ein Staub, ein Punct, ein Nichts,

Und ich verlohr mich selbst. Dieß schlug mich plötzlich nieder;

Verzweiflung drohete der gantz verwirrten Brust:

Allein, o heylsams Nichts! glückseliger Verlust!

Allgegenwärt'ger GOtt, in Dir fand ich mich wieder. ${ }^{46}$

Es handelt sich um den „wohl erste[n] Text in der deutschen Literatur überhaupt, der sich der Wahrnehmung des leeren physikalischen Raumes ausliefert und sie beschreibt." ${ }^{47}$ Dabei besteht eine irritierende Spannung zum Motto: Der Blick in den gestirnten Himmel zeigt weniger - wie das Zitat aus Jesus Sirach sugge-

45 Hunfeld: Blick ins All (Anm. 38), S. 64.

46 Ich zitiere nach der Ausgabe: B.H. Brockes: Irdisches Vergnügen in GOTT, bestehend in Physicalisch- und Moralischen Gedichten. Erster Theil. 5. Auflage. Tübingen 1732, S. 54.

47 Albrecht Koschorke: Die Geschichte des Horizonts. Grenze und Grenzüberschreitung in literarischen Landschaftsbildern. Frankfurt/M. 1990, S. 111. 
riert - die Herrlichkeit des Herrn in seiner Schöpfung an, als die Gefahr, sich in der "Penetration des unendlichen Raumes " ${ }^{48} \mathrm{zu}$ verlieren. Das Experiment einer ,absoluten Beobachtung', wie es hier simuliert wird, mündet um ein Haar in die Annihilation des Wahrnehmungssubjekts. ${ }^{49}$ Brockes aktualisiert Form und Textsorte des epischen Visionsberichts. Dabei bleiben - abgesehen von der stereotypen Zeitangabe (,jüngst“) - alle konkreten Umstände und Rahmungen des Erlebnisses ausgespart und unbestimmt. Unvermittelt setzt der Text mit dem Eintauchen in die "Sapphirne Tieffe" des Himmels ein; der Blick des Sprechers ist haltlos, die Wahrnehmung absolut, gleichsam randlos, und der Leser wird in diese rahmen- und randlose Wahrnehmung, in den Absolutismus des ästhetischen „Totaleindrucks“, buchstäblich mitgerissen..${ }^{50}$ Die leitende metaphora continua des Textes - die Überblendung von tiefster Höhe und höchster Höhe, Firmament und Meeresgrund - ist als argute Pointe kaum originell. Brockes gewinnt ihr jedoch ambivalente, ja negative Züge ab. Von der "Süße“ des Versinkens (wie in Giacomo Leopardis L'infinito: „e 'l naufragar m'è dolce in questo mare“) ist nirgends die Rede, kein Schiff bietet Halt und Zuflucht. Brockes' erleidet nicht Schiffbruch,

48 Koschorke: Geschichte des Horizonts (Anm. 47), S. 112.

49 Das lyrische Subjekt begegnet hier dem „mysterium tremendum “ bzw. einer „tremenda majestas“. Dieses „Moment der schlechthinnigen Übermacht“ induziert dem Subjekt „das Gefühl des eigenen Versinkens Zunichtewerdens Erde-, Asche- und Nichts-Seins“. So Rudolf Otto: Das Heilige. Über das Irrationale in der Idee des Göttlichen und sein Verhältnis zum Rationalen. München 2004 (zuerst 1917), S. 23. Dieses Gefühl führt, wie Otto weiter schreibt, „zu der ,annihilatio' des Selbst auf der einen Seite und zu der Allein- und All-realität des Transzendenten auf der anderen Seite, wie sie gewissen Formen der Mystik eigen sind."(S. 24). Von Kant und Schiller her gesehen haben wir es bei Brockes' auto-ästhetischem Experiment mit einer Erfahrung des Erhabenen, mit Kant genauer des „mathematisch Erhabenen“, zu tun. Immanuel Kant: Kritik der Urteilskraft. In ders.: Werke in 6 Bänden. Band 5: Kritik der Urteilskraft und Schriften zur Naturphilosophie. Darmstadt 1957, § 25, S. 333. Das Erhabene ist, so könnte man sagen, eine systematische Überforderung der Wahrnehmungspotentiale des Menschen, ein hyper-ästhetisches Phänomen, dessen Effekte gestaltpsychologisch auf dem Verlust von Kontur und „Bestimmtheit“ beruhen und dessen Sinn jenseits der Ästhetik - in der ,indirekten Darstellung des Übersinnlichen“ - liegt, Friedrich Schiller: Über Anmut und Würde. In ders.: Sämtliche Werke. Band 5: Philosophische Schriften, Vermischte Schriften. Düsseldorf 1997, S. 519: „Jede Erscheinung, deren letzter Grund aus der Sinnenwelt nicht kann abgeleitet werden, ist eine indirekte Darstellung des Übersinnlichen.“ Kant: „Erhaben nennen wir das, was schlechthin groß ist“. Es übersteigt damit die "Auffassung (apprehensio) und Zusammenfassung (comprehensio aesthetica)". Kant: Kritik der Urteilskraft § 26, S. 337; Kant: Ebd., S. 336: „Erhaben ist, was auch nur denken zu können ein Vermögen des Gemüts beweiset, das jeden Maßstab der Sinne übertrifft." Vgl. Carsten Zelle: Das Erhabene in der deutschen Frühaufklärung. Zum Einfluß der englischen Physikotheologie auf Barthold Hinrich Brockes' Irdisches Vergnügen in Gott. In: Arcadia 28 (1990), S. 225-240.

50 Dieser Effekt ähnelt jenem, den Kleist in einer berühmten Rezension („Empfindungen vor Friedrichs Seelandschaft", 1810) über Caspar David Friedrichs Seelandschaft beschreibt: „Das Bild liegt, mit seinen zwei oder drei geheimnißvollen Gegenständen, wie die Apokalypse da, als ob es Youngs Nachtgedanken hätte, und da es, in seiner Einförmigkeit und Uferlosigkeit, nichts, als den Rahm, zum Vordergrund hat, so ist es, wenn man es betrachtet, als ob einem die Augenlider weggeschnitten wären." Heinrich von Kleist: Sämtliche Werke und Briefe. Hrsg. von Helmut Sembdner. 2 Bde. München 1993, Bd. 2, S. 327. 
er ertrinkt, weil er dem Element ungeschützt ausgesetzt ist. Schon mit der ersten Zeile setzt dieser Sturz ins Bodenlose ein. Des „Abgrunds Raum“ wird mit einer "Gruft" gleichgesetzt. Dies gibt der Betrachtung des göttlichen Kosmos etwas Ambivalentes: Schwindel, Ohnmacht, (Beinahe-)Tod, kurz afflictio und desperatio, muss gewärtigen, wer sich der „Herrlichkeit an der mächtigen grossen Höhe“ (wie es im Motto gebenden Psalm heißt) ausliefert. So scheint der Text sein Motto zu konterkarieren: Naturerfahrung und Gotteserfahrung stehen in einer Spannung zueinander, bilden buchstäblich eine mise en abyme, die der Sprecher - das aisthetische Subjekt - durchschreiten muss, um eine angemessene Haltung für den weiteren Zyklus einzuüben. ${ }^{51}$

Während Leopardis infinito das Erbe des idealistischen Sublimen antritt, das scheinbar ohne „Religionströstungen" ${ }^{52}$ auskommt, speist sich Brockes' Text aus älteren Codes und Schichten. Vorstellungen vom Versinken und Ertrinken im Abgrund der Gottheit gehören zur Topik mystisch-ekstatischer Rede, wie ein Beispiel aus Johannes Schefflers / Angelus Silesius' Cherubinischem Wandermann zeigt:

\section{Die glükseelige Ertrinkung.}

Wenn du dein Schiffelein aufs Meer der GOttheit bringst: Glückseelig bistu dann/ so du darinn Ertrinkst. ${ }^{53}$

Die Vorstellung vom ,glückseligen Ertrinken' in Gott ist der Kern einer ekstatischen (Selbst-)Auslöschungsphantasie, die Freud viel später, von Romain Rolland inspiriert, als „ozeanisches Gefühl“ ${ }^{54}$ bezeichnen wird. In den Spielarten einer "gottlosen Mystik“ um und nach $1900^{55}$ wirkt sie, von Schopenhauer und Nietzsche geprägt, als Sehnsucht nach der Aufhebung des principium individuationis weiter: Philosophisch in Freuds Todestrieblehre, poetisch in Gottfried Benns ekstatischen Regressionsphantasien, Trance-Zuständen und „Lockerungen“, seinen performativen Entgrenzungen (,Karyatide“) oder Zerfaserungen der Diskursivitätsstruktur des Textes (Rönne-Novellen), die in einer Geschichte der literarischen Ekstatik einen besonderen Platz einnehmen müssten. ${ }^{56}$

51 Auch Kant gebraucht die Figur des ,Abgrunds“ im Zusammenhang mit Enthusiasmus und Einbildungskraft: „Das Überschwengliche für die Einbildungskraft [...] ist gleichsam ein Abgrund, worin sie sich selbst zu verlieren fürchtet". Kant: Kritik der Urteilskraft (Anm. 49), $\S 27$, S. 345 .

52 Friedrich Schiller: Werke. Nationalausgabe. Hrsg. von Herbert Kraft. Bd. 12. Weimar 1989, S. 24.

53 Angelus Silesius (Johannes Scheffler): Cherubinischer Wandersmann. Kritische Ausgabe. Hrsg. von Louise Gnädinger. Bibliogr. ergänzte Ausg. Stuttgart 2000, IV 139, S. 174.

54 Sigmund Freud: Gesammelte Werke. Bd. 10: Werke aus den Jahren 1913-1917. Frankfurt/M. 1973 S. 423 (Das Unbehagen in der Kultur).

55 Uwe Spörl: Gottlose Mystik in der deutschen Literatur um die Jahrhundertwende. Paderborn 1997.

$56 \mathrm{Zu}$ diesem Gesamtkomplex einer Mystik der klassischen Moderne vgl. Wolfgang Riedel: Wandlungen und Symbole des Todestriebs. Benns Lyrik im Kontext eines metapsychologi- 
Bei Scheffler / Silesius ist die Rede vom "Abgrund der Gottheit" noch unmittelbar auf die Tradition der mittelalterlichen Mystik bezogen. Dies lehrt schon der Blick auf Autoren und Texte, die in der Vorrede zum Cherubinischen Wandersmann zitiert werden. Hier ist die Rede vom „Abgrunde der Gottheit“ ein stehendes Motiv, um die Vorstellung der „Vergöttung in GOtt“ zu semantisieren. Dies gilt auch für die Bilder des Selbstverlusts in der unio mystica, vor allem aber auch für die oxymorischen Fügungen wie „unsichtbares Licht ", ${ }^{57}$, lichte Dunkelheit", später „o heylsams Nichts! glückseliger Verlust“, die in der Tradition apophatischen Sprechens seit Ps.-Dionysos Areopagita zur paradoxalen Kommunikation und Prädikation der Gottheit dienen. Andererseits nähert sich Brockes' Himmelsund Seelenreise narrativen und semantischen Beständen der Visionsliteratur und der Jenseitsreisen, die Brockes - siehe oben - an anderer Stelle in durchaus säkularer, ,entkoppelterer' Form durcharbeitet. ${ }^{58}$ Wenn die Protagonisten solcher Jenseitsfahrten eine „fundamentale Veränderung ihres Heilsstatus [erleben], eine durch den Raum und die Erkenntnisse induzierte Konversion, die sich im Sinne eines radikalen Bewusstseinswandels wiederum auf die diesseitige Existenz auswirkt" ${ }^{49}$ so lässt sich dies auch über Brockes kosmologische visio im Eingang zum Irdischen Vergnügen sagen.

In dieser Grenzerfahrung ereignet sich eine radikale Subjekterfahrung, die jedoch radikal subjektiv nicht $\mathrm{zu}$ fassen ist. Wo das Individuum sich, entleert' und auf Überindividuelles bezieht, wird das principium individuationis auch sprachlich aufgehoben. Das Individuum ist unaussprechlich - es sei denn in den Formen und Formeln einer Rede, die schon deshalb so topisch ist, weil sie an die Grenze des Kommunikablen überhaupt führt. Hier gewinnt Brockes' spätbarocke argutia-Poetik mit ihrem Sinn für Überraschung, Staunen und Verwunderung einen neuen Sinn. Das Staunen über die Natur wird so in das des Lesers über die argute Überblendung von Höhe und Tiefe, des von Freud so genannten „Gegensinn[s] der Urworte ${ }^{\prime 60}$ verwandelt. Aber die Gleichsetzung des Höchsten (Firmament) mit dem Tiefsten (Meeresgrund), des forschenden Blicks mit dem Bad im Ozean der Welten, ist mehr als ein argutes Sprachspiel wie vergleichbar in Hoffmannswaldaus Gedicht So soll der Purpur deiner lippen. ${ }^{61}$ In Stil und Verfahrensweise

schen Gedankens. In: Sigmund Freud und das Wissen der Literatur. Hrsg. von Peter-André Alt, Thomas Anz. Berlin, New York 2008, S. 101-120.

57 Vgl. etwa: „Die verborgene Finsternis des unsichtbaren Lichtes der ewigen Gottheit ist unerkannt und wird auch nimmermehr erkannt werden." Meister Eckhart: Predigt 51. Die deutschen Werke. Hrsg. von Josef Quint. Bd. 2. Stuttgart 1970, S. 476 f. (= Ausgabe Largier (1993). Bd. 1. Frankfurt/M. 2002, S. 548 f.).

58 Einen Überblick bieten Benz und Weitbrecht: Formierung des Jenseits (Anm. 12), S. 229-243; weiterhin Weitbrecht: Aus der Welt (Anm. 12); Brigitte Pfeil: Mittelalterliche Jenseitsvorstellungen (Anm. 12) S. 133 f.; Dinzelbacher: Vision und Visionsliteratur (Anm. 12); Mittelalterliche Visionsliteratur (Anm. 12), S. 29-39.

59 Weitbrecht: Aus der Welt (Anm. 12), S. 150.

60 Sigmund Freud: Gesammelte Werke. Bd. 8, Frankfurt/M. 1999 (1948), S. 214-21.

61 Benjamin Neukirch: Herrn von Hoffmannswaldau und andrer Deutschen auserlesener und bissher ungedruckter Gedichte. Hrsg. von Angelo George de Capua und Erika Alma 
sind Hoffmannswaldaus und Brockes' Texte durchaus verwandt. Beide stehen im Horizont von concettismo und argutia-Poetik; beide sind auf dasselbe Modell - Giambattista Marino - bezogen, dessen Strage degli innocenti Brockes auch übertragen hat (Verteutschter Bethlehemitischer Kinder-Mord des Ritters Marino, 1725). ${ }^{62}$ Bei Brockes gewinnen Metapher und Konzept jedoch einen existentiellen Sinn. Die Metapher entspringt der Ausdrucksnot (egestas sermonis). „Mangel und Verlegenheit" des Ausdrucks zwingen dazu, dass man (wie schon Cicero schreibt), „anderswoher nimmt, was man nicht hat." ${ }^{63}$ Die spätbarocke Pointenkunst wird - wie schon in der Mystik des 17. Jahrhunderts, bei Czepko oder Silesius - eine Ausdrucksfunktion im Rahmen negativer Theologie.

Im Vergleich mit der genuinen Mystik eines Angelus Silesius zeigen sich jedoch auch die Unterschiede. Sie gehen nicht ohne weiteres auf im Begriff der Säkularisierung oder Profanierung. Angemessener wäre es, von einer Pluralisierung der Bezugssysteme und Lesarten, von neu hinzutretenden Ambiguitäten und Ambivalenzen zu sprechen. Denn die ,alte' theologische Lesart verschwindet nicht einfach, sondern wird durch eine neue überlagert und durchdrungen, die nun ganz der Eigenlogik der neuen Wissenschaft(en) und ihrer Epistemologien verpflichtet ist. Um dies zu zeigen, lässt sich ausgehen von der thomasischen Bestimmung der Mystik als cognitio dei experimentalis. Eine solche „experimentale Gotteserkenntnis“ prägt unseren Text gleich doppelt: In diesem Begriff sind theologische, aisthetische und ästhetische Erfahrung integriert. Das Gedicht behandelt eine sinnliche, ja körperliche Erfahrung, die zu einer existentiellen Wende zu Gott führt. Andererseits lässt sich diese Erfahrung auch ganz ,säkular’ lesen. Es handelt sich dann um physiologisches (Selbst-)Experiment in ästhetischer Form. Man erkennt die Genealogie der Wissenschaft aus der Theologie. Kontemplation und Meditation gehen in wissenschaftliche Beobachtung und Selbstbeobachtung über. Entscheidet man sich dafür, unter der Oberfläche der religiösen Semantik das Wahrnehmungsexperiment zu sehen, dann ähnelt das „Firmament“ prinzipiell den zahlreichen anderen, instrumentell bewaffneten Vorstößen des Irdischen Vergnügens ins „innerweltlich Unsichtbare“, 64 sei es im Großen oder im Kleinen,

Metzger. Ndr. d. Ausg. 1697 mit einer kritischen Einleitung und Lesarten. Tübingen 1961, S. $449-450$.

62 Ralph-Georg Czapla: Das Bibelepos in der frühen Neuzeit. Zur deutschen Geschichte einer europäischen Gattung. Berlin, Boston 2013, S. 401-405; Klaus Ley: G.B. Marino/B.H. Brockes: Der Bethlehemitische Kinder-Mord. Zur italienischen Schreibart und ihrer Bedeutung für die Dichtung der frühen Aufklärung in Deutschland. In: Beiträge zu Komparatistik und Sozialgeschichte der Literatur. Hrsg. von Norbert Bachleitner, Alfred Noe und Hans-Gert Roloff. FS Alberto Marino. Amsterdam, Atlanta 1997, S. 275-339; Willi Hirdt: Zwischen Abscheu und Ergötzen. Vom Mythos der „La Strage degli Innocenti“. Guido Reni, Giambattista Marino und Barthold Heinrich Brockes. In: Archiv für das Studium der neueren Sprachen und Literaturen 160 (245) 2008, 1, S. 107-129.

63 Marcus Tullius Cicero: De oratore - Über den Redner. Buch 3. Lat.-dt. 3. erw. Aufl. Hrsg. und übersetzt von Harald Merklin. Stuttgart 1997, S. 155 f.

64 Hans Blumenberg: Das Interesse am innerweltlich Unsichtbaren. In ders.: Die Legitimität der Neuzeit. Erneuerte Ausgabe. Frankfurt/M. 1996, S. 422-439. 
mit Teleskop oder Mikroskop. Es ist oft betont worden, wie sensibel Brockes versucht, kleinste, transitorische ästhetisch-sinnliche Eindrücke in poetischer ,Malerei' zu erfassen. Ein schönes Beispiel bietet z. B. das Gedicht „Die durch Veränderung von Licht und Schatten sich vielfach verändernde Landschaft". Gegenüber solchen sensualistisch inspirierten Texten des Irdischen Vergnügens, die nuancierte Wahrnehmungssplitter und -reflexe registrieren, stößt der mimetische furor in "Das Firmament" an eine Grenze, ein Extremum, das gleichsam vor jeder Mikro-Mimesis ausgelotet werden muss. Brockes' Kosmos ist ein „Kosmos der Sichtbarkeit", 65 in der sich die göttliche Licht-Spur offenbart. Das „Firmament" ist daher das ,Negativ', der dunkle Abgrund und Ungrund der Dinge. Es kontrastiert mit der Feier des Lichts und der Sichtbarkeit im Langgedicht "Die Sonne“. Die Sonne erscheint hier auf den Spuren der Hermetiker ",als Emanation und Medium des alles spendenden göttliche Ur-Lichts" ${ }^{\prime 66}$ Sie ist „Lebens-Quelle, Brunn der Strahlen, / Sonne, Göttlichs Schatten-Bild“,

Ursprung der Belebungs-Kräfte!

Ausfluß aller Geistigkeit!

Brunnquell aller Zeugungs-Säfte!

Feind von aller Dunckelheit

$[\ldots] .^{67}$

Die Abwesenheit der Sonne würde nicht nur der Welt selbst, sondern auch ihrer poetischen Registratur im Irdischen Vergnügens ein Ende bereiten: „Dann wann sich dein Strahl entfernet: / Stirbet die gefror'ne Welt". Brockes geht noch weiter: Wenn nur das Licht Leben und Heil verspricht, muss das Dunkel, die Nacht zur „Hölle“ werden:

Welch ein Abgrund voller Schrecken,

Welche düstre Kercker-Kluft

Würde sich bey uns entdecken,

Welche grause Todes-Gruft?

Würde nicht dieß Rund der Erden

Augenblicks zur Hölle werden,

Wenn der holden Sonnen Schein

Stets uns sollt' entrissen seyn?

(S. 113)

„Das Firmament" bietet ein Gegenstück hierzu. Auch wenn von Nacht und Sternenhimmel nicht explizit die Rede ist, deutet das Bild der "Sapphirne[n] Tieffe", die Rede von "Grufft" und „lichter Dunckelheit" doch in diese Richtung. „Das

65 Hunfeld: Blick ins All (Anm. 38), S. 70.

66 Kemper: Irdisches Vergnügen (Anm. 38), S. 108.

67 Kemper: Irdisches Vergnügen (Anm. 38), S. 111. 
Firmament" gehört zu den wenigen ,dunklen', abgründigen Texten des Irdischen Vergnügens. Seine Position als Einleitungsgedicht mag daher zunächst überraschen. Und dennoch ist sie funktional gut begründet, denn Brockes steckt hier den Rahmen seiner Naturbetrachtung und seines ,vernünftigen Gottesdienstes insgesamt $\mathrm{ab}$ - in ästhetischer, epistemologischer und theologischer Hinsicht. Bevor er sich anschickt, alles zu schildern, schildert er das All. Dabei wird offenbar, wie sich die Grenzen der Wahrnehmung und die Wahrnehmung der Grenzen wechselseitig bedingen: „Die Grenzen des Kosmos markieren zugleich die Grenzen der Mimesis ${ }^{\prime 68}{ }^{6}$ Der Blick zum Firmament stößt nicht zu den Grenzen des Alls vor, wohl aber zu den Grenzen der comprehensio aesthetica. Dieser liminale Vorbehalt, der auch z. B. das „Sonnen“-Gedicht durchzieht, dieses ästhetischaisthetische Ausloten der Grenzen des Sichtbaren, überfordert die Codes spätbarocker Naturlyrik, wie sie das Irdische Vergnügen bestimmen. Die kosmologische Ausdrucksnot, die durch das Heraustreten - die Ek-Stasis - des Ichs aus der konturierten Lebenswelt erzwungen wird, aktiviert durch die argutia-Ästhetik hindurch ältere religiöse Codes und Systeme, Bilder und Sprechweisen - in diesem Fall solche der Mystik. Dennoch ist Brockes kein Mystiker (mehr). Die intertextuellen Reminiszenzen codieren eine Natur-, nicht eine Gotteserfahrung. Die ,glückselige Ertrinkung' vollzieht sich in einem newtonschen Kosmos, der Schwindel ist ein Effekt der Pluralität der Welten: „Ein Sternchen, dessen Schein so klein, / Schliesst eine Gröss' verschiedner Welten ein.“ („Das Große und das Kleine $\left.{ }^{\prime \prime}\right) \cdot{ }^{69}$ Das All, dieser "Abgrund ohne Grund", wie es auch dort heißt, ist jedoch stets nur das „Bild der Ewigkeiten [...], so nur aus GOtt allein, ohn' End' und Anfang stammen“ - nicht Gott selbst. Die mystisch codierte Naturerfahrung lässt sich - dies zeigt das Ende - nicht pantheistisch aufrechnen.

\section{Poème de passage - Nahtod und Naturerfahrung}

In seiner Intensität ekstatisch-visionären Erlebens ist Brockes' Text in der Literatur des 18. Jahrhunderts - nicht nur in einer Literaturgeschichte der Ekstase - singulär. Er ist dies, weil er an elementare anthropologische Grenzerfahrungen appelliert. Die Unendlichkeit „kann nur im Tod geschaut werden, den das Ich imaginativ erleidet ${ }^{\prime 70}$ In der Tat ist die "Vorstellung ausgehaltene[n], sprachlich simulierte Tod[es] “71 das zentrale Motiv im Gedicht neben dem des Ertrinkens. Es handelt sich gewissermaßen um ein poème de passage, eine lyrische Nahtoderfahrung, ${ }^{72}$ ähnlich jener, die Raymond Moody in seinem Bestseller Life

68 Hunfeld: Blick ins All (Anm. 38), S. 66.

69 Kemper: Irdisches Vergnügen (Anm. 38), S. 31.

70 Hunfeld: Blick ins All (Anm. 38), S. 69.

71 Koschorke: Geschichte des Horizonts (Anm. 47), S. 113.

72 Ein Überblick bei Malte Meesmann: Immanente Strukturen der Nahtod-Erfahrung. In: Unterwelten. Modelle und Transformationen. Hrsg. von Joachim Hamm und Jörg Robert. Würzburg 2014, S. 285-308. 
after Life (Leben nach dem Tod) beschrieben hat. ${ }^{73}$ Eine neuere Definition beschreibt die near death experience (NDE) folgendermaßen:

NDE are generally understood to be the unusual, often vivid and realistic, and sometimes profoundly life-changing experience occurring to people who have been physiologically close to death, as in cardiac arrest or other life-threatening conditions, or psychologically close to death, as in accidents or illnesses in which they feared they would die. ${ }^{74}$

Dokumentierte Berichte über Nahtoderlebnisse ähneln semantisch und motivisch immer wieder Ekstaseerlebnissen. „In der Vergangenheit hatten diese Erlebnisse oft andere Namen. Man bezeichnete sie als Visionen, Erleuchtungen, mystische oder religiöse Erfahrungen. In der Antike sah man in ihnen Berichte von Reisen in die Unterwelt." ${ }^{75}$

Die Auslöser für solche Nahtoderfahrungen sind vielfältig: ${ }^{.76}$ Reanimation, Komplikationen bei Operationen, momentaner Verlust des Bewusstseins, Unfälle, Drogen, Depression, aber auch selbst induzierte Ausnahmezustände, wie wir sie in Brockes' Gedicht vor uns haben. Drei typische Formen von Nahtoderlebnissen sind Absturzerlebnis, Ertrinken, Herzrhythmusstörung. Eine besondere Stellung nimmt die so genannte „out-of-body-experience ${ }^{\text {" } 77}$ ein, die ja - schon begrifflich - der Erlebnisform der „Ek-Stasis“, des Hinaustretens, entspricht. In der aktuellen Diskussion stehen sich eine physiologische und eine metaphysische Deutung dieser Phänomene letztlich unversöhnlich gegenüber. Während eine Seite die Nahtoderfahrung als ein "präformiertes Reaktionsmuster des Gehirns" versteht, sieht die anderen in ihr den Beleg für ein „endloses Bewusstsein “" ${ }^{\prime 7}$ an dem das Subjekt an der Schwelle zum Tod partizipiert. Das ist - und hier schließt sich der Kreis - die Wiederkehr der platonischen Anamnesis-Theorie, der gnostischneuplatonisch-mystischen Einheitsvorstellungen auf medizinischer Grundlage.

An den eigentlichen Nahtodberichten erstaunt immer wieder, "dass sie von kulturellen, medizinischen und demographischen Faktoren unabhängig zu sein schein[en]. " 79 Ihre literarisch-narrative Grundstruktur ist hochgradig topisch. Das Unerhörte, Inkommensurable und ,ganz Andere' erzwingt den Rekurs auf alte topisch-archetypische Narrative und Motive. Dabei stellt sich meist ein Ge-

73 Raymond A. Moody: Live After Life: The Investigation of a Phenomenon - Survival of Bodily Death. Covington / Georgia 1975.

74 Bruce Greyson: The near-death experience Scale. Construction, reliability and validity. In: Journal of Nervous and Mental Diseases 171 (1983), S. 369-375; vgl. Meesmann: NahtodErfahrung (Anm. 72).

75 Pim van Lommel: Endloses Bewusstsein. Neue medizinische Fakten zur Nahtoderfahrung. Düsseldorf 2009, S. 34.

76 Meesmann: Nahtod-Erfahrung (Anm. 72), S. 291.

77 Moody: Life after Life (Anm.73), S. 49-68.

78 van Lommel: Endloses Bewußtsein (Anm.75).

79 Carol Zaleski: Nah-Toderlebnisse und Jenseitsvisionen vom Mittelalter bis zur Gegenwart. Frankfurt/M. 1993/5, S. 238. 
fühl der Geborgenheit ein; es kommt zu Begegnungen und Erlebnissen, die nach der Rückkehr ins Leben und Bewusstsein zu einer nachhaltigen inneren Konversion führen. ${ }^{80}$ Dieselbe Polarität von Geborgenheit und Umkehr strukturiert auch Brockes Text. Darüber hinaus finden sich zahlreiche topische Elemente von Nahtoderfahrungen einerseits, Visionsliteratur andererseits wieder: Die narrative Struktur, das Versinken im Meer des Unendlichen, der Durchgang durch den Tod, sogar die „out-of-body-experience“, die einer Studie von Long und Perry (2010) zufolge in 75,4 \% aller Fälle berichtet werden. ${ }^{81}$ Sie ist das medizinische Korrelat der Ekstase, der auch von Brockes bezeichnete "Augenblick“, in dem das commercium mentis et corporis aufgelöst wird, Leben und Tod sich scheiden - eine ambivalente, ängstigende Erfahrung: Während die Sinne in der „ungeheuren Gruft" des heraufdämmernden Alls versinken, „entsatzte sich mein Geist“.

Mit diesen Überlegungen ist ausdrücklich nicht impliziert, dass dem „Firmament" eine real-biographische Nahtoderfahrung vorausgeht und erlebnishaft zugrundeliegt. Es sollte lediglich gezeigt werden, wie mystisch-ekstatisches Sprechen und Nahtoderfahrung semantisch-motivisch miteinander korreliert sind - und dies nicht erst bei Brockes. Dennoch zeichnet sich die typische Struktur des Nahtoderlebnisses - Durchgang durch den Tod, Wiedergeburt, Umkehr sehr deutlich ab. Vor dieser Folie werden auch die dunklen Aspekte des Textes sichtbar: Denn keinesfalls handelt es sich um eine ungetrübt positive, lichtvolle und emphatisch als beglückend wahrgenommene Erfahrung, wie sie die meisten Nahtoderfahrungen bieten, keine Begegnung mit einem hellen Licht am Ende eines Tunnels, wie sie Hieronymus Boschs Visionen über das Jenseits (1490) bieten im Gegenteil. Eher wird man von einer negativen, oder doch zumindest ambivalenten Erfahrung sprechen, die erst am Ende durch die Vergewisserung in Gott aufgehoben wird. Gerade das Dunkle, Unbestimmte und Unkonturierte entfaltet einen gefährlichen Sog, der das Wahrnehmungssubjekt in "des Abgrunds Raum" zieht. Wie ein Wirbel ,verschlingt' es den Blick, zieht ihn in seine „unmäßig-tieffe Höle“. Das Bild der "Höle“ durchzieht den Text in mehrfacher Spiegelung: Es

80 Carol Zaleski hat in ihrem Buch über "Nah-Toderlebnisse und Jenseitsvisionen“ (Anm. 79) (angestoßen durch Moody) den Konnex zwischen Augenzeugenbericht und literarischer Tradition in einem weiten Bogen von der Antike bis ins späte Mittelalter (z. B. die Literatur über das Purgatorium des hl. Patrick) verfolgt. Eine Untersuchung über Vision und Nahtod in der Moderne (seit 1500) steht aus. Dabei bietet gerade die Literatur der klassischen Moderne eine Vielzahl von Berichten über , andere Zustände' und Nahtoderlebnisse, die sich immer wieder in die Form der Jenseits- oder Unterweltreise kleiden: Ich erinnere an Rilkes Duineser Elegien oder Hofmannsthals Gedicht Erlebnis, das einen regelrechten Nahtodbericht in Form eines descensus darstellt. Es kulminiert in den Zeilen: „Und still versank ich in dem webenden, / Durchsichtigen Meere und verließ das Leben“ und weiter: „Das ist der Tod. Der ist Musik geworden, / gewaltig sehnend, süß und dunkelglühend, / Verwandt der tiefsten Schwermut". Hugo von Hofmannsthal: Gesammelte Werke in zehn Einzelbänden. Hrsg. von Bernd Schoeller in Beratung mit Rudolf Hirsch. Gedichte. Dramen I (1891-1898). Frankfurt/M. 1996, S. 19.

81 Jeffrey Long, Paul Perry: Beweise für ein Leben nach dem Tod. Die umfassende Dokumentation von Nahtoderfahrungen aus der ganzen Welt. München 2010, S. 21. 
findet sich einerseits im „,holen Lufft-Raum“, dann in der „Höle“ des Firmaments, schließlich in der "Gruft voll unsichtbaren Lichts“. All diese Bilder transportieren die Idee des Umfangenden, Einschließenden, Umhegenden. Sie sind - im Sinne C. G. Jungs - Aktualisierungen des Mutter-Archetyps: „Das Grab, der Sarkophag, die Wassertiefe, der Tod", so C.G. Jung in seinem Aufsatz Die psychologischen Aspekte des Mutterarchetyps (1938), geben dem Mutterarchetyp dabei einen „,negativen, nefasten Sinn" ${ }^{82}$ Weitere Realisationen sind „das Geheime, Verborgene, das Finstere, der Abgrund, die Totenwelt, das Verschlingende, Verführende und Vergiftende, das Angsterregende und Unentrinnbare. ${ }^{.83}$

All diese Prädikationen treffen auf die eine oder andere Weise auf unseren Text zu: Das Ich setzt sich willentlich einer Grenzerfahrung aus, die einen gefährlichen Sog, eine Art Todestrieb aktiviert. Es handelt sich, wie gesagt, um ein wahrnehmungspsychologisches Extremexperiment am eigenen Körper, eine selbst-induzierte Bewusstseinseklipse. Dieser Selbstversuch scheint spätestens in Vers 18 in prekärer Weise zu entgleiten: Dem Auge misslingt der Zugriff auf den unendlichen Raum (die comprehensio aesthetica), dem Individuum droht die totale Auslöschung. Angesichts dieser negativen Ek-Stasis bzw. out-of-body-experience erfährt das in Körper und Geist dissoziierte Ich eine existentielle Verunsicherung: „Verzweiflung drohete der ganz verwirrten Brust". Contemplatio droht in desperatio umzuschlagen, die an der Existenz Gottes verzweifelt. Doch es folgt - noch einmal - die consolatio: In der Ubiquität Gottes, mystisch als „heylsams Nichts" gewendet, wird der drohende Gottesverlust abgewendet. Im Gang des Textes wirkt dieser Sprung in Gott - die physikotheologische Regression - einigermaßen abrupt. Dieses radikale ,Auftauchen' aus dem mystischen Tiefenrausch und Todestrieb leisten die beiden abschließenden Zeilen. Sie setzen den ,nefasten Aktualisierungen des Mutterarchetyps eine positive, väterliche gegenüber: die Vision eines das Subjekt integrierenden, allgegenwärtigen Gottes.

Dieser Sprung in die metaphysische Geborgenheit ist als Pointe des Textes wohl überlegt. Auch hierin kommt dem Text eine vorbereitende, propädeutische Funktion für die Sammlung insgesamt zu. Denn, anders als das Motto es andeutet, ist die göttliche „Herrlichkeit an der mächtigen Höhe“ nicht unmittelbar, sondern nur indirekt zu ermitteln - und dies nur unter Lebens- und Heilsgefahr. So radikal der Text in poetischer Hinsicht ist, so konservativ ist am Ende seine Botschaft. Denn sein Hauptteil (v. 18-20) ist nichts anderes als eine eindringliche, am eigenen Erkenntnisleib durchgeführte Warnung, sich nicht , an die Kreatur zu verlieren'. Der Sinn der poetischen Nahtoderfahrung heißt Begrenzung und Einhegung der curiositas. Der Sinn des Erlebnisberichts, der poetischen Konfession, liegt in der existentiellen Rettungserfahrung der Schlussverse. Der Leser ist aufgerufen, sie bei der eigenen Betrachtung der Natur - bzw. bei der fortschreiten-

82 Carl Gustav Jung: Die psychologischen Aspekte des Mutterarchetyps. In ders.: Taschenbuchausgabe in elf Bänden. Hrsg. von Lorenz Jung auf der Grundlage der Gesammelten Werke. München 2001, S. 75-106, hier S. 80.

83 Jung: Mutterarchetyp (Anm. 82), S. 81. 
den Lektüre des Irdischen Vergnügens - nicht zu vergessen. Rettung und Umkehr ergeben sich erst da, wo die Verlusterfahrung qua liminalem Übergang gewendet wird in eine Wiedergeburt in Gott. Dies verleiht dem ästhetisch-symbolischen Durchgang durch den Tod den Rang einer echten Konversion. „Das Firmament“ ist ein Bekehrungsgedicht, eine lyrische confessio, die nebenbei der frühaufklärerischen Naturbetrachtung Grenzen setzt. Dazu muss der curiositas- und mit ihm der Pantheismusvorwurf abgewehrt werden. Der gestirnte Himmel, das All, ist eben nur „Bild der Ewigkeiten [...], so nur aus GOtt allein, ohn' End' und Anfang, stammen". So bedarf das Subjekt des Sprunges von der creatura zum creator, ein Sprung, der eine symbolische Wiedergeburt nach dem symbolischen Nah- oder Beinahe-Tod darstellt. Es ist der Sprung aus dem Abgrund des Textes. Die Schöpfung ist damit ambivalent: In der Logik vom ,Buch der Natur ${ }^{84}$ ist sie als Medium Trenn- und Verbindungslinie in einem. Wie in Baldes Enthusiasmen oder in Kirchers iter ecstaticum wird eine religiöse Form - die ekstatische Himmels- und Seelenreise - zum Medium der (Selbst-)Erfahrung. Das religiöse Wissen des Textes geht nicht in der Säkularisierung einer Form auf.

84 Dazu Hans Blumenberg: Das Hamburger Buch der Natur und sein Königsberger Reflex. In ders.: Die Lesbarkeit der Welt. Frankfurt/M. 1981, S. 180 ff. 
(C) 2015, Otto Harrassowitz GmbH \& Co. KG, Wiesbaden ISBN Print: 9783447104975 — ISBN E-Book: 9783447194136 


\title{
„Wo bin ich?" \\ Zur Orientierung der religiösen Lyrik im 18. Jahrhundert am Beispiel von Barthold Heinrich Brockes und Friedrich Hölderlin
}

\author{
Kevin F. Hilliard
}

Zum Erstaunen bin ich da.

(Goethe, Parabase)

Die Lyrik ${ }^{1}$ hatte es im 18. Jahrhundert nicht leicht, sich zu behaupten. „J'ai souvent ouï dire à Despréaux“, erinnerte sich Jean-Baptiste Rousseau, "que la philosophie de Descartes avait coupé la gorge à la poésie“, und dem Verdikt des Literaturpapstes Boileau fügte er aus eigener Einsicht hinzu: „Il est certain que ce qu'elle emprunte des mathématiques [d. h. der neueren Philosophen] dessèche l'esprit“. Solche Klagen gegen den philosophischen Zeitgeist häuften sich im Laufe des 18. Jahrhunderts.

Il regne depuis peu en France un goût de Précision \& de Méthode, qui va mal avec les fougues \& les emportemens de l'Ode. Une je ne sçai quelle fureur de Logique s'est emparé des Esprit[s], [et] a fait de nous des Raisonneurs; nous en sommes insuportables, \& je ne conçois pas comment nous avons pû sacrifier si légérement au petit honneur de penser, le plaisir de sentir. $^{3}$

Ähnliche Klagen wurden auch in England erhoben: „But now the mystic tale, that pleas'd of yore / Can charm an understanding age no more ${ }^{\prime 4}{ }^{4}$ Und wie für Addison war für Herder sein Jahrhundert, das "Jahrhundert der Philosophie“,

1 Es wird im Folgenden nur von der ,hohen Lyrik' die Rede sein. Die liedhafte, leichte Dichtung spielt hier keine Rolle.

2 J.-B. Rousseau an Brossette, 27 July 1715; zitiert von E. F. Carritt: A Calendar of British Taste from 1600-1800. London o. J., S. 177. ,Mathematisch' bzw. ,geometrisch' war die deduktive Methode der kartesianischen Philosophie. Vgl. René Descartes: Meditationes de prima philosophia (1641). In ders.: CEuvres Bd. 7. Hrsg. von Charles Adam und Paul Tannery. Paris 1964, S. 1-90: „ord[o] [...] quàm illum qui est apud Geometras usitatus“ (S. 13).

3 Toussaint Rémond de Saint-Mard: Réflexions sur la Poësie en général, Sur l'Eglogue, sur la Fable, sur l'Elégie, sur la Satire, sur l'Ode \& sur les autres petits Poëmes. La Haye 1734 S. 225-226.

4 Joseph Addison: Account of the Greatest English Poets; zitiert von Carritt: Calendar (Anm. 2), S. 129.

5 Johann Gottfried Herder: Versuch einer Geschichte der lyrischen Dichtkunst. In ders.: Sämtliche Werke Bd. XXXII. Hrsg. von Carl Redlich. Berlin 1899, S. 85-140, hier S. 136. 
schlicht eine „unpoetische Zeit": ${ }^{6}$ auf „ein[em] Feld, das der Weltweise ausgejätet, auf dem er betrachtungsvoll spaziert[,] [kann] [...] der Dichter [...] nicht [...] wandeln".7

Unter den Angriffen der philosophischen Partei geriet insbesondere die geistliche Dichtung in Bedrängnis. ,'Tis apparent", behauptete Shaftesbury,

[...] that the Manners, Actions, and Characters of Sacred Writ, are in no wise the proper Subject of other Authors than Divines themselves. They are Matters incomprehensible in Philosophy: They are above the pitch of the mere human Historian, the Politician, or the Moralist; and are too sacred to be submitted to the Poet's Fancy, when inspir'd by no other Spirit than that of his profane Mistresses, the Muses. ${ }^{8}$

Bedroht waren aber nicht nur die biblische und geistliche Dichtung. Wenn die Musen wirklich zu verbuhlten „Gebieterinnen“ über die eitle Fantasie des Poeten herabgekommen waren, hatten sie offenbar auch ihren Chorführer Apoll im Stich gelassen; es konnte also auch um die Weisheit in dichterischer Form nicht gut bestellt sein.

Und in der Tat: auf die Grundfragen des menschlichen Daseins hatte die Philosophie Antworten parat, die umso klarer ausfielen, je weniger sie die Dichtung um Hilfe ersuchte. Die Dichtung befand sich damit im gleichen Fall wie die Theologie; denn auch (und vor allem) von dieser wollte sich die Philosophie emanzipieren. Umgekehrt waren also Theologie und Dichtung tendenziell Verbündete im Streit mit der Philosophie. In diesem Aufsatz soll zunächst in allgemeiner Form davon die Rede sein, wie man einander dabei gegenseitig aushalf. Vor diesem Hintergrund sollen dann Beispiele aus der Lyrik von Barthold Heinrich Brockes behandelt werden. Den Abschluss wird ein Ausblick auf die Lage um 1800 bilden.

\section{Die Form der philosophischen Weisheit}

Drei Zitate:

[D]a wir eine vernünftige Seele haben, die zu deutlichen Vorstellungen, und Begriffen geschickt, und aufgelegt ist, woran es denen unvernünftigen Thieren mangelt, so ist dieses die erste Pflicht, worzu uns die Seele selbst verbindet, dass wir die Wahrheit suchen, und uns um diejenigen Wahrheiten vornämlich, und insonderheit bekümmern, woran uns am meisten gelegen. [...] [So bald] ein Mensch [...], der auch nur anfängt menschlich

6 Johann Gottfried Herder: Über die neuere deutsche Literatur. Zwote Sammlung von Fragmenten. In ders.: Werke in zehn Bänden Bd. 1. Hrsg. von Ulrich Gaier. Frankfurt a. M. 1985, S. 261-365, hier S. 349.

7 Herder: Versuch einer Geschichte der lyrischen Dichtkunst (Anm. 5), S. 122-123.

8 Anthony Ashley Cooper, Earl of Shaftesbury: Soliloquy; or, Advice to an Author. In ders.: Characteristicks of Men, Manners, Opinions, Times. Indianapolis 2001 (nach der 6. Aufl. London 1737-38). Bd. 1, S. 95-224, hier S. 220-221. 
zu denken, [...] sich selbst ansiehet, so bald siehet er sich gezwungen zu fragen: Wer bin ich? Wo bin ich? Woher bin ich kommen? ${ }^{9}$

Warum? Wer? Wo bin ich? Zum Glück. Ein Mensch. Auf Erden.

Bescheide sonder Licht, die Kindern gnügen werden! ${ }^{10}$

'Tis admirable ${ }^{11}[\ldots]$ to consider, That a Man shou'd have been long come into a World, carry'd his Reason and Sense about with him, and yet have never seriously ask'd himself this single Question, „WHERE am I? or What?" but, on the contrary, shou'd proceed regularly to every other Study and Inquiry, postponing this alone, as the least considerable. ${ }^{12}$

Der kursächsische Pfarrer und Schulinspektor Johann Gottlieb Walpurger, Gotthold Ephraim Lessing und der Earl of Shaftesbury waren sich einig, dass es bestimmte Fragen gibt, denen der Mensch kraft seiner Vernunftbegabung nicht ausweichen kann und nicht ausweichen darf. Für Walpurger ist es jedoch selbstverständlich, dass die Sinnsuche in religiöse Bahnen gelenkt werden soll. Dem Fragenden wird auch sogleich die Antwort einsouffliert: „Man darf ihm nur ein Wörtgen von einem Höhern Wesen sagen, von welchem Himmel und Erde, und er selbst dependent ist, so wird er aufmerksam und sucht sich denjenigen bekannt zu machen, dem er alles, was er hat, zu danken hat" ${ }^{13}$ Und wenn er dann „tüchtige Lehrmeister" bekommt, wird er „alsbald“ Gottes „unendliche Macht, Weisheit und Güte“ ",begreifen" lernen. ${ }^{14} \mathrm{Zu}$ diesen „Lehrmeistern" zählte Walpurger selbst, dessen Amt es ja war, im schulischen und kirchlichen Unterricht für die entsprechende Unterweisung zu sorgen.

Lessing genügen die Lehrmeinungen als Antworten nicht mehr. „Bescheide sonder Licht" sind sie ihm, denen nur mehr die „Einfalt [...], mit starrverwandten Blicken, / Mit gierig offnem Mund, und Beifallsreichem Nicken" Glauben schenken kann. ${ }^{15}$ Freilich bietet sich ihm keine bessere Auskunft an. Seine Suche mündet in zermürbendem Zweifel; das Lehrgedicht „Die Religion“ blieb Fragment.

Auch Shaftesbury hält nicht viel von den bisher erteilten Antworten auf die Sinnfrage. Von dem philosophischen „Study and Inquiry“ verspricht er sich aber, im Gegensatz zu Lessing, Erfolg. Die entscheidende Voraussetzung ist, dass der Einzelne die Verantwortung dafür an keinen Zweiten abgibt, als ob es möglich

9 Johann Gottlieb Walpurger: Cosmotheologische Betrachtungen derer wichtigsten Wunder und Wahrheiten im Reiche der Natur und Gnaden zur Verherrlichung ihres glorwürdigen Urhebers[,] zur Beschämung des Unglaubens und zur allgemeinen Erbauung Schrift- und Vernunftmässig ausgefertiget. Zweyter Theil. Chemnitz 1749, S. 445-446.

10 Gotthold Ephraim Lessing: Die Religion. In ders.: Werke und Briefe in zwölf Bänden Bd. 2. Hrsg. von Jürgen Stenzel. Frankfurt a. M. 1998, S. 264-276 (hier S. 267).

11 Hier in dem Sinne: verwunderlich.

12 Shaftesbury: Miscellany III. In ders.: Characteristicks (Anm. 8) Bd. 3, S. 82-115, hier S. 98.

13 Walpurger: Cosmotheologische Betrachtungen (Anm. 9), S. 446.

14 Walpurger: Cosmotheologische Betrachtungen (Anm. 9), S. 446.

15 Lessing: Die Religion (Anm. 10), S. 267. 
wäre, ,"[to] leav[e] the Examination [...] to others commission'd, as he supposes, to understand and think for him ${ }^{\prime \prime}{ }^{16}$ Die philosophische Sinnsuche grenzt er ausdrücklich von allen katechetischen Übungen $a b .{ }^{17}$ Gerade durch die Ähnlichkeit der Frageform ${ }^{18}$ werden die Unterschiede in der Sache unterstrichen. Nicht gelerntes Wissen wird abgefragt. Es gibt zwar auch bei Shaftesbury einen Lehrmeister, aber nur innerhalb des Ichs, als eine Rolle im Selbstgespräch: „By virtue of [...] Soliloquy he becomes two distinct Persons. He is Pupil and Preceptor. He teaches, and he learns ${ }^{\prime 19}{ }^{19}$ Beide Personen gehören nur dem einem Ich an. Die Sinnsuche wird zwar auch bei Walpurger von einem Ich initiiert. Aber bei Shaftesbury behält das Ich von Anfang bis Ende die Alleinregie über den von seinen Fragen ausgelösten Prozess und ist damit in einem radikaleren Sinne konstitutiv, als es bei Walpurger der Fall war. Shaftesbury gehört damit in eine Reihe mit den „Philosophen des späten 17. Jahrhunderts, die das Da-Sein unhinterfragbar auf den jeweils bestimmten Ort und die bestimmte Zeit fest[legen], zu denen ein unverwechselbares Individuum ,Ich bin hier' sagt “. ${ }^{20}$

Das Ich steht dabei für die Voraussetzungslosigkeit der Fragestellung, und diese umgekehrt inszeniert die Voraussetzungslosigkeit des Ichs. Mit der Frage „WHere am I? or What?" wird bei Shaftesbury das bloße Lebewesen zum Menschen; er wird gleichsam zu seinem eigenen Schöpfer. Daher gibt es bei ihm auch keine Entsprechung zu Walpurgers letzter Frage: „Woher bin ich kommen?“ Und so wie die Sinnfrage im Leben des Einzelnen einen Einschnitt macht - als ob man „on a sudden [were] transported into a new Scene of Life ", 21 sagt Shaftesbury - so markiert sie auch kulturgeschichtlich einen radikalen Bruch, indem ihre Beantwortung ohne Rekurs auf irgendwelche Traditionen oder Lehrmeinungen auskommen soll. Mit ihr beginnt gleichsam eine neue Zeitrechnung; wo sie einsetzt, wird jede Zeit zur Neuzeit.

Shaftesburys Formulierung der Sinnfrage ist daher nicht schon deswegen im historischen Sinne neuzeitlich, weil in ihr Subjektivität so radikal gesetzt ist. Dieselbe Inszenierung subjektiver Voraussetzungslosigkeit kann man auch bei Shaftesburys Vorbildern Epiktet und Marc Aurel finden, ${ }^{22}$ unter anderen Vor-

16 Shaftesbury: Miscellany III (Anm. 12), S. 98.

17 Shaftesbury: Soliloquy (Anm. 8), S. 189.

18 Der katholische Katechismus kennt die Fragen: „Woher kommen wir? Wohin gehen wir? Wozu leben wir?"

19 Shaftesbury: Soliloquy (Anm. 8), S. 100.

20 Ulrich Gaier: Die anthropologische Dimension von Einzelsinn-Ästhetiken. In: Herder und die Künste. Ästhetik, Kunsttheorie, Kunstgeschichte. Hrsg. von Elisabeth Décultot und Gerhard Lauer. Heidelberg 2013, S. 13-31, hier S. 13.

21 Shaftesbury: Miscellany III (Anm. 12), S. 98.

22 Vgl. Shaftesbury: 'A $\sigma \kappa ́ \mu \alpha \tau \alpha$ (The Philosophical Regimen). In: The Life, Unpublished Letters, and Philosophical Regimen of Anthony, Earl of Shaftesbury. Hrsg. von Benjamin Rand. London 1900, S. 1-272, hier S. 114, 115, 116, 123 (Epiktet), S. 112, 113, 117, 119 (Marc Aurel). Zur Kritik an dieser Edition s. Mark-Georg Dehrmann: Produktive Einsamkeit. Studien zu Gottfried Arnold, Shaftesbury, Johann Georg Zimmermann, Jacob Hermann Obereit und Christoph Martin Wieland. Hannover 2002, S. 36 Anm. 65. 
zeichen auch bei Augustinus. ${ }^{23}$ Das Paradoxon, dass Subjektivitätskonzepte und -techniken faktisch in historischen Abhängigkeitszusammenhängen stehen, sollte uns vorsichtig machen, bei dem Einzelfall, wie er uns bei Shaftesbury begegnet, gleich die Geburt des neuzeitlichen Subjekts und den Anbruch der Moderne auszurufen. Die neue Zeitrechnung, die mit dem Denkprozess einsetzt, ist vielmehr diesem selber inhärent und gilt immer nur für das Ich, das sich ihm unterzieht. ${ }^{24}$ Erst aus der Vervielfältigung solcher Einzelaktionen ergibt sich ein neues Epochenprofil. Auch das ist paradox: „Subjektivität“ wird erst dann zu einem Epochenphänomen, wenn sie im gesellschaftlichen Diskurs eine Systemstelle zugewiesen bekommt und damit replizierbar wird.

In diesem Sinne war es bekanntlich Descartes, der Schule machte. In dessen Discours de la méthode pour bien conduire sa raison von 1637 beginnt die Wissenssuche damit, dass das Subjekt als einzige Begründungsinstanz die "Precepteurs" entfernt und ihre Lehren tilgt, um dann so zu verfahren, als ob es neu auf die Welt käme, nur diesmal mit einer voll funktionsfähigen Vernunft: „[comme] si nous auions eu l'vsage entier de nostre raison dés le point de nostre naissance, \& que nous n'eussions iamais esté conduits que par elle ${ }^{\prime 25}$ Bei Thomasius, um 1690, ist dieses Vorgehen bereits in der wissenschaftlichen Propädeutik verankert. ${ }^{26}$ Wenn also am anderen Ende des Zeitraums Kant zum "Selbstdenken“ aufruft, ${ }^{27}$ damit das von aller ,Vormundschaft' befreite Subjekt ${ }^{28}$ auf eigene Faust und für sich selbst die Fragen beantworten möge, in denen sich das „ganze Interesse [der] Vernunft [...] vereinigt" ${ }^{29}$ ist das im Grunde nur die Wiederholung einer bekannten und mittlerweile zur Norm gewordenen pädagogischen Maxime. In diesem

23 Umfassend zur Geschichte des Selbstgesprächs: Günter Butzer: Soliloquium. Theorie und Geschichte des Selbstgesprächs in der europäischen Literatur. München 2008. Dort zu Shaftesbury S. 329-341.

24 Die Moderne ist damit eine „,anthropologische“, keine „historische Kategorie“: s. Thomas E. Schmidt zu Peter Sloterdijk: Die schrecklichen Kinder der Neuzeit. Berlin 2014. In: Die Zeit. Nr. 26. 18. 6. 2014, S. 47.

25 René Descartes: Discours de la méthode pour bien conduire sa raison, \& chercher la vérité dans les sciences. Leiden 1637, S. 14.

26 Christian Thomasius: Ausübung der Vernunftlehre. Halle 1691. Nachdruck Hildesheim 1968. Auszug in: 18. Jahrhundert. Texte und Zeugnisse. Hrsg. von Walther Killy. München 1983, S. 9-11.

27 „Die Maxime, jederzeit selbst zu denken, ist die Aufklärung“. Immanuel Kant: Was heißt: Sich im Denken orientieren? In ders.: Werke Bd. 3. Schriften zur Metaphysik und Logik. Hrsg. von Wilhelm Weischedel. Wiesbaden 1958, S. 265-283, hier S. 283.

28 Immanuel Kant: Beantwortung der Frage: Was ist Aufklärung? In ders.: Werke Bd. 6. Schriften zur Anthropologie, Geschichtsphilosophie, Politik und Pädagogik. Hrsg. von Wilhelm Weischedel. Frankfurt a. M. 1964, S. 51-61, hier S. 53-54.

29 Immanuel Kant: Kritik der reinen Vernunft. In ders.: Werke Bd. 2. Kritik der reinen Vernunft. Hrsg. von Wilhelm Weischedel. Wiesbaden 1956, S. 677. Kants Fragenkatalog lautet bekanntlich: „1. Was kann ich wissen? 2. Was soll ich tun? 3. Was darf ich hoffen?“ (ebd.) 
Sinne lässt sich auch Kants Frage „Was heißt: Sich im Denken orientieren?" als sublime Fortsetzung von Shaftesburys „Where am I?" verstehen. ${ }^{30}$

Für unseren Zusammenhang ist eine weitere Gemeinsamkeit dieser tabula rasa-Entwürfe von besonderer Bedeutung. Es herrscht in ihnen eine gewisse Askese, die sich nach innen als Wachsamkeit gegenüber der eigenen Anfälligkeit für unkontrollierte Gemütsbewegungen, nach außen als eine Abwehrhaltung gegenüber den kulturellen Praktiken manifestiert, die solchen Gemütsbewegungen Vorschub leisten. Zu diesen Praktiken gehören das Erzählen, das Fabulieren, das Dichten. Descartes wusste, „que la gentillesse des fables reueille l'esprit [...] [et] que la Poësie a des delicatesses \& des douceurs rauissantes “. ${ }^{31}$ Als aber der Zeitpunkt kam, wo es mit der Wahrheitssuche ernst wurde, glaubte er „auoir desia donné asses de tems [...] a la lecture des liures anciens, \& a leurs histoires, \& a leurs fables“. ${ }^{32}$ Denn „les fables font imaginer plusieurs euenemens comme possibles qui ne le sont point ${ }^{\prime 3}{ }^{33}$ Die, die in der Dichtung und in der kaum weniger fabelhaften Geschichte ein Mittel suchten „[pour] regl[er] leurs meurs“, seien „,suiets a tomber dans les extrauagances des Paladins de nos romans, \& a conceuoir des desseins qui passent leurs forces". ${ }^{34}$

Descartes scheint hier auf die Kritik des Don Quixote am Ritterroman anzuspielen. Ausdrücklich ist das bei Shaftesbury der Fall, der zu Beginn des 18. Jahrhunderts als ein zweiter "Spanish Cervantes" gegen die Verführungen und Selbstüberschätzungen, die eine allzuwillige Hingabe an die Gaukelbilder der Einbildungskraft und der Poesie mit sich brachte, zu Felde gezogen war. ${ }^{35}$ Andere mochten Silben zählen („,scan Syllables“) ${ }^{36}$ und Luftschlösser bauen (,,build [...] Castles in the Air"), um ihrer "aerial Fancy, or heated Imagination“ Lauf zu lassen. ${ }^{37}$ Der Philosophie komme es dagegen zu, die „Fancys, Passions, and Humours" zu regulieren („regulate $\left.{ }^{\prime \prime}\right) .{ }^{38}$ Ihre Befugnisse erstreckten sich dabei auf alle Aspekte der Dichtkunst, bis in Stilfragen hinein, wo Shaftesbury im Namen der Vernunft ein zähes Handgefecht gegen alles Hochtrabende, Aufgeblasene, Überhitzte führte - gegen „the Miraculous, the Pompous, or what we generally call

30 Vgl. auch Hume, der Shaftesburys Fragen „Where am I? or What?“ wörtlich wiederholt, um sie freilich auf seine eigene, eigenwillige Weise zu beantworten oder vielmehr beiseitezulegen. David Hume: A Treatise of Human Nature. Hrsg. von L. A. Selby-Bigge. Oxford 1965, S. 269.

31 Descartes: Discours (Anm. 25), S. 7. Vgl. auch das Bekenntnis: „I'estois amoureux de la Poësie“ (ebd. S. 7-8).

32 Descartes: Discours (Anm. 25), S. 8.

33 Descartes: Discours (Anm. 25), S. 8.

34 Descartes: Discours (Anm. 25), S. 8.

35 Shaftesbury: Miscellany V. In ders.: Characteristicks Bd. 3 (Anm. 8), S. 139-209, hier S. 156.

36 Shaftesbury: Soliloquy (Anm. 8), S. 184.

37 Shaftesbury: Miscellancy V (Anm. 35), S. 145. Vgl. A Letter Concerning Enthusiasm. In ders.: Characteristicks Bd. 1 (Anm. 8), S. 1-36, hier S. 30.

38 Shaftesbury: Soliloquy (Anm. 8), S. 176; vgl. S. 199: „Every Man indeed who is not absolutely beside himself, must of necessity hold his Fancys under some kind of Discipline and Management. The stricter this Discipline is, the more the man is rational, and in his Wits. The looser it is, the more fantastical he must be, and the nearer to the Madman's state." 
the Sublime", gegen das Staunen als dessen Grundaffekt, und gegen die Kunstmittel, mit denen dieses "Astonishment" erregt werden sollte, "the variety of Figures, the multiplicity of Metaphors" usw. ${ }^{39}$ Und Shaftesbury machte noch die feine Bemerkung, dass die Dichter das wirkliche Staunen am wirksamsten durch ein fingiertes erweckten: „The known way of pleasing such as these, is to make 'em wonder, and lead the way for 'em in this Passion, by a feign'd surprize at the miraculous Objects we set before 'em. ${ }^{40}$ Nichts anderes tue Horaz in seinen Musen- und Gottesanrufungen. ${ }^{41}$ Davon wird weiter unten noch die Rede sein. ${ }^{42}$

In Fortsetzung der Bemühungen Descartes' und Shaftesburys definiert Adam Smith die Philosophie geradezu als „one of those arts which address themselves to the imagination" - aber nicht etwa, weil sie die Aufgabe hätte, diese zu erregen, sondern im Gegenteil, weil es ihr Amt ist, ihre Unruhe zu zügeln:

Philosophy is the science of the connecting principles of nature. Nature [...] seems to abound with events which appear solitary and incoherent with all that go before them, which therefore disturb the easy movement of the imagination [and] which make its ideas succeed each other [...] by irregular starts and sallies [...]. Philosophy, by representing the invisible chains which bind together all these disjointed objects, endeavours to introduce order into this chaos of jarring and discordant appearances, to allay this tumult of the imagination, and to restore it [...] to [a] tone of tranquillity and composure. ${ }^{43}$

39 Shaftesbury: Soliloquy (Anm. 8), S. 149. Der Leitgedanke ist hier das „nil admirari“ der Stoa. 40 Shaftesbury: Soliloquy (Anm. 8), S. 149.

41 Shaftesbury: A Letter Concerning Enthusiasm (Anm. 37), S. 3-4, 32-33.

42 Günter Butzer vertritt die Auffassung, Shaftesbury habe bei aller Ironie der Dichtung eine positive Rolle in der Psychagogie zugedacht, und stellt eine „untergründige Affinität des scheinbar so rationalen Soliloquiums mit der enthusiastischen Rede" fest (Soliloquium (Anm. 23), S. 337). Es ist aber in der Tat die Frage, welches Gewicht man der Ironie in seinen Äußerungen beilegen will; und ob der Aufbau des ersten Teils der Characteristicks nicht auch eine sorgfältig überlegte Progression darstellt (s. dazu Shaftesbury: Miscellany III (Anm. 12), S. 82), von anfänglich spielerischen Ausführungen im Letter Concerning Enthusiasm und dem Essay on the Freedom of Wit and Humour bis zum Soliloquy, wo im Ernst die Scheidung von "Fancy" und dem Ich ins Werk gesetzt wird: „FANCY and I are not all one. The Disagreement makes me my own." (Soliloquy (Anm. 8), S. 200) Zwar behauptet Shaftesbury „We retain on Virtue's side the noblest party of the Muses"; bei näherem Hinsehen jedoch stellt sich heraus, dass dies nur für die Dichtung der Antike gilt, und dass die Musen in der Neuzeit sich ,,in favour of Disorder" haben missbrauchen lassen (Soliloquy (Anm. 8), S. 195). - Ausgeglichener: Mark-Georg Dehrmann: Produktive Einsamkeit, S. 35-55; Barbara Schmidt-Haberkamp: ,Go to the poets'. Die Kunst des Selbstgesprächs bei Shaftesbury. In: Aufklärung. Interdisziplinäres Jahrbuch zur Erforschung des 18. Jahrhunderts und seiner Wirkungsgeschichte 23 (2011), S. 17-40.

43 Adam Smith: The Principles which Lead and Direct Philosophical Enquiries; Illustrated by the History of Astronomy. In ders.: Essays on philosophical subjects. Hrsg. von Joseph Black und James Hutton. London 1795, S. 2-93, hier S. 20. 
Kant bringt schließlich denselben kritischen Impuls auf die knappe Formel "Die Vernunft fühlt nicht", ${ }^{44}$ und zieht über das "Genie“ her, das durch seine „Machtsprüche und große Erwartungen“ das Gemüt „bezaubert", an der Vernunft aber Verrat übt. ${ }^{45}$ Vom 17. bis in das späte 18. Jahrhundert also zieht die Philosophie beharrlich gegen die Extravaganzen der Dichtkunst wie auch die anmaßenden und kaum weniger extravaganten Ansprüche der Theologie zu Felde, um dem Ich für eine unvoreingenommene, sachliche, von keinen Affekten und Eingebungen gestörte Sinnsuche einen Freiraum zu schaffen.

\section{Die Antwort der Theologie}

Bevor wir uns der Lyrik nähern, müssen wir die Strategie umreißen, mit der die Theologie auf die philosophische Herausforderung reagierte. Denn nur in diesem Rahmen sind die Entwicklungen in der Lyrik des 18. Jahrhunderts zu verstehen.

Die theologische Diskussion kann natürlich hier nicht in aller Ausführlichkeit ausgebreitet werden. Bei aller Komplexität im einzelnen ist jedoch eine klare überkonfessionelle Linie zu erkennen. Der in den Jahren 1748-51 erschienene, 1773 wieder aufgelegte Vertheidigter Glaube der Christen des reformierten Hofpredigers in Berlin, August Friedrich Wilhelm Sack, mag als Beispiel dienen. Dieses Traktat lässt sich in etwa so zusammenfassen: Was von der neuen Philosophie als theologische Altlast entsorgt worden war, musste die christliche Apologetik zu retten versuchen. Von der gesunden Vernunft glaubte man dabei nichts befürchten zu müssen. ${ }^{46} \mathrm{Im}$ Vertrauen auf deren Licht konnte man die zur Heilslehre gehörigen Offenbarungswahrheiten und die symbolischen Bücher erst einmal hintanstellen und erst nach und nach zu ihnen hinführen. Dem zweifelnden philosophischen Subjekt konnte man daher getrost einen ebenso seiner Vernunft vertrauenden Sinnsucher gegenüberstellen. Auch dieser hatte, wie sein philosophischer Widerpart, die Aufgabe, noch einmal von vorne zu beginnen. Nur bedeutete dieser Anfang zugleich auch eine Rückkehr zum alten Wahren. Die erste Menschheit hatte eine prisca theologia von der Natur und von Gott empfangen. Noch in der Gegenwart konnte jeder, der sich denselben Eindrücken noch einmal aussetzte, aus dieser Quelle schöpfen. Was in der Menschheitsgeschichte längst Tatsache geworden war, konnte jeder Spätgeborene noch einmal nachvollziehen.

Unter den Formen, die diese Denkbewegung protokollierten, bot sich auch unter theologisch-apologetischen Vorzeichen das Soliloquium an. Die neuphilosophische Variante, wie sie von Descartes und Shaftesbury propagiert wurde, hatte keineswegs das Feld für sich. Wie diese selbst ja eigentlich nur die von allen Affekten bereinigte Version der geistlichen Meditation war, bestand neben und

44 Kant: Was heißt: Sich im Denken orientieren? (Anm. 27), S. 274.

45 Kant: Was heißt: Sich im Denken orientieren? (Anm. 27), S. 281.

46 So verspricht Sack sich viel von den ",aufgeklärten Zeiten“, wo der "gute Verstand“ sich ausbreitet. August Friedrich Wilhelm Sack: Vertheidigter Glaube der Christen. Erstes Stück. Berlin 1748, S. 68. Das Verlagsemblem von Haude und Spener, das auch hier die Titelseite ziert, zeigt eine behelmte Minerva mit dem Wahlspruch: „sapere aude“. 
nach ihm diese selbst in unverminderter Stärke weiter. Sacks Vertheidigter Glaube hat die Form eines Selbstgesprächs. Einige andere hatten dabei sogar die Klugheit, sich in einen neumodischen philosophischen Mantel zu hüllen. Der zweite, posthum erschienene Teil von Fénelons Démonstration de l'existence de Dieu setzte mit eben jenem Gestus des Zweifels ein, mit dem Descartes 1641 seine Meditationes de prima philosophia eingeleitet hatte; und auch diese Schrift hatte die Form eines Selbstgesprächs. ${ }^{47}$ Und genauso wie Fénelon sich Descartes' Methode zu eigen machte, konnte Johann Joachim Spalding an Shaftesbury anknüpfen, wie Mark-Georg Dehrmann gezeigt hat. ${ }^{48}$ Fénelons Démonstration und Spaldings Bestimmung des Menschen, beides Erfolgsbücher des 18. Jahrhunderts, bedienten sich der Form nach bei ihren suspekten philosophischen Vorgängern, um dem Inhalt nach für ein naturtheologisches Christentum zu plädieren. Von solchen Umfunktionalisierungen konnte die Dichtung profitieren, zumal Fénelon und Spalding im Gegensatz zu ihren philosophischen Rivalen vor der Affekterregung nicht zurückscheuten und damit auch in ihrem Pathos mit der Lyrik konvergierten. ${ }^{49}$

47 „Il me semble que la seule maniere d'éviter toute erreur, est de douter sans exception de toutes les choses dans lesquelles je ne trouverai pas une pleine évidence." François de Salignac de la Mothe Fénelon: Euvres philosophiques ou démonstration de l'existence de Dieu. Paris 1718, S. 315-522, hier S. 317.

48 Mark-Georg Dehrmann: Das „Orakel der Deisten“. Shaftesbury und die deutsche Aufklärung. Göttingen 2008, S. 130-153; vgl. auch Clemens Schwaiger, Zur Frage nach den Quellen von Spaldings „Bestimmung des Menschen“. Ein ungelöstes Problem der Aufklärungsforschung. In: Aufklärung. Interdisziplinäres Jahrbuch zur Erforschung des 18. Jahrhunderts und seiner Wirkungsgeschichte 11 (1999), S. 7-19, hier S. 11. Die Verszeile aus den Satiren des Persius, "Quid sumus et quidnam victuri gignimur?“ (Satiren III, Z. 67; „Was sind wir und wozu geboren?"), das Spalding seiner Bestimmung des Menschen voranschickte (Betrachtung über die Bestimmung des Menschen. 3. Aufl. Berlin 1749, S. A2r), fand sich auch bei Shaftesbury (Miscellany III (Anm. 12), S. 91). Shaftesbury leitete damit über zu seiner eigenen, bereits zitierten Formulierung: „WHere am I? or What?" (vgl. Schwaiger, S. 13).

$49 \mathrm{Zu}$ den Gründen, die einen christlichen Apologeten dazu bewegen konnten, zur Form des Selbstgesprächs zu greifen, s. Sack: Vertheidigter Glaube der Christen. Erstes Stück (Anm. 46): „Die Ursach dieser Wahl ist, weil sich diese Art zu schreiben vor eine so ernsthafte und wichtige Sache, als die Religion ist, meines Bedünkens nach am besten schickt, in dem sie den Verstand und das Herz zugleich beschäftigt" (S. 33-34). Bei ihm bleibt allerdings der Vortrag merklich trocken. Vgl. dagegen bei Fénelon die Affektsignale „où suis-je? que suis-je!“ (Fénelon: Euvres philosophiques (Anm. 47), S. 326) - hier allerdings nach augustinischem Vorbild als Ausdruck von Verzweiflung über die Hinfälligkeit des menschlichen Geistes im Zeichen des Sündenfalls. Vgl. Ps.-Augustinus: Meditationes, Kap. XXXIX: „Quò tendebam, \& quò deueni? Vbi sum, \& vbi non sum?" (Divi Aurelii Augustini Hipponensis episcopi, Meditationes, Soliloquia, Et Manuale. Köln 1598, S. 113). „Warnach strebte ich doch / und wohin bin ich kommen? Wo bin ich doch vnnd wo bin ich nicht?" (Drey Büchlein deß H. Augustini / welche zu Latein Meditationes, Soliloquia und Manvale genennet. Köln 1597, S. 229). Zur pessimistischen Anthropologie von Fénelons Schrift S. das einleitende Zitat aus Augustinus: De libero arbitrio: „Human autem anima rationalis est, quæ mortalibus vinculis peccati pœna tenebatur" (Euvres philosophiques (Anm. 47), S. 4). 


\section{Die Antwort der Dichter}

Diese apologetischen Lösungen der Theologie waren für die Dichtung in hohem Maße anschlussfähig, wobei man hier den weiteren Vorteil hatte, sich noch stärker von allen im engeren Sinne dogmatischen Inhalten entfernen zu können.

Der Gegner war aber der gleiche. Nach dem Selbstverständnis der neuen Philosophen war es ausgemacht, dass vor dem offenen Horizont einer voraussetzungslos einsetzenden Selbstbefragung die katechetisch memorierten Glaubenssätze der Offenbarungsreligion ${ }^{50}$ mit ihren unüberprüfbaren historischen Tatsachenbehauptungen und ihren abstrusen metaphysischen „Dunkelheiten“ und „Überschwenglichkeiten“ nicht bestehen konnten. ${ }^{51}$ Genauso aber sah sich die geradezu auf „Überschwenglichkeiten“ spezialisierte Dichtkunst einem kalten Zugwind ausgesetzt. „The MusEs [...] must make a very indifferent figure in this philosophical Draught ", ${ }^{52}$ so Shaftesbury, mit halbem (oder gespieltem?) Bedauern, über die ernüchternde Wirkung der philosophischen Kur, die er dem Subjekt verschrieb, damit es sich ohne Kräftevergeudung und Ablenkung der eigentlichen Aufgabe des gewissenhaften Selbstgesprächs widmen könne.

Wie reagierten die Dichter auf diesen Frontalangriff? Langfristig konnte nur eine Strategie der Abkoppelung von der philosophischen Wahrheitssuche und der Entwicklung alternativer Begründungen für die Dichtung wirksam sein z. B. indem man sie, wie in der Romantik, zum Spielfeld heterokosmischer Entwürfe erklärte, oder ihr das Feld partikularer Wirklichkeiten zuwies, wie im Realismus. Dafür war man im 18. Jahrhundert aber noch nicht bereit. Zu sehr verwurzelt war die sich an der antiken paideia orientierende und in der Schulpraxis institutionalisierte humanistische Vorstellung eines Verbunds und einer gemeinsamen Zielsetzung der Wissenschaften und Künste - eine Einheit, wie sie z. B. Scaliger im Eingangkapitel seiner Poetik beschwor, wo er von der Rhetorik ausgehend sowohl dieser als auch der Philosophie und der Dichtkunst die Aufgabe der "suasio“ zuwies. ${ }^{53}$ Was war also zu tun, jetzt, da die neue Philosophie willens schien, aus diesem Verbund auszuscheren?

50 Zum Katechisieren als Memorieren, S. Shaftesbury: Miscellany V (Anm. 35), S. 150.

51 „Dunkelheiten“ und „Überschwenglichkeiten“: Immanuel Kant: Kritik der praktischen Vernunft. In ders.: Werke Bd. 4. Hrsg. von Wilhelm Weischedel. Darmstadt 1956, S. 103-302 (hier S. 300). Vgl. Shaftesbury: A Letter Concerning Enthusiasm (Anm. 37), S. 4-5; Soliloquy (Anm. 8), S. 189-90, 222. 1637 äußert sich Descartes noch vorsichtiger; dennoch ist auch bei ihm die kritische Stoßrichtung gegen die jenseits der menschlichen Vernunft angesiedelten Wahrheiten (Discours (Anm. 25), S. 9-10) sowie die nur durch "la coustume \& l'exemple" beglaubigten Meinungen (ebd., S. 18) deutlich genug.

52 Shaftesbury: Miscellany II. In ders.: Characteristicks Bd. 3 (Anm. 8), S. 19-81, hier S. 21.

53 Julius Caesar Scaliger: Poetices libri septem. [Genf] 1561, S. 3. Vgl. auch das immer wieder zitierte horazische "Scribendi recte sapere est et principium et fons. / Rem tibi Socraticae poterunt ostendere chartae" (Horaz, Ad Pisones [Ars poetica], Z. 309-310). In Gottscheds Übersetzung: „Vernunft und Klugheit sind die Quellen schöner Lieder, / Durchblättert nur mit Fleiß die Bücher hin und wieder, / Darinn des Socrates berühmte Weißheit steht: / So findet ihr den Stoff der ein Gedicht erhöht." Johann Christoph Gottsched: Versuch einer cri- 
Für eine gegenläufige Strategie bot sich das Lehrgedicht an, für das die Voraussetzung einer Harmonie zwischen Philosophie und Dichtkunst geradezu konstitutiv war. In der Tat war das 18. Jahrhundert eine Blütezeit der didaktischen Poesie. ${ }^{54}$ Auch hier wurden die Gewissensfragen, die die Philosophen bewegten, gestellt; so z. B., in wünschenswerter Deutlichkeit, in René Alexandre de Culants dem preußischen König Friedrich II. gewidmete L'Homéide (1781), deren vier Gesänge jeweils eine dieser Fragen aufgreifen und zu beantworten versuchen: Où suis-je? Qui suis-je? Que ferai-je? Que deviendrai-je? ${ }^{55}$

Hier soll es jedoch um die Lyrik gehen, auch wenn diese historisch betrachtet keine festen Konturen hat und die Übergänge zum Lehrgedicht in vielen Fällen fließend sind. ${ }^{56}$ In der Ode (als Sammelbegriff für die in Frage kommende ,hohe Lyrik) war eher mit Widerstand gegen die Ansprüche der Philosophie zu rechnen. Dennoch gab es auch hier durchaus Stimmen, die für eine Kompromisslösung plädierten. In Frankreich wurde auf einem Seitenschauplatz der großen querelle des anciens et des modernes gerade über diese Frage ein Streit geführt. Für die einen - angeführt von Houdar de la Motte, sekundiert von Fontenelle - musste sich die Ode der Philosophie anschmiegen: „Entouziasme tant qu'on voudra, il faut qu'il soit toûjours guidé par la raison, \& que le poëte le plus échaufé se rappelle souvent à soi, pour juger sainement de ce que son imagination lui offre ${ }^{\prime \prime} .^{57}$ Die andere Partei scharte sich um Jean-Baptiste Rousseau, und hatte in Rémond de Saint-Mard ihren theoretischen Wortführer. Sie behauptete das alte Recht der Ode, von hohen Dingen in hohen Tönen zu singen: „Je veux", sagt Saint-Mard, „qu'un Poëte qui fait un Ode, frapé de la dignité de sa matiere, élevé \& soutenu par elle, ne parle plus comme le reste des Hommes ${ }^{\prime 5}{ }^{58}$ In Deutschland findet man

tischen Dichtkunst. Leipzig 1730, S. 38-39. Deutlicher noch die Anmerkung „wie nöthig es auch Dichtern sey, die Welt-Weisheit inne zu haben“ (ebd., S. 19).

54 Vgl. Christoph Siegrist: Das Lehrgedicht der Aufklärung. Stuttgart 1974.

55 René Alexandre de Culant: L'Homéide, poëme ein quatre chants. Où suis-je? Qui suis-je? Que ferai-je? Que deviendrai-je? Cologne 1781. Trotz des berüchtigten fiktiven Verlagsnamens „Pierre Marteau“ und einiger Seitenhiebe gegen Offenbarung (S. 35 Anm.), Christenheit (S. 69 Anm.) und den Fanatismus der Konfessionen (S. 72-75) ist das Gedicht kein radikalphilosophisches Traktat; es will den , atheistischen' Spinozismus widerlegen und propagiert einen gemäßigten Deismus (S. 53-60, 77).

56 Auch die Länge taugt nur bedingt als Unterscheidungsmerkmal: denn längere Gedichte enthalten oft Passagen gesteigerten Affekts, die man kaum umhin kann, ,lyrisch' zu nennen. Die Hymne an Venus zu Beginn von Lukrez' De rerum natura war ein oft kommentiertes Beispiel. Z.B. Shaftesbury: A Letter Concerning Enthusiasm (Anm. 37): „Even the cold LucRETIUS makes use of Inspiration, when he writes against it" (S. 33).

57 Odes de M. de la Motte, avec un discours sur la Poésie ein général, \& sur l’Ode en particulier. 2. Aufl. Paris 1729, S. 40. Der discours (S. 15-86) wurde 1709 verfasst. Vgl. Bernard le Bovier de Fontenelle: Sur la poésie en général. In ders.: Oeuvres complètes. Hrsg. von Alain Niderst. Bd. 5. Paris 1993, S. 537-561. Die Zeitgenossen („ses partisans mêmes“) urteilten, dass La Motte „moins Poëte que Philosophe“ gewesen sei (s. Discours sur l'apologue. In: Histoire de l'Académie Royale des Inscriptions et Belles-Lettres. Bd. 6. Paris 1751, S. 45-54, hier S. 54).

58 Saint-Mard: Réflexions sur la Poësie (Anm. 3), S. 216; s. auch S. 43-46. Vgl. Rousseaus gegen die „réformateurs austères / De nos priviléges sacrés“ gerichtete Ode "Sur les divinités 
einen ähnlichen, die französische querelle verlängernden Parteienzwist; die Namen Gottscheds auf der einen, ${ }^{59}$ der Schweizer, später auch Herders auf der anderen Seite, ${ }^{60}$ mögen hier als Stichworte genügen. ${ }^{61}$ Diese zweite Partei wehrte sich dagegen, die Dichtkunst einer philosophischen Kur zu unterziehen. Sie wollte zugleich im vollsten Sinn des Wortes poetisch sein und Dienerin der Wahrheit;;2 nur dass sie sich weigerte, sich diese von der neuen Philosophie vorschreiben zu lassen. Was konnte also diese Partei ins Feld führen, um der Verdrängung der Lyrik aus ihrer Rolle in der Wahrheitsfindung vorzubeugen?

Zunächst konnte sie die Emotion gegen die ratio ausspielen. Für die Philosophen waren die Affekte als Störenfriede aus dem besonnenen Selbstgespräch der Vernunft mit sich selbst fernzuhalten. Vor allem gegen das Staunen musste man sich wappnen. Demgegenüber konnten die Dichter darauf hinweisen, dass wie nach Platon und Aristoteles die Philosophie selbst aus dem Staunen hervorgeht, ${ }^{63}$ sie von ihm auch nicht zu trennen ist. Denn was wäre ein Wissen, das nicht von Staunen begleitet wäre? Wie soll sich das Wissen der Seele eindrücken, wenn sie von keinem übermächtigen Affekt begleitet und beglaubigt wird?

Daher wurden die Odendichter der Zeit nicht müde, ihr erregtes Staunen über die Entdeckungen, die ihnen zuteil wurden, an den Tag zu legen. Das Markenzeichen dieses Staunens war das dem „quo me Bacche rapis“ des Horaz ${ }^{64}$ nachempfundene, epidemisch um sich greifende "où suis-je?“ bzw. „wo bin ich?" der hohen Lyrik, das nur den Fehler hatte, das es sich ebenso rasch abnutzte und der philosophischen Partei Anlass zum Spott gab. ${ }^{65}$ Dessen ungeachtet kann man sa-

poétiques", in: Jean-Baptiste Rousseau: Euvres. Hrsg. von Antoine de Latour. Paris 1869, S. 272-277, hier S. 276. In seinen eigenen Gedichten äußerte sich Saint-Mard allerdings konzilianter der Philosophie gegenüber: s. La Sagesse, poëme, in: Remond de Saint-Mard: Euvres. Lettres Philosophiques. Bd. 3. Amsterdam 1750, S. 247-252 und die Anmerkungen dazu S. 252-254.

59 Vgl. Gottsched: Versuch einer critischen Dichtkunst (Anm. 53), S. 37.

60 Vgl. Herder zur "einfältig hohe[n] poetische[n] Theopnevstie“ der Ode; Fragmente einer Abhandlung über die Ode, in Herder: Werke Bd. 1, S. 77-96 (hier S. 80). Zu Herder s. K. F. Hilliard: „Absteigerungen“ des Affekts: Herders Odentheorie in der Spannung zwischen Verlust und Bewahrung des Heiligen. In: Heilige versus unheilige Schrift. Hrsg. von Martin A. Hainz. Wien 2010, S. 71-85.

61 Auffällig in unserem Zusammenhang ist das Lob, das Gottsched dem „,berühmten Englischen Grafen von Schaftesbury" spendet: Versuch einer critischen Dichtkunst (Anm. 53), Vorrede, o. S.

62 Vgl. Christian Helmreich: Herders Lyrik. Über die Möglichkeit von Poesie im prosaischen Zeitalter der Sprache. In: Herder und die Künste (Anm. 20), S. 141-159, hier S. 155-158.

63 Platon: Theætetus, 155d; Aristoteles: Metaphysik, 982b.

64 Oden III. 25, Z. 1. Vgl. auch „quo, Musa, tendis?“, Oden III. 3.

65 „Dans les Ouvrages qui se prétendent dictés par l'enthousiasme, il est très-ordinaire d'y trouver: Que vois-je? où suis-je? qu'entends-je? qui annoncent toujours de grands choses. Nonseulement cela est trop usé et déchu de sa noblesse par le fréquent usage, mais il me paroît singulier que l'enthousiasme se fasse une espèce de formulaire réglé comme un acte judiciaire“ (Fontenelle (Anm. 57), S. 546). „On s'est persuadé que l'Ode appellée Pindarique, ne devoit aller qu'en bondissant: de-là tous ces mouvemens qui ne sont qu'au bout de la plume, \& ces formules de transports, Qu'entends-je? Que vois je? Où suis-je? qui ne se terminent à rien“ 
gen, dass Shaftesburys „single Question, „Where am I? or What?“, die Frage also, mit der das klärende Orientierungsgespräch des philosophischen Subjekts über seine wahre Bestimmung eingeleitet wurde, in diesem scheinbar so ganz anders gearteten, staunenden „wo bin ich?" der erhabenen Erregung ihren Widerpart hatte. Dieses „wo bin ich?“ ist zwar keine wirkliche Frage, sondern zunächst nur ein Ausruf ohne semantischen Inhalt; dennoch führe nur von ihm, so der Anspruch der hohen Lyrik, der Weg zu wahrer Einsicht.

Das hört sich nun so an, als ob die Lyrik nur in einem bewährten rhetorischen Schachzug das movere dem philosophischen docere überordnen wollte. Das war zwar gewiss der Fall; es war hier aber auch ein weiteres Argument im Spiel, das für unseren Zusammenhang von Bedeutung ist. Das movere, so kann man sich diesem Argument nähern, hatte nicht nur systematisch, sondern auch historisch eine Priorität gegenüber dem docere. Es stellte innerhalb der Rede gleichsam deren archaische Schicht dar. In ihm tauchte man gleichsam zurück an den Anfang menschlichen Fühlens und Denkens. ${ }^{66}$

Der Ausruf als Indifferenzstelle zwischen reinem Staunen und Wissen gehörte phylogenetisch, in der Geschichte der Menschheit, an den Anfang der Zeit. Und dieser Ausruf war von Anfang an Dichtung:

La premiére expression lyrique fut une exclamation. L'Homme sortant du néant, ouvrant les yeux sur l'Univers, sentant sa propre existence par les impressions agréables qu'il recevoit par tous ses sens, ne put s'empêcher

(Jean-François Marmontel: Poétique françoise Bd. 1. Paris 1763, S. 293). Vgl. Jean le Rond d'Alembert: Réflexions sur l'Ode. In ders.: Mélanges de Littérature, d'Histoire et de Philosophie. 2. Aufl. Bd. 5. Amsterdam 1767, S. 453-468, hier S. 460. „[...] der so häufig gebrauchte, aber auch durch Gebrauch schon abgenutzte Anfang: Wo bin ich? Wie ist mir?" (Johann Jakob Engel: Anfangsgründe einer Theorie der Dichtungsarten aus deutschen Mustern entwickelt. Berlin und Stettin 1783, S. 305). Selbst Herder klagte über „das so oft mißbrauchte: quo me, Bacche, rapis“ (Herder: Kritische Wälder. Oder einige Betrachtungen die Wissenschaft und Kunst betreffend. Zweites Wäldchen. In ders.: Sämtliche Werke Bd. III. Hrsg. von Bernhard Suphan. Berlin 1878, S. 189-364, hier S. 343). Vgl. auch zu den „unnatürliche[n] Ausrufungen" der neueren Dichter, in ders.: Über die neuere deutsche Literatur. Zwote Sammlung (Anm. 6), S. 339. Dabei konnte auch er der Versuchung nicht widerstehen: „Wohin! wohin! reißt du [...] Phantasei [...] mich fort [...] Wo bin ich!“" (Dithryambe. In ders.: Sämtliche Werke Bd. XXIX. Hrsg. von Carl Redlich. Berlin 1889, S. 265-266, hier S. 265); vgl. auch „Wer bin ich?" (Zweites Selbstgespräch, in ders.: Werke. Bd. 3. Hrsg. von Ulrich Gaier. Frankfurt a. M. 1990, S. 780-782, hier S. 780). Auch Schiller verschmähte die Formel nicht: S. „Aber wo bin ich?“ (Der Spaziergang, in Schiller: Sämtliche Werke. Hrsg. von Gerhard Fricke und Herbert G. Göpfert. 3. Aufl. Bd. 1. München 1962, S. 228-234, hier S. 233). Ihre Abnutzung war z.T. darauf zurückzuführen, dass sie in der panegyrischen Lyrik der Zeit breite Verwendung fand, um das angebliche Staunen des Dichters über die glänzenden Eigenschaften und Taten fürstlicher und ähnlich erhabener Personen auszudrücken. Ein Beispiel für viele: Ode sur le sujet proposé par l'Académie Françoise pour le Prix de l'année 1749. Par M. Le Brun. [Paris] 1749, S. 4 (das besagte Thema war: „L'Amour des François pour leurs rois consacré par des Monumens publics“).

66 Im Hinblick auf Herders Theorie der Lyrik urteilt Helmreich (Anm. 62): „Dichtung als Sprache, in der sich die Kraft der uns berührenden Affekte unverfälscht manifestiert, besitzt geradezu archäologisches Potential“ (S. 149). 
de s'écrier: \& ce cri fut à la fois un cri de joie, d'admiration, d'étonnement, de reconnoissance, causé par une multitude d'idées aussi frappantes par elles-mêmes que par leur nouveauté. ${ }^{67}$

In diesem ersten Ausruf war alle Lyrik der Folgezeit bereits enthalten. Die Ode war nach Sulzers prägnantem Ausdruck nichts anderes als die „erweiterte [...] Ausrufung“. 68 Auch sie war ursprünglich eine Schöpfung des „neugeschaffnen Naturmenschen". 69 "Das dichterische Genie“ der Jetztzeit konnte aber im richtigen Zustand der Erregung diese Urerfahrung nacherleben, "sich in das erste Zeitalter versetzen, alle Dinge so ansehen, als wenn sie ihm zum erstenmal erschienen". ${ }^{70}$

Klar war auch, dass mit einer Rückbesinnung auf dieses archaische Erbe nicht nur der Lyrik, sondern auch der Religion ein Dienst erwiesen würde. Denn es galt weiter als ausgemacht, dass in diesen Menschheitsanfängen Theologie, Philosophie und Dichtung eine Einheit gebildet hatten. "In early days", sagt selbst Shaftesbury, ",Poets were looked upon as authentick Sages" ${ }^{71}$ Für Dacier war die Poesie "d'abord la fille de la Religion ${ }^{\text {" }}{ }^{72}$ Die prisca theologia wurde zuerst von den Dichtern an die Menschen weitergegeben. ${ }^{73}$ Die Konjunktur der natürlichen Theologie um 1700 gab auch der Lyrik die Möglichkeit, rückläufig zum historischen Zeitengefälle ihre alte Würde als Vermittlerin göttlicher Weisheit zu behaupten. ${ }^{74} \mathrm{Um}$ gekehrt musste jede gelungene Ode zugleich eine Rettung religiösen Empfindens sein, denn nur im Staunen wurde die Ode zu dem, was sie immer schon war. Rechristianierung und Relyrisierung waren damit zwei Aspekte desselben Projekts.

67 Charles Batteux: Cours de belles lettres distribué par exercises. Tome second. Paris 1748, S. 27 (im Kapitel „Histoire abrégée de l'Ode“ (S. 27-36)). Vgl. Jean-Jacques Rousseau: „Le premier langage de l'homme, le langage le plus universel, le plus énergique [...] est le cri de la nature". Discours sur l'origine et les fondements de l'inégalité parmi les hommes. In: Rousseau: Discours sur les sciences et les arts. Discours sur l'origine de l'inégalité. Hrsg. von Jacques Roger. Paris 1971, S. 139-249, hier S. 190.

68 Johann George Sulzer: Allgemeine Theorie der schönen Künste. Bd. 2. Leipzig 1774, S. 831 (Artikel „Ode“).

69 Herder: Fragmente einer Abhandlung über die Ode (Anm. 60), S. 88.

70 Herder: Versuch einer Geschichte der lyrischen Dichtkunst (Anm. 5), S. 113.

71 Shaftesbury: Soliloquy (Anm. 8), S. 98.

72 [André Dacier] La Poëtique d'Aristote Traduite en François. Avec des Remarques. Paris 1692, S. iiij. „Dacier ist der Meynung, die Religion sey die Hebamme der Poesie gewesen, und man habe die ersten Lieder bloß zum Lobe GOttes gemacht und abgesungen" (Gottsched: Versuch einer critischen Dichtkunst (Anm. 53), S. 69). Gottsched selbst widerspricht (ebd.) diesem Gemeinplatz (ebd.).

73 Z.B. Scaliger: Poetices libri septem (Anm. 53), S. 5. Vgl. Kuni Sakamoto: Creation, Trinity and prisca theologia in Julius Caesar Scaliger. In: Journal of the Warburg and Courtauld Institutes 73 (2010), S. 195-207.

74 Vgl. das umfangreiche „Verzeichniß der Alten und Neuen Scribenten, die sich haben lassen angelegen seyn durch Betrachtung der Natur, und der Geschöpfe die Menschen zu Gott zu führen", in William Derham: Astrotheologie. Übersetzt von Johann Albert Fabricius. 2. Aufl. Hamburg 1732, S. XIII-LXXX. 


\section{Brockes}

Fénelons oben erwähnte apologetische Schrift war in Hamburger literarischen Kreisen bald nach ihrem Erscheinen gut bekannt, nachdem ihr erster Teil schon 1714 von Johann Albert Fabricius ins Deutsche übersetzt worden war. ${ }^{75}$ Fabricius' Schüler und Freund Barthold Heinrich Brockes ${ }^{76}$ zog nach, als er 1728 im dritten Teil seines Irdischen Vergnügens in Gott ein anderes, ähnliches Werk der französischen Erbauungsliteratur in einer Parallelübersetzung verdeutschte; aus Charles Claude Genests Principes de philosophie ou preuves naturelles de l'existence de Dieu et de l'immortalité de l'ame (1716) wurden die Grund-Sätze der Welt-Weisheit des Herrn Abts Genest. ${ }^{77}$ Sowohl Original wie Übersetzung liefern Anschauungsmaterial für die Christianisierung und Lyrisierung des philosophischen Selbstgesprächs.

Genests Principes de Philosophie griffen, wie es der Titel schon nahelegt, in freier Form Gedanken aus Descartes' Principia Philosophiæ von 1644 auf, ${ }^{78}$ zumeist in recht trockenem Tonfall, streckenweise aber in Form eines enthusiasmierten Selbstgesprächs. Die theologischen und apologetischen Inhalte traten dabei stark in den Vordergrund. Diese Theologisierung fiel insofern nicht schwer, als auch Descartes sich anheischig gemacht hatte, das Dasein Gottes, den Dualismus von Leib und Seele und die Unsterblichkeit der letzteren philosophisch zu beweisen. ${ }^{79}$

75 François de Salignac de la Mothe Fénelon: Augenscheinlicher Beweiß, dass ein GOTT sey, hergenommen aus der Erkäntnis der Natur, und also eingerichtet, dass es auch die Einfältigen begreiffen können. Übersetzt von Johann Albert Fabricius. Hamburg 1714.

$76 \mathrm{Zu}$ ihrem Verhältnis s. Henrik Petersen: B. H. Brockes, J. A. Fabricius, H. S. Reimarus. Physikotheologie im Norddeutschland des 18. Jahrhunderts zwischen theologischer Erbauung und Wissensvermittlung. Diss. Kiel 2004, S. 152-156.

77 Ich zitiere im laufenden Text unter der Sigle „Brockes 1728“, nach der 1. Auflage: Herrn B. H. Brockes [...] verdeutschte Grund-Sätze der Welt-Weisheit, des Herrn Abts Genest, nebst verschiedenen eigenen theils Physicalischen theils Moralischen Gedichten, als des Irdischen Vergnügens in GOTT Dritter Theil; zum Druck befördert von Joh. George Hamann. Hamburg 1728. Vgl. Charles Claude Genest: Principes de philosophie ou preuves naturelles de l'existence de Dieu et de l'immortalité de l'ame. Paris 1716. In seinem Delectus argumentorum et syllabus scriptorum, qui veritatem religionis Christianæ adversos atheos, epicureos, deistas seu naturalistas, idololatras, Iudæos et Muhammedanos lucubrationibus suis asseruerunt (Hamburg 1725) lobt Johann Albert Fabricius Genests Schrift als „,carmen elegantis“ (S. 288); vgl. Johann Georg Hamann: Vorrede zu Brockes 1728, S. 3ํ. Möglich also, dass Fabricius die Anregung zu Brockes' Übersetzung gab . Das allgemeine Urteil war dem Gedicht Genests weniger günstig: dieses „espèce de Poëme“ sei ,[un] ouvrage auquel le Public n'a fait qu'un froid accueil, parce qu'il est venu dans un tems où la faveur du Cartesianisme étoit déja bien diminuée" (Lettres de M. l'Abbé d'Olivet [...] à M. le Président Bouhier. In: Recueil d'opuscules littéraires, avec un discours de Louis XIV. à Monseigneur le Dauphin. Amsterdam 1767, S. 92 216, hier S. 125-126); vgl. auch den Vorwurf, er sei „den Grund-Lehren des Des Cartes allzu genau" gefolgt (Hamann: Vorrede zu Brockes 1728, S. $2^{v}$ ).

78 Vgl. Genests Apologie des Descartes in der "Preface“ zu den Principes de Philosophie (Anm. 77), o. S. Außer Descartes nennt er u. a. Bossuets Unterhaltungen, Malebranches Werke und Polignacs Anti-Lucretius als Quellen für sein Werk.

79 Vgl. René Descartes: Principia philosophiæ, I. 13-18; und den vollen Titel der Erst- und Zweitausgabe der Meditationes de prima philosophia, in qua Dei existentia et animæ immortalitas demonstratur (1641) bzw. in quibus Dei existentia, E animæ humane à corpore distinctio, demonstrantur (1642). 
Freilich konnte angesichts der Bedenken, die viele Theologen der kartesischen Philosophie dennoch entgegenbrachten, eine weitere, deren Rechtgläubigkeit unterstreichende Bearbeitung nicht schaden. ${ }^{80}$ Und es sind vor allem die theologischen Stellen, wo der Glaube an einen allgütigen Gott auf dem Spiel steht, wo der Dichter in Feuer gerät.

An dieser Stelle lenke ich den Blick vom französischen Original auf die (recht treue) Brockessche Übersetzung. Leitend für Genest wie für Brockes war die traurige Erkenntnis, dass die Menschen für die Schönheit und Ordnung, die in der Schöpfung herrschten, blind, und deshalb für die Weisheit des Schöpfers unempfindlich seien. ${ }^{81}$ Dabei müsste, um Fénelon zu zitieren, der sich ganz ähnlich ausdrückt, $^{82}$ ein einziger Augenaufschlag genügen, diese den Menschen fühlen zu lassen. "Je ne puis ouvrir les yeux, sans admirer l'art qui éclate dans toute la Nature. Le moindre coup d'œil suffit pour appercevoir la main qui fait tout." ${ }^{83}$ Wie also wäre es, wenn man diesen Augenaufschlag neu inszenieren, „den ersten Augenblick, wenn unser Auge schaut" wiederholen könnte (Brockes 1728, S. 21)? Um der Abschleifung der Sinneseindrücke durch die Gewöhnung entgegenzuwirken, müsste man sich vorstellen, man käme zum erstenmal zu Bewusstsein: „Erwachsen, dencke man: man käm' erst auf die Welt. / Gleich wird uns eine Welt, die neu ist, vorgestellt" (Brockes 1728, S. 29). Und sogleich ist das Wunder vollbracht:

Ich weiß nicht, ob es im - obs ohne Traum geschehe;

Und sehe, wenigstens bedünckt mich, dass ich sehe,

Ein' Erd', ein Sonnen-Licht, Gebirge voller Wälder,

Beblühmte Hügel hier, dort angenehme Felder.

Ich hör', wie mit des Bachs sanfft rauschendem Gezische

Der liebliche Gesang der Vögel sich vermische.

Ist dies ein süsser Traum? nichts weiß ich, was geschehe,

Aufmercksam, gantz erstaunt, vernehm ich und ich sehe.

Wer bin ich? Wo bin ich? Woher bin ich gekommen? ${ }^{84}$

Und was geschicht in mir?

Ich wancke hin und her und zweifle für und für.

80 Zum „zweideutigen Charakter“ und der „zweideutigen Rezeption“ der kartesischen Philosophie vgl. Panajotis Kondylis: Die Aufklärung im Rahmen des neuzeitlichen Rationalismus. Hamburg 2002, S. 191-209.

81 Brockes 1728, S. 3. Die jeweilige Stelle im Original steht auf der gegenüberliegenden, mit geraden Ziffern bezeichneten Seiten (hier S. 2). Die Blindheit, die Genest und Brockes beklagen, ist auch die des ausdrücklich als Gegner genannten Spinoza. Klingt in der Anklage, er leide an einer „,étrange aveuglement", einer „elend[en] [...] Blindheit“ (Brockes 1728, S. 24/25) der alte Vorwurf der Blindheit der Juden nach?

82 Fénelon: Euvres philosophiques (Anm. 47), S. 4-6.

83 Fénelon: Euvres philosophiques (Anm. 47), S. 1-2.

84 Dies sind wortgenau die Fragen, die Walpurger später stellen sollte (s. oben). Ob er sie aus Brockes abgeschrieben hat, lässt sich allerdings bei der Ubiquität ähnlicher Fragenkataloge in der Literatur der Zeit nicht ausmachen. 
Von einem Ding ist mir der Zweifel doch benommen:

Ich glaube, dass ich seh', ich glaube, dass ich höre. (Brockes 1728, S. 31)

Die den „Zweifel“ zerstreuende Versicherung, dass das Bewusstsein selbst im Traum aktiv ist, und dass man sich damit immerhin nicht über das eigene Dasein täuschen kann, ist dem kartesischen „,cogito ergo sum“ nachgebildet. Der mittlere Teil jedoch hebt die Gedankenführung ins Erhabene. Das Sehen und Erkennen sind nun von einem ,Erstaunen' begleitet, und dieses wird im Ausruf „Wer bin ich? Wo bin ich?" usw. in die entsprechende sprachliche Geste umgewandelt. ${ }^{85}$

Gerade diese Stelle ist es, die im Titelkupfer dargestellt wird. Auch diese ist aus der französischen Originalausgabe „übersetzt" (vgl. Abbildungen nächste Seite).

Auf den ersten Blick ähneln sich die beiden Stiche. Dann aber merkt man, dass aus dem Bild einer schönen Landschaft eine Darstellung des Gartens Eden, aus dem Bild eines Menschen quiconque eine Darstellung Adams, des ersten Menschen geworden ist. Denn zu den zahmen Tieren aus den gemäßigten Klimazonen, die bei Genest die Landschaft bevölkern, sind nun auch wilde und exotische gekommen, die jedoch in paradiesischer Unschuld neben den anderen lagern, am auffälligsten der Löwe im Vordergrund, der friedlich neben dem Hasen hockt (im Hintergrund sind noch ein Elefant, ein Wolf und ein Bär zu erkennen). In Brockes' Fassung ist also das Ich des Gedichts der Antitypus Adams. Damit bekommt die Stelle eine theologische Tiefendimension, die bei Genest fehlt. Dass der neugeborene Mensch über den Anblick der Schöpfung noch erstaunen kann, liegt daran, dass er ebenso der noch unschuldige Adam ist, dem die Sünde die Sinneswahrnehmung nicht verdunkelt hat. ${ }^{86}$

85 Bei Genest lautet die Stelle: „Attentif, étonné, je regarde, j'écoute, / Qui suis-je? Où suis-je? Et d'où suis-je venu? / Qu'arrive-t-il en moi?" (Brockes 1728, S. 30). Vgl. den Fragenkatalog bei Fénelon: „Où suis-je? que suis-je? où est-ce que je vais? où m’arrêterai-je?“ (Euvres philosophiques (Anm. 47), S. 355)

86 Die Frage wäre natürlich, wer für diese bildliche Übersetzung verantwortlich ist. Dem Stich von Charles-Louis Simonneau d. Ä. (1645-1728) nach einem Entwurf von Nicolas Vleughels (1668-1737) entspricht das von dem Hamburger Künstler Christian Fritzsch (1695-1769) verfertigte Bild („C. Fritzsch del[ineavit] \& sculps[it]"). Fritzsch hat in der Folgezeit noch öfter den bildlichen Schmuck zu den Schriften von Brockes beigetragen, u. a. zu Brockes: Auszug der vornehmsten Gedichte aus dem [...] Irdischen Vergnügen in GOTT (Hamburg 1738). Besonders interessant ist in unserem Zusammenhang sein Titelkupfer zu Brockes: Harmonische Himmels-Lust im Irdischen, oder auserlesene, theils neue, theils aus dem Irdischen Vergnügen genommene, und nach den 4 Jahres-Zeiten eingerichtete Musicalische Gedichte und Cantaten. Hrsg. von B. H. Brockes Jun. (Hamburg 1741), das in der zweiten Auflage von 1744 als Entwurf des jüngeren Brockes ausgewiesen wird. Nimmt man noch hinzu, dass Fritzsch 1744 ein Brustbild des Dichters gestochen hat (Nürnberg, Germanisches Nationalmuseum, Graphische Sammlung (Paul Wolfgang Merkel'sche Familienstiftung), InventarNr. MP 2926, Kapsel-Nr. 49), wird man wohl ein engeres Vertrauensverhältnis zwischen dem Dichter und dem Künstler vermuten dürfen; so dass das Titelkupfer zur Genest-Übersetzung, wenn nicht nach Anleitung des ersteren, so doch mit seinem Einverständnis zustande 


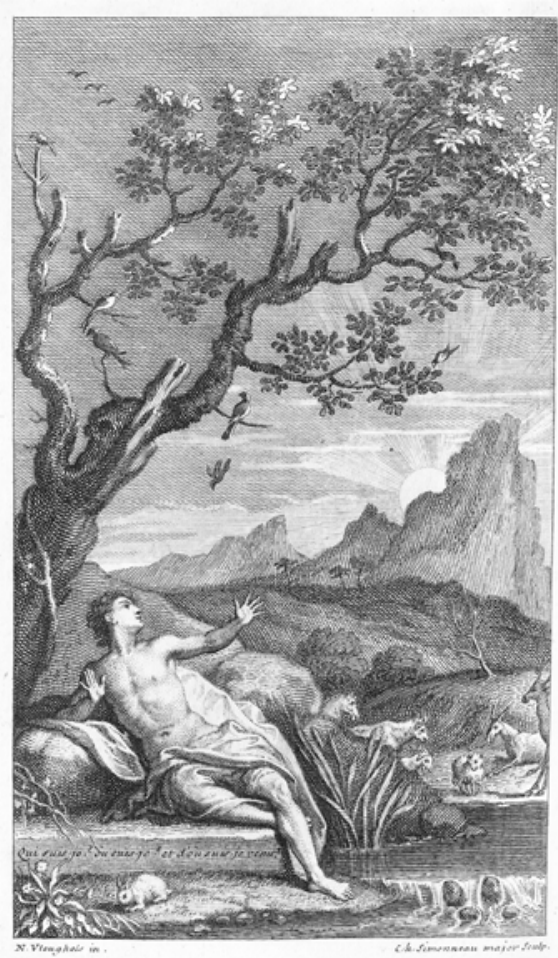

Abb. 1:

Titelkupfer von Charles Claude Genest, Principes de Philosophie (1716). Bayerische Staatsbibliothek München (P.o.gall. 894).

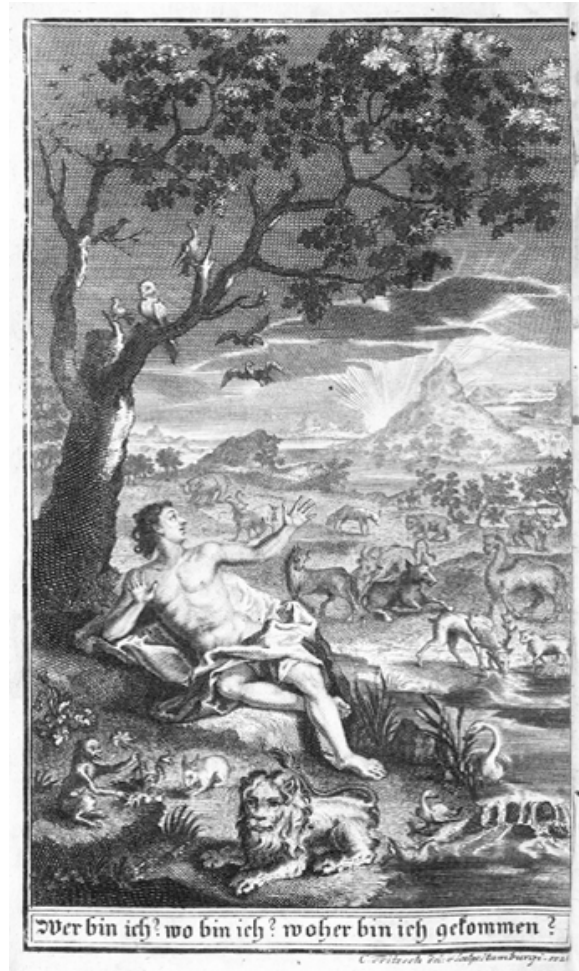

Abb. 2:

Titelkupfer von Barthold Heinrich Brockes, Verdeutschte Grund-Sätze der Welt-Weisheit (1728). Bayerische Staatsbibliothek München (P.o.germ. 187 m-3).

Dieser erste Mensch ist es also, der hier in einem Ur-Staunen die ersten Fragen an Gott und Welt stellt. Die Ahnung des Anfangs - über beide Landschaften geht gerade die Sonne auf - wird er bei abnehmender Erregung in gesichertes Wissen zerlegen; in noch unentwickelter Form ist dieses aber hier schon gegenwärtig. Das Gedicht wiederum versucht die Neuinszenierung dieses Augenblicks, dieses ersten Augenaufschlags, damit der Leser im imaginativen Nachvollzug aus seiner Sünden- und Sinnenträgheit aufwachen möge, um die Schöpfung, den Schöpfer, und sich selbst mit ungetrübtem Sinn und Geist wahrzunehmen. Und zugleich kehrt die Lyrik zu ihrem Ursprung zurück, zum ersten Gottesmorgen,

gekommen sein dürfte. Freilich rückt auch unabhängig von der Urheberfrage das Frontispiz den Text in einen neuen Zusammenhang. 
als Gefühl, Wissen, Andacht eins waren; der Ausruf ist, wir erinnern uns, Lyrik in höchster Konzentration, aus dem wie aus dem Urknall alle dichterische Rede sich in der Folgezeit herauskristallisieren sollte.

Das Lyrische ist hier freilich nur ein in Augenblicken aufleuchtendes Moment innerhalb der Lehre. Das in diesen Augenblicken affektiv aufgeladene Selbstgespräch beruhigt sich im weiteren Verlauf zum Selbstunterricht; das Lyrische geht im Lehrgedicht auf. Dort ist der Staunende zugleich Lehrer und Lernender, „Pupil and Preceptor", wie es bei Shaftesbury hieß (wobei freilich die Schöpfung der eigentliche Lehrmeister ist). Die Ausdifferenzierung dieser Rollen bot dem Dichter aber neben der monologischen Realisierung eine zweite Möglichkeit dramatisch-lyrischer Aneignung an, die ich jetzt in einem neuen Beispiel veranschaulichen möchte.

Man konnte nämlich erstens die eben erwähnten Rollen weiter ausdifferenzieren und vollends auf die "two distinct Persons" Shaftesburys verteilen, das Selbst- also in ein echtes Zwiegespräch verwandeln. Damit wurde es zweitens möglich, auch das oben beleuchtete Motiv einer wiederholten Erschaffung des Menschen deutlicher in Szene zu setzen, indem man mehr oder weniger metaphorisch den „Preceptor" zum Schöpfer des „Pupils“ machte. Das führte in die Nähe des Pygmalion-Stoffes. In der Tat kam gerade in unserem Zusammenhang dieser Mythos in der Literatur des 18. Jahrhunderts neu zur Geltung. Er machte es möglich, unter Wahrung aller affektiven Momente in der zum Leben erwachenden Bildsäule gleichsam in Zeitlupe die ersten Regungen des Bewusstseins zu beobachten, in der Figur des Bildhauers aber gleich auch den Lehrer zur Stelle zu haben, der seinem Geschöpf die neue Welt, in die es getreten ist, erklären kann. Von Boureau-Deslandes, Bodmer, Jean-Jacques Rousseau und anderen wurde unter verschiedenen, mal materialistischen, mal theistischen Vorzeichen der Mythos neu durchgespielt. ${ }^{87}$ Für die theologisch konservative Richtung bestand dabei die besondere Attraktion darin, dass in der Figur des Lehrenden die reine Selbstbezüglichkeit des neuphilosophischen Modells durchbrochen wurde, und in der Notwendigkeit des Lehrens die Notwendigkeit einer Offenbarung un-

87 [André François Boureau-Deslandes:] Pigmalion, ou la Statue animée. London 1742 (deutsch: Pigmalion, oder die belebte Statüe. Hamburg 1748); [Johann Jakob Bodmer:] Pygmalion und Elise. In: Neue Erzählungen verschiedener Verfasser. Frankfurt und Leipzig 1747, S. 1-68 (eine Replik auf Boureau-Deslandes). Condillacs Traité des sensations (1754) und Charles Bonnets Essai analytique sur les facultés de l'âme (1760) übersetzten den Mythos in eine philosophische Versuchsanordnung. Zum ganzen Komplex S. Eugenio Pesci: Saggio introduttivo. Materialismo, tradizioni filosofiche e gusto estetico nel „Pigmalion, ou la Statue animée” de A.-F. Deslandes. In: Antoine-François Deslandes: Pigmalion, ou la Statue Animée. L'Optique des Mœurs. Hrsg. und übers. von Eugenio Pesci. Quaderno VI: Maggazino di filosofia. Milano 2008, S. 7-102; Hans Sckommodau: Pygmalion bei Franzosen und Deutschen im 18. Jahrhundert. Universität Frankfurt am Main: Wissenschaftliche Gesellschaft, Sitzungsberichte 8 (1969), Nr.3. Wiesbaden 1970; Joachim Gessinger: Auge und Ohr: Studien zur Erforschung der Sprache am Menschen 1700-1850. Berlin und New York 1994, S. 38-49, 89-114. Eine explizit christliche Vorstellung von Gott als Bildner des Menschen wie aus einem „Stück Marmor" findet sich bei Sack, Vertheidigter Glaube der Christen (Anm. 46), S. 94-95, hier S. 94. 
terschwellig suggeriert werden konnte; denn Offenbarung war ja nichts anderes als „,väterlicher Unterricht“. 88

Brockes schrieb zwar kein Pygmalion-Gedicht, wie er überhaupt von aller antiken Mythologie Abstand nahm. Seine „Erzehlung. Zum Neu-Jahrs-Gedicht auf das 1745ste Jahr", 1746 im achten Teil des Irdischen Vergnügens in Gott erschienen, hat aber eine analoge Struktur. ${ }^{89}$

In der Einleitung zur Verserzählung feuert sich Brockes noch einmal an, seine Leser zur Betrachtung von Gottes Werken in der Natur zu erheben. Dazu müsse die Dichtung die gewohnten Bahnen verlassen:

[...] Um uns selbst nun zu erhöhn,

In des Schöpfers Wunder-Werken, wenn wir Ihn darinn ersehn;

Tret' ich eine neue Bahn, (gieb, o Gott, dass es gelinge,

Wenn ich in der Allmacht Tiefen, mit erstaunter Ehrfurcht, dringe!)

Durch ein neues Dichten, an. (Brockes 1746, S. 413)

So „neu“ war fünfundzwanzig Jahre nach dem Erscheinen des ersten Teils des Irdischen Vergnügens Brockes' Manier zwar nicht mehr. In einem anderen Sinne ist jedoch die ,Neuheit' zwingend und bleibend ein Merkmal des Brockesschen Gedichts. Nicht nur deshalb, weil das ,Erstaunen' über Gottes „Allmacht“ immer wieder neu erregt werden muss; sondern auch, weil dieses Staunen selbst ein Affekt des Anfangs ist. Wo Staunen ist, da ist Anfang. Und sobald im Staunen sich der Affekt sprachlich entlädt, ist auch in ihm ein „,neues Dichten“ enthalten. ${ }^{90}$

Dieses wie das Staunen selbst wird auch in der auf dieses Proömion folgenden Erzählung thematisiert. Die Geschichte handelt von einem in einer Höhle erzogenen Jüngling, Cernamir, und seinem Lehrer, Silvio, der mit ihm das Experiment anstellt, wie ein in der Natur zu vernünftiger Betrachtung des Weltgebäudes angeleiteter Mensch auf die erste Begegnung mit der Zivilisation reagiert - wahrlich eine „neue Art", einen Menschen „in die Welt zu führen" (Brockes 1746, S. 415). Kennengelernt hat Cernamir vor diesem Zeitpunkt nur die "gestirn-

88 Sack: Vertheidigter Glaube der Christen (Anm. 46), S. 21; vgl. ebd. S. 21, 98. „Was von eintzelen Menschen wahr ist, die ohne Unterricht zu gar keiner vernünftigen Erkänntniß haben gelangen können; das ist [...] von gantzen Völckern wahr. [...] [Daher die] gantz unentbehrliche Nothwendigkeit [...] eines höheren Unterrichts, oder einer Offenbarung" (ebd. S. 14-15).

89 Barthold Heinrich Brockes: Irdisches Vergnügen in GOTT, bestehend in Physicalisch- und Moralischen Gedichten. Achter Theil. Hrsg. von B[arthold]. H[einrich]. B[rockes]. jun. Hamburg 1746, S. 412-428. Nachweise werden im fortlaufenden Text unter der Sigle „Brockes $1746^{\prime \prime}$ belegt.

90 Nicht von ungefähr hat "das Neue“ in der wirkungsästhetischen Diskussion der Zeit einen so hohen Stellenwert; s. zusammenfassend den Artikel "Neu“ in Sulzer: Allgemeine Theorie der schönen Künste (Anm. 68), Bd. 2, S. 815-818. Zumal die Ode hat die Aufgabe, das Neue in die Welt zu setzen: „Also dienet überhaupt die lyrische Poesie dazu, dass jedes Vermögen der Seele dadurch [...] einen neuen Schwung und neue Kräfte bekommt" (ebd., S. 838, Artikel „Ode“). Vgl. auch Gottsched: die Ode „wagt neue Ausdrückungen und Redensarten“ (Versuch einer critischen Dichtkunst (Anm. 53), S. 335); und Batteux zur „nouveauté" der Gedanken in der Ode (s. oben). 
te Pracht" des „Firmaments", woran sich ein physikotheologischer Unterricht anschloss (Brockes 1746, S. 416). Immerhin hat Silvio ihm das Schreiben beigebracht (Brockes 1746, S. 418).

So in die Wege geleitet, kann nun das Experiment beginnen. Cernamir bekommt einen Schlaftrunk und wird in bewusstlosem Zustand in ein Haus in der Stadt geführt (Brockes 1746, S. 417-418). Er erwacht und sieht sich, von dem mitgebrachten „bekannten Schreib-Tisch" und „Lehn-Stuhl“ abgesehen, in einer völlig neuen Umgebung. Er ,besieht ' und ,betastet' alles. Von "des ganzen Zimmers Symmetrie" und den "zierlichen Mobilien“ ist sein "Geist" "gerührt" (Brockes 1746, S. 418). Um seine „zerstreuten Ideen“ (ebd.) zu sammeln, greift er zur Feder und bringt "folgende Gedanken, in Eile, zu Papier":

„Wo bin ich? Ist, was mir hier in die Augen fällt,

Auch wirklich? Bin ich hier in einer neuen Welt?

Ist alles das, was hier vorhanden,

Und was ich fühl' und seh, von ungefehr entstanden?

Ist es, so wie es ist, gewachsen? Oder muß

Ein Geist gewesen seyn, der, nach vernünftgem Schluß,

Die Theile so gefügt; der alles, mit Bedacht,

Zu solcher Ebenmaß so ordentlich gebracht?" (Brockes 1746, S. 419) ${ }^{91}$

Nachdem von außen, von unsichtbarer Hand, die Fensterläden aufgemacht werden, besieht er die Häuser und die Menschen in ihnen, und erinnert sich an Silvios Lehren von "der Welten Vielheit“ und von diesen Welten als einer "großen Stadt der Gottheit“ (Brockes 1746, S. 421). ${ }^{92}$ Wieder muss er seine Gedanken aufschreiben:

„[...] Bewunderns-würdge Himmels-Stadt!

Die wohl mit allem Recht den Namen der Residenz des Schöpfers hat:

Du füllst mit Ehrfurcht, voller Andacht, den Geist, mein ganzes Wesen, an,

Daß ich, mit Lust darinn versunken, erstaunt, nichts weiter denken kann."

Hier warf er seine Feder nieder, und sich selbst in den Stuhl zurück, Ganz ausser sich von tiefem Denken. (Brockes 1746, S. 422)

Jetzt tritt Silvio ein. Er wirft einen Blick auf das „voll geschriebne Blatt“, und kann sich angesichts der "erhabne[n] Richtigkeit" "der Ideen und des Ausdrucks" überzeugen, dass sein Experiment geglückt ist (Brockes 1746, S. 423).

Wir werden hier Zeuge, wie von einem gleichsam „neugeschaffnen Naturmenschen“, um Herders Ausdruck noch einmal aufzugreifen, das erste Gedicht

91 Cernamir macht hier die Erfahrung nach, die Fénelon in seiner Démonstration de l'existence de Dieu in einem Gedankenexperiment angestellt hatte, wo er sich fragt, welche Schlüsse auf einen Schöpfer ein Mensch wohl machen würde, der auf einer wüsten Insel eine vollkommen schön gebildete Statue fände (Fénelon: Euvres philosophiques (Anm. 47), S. 12-14).

92 Silvio erweist sich hier als Leser von Fontenelles Entretiens sur la pluralité des mondes (1686). 
geschrieben wird - ein Gedicht, das programmgemäß aus dem durch die nun schon bekannten Fragen markierten Staunen hervorgeht und alle Merkmale des Erhabenen an sich hat. Der lyrische Anfang ist eins mit dem "tiefe[n] Denken“; auf natürlichem Wege werden so im ",neuen Dichten“ Erregung und Erleuchtung eins. Selbstverständlich auch, dass beide Erfahrungen das erschütterte, wachgerüttelte, neugeborene Ich unweigerlich zu Gott führen.

Im Windschatten christlicher Apologetik versuchte Brockes in epochentypischer Weise den lyrischen Ton sowohl für die Lehre als auch für die Affekterregung nutzbar zu machen. Die Lyrisierung diente dabei nicht nur als rhetorisches Mittel zum guten didaktischen Zweck. Sondern das gattungskonstituierende Staunen war an sich schon die Lehre. In ihm erfuhr der Mensch seine wahre Bestimmung in der Welt. Lyrik war in nuce die prisca theologia, die es für die Gegenwart zu bewahren und zu erneuern galt.

\section{Abgesang: Hölderlin}

Es war in diesen Ausführungen von dem Projekt die Rede, den neuen Philosophen die Redehoheit streitig zu machen, ihnen das auf alle alten Gewissheiten verzichtende Soliloquium aus der Hand zu reißen, und dieses durch einen Rekurs auf die prisca theologia und die ewig ursprüngliche Dichtung für christliche Inhalte wieder zu öffnen. Hand in Hand damit ging die zumindest punktuelle Lyrisierung des Selbstgesprächs. Erst in ihren lyrisch-affektiven Steigerungen könne der menschlichen Selbstreflexion der aus der Isolation des Selbstbewusstseins herausführende Durchbruch zum wahren Wissen von Gott und Welt gelingen.

Gegen die Entwürfe der neuen Philosophie setzte man sich chronotopisch zur Wehr, indem man ihrer historischen Stunde Null die alles überstrahlende Kraft des Schöpfungsbeginns setzte. Die lyrische Selbstverständigung wurde zu einem immer wieder neu erlebten adamitischen Erwachen umgedeutet. ${ }^{93}$ Hören wir ein letztes Beispiel, aus dem Umkreis der bereits erwähnten Nacherzählungen des Prometheus-Mythos. In Bodmers Pygmalion und Elise erwacht die Statue zum Bewusstsein, als Pygmalion gerade abwesend ist. Nach ersten, eher ruhigen Beob-

93 Vgl. diese Szene in Klopstocks Messias, wo nach dem Versöhnungsopfer Christi am Kreuz die Toten zum Leben erwachen, unter ihnen Eva: „Eva begann sich empor zu heben. Wer bin ich geworden? / Bin ich in Eden? Wo bin ich? Ich lebe wieder im Leibe / Meiner ersten Erschaffung? O dort ist Adam! Wie glänzt er! / Und wie glänz ich!“ (Friedrich Gottlieb Klopstock: Der Messias. Bd. 3. Halle 1769, S. 12). In Christian Scrivers mehrfach wiederaufgelegtem Seelen-Schatz, einem der bedeutendsten Erbauungsbücher der Zeit, erwacht der von Christus wiederauferweckte Jüngling zu Nain mit den (zum biblischen Bericht hinzugedichteten) Worten: „Hilff ewiger GOtt! wie geschicht mir? wo bin ich? bin ich wieder in der Welt?" (M. Christian Scrivers [...] Seelen-Schatz, Vierdter Theil. 11. Aufl. Magdeburg und Leipzig 1737, S. 294). Nicht unmöglich, dass Klopstock als gebürtiger Quedlinburger (geb. 1724) das Werk des ehemaligen dortigen Oberhofpredigers (1629-1693) gekannt hat. Zu Scriver s. Martin Brecht: Ein "Gastmahl" an Predigten. Christian Scrivers Seelenschatz (1675-1692). In: Pietismus und Neuzeit 28 (2002), S. 72-117. 
achtungen im Umkreis seiner Werkstatt empfindet sie eine Beklemmung, sich so „enge eingesperrt“ zu finden, und folgt einem „herrlichen Glantz", der von einer Seite „einzudringen scheint“. Dies ist das Zeichen für die volle Entfaltung ihrer sinnlich-geistigen Kräfte:

Mit diesen Worten trat sie aus dem Saal in die Galerie, wo ihr plötzlich das prächtige Schauspiel der Natur begegnete, und alles Vermögen ihrer Sinnen und ihres Gemüthes in ihre Augen zusammenholete. Es war gleich an dem, daß die Sonne den Rand ihrer beleuchtenden Kugel aus der östlichen See hervorrekete, und unten den grossen Ocean, oben die ungemessene Bühne des blauen Himmels mit ihren sanften Strahlen tausendfältig bemahlete. Dieses unermeßliche Feld, die immer wechselnden und tausendfach gefärbten Gegenstände darauf, die Höhe der Farben, schlugen diesen neuen Menschen in eine taumelnde Entzükung; sie fiel mit geschlossenen Augen auf die Knie. Doch erholete sie sich selber augenblicklich, und da sie die Sonne jezo mit ihrer gantzen Scheibe auf dem Ende des Horizontes hervorbrechen sah, sagte sie: $\mathrm{O}$ du, ohne Zweifel das Auge des Himmels, das alles siehet und alles zu sehen giebt! du hast es gesehen, als ich ward, und warest eh ich noch gewesen. Sage mir denn, wie ward ich so? Wer hat mich zu diesem Wesen, das sich selber fühlet und sich so beweget und denket, geholfen? Ich könnte glauben, daß du es seyst, oder derjenige, dessen Auge du bist. Oder warest du selber noch nicht, ehe vor wenig Augenblicken ein grösseres Wesen dich angezündet und mit diesem Meer von Strahlen begabet hat? ${ }^{94}$

Hier sind alle Motive noch einmal gebündelt, die uns beschäftigt haben, und einige ergänzende noch dazu. Die Neuschöpfung des Menschen, das staunende erste Gewahrwerden der Schöpfung, die symbolische Szenerie des Sonnenaufgangs, die ersten Orientierungsfragen des Ichs, die instinktive, nach Antworten suchende Hinwendung an ein Höheres, die über sich selbst schon hinwegeilende Naturfrömmigkeit, die sich zunächst die Sonne als Göttliches vorstellt, um bereits im nächsten Augenblick mit sicherem Instinkt hinter diesem sichtbaren einen unsichtbaren Gegenstand der Verehrung zu vermuten, der biblische Tonfall (,,[du] warest eh ich noch gewesen“ ist eine Reminszenz an Hiob Kap. 38), in dem die Naturreligion für die geoffenbarte durchsichtig wird, der (auch in Prosa) erregte, gesteigerte Ausdruck, die Erweiterung des Selbstgesprächs zum Dialog - all dies ist für die hier untersuchten lyrischen Meditationen typisch, in denen dem Druck der Gegenwart die Kraft eines zeitlos gültigen Anfangs entgegengesetzt wird.

Viele Theologen und Dichter der Zeit ließen sich durch dieses Projekt inspirieren. Der erste Teil von Herders Ältester Urkunde des Menschengeschlechts (1774) ist ein einziger Hymnus auf die Erziehung des ersten Menschen durch die morgen-

94 Bodmer: Pygmalion und Elise (Anm. 87), S. 15-16. 
rötliche Offenbarung. ${ }^{95}$ Noch um 1800 erlebt das Projekt in Hölderlins Oden und Hymnen eine grandiose Steigerung. Eben dort zeichnet sich aber auch sein Ende ab. Gewiss, es gibt in Hölderlins Dichtung viele Aufschwünge und enthusiasmierte Blicke in eine von göttlicher Allgegenwart durchleuchteten Welt. ${ }^{96}$ Ebenso eindrucksvoll, origineller, und, weil auf die Ersatzleistungen der Hoffnung verzichtend, letztlich auch glaubwürdiger, sind auch die das Verebben jeglicher Gewissheit gestaltenden Gedichte. In der Umkehrung werden darin alle Themen, die hier behandelt wurden, noch einmal sichtbar. Hier zum Abschluss ein Beispiel, das sich wie eine negative Kontrafaktur der Szene in Bodmers Erzählung liest:

\section{Sonnenuntergang}

Wo bist du? trunken dämmert die Seele mir

Von aller deiner Wonne; denn eben ists,

Daß ich gelauscht, wie, goldner Töne

Voll, der entzückende Sonnenjüngling

Sein Abendlied auf himmlischer Leier spielt';

Es tönten rings die Wälder und Hügel nach.

Doch fern ist er zu frommen Völkern,

Die ihn noch ehren, hinweggegangen. ${ }^{97}$

Auch in diesem im wörtlichsten Sinne lyrischen Gedicht (es ist nach Apolls „Leier" gestimmt) setzt die Rede mit einem Ausruf ein. Er ist zunächst als Ausdruck der Verzückung zu verstehen. Zunehmend wird in ihm aber die Endzeitklage eines Verlassenen hörbar. Die Sonne beleuchtet kein in neuem Glanze erstrahlendes Morgen-, sondern ein sich verdunkelndes Abendland. Sie geht unter, nicht auf. Im Wechsel von der Person der Anrede in die dritte Person, und im Übergang vom Präsens zum Präteritum werden die Phasen ihres Verschwindens markiert. In genauer Entsprechung dazu nimmt die in der Eingangsfrage noch verspürte, schon in der zweiten Zeile bereits der Vergangenheit angehörende lyrische Erregung im Laufe des Gedichts immer stärker ab. Das letzte Wort gibt unvermutet eine nüchterne und ernüchternde Antwort auf die Frage zu Beginn, die erst jetzt, hinter dem Ausruf, als tatsächlich Auskunft verlangende erkennbar wird: „Wo bist du?“ - „hinweggegangen“.98 Die Trunkenheit des Anfangs ist für den Dichter und den Hörer für immer dahin. Warum? Weil uns Abendländern

95 Johann Gottfried Herder: Werke. Bd. 5. Hrsg. von Rudolf Smend. Frankfurt a.M. 1993, S. 179660, hier S. 179-301. Vgl. besonders „Unterricht unter der Morgenröte“, S. 246-257.

96 In diesem Zusammenhang besonders zu erwähnen: Des Morgens. In Hölderlin: Sämtliche Werke. Kleine Stuttgarter Ausgabe. Hrsg. von Friedrich Beissner. Bd. 1. Stuttgart 1946, S. 299.

97 Hölderlin: Sämtliche Werke (Anm. 96), S. 256.

98 Dies ist auch die Antwort auf die in Hölderlins Gedicht aufgegriffene, epochale Frage Schillers in „Die Götter Griechenlands“: „Schöne Welt, wo bist du?“ Schiller: Sämtliche Werke Bd. 1 (Anm. 65), S. 167. 
die naive Geisteshaltung „frommer Völker" fehlt, die in der Sonne einen Sonnengott erkennt und verehrt, und weil die schwärmerische Stimmung des Einzelnen, die im Farbkonzert des Abendrots die „himmlische Leier“ eines Apoll zu hören meint, für einen solchen Nationalglauben keinen dauerhaften Ersatz bieten kann. Im Gedicht ,tönt' diese momentane Verzückung zwar noch ,nach' (Z. 6), wie das Wort selbst innerhalb des Gedichts ein Echo der "goldnen Töne“ (Z. 3) des Sonnen- und Dichtergottes ist. Als Nachhall ist aber dieses ,Nachtönen' parasitär, unwesentlich, schattenhaft, von Anfang an im Schwinden begriffen. Das Gedicht, das wir lesen, ist ein letzter Ausklang eines mächtigeren Gesangs. Was soll ein Dichter schon sagen, wenn Apolls Leier nicht mehr "tönt"? Eine untergegangene Sonne kann weder begeistern, noch wärmen, noch erleuchten. Denn mit der Erregung ist auch das in ihr gespeicherte Wissen verloschen.

Semantisch entscheidend ist auch der Wechsel vom scheinbar selbstbezüglichen „wo bin ich?" der bisherigen Beispielsreihe zum vokativen „wo bist du?" Hölderlins. Hölderlin bringt darin die Einsicht auf den Begriff, dass der „wo bin ich?"-Ausruf der Lyriker zwar nicht grammatisch-formal, wohl aber der Sache nach darin immer schon auf ein Gegenüber angelegt war, indem er einen Dezentrierungsschock des Ichs und im Ich, einen durch die überwältigende Konfrontation mit einem Anderen ausgelösten Orientierungsverlust des Subjekts, registrierte. Das lyrische Subjekt erfuhr sich selbst nur in Beziehung auf dieses Andere, als ein durch dieses Entrücktes. Im Gegensatz zum neu-philosophischen, das Subjekt absolut setzenden Selbstgespräch, war die lyrische Selbstbesinnung daher immer schon eingebettet in einen dialogischen Zusammenhang. Die auch grammatisch als Anrede kenntlich gemachte Variante Hölderlins kehrt nun dieses Dialogische explizit hervor. Schon darin gibt er zu erkennen, dass er von dem philosophischen Modell der Sinnsuche abrückt.

Nun ist aber die Erfahrung der Ode, dass der Dialogpartner sich dem Dichter schrittweise entzieht; das Gedicht wird damit gegen seine eigene Absicht zum Monolog. Mit dem Ende des Dialogs ist auch die lyrische Erregung dahin. Nach dieser entlyrisierenden Beruhigung könnte, ginge es nach Descartes oder Shaftesbury, das philosophische Selbstgespräch beginnen, denn nur unter der Bedingung der Isolation des Subjekts und einer Stilllegung der Affekte in ihm kann diese in Gang kommen. Davon will aber Hölderlin nichts wissen. Dunkelheit und Einsamkeit, seit jeher der Nährboden für die meditative Einkehr ins Ich, bedeuten ihm nur ein Nichts, in dem sich auch das Ich auflöst. ${ }^{99}$ Am Ende von „Sonnenuntergang“ steht nicht einmal mehr dessen Klage, ${ }^{100}$ sondern konsequenterweise sein Verstummen.

Noch in seiner lakonischen Kürze legt „Sonnenuntergang“ Zeugnis ab von der gespenstischen Kurzlebigkeit der Inspiration in einer sich verdunkelnden

99 So jedenfalls in diesem Gedicht. Andere Möglichkeiten erprobt er z. B. in Brod und Wein.

100 Im Gegensatz zur Larmoyanz von Abendphantasie: „Dunkel wirds und einsam / Unter dem Himmel, wie immer, bin ich“ (Sämtliche Werke Bd. 1 (Anm. 96), S. 298). 
Zeit. ${ }^{101}$ Das ist kein erstes Gedicht, sondern ein letztes; kein Anfang, sondern ein Ende - es sei denn, man wäre bereit zu glauben, dass Lyrik von sich aus, als Lyrik, ohne Rückendeckung durch eine wie auch immer verstandene Theologie, das Staunen des Anfangs stiften könnte. Ansonsten bliebe nur eine profanierende Ernüchterung der lyrischen Rede. In der Spannung zwischen diesen Alternativen bewegt sich die Lyrik seither. Und wenn sie bei dieser Lage der Dinge noch Wissen transportieren kann, dann nur in prekärer und bruchstückhafter Form.

101 Eine längere Fassung, Dem Sonnengott, blickt freilich hoffnungsvoll der Rückkehr Apolls entgegen (Sämtliche Werke Bd. 1 (Anm. 96), S. 255). 


\section{Episteme in Bewegung. Beiträge zu einer trans- disziplinären Wissensgeschichte}

Herausgegeben von Gyburg Uhlmann im Auftrag des Sonderforschungsbereichs 980 "Episteme in Bewegung. Wissenstransfer von der Alten Welt bis in die Frühe Neuzeit"

1: Eva Cancik-Kirschbaum,

Anita Traninger ( $\mathrm{Hg}$.)

Wissen in Bewegung Institution - Iteration - Transfer

2015. Ca. 608 Seiten, $g b$

ISBN 978-3-447-10498-2

$\odot E-B o o k:$ ISBN 978-3-447-19414-3

je ca. $€ 78,-(D)$

Institutionen geraten normalerweise gerade nicht in den Blick, wenn es um Prozesse des Wissenswandels geht. Vielmehr ist es eine weithin geteilte Überzeugung, dass Wandel wenn, dann stets nur außerhalb dieser Kreativitätsblockierer stattfindet. Nun ist aber gerade dort, wo vermeintlich rigide und stur am Überkommenen festgehalten wird, stets auch Wandel feststellbar. Ganz offensichtlich bringen also Praktiken, die auf Wiederholung gepolt sind und so institutionelle Zusammenhänge stabilisieren sollen, zugleich auch Veränderung hervor. Dieses Zusammenspiel von Wiederholung und Veränderung wird in diesem Sammelband mit dem Begriff der ,Iteration' gefasst. Die Autorinnen und Autoren zeigen anhand einer breiten Palette historischer Fallbeispiele, welche Varianten des Wechselspiels von Wiederholung und Wandel zu beobachten sind und welche Befunde sich daraus für eine transdisziplinäre Wissensgeschichte ergeben.

Der Band eröffnet die Reihe „Episteme in Bewegung. Beiträge zu einer transdisziplinären Wissensgeschichte", in der die Ergebnisse der Zusammenarbeit im Sonderforschungsbereich 980 , angesiedelt an der Freien Universität Berlin, präsentiert werden.
2: Peter-André Alt, Jutta Eming, Tilo Renz, Volkhard Wels ( $\mathrm{Hg}$.)

\section{Magia daemoniaca, magia naturalis, zouber (AT)}

Schreibweisen von Magie und Alchemie in Mittelalter und Früher Neuzeit

2015. VI, 447 Seiten, 22 Abb., gb ISBN 978-3-447-10495-1

$\odot$ E-Book: ISBN 978-3-447-19412-9

je ca. $€ 88,-(D)$

Dem Forschungsprogramm des Sonderforschungsbereichs 980 „Episteme in Bewegung" entsprechend, widmen sich die Beiträge des Bandes unterschiedlichen Transfers zwischen den Wissensbereichen der Magie, der Alchemie und der Dichtung vom Mittelalter bis in die Frühe Neuzeit. Dabei stehen ,Schreibweisen' als die jeweiligen Formen der Darstellung von Wissen im Zentrum des Interesses. Magische und alchemische Texte haben in der Geschichte einen ebenso exklusiven wie prekären Status und bedienen sich daher häufig Verfahren der sprachlichen Verschlüsselung. Aus heutiger Perspektive können diese Verfahren als literarische charakterisiert werden; im historischen Kontext haben sie eigene Funktionen, die teilweise erst noch bestimmt werden müssen. Darüber hinaus ist magisches und alchemisches Wissen vielfach in die Literatur überführt worden und hat dabei wiederum formale und inhaltliche Veränderungen erfahren. Der Band widmet sich damit der doppelten Fragestellung, wie Wissen über Magie und Alchemie im Mittelalter und in der Frühen Neuzeit vermittelt wird und auf welche Weisen gerade literarische Texte dieses Wissen spiegeln, verarbeiten und modifizieren. 


\section{Episteme in Bewegung. Beiträge zu einer trans- disziplinären Wissensgeschichte}

Herausgegeben von Gyburg UhImann im Auftrag des Sonderforschungsbereichs 980 "Episteme in Bewegung. Wissenstransfer von der Alten Welt bis in die Frühe Neuzeit"

\section{3: Peter-André Alt, Volkhard Wels (Hg.) Religiöses Wissen in der Lyrik der Frühen Neuzeit}

2015. VI, 334 Seiten, 12 Abb., gb ISBN 978-3-447-10497-5

Ca. $€ 68,-(D)$

4: Almut-Barbara Renger, Alessandro Stavru (Eds.)

Pythagorean Knowledge from the Ancient to the Modern World: askesis, religion, science

2016. Ca. 554 pages, hc

Ca. $€ 89,-(D)$

In Vorbereitung / In Preparation

In both ancient tradition and modern research Pythagoreanism has been understood as a religious sect or as a philosophical and scientific community. Numerous attempts have been made to reconcile these pictures as well as to analyze them separately. The most recent scholarship compartmentalizes different facets of Pythagorean knowledge, but this offers no context for exploring their origins, development, and interdependence. This collection aims to reverse this trend, addressing connections between the different fields of Pythagorean knowledge, such as eschatology, metempsychosis, metaphysics, epistemology, arithmology and numerology, music, dietetics and medicine as well as politics. In particular, the contributions discuss how the Pythagorean way of life related to more doctrinal aspects of knowledge, such as Pythagorean religion and science. The volume explores the effects of this interdependence between different kinds of knowledge both within the Pythagorean corpus and in its later reception. Chapters cover historical periods from the Archaic Period (6 $6^{\text {th }}$ century BC) to Neoplatonism, Early Christianity, the European and Arabic Middle Ages, and the Renaissance through to the Early Modern Period ( $17^{\text {th }}$ century AD). Contributions by E. Afonasin, L. Arcari, D. Baltzly, A. Barker, H. Bartoš, A. Bernabé, J. Bremmer, L. Brisson, F. Casadesús, M. Catarzi, S. Chrysakopoulou, G. Cornelli, E. Cottrell, S. Galson, M. Giangiulio, T. Iremadze, A. Izdebska, C. L. Joost-Gaugier, S. Kouloumentas, B. La Sala, R. McKirahan, C. Montepaone, H.-P. Neumann, A. Palmer, A. Provenza, I. Ramelli, D. Robichaud, B. Roling, W. Schmidt-Biggemann, E. Spinelli, I. F. Viltanioti, and L. Zhmud.

5: Angelika Neuwirth, Nora Katharina Schmid, Nora Schmidt (Hg.)

\section{Denkraum Spätantike}

Szenarien der Reflektion von „Antiken“ im Umfeld des Koran

2016. Ca. 432 Seiten, gb

Ca. $€ 68,-(D)$

In Vorbereitung / In Preparation 